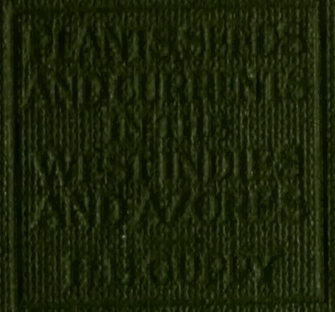




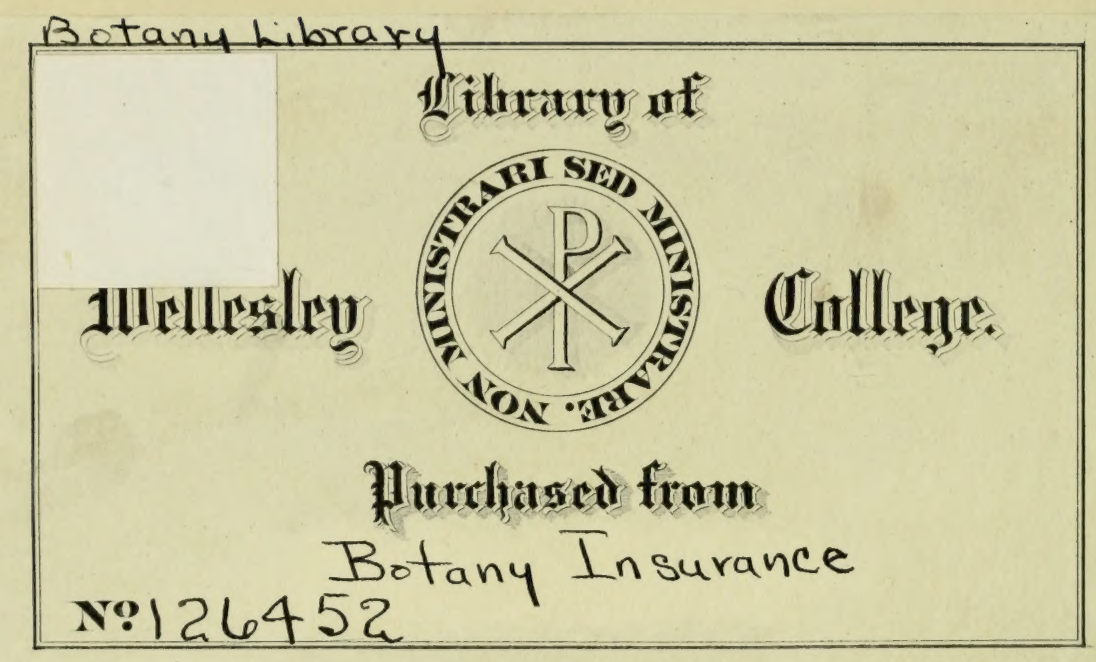


Digitized by the Internet Archive in 2014 

PLANTS, SEEDS, AND CURRENTS IN THE WEST INDIES AND AZORES 


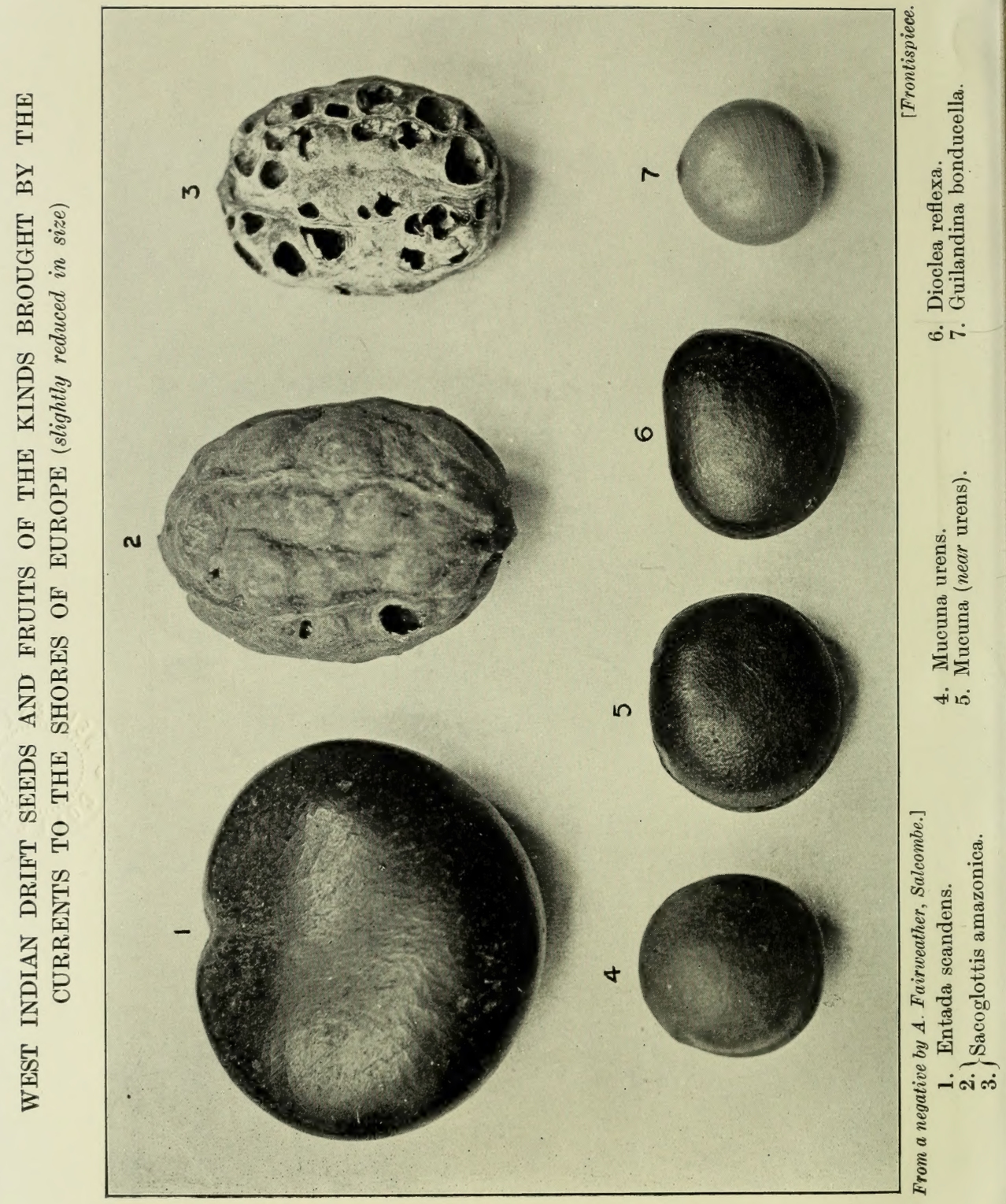




\section{PLANTS, SEEDS, AND CURRENTS IN THE WEST INDIES AND AZORES}

THE RESULTS OF INVESTIGATIONS CARRIED OUT IN THOSE REGIONS BETWEEN 1906 AND 1914

BY

H. B. GUPPY, M.B., F.R.S.E.

WITH THREE MAPS AND A FRONTISPIECE

\section{LONDON}

WILLIAMS AND NORGATE

I4 HENRIETTA STREET, COVENT GARDEN, W.C. 
e Printed in Great Britain BY RichaRd Clay \& Sons, Limited, BRUNSWICK ST., STAMFORD ST., S.E., AND BUNGAY, SUFFOLK.

$$
126452
$$

$$
\begin{gathered}
\text { SCIENCE } \\
\text { OK } \\
101 \\
685
\end{gathered}
$$




\section{PREFACE}

WiтH the exception of the section on the Azores, this work was practically completed before the war began; and it is now presented very much as it was written in the pre-war period. Unfortunately I greatly under-rated the task involved in the production of the fair copy; and for this reason, as well as through sickness and other causes, there has been considerable delay in its preparation for the press.

Associated with my observations on seeds and fruits, the results of which were published in 1912 under the title of Studies in Seeds and Fruits, the work embodied in these pages represents about ten years of my life. The two winters of 1906-8 were spent in Jamaica, that of 1908-9 mainly in Grenada but also in Tobago and Trinidad, and that of 1910-11 in the Turks Islands. Subsequently two sojourns were made in the Azores, the first from the middle of February to the end of April 1913, and the second from the middle of June to the middle of August 1914.

The great lesson that I have learned from the numerous difficult distribution-problems presented in the West Indian region, is that one can no longer fight shy of accepting in principle the conclusions relating to past changes in the arrangement of land and water in the Caribbean area, which have long been formulated by English and American geologists and zoologists. The witness of the living plant is often quite as insistent as the testimony of the rocks. Yet, although the original holders of such views stood more or less alone in their advocacy of them forty or fifty years ago, some of them, like Mr. Lechmere Guppy, who died recently at Port-of-Spain, lived to see their final justification.

The inclusion of the Azores within my field of investigation arose from a desire to come in contact with some of the problems presented by the floras of the Atlantic Islands. In the previous decade, 1896-1906, I had been brought face to face with problems offered by the islands of the Pacific. Polynesia and the history of its plant-stocking had occupied much of my thoughts during a long period, and I turned to Macaronesia with the hope that as typified in the Azores this region might bring me once again under the spell cast by the problems of oceanic distribution. Yet the outlook was at first far from encouraging, and it was suggested to me that it was scarcely worth while to take up the study of islands, concerning which we had long known all that was worth knowing. However, a re-perusal of Hooker's famous lecture on insular floras whetted my curiosity, and I soon found that the Macaronesian 
islands were rich in distribution-problems almost as fascinating as those presented by Hawaii and other Polynesian groups.

Yet but few of these problems were directly indicated in the catalogues of the floras accessible to me; and I realised here, as I did in the Pacific, that the work of the systematist in framing a catalogue of a flora represents the means to an end and not the end itself. In other words, with a list of a flora in our hands we stand only at the threshold of the study of distribution. Here also I realised that there is no region so well known that it would not greatly benefit by a thorough overhaul of all the data from a generally accepted standpoint of distribution; and the conviction forced itself upon me that the student of distribution will find his task nearest-at-hand, not in the discovery of new facts, but in the elaboration of old ones, and in the adoption of a uniform method of treatment. The elimination of the introduced plant should be the first goal of the student of distribution. Yet it is not possible for him to procure intelligible results, since he employs one method for the British Islands, another for the Azores, another for New Zealand, and a fourth for the Hawaiian Islands. The story of the weed all over the globe is full of significance, but only for the student of the early history of man.

H. B. Guppy.

"Rosario," Salcombe,

South Devon.

Nov. 23, 1916. 
LIST OF SOME BOTANICAL AND OTHER WORKS QUOTED IN THESE PAGES IN CONNECTION WITH DISTRIBUTION IN THE WEST INDIAN REGION AND ELSEWHERE

(Other lists dealing with special subjects are given at the end of chaps. ii, iii, xi, xiii, $x v$, xix.)

Catesby, M., Natural History of Carolina, Florida, and the Bahamas; i. 1731; ii. 1743 .

Ernst, A., The New Flora of the Volcanic Island of Krakatau, trans.

by A. C. Seward, Cambridge, 1908.

FAWCETT, W.

RENDle, A. B. $\}$ Flora of Jamaica, vol. iii. 1914.

Grisebach, A. H. R., Flora of the British West Indian Islands, 1864.

Guppy, H. B., Dispersal of Plants as illustrated by the Flora of Keeling Atoll, Journal of the Victoria Institute, London, 1889.

Plant-Dispersal, 1906 (vol. ii. of Observations of a Naturalist in the Pacific).

Plant-Distribution from an Old Standpoint, Trans. Vict. Inst., London, 1907.

Distribution of Plants and Animals, Petermann's Mitteilungen, 1910, heft 2.

Studies in Seeds and Fruits, 1912.

Harshberger, J. W., Phytogeographic Survey of North America

(Engler and Drude's Die Vegetation der Erde, vol. xiii. Leipzig and New York, 1911).

The Vegetation of South Florida, Trans. Wagner Free Institute of Science of Philadelphia, 1914.

Hart, J. H., Herbarium list, Botanical Department, Trinidad, 1908. Hemsley, W. B., Reports on the Scientific Results of the Voyage of H.M.S. Challenger, Botany, vol. i. 1885 (reference to this work is often abbreviated to Chall. Bot.).

Hooker, W. J., The Niger Flora, 1849, including sections by G. Bentham, J. D. Hooker, and others.

Millspaugh, C. F., Plantæ Utowanæ, 1900 (plants collected in the Antillean cruise of the yacht Utowana).

Plantæ Yucatanæ, 1903-4.

Flora of the Sand-keys of Florida, 1907.

Prænunciæ Bahamenses, 1906-9.

(All publications of the Field Columbian Museum, Chicago.) 


\section{viii LIST OF SOME BOTANICAL AND OTHER WORKS}

SAFford, W. E., Classification of the genus Annona, Contributions from the United States National Herbarium, vol. 18; Smithsonian Institution, Washington, 1914.

(Numerous botanical papers by this author, which are of great importance both to the botanist and to the student of the races of man in the tropics of the New World, have appeared in the last few years in the Journal of the Washington Academy of Sciences, 1912-15; in the Volta Revierw, Washington, 1912; in the Bulletin of the Torrey Botanical Club, 1912; in the Journal of Heredity, Washington, 1915; and in the Smithsonian series of publications above named.)

Scharff, R. F., Distribution and Origin of Life in America, London, 1911.

Schimper, A. F. W., Die Indo-Malayische Strandflora, Jena, 1891.

Spruce, R., Notes of a Botanist on the Amazon and Andes, 1908 (edited by A. R. Wallace).

Urban, I., Symbolæ Antillanæ, vol. i. 1898-1900; ii. 1900-1901; iii. 1901-1903; iv. 1903-1911, Leipzig. 


\section{CONTENTS}

CBAP.

I WEST INDIAN BEACH-DRIFT

II WEST INDIAN DRIFT ON EUROPEAN SHORES • . 20

III THE CURRENTS OF THE ATLANTIC AND THE TRACKS OF DRIFTING SEEDS AS ILLUSTRATED BY BOTTLEDRIFT . . . . . . . . . .

IV THE SIMILARITY BETWEEN THE WEST INDIAN AND WEST AFRICAN LITTORAL FLORAS AS EXPLAINED BY CURRENTS . . . . .

V RHIZOPHORA MANGLE AND THE PLANTS OF THE GREAT MORASS OF THE BLACK RIVER DISTRICT IN JAMAICA

VI THE LARGER FOREIGN DRIFT OF THE TURKS ISLANDS .

VII THE LARGER FOREIGN DRIFT OF THE TURKS ISLANDS (continued) . . . . . . . . . . . 138

VIII MISCELLANEOUS PLANTS • • • • • • . . 166

IX MISCELLANEOUS PLANTS (continued) • . . . 197

X Miscellaneous plants (continued) . . . . 225

XI THE GENERAL CHARACTERS AND GEOLOGICAL STRUCTURE OF THE TURKS ISLANDS . . . . . 254

XII THE FLORA OF THE TURKS ISLANDS . . . . 277

XIII THE CURRENT-CONNECTIONS IN THE SOUTHERN HEMISPHERE . . . . . . . . . . 294

XIV DIFFERENTIATION . . . . . . . . . 313

XV DISTRIBUTION $\quad$ • . . . . . . . . . . 323

XVI THE INFLUENCE OF THE DIVERGENCE OF THE CONTINENTS ON THE DISTRIBUTION OF SPHAGNUM AND

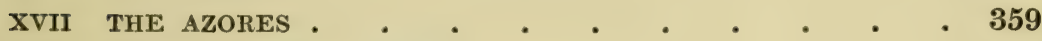

XVIII THE AZORES (continued) . . . . . . . . . 389

XIX THE AZORES (continued) . . . . . . . 417

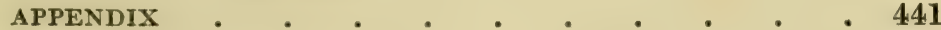
INDEX . . . . . . . . . . . 505 



\section{MAPS AND ILLUSTRATIONS}

WEST INDIAN SEEDS AND FRUITS REPRESENTED IN EUROPEAN BEACH-DRIFT - Frontispiece

THE OCEAN CURRENTS . . . . . . . . . To face page 46 THE TURKS ISLANDS . . . . . . . . . , , , 254

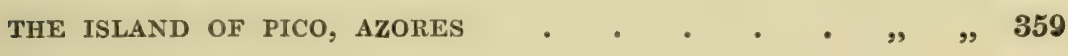





\title{
PLANTS, SEEDS, AND CURRENTS IN THE WEST INDIES AND AZORES
}

\author{
CHAPTER I \\ WEST INDIAN BEACH-DRIFT
}

The study of the stranded seed and fruit-drift of the West Indian region, as in the case of my previous investigations in the Pacific Islands, offered a means of approaching the great problems of plant distribution. The inquiry was extended over four winters (19061911), and was principally carried out in Jamaica, the Turks Islands, Trinidad, Tobago, and Grenada. The last winter was spent in the Turks Islands with the object of studying the seed-drift most fitted for the traverse across the North Atlantic in the Gulf Stream, since in those small islands one is able to discriminate with confidence between the drift of local origin and that brought from outside regions by the currents.

Generally speaking, the drift has much the same character over all this region, except perhaps in Trinidad and the adjacent island of Tobago, where there is added a quantity of strange seeds and fruits brought by the Equatorial Current from the Amazon and the Orinoco and from the estuaries and shores of the Guianas and Brazil. It is also highly probable, as is shown in the discussion of the bottledrift data in a later chapter, that West African seed-drift is transported by the same current to the West Indies; but there are obvious difficulties in the way of recognising it, since most of the littoral plants that constitute the principal sources of the drift are common to both sides of the tropical Atlantic.

ITS Sources.--The seeds and fruits found in the floating drift of these seas are derived partly from plants growing on the beaches, partly from plants of the mangrove swamps, and partly from inland plants growing on river-banks and on the slopes above. They are to be found in quantities on the beaches, especially in the vicinity of estuaries. But the scanty materials stranded on the coasts of Europe, as described in Chapter II., are but the residue of a vast amount of vegetable débris brought down by rivers to the coast and washed off the beaches by the currents. By far the greater mass of these materials must soon find a resting-place amongst the deposits at the bottom of the sea in the vicinity of their source. 
The Sifting Process.-This sifting out of the less buoyant materials is well illustrated when we compare the vegetable drift thrown up on the small islands of the Turks Group with that deposited on the beaches of the larger islands in the neighbourhood of estuaries, as in the case of the Orinoco drift piled up on the south side of Trinidad, or, to take a less conspicuous example, of the drift stranded on the south coast of Jamaica in the vicinity of the Black River. These matters will be mentioned in a later page; but here it may be said that the foreign drift, which makes up nearly all of the larger materials stranded on the Turks Islands, presents us with the seeds and fruits that are most likely to be carried in the Gulf Stream across the Atlantic. The beach-drift of this small group displays the West Indian drift in transit at an early stage of the North Atlantic traverse.

If we desired to know what seeds and fruits of the floating drift of the West Indian seas we ought to find on the shores of Europe, we must look for them, not on the beaches of the larger islands where they would be mixed with and sometimes lost among a mass of vegetable materials of local origin, but on the coast of some low, scantily vegetated, outlying islet standing well removed from the main islands. Such an islet would receive on its beaches a sample of the drift after it has lost all the less buoyant constituents during a flotation of some weeks in the open ocean. These are just the opportunities which are offered in the several small islands and islets of the Turks Group. Here in sample we see the oceanic drift that is carried swiftly by the Gulf Stream through the Florida Channel and then past Cape Hatteras eastward to the shores of Europe.

General Description of Drift.-With this object in view I will at first generally describe West Indian beach-drift, referring in passing to some of its special characters in particular localities.

In the West Indies, as elsewhere, the local drift is generally predominant, that is to say, the drift derived from plants growing in the vicinity, whether at the border of the beaches, or in the coastal and estuarine mangrove swamps, or in the interior along the sides of rivers. It is from the beaches near a large estuary that we can form the best idea of the nature of the materials that any particular region supplies to the currents for oceanic transport. If we confined our attention entirely to the drift brought down by rivers, or to the materials supplied by shore vegetation, our conception of its general composition would be incomplete. It is on a beach near an estuary, where the seeds and fruits derived from the beach plants are mingled with those from the mangrove vegetation and from the riverside plants of the interior, that we can learn our lesson concerning local drift.

Yet this would take no cognisance of the foreign drift, the materials brought from a distance, often from a continental coast or from some island hundreds of miles away. This is liable to be masked by the local drift on a beach near an estuary. It is best sought for and most easily recognised on some long stretch of beach far from an estuary, since it is often not difficult there to differentiate between it and the drift supplied by the beach vegetation. But here again obstacles may arise. Some knowledge of the flora must be acquired, 
and in a large island like Jamaica this is not a light undertaking. Even with Grisebach's Flora of the British West Indian Islands at my disposal, a work that bears especially on Jamaican plants, it was not possible to say with certainty that three of the most interesting plants represented in Jamaican beach-drift, Carapa guianensis, Manicaria saccifera, and Sacoglottis amazonica, though not accredited to the island, did not still survive in some of its extensive coastal swamps. It will, however, be subsequently shown that in the light of more recent investigations the probability of their not existing there is very great.

These are difficulties likely to crop up in the case of all large tropical islands. Yet the incrusting cirripedes, Serpula, and other organisms will frequently aid us in determining whether any particular fruit or seed is from beyond the sea. It is only the outlying sand-key, such as occurs in the Turks Islands, that affords the opportunity of safely differentiating the foreign drift on a beach. Here after a few weeks spent in examining the local flora there is little or no trouble in making the discrimination.

The riverside vegetation above the mangroves, the mangrove formation of the estuary and of the coast swamp, the plants of the beach and its border, all contribute to the floating drift of these seas.

River-Drift above the Mangroves.-A good deal of the materials brought down by the river, and I have in this sketch the Black River of Jamaica chiefly in my mind, consists of aquatic plants, such as Pontederias and Pistias, and of foliage, portions of tree-branches, etc., which do not count in distribution, and in the case of the floating plants are soon destroyed by the salt water or dry up when stranded on the beaches. These aquatic plants form a special feature of the floating drift of rivers of tropical America, and I have referred to them in the instance of the Guayas River in Ecuador in my book on Plant Dispersal (p. 488). Yet the plants of the riverside and of the wooded slopes of the river-valley above the mangrove-bordered estuary add a great variety of fruits and seeds to the drift floating in the stream, as illustrated in the description of the Black River given near the close of this chapter.

Many of these floating fruits and seeds have little or no effective value for distribution except along the same river-system. Thus in the Black River drift occur in numbers the germinating fruits of Grias cauliflora, the germinating seeds of Symphonia globulifera, of Crinum, and of Crudya spicata; and one may add the seeds of Fevillea cordifolia, which even when they escape the fate of germination in the river-drift are far from suited for dispersal over the sea. It is of importance to remember that through this tendency to germinate when afloat many of the seeds and fruits of the drift of tropical rivers are rendered useless for purposes of dispersal even across narrow tracts of sea.

But amongst the fruits and seeds found afloat in West Indian river-drift, excluding those supplied by the mangroves and their associates, many others have no effective value for purposes of distribution. Although the gourds of Crescentia trees and the fruits of Acrocomia palms are characteristic of this floating drift, the first 
named carry seeds that have a fleeting vitality and the second float only for a few days. Acrocomia fruits, it is true, are represented in the drift of the Turks Islands, but merely in the form of the empty "stones," which, after being freed by the decay of the outer coverings of the stranded fruit, acquire buoyancy only through the loss of the seed. Then again both Andira inermis, a tree of the riverside, and Mammea americana, a tree of the forested slopes of the river-valley, add their fruits as a rule to the floating drift; but it is very doubtful whether their seeds would be fit for germination when the fruits are stranded on some distant island.

The fruits and seeds carried down by a West Indian river from the interior to the sea that would be fitted for crossing unharmed a broad tract of ocean are comparatively few. Taking all the kinds of seeds and fruits brought down to the sea by the Black River from its basin above the mangroves, I don't suppose that twenty per cent. would be capable of reproducing the plant after a traverse of a hundred miles of ocean. The seeds which are brought down by a Jamaican river from the interior to the coast in a sound condition and capable of sustaining without injury the effects of prolonged flotation in the sea, would include such leguminous seeds as those of Entada scandens, Mucuna urens, and Dioclea reflexa, all of which figure in the West Indian drift stranded in a sound condition on the shores of Europe. Then there would be the "stones" of Spondias lutea and the long pods of Cassia grandis, which, after they have been transported by the rivers to the sea, would still be able to carry some of their seeds unharmed far across the ocean.

Drift supplied by the Mangrove Formation.-We come now to the vegetation of the mangrove formation as a source of the floating drift of West Indian seas. We have to distinguish here between the true mangroves and their associates. Together they form colonies everywhere, whether on the surface of some newly raised islet or key, or on the coast, or in the estuaries of the larger islands. Rhizophora mangle, Laguncularia racemosa, and Avicennia nitida are the mangrove trees proper; and one of their most prominent characteristics is their viviparous habit, which, however, is less pronounced with Laguncularia than with the others. The occasional associates of the mangroves in the larger islands are Anona palustris and Carapa guianensis. In Trinidad we find also Manicaria saccifera and Sacoglottis amazonica together with a species of Bactris, a palm that grows in similar situations. The Manicaria and Sacoglottis trees are conspicuous constituents of the estuarine floras of the great rivers of Venezuela, the Guianas, and Brazil. Though they only just enter the West Indian region, their fruits are distributed by the currents far and wide over the Caribbean Sea.

All the above-named trees of the mangrove swamps contribute to the floating drift of these seas, the true mangroves being represented in the case of Rhizophora by long seedlings, in the case of Avicennia by the germinating fruits and seedlings, and in that of Laguncularia by the fruits, which are often in the germinating condition. Uninjured by flotation in sea-water these seedlings and germinating fruits are cast ashore, and very soon establish themselves. 
On the other hand, with the associates of the mangroves the floating fruit or seed has many difficulties to contend with that considerably restrict its capacities for distribution. Thus the seeds of Anona palustris and of Carapa guianensis are very apt to germinate when afloat in river-drift; and my observations indicate that the germinating seed would soon be killed when it reached the sea-water, though the dead seed might float a long time and be thrown up in a more or less empty or unsound condition on some distant shore. So again with Manicaria saccifera, the seeds do not seem to be able to withstand sea-water immersion for a long period, though the fruit with a decaying or dead seed may be transported by the currents for a great distance. Sacoglottis amazonica is rather better adapted in these respects.

Drift supplied by the Plants of the Beach and its Borders.In the last place we will deal with the plants of the beach and its borders that add their buoyant seeds and fruits to the drift of the West Indian seas. Those which are most generally distributed, being those which are most characteristic of the drift, are enumerated below. In point of size the drift derived from beach plants in the West Indies offers a great contrast to that supplied by the beach vegetation of the tropical islands of the Indian and Pacific oceans. In the West Indies we miss the large fruits of Barringtonia speciosa, Cerbera cdollam, Ochrosia parviflora, Heritiera littoralis, Cycas circinalis, Pandanus, etc., trees that give character to the vegetation of the beaches of many an island and many a tract of continental coast in those oceans. The largest fruits of the common West Indian beach-drift, such as those of the Manchineel (Hippomane mancinella), Thespesia populnea, and Ecastaphyllum brownei, are not more than $1 \frac{1}{2}$ inches $(37 \mathrm{~mm}$.) across; and most of the other plants contribute seeds and seed-like fruits varying from a sixth to three-quarters of an inch (4-18 mm.) in size.

\section{The Beach Plants commonly represented in the Floating and Beach Drift of the West Indies.}

(One or two of the plants, like Conocarpus erectus, are perhaps most characteristic of the borders of the mangrove swamps, but since they thrive also amongst the vegetation bordering the beach they are here included.)

Canavalia obtusifolia (seeds).

Chrysobalanus icaco (stones).

Coccoloba uvifera (stone-like fruits).

Colubrina asiatica (seeds).

Conocarpus erectus (achenes).

Ecastaphyllum brownei (legumes).

Guilandina bonducella (seeds).

Hibiscus tiliaceus (seeds).

Hippomane mancinella (stones).

Ipomøa pes-capra (seeds).

Scarvola plumieri (stones). 


\author{
Sophora tomentosa (seeds). \\ Suriana maritima (seed-like nucules). \\ Thespesia populnea (seeds liberated by the decaying fruit). \\ Tournefortia gnaphalodes (pyrenes). \\ Vigna luteola (seeds).
}

There are one or two trees typically represented in West Indian beach-drift which ought to be mentioned, their fruits being carried long distances by the currents, such as Terminalia katappa and Cassia fistula. Both have been introduced from the Old World. The last named is discussed at length on a later page. The first is dealt with in my book on Plant Dispersal. It is a typical littoral tree of the tropics in the eastern hemisphere; and in the West Indies it is tending to escape from cultivation to find a home on the beach.

Cirripedes, Serpula, and similar organisms, that have attached themselves to floating drift, often enable one to distinguish the larger seeds that have been brought from a distance before being stranded. Where the plants concerned grow in the neighbourhood it is not easy, as before remarked, to discriminate between the foreign drift and the drift of local origin. The difficulties are well exhibited in an island like Jamaica. The large seeds of Entada scandens are common on the beaches of the north coast; but the plant grows in the island, and one cannot in the absence of incrusting shells of marine organisms determine whether a weather-beaten seed lying on the beach came originally from some neighbouring coast, such as from Cuba, or whether it has acquired its weathered appearance from lying exposed for a long period on the shore. On the other hand, the fruits of Manicaria saccifera and Sacoglottis amazonica would be rightly regarded as of foreign origin, since there is little probability of the plants growing in the island.

The Sorting Influence of the Waves.-The waves often sort out the finer beach-drift, and deposit it in a line above the larger and heavier fruits and seeds which are usually mixed up with Sargasso weed, drift-wood, and similar materials. Small pumice pebbles and Spirula shells mark the line of deposition of the smaller seeds and fruits belonging to such plants as Hibiscus tiliaceus, Ipomoea pescapra, Suriana maritima, Tournefortia gnaphalodes, Vigna luteola, etc. It is, however, the larger drift that usually claims attention, the smaller materials being often overlooked.

From my observations at St. Croix, Turks Islands, Grenada, Tobago, Trinidad, Jamaica, and Colon, it is evident that the beachdrift displays much the same general characters over the West Indian region. At the same time in addition to the seeds and fruits that are found on most of the coasts, whether insular or continental, each locality often presents some peculiar feature. Thus on the Colon side of the Panama Isthmus there are to be found on the beaches the large fruits of Prioria copaifera and empty palm fruits of Astrocaryum, etc. In Jamaica we find the fruits of Grias cauliflora; and in Trinidad the ordinary seeds and fruits of the drift are often masked by the large amount of strange fruits and seeds brought down by the Orinoco and stranded on its south coast. 
Method of Identifying the Constituents of the Drift--My previous experience of the seed-drift of the islands of the Pacific and more especially of the American borders of the ocean, as in Ecuador and at Panama, had made me familiar with many of the constituents of West Indian drift. On the other hand, my later West Indian experiences helped me to identify constituents in the drift on the Pacific coasts that I had not before recognised. The method employed was to search for the parent plant. In some cases a long time passed, as in that of Dioclea reflexa, before success crowned my efforts. This plant is of particular interest, as it is one of the few possessing seeds that are transported by the Gulf Stream in a sound condition to the shores of Europe. Ultimately I tracked it to one of its homes in the mountains of Grenada, and one of my chief objects of making a sojourn of some weeks in that locality was to investigate the conditions that led to its supplying its seeds to the drift.

The same plan was followed in Jamaica whenever I came upon some new seed or fruit on the beaches. With the aid of my coloured companions, who were very zealous in helping me to find its source, it was often not very difficult. Thus it was not long before I found the parent plants of the Anchovy tree (Grias cauliflora) and of the large seeds of the Antidote Vine (Fevillea cordifolia) so common on beaches in the Black River district.

Certain seeds and fruits common in the Jamaican drift eluded my efforts in this direction, and usually because the plants did not grow in the island. Two conspicuous offenders in this way were the fruits of Sacoglottis amazonica and Manicaria saccifera, two of the most interesting components of West Indian beach-drift. However, I was introduced to them by the late Mr. Hart of Trinidad. The source of the fruits of the first named was for a long time unknown, and Mr. Hart played a prominent part in the inquiry that led to their identification. Though not Jamaican, both are included in the Trinidad flora, growing mostly as I learnt in the swamps on the south side of the island. But as found on the Trinidad beaches the fruits often display evidence of long flotation in the sea in the marine organisms incrusting them. They have their chief home in the swamps of the Amazon and the Orinoco, and many of the fruits found in the Trinidad and Tobago beach-drift are doubtless thence derived. It was the presence of these fruits of Manicaria and Sacoglottis on the beaches of the south coast of Jamaica that long ago led Sir D. Morris to recognise an element of drift hailing from the Orinoco and the Amazon, a subject dealt with in connection with Jamaican beachdrift in a later page.

Orinoco and Amazon Drift distributed over the West Indian REgion.- "Orinoco drift" is a term often on the lips of residents in Trinidad, Tobago, and Grenada. They apply it to all the drift brought by the Equatorial Current, much of which must come from the Amazon as well as from the shores of Brazil and of the Guianas. Most of this drift finds its way into the Caribbean Sea between Barbados and the Spanish Main, either entering the Gulf of Paria and emerging through the Bocas, or floating through the passages separating Trinidad, Tobago, and Grenada. As indicated 
by the bottle-drift data, to be dealt with in a later chapter, most of the vegetable drift carried by this current would be borne across the Caribbean Sea in the direction of the coasts of Honduras. The materials that escaped being stranded on the shores of Central America or on the south coast of Jamaica, on the Cayman Islands, and on the south-west shores of Cuba, would be carried through the Straits of Yucatan into the Gulf of Mexico, some portion being beached on the shores of that gulf, the remainder ultimately reaching the Straits of Florida.

Reference will subsequently be made to several bottles that have accomplished this passage in part, and to others that have done so in its entirety. Occasionally one of them stranded on the beach tells the story of the seed-drift lying around it. Thus, a bottle from Ceara on the north coast of Brazil, which Mr. Savage English mentions as cast up on Grand Cayman, clearly demonstrates the part played by the Equatorial Current in carrying drift to the Cayman Islands. "The quantity of living seed afloat at this western end of the Caribbean Sea" (thus he writes in the Kerw Bulletin, 1913) "must be immense, for it is hardly possible to examine more than a few feet of the windward beaches of Grand Cayman without finding a seed of some sort; leguminous, probably, if it is not one from a Manicaria palm, though there are plenty of others."

The Mode of Distribution of Orinoco and Amazon Drift.Although the main track of the Orinoco and Amazon drift is chiefly restricted to the southern part of the West Indian region, any differentiation that the Equatorial Current might effect in the distribution of littoral plants, as it pursues its westerly course across the Caribbean Sea, would be obliterated by time. The usual variation of the winds between north-east and south-east would often bring about the deflection of the floating drift; and we get cases like that of Jamaica, which receives some of the drift brought by the Equatorial Current on its southern shores and a quantity of Cuban and Haitian drift on its northern coasts during the prevalent north-easterly winds. Over most of the West Indian region outside the direct influence of the Equatorial Current there is a prevailing north-westerly and westerly set of the surface waters; and it is in this manner that the beaches of the Turks Islands are often piled up with drift from San Domingo, Porto Rico, and the Leeward Islands.

The Turks Islands and their Suitability for the Study of SEED-DRIFT.- Though the prevailing winds in the Turks Islands are easterly, north-westerly winds occur at times in the winter months when different climatic conditions reign and the routine of the year is reversed for man, beast, and plant. The lee or protected sides of the islands for the greater portion of the twelve months now become the weather sides. At such times, when the sea breaks heavily on the shores, steamers cannot land either passengers or cargo, and proceed on their course to Haiti or Jamaica, or run for protection to the "Hawk's Nest," the name of the anchorage off the southern extremity of Grand Turk. Boats cannot ply between the islands, and communication is interrupted for days together when the weather is bad. Small craft accustomed to beat back from the islands to 
leeward now set their sails to the fair wind and accomplish in a few hours a passage that generally occupies days. At these times the stranding of drift on the eastern sides of the cays is suspended, and the drifting seed is beached on the western shores. This is an example of what must happen over much of the West Indian region when Nature for short periods breaks through her régime and quite different climatic conditions assert themselves. It will thus be understood how time would in the end prevent any marked differentiation in the distribution of littoral plants in the West Indian region.

For a satisfactory study of the West Indian beach-drift it was necessary to find a place where the local flora could be largely excluded as a probable source of materials. In Jamaica, for instance, it was apparent that much of the beach-drift could have been furnished by the plants of the island; and often the only indications of a foreign origin were the signs of long immersion in the sea afforded by incrusting Serpula, Balani, Polyzoa, etc., and by the borings of molluses. But most of the stranded seeds did not display these evidences of a long ocean journey; and in such cases one could rarely be sure of one's ground.

This was one of the reasons why I selected the Turks Islands at the south-eastern end of the Bahamas for a more thorough examination of West Indian seed-drift. Almost all of the larger fruits and seeds that are stranded on the eastern beaches of the various islands or cays, making up this little archipelago, belong to plants that are not only absent from this small group, but are not included in the Bahamian flora. The flora of the Turks Islands, which I have dealt with briefly in Chapter XII., is largely littoral in character, almost entirely Bahamian in composition, and as such displays a combined West Indian and Florida facies.

Author's Indebtedness to Dr. Millspaugh.-Having the good fortune to meet Dr. Millspaugh on Grand Turk, I thus acquired more precise notions of the relation between the stranded drift and the plants of this archipelago. Dr. Millspaugh very kindly lent me the manuscript of the Flora of the Bahamas, by Dr. Britton and himself. From its pages I obtained a general idea of the Bahamian flora, to which the plants of the Turks Islands belong. This generous loan of a work before its publication, a work representing the results of years of exploration and research, was quite spontaneous, and I shall always take a keen pleasure in recalling the circumstance. Its perusal enabled me to approach the subject of the relation between the plants represented in the beach-drift and the plants of the flora of the Turks Islands with far greater confidence than I should have otherwise possessed.

But in another way the author is deeply indebted to the labours of the American botanists. One of the most methodical examinations hitherto made of the vegetation of the sand-islets of a coral-reef region was carried out in 1904 by Mr. O. E. Lansing in the sand-keys lying to the westward of Key West, Florida. He was commissioned by the Field Columbian Museum of Chicago; and his collections, comprehensive notes, and maps form the subject of a paper on the Flora of the Sand-Keys of Florida, by Dr. Millspaugh in the publica- 
tions of the same institution (Bot. Ser. 1907). A discussion of this paper is given in Note $\mathbf{7}$ of the Appendix. I may remark that the Florida "key" is the equivalent of the Bahamian "cay," and that both terms will be employed here in their respective associations.

The beach plants of the Turks Islands, which in the smaller cavs occupy much of their surface, are, as a rule, common West Indian species and are generally distributed through the Bahamas, occurring also in the Florida keys.

The Stranded Drift of the Turks Islands.-The mangrove formation, which is still fairly extensive in area on Grand Turk in spite of the salt-making industry, is very limited in its composition, and lacks most of the accessory plants that give variety to the great mangrove formations of the large West Indian Islands. In its restricted composition and in its constituent trees (Rhizophora mangle, Laguncularia racemosa, Avicennia nitida, with Conocarpus erectus at the borders) the mangrove belt of the islands of the Turks Group approaches very closely that of the Florida Keys. So abundant is the foreign drift on the beaches of the cays of the Turks Group that the seeds and fruits of the local mangrove and beach plants scarcely figure in it. Here we shall be concerned only with the larger stranded seeds and fruits from other regions. The smaller and local drift is discussed in Note 2 of the Appendix.

During my sojourn of three months in the Turks Group I visited all the islands or cays, and collected or recorded about 2000 foreign seeds or fruits, all of them doubtless derived from the islands to the southward and eastward, San Domingo, Porto Rico, and the Leeward Islands. In Note 13 of the Appendix it is shown from the indications of bottle-drift stranded on the south-eastern Bahamas, and from the course taken by bottles dropped into the sea in this neighbourhood, that the prevailing set of the surface currents in this region is in a W.N.W. direction, and that the Turks Group lies in the track of drift on its way in the Antillean Stream from the islands to the eastward and southward to the Florida Straits, where it gets within the influence of the Gulf Stream.

The analysis given below illustrates the relative frequency of the several kinds of seeds and fruits that figure in the beach-drift. As above remarked the local seed-drift is derived from plants growing in the vicinity, whether in the mangrove swamps or on the sandy beaches, the present discussion being almost exclusively restricted to the seeds and fruits of plants not growing on the islands, the local materials being largely disguised by the mass of drift from a distance.

There are, however, named in this list the seeds of Guilandina bonducella, which grows in the larger islands of the Turks Group away from the beach. But since these drift seeds were best represented on Greater Sand Cay at the southern end of the group, a cay which does not possess the parent plant but is the first to receive the foreign drift, it is apparent that they must be included in the list.

Some of the drift is washed into the interior of the cays during hurricanes, and may be found between the sand-hills a hundred yards and more from the beach. It will be noticed in the following table that more than half of the foreign seeds and fruits stranded 
on the beaches of the Turks Islands would be able to reproduce the plant.

Table Showing the Constituents of the larger Drift Stranded on the Eastern Shores of the Turks Islands, all being op Foreign Origin.

(The numbers illustrate their relative frequency. Leguminous plants are marked L, and palms P. Further details respecting distribution, station, and other matters will be found on the pages indicated.)

\begin{tabular}{|c|c|c|c|c|}
\hline & $\begin{array}{c}\text { Fruit (F) } \\
\text { or } \\
\text { Seed (S) }\end{array}$ & $\begin{array}{c}\text { Number } \\
\text { per } \\
\text { Thousand }\end{array}$ & Condition of Seed & $\begin{array}{l}\text { Pages for } \\
\text { further } \\
\text { Details }\end{array}$ \\
\hline L. Ecastaphyllum (?) & $\mathbf{F}$ & 200 & Decaying or decayed . . & 111 \\
\hline Spondias lutea . & $\mathrm{F}$ & 200 & Usually sound . . . . & 111 \\
\hline Hippomane mancinella & $\mathrm{F}$ & 110 & Sound . . . . . & 113 \\
\hline Terminalia katappa & $\mathrm{F}$ & 108 & Sound . & 116 \\
\hline L. Entada scandens & $\mathrm{S}$ & 100 & Sound $\cdot \cdot \quad \cdot \quad \cdot \quad \cdot \quad \cdot$ & 117 \\
\hline $\begin{array}{l}\text { L. Mucuna urens (and an } \\
\text { allied species). }\end{array}$ & $\mathrm{S}$ & 60 & Sound . . . . . . . . & 120 \\
\hline Fevillea cordifolia . & $\mathrm{S}$ & 50 & $5 \%$ apparently sound & 124 \\
\hline P. Manicaria saccifera & $\mathbf{F}$ & 40 & $2 \%$ sound. & 127 \\
\hline L. Dioclea reflexa. . & $\mathrm{S}$ & 14 & Sound $\cdot \cdot \cdot \cdot \cdot$ & 130 \\
\hline Sacoglottis a mazonica. & F & 14 & $\begin{array}{l}\text { A few fruits with sound } \\
\text { seeds }\end{array}$ & 133 \\
\hline L. Guilandina bonducella & S & 10 & Sound . . . . . . & 138 \\
\hline L. Hymenæa courbaril . & F & 10 & Some seeds sound & 140 \\
\hline Carapa guianensis. & $\mathrm{S}$ & 10 & $10 \%$ appear sound & 141 \\
\hline Mammea americana & F & 6 & $\begin{array}{l}\text { Germinative } \\
\text { doubtful }\end{array}$ & 144 \\
\hline Crescentia cujete & $\mathbf{F}$ & 4 & Dead . . . . . . & 145 \\
\hline Crescentia cucurbitina. & $\mathrm{F}$ & 2 & Dead $. \quad . \quad . \quad . \quad$. & 147 \\
\hline L. Andira inermis . . & F & 3 & $\begin{array}{c}\text { Germinative eapacity } \\
\text { doubtful }\end{array}$ & 150 \\
\hline L. Cassia grandis . & F & 3 & A third of the seeds sound & 152 \\
\hline L. Cassia fistula & $\mathbf{F}$ & 2 & A sixth of the seeds sound & 152 \\
\hline Calophyllum calaba & $\mathbf{F}$ & 2 & Decaying or decayed. & 155 \\
\hline Sapindus saponaria & $\mathrm{S}$ & 2 & Not examined. & 156 \\
\hline L. Drepanocarpus lunatus & $\mathbf{F}$ & 1 & Empty pod . . . & 159 \\
\hline Omphalea diandra. & $\mathrm{S}$ & 1 & $\begin{array}{c}\text { Germinative } \\
\text { doubtful }\end{array}$ & 159 \\
\hline P. Acrocomia & F & 1 & Fruits empty & 160 \\
\hline Ipomœa tuberosa . & $\mathrm{S}$ & 1 & Sound $\cdot$. . . . . & 161 \\
\hline \multirow[t]{2}{*}{ Mangifera indica . } & $\mathbf{S}$ & 46 & Empty . . . . . & 164 \\
\hline & & 1000 & & \\
\hline
\end{tabular}

We find washed up on the weather beaches of the Turks Islands almost all the larger fruits and seeds that are characteristic of the beach-drift over the West Indian region; and they are all the more interesting in these islands because, with few exceptions, they are foreign to the local flora.

JAMAICAN BEACH-DRIFT.-Almost all of them came under my notice in the beach-drift of the coasts of Jamaica. Amongst the exceptions are the seeds of Carapa guianensis and the pods of Hymencea courbaril. The first named, however, were included in a collection of Jamaican beach-drift sent by Mr. Morris (afterwards Sir D. Morris) to Kew about thirty years ago, the contents of which are given in the list 
appended. But this list is only partly illustrative of Jamaican drift, and principally of the larger fruits and seeds. To supplement it we should have to add many of the names of the beach plants contributing regularly to West Indian stranded drift which are given in the list on page 5, such as Canavalia obtusifolia, Chrysobalanus icaco, Coccoloba uvifera, Conocarpus erectus, Hippomane mancinella, Sophora tomentosa, Thespesia populnea, etc.; and besides there would be the mangroves (Rhizophora, Laguncularia, Avicennia) already discussed in this chapter, as well as Mammea americana, Grias cauliflora, etc. All the seeds and fruits most typical of West Indian beach-drift may be found on the coasts of Jamaica. But the point with which we are more immediately concerned here is that almost all the larger foreign drift stranded on the Turks Islands can be found on the Jamaican beaches.

List of Seeds and Fruits washed Ashore at the Palisadoes Plantation on the South Coast of Jamaica, being a Collection Sent to Kew by Mr. Morris about 1884, and Described by Mr. Hemsley in Part IV. of his Work on the Botany of the "Challenger" Expedition (1885).

The localities in which the different seeds and fruits have been found by me in the West Indian beach-drift are indicated by abbreviations explained below. The drift specimens not named by Mr. Hemsley but since identified are marked *.

Calophyllum calaba. Tur., Jam.

*Sacoglottis amazonica. Tur., Jam., Trin., Col.

Carapa guianensis. Tur., Trin.

Spondias lutea. Tur., Jam., Trin., Col.

*Dioclea reflexa. Tur., Jam., Trin.

Mucuna urens. Tur., Jam., Trin., Col.

Mucuna sp. Tur., Jam., Trin.

Ecastaphyllum brownei. Jam., Col.

Guilandina bonduc.

Guilandina bonducella. Tur., Jam., Trin.

Cassia fistula. Tur., Trin.

Dimorphandra mora. Trin.

Entada scandens. Tur., Jam., Col.

Fevillea cordifolia. Tur, Jam., Trin.

Ipomoa pes-capræ. Tur., Jam., Trin., Col.

*Ipomøa tuberosa. Tur., Jam.

Omphalea diandra. Tur., Trin.

Juglans sp. Trin.

Manicaria saccifera. Tur., Jam., Trin.

Astrocaryum sp. Trin., Col.

Under their respective headings in a later part of this work will be found the accounts of the identification by Sir D. Morris and by Mr. Hemsley of the fruits or seeds of Sacoglottis and of Ipomoea tuberosa. The seeds of Dioclea reflexa are included in the Morris collection in the Kew Museum. 
Explanation of the abbreviations.-Tur. = Turks Islands; Trin. = Trinidad and the adjacent islands of Tobago and Grenada; Jam. = Jamaica; Col. = Colon.

Note.-Further details concerning the condition in which the seed and fruits occurred in the drift and other particulars will be found on the pages shown in the index.

Beach-drift of Trinidad and the Neighbouring Islands of Tobago and Grenada.-In the same way almost all the larger fruits and seeds most frequent in the beach-drift of the Turks Islands came under my notice on the beaches of Trinidad, Tobago, and Grenada. An important exception existed in the seeds of Entada scandens, a plant that is not a mémber of the floras of this part of the West Indian region, and is seemingly absent from those of the district of the Amazon and the Orinoco. Together with much strange drift on these beaches I found the fruits and seeds of Carapa, Cassia, Crescentia, Dioclea, Fevillea, Hippomane, Mammea, Manicaria, Omphalea, Mucuna, Sacoglottis, and Spondias named in the Turks Islands list. Fruits of palms are also frequent, including those of Astrocaryum and Bactris, the last probably derived from the palms growing in the coastal swamps of the locality.

But on the Trinidad and Tobago beaches occurs much drift that is strange to the West Indian region, and is evidently derived from the Orinoco district as well as from the rivers of the Guianas and from the valley of the Amazon. Amongst the leguminous seeds are those of a species of Mucuna, $1 \frac{1}{2}$ inches across (its incrusting marine organisms often telling a story of a long sea-passage), and the seeds of a species of Guilandina unknown to me from elsewhere. References to the seeds of these plants will be found later. But there is much of the strange drift piled on the south coasts of Trinidad that would not withstand long immersion in the sea. This is certainly true of a remarkable fruit which, as Prof. Pax informs me, seems to be a species of Hippocratea; but several of the other fruits and seeds have not been identified.

Amongst the unusual objects thrown up on the coasts of Trinidad are the huge brown embryos, three to four inches long and bare of coverings, of Dimorphandra mora, a common leguminous forest tree of British Guiana and also a native of this island. I was not aware of their identity until I recognised them in the Kew Museum. According to Hemsley the embryo of this tree is one of the largest in the vegetable kingdom (Chall. Bot., IV., 301). An empty pod was included in the Morris collection of Jamaican beach-drift. These naked seeds are of a very tough, durable nature; but it seems scarcely likely that they would retain their vitality after prolonged flotation in the sea.

Another singular woody fruit, top-shaped, deeply grooved, and $2 \frac{1}{2}$ inches in size, is identical with a fruit which is named Juglans jamaicensis in the drift collection of the Kew Museum, and is perhaps the one referred to by Hemsley under Juglans with a query in his account of the Morris collection (Ibid., IV., 303).

Drift on the Colon Beaches.-Much of the larger drift that is 
common to Trinidad, Tobago, Grenada, the Turks Islands, and Jamaica was observed by me at Colon on the extreme western border of the Caribbean Sea. On these beaches occurred the fruits and seeds of Hippomane mancinella, Manicaria saccifera, Mucuna urens, Sacoglottis amazonica, Spondias lutea, etc. Reference has already been made to one or two of the peculiar features of the beach-drift on the Colon side of the Panama Isthmus.

The Absentees from the Beach-Drift of the Turks Islands.It is thus evident that most of the larger foreign drift of the Turks Islands is to be found on the beaches throughout the West Indian region. But the beach-drift of this small group does not contain all the larger fruits and seeds that in one locality and another are characteristic of West Indian drift; and we shall see that their absence is significant of the weeding-out or exclusion of the drift least fitted for the accomplishment of the transatlantic passage, of which the Turks Islands represent the end of an early stage. For instance, it lacks the fruits of Grias cauliflora which are so characteristic of Jamaican beach-drift and are probably confined to that part of the West Indies. It lacks also the pods of Ecastaphyllum brownei, which form a common feature in the stranded drift of Jamaica and doubtless also of Cuba, as well as of the Caribbean side of the Panama Isthmus, as at Colon. Neither of these drift fruits seem to have been recorded from the stranded drift on the western shores of Europe, nor are they likely to be found there; and their absence from the beaches of the Turks Islands is an indication of their unfitness for the ocean traverse. Nor do we find thrown up on the beaches of this outlying West Indian group several of the strange fruits stranded with much other Orinoco drift on the south coast of Trinidad, and doubtless not possessing great floating powers.

Generally speaking (it may be added) I found nearly all the drift seeds and fruits on the Turks Islands beaches that my previous experience in other parts of the West Indies led me to expect. An exception, however, which is concerned with the absence of the empty fruits of Astrocaryum, a genus of palms, is dealt with on page 181, but it is highly probable that I overlooked them, since their occurrence on the beaches of the Azores implies great capacity for transport by currents, though in an ineffective state.

Oceanic Drift in Transit represented on the Beaches of THE TURKs IsLands.--Since in this small group the local flora can be readily excluded, we are here presented with oceanic drift in transit. The drift here stranded is something more than a sample of the material that is for ever being drifted in the Antillean Stream westward and northward past and through the Bahamas towards the Florida Straits, where the Gulf Stream concentrates its energy before proceeding to traverse the North Atlantic. It represents the residue of all the vegetable débris (fruits, seeds, bark, leaves, branches, tree-trunks, etc.) brought down to the sea by the rivers, or carried off by the currents from the shores, of the large islands lying to the southward and eastward. Since much of this material possesses limited floating powers, it would go to the bottom in a short time. After drifting about for weeks or months the mass of vegetable débris, 
once very large, now very small, reaches the Turks Islands at the south-eastern extremity of the Bahamas. Depositing on those small islands a sample of its contents, it continues its drift westward and northward towards the last starting-point of the swift current of the Gulf Stream in the Straits of Florida before it begins the Atlantic traverse.

How truly the sample represents the seeds likely to be drifted across the Atlantic is shown in the fact that practically all the seeds and fruits known to me as having been stranded on the coasts of Europe occur in the drift of the Turks Islands, making up as much as a third of the total. A list of them is given in the following chapter. We are thus able to detect at a glance the larger seeds and fruits of the drift which are most likely to accomplish the traverse of the North Atlantic without loss of the germinative capacity. The results obtained in the Turks Islands therefore fully justified my selection of this locality for the observation of Nature's method of sifting the drift of the West Indian region before it gets within the influence of the Gulf Stream in the Florida Sea.

The Black River of Jamaica as a Source of a Drift.-As an example of the manner in which rivers convey seeds and fruits to the sea in the West Indian region, I will take the case of the Black River, the largest river in Jamaica. Above the mangrove belt of Rhizophora mangle, Laguncularia racemosa, and Avicennia nitida, all of them trees that contribute to the floating drift, one passes into a region where the Anchovy Pear (Grias cauliflora) is the most conspicuous tree on the riverside, its large germinating fruits frequently floating past in the stream. Although in places taller trees closely line the river, it is the Anchovy Pear with its terminal head of large leaves, four or five feet long, and its flowers and fruits growing from the simple straight trunk, that first catches the eye. One of the loftier trees is the Paki tree (Crescentia cucurbitina), with its gourds hanging suspended over the water and often to be noticed floating down the river. A Crinum flourishes at the water's edge, its large fleshy seeds frequently occurring in the germinating condition in the floating drift. Here and there, hanging in leafy festoons from the tree branches as they spread over the water, is the Antidote Vine (Fevillea cordifolia), which with Grias cauliflora may be regarded as amongst the most interesting plants at the riverside. Its large fruits, like cannon-balls, were occasionally to be seen afloat. The Hog Gum tree (Symphonia globulifera), one of the Guttiferæ, grows also on the banks, its large germinating seeds floating in numbers in the stream.

Beyond the lower wooded district at the riverside, one passes into an open savannah-like region, much of which is swamp. It is known as the Great Morass, and is the home of the alligator. A reed-like growth of Typha, Papyrus-like Cyperi, and other tall sedges, which add little or nothing to the floating seed-drift, lines the banks; whilst clumps of Grias trees decked with Ipomœas occur at intervals by the water-side. In this open country, in places where the ground is rather drier, one notices on or near the banks various trees that are represented by their fruits or their seeds in the floating drift, such as 
Paritium (Hibiscus) elatum, Crescentia cujete (Calabash tree), and the Angeleen tree (Andira inermis). For miles inland this swampy plain extends. Above Lacovia the hilly country is entered, the banks steep and the slopes well wooded. Here reappear the Anchovy Pear tree, the Antidote Vine, the Angeleen tree, and Paritium elatum; and amongst other trees occurs Crudya spicata, the large seeds of which, often as large as those of Entada scandens and possessing the same name of " Cocoon," may be observed floating in numbers in the germinating condition in the stream. Amongst the tall trees on the steep slopes grow Cassia grandis, the long pods of which occur in the floating drift, and a species of Ficus, the fruits of which could only float for a short time; whilst Mucuna urens, a climber on the trees, adds its seeds to the floating drift.

I have mainly referred to the vegetation that contributes to the floating drift of fruits and seeds carried by the stream. The clumps of tall Sabal palms ( $S$. umbraculifera), that dot the surface of the Great Morass, make little or no addition to the drift, as the fruits possess but slight buoyancy, and the same may be said of other palms (Euterpe, etc.). The same remark applies to the climbing aroids (Syngonium and Philodendron) that often conceal the tree-trunks.

But brief reference need here be made to a multitude of aquatic and subaquatic plants, Ceratophyllum, Nymphoea, Pontederia, Potamogeton, Sagittaria, Utricularia, etc., that, except in the fourth and fifth cases, were not represented by their seeds or their fruits in the floating drift. In the lower part of the river the floating seed-drift often accumulates amongst the patches of Water Hyacinth (Pontederia), and here may be found the Water Lettuce (Pistia) and portions of Azolla. In concluding these remarks on the Black River, I may call attention to the frequency of germinating fruits and seeds in the floating drift, as already noticed in the cases of Crinum, Crudya, Grias, and Symphonia.

In the foregoing remarks the Great Morass of the Black River district is dealt with as a source of river-drift. A detailed description of it will be found in Chapter V.; and there also will be found an account of the Great Morass of Westmoreland in the south-west part of the island. The Cabarita, one of the larger rivers that drain it, presents most of the characters of the Black River as regards vegetation, though on a smaller scale. As will subsequently be shown, many of the conspicuous features of the Black River Morass are represented in the portion of the Great Morass of Westmoreland that extends westward from Savanna-la-mar to Negril, Grias cauliflora being especially prominent on the banks of streams in this part of the island.

The Roaring River Falls, Jamaica.-At these falls on the north coast of Jamaica there are some fine specimens of the Grias tree, which grows not only near the brink of the falls, but half-way down the precipitous slopes of calcareous tufa that form their face. At the cost of a wetting I clambered down the steep slopes to their base. Fruits carried over the falls have caught in crevices in their descent, and there germinating have developed into trees. Below the falls the Grias trees are associated with tall trees of Bucida buceras and 
Crescentia cucurbitina. Prof. Harshberger, who visited this locality, refers to the Bucida and Grias trees (Phyt. Surv. N. Amer., p. 678). The "olive tree," as the Jamaicans name Bucida buceras, is a characteristic swamp tree of the estuaries on the north side of the island. Owing to the lack of mature fruits the opportunity of studying this interesting tree from the standpoint of dispersal was not presented to me.

Comparison of the Beach-drift on the Pacific and West Indian Coasts of Tropical America.-A few remarks may here be made on the small contrast that exists between the beach-drift on the Pacific coasts of tropical America and on the West Indian or Caribbean side. As discussed in the case of the Ecuadorian and Panama beach-drift in my book on Plant Dispersal (p. 498), many of the familiar mangrove and beach plants occur on both sides of the continent and add their fruits and seeds to the drift, such as Rhizophora mangle, Laguncularia racemosa, Avicennia nitida, Canavalia obtusifolia, Conocarpus erectus, Ecastaphyllum brownei, Hibiscus tiliaceus, Hippomane mancinella, Ipomoea pes-caprce, etc. To these may now be added Scaevola plumieri, a characteristic West Indian strand shrub that occurs also on the Pacific coasts.

Equally common on the beaches of the West Indies and Colon on the Atlantic side and of Ecuador and Panama on the Pacific side are the seeds of Entada scandens and Mucuna urens and the fibrous "stones" of Spondias lutea. Much of the drift found afloat in the estuaries on the Pacific coast could be matched in those of the West Indian region, since many of the estuarine and swamp plants are the same. If we supplement the account given in my previous work of the drift carried down to the sea by the Guayaquil River in Ecuador with the names of two floating fruits not there identified, namely, the gourds of Crescentia cujete and the fruits of Grias cauliflora, we emphasise the resemblance between the character of the drift carried into the Pacific Ocean by the Ecuadorian rivers and of that discharged into the Caribbean Sea by the Black River in Jamaica. Amongst the beach-drift gathered by me on both sides of the Panama Isthmus were the large pods of Prioria copaifera, as identified at Kew. They seem to be quite useless for dispersal by currents, since the seeds of the fruits examined were always decayed. This is the type species of a genus which was first described by Grisebach (p. 215) from a rare Jamaican tree.

There are, however, differences between the drift found on the Pacific and Atlantic sides. Thus since neither Manicaria saccifera nor Sacoglottis amazonica occur on the Pacific border of the continent, their fruits have not been found in the drift. Here the empty seeds of the Vegetable Ivory palm, Phytelephas macrocarpa, constitute one of the principal features of the floating and stranded drift of coasts and estuaries in Ecuador, the sound seeds possessing no floating power. It is remarkable that this palm which abounds on the banks of the Magdalena River does not contribute to West Indian drift. We learn from Spruce's Notes of a Botanist on the Amazon and in the Andes that the Eastern and Western Andes possess in each case a separate species of the genus. 


\section{Summary}

1. After remarking that beach-drift has much the same general characters over the West Indian region, it is pointed out that its principal sources are the plants of the beach, of the coastal and estuarine mangrove swamps, and of the riverside in inland districts (p. 1).

2. Whilst the beaches near an estuary in a large island are the most suitable localities for the drift in the mass, it is in the low islet lying far out to sea that we find the best opportunity of investigating the portion of it that is most fitted for oceanic transport. Such an islet receives only the residue of a vast amount of vegetable débris which for the most part soon goes to the bottom (p. 2).

3. The distinction is drawn between local and foreign beach-drift, the latter which is derived across the sea from other islands being likely to be masked by the local materials (pp. 2, 3).

4. As illustrating the part taken by rivers above the mangrovelined estuary in supplying drift to the beaches, the Black River of Jamaica is taken as an example; and it is shown that on account of the tendency to germinate when afloat many of the seeds and fruits of riverside plants have little or no effective value for over-sea distribution (p. 3). In others again the floating power is either absent or slight; whilst there may be cases where the buoyancy is great, but the seeds have a fleeting vitality and soon decay. The conclusion is formed that not one-fifth of the seeds and fruits brought down by a West Indian river from inland districts to the sea would be capable of reproducing the plant after a traverse of a hundred miles of ocean (pp. 4, 5).

5. The mangrove formation as a source of drift is next discussed. It is shown that whilst the true mangroves (Rhizophora, Laguncularia, Avicennia) are in one form or another well adapted for oversea transport, in the case of their associates (Anona, Carapa, Manicaria, Sacoglottis, etc.) the floating seed or fruit has many difficulties to contend with, which considerably restrict their capacities for effective distribution by currents (pp. 4, 5).

6. Then the plants of the beach-borders are dealt with from the same standpoint, and a list is given of West Indian beach plants commonly represented in the drift. It is remarked in passing that in their much smaller size the fruits of West Indian beach trees offer a great contrast to those of the trees of the far more luxuriant beach vegetation of the tropical islands of the Indian and Pacific Oceans (pp. 5, 6).

7. The difficulty in discriminating between local and foreign drift is again alluded to, and reference is made to the sorting out by the waves of the finer and larger components of the beach-drift (p. 6).

8. Whilst fresh emphasis is laid on the uniformity in general characters of the beach-drift of the West Indian region, it is shown that each locality may present some peculiar feature (p. 6).

9. The author then refers to his method of identifying the constituents of the drift (pp. 7, 8).

10. The distribution over the West Indian region of the seeds and 
fruits brought north from the estuaries of the Orinoco, the Guiana rivers, and the Amazon is discussed (p. 7).

11. Reasons are given for the belief that however uniformly surface currents seem to act in distributing the seeds and fruits of littoral plants in this region, Nature in the course of ages breaks through her régime frequently enough to prevent any marked differentiation in the distribution of littoral plants (p. 8).

12. The author then deals with his selection of the Turks Islands at the south-eastern extremity of the Bahamas for the methodical investigation of the drift fruits and seeds best adapted for oceanic transport, one of the principal reasons being that here it would be easy to exclude the drift of local origin. The results proved the correctness of this surmise, since almost all the larger fruits and seeds in the beach-drift of these islands belong to plants that are strangers to the Bahamas (p. 8).

13. A detailed account of the drift stranded on the Turks Islands is given, with a tabulated analysis showing the relative frequency of the constituents of the foreign fruits and seeds, and the conclusion is formed that almost all that are characteristic of West Indian drift have been carried there by the currents (p. 10). In confirmation of this conclusion a comparison is made with the beach-drift of other West Indian localities, such as Jamaica (p. 11), Trinidad (p. 13), etc.

14. The beach-drift of the Turks Islands is thus considered as representing oceanic drift in transit. After drifting about for weeks or months the mass of vegetable débris, once very large, now very small, reaches this group. Depositing on these small islands a sample of its contents, it continues its passage in the Antillean Stream towards the Florida Straits, where the Gulf Stream gathers its energy before commencing its Atlantic traverse. How truly the sample represents the materials likely to be drifted across the Atlantic is shown in the fact that one-third of the fruits and seeds that figure in the foreign drift of the beaches of the Turks Islands have been found stranded on the coasts of Europe (p. 14).

15. A more detailed description is given of the vegetation of the Black River as a source of drift (pp. 15, 16); and the chapter is concluded with a comparison of the beach-drift on the Pacific and Caribbean sides of tropical America, in which it is shown that although there is a close resemblance in general composition there are important differences in details (p. 17). 


\section{CHAPTER II}

\section{WEST INDIAN DRIFT ON EUROPEAN SHORES}

In order to give point and method to my numerous observations on the dispersal of plants by currents in the West Indian region, as illustrated by the examination of the beach-drift and by various buoyancy experiments, I will at first let the discussion centre around the fact that some of the materials reach the shores of Europe.

The Literature of the SubJect.-Although it is not possible for me to deal exhaustively with the numerous references to the occurrence of West Indian seeds and fruits on the coasts of Europe which have been made since De l'Escluse, " better known under the Latinised appellation of Clusius," first figured some of them, in ignorance of their origin, in his Exoticorum Libri in 1605, the history of the subject will be found treated with some detail in this chapter. Those curious in the matter will find an excellent general account of our knowledge up to the middle of last century in Dr. Gumprecht's Die Treibproducte der Strömungen in Nordatlantischen Ocean (1854). His object was to sum up the evidence supplied by the variety of natural products from tropical regions thrown up on the north-west coasts of Europe in favour of the extension of the Gulf Stream into high northern latitudes, a theory that had been vigorously opposed by Rennell and others. It is difficult for us to realise that such a necessity ever existed. Yet it did; and one result was the publication of this paper in the Zeitschrift für Allgemeine Erdkunde on the drift-materials transported by the North Atlantic currents, in which almost all the facts then known were gathered together and discussed with the usual German acumen and thoroughness.

The subject of the West Indian drift on European beaches was dealt with by numerous writers during the last century in their treatment of the currents of the North Atlantic. Amongst them may be mentioned Humboldt in his Voyage aux régions équinoxiales, Paris, 1807, etc.; Sartorius von Waltershausen in his Physischgeographische Skizze von Island, 1847; Schjöth in his work on different marine phenomena $(\mathrm{Om}$ enkelte af Havets Phänomene, Christiania, 1848); Irminger in his paper on the ocean currents (Zeitsch. für Allgem. Erdk. 1854); Fogh in a paper on the Gulf Stream in Tiddsskrift for populore Fremstillinger af Naturvidenskaben, Copenhagen, 1857, where he gives a sketch of the history of our acquaintance with the subject; Vibe, chief of the Norwegian General Staff Survey, in his Küsten und Meer Norwegens, published in a supplementary volume of Petermann's Mittheilungen (1859-61); and Kohl, who in 
his Geschichte des Golfstroms, Bremen, 1868, also deals with some of the earlier references.

Amongst those who have specially dealt with the botanical side of the subject in recent years are Hemsley, Lindman, and Sernander. The two last named were exclusively concerned with the drift of the Scandinavian beaches, and their results are given by Sernander in his work on the "distribution-biology" of the Scandinavian plant-world (Upsala, 1901). The first named reopened the whole inquiry in his botanical contribution to the reports of the Challenger Expedition, and in its pages largely guided the investigations of later students like myself. But it would be unjust if one did not refer to one of the old veterans who did so much to establish clear conceptions concerning the nature and source of the foreign seeddrift on our European coasts. In the foremost place comes Sir Hans Sloane, who from experience derived from a sojourn of fifteen months in Jamaica, 1688-9, was enabled to identify the names and determine the origin of several of the strange seeds and fruits stranded on the Irish and Scottish coasts and on the islands to the north, his results being given in the Philosophical Transactions for 1695-7, and in the account of the natural history of Jamaica, which occupies most of his work on the West Indies. He naturally came to the conclusion that these West Indian seeds had been brought by the "Currents and Seas."

The Early Scandinavian References.-It is interesting to notice how in Scandinavia the crude surmises of the early writers on the natural history of these regions gave place to the more accurate determinations of the Linnean school of botanists. In the first place stands Peter Claussen (Peder Clausson), the Norse writer, who in his Description of Norway published in 1632, nine years after his death, refers to the seeds of Entada scandens as "stones floated on to the coast," both in Scandinavia and the Faroe Islands. Claussen was merely reiterating the old Norse belief, which found expression in such names as " adder-stones," "eagle-stones," etc., that were applied to these drift seeds, a matter mentioned again in a later page of this chapter. One of the earliest to perceive their real nature was Olaus Worm, a Danish naturalist of the seventeenth century, whose Epistolae are quoted by Gumprecht (p. 420). He determined them to be leguminous, and referred them to two genera of Indian beans. Amongst the first to recognise their place of origin was Provost Lucas Jacobsen Debes, who in his Faeroa Reserata or Faeroe Revealed, published at Copenhagen in 1673, stated his opinion that the seeds came from the West Indies and were "brought hither by the Stream." This early reference to the Gulf Stream striking the north-west shores of Europe may merit the attention of the geographical student.

But the popular notion as to their inorganic origin long survived, and it succumbed only to give place to another erroneous idea that they were the product of marine plant-like organisms, such as the "alcyonarian sea-shrubs." Thus Pontoppidan, the famous Bishop of Bergen, in his book on the Natural History of Norway, which was issued at Copenhagen in 1751, gave the name of Faba marina, or Sea 
Bean to the stranded seeds of Entada scandens, regarding them as the products of the "sea-trees" (sea-fans, etc.). These "sea-shrubs" may attain a considerable size on our coasts. Sloane, who in his return voyage from the West Indies touched at the Scilly Islands, writes (II., 347 ) that " on these rocks grows the Frutex marinus, flabelliformis," a specimen seen by him having "such dimensions and beauty that King Charles II. kept it many years, even to his death, for the ornament of his closet."

Sea Bean and Sea Nut are names still applied, as $\mathbf{I}$ found, in various parts of the world to the seeds of Mucuna and Entada when picked up either afloat in the sea or stranded on the beach; and one hears at times some singular opinions as to their origin. On one occasion I had a difficulty in persuading a gentleman, who wore a seed of Mucuna urens as a charm on his gold chain, that it was not some spontaneous production of the waves. The appellation of Gulf Nut, used at times by those who gather these seeds on European beaches, would be more appropriate.

Gunnerus, Bishop of Drontheim, and Ström, the Norwegian naturalist, first supplied the materials for the identification of the tropical elements of Scandinavian beach-drift to the Linnean botanists; and, as Sernander points out (p. 116), it is through the work of Tonning, a pupil of Linnæus, that their observations are usually known to the world (Amæen. Acad., VII). Although seemingly not acquainted with Sloane's writings, Gunnerus formed independently the same conclusions respecting the origin of the foreign seeds and fruits in the drift. His observations were published in the memoirs of the Drontheim Society (Copenhagen, 1765); and the results together with the botanical identifications of the plants were incorporated by Tonning in his paper. Ström refers to the foreign drift in his description of the bailiwick of Söndmöre, published in 1766, a work quoted by Gumprecht (p. 420). I do not gather that the matter attracted the special attention of Linnæus beyond the fact that in the following volume of the Amcenitates he cites, in illustration of the ocean's part in seed-distribution, the seeds and fruits washed up on the coasts of Norway, as specified by Tonning.

The Early Scottish References.-In their quaint descriptions of the Hebrides, the Orkneys, and the Shetland Islands, the old authors often give prominence to the foreign drift seeds stranded on their shores. Under the curious name of "Molucca Beans" we find their virtues described, both real and imaginary. Master James Wallace, minister of Kirkwall, in A Description of the Isles of Orkney published in 1693, and his son, Dr. James Wallace, F.R.S., in the edition of his father's book, which was issued with additions in 1700, were among the first to direct the attention of British naturalists to this matter. In $1703 \mathrm{Mr}$. Martin Martin, a native of the Hebrides, gave to the world an account of these islands in A Description of the Western Islands of Scotland, where he dwells especially on the medicinal virtues of the "Molocca Beans" and on their efficacy as charms against the "evil eye." Mr. Thomas Pennant in A Voyage to the Hebrides in 1772 places these " nuts commonly called Molucca Beans" amongst the amulets employed by the islanders. 
In the foregoing pages I have paid the debt due to many of my earlier predecessors in this line of research, and must refer the reader for a fuller description of many of the works named to the bibliography at the close of this chapter.

The Original Popular Names in Europe of the West Indian Drift Seeds and the Superstitions connected with them.Reference has already been made to "Molucca Beans" as the name of these seeds in the Hebrides and Orkney groups in the latter part of the seventeenth century. Its origin is obscure. The younger Wallace (1700) particularly observes that he did not know the reason of this name as used by the Orkney islanders; but Sloane in his Natural History of Jamaica (II., 41), published a few years after, states that the seeds " are called Molucca Beans by the Inhabitants of Scotland, they supposing them to have come from those islands by an imaginary North East Passage." Several writers quote in this connection the Scotia Illustrata of Sir Robert Sibbald, Geographer Royal to Charles II., a work issued in 1694; but he merely includes Phaseoli Molucani in a catalogue of marine plants and other things "quæ in Mari proveniunt" (II., lib. 4, p. 55). The appellation is employed in dictionaries of the Scottish language in the interpretation of the vernacular names applied to the foreign seeds of the beach-drift, a matter alluded to later in this chapter; but no endeavour to throw light on the origin of the epithet "Molucea " came under my notice. It is, however, noteworthy that both Martin and Sibbald in the works above quoted use the expression "Indian Nuts" or Nux Indica to distinguish one or more of the Molucca Beans.

Gumprecht (p. 420) gives a number of Scandinavian vulgar names of these drift seeds, as obtained from the older Norwegian writers, names which indicate the prevalent superstitious beliefs connected with their origin " Ormesteen " or Adder-stone, "Lösningsteen " or Solvent-stone, "Buesteen" or Bent-stone, are some of the old Norse names cited. The first was probably applied to the pale-coloured marble-like seeds of Guilandina bonducella, and the third to the seeds of Erythrina on account of their form. The Solvent-stone, according to Tonning, was the name of the large seed of Entada scandens, doubtless in indication of some special virtue attributed to it by the people.

It was around the Entada seeds that superstition often centred. Debes, the historian of the Faroe Islands, displays some irritation against Claussen who credited the Faroe islanders with the Norwegian belief that one of these seeds " doth bring forth another stone when it is kept long." "It is very certain " (Debes goes on to explain) " that these seeds are found here; but the inhabitants have not that superstitious opinion of them. Neither is it any stone, but a West Indian bean, as hath been told me by a very knowing man." Debes wrote his book about 1670. It was published in Copenhagen in 1673, and the English translation by J.S. (identified in the British Museum catalogue as John Sterpin) was issued in London in $\mathbf{1 6 7 6 .}$ We learn from Debes and Claussen that both in the Faroe Islands and in Norway the seeds of Entada scandens were named "Vette Nyre." This is translated by Sterpin as "Fairies' Kidneys"; but 
Gumprecht (p. 417) turns it into German in the shape of "Fette Niere," of which "Fat Kidney" would be the English equivalent. Both in colour and form these seeds might be compared with kidneys, and Sterpin's rendering is the one adopted in the pages of Fogh, Vibe, and Kohl, the name being regarded as the equivalent of the German "Zauber-Nieren" (magic or fairy kidneys), which becomes intelligible in the light of the employment of these drift seeds as charms.

It is, therefore, not a matter for surprise that these strange seeds when picked up on the beaches of north-western Europe have been used as charms. We have already remarked on their employment for this purpose. Pennant, as we have seen, in his book on the Hebrides classifies them among the amulets. But it is to the earlier work of Martin on the same islands that we are indebted for particulars in this respect. Of the seeds stranded on the island of Harris he writes: "There is a variety of nuts, called Molluka Beans, some of which are used as Amulets against Witchcraft or an Evil Eye, particularly the White one, and upon this account they are Wore about Childrens Necks, and if any Evil is intended to them, they say the Nut changes into a black colour. That they did change colour I found true by my own observation, but cannot be positive as to the Cause of it." (This white nut is evidently the seed of Guilandina bonducella.) Martin goes on to say that it is called "Virgin Marie's Nut," and he gives an instance of its effect in removing the spell of witchcraft from cows which gave blood instead of milk.

Whilst noticing the employment of these drift seeds as charms one may direct attention to an interesting observation made by Hemsley in the Annals of Botany for 1892. He refers to a peculiar virtue which not so long ago the people of the Hebrides ascribed to the black seeds of Ipomoe tuberosa, one of the most remarkable of the West Indian seeds thrown up on those islands. He is quoting from an extract of the journal of Colonel H. W. Fielden, which was sent with one of these seeds to Kew about 1891. The specimen was given to this officer by a woman of North Uist, in whose family it had been kept for a couple of generations. Known amongst the Roman Catholic inhabitants of Long Island under a Gaelic name signifying "Mary's Bean," it was believed to ensure easy delivery when clenched in the hand of a woman in childbirth.

Doubtless the belief in the protective powers of the West Indian seeds thrown up on their coasts yet lingers with the fisherfolk of the Scottish islands; and in the Shetlands, as I have been told, the wives of the fishermen still make ornaments of them. But these islanders appreciate these gifts from the waves in another way. Martin tells us of the medicinal uses to which the Hebrideans and the people of Mull put the Molucca Beans or Indian Nuts. We are informed that for the cure of dysentery and similar complaints the powdered kernels of the black "Molocea" Bean (Entada scandens) and of the "white Indian Nut" (Guilandina bonducella) when drunk in boiled milk are "by daily experience found to be very effectual." One would have scarcely expected the seeds of the last named to be very efficacious; but Sloane states (II., 41) that numerous virtues were ascribed to the seeds of Guilandina bonducella in the West 
Indies, and that their medicinal value was greatly esteemed by the Turks.

Almost everywhere on the European shores of the Atlantic the stranded seeds of Entada scandens seem to have been used as snuffboxes; and in some places they served as tinder-boxes or matchboxes. Many of the old authors (Sibbald, Debes, the two Wallaces, Sloane, etc.) allude to the snuff-boxes improvised from these seeds on the north-west coasts of Scotland, the Orkney Islands, and the Faroe Islands; and it is evident from the condition of seeds sent to me from the Shetland Islands that the islanders utilised them for one or other of these purposes. In Scandinavia they were also thus employed. Thus De Capell Brooke, in his account of his travels in these regions in 1820, refers to the conversion by the Sea Finns of the seeds of Entada scandens into snuff-boxes.

According to Martin the "black" Molucca Bean was specially named "Crospunk" in the Hebrides. In Warrack's A Scots Dialect Dictionary (1911) this name is applied to " the Molucca beans drifted to the shores of some of the western islands"; but no etymology is given. This information was apparently derived from Jamieson's Etymological Dictionary of the Scottish Language, in which Martin is quoted as the authority. The suggestion in Jamieson's work (edit. 1879) that the word "would seem literally to mean in Gaelic the point of the cross" can scarcely be sustained, since a more probable origin presents itself in the old Scottish term spunk-box for matchbox or tinder-box. Evidently the large seeds of Entada scandens are here implied. We have already noted their use as snuff-boxes, match-boxes, etc., and the writer has himself found them in use as match-boxes at the present day in several of the tropical homes of the plant. Originally the spunk-box was the Hebridean's tinder-box and afterwards his match-box; and when the West Indian drift seed served the same purpose he gave it the same name. The prefix need present no difficulty, since in Gaelic crò is a prefix possessing among other meanings those of witchcraft and sorcery. (See Dictionarium Scoto-Celticum, a Dictionary of the Gaelic Language: Edinburgh, 1828.) On this view crospunk might signify "the magician's tinder-box." We have already seen that in the Faroe Islands nearly two and a half centuries ago the same West Indian drift seed was known as Fairy's Kidney.

Before discussing the West Indian seed-drift of European beaches according to the localities in which it has been found, I will give the list of the seeds and fruits that are most characteristic of it(pp. 26, 27).

It is doubtful whether the seeds of any but the leguminous plants in the following list would retain their germinative capacity, which, it may be observed, has been established in the cases of the Entada, Guilandina, and Mucuna seeds. It would be hopeless to attempt to raise plants from the Manicaria specimens, and the result would be uncertain in the case of Sacoglottis and Sapindus. The prospects of success would be greater with Ipomoea tuberosa. The seeds of Crescentia gourds would be lifeless, and the fruits of Astrocaryum would be empty. Dioclea seeds would be sound, and Erythrina seeds might preserve their vitality. 


\section{List of the Characteristic West Indian Drift Segds and Fruits}

\begin{tabular}{|c|c|c|c|c|c|c|c|}
\hline & & $\begin{array}{l}\text { FRANCE } \\
\text { (north } \\
\text { coast) }\end{array}$ & $\begin{array}{c}\text { ENGLAND } \\
\text { (southern } \\
\text { and south- } \\
\text { western } \\
\text { coast) }\end{array}$ & $\begin{array}{l}\text { WALES } \\
\text { (south } \\
\text { coast) }\end{array}$ & $\begin{array}{c}\text { IR ELAND } \\
\text { (west } \\
\text { coast) }\end{array}$ & $\begin{array}{l}\text { SCOTLAND } \\
\text { (west } \\
\text { coast) and } \\
\text { HEBRIDES }\end{array}$ & ORKNEYS \\
\hline I. & $\begin{array}{l}\text { SACOGLOTTIS } \\
\text { AMAZONICA } \\
\text { (Humiriaceæ) }\end{array}$ & & + & & & + & \\
\hline II. & $\begin{array}{l}\text { SAPINDUS } \\
\text { SAPONARIA } \\
\text { (Sapindaceæ) }\end{array}$ & & & & & & \\
\hline III. & $\begin{array}{l}\text { GUILANDINA } \\
\text { BONDUCELLA } \\
\text { (Leguminosæ) }\end{array}$ & & + & & + & + & + \\
\hline IV. & $\begin{array}{l}\text { ENTADA } \\
\text { SCANDENS } \\
\text { (Leguminosæ) }\end{array}$ & + & + & + & + & + & + \\
\hline V. & $\begin{array}{l}\text { MUCUNA URENS } \\
\text { (Leguminosæ) }\end{array}$ & & + & & + & + & + \\
\hline VI. & $\begin{array}{l}\text { MUCUNA near } \\
\text { URENS } \\
\text { (Leguminosæ) }\end{array}$ & & + & & + & + & + \\
\hline VII. & $\begin{array}{l}\text { Dioclea } \\
\text { REFLEXA } \\
\text { (Leguminosæ) }\end{array}$ & & & & & & + \\
\hline VIII. & $\begin{array}{l}\text { ERYthriNa } \\
\text { (Leguminosæ) }\end{array}$ & & & & & & + \\
\hline IX. & $\begin{array}{l}\text { ІРОмєА } \\
\text { TUВEROSA } \\
\text { (Convolvulaceæ) }\end{array}$ & & & & & + & + \\
\hline $\mathrm{X}$. & $\begin{array}{l}\text { Gourds } \\
\text { (Crescentia ? } \\
\text { Bignoniaceæ) }\end{array}$ & & & & & & \\
\hline $\mathrm{XI}$. & $\begin{array}{l}\text { MANICARIA } \\
\text { SACCIFERA } \\
\text { (Palmaceæ) }\end{array}$ & & & & & + & \\
\hline XII. & $\begin{array}{c}\text { ASTroCARYUM } \\
\text { (Palmaceæ) }\end{array}$ & & & & & & \\
\hline
\end{tabular}


fodnd on the Beaches of Western Europe and of the Azores.

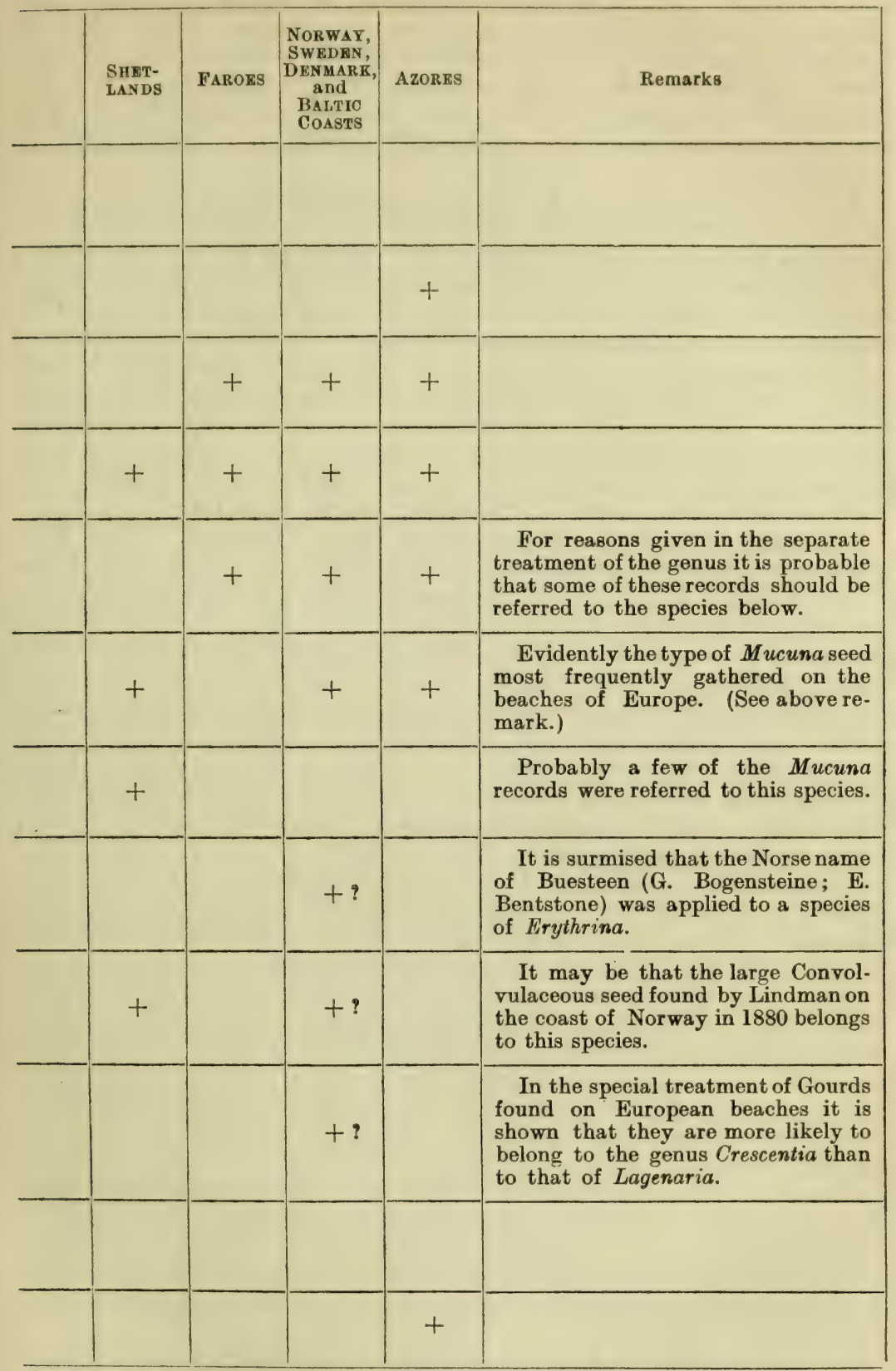

will be found by consulting the Index. 
There have also been recorded from European beaches such tropical fruits as those of Anacardium occidentale (Cashew-nut), Arachis hypogaa (Pea-nut), Caryocar nuciferum (Butter-nut of Guiana), Cassia fistula, Cocos nucifera, Garcinia mangostana (Mangosteen), etc., all of which, whether introduced or indigenous, are now growing in the New World. The extreme probability of their having been derived from ships in the vicinity is pointed out in later pages.

The South-West of England.-Respecting the occurrence of West Indian seeds on the beaches of the south-west of England, the following remarks may be made. Mr. Hamilton Davey, the author of The Flora of Cornwall, tells me that he has often found on the Cornish coast between St. Ives and Newquay large seeds which he took to be those of Entada scandens, and that he had them sawn through for the benefit of his students. It is well known that Gulf Stream drift is not infrequently beached on the north coast of Cornwall. The Great Western Railway Company, in advertising the climatic attractions which the "Cornish Riviera" derives from the Gulf Stream, informs the public that "many have been the instances of West Indian drift cast upon the shores of St. Ives Bay."

I noticed a seed of Mucuna urens from Cornwall in the Kew Museum. There is also exhibited there a fruit of Sacoglottis amazonica gathered on the South Devonshire coast by Mrs. Hubbard in November 1887. The find of the Sacoglottis fruit by Mrs. Hubbard had an important result. The fruit was unknown at Kew, and the requisite inquiry instituted by Sir D. Morris, Mr. Hillier, and others led to the identification of this and other fruits of the same plant from the drift of West Indian beaches, a matter dealt with in the discussion on Sacoglottis amazonica. Sir D. Morris, when referring to these drift fruits in Nature for November 21, 1895, gives Mrs. Hubbard's Devonshire locality as Bigborough Bay. Evidently Bigbury Bay, a few miles west of Salcombe, is here meant.

On April 28, 1909, I found on the beach at Sewer Mill Cove, near Salcombe, South Devon, two seeds lying within a few paces of each other, both in a sound condition, one of Guilandina bonducella and the other of the Mucuna species near M. urens. On January 18, and April 2, 1912, I came upon solitary seeds of Entada scandens at Moor Sands and at Sewer Mill Cove, beaches lying east and west of Salcombe, one of them with the base of a Balanus shell still attached. Though in both cases the seeds appeared sound, they possessed rattling broken kernels, and neither of them could have been germinable. The drift is sometimes carried far up the English Channel. Thus a Mucuna seed has been picked up at Portsmouth (Hemsley in Chall. Bot., IV., 291), and in the Kew Museum there is a seed of the same genus, labelled "near urens," which was found at St. Helens in the Isle of Wight. A seed of Entada scandens, now in the Kew Museum, was given to me by Miss M. Moseley, who found it in 1897 on the beach at Vimereux near Boulogne.

It is noteworthy that my discovery on the south coast of Devon of seeds of Entada scandens in the middle of January and early in 
April 1912, corresponds with the drifting into these latitudes from the southern waters of the North Atlantic of large quantities of Physalia (Portuguese men-of-war) and other pelagic organisms. Dr. Orton in Nature, February 27, 1913, observes that during March and early April 1912, numbers of Physalia were cast on our shores at various points between Cardigan Bay and Seaford in Sussex, and that together with Velella others were washed up at the same time on the coasts of France. (With respect to the Velella a French naturalist is cited.) At the end of March 1912 I noticed "Portuguese men-of-war" stranded in quantities on the beaches of South Devon between Start Point and Bolt Tail. On showing some of them to persons in the habit of crossing Salcombe Harbour daily, I learned that these creatures had been recently observed sailing up the harbour in small fleets. Their condition on the beaches indicated that whilst some had been beached only for a day or two, others had been lying there for a week or more. Dr. Orton regards this extensive incursion into our latitudes of the surface organisms of southern waters as the result of the almost continuous high southerly to south-westerly winds in the south-eastern part of the North Atlantic in the early part of the year.

There was a similar invasion of our seas by southern pelagic organisms in the early part of 1913. Commander Campbell Hepworth, in a paper in the Geographical Journal (November and December 1914), quotes from Dr. Orton's letter in Nature, and adds on the authority of Dr. Allen that Physalia occurred on the south coast of England in February, March, and April 1913. No West Indian drift seeds were noticed by me on the south coast of Devon in this connection; but early in January of that year after a long period of strong south-westerly winds I found an abundance of the horny skeletons of Velellae on a beach near Salcombe. During the first two or three days of January 1916 an enormous number of Velellce were piled up on the beaches of South Devon, east and west of Salcombe, in the living state. The spectacle was unique. Commander Hepworth refers to the occasional presence " especially off the west coast of Ireland, but seldom off Devon and Cornwall" of Ianthina (Violet Sea-snail) and Velella. However, Ianthina often came under my notice as a boy on the Cornish beaches. The association in this paper on the Gulf Stream of the indications of the pelagic organism with those of the thermometer and hydrometer endows it with special value for the student of dispersal by currents.

On the beaches of South Devon one occasionally finds Pea-nuts (Arachis hypogcea), half-eaten ears of Maize, Coco-nuts, etc., evidently thrown over from ships approaching the English Channel, besides other fruits and seeds, the origin of which is uncertain. Thus on May 16, 1911, two large Sapotaceous seeds, $2 \frac{1}{8}$ inches in length, were picked up by me on Rickham and Moor Sands beaches near Salcombe. Dr. Rendle tells me that a specimen sent to him presumably belonged to Lucuma, the species being doubtful. From a comparison with seeds in my collection of Lucuma mammosa, the familiar Mammee-Sapota of the West Indies, it is evident that the drift seeds do not belong to that species, though similar in size. 
Then again on November 17, 1914, I found washed up on Rickham beach a nearly entire fruit of Passiflora and a portion of a second fruit. The seeds of both were dead. On January 11, 1916, I picked up on the same beach another entire fruit of the same species of Passiflora, containing sound seeds from which I am now raising healthy seedlings. It was lying amongst the dead Velella that had been thrown up in such quantities a few days before, and doubtless arrived with them. The fruits reminded me of the Water Lemon of Jamaica ( $\boldsymbol{P}$. laurifolia); but since Passifloras are cultivated in England, and some grow almost wild in Ireland and in the south-west of England, we can scarcely look to the West Indies for the source of these drift fruits. Further details will be found given in connection with Passiflora in the Turks Islands.

The South Coast of Wales.-West Indian drift seeds and fruits are sometimes carried into the Bristol Channel and stranded on the Welsh coasts. Several years ago Dr. A. Lloydd-Jones sent to Kew a seed of Entada scandens, "said to be exactly like one picked up in Swansea Bay" (Kerw Bulletin, 1893, p. 114). On these coasts, as on the shores of the English Channel, the buoyant portions of edible tropical fruits thrown over from passing ships must often be cast up on the beaches, and allusion has above been made to this point with respect to the south coast of Devon. Thus in the Kew Museum there is a perfect specimen of a Mango-stone (Mangifera indica) from the coast of South Wales, which was probably thus derived. As is shown in a later page, empty Mango-stones are of common occurrence on West Indian beaches and elsewhere. There is also in the drift collection of the Kew Museum a fruit from South Wales which is labelled Caryocar nuciferum, the "butter-nut" of British Guiana, sometimes imported into Great Britain.

The West Coast of Ireland.- It is shown in the next chapter that much of the bottle-drift which reaches the shores of the United Kingdom from the seas of the West Indies, Florida, and the Southeastern United States is stranded on the west side of Ireland. This fact would lead us to expect that the Irish coasts would receive the bulk of the West Indian seed-drift thrown up on our shores. But I gather that though often found it has rarely been recorded. The principal fact usually cited is that given by Sir Hans Sloane in his book on the West Indies (II., 41) and in his paper in the Philosophical Transactions (Vol. XIX.), which were written more than two centuries ago. He there alludes to seeds of the " ash-coloured Nickar" and of the "Cocoon" found on these coasts. There can be no doubt that the seeds of Guilandina bonducella and Entada scandens are here indicated. From a drawing made of a plant raised from a seed picked up on the west coast of Ireland Robert Brown determined the species to be Guilandina bonduc (Hemsley in Chall. Bot., IV., 277). Since, however, the seeds of this species are not as a rule buoyant in the West Indies and are not a frequent constituent of West Indian beach-drift, it is more probable that the seeds in question belonged to the allied species, G. bonducella, the seeds of which have been found in almost every European locality where West Indian drift 
has been observed. For further details on this point Note 9 of the Appendix should be consulted.

Through the courtesy of Mr. Lloyd Praeger I have received whilst preparing this work some more particulars about West Indian seeds on the western sea-borders of Ireland. The following extract is from a letter of April 29, 1915, written to him by Miss M. C. Knowles of the National Museum, Dublin: "On p. 133, Irish Naturalist for 1897, I see Mucuna urens was picked up on the shores of Kilkee (Co. Clare). Mr. Tomlinson sent me Entada scandens that he had found on the north coast a short time ago, but he did not give me the locality. I have found it at White Park Bay (Co. Antrim) on several occasions."

On September 2, 1915, Miss Knowles wrote to tell me of two seeds, Entada scandens and Mucuna sp., just brought to her, which were found by the Rev. Br. S. O'Connell in a cave at Kilkee. They were sent to me for inspection by the Rev. Br. M. A. Hoban. Both of them appeared to be sound and germinable. The Mucuna seed came nearest to those of $M$. urens. I may add that with the object of directing interest to this matter I sent in May 1915 to the National Museum, Dublin, a collection of West Indian drift seeds most likely to be found on the Irish coasts.

The West Coast of Scotland and the Hebrides.-As already observed, Sir Robert Sibbald in his Scotia Illustrata (II., lib. 4, p. 55, 1694) includes, without commenting on their origin, Phaseoli Molucani and Nux Indica in a catalogue of marine plants and other things "quæ in Mari proveniunt." The use of the name Molucca Beans has been before explained. The Indian Nut, "of which snuff-boxes are made," is evidently Entada scandens, and is thus regarded by Sloane, who identifies it in his paper in the Philosophical Transactions with the Cocoon, which is its native name in Jamaica. Amongst the West Indian seed-drift stranded on the north-west coasts of Scotland and on the Hebrides, and described by Sloane in his Voyage to Jamaica, etc. (II., 41, 186), are represented Guilandina bonducella, Sacoglottis amazonica, and Manicaria saccifera. The first named can be at once recognised from his account. As regards the other two species, the identification of the Manicaria fruits was made by Plukenet; whilst the description of the Sacoglottis fruits, as quoted by me under that head, leaves no room for doubt as to their identity.

We have before referred to the account which Martin gives in his Description of the Western Islands of Scotland (1703) of the medicinal uses to which the Hebrideans and the people of Mull put the Molucca Beans and Indian Nuts washed up on their shores, and we have dwelt also on his account of the superstitions attached to them. Amongst the seeds he mentions we can recognise those of Entada scandens and Guilandina bonducella. He adds (p. 283) that the Steward of St. Kilda told him that they had found Molucca Beans in a nest of the Solan Goose, it being the habit of these birds to carry to their nests many things they find afloat in the sea. This is interesting in connection with the discovery by Sir William Milner of large West Indian seeds in the crops of nestling petrels at St. Kilda, a matter which drew the attention of Darwin, and is treated 
in Note 59 of my work on Plant Dispersal. Mr. Charles Dixon in Ibis (1885) refers to Sir W. Milner's observation in the case of the Fulmar Petrel and speaks of them as Brazilian seeds brought by the Gulf Stream, adding that he himself found a specimen in the crop of one of these birds in the same locality. Sir W. Milner, it appears, procured several of these seeds from the crops of the birds, and Mr. Dixon says that the natives of the island find them at times. The reference by Darwin is made in letters to Hooker in 1859 (Life and Letters, 1888, II., 147-8). He remarks on the curious fact of " petrels at St. Kilda apparently being fed by seeds raised in the West Indies." Unfortunately the seeds were never identified, and more than forty years afterwards, when Mr. Hemsley applied to Sir Joseph Hooker for particulars, too long an interval has elapsed for the determination of this point. The West Indian drift seeds carried to our islands that would be most likely to be swallowed by sea-birds would be those of Guilandina bonducella. When in the Keeling Islands I was informed by residents that the seeds of this plant, which grows on the islands, are sometimes found in the stomachs of sea-birds, such a frigate-birds and boobies.

Pennant in his Voyage to the Hebrides in 1772 (I., 266) refers to " the nuts commonly called Molucca Beans which are frequently found on the western shores of the Hebrides." He is one of the first to employ the Linnean designations in naming the seeds stranded on the Western Islands of Scotland, and his list comprises Dolichos (Mucuna) urens, Guilandina bonduc, G. bonducella, and Mimosa (Entada) scandens, all, as was long before pointed out by Sloane, natives of Jamaica. He adds C. Bauhin's description, derived from Clusius, of a fifth kind, which is evidently the composite seed of Ipomcea tuberosa, and special reference to it in this connection will be made when dealing with that species. There is in the Kew Museum another drift seed of the same species of Ipomøa from the Hebrides, which was obtained by Colonel Fielden about 1891.

A well-known Genevese naturalist, Necker de Saussure, made a long sojourn in the Hebrides between 1806 and 1808. Speaking of the "American" seeds, Dolichos (Mucuna) urens and Mimosa (Entada) scandens, which had been thrown up by the waves, he says that when traversing South Uist he observed them in every cottage (Voyage en Écosse et aux Iles Hébrides, 1821, III., 22). There are doubtless numerous references in modern works to the West Indian seeds transported to these islands. For instance, Mr. C. V. Peel in his Wild Sport in the Outer Hebrides, 1901, mentions the seeds of the two species just named as occurring with much other Atlantic drift on the west coast of North Uist.

The ORKney IsLands.-These islands are of special interest in the story of this investigation, since the stranded "Molucca Beans" (as they were called), which were figured by the two Wallaces, the early historians of the group, were in most cases identified by Sloane with seeds familiar to him in Jamaica (Phil. Trans. 1695-7). Standing thus on firm ground when he surmised that the seeds had been brought by the sea from the West Indies, Sloane forestalled by quite two generations the Norwegian observers of the middle of 
the eighteenth century. Yet, as before remarked, even Sloane must in this respect give way in point of priority by at least a quarter of a century to Debes (1670) and his informant, the "very knowing man," who regarded the strange seeds stranded on the Faroe Islands as "brought hither by the Stream" from the West Indies.

But to return to the Wallaces, I examined the three editions of this early description of the Orkney Islands that are in the British Museum library. The first, "A Description of the Isles of Orkney by Master James Wallace, late minister of Kirkwall, published after his Death by his Son" was issued at Edinburgh in 1693. It was written about 1688 at the instigation of Sir Robert Sibbald, Geographer to Charles II. Under the head of substances cast up by the sea he alludes (p. 14) to the frequent occurrence of "these pretty Nuts (named Molluca Beans in the margin) of which they use to make Snuff-Boxes. There are four sorts of them (he adds) the figures of which are set down." In the plate under the name of "Molocea Beans" are figured the seeds of Entada scandens, a species of Mucuna, probably M. urens, a species of Erythrina, and Ipomœe tuberosa.

Though written without any mention of his father's book, $A n$ Account of the Islands of Orkney by James Wallace, M.D., F.R.S. (London, 1700), is evidently an enlarged edition of the previous work. With access to Sloane's paper in the Philosophical Transactions (1695-7), which his father could not have had, the author thus writes (p. 36): "After storms of Westerly Wind, amongst the Sea-Weed they find commonly in places exposed to the Western Ocean these Phaseoli that, I know not for what reason, go under the name of Molucca Beans. The ingenious Doctor Sloan in the Philosophical Transactions, Number 222, gives a very satisfactory account, how from the $\boldsymbol{W}$ est Indies, where they commonly grow, they may be thrown in on Ireland, the Western parts of Scotland, and Orkney. You have the figures of four different sorts of them." However, in his plate there is a fifth figure of " another molucca bean " which is certainly Guilandina bonducella. The drawing of the seed of Entada scandens is here enlarged to natural size, and in the place of his father's figure of a Mucuna seed there is a drawing of a Dioclea seed. The other seed-figures, one of an Erythrina species and the other of I pomoea tuberosa, are unchanged.

The third edition, which is entitled "A Description of the Isles of Orkney by the Rev. James Wallace, reprinted from the edition of 1693 and with additions by the Author's son in the edition of 1700," was edited by John Small and published at Edinburgh in 1883 . This work contains both the plates of the seed-drawings of the two earlier editions. It may here be remarked that an additional reference to the occurrence of the seeds of Ipomoea tuberosa on the Orkney beaches at the close of the seventeenth century is made by Petiver, of which further mention will be made.

The next important reference to seeds of West Indian beach-drift on the coasts of these islands is to be found in "An Account of four sorts of strange beans, frequently cast on shoar on the Orkney Isles, 
with some conjectures about the way of their being brought thither from Jamaica, where three sorts of them grow" by Sir Hans Sloane (Phil. Trans. 1695-7). After referring to the mention of them by Sibbald and the elder Wallace, he deals with them successively. The first he identifies with the Jamaican " Cocoon," the name given in that island to the seed of Entada scandens, as known to botanists. The second, he says, is the Jamaican "Horse-eye bean," which from his description is evidently the seed of Mucuna urens, a seed that bears the same popular name in our own time. The third, he says, is the "ash-coloured Nickar" of Jamaica, called so, as he goes on to state, from its being "very like a Nickar," such as boys play with. I may add that " knicker," " nicker," etc., were forms of an old English and Scottish name for marbles. Botanists have no hesitation in recognising here the seeds of Guilandina bonducella. It bears the same common name in the West Indies now. Of the source of the fourth he states that "authors are silent"; but although he remarks that he "had never seen it grow," his reference to it as described and figured by Clusius, the elder Wallace, and others, undoubtedly points to its being the seed of Ipomcea tuberosa, as determined in recent years by Mr. Hemsley, and to which further allusion will be made. I have not come upon any recent references to West Indian drift seeds in the Orkney Islands, but one may note that Mr. Bullock, the naturalist, gathered seeds of Entada scandens there about a century ago (A. de Capell Brooke in Travels in Sweden, etc., in 1820, p. 317).

The Shetland Islands.-In connection with the occurrence of West Indian seed-drift in this archipelago I put myself in communication with Mr. John Fox, then stationed in that group, and through his kindness was able to inspect two seeds from the Shetland beaches, one of Entada scandens, the other of Dioclea reflexa, both of them in sound condition, which were courteously loaned by Mr. J. Tulloch of Lerwick. Mr. Fox subsequently sent me two seeds of Entada scandens, one of the species of Mucuna near M. urens, and a seed of Ipomoea tuberosa, the last being the species above named as found on the Orkney beaches, and it is one that is represented in my drift collections from Jamaica and the southern extremity of the Bahamas. All these seeds were picked up on the Shetland coasts, and Mr. Fox tells me that the wives of the fishermen make ornaments of them. In reply to a letter asking for further information, Mr. Tulloch kindly furnished me with references to Shetland literature, but added that he knew of no mention there of Gulf Stream drift. At his suggestion I wrote to Mr. Peterson, postmaster of Foula, an island at the southwest corner of the group; but on doing so I learned that that island is not suited for retaining drift, and that during a residence of over fifty years Mr. Peterson had never seen any of the seeds described to him by me.

The Faroe Islands.- The occurrence of these strange drift seeds on the Faroe Islands formed a subject of remark for Peter Claussen in his Description of Norway, which was written at the close of the sixteenth or the beginning of the seventeenth century; but, as previously stated, he had no idea of their true nature. Debes, 
who wrote the preface of his book on these islands in 1670, has been already mentioned in connection with the drift seeds. It was, however, with those of Entada scandens as found on the Faroe beaches that he was especially concerned, and from his description of them there can be no doubt as to their specific identity.

In $1817 \mathrm{H}$. C. Lyngbye, a Danish algologist, visited the Faroes, and in his Tentamen Hydrophytologia Danica of 1819 he remarks (p. 60) that he picked up on the shores seeds of Mimosa scandentis (Entada scandens), Dolichos urentis (Mucuna urens), and Guilandina bonducella. In recent years Ostenfeld and Borgesen have again directed attention to the West Indian seeds and fruits washed up on these islands, and they mention those of Cocos, Guilandina, and Entada scandens as coming under their notice (Botany of the Faeroes, pp. 116, 812 : Copenhagen, 1901-8).

ICELAND AND GREenland.-Seeds and fruits and drift-wood from the New World are stranded on the shores of Iceland and Greenland, as we learn from the Danish navigator, Admiral von Löwenörn (1786), and from Barrow (1817), Sartorius von Waltershausen (1847), Irminger (1854), and others. In his Physical Geography (1873, p. 206) Laughton quotes from the report of the United Coast Survey for 1860, to the effect that drift from the West Indian islands is stranded in very considerable quantities on the south coast of Iceland, where, "on the beach under Snaefell, trees with their roots, and scraps of bark, logs of mahogany, and seeds which grow in Jamaica at the nearest, roll in the surf." We learn from Irminger (Zeitsch. f. Allg. Erdk., III., 187-90, 1854) that "many kinds of Mimosas (i.e. seeds) are to be found on the coasts of Norway, Faroes, Iceland, and Greenland, and also drift-wood." Von Waltershausen in his work on the physical geography of Iceland (p. 347) refers to, without naming, the tropical seeds and fruits thrown up with much drift-timber on the coasts. With respect to Greenland Laughton (p. 249) quotes Irminger to the effect that " beans of Mexican growth are often washed up on the Greenland shores "; and Kohl observes (p. 160) that in the southern Danish settlements of Greenland on the shores of Davis Strait every one knows the seeds of Entada scandens, which are often cast up by the waves.

The Scandinavian Coasts.-The West Indian drift thrown up on the Norwegian coast has been several times mentioned in previous pages. Claussen and Worm in the seventeenth century and many others in the eighteenth century, such as Gunnerus, Pontoppidan, Ström, Tonning, etc., interested themselves in the matter. In the early part of the nineteenth century Wahlenberg, the Swedish naturalist, in his Flora Lapponica (1812, p. 506) referred to the seeds of Mimosa scandentis (Entada scandens) and Dolichos urentis (Mucuna urens) as washed up on the north and north-west coasts of Norway. A few years after, A. de Capell Brooke in the account in his Travels through Sweden, Norway, and Finmark to the North Cape in 1820 (pp. 295, 317, 318) alluded to the drift from the New World cast up on the Norwegian coasts. On the Tromsoe and Röst coasts much timber was found, including baulks of Honduras mahogany. Seeds of Entada scandens are (he says) thrown up after great storms. 
Mr. Bullock, the naturalist, who had himself picked them up on the Orkneys, identified the seeds.

In recent times we have Lindman and Sernander. The last named deals especially with the subject in his Den Skandinaviska Vegetationens Spridningsbiologi (Upsala, 1901, p. 116, etc.); and the results obtained by Lindman and his predecessors, including the Linnean botanists, are there discussed under the name of "Gulf Stream products." Lindman made a comprehensive study of the subject in 1880. It appears that the coasts northward from Söndmöre to Lofoten and Tromsoe receive most of the West Indian seeddrift. But it reaches as far north as the vicinity of the North Cape, and may even, as Robert has shown, double that promontory and enter the White Sea. To the south it extends to the Swedish and Danish coasts, and it is found on the shores of the Baltic Sea. The seeds of most frequent occurrence are those of Entada scandens, Guilandina bonducella, and Mucuna urens. In the first two cases Lindman procured the germination of the seeds. Those of Entada scandens have even been found in a subfossil condition in the peatbogs of Tjörn on the south-west coast of Sweden, having been originally stranded in post-glacial times on a beach in that locality.

A word may be said here on the doubling of the North Cape by West Indian seed-drift. That the seeds reach the extreme north was long ago mentioned by Wahlenberg in the work quoted above, where he refers to them as washed up on the Finmark coast. Robert, the French naturalist, who was in this region in 1835-6, states that his companions found the seed of Mimosa (Entada) scandens on the island of Mageroe, on which the North Cape lies. Lottin, he says, picked up a seed of the same plant near the same promontory in "Laponie" (Lapland), which would indicate a locality to the east of the cape. Robert himself found the same seed on the shores of the White Sea. Gumprecht, Fogh, Vibe, and others allude to these interesting discoveries, the references to which are given at the close of the chapter.

Amongst the stranded drift named in Sernander's list are the fruits of Anacardium occidentale, Cassia fistula, Cocos nucifera, Garcinia mangostana (Mangosteen), Lagenaria vulgaris, etc. The Mangosteen fruit was found by Lindman in 1879 cast up on one of the Lofoten Islands, and was doubtless thrown over from a ship in the vicinity. The two first named have not been found since the time of Gunnerus and Ström in the middle of the eighteenth century; and, as indicated in later pages, their West Indian origin as components of Scandinavian beach-drift is improbable. Gourds and calabashes, sometimes " worked," have been known to be stranded from time to time on the coasts of Norway ever since the days of Gunnerus and Ström. In the discussion of Crescentia it is stated that there are grounds for the belief that some of these gourds of Norwegian beach-drift belong to this genus. Crescentia gourds are in common use in the West Indies, and form a characteristic feature of the drift on West Indian beaches, the tree (C. cujete) being a native of that region. Lagenaria gourds most probably reached the coasts of Norway from passing vessels. Coco-nuts have been picked up on Norwegian beaches 
since the middle of the eighteenth century. They were mentioned by Ström, Tonning, and Linnæus; and Sernander observes that they are generally more or less injured. When at Trinidad some years ago the present writer was informed by Dr. Fredholm that in 1885 he found three coco-nuts within a space of a hundred yards on a beach of one of the Lofoten Islands, evidently derived from a wrecked or a passing ship.

There must be numerous references in Danish literature to West Indian seed-drift on the western coasts of Denmark. In Petermann's Mittheilungen for 1877 (XXIII., 316) mention is made of an interesting note by Prof. Erslev on the occurrence there of seeds of Entada scandens and other tropical products which have been brought by marine currents to the shores of Jutland (see the list of works quoted at the end of the chapter).

The Azores.- The occurrence of West Indian seeds on the beaches of the Azores has long been known. Darwin, who was especially interested in the subject, obtained a number of seeds of Entada scandens and Mucuna urens from these islands and sent them to Hooker at Kew, who referred to the matter in his lecture on "Insular Floras" delivered before the British Association in 1866 (reprint of 1896, pp. 15, 28 ; see also Hemsley's Chall. Bot., IV., 291). Speaking of the Azores, Hooker remarked that "the large Bean-like seeds of Entada, a West Indian climber, are thrown up abundantly on the islands by the Gulf Stream, but never grow into plants, if indeed they ever germinate on their shores." These seeds were sown at Kew, and "many germinated and grew to be fine plants, showing that their immersion during a voyage of nearly 3000 miles had not affected their vitality." (The Mucuna seeds are mentioned by Hemsley as above quoted.)

During my sojourns on the Azores, especially on the north coasts of San Miguel and at the western end of Pico, I paid much attention to this point and obtained the following results. The drift seeds are familiar to the people of the coast towns and villages, and are as often picked up whilst floating off the shores by the fishermen as they are gathered by the children on the scanty beaches. When the purpose of my visit became known in any coast town or village I was usually supplied with several specimens of Entada scandens and of the two species of Mucuna (M. urens and an allied species) represented in European beach-drift. Other drift seeds and fruits are often overlooked or disregarded. Amongst them would be the seeds of Guilandina bonducella. On my displaying a specimen to the people of Magdalena at the west end of Pico they soon brought me a seed which had been found on the beach. The seeds were nearly always sound.

I searched several beaches and picked up the following fruits and seeds : two sound seeds of Sapindus saponaria, one at Magdalena and the other at Porto Pym (Fayal); an empty fruit of Astrocaryum near Magdalena; and a woody fruit, probably belonging to the Juglandea, on San Miguel. The more conspicuous seeds of Entada and Mucuna are soon found on the beaches by the inhabitants. The seeds of Sapindus saponaria are particularly interesting, since, 
as far as I know, they have not been recorded from European beaches. They are characteristic of West Indian beach-drift, and have been known to germinate in the Bermudas after having been brought there by the Gulf Stream.

The complete list of West Indian drift seeds and fruits known to me as stranded on the Azores would be as follows :-

Entada scandens.
Mucuna urens
Mucuna near M. urens.
Guilandina bonducella
Sapindus saponaria.
Astrocaryum (Palmacea).

Note.-Of these the first four have been recorded from European beaches. As in Europe, of the two kinds of Mucuna seeds that of the true $M$. urens is least common, two-thirds of the seeds belonging to the allied species and one-third to $M$. urens proper. The fruit of Juglandea, being of doubtful origin, has not been included in the list.

It is highly probable that these seeds reached the Azores from the West Indies by the circuitous Gulf Stream route. The intervention of the Sargasso Sea $\left(20^{\circ}-35^{\circ} \mathrm{N}\right.$. lat. and $40^{\circ}-70^{\circ} \mathrm{W}$. long. $)$, where there is little or no surface circulation, bars the direct route from the West Indian region. As indicated by the bottle-drift data dealt with in Note 12 of the Appendix, this seed-drift must have been at first carried northward past Cape Hatteras towards the Nova Scotian and Newfoundland coasts, which would involve a tedious drifting passage of at least a year's duration.

Amongst the other constituents of Azorean beach-drift are Ianthina shells, Portuguese men-of-war (Physalia), a little dead Sargasso weed, and pumice, the last often abundant, and as shown in Note 23 in great part of local origin. The Sargasso question is treated in Note 29 of the Appendix; but it may be here stated that living specimens did not come under my notice on the Azores beaches, the dead fragments, which are well incrusted with polyzoa, having been derived, not directly from the Sargasso Sea to the south-west, but by the circuitous route to the northward, past Cape Hatteras, which is taken by the West Indian seed-drift.

The Canary Islands and Madeira.-The writer has come upon no record of West Indian seeds stranded on these islands; but from the indications of bottle-drift discussed in Notes 27 and 28 of the Appendix it is evident that seeds from the tropies of the New World must be at times carried there. Although he spent several days in examining the north coasts of Teneriffe, no seed-drift that he could recognise as hailing from the New World came under his notice. The shores of this island are as a rule not well suited for catching drift; but there are localities, as in the cases of beaches east of Orotava and on the east side of Point Hidalgo, where a considerable amount of oceanic drift is cast up, as shown in the abundance of Spirula shells, Portuguese men-of-war (Physalia), etc. It may 
be added here that Mr. Samler Brown in his Guide to Madeira and the Canary Islands (8th edit., 1905) deals with many kindred matters, but says nothing of the stranding of West Indian seeds.

The Risks of Premature Generalisations on the Dispersal of Seeds by the Great Oceanic Currents. - The discussion to which this chapter has been devoted opens up a number of other questions; and perhaps the one that will first present itself is that connected with the path followed by the floating seed in its traverse of the Atlantic. Without a fairly precise acquaintance with the working of the currents in this direction it is hazardous to generalise on the subject, and to indulge in a picturesque description of the currents at work in distributing seeds.

The floating seed can tell its own story, but in a very imperfect fashion. It can tell us nothing of its route and often nothing of the duration of its ocean traverse; and although we should be usually right in assuming that a tropical seed found on European beaches came from the West Indies, it would not follow that it grew in that region. There would be possibilities that it came originally from the shores of the Spanish Main, or from the estuary of the Amazon, or even from the mouth of the Niger, before it came within the influence of the Gulf Stream in the Florida Sea. Nor could we read its history in its specific name, since the great majority of tropical seeds transported by the currents belong to littoral and estuarine plants common to both the African and the American sides of the tropical Atlantic, and under such circumstances any discrimination as to source would be hazardous.

The need thus presents itself of looking elsewhere for evidence to supply what is lacking in the testimony of the drifting seed, and in our need we appeal in the following chapter to the evidence of bottle-drift. This is all the more requisite since some of the statements one reads concerning the agency of currents in dispersing seeds require considerable qualifications and illustrate the necessity of exact knowledge of the principles regulating the process. Thus in the English form by Prof. Ainsworth Davis of Pouchet's L'Univers (1906, p. 394) Dr. Karl Müller in Les Merveilles du Monde Végétal is thus quoted: "The great current which springs from the eastern coast of South America has been known to bear a flotilla of thirteen species of plants from Brazil and Guiana to the shores of Congo in Africa. . . A Another grand oceanic current, traversing an immense space of the torrid zone, constantly transports fruits from the shores of India, which its waves tumultuously scatter on the rocks of Brazil."

With regard to these currents it is not apparent what the writer could have intended, since the great equatorial currents could only carry materials from the Congo to Brazil, whilst there is no great oceanic current that constantly transports Indian drift to Brazil. It is true that a bottle has been known to reach the Brazilian shores from off the coast of Natal, and that drift from the Indian Ocean can at times find its way into the South Atlantic in a small branch of the Agulhas Current that doubles the Cape, instead of being 
deflected eastward with the main stream; but it would certainly be erroneous to speak of a grand oceanic current establishing constant communication between India and Brazil. On a later page attention is called to a serious blunder by which a bottle is made to reach India from the tropical Atlantic instead of from the mouth of the Red Sea, through a confusion between east and west longitude. In this case fortunately the published record itself supplied the refutation; but this would not always be possible, especially in cases where the supposed fact is quoted without the data.

Transport of Mahogany Logs to the Coasts of Greenland, ICELAND, and THE North-West of Europe.- It is to be expected that seed-drift from the tropics of the New World would be sometimes accompanied by trunks of trees from the same region. Gumprecht (p. 430) mentions that Löwenörn, the Danish admiral, found logs of mahogany in $\mathbf{1 7 8 6}$ on the east coast of Greenland; and he adds that trunks of the same tree are thrown up on the west coast near the island of Disco. In the last case the wood was in such good condition that the Danish governor had a table made of it. I have already referred to Laughton's quotation from the report of the United States Coast Survey for $\mathbf{1 8 6 0}$ that mahogany logs are rolled in on the coast of Iceland. Lyngbye avers in his Tentamen Hydrophytologia Danica, 1819, that he saw on the Faroe Islands a portion of a canoe made of mahogany. Gumprecht (p. 426) and Kohl (p. 159) refer to Irminger's observation of masses of drift-wood on the west side of the Faroe Islands. Drift-timber is also cast ashore on the Shetland Islands, [which may hail from the tropics of the New World. Mr. Fox sent me a piece of cedar(?) which was chopped from a baulk about twenty-five feet long. It was honeycombed by the borings of the Teredo, and was stranded on the west coast. We learn from De Capell Brooke (p. 295) that much timber is beached on the Norwegian sea border in the Tromsoe district and on Röst, and he particularises Honduras mahogany. One may note in this connection Pennant's statement that " part of the mast of the Tilbury man-ofwar, burnt at Jamaica, was taken up on the Western Coast of Scotland" (A Voyage to the Hebrides in 1772).

Living Turtles carried by the Gulf Stream to the Hebrides, the Orkneys, and the Shetlands.-This matter has already been incidentally alluded to. Pennant in his Voyage to the Hebrides in 1772 observes that "American tortoises, or turtle, have more than once been taken alive on these coasts, tempestdriven from their warm seas." Necker de Saussure in his paper in the Bibliothèque Britannique (1809), as quoted by Gumprecht (p. 416), also mentions the stranding of turtles in connection with his sojourn in this group. Mr. Peel in his bookWild Sport in the Outer Hebrides, 1901 (p. 3), tells us that young turtles together with West Indian seed-drift are washed up on the shores of those islands. The Rev. James Wallace, writing of the Orkney Islands at the close of the seventeenth century, states that "sometimes they find living Tortoises on the shore" (1883 edition, p. 17). Some particulars of the discovery of one of these turtles in the Shetlands are given by the Rev. John Brand in his Brief Description of Orkney, Zetland, etc." 
(Edinb. 1701, p. 174 of the 1883 edition). It appears that a specimen, only about a foot in length, was " found alive upon the sand in an ebb" in the parish of Northmevan on the shore of Urie Firth. The occurrence is characterised as a very rare event. From the remarks of Mr. Peel and Mr. Brand it would seem that the turtles stranded on the coasts of the Hebrides and the Shetlands are usually young specimens. Turtles are often carried north from the Florida Straits by the Gulf Stream. On one occasion the writer was on board a steamer, bound north from the Bahamas to Philadelphia, which, shortly after passing the Hatteras Lightship in $36^{\circ} \mathrm{N}$. lat., nearly ran down a large turtle. It raised its head as if in astonishment, and as it swept past the ship's side it was noticed that numerous large Balani had established themselves on its back.

It may be here added that in the London Times for June 19, 1916, allusion is made to a large turtle, weighing nearly a ton, which was taken alive a few days previously in a net off Scilly. In the same net was captured a thresher-shark, nearly 12 feet in length, a species frequenting the seas of temperate latitudes. The turtle, if of West Indian origin, should have been accompanied by seed-drift from that region; but the writer has not since found any drift from warm seas on the South Devon coast. (September 9, 1916. The turtle proved to be the Leathery Turtle which breeds in the Danish West Indies.)

\section{SUMMARY}

1. In order to give point and method to the author's observations on the dispersal of plants by currents in the West Indian region, as illustrated by the examination of the beach-drift and by various buoyancy experiments, the discussion is at first allowed to centre around the fact that some of the materials reach the shores of Europe.

2. The literature of the subject goes back to the time of Clusius, who first figured some of the fruits and seeds in his Exoticorum Libri of 1605. Amongst those who interested themselves in the matter, down to the close of the eighteenth century, were Peter Claussen, the Norse writer (1632); Provost Debes in the case of the Faroe Islands (1673); Petiver, the laborious compiler of the Gazophylacium Natura (1695); Sir Hans Sloane (1695-7); the two Wallaces in the case of the Orkney Islands (1693 and 1700); Martin in that of the Hebrides (1703); Pontoppidan, Bishop of Bergen (1751); Gunnerus, Bishop of Trondhjem (1765); Ström, the Norwegian naturalist (1766); Tonning, the pupil of Linnæus (1768), and Pennant in the case of the Hebrides (1790). Amongst the numerous writers of the nineteenth century who have treated the subject in more or less detail are Humboldt (1807); Necker de Saussure, who sojourned in the Hebrides between 1806 and 1808; Sartorius von Waltershausen in the case of Iceland (184:7); Irminger, famous for his investigations of the currents of the North Atlantic (1854); Gumprecht, whose paper on the drift-products of the North Atlantic (1854) is invaluable to all students of the subject; Fogh in his paper on the Gulf Stream (Copenhagen, 1857); Vibe, chief of the Norwegian 
General Staff Survey (1859-61); and Kohl in his history of the Gulf Stream (Bremen, 1868). Among those who have specially dealt with the botanical side of the subject in recent years are Lindman (1883); Hemsley (1885); and Sernander (1901). The years named refer to the date of the publication concerned, usually the earliest when there is more than one (pp. 20-23).

3. Reference is then made to the popular names in Europe of the West Indian drift seeds and to the superstitions connected with them. One of the earliest designations was "Molucca Beans," a name applied in Scotland and in the neighbouring islands (pp. 23-25).

4. A list is given of the twelve characteristic West Indian seeds and fruits that have been recorded, as far as is known to the writer, from European beaches and from the Azores, the localities being tabulated (pp. 26, 27). The plants supplying them are in half the cases leguminous. Those most frequently represented are Entada scandens, Mucuna urens, and Guilandina bonducella. Amongst the most interesting are Sacoglottis amazonica and Ipomœa tuberosa (pp. 26, 27.)

5. The records of West Indian drift seeds and fruits on the eastern side of the North Atlantic, as far as they are known to the writer, are then described under the headings of localities : the south-west of England (p. 28); the south coast of Wales (p. 30); the west coast of Ireland (p. 30); the west coast of Scotland and the Hebrides (p. 31); the Orkney Islands (p. 32); the Shetland Islands (p. 34); the Faroe Islands (p. 34); Iceland and Greenland (p. 35); the Scandinavian coasts (p. 35), mention being made of the doubling of the North Cape by seeds of Entada scandens (p. 36); the Azores, four of the six kinds of seeds and fruits found here being recorded from European beaches (p. 37); the Canary Islands and Madeira, reference being made to the fact that although the writer has not come upon any record of the occurrence of West Indian drift on these islands the indications of bottle-drift point to its probability (p. 38).

6. The risks of premature generalisations on the dispersal of seeds by the great ocean currents are then dwelt on, and a particular instance is given. Since the seed itself can tell us little of its track, the necessity is urged of looking elsewhere for evidence of the modes of the working of the currents in transporting drift, and the writer accordingly appeals to the evidence supplied by bottle-drift, a subject to which the following chapter is devoted (pp. 39, 40).

7. The chapter concludes with remarks on the transport of logs of mahogany to the coasts of Greenland, Iceland, and North-west Europe, and on the stranding of living turtles on the shores of the Hebrides, the Orkneys, and the Shetlands (pp. 40, 41).

\section{BIBLIOGRAPHY}

BAdHis, C., Pinax Theatri Botanici, 1623. (He quotes on p. 405 the work of Clusius (see below) as regards a drift seed since identified as belonging to I pomaea tuberosa.)

Bathin, J., Historia Plantarum, 1650. (Quoted by Sir D. Morris in connection with the drift fruits of Sacoglottis amazonica in Nature, January 31, 1889.)

Borgesen. See under Warming. 
Brand, J., A Brief Description of Orkney, Zetland, Pightland-Firth and Caithness: Edinburgh, 1701. (Included also in Pinkerton's Voyages and Travels, 1809, iii., 789. Reprinted at Edinburgh in 1883.)

Brooke, A. DE CAPELL, Travels through Sweden, Norway and Finmark to the North Cape in 1820 : London, 1823.

Cundssen, P., A Description of Norway, 1632.

Clusios, C. (De l'Escluse), Exoticorum Libri Decem, 1605. (See Note 2 at the end of this list.)

Deвеs, L. J., Færoæ og Færoeske Indbyggeris Beskrivelse: Copenhagen, 1673. (Another title "Færoa Reserata" is employed in the pages of Vibe and Fogh. An English translation by J. S. (John Sterpin) was issued in London in 1676.)

Erslev, Tropical Drift on the Coast of Jutland, Det Danske Geografiske; Selskab's Tidskrift, Nos. 3 and 4, p. 79, 1877; and Petermann's Mittheilungen, xxiii., $316,1877$.

Frelden, H. W., quoted by Hemsley in Annals of Botany, vi., 1892, concerning a drift seed of I pomoea tuberosa in the Hebrides.

Fogн, C., Golfstrommen, Tidskrift t . populoere Fremstillinger af Naturvidenskaben, Copenhagen, 1857, vol. iv., ser. i. [Quoted at length by Vibe (see below).]

GUmprecht, T. E., Die Treibproducte der Strömungen im Nordatlantischen Ocean, Zeitschrift für Allgemeine Erdkunde, No. 18, December 1854.

Gunnerus, J. C., on Scandinavian drift in Det Trondhjemske Selbskabs Skrifter, vol. iii. : Copenhagen, 1765.

Hemsley, W. B., Reports of the "Challenger" Expedition, Botany, vol. i., part iv., 1885.

, Annals of Botany, vol. vi., 1892.

Hepworth, W. W. CampbelL, The Gulf Stream, Geographical Journal, November and December 1914.

Hомвоцdт, F. H. A. von, Voyage aux régions équinoxiales, vol. i. : Paris, 1807, etc.

Irminger, C., on Iceland drift, Zeitschrift für Allgemeine Erdkunde, 1854, iii., 187.

Jonston, J., Historia naturalis de Arboribus et Fructibus, 1662. (Quoted by Sir D. Morris in Nature, November 21, 1895.)

Конг, J. G., Geschichte des Golfstroms und seiner Erforschung: Bremen, 1868.

Lavghton, J. K., Physical Geography, 1873.

LindmaN, C., Om drifved och andra af hafsströmmar uppkastade naturföremal vid Norges kuster: Göteborg, 1883. [Quoted at length by Sernander (see below).]

Lymgrye, H. C., Tentamen Hydrophytologiæ Danicæ, 1819. (In connection with the Faroe Islands.)

Martin, M., A Description of the Western Islands of Scotland : London, 1703. (Martin Martin was a native of the Hebrides and took his M.A. degree at Edinburgh in 1681. A second edition of his book was issued in London in 1716, and a reprint of the first edition in Edinburgh in 1884. In a copy of the 1716 edition in the library of the British Museum there are marginal notes by J. Toland and Lord Molesworth, written about 1720-21. Toland flourished 1670-1722. Martin's work is also included in Pinkerton's Voyages and Travels, 1809, iii., 572.)

Monaco, Prince op. The results of his experiments with floats in the North Atlantic were published from time to time in the Comptes Rendus de l'Academie des Sciences between 1885 and 1892. Most of them were summed up in vol. cviii. (1889); but he subsequently recovered some more floats, and this led to a further summary with tabulation of results in vol. cxir. (1892).

MorRIS, SIR D., on the drift fruits of Sacoglottis amazonica, etc., in Nature, January 31,1889 , and November 21, 1895.

MÜLLER, K., Les Merveilles du Monde Végétal. [Not consulted. The work is quoted in the English edition of Pouchet's L'Univers (see below).] 
Neml, P., A Tour through some of the Islands of Orkney and Shetland : Edinburgh, 1806. [His references to Molucca Beans (pp. 60, 213) contain nothing that is not given by the Wallaces and others.]

Ostenfeld. See Warming.

Pres, C. V., Wild Sport in the Outer Hebrides, 1901. (There is a reference on p. 3 to West Indian drift seeds.)

Pennant, T., A Tour in Scotland and a Voyage to the Hebrides in 1772 : London, 1790. (Also included in Pinkerton's Voyages and Travels, 1809, iii., 289.)

Petiver, J., Musei Petiveriani : London, 1695 (octavo).

- Gazophyllacii Naturæ: London, 1702 (octavo).

- Jacobi Petiveri Opera, Historiam Naturalem Spectantia aut Gazophylaceum : London, 1764. A large folio work in two volumes containing 1000 figures of natural history. The contents of all the plates are described with the exception of the first fifty, the descriptions of which are given in the volume of 1702 .

Pontoppidan, E., Det förste Forsög paa Norges Naturlige Historie: Copenhagen, 1751. [An English translation was published in London in 1755.]

Podcher, F. A., The Universe, translated from the French by J. R. Ainsworth Davis, 1906, p. 394. Dr. Karl Müller in Les Merveilles du Monde Végétal is quoted.

Robert, E., Voyage en Islande et au Groenland, sous la direction de M. Paul Gaimard, Mineralogie et Geologie, part i., p. 131: Paris, 1840. (Reference is here made to the occurrence of seeds of Entada scandens at the North Cape and on the shores of the White Sea. In this connection Gumprecht (p. 421) quotes Robert in citing Le Bulletin de la Société Géologique de France, xiii., 30.)

Sadssure, Necker dr, Voyage en Écosse et aux Iles Hébrides, iii., 22 : Paris, 1821. (With reference to the tropical drift of the Hebrides, Gumprecht (p. 416) quotes a paper of this naturalist in the Bibliothèque Britannique, Sciences et Arts, 1809, xlii., 90.)

Scнјӧтн, A., Om enkelte af Havets Phänomene (On different Marine Phenomena): Christiania, 1848. Quoted by Vibe (see below).

SERNANDER, R., Den Skandinaviska vegetationens spridningsbiologi (The distribution-biology of the Scandinavian plant-world), mit einem deutschen Pésumé : Upsala, 1901. (An extensive bibliography is appended.)

Sibbald, Sir R., Scotia Illustrata sive Prodromus Historiæ Naturalis Scotiæ: Edinburgh, 1694. (The earliest work known to the writer in which West Indian seeds stranded on the shores of Scotland and of the neighbouring groups of islands are designated "Molucca Beans.")

Sloane, Sir Hans, Catalogus Plantarum quæ in insula Jamaica sponte proveniunt, 1696 , p. 214, quoted by Sir D. Morris in Nature, November 21, 1895, and by Gumprecht (p. 411).

- An Account of four sorts of strange Beans frequently cast on shore on the Orkney Isles, Philos. Trans., xix., 298, 1695-7.

-, A Voyage to the Islands of Madera, Barbados, Jamaica, etc., 1707 and 1725. (Nearly all the work is occupied with "The Natural History of Jamaica," an island where he sojourned about fifteen months, 1688-9.)

Strö̀, Physisk og Oeconomisk Beskrivelse over Fogderiet Söndmör beliggende i Bergens Stift i Norge: Soroe, 1766. (Quoted by Gumprecht on p. 420.)

TABERn fmontands. See Note 2 at the end of this list.

Tonning, Amcenitates Academica, vii., 477. (A pupil of Linnæus and the first botanist who identified the tropical fruits and seeds cast up on Scandinavian beaches.)

Vibe, A., Küsten und Meer Norwegens, in Petermann's Mittheilungen, Ergängzungsband, i., 1859-61.

Wahlenberg, G., Flora Lapponica, p. 506 : Berlin, 1812.

Wallace, Rev. J., A Description of the Isles of Orkney by Master James Wallace, late Minister of Kirkwall, published after his Death by his Son : Edinburgh, 1693. 
Wallace, Dr. J., An Account of the Islands of Orkney by James Wallace, M.D., F.R.S. : London, 1700. (This writer is the son of the Rev. J. Wallace. The work is his father's with additions, but without acknowledgment. In 1883 there was published at Edinburgh a reprint of the 1693 edition, edited by J. Small, which included the materials added by the son in that of 1700.)

Waltershadsen, Sartorius von, Physisch-geographische Skizze von Island, 1847.

Warming, E., and colleagues, Botany of the Færoes : Copenhagen, 1901-8.

Worm, O., a Danish naturalist of the seventeenth century whose "Epistolæ" are quoted by Gumprecht (p. 420) in connection with Scandinavian tropical seeddrift.

Note 1.-Gumprecht (pp. 421, 428-30) gives references in connection with driftwood stranded in high latitudes in the North Atlantic to Petherick, Olafsen, Povelsen, Crantz, von Löwenörn, de Pauw, Rennell, Irminger, Robert, Barrow, etc.

Note 2.-Though the "Exoticorum Libri" of Clusius are mentioned by old and modern botanists in association with West Indian drift seeds, he merely described and figured certain unknown fruits and seeds that had been given to him and supplies no information about them. However, Gumprecht (p. 418) states that they were also described and figured "in seinen Anmerkungen zu des spanischen Botanikers Nicolas Monarde Bericht (Exotica, c. 49, p. 335) über die Pflanzen Westindiens." $\mathrm{He}$ says the same (ibid.) of a botanical work of Tabernæmontanus, but gives no reference.

Note 3.-Whilst this work was going through the press I have been able, through the kindness of Miss U. Warren, to inspect two seeds, evidently sound, of Entada scandens, which were found near Padstow on the north coast of Cornwall. 


\section{CHAPTER III}

THE CURRENTS OF THE ATLANTIC AND THE TRACKS OF DRIFTING SEEDS AS ILLUSTRATED BY BOTTLE-DRIFT

As indicative of the path followed by the drifting seed in its passage across the Atlantic and of the time occupied in the ocean traverse, the track of the drifting bottle offers very valuable data. But it may be at once stated that there is no intention of dealing here with all the materials which have accumulated in recent years with reference to this subject. They are merely sampled in these pages with the special object of throwing light on the interchange of seed-drift between the Old and the New World. Notwithstanding these limitations, the materials are quite as much as I can handle; and any extension of the inquiry would result in the opening up of the whole subject of bottle-drift, which would lead me far beyond the limits set for this discussion.

One of the earliest to make a collection of bottle-drift data was H. Berghaus, who, in 1837, in the first volume of his Allgemeinen Länder und Völkerkunde, published a list of twenty-one bottle-drifts, and laid down in a chart in his Physikalischen Atlas several interesting examples. I have not had access to these works, and am indebted to Schott for the reference. Shortly afterwards a chart of bottle-drifts constructed by Daussy, a Frenchman, is stated to have been published; but I have not been able to find it. It is mentioned by Kohl in his Geschichte des Golfstromes (1868); but the author's name is given as Dayssy, and one is referred for particulars to Nouvelles Annales des Voyages (tome lxxxii., Paris, 1839), where one finds only a brief notice of the results obtained. Schott (p. 2) alludes to the missing chart, but he merely quotes Kohl. After some search I found in Comptes Rendus (tome viii., p. 81, 1839) a short paper of two and a half pages by M. Daussy, entitled "Sur les observations de courants faites au moyen de bouteilles jetées à la mer." He states that he had utilised ninety-seven bottle-drift observations in his table and chart, which, however, do not accompany his paper. Probably they lie among the unpublished records of the Academie des Sciences of Paris.

Major Rennell, in his Investigation of the Currents of the Atlantic Ocean (1832), deals with the subject, and especially with the bottledrift from high northern latitudes, many interesting examples being given. In 1852 Commander Becher published in the Nautical Magazine, with charts, the data for about 180 bottle-drifts in the North Atlantic, two-thirds of which had been previously published 


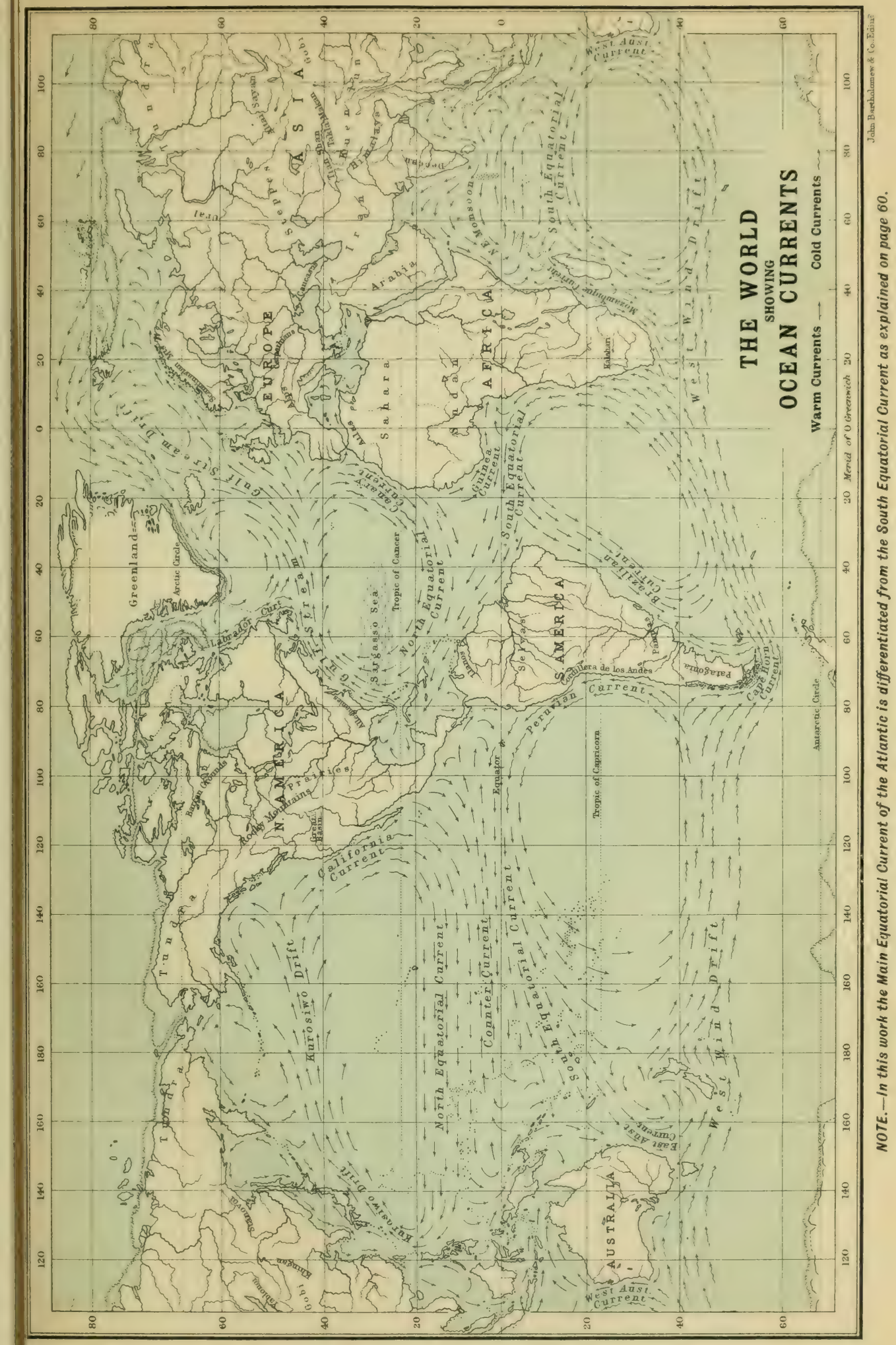



in the same journal for 1843. These results, where suitable, have been utilised by me. However, most of my materials have been supplied from the results gathered in recent years by the United States Hydrographic Office in Washington and by the Deutsche Seewarte in Hamburg. The first were published on the backs of the North Atlantic Pilot Charts, while the second were embodied in Dr. Schott's memoir Die Flaschenposten der Deutschen Seewarte, 1897. By far the most extensive and systematic inquiry ever made in this direction was that conducted by Albert, Prince of Monaco, from 1885 to 1887 . Floats, specially devised, were employed; but the mode of presentment of his results and the absence of his chart have stood in the way of my employing them as much as I could have wished. As will be seen from the following pages, however, they have proved of great value.

Whilst my facts for the North Atlantic are mainly derived from the American Pilot Charts and for the South Atlantic from Dr. Schott's work, those for the equatorial seas are chiefly derived from both these sources and to a less degree from the Nautical Magazine. With great courtesy the U.S. Hydrographic Office supplied me with a set of four bottle-drift charts, covering the eight months from October to May 1900-8, and affording the data and tracks for about 650 bottles. Dr. Schott, whilst preparing his memoir, had at his disposal the materials for 643 bottle-drifts in the Atlantic, Indian, and Pacific Oceans. Of these 452 are concerned with the North Atlantic and $\mathbf{1 0 2}$ with the South Atlantic, forty-three with the Indian Ocean, and forty-six with the Pacific Ocean. The tracks for most of the Atlantic bottle-drifts are laid down in his charts. Thus in the case of the North Atlantic about three-fourths are thus laid down. The tracks of all those in the Indian and Pacific Oceans are represented in separate charts, and some highly interesting data are given for a few bottles in the belt of the Westerly Winds in high southern latitudes. But the weak point in the memoir is the deficient supply of facts relating to the duration of each drift. In this respect Dr. Schott only samples the subject, referring the reader for the complete data to the Archiv der Seewarte and the Annalen der Hydrographie. However, sufficient materials are given in his pages for the elucidation of this part of the inquiry.

With regard to the Prince of Monaco's investigations during three voyages in the North Atlantic, 1885-7, it may be said that in the first voyage (1885) 169 floats were dropped into the sea to the northwest of Corvo in the Azores. In the second (1886) as many as 510 floats were cast over about midway between the Azores and Southwestern Europe along a line, $\mathbf{4 5 0}$ miles in length, nearly on the meridian $17^{\circ} 40^{\prime} \mathrm{W}$. of Greenwich and between the latitudes of $42^{\circ} 32^{\prime}$ and $50^{\circ} \mathrm{N}$. In the third voyage 931 floats were thrown over between the Azores and the Banks of Newfoundland and sixty-five to the north of those islands, at average intervals in most cases of 1180 metres, along a line 700 miles in length. Out of this total of 1675 floats, 226, or $13 \frac{1}{2}$ per cent., were recovered. From time to time, between 1885 and 1892 , the results were given to the world in the Comptes Rendus hebdomadaires des Sciences. Most of them were 
summed up in Vol. CVIII. (1889); but fifty-six floats were afterwards returned, and this led to a final summary and tabulation of results in Vol. CXIV. (1892). This final report is said to have been accompanied by a chart in which the Prince of Monaco laid down the tracks of all of the recovered floats. This chart, to my great disappointment, I failed to find. Reference to these very important investigations has been made in various English journals, such as Nature and the publications of the Royal Geographical Society. The Prince himself contributed a general account of his results to the Proceedings of the Society just named for 1892 in a paper entitled "A New Chart of the Currents of the North Atlantic." He read a paper before the British Association in 1892, but it is not given in the Annual Report. His results will be utilised, as occasion requires, in the succeeding pages; but it may be here observed that these floats were stranded on all the eastern shores of the North Atlantic from the North Cape to Morocco. About 9 per cent. of the

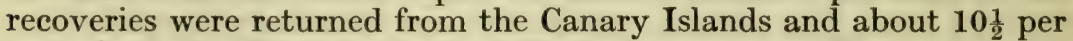
cent. from the West Indies and Central America. The reader will perhaps be surprised at the large number of these floats that reached the tropical regions of the New World, and this will prepare him for much that follows in the succeeding pages of this chapter.

The Value of Bottle-drift Data for the Study of the Dispersal of Seeds by Currents.-I will not enter here into the old controversy as to the value of bottle-drifts for the investigation of currents. Here, as in most other controversial matters, the via media between wholesale condemnation and uncritical acceptation may be confidently pursued. We are only now concerned with the surface-flow, which is all that the currents signify for us in the transport of floating materials. Although, as the compiler of the American charts remarks, the individual drifts are but the resultant effect of all the forces to which the bottle is exposed during its passage, yet, as he goes on to say, the tracks followed by these floating bottles furnish a fair conception of the drift-currents. When we look at the American and German charts and notice how uniform and consistent is the direction taken by bottles cast into the sea within the limits of well-known currents like the Gulf Stream and the Main Equatorial Current, it would be idle to cavil at the assumption that they are transported by these currents. The water-logged derelict from off Cape Hatteras, the baulk of mahogany from West Indian waters, the living turtle from the warm latitudes of the New World, the floating bottle containing the record of its start in Cuban waters or in Florida seas, the buoyant seed that could only have grown in the West Indian islands or on the tropical mainland of America, all tell the same story when they reach the coasts of Europe.

The Proportion of Recoveries.-Naturally, the proportion of recoveries among ordinary bottles is small; but much depends on locality. Dr. Schott especially alludes to this matter (p. 3, etc.). The proportion may be as high as 10 per cent. in the case of bottles dropped overboard in the warm latitudes of the middle of the Atlantic, whence they are borne westward to the West Indies; and 
when conspicuous, specially devised floats are used, as with the Prince of Monaco's investigations in the North Atlantic, it may be as much as $13 \frac{1}{2}$ per cent. Very few bottles are returned from the West African coasts, and the same may be said of those thrown over in high southern latitudes. In the last case the rare recoveries possess a high interest. Thus out of sixty bottles dropped overboard by Dr. G. Neumayer during a voyage in 1864 from Australia to the equatorial Atlantic by Cape Horn, only one was recovered after a lapse of four years, and that was a bottle that was drifted from Cape Horn to South-east Australia (Schott, p. 2). A similar experience is recorded in the London Times for April 17, 1912. Of forty bottles dropped overboard during a voyage in 1908 from London to Melbourne by the Cape of Good Hope, only one record was returned, and that was concerned with a bottle which was washed up on the coast of Chile, after drifting from a position lying some hundreds of miles to the south-west of Cape Leeuwin, Australia.

The Difficulties connected with the Delay in the Recovery of the BotTles.-These difficulties prove to be not so great as at first they seem to be. The belated "finds" become very evident when one handles numerous data for the same drift-passage; and at times the records for a set of bottles dropped over at or near the same time display internal evidence of critical value. Thus, if the one that has travelled the longest distance is found first, it is fair to infer, in the case of transatlantic drifts, that the delay in its recovery was relatively short. As explained in a later page, in order to eliminate this disturbing element as much as possible, I have utilised, when estimating the average drifting-rate for a particular traverse, only the records for the bottles with the quickest rates up to 20 or 25 per cent. of the total. I have since ascertained that the Prince of Monaco adopted a similar method in determining the mean velocity of the "drifts." When they were numerous, he took the average of the fastest third or fourth. When they were few, he selected the most rapid example. At times the remark of the finder that the bottle appeared to have been stranded at the last tide is very serviceable; but the record is particularly valuable when, as occasionally happens, the bottle has been found afloat.

The Tracks of Bottles thrown Overboard together.Interesting results are supplied by the American charts in the cases of bottles thrown over together off the eastern coasts of the United States. They may be distributed fanwise, and are then cast ashore on the coasts of Europe in places far removed from each other, or they may be recovered on the European side only a few miles apart. Thus, out of eight bottles thrown together into the sea off Cape Hatteras from the s.s. New York on March 24, 1906, one was found on the coast of Scotland, two on the Irish coast, two near Arcachon on the shores of the Bay of Biscay, one in the Azores, one in the Bermudas, and one on Grand Turk at the southern end of the Bahamas. As an example of bottles drifting in company across the Atlantic, I will take the case specially noted in these charts. From the s.s. Cherokee two bottles were put overboard together near 
Cape Hatteras on October 26, 1905, and they were recovered on June 10 and 19, 1907, in the vicinity of Bray Head and Cape Clear on the south-west shores of Ireland, about fifty miles apart as the bird flies. A very remarkable instance of this kind is recorded by Mr. Wood-Jones in the Indian Ocean, though there was here an unexplained delay in the recovery of one of the bottles. Two bottles, dispatched on November 15, 1905, from Keeling Atoll, were found at " exactly the same spot" at Brava on the coast of equatorial East Africa in $1^{\circ} 6^{\prime} \mathrm{N}$. lat. The first was recovered on May 27, 1906, and the second on July 11, 1907 (Coral and Atolls, pp. 294-5, 1910). It is probable that these two bottles drifted together and that from some cause the second was overlooked.

But this is the exception and not the rule. Rennell, in his book on the Atlantic currents, refers to two bottles thrown over from H.M.S. Nerwcastle on June 20, 1819, rather over 300 miles south-east of Cape Cod in localities about twenty miles apart, one of which was picked up on May 20, 1820, on the north coast of San Jorge in the Azores, and the other near the island of Aran on the north-west coast of Ireland on June 2, 1820, the difference in latitude represented by the divergence of the two tracks being about sixteen degrees. [These two cases are included by Becher in his list of bottle-drifts in the Nautical Magazine for 1852 (Nos. 97 and 98), but the positions there given of the starting-places are about sixty miles apart.] The separation of bottles thrown over together may be soon effected, even where there is no reason to suspect the presence of contiguous currents. Schott (p. 18) alludes in this connection to Hensen's experiment in Kiel Bay with ten weighted glass globes, which after twenty-four hours displayed an extreme separation of a German mile (nearly five English miles). Of course, when the bottles are dropped overboard in the disputed area between two contrary currents, as in the case of the Main Equatorial Stream and the Guinea Current, great divergencies are to be looked for. A striking instance is mentioned in Note 19 of the Appendix. Of two bottles that were cast over together in the vicinity of St. Paul's Rocks in the middle of the Atlantic, one was thrown ashore on the coast of Sierra Leone and the other on the shores of Nicaragua.

The Divergent Tracks of Derelicts and Casks.-Derelicts display some curiously divergent courses in the North Atlantic. Reference is made in Notes $\mathbf{1 5}$ and $\mathbf{1 6}$ of the Appendix to two derelicts which commenced their drifting passage within sixty miles of each other, about 200 or 250 miles north of Cape Hatteras, at the same season (February and March), but in different years. One was stranded in the Hebrides and the other on the Panama Isthmus, after periods of ten and eighteen months respectively. Waterlogged derelicts are especially instructive, since their position at different stages of their track is often determined by the observations of passing vessels. In the Nautical Magazine for 1843 (p. 757) and 1852 (p. 672) allusion is made to the drift of some casks of blubber from the ship William Torr that was wrecked in Davis Straits. As they were carried eastward and southward towards Ireland and the north of France they became more and more separated, so that 
after crossing the 20th meridian of west longitude, a drift probably of at least 1500 miles, the most northerly and southerly casks were nine or ten degrees of latitude apart.

The Circulatory Movement of the Surface-waters of the North Atrantic.-Broadly viewed, to adopt the standpoint of the Prince of Monaco, this movement has its centre somewhat to the south-west of the Azores. The circumferential waters, after skirting the eastern shores of North America, cross the ocean to the shores of Europe, and then bending south along the African coast, curve west in the vicinity of the Cape Verde Islands and follow the line of the North Equatorial Current to the West Indian region. Between the tracks involved in a very long circuit at the circumference of the movement and a very short one around its centre several intermediate tracks are possible for drift.

With these preliminary remarks I will at once proceed to deal with the evidence of the drifting bottle, and it may be here said that it is with the long outer circuit of the North Atlantic that the tracks of the bottles laid down in the American and German charts are mainly concerned. They represent the course followed by West Indian drift in reaching Europe, and the course that would be afterwards pursued by the same drift in returning to the West Indian region, or by European and West African drift in reaching the New World. A large segment of this circuit did not come within the area covered by the Prince of Monaco's investigations, namely, that lying between the West Indies and a line uniting Newfoundland with the Azores. It is here that the materials supplied by the American charts are most valuable.

Whether the circuit is accomplished by the same bottle or by different bottles the indications are the same. Even if it cannot often be absolutely demonstrated by one example (see Note 15 of the Appendix), the circuit of the North Atlantic can be illustrated in piecemeal fashion by the records of two or three examples. Leaving the warm waters of the West Indian seas, the drifting bottle would be carried swiftly by the Gulf Stream through the Straits of Florida, whence it would be borne northward past Cape Hatteras to the parallels of $40^{\circ}$ to $45^{\circ}$ south of Cape Race. Then, coursing eastward, it would, on approaching the 40th meridian of west longitude, come to a parting of the tracks. Whilst the great bulk of the drift would continue its easterly course towards the shores of Europe, a portion would be deflected south to the Azores. Much of this would be stranded on these islands, but much also would traverse the group, and after passing well to the westward of the Canaries would come within the influence of the North Equatorial Current, ultimately reaching the Bahamas or the Florida coasts, or even the Bermudas. But our interest lies with the fate of the great mass of the drift. Continuing its easterly course, but with a northerly trend, most of it would be spread out fanwise and would be distributed over the whole length of the western shores of Europe from the North Cape to Cape St. Vincent, even reaching Morocco. Yet a small portion of it would keep to the open ocean. Carried south in the Portuguese Current, it would leave samples of its materials on the beaches of 
Madeira and the Canary Islands, and after approaching the vicinity of the Cape Verde Group it would get into the full stream of the North Equatorial Current, and thus be borne to the West Indian region. Whilst, as already indicated, the conclusions for the first portion of this circuit are mainly based on the American charts, those for the remainder are also founded on the Prince of Monaco's results. With these introductory remarks I will first deal with the traverse of the North Atlantic by drift from the American to the European side of the ocean, and afterwards with the return passage from European and African waters to the West Indian region.

The Passage of Bottle-drift from the West Indies and the East Coasts of North America to the Shores of Europe

\section{TABLE I}

The traverse from the West Indies to the shores of Europe

(Compiled from the American, German, and English sources above named. The columns A, B, C, D, indicate not only the starting-places of the bottles, but also the track pursued by them in the passage from the New to the Old World. The circuit of the North Atlantic is also illustrated by those bottles, which, on approaching the shores of Europe, were deflected south, and after passing through the Canary Islands, were returned to the West Indian region in the North Equatorial Current.)

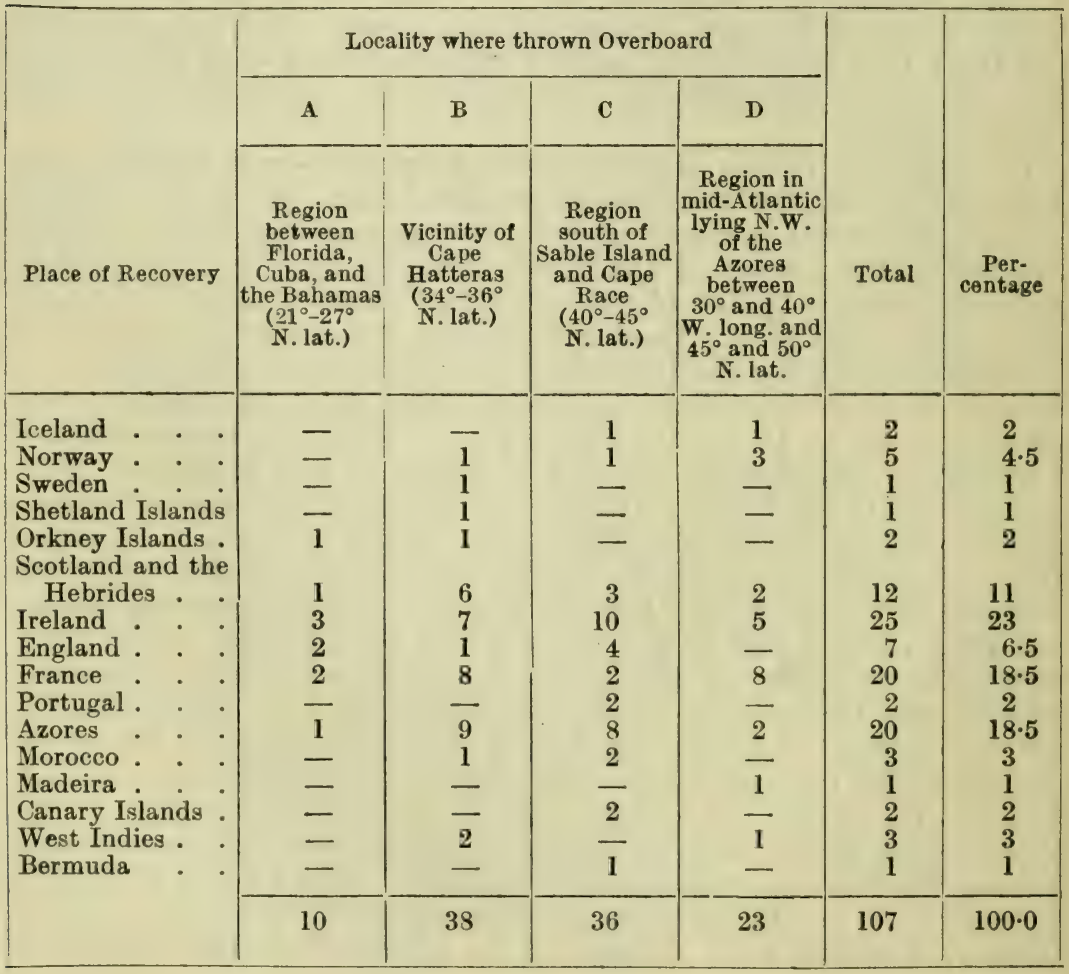


The Passage of Bottle-drift from the West Indies and the East Consts OF North America to the Shores of Europe (continued)

TABLE II

\section{The results of the researches of the Prince of Monaco}

(The specially devised floats employed were deeply immersed and were thus less likely to be directly influenced by the wind than the ordinary bottle as usually employed. Only the latter part of the traverse from the West Indian region to the shores of Europe is here illustrated, namely, the portion east and north of a line drawn from the Azores to the Banks of Newfoundland. Quite two-thirds of the floats were dropped into the southern half of the area traversed by the Gulf Stream, using that term in a general sense; and this explains the large percentage of floats that were deflected south to the Canaries and ultimately reached the West Indies in the North Equatorial Current.)

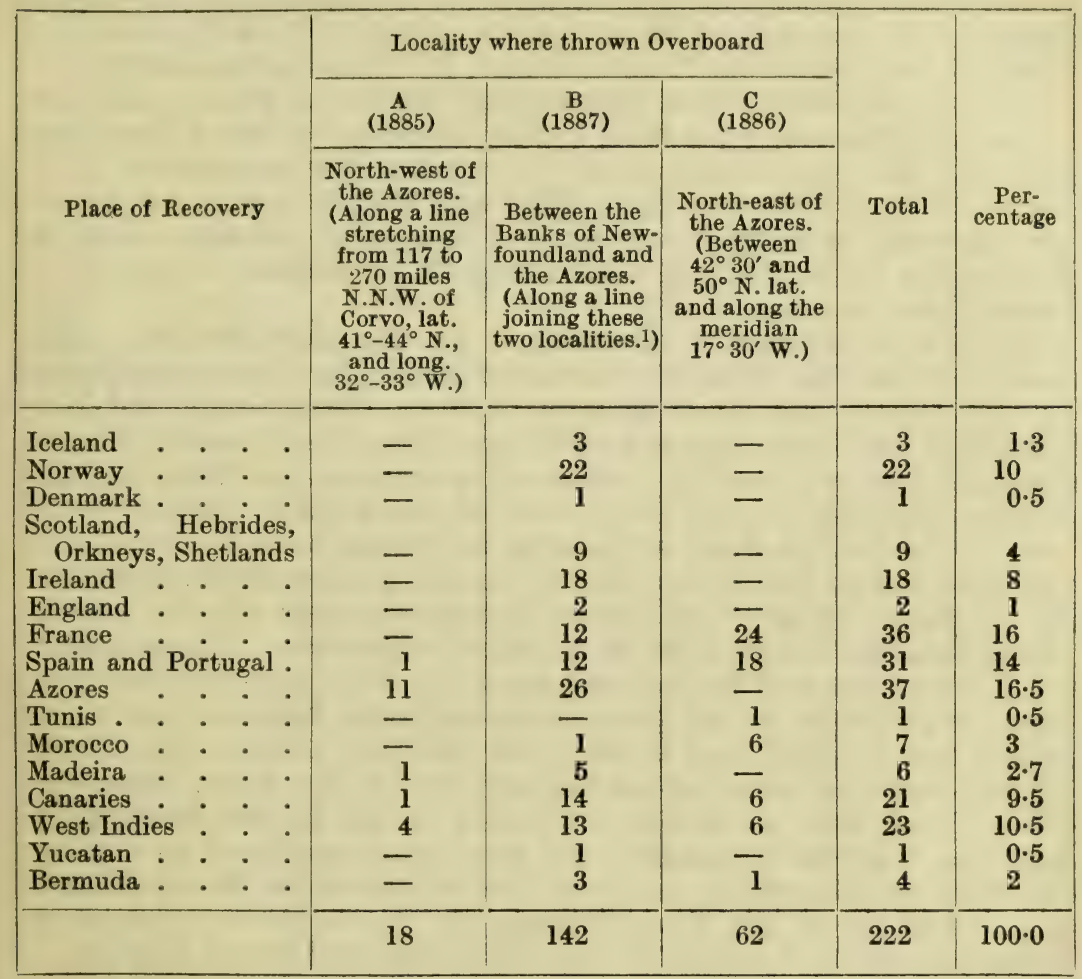

The Passage of Bottle-drift from the West Indies and the East Coasts of North America to the Shores of Europe.-This traverse is well illustrated in the two tables above, about which a few explanatory observations may here be made. Three-fourths of the materials employed in the first table are furnished by the Pilot

1 The Prince of Monaco includes in these results a small group of floats (about an eighth of the total) dropped overboard due north of the Azores between the positions $49^{\circ} 31^{\prime} \mathrm{N}$. and $29^{\circ} 7^{\prime} \mathrm{W}$. and $48^{\circ} 58^{\prime} \mathrm{N}$. and $26.7 \mathrm{~W}$. 
Charts of the North Atlantic published by the United States Hydrographic Office for the eight months October to May 1900-8, the rest being supplied by Dr. Schott's memoir Die Flaschenposten der Deutschen Seerwarte (1897), the Nautical Magazine for 1852, and in a few cases from sundry sources. The second table deals with the results of the researches of the Prince of Monaco, and have been prepared from his papers in the volumes of the Comptes Rendus from 1885 to 1892.

In the first table there are given the records for 107 bottles that started from the four regions A, B, C, D in their traverse of the North Atlantic. Since all the four starting-places lie in the main track of the drifting bottles from the tropies of the New World to the shores of Europe, the limits being determined by the data themselves, it follows that all the materials in this table may be used to illustrate the passage of West Indian bottle-drift to the shores of Europe. But this table tells us more. It tells us of the bottles that were deflected south when approaching European waters, and were ultimately returned to the West Indian region in the North Equatorial Current. In other words, it also illustrates the completion of the circuit of the North Atlantic. With this last, however, we are not here specially concerned, except in so far as it informs us of the distribution of bottle-drift that leaves West Indian waters on its transatlantic passage.

The course pursued is determined by the Gulf Stream. After emerging from the Florida Strait, the bottles are borne northward by this current past Cape Hatteras towards Nova Scotia and Newfoundland, and then eastward with a northerly trend towards Europe, spreading out in a fan-like fashion after crossing the 40th meridian of west longitude to the north-west of the Azores. About 18 per cent. of the bottles dealt with in the table were soon diverted south and stranded on the Azores, but by far the greater number, amounting to about 75 per cent., were distributed over all the exposed coasts from the North Cape of Norway to Morocco. The remaining seven of the hundred bottles, still speaking of them in a proportional sense, were borne in the Portuguese or North African Current yet further south. One was beached on Madeira, two on the Canary Islands, and four came within the influence of the North Equatorial Current and were ultimately recovered in the Lesser Antilles, the Bahamas, and the Bermudas. Of those just mentioned as reaching the West Indian region, one from the middle of the North Atlantic was picked up in the Turks Islands at the south-east end of the Bahamas, whilst two from off Cape Hatteras were found respectively on the island of Anguilla in the Lesser Antilles and on that of Eleuthera in the North-west Bahamas, the circuit of the North Atlantic being almost completed in the last case.

It may here be observed that the fan-like distribution of bottledrift from the New World on the coasts of Europe, though naturally most pronounced when we lay down on a chart the tracks of numbers of bottles from the same locality covering a period of several years, is also well exhibited in the case of bottles thrown over together. This is well exemplified in the case of bottles that begin the ocean 
traverse in the vicinity of Cape Hatteras. If we take a period of years, they may be distributed, as shown in the preceding table, over the whole stretch of seaboard from the north of Norway to Morocco, which represents a range of about forty degrees of latitude. These bottles were dropped over not only in different years, but in different seasons and within an area covered by two degrees of latitude. One could scarcely expect such a divergence of tracks in the case of bottles thrown overboard together off the same headland. Yet it may be large; and in this connection reference may again be made to the divergence of the eight bottles thrown over together off Cape Hatteras (see p. 49). Of the five thrown up on the shores of Europe, the extreme range in latitude was almost eleven and a half degrees, the northernmost being cast up on the island of Colonsay off the west coast of Scotland and the southernmost on the shores of the Bay of Biscay in the vicinity of Arcachon. Yet we have to assume a much greater divergence for the whole group of bottles, since three of them were deflected south and were recovered on the Azores, the Bahamas, and the Bermudas.

Various disturbing influences doubtless affect in different years and seasons the distribution of drift from the New World in its traverse of the North Atlantic. But of this we may be assured that there is no one tract of seaboard on the European side that receives all its transatlantic drift from the same region of the New World. The Irish coasts receive drift from all latitudes on the American side of the North Atlantic between the Caribbean Sea and Davis Strait. So also the North Cape of Norway receives drift alike from the Greenland coasts, from off Cape Hatteras, and from the Florida seas. For particulars relating to bottle-drift from Davis Strait and the south end of Greenland reference may be made to the concluding remarks of Note 27 of the Appendix.

Coming to the Prince of Monaco's results in the second table, it may be at first observed that they only lend themselves in part for the discussion of the traverse of the North Atlantic from the New to the Old World, since they are not concerned with the first half of the passage from the Florida Straits to a line drawn from the Newfoundland Banks to the Western Azores, and even with this limitation their indications mainly apply to the southern portion of the drift that the Gulf Stream bears eastward towards Europe. But what we lose in one way we gain in another, since they offer a splendid illustration of the circulatory movement of the surface-currents of the North Atlantic, which formed one of the principal objects of this unrivalled series of investigations. It will be observed that the results for $\mathbf{1 8 8 5}$ and $\mathbf{1 8 8 6}$ mainly illustrate this southern divergence of the drift, which begins to the north-west of the Azores and is continued until after the 20th meridian of west longitude is crossed. Of the eighty floats recovered in these two sets of observations, not one was found north of the coasts of France, and ten of them, or a proportion of $12 \frac{1}{2}$ per cent., were returned to the Prince of Monaco from the West Indies. This is four times as great as that represented in Table I. for bottles that in reaching the West Indian region have practically performed the circuit of the North Atlantic; and it 
should be noticed that the proportion of bottles stranded on Madeira and the Canaries is tripled in the case of the Prince of Monaco's floats thrown over in 1885 and 1886.

The Prince's results for $\mathbf{1 8 8 7}$ are most suited for comparison with those of Table I. But even here it is obvious that if we make a cross-section of the Gulf Stream drift in mid-Atlantic, these results are more concerned with the southern half than with the northern half of the section. Thus the great increase in the proportion of floats deflected towards warm southern latitudes is here repeated, about 13 per cent. being carried to Madeira and the Canaries and about 10 per cent. to the West Indian region. This tendency is well exhibited in the differences in the two cases between the proportions of bottles or floats stranded on the European side of the Atlantic in latitudes north of the French coasts. This proportion in the case of the results given in Table I. is as much as 51 per cent., whilst for the results obtained by the Prince of Monaco for 1887 it is barely 39 per cent.

With these exceptions, most of the principal features in the distribution of transatlantic drift that are illustrated in Table I. are reproduced in the Prince of Monaco's results. His floats were found on all coasts of the European side of the North Atlantic from Norway to Morocco, and they even penetrated into the Mediterranean. It may be added that the large proportion of the floats recovered in Norway in the series of experiments made in 1887 is to some extent counterbalanced by the diminished proportion found on the coasts of Ireland and Scotland, inclusive of the islands near.

The Passage of Bottle-drift from the European and African Side of the North Atlantic to the West Indies.-This has already been demonstrated by implication from the data in the previous tables that are employed to establish the completion of the circuit of the North Atlantic by drifting bottles and floats. But we will here deal with those bottles that commence the ocean traverse in European or African waters, or in different parts of the track to the New World; in other words, with those that perform the last half of the circuit. As before observed, bottle-drift in European waters is carried south in the Portuguese or North African Current past Madeira and Canary Islands to the vicinity of the Cape Verde Group, whence it is borne westward in the North Equatorial Current to the West Indies. Before discussing this subject I will give the materials on which my conclusions are based (see table, p. 57).

Although the table largely explains itself, some additional remarks may here be made; and in the first place I will give a few details about the "places of recovery." Most of the bottles entered in Column A, under the heading "Bahamas," were recovered at the south-east end of the Bahamian group, namely, on the Turks, Caicos and adjacent islands. Out of the twenty-six there recorded, twenty are thus accounted for. Two were found in the middle of the group and four at the north-west extremity. Of the twenty bottles found in the Greater Antilles, as given in Column B, four were stranded on the south coast of Jamaica and on the small islands near, whilst all the rest were beached on the coasts of Cuba, Hispaniola and Porto 
Table Illustrating the Passage of Bottle-Drift from the European and African Side of the North Atlantic to the West Indies

There are here shown the places of recovery in the West Indies and on the American mainland of bottles thrown over in most cases on the eastern side of the North Atlantic between the south-west of Ireland and the Cape Verde Group and transported across the ocean in the North Equatorial Current.

(The materials are derived from the bottle-drift charts of the U.S. Hydrographic Office for October to May 1900-8, from Dr. Schott's Die Flaschenposten der Deutschen Seewarte, 1897, from Commander Becher's papers in the Nautical Magazine for 1852, from Major Rennell's Investigation of the Currents of the Atlantic Ocean, 1832, etc.; the two first named being the principal sources.)

\begin{tabular}{|c|c|c|c|c|c|c|c|c|}
\hline \multirow[b]{3}{*}{ Starting place } & \multicolumn{6}{|c|}{ - Places of Recovery } & \multirow[b]{3}{*}{ Total } & \multirow[b]{3}{*}{ Remarks } \\
\hline & $\boldsymbol{A}$ & B & $\mathrm{c}$ & D & $\mathrm{E}$ & $\mathbf{F}$ & & \\
\hline & 志 & 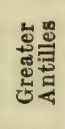 & 总高 & 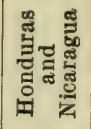 & 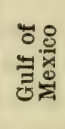 & 冚 & & \\
\hline $\begin{array}{l}\text { Off the S.-W. } \\
\text { coast of Ireland }\end{array}$ & 1 & - & - & - & - & - & 1 & $\begin{array}{l}\text { From the } \\
\text { land } 260 \text { miles }\end{array}$ \\
\hline $\begin{array}{l}\text { Off the coasts } \\
\text { of Spain and Por- } \\
\text { tugal }\end{array}$ & 2 & 2 & 9 & 1 & - & - & 14 & $\begin{array}{l}\text { Within the } \\
\text { region } 36^{\circ}-45^{\circ} \\
\text { N. lat., } 9^{\circ}-20^{\circ} \\
\text { W. long. }\end{array}$ \\
\hline $\begin{array}{l}\text { Vicinity of Ma- } \\
\text { deira and the } \\
\text { Canary Islands }\end{array}$ & 6 & 6 & 3 & - & 2 & - & 17 & - \\
\hline $\begin{array}{l}\text { About midway } \\
\text { between the Can- } \\
\text { ary and Cape } \\
\text { Verde Islands }\end{array}$ & 3 & 4 & 3 & 4 & 1 & 1 & 16 & - \\
\hline $\begin{array}{l}\text { Vicinity of the } \\
\text { Cape Verde Is- } \\
\text { lands }\end{array}$ & 7 & 4 & 13 & 5 & - & 3 & 32 & $\begin{array}{l}\text { Within the } \\
\text { region } 11^{\circ}-19^{\circ} \\
\mathrm{N} . \text { lat., } 21^{\circ}- \\
30^{\circ} \text { W. long. }\end{array}$ \\
\hline $\begin{array}{l}\text { Mid-Atlantic, } \\
\text { about half-way } \\
\text { between Cape } \\
\text { Verde and the } \\
\text { West Indies }\end{array}$ & 7 & 4 & 12 & 2 & - & - & 25 & $\begin{array}{l}\text { Between } 13^{\circ} \\
\text { and } 21^{\circ} \mathrm{N} . \text { lat. } \\
\text { and } 35^{\circ} \text { and } \\
50^{\circ} \mathrm{W} \text {. long. }\end{array}$ \\
\hline Totals . . . & 26 & 20 & 40 & 12 & 3 & 4 & 105 & - \\
\hline Percentages & 25 & 19 & 38 & 11 & 3 & 4 & 100 & - \\
\hline
\end{tabular}

Note.-The percentages may be taken as illustrating the distribution of drift carried by the North Equatorial Current to the tropics of the New World from the European and African side of the Atlantic. 
Rico. In the cases of Cuba and Hispaniola they were found in about the same proportions and equally distributed on both the north and south sides of the islands. Those mentioned under Column $\mathbf{C}$ were well distributed over the Lesser Antilles north of Barbados and St. Vincent, and, with the exception of one stranded on the Grenadines, never south of those two islands. Of the remainder it may be said that most of those brought to the shores of Honduras and Nicaragua were found in the former region, that those carried through the Straits of Yucatan into the Gulf of Mexico were either cast up on the coasts of Texas and Louisiana or were hurried along in the Gulf Stream and deposited on the east coast of Florida.

Taking the bottles starting from the eastern side of the ocean, no consistent discrimination can be made between the groupings of the places of recovery and the starting localities. As far as the data go, they show that almost from every one of the localities bottles may be transported all over the West Indian islands north of Barbados and St. Vincent. South of these two islands is the track by which the drift of the Main Equatorial Current chiefly enters the West Indian region; whilst on the north, extending as far as the Bahamas, lies the area that receives the drift of the North Equatorial Current. It is with the distribution in the West Indian region of the drift brought across the North Atlantic by this current from latitudes, generally speaking, north of the tenth parallel ( $\mathbf{N}$. lat.) that the table above given is exclusively concerned. The concentration of drift at the south-east end of the Bahamas is remarkable. Onefifth of all the bottles brought by the North Equatorial Current to the West Indian islands was stranded on the Turks, Caicos and neighbouring islands.

The noticeable proportion of bottles stranded on the east coast of Florida, after being thrown over in the vicinity of the Canary and Cape Verde Islands, is a feature of the foregoing table. Those that have crossed the Caribbean Sea, after passing through the islands of the Lesser Antilles, often strike the coasts of Nicaragua and Honduras; but almost as many pass to the northward through the Straits of Yucatan, and, if not beached on the north-western shores of the Gulf of Mexico, enter the Florida Straits and are thrown up, as in the case of these bottles, on the east coast of Florida. The story of the bottle-drift cast up at different stages of the long passage from the African side of the North Atlantic to the Florida seas clearly indicates the track across the Caribbean Sea and the Gulf of Mexico; and both the American and German authorities are at one on this point. At the same time it is evident that occasionally the Florida waters may be reached by the shorter route through the Bahamas by the agency of the Antillean Stream, a subject referred to later on in this chapter and in Note 13 of the Appendix.

It is to be expected that bottles which reach the Florida seas, after drifting across the North Atlantic from the African side, would sometimes be caught in the rapid current of the Gulf Stream in the Florida Straits and be carried northward and eastward to the coasts of Europe. It is brought out in the previous tables (pp. 52, 53) that this is not infrequent with bottles dropped overboard in the 
Florida region; and we have a good example in the case of those from the African side numbered 206 in Schott's memoir (map ii., pp. 9, 23, 26). Starting from a position about 150 miles south-west of the Cape Verde Islands (lat. $13^{\circ} 16^{\prime} \mathrm{N}$., long. $25^{\circ} 51^{\prime}$ W.) on May 19, 1887, it was recovered at Clifden, on the west coast of Ireland (Co. Galway), on March 17, 1890. The distance traversed in its passage in the North Equatorial to the West Indies, and thence to Europe in the Gulf Stream drift, was computed at $\mathbf{7 7 0 0}$ miles by the southern route through the Lesser Antilles and then across the Caribbean Sea and the Gulf of Mexico, and at 6300 miles by the more direct northern passage between the Bahamas and the Greater Antilles. Dr. Schott gives a facsimile of the paper enclosed in the bottle, duly filled up and signed by the sender and the finder. It is not possible to determine which of the two routes in West Indian waters this bottle pursued; but that drift from the Caribbean Sea may reach the shores of Europe is indicated by the track of a bottle (No. 110) in the Nautical Magazine for 1852. It was thrown over about a hundred miles off the south coast of Jamaica in lat. $16^{\circ} \mathrm{N}$. and long. $78^{\circ} 5^{\prime} \mathrm{W}$., and was found on the coast of Ireland; but the time occupied in the drift is not supplied. Such are some of the principal indications afforded by bottle-drift of the work that would be performed by the North Equatorial Current in carrying seed-drift from the Old to the New World.

However, some curious questions arise in connection with the debatable region of the Guinea Current. To the southward of the Cape Verde Group and confined between the parallels of $2^{\circ} \mathrm{S}$. and $10^{\circ} \mathrm{N}$, and between the meridians of $20^{\circ}$ and $32^{\circ} \mathrm{W}$., lies a region in which the bottles become the sport of conflicting currents. Here the Guinea Current flowing east is interposed between the North and Main Equatorial Currents flowing west, and, owing to the shifting boundaries of the several streams, bottles cast over at the same spot may be carried to opposite sides of the Atlantic. Dr. Schott (pp. 10, 18; map i.) gives the case of two bottles thrown together into the sea a little north and east of St. Paul's Rocks, one being recovered on the coast of Sierra Leone and the other on the shores of Nicaragua. In the same note of the Appendix (Note 19) in which the details of these remarkable drifts are given, reference is made to the possibility that under certain conditions seeds may be transported from the coasts of North Brazil to the shores of Sierra Leone and Liberia in the counter-current formed at certain seasons by the westward extension of the Guinea Current. This is probably a rare event, but a particular example of bottle-drift is mentioned in this connection. With this exception, no opportunity of American seed-drift reaching Africa across the tropical latitudes of the North Atlantic is indicated by the numerous bottle-drift data at my disposal.

The Currents of the South Atlantic.-Before proceeding to deal with the passage of bottle-drift across the South Atlantic in the Main and South Equatorial Currents, I will state the view of the currents in this ocean that is adopted in these pages. It seems usual to speak in a collective sense of the Southern Equatorial Current as dividing, when approaching Cape St. Roque, into the 
Guiana Current, running northward to the West Indies, and the Brazil Current (the smaller of the two), flowing southward along the coast of South Brazil. But by some the distinction is made in mid-Atlantic between the Main Equatorial Current, which is known as the Guiana Current as it approaches the West Indian region, and the South Equatorial Current, which is known as the Brazil Current when it turns to the south of Cape San Roque. This distinction is accepted in this work, and reasons are adduced in Note 18 of the Appendix in support of the view that the differentiation already exists in mid-Atlantic, the island of Ascension being situated within the northern or main stream and that of St. Helena within the southern stream. Thus regarded, the Main Equatorial courses westward from the Gulf of Guinea between the parallels of $2^{\circ} \mathrm{N}$. and $10^{\circ} \mathrm{S}$., whilst the South Equatorial flows west in the Central Atlantic between the parallels of $10^{\circ}$ and $20^{\circ} \mathrm{S}$.

Though these currents are contiguous in mid-ocean, they have different origins and, of course, different destinations. The Main Equatorial in its birthplace in the Gulf of Guinea is fed by the Guinea Current on its north side, and on its south side by the inshore waters of the South African Current. It proceeds north of Cape St. Roque to the West Indies, following the trend of the coasts of North Brazil, the Guianas and Eastern Venezuela, and gathering drift on its way not only from those shores, but from the Amazon, the rivers of the Guianas, and the Orinoco. On the other hand, the South Equatorial Current may be regarded as fed by the off-shore or outside waters of the South African Current, and probably carries less African drift. As it crosses the Atlantic it includes St. Helena, but not Ascension, within its zone. It is then deflected south of Cape St. Roque and flows down the coast of Brazil, finally gathering the drift of the Rio de la Plata. Then, blending with the South Atlantic Connecting Current, its waters make the return journey past Tristan da Cunha to the South-west African coasts. It should, however, be noted that some of the waters of the Brazil Current probably flow southward to unite with those of the West Wind Drift Current, the easterly surface-current of the "Roaring Forties." In this manner South American drift would be carried eastward towards Australia.

The Transport of Bottle-drift in the Main Equatorial, Current.- Having thus described the view of the current system in the South Atlantic which is adopted in these pages, I will proceed to deal with the indications of the bottle-drift in the case of the Main Equatorial Current. Generally speaking, whilst the mass of this bottle-drift of the North Equatorial Current strikes the West Indies to the north of Barbados and St. Vincent, most of the drift of the Main Equatorial Current enters the West Indian region to the south of those islands. Many of the bottles brought by the southern current-about 30 per cent.-are stranded on the coasts of Trinidad and Tobago and on the Venezuelan shores of the Gulf of Paria. The others are either thrown up on the isles of the Lesser Antilles, mainly in the south, or pass between them into the Caribbean Sea, where they mingle with the bottle-drift of the North Equatorial 
Current, and are subsequently dispersed over the shores of the Caribbean Sea and of the Gulf of Mexico, reaching in some cases the coasts of Florida.

As indicated by the data at my disposal, the general distribution of the bottle-drift of the Main Equatorial Current in the tropies of the New World is as follows-

Places of Recovery of Sixty Bottles cast Overboard in the Main Equatorial Current between the Coast of North Brazil and the Vicinity of St. Paul's Rocks

(The data are obtained from Schott's memoir in three-fourths of the cases and from the American charts for the rest)

The Guianas

Trinidad mainly, but including also Tobago and the neighbouring coast of Venezuela .

The Lesser Antilles (chiefly in the southern islands) .

5 per cent.

The Greater Antilles (south coasts of Hispaniola, Cuba, and Jamaica, including the off-lying Cayman Islands

The Bahamas

The coasts of Central America (Nicaragua and Honduras)

The Gulf of Mexico (chiefly on the western shores)

The coasts of Florida

26,

$31 \quad$,

. 13,

$2 \quad$,

. $\begin{aligned} & \\ . & 5\end{aligned}$

100

The convergence of the drift towards the limited region comprised by Trinidad and its vicinity is conspicuous. But the materials stranded in this locality are probably equalled in amount by those that are carried swiftly past this region into the Caribbean Sea through the Trinidad and Grenada passage to be thrown up ultimately on the south coasts of Hispaniola, Cuba and Jamaica, on the shores of Nicaragua and Honduras, on the western borders of the Gulf of Mexico, and on the coasts of the Florida seas. If we separate the bottles at their starting-place into two groups, those belonging to the St. Paul's Rocks area and those nearer the coast of North Brazil, we find that the concentration on Trinidad and its vicinity is least marked in the case of the bottles approaching from the vicinity of St. Paul's Rocks, the proportion reaching Trinidad from this region of the Atlantic being only about 20 per cent., as compared with nearly 40 per cent. in the case of those carried past the shores of North Brazil.

But although the great mass of the stream of the Main Equatorial Current passes into the Caribbean Sea, there is a subsidiary branch which, after skirting the eastern and northern side of the Lesser Antilles, unites with the North Equatorial Current and ultimately 
reaches the Bahamas, the north coasts of the Greater Antilles, the Florida Strait and the Bermudas. This is the so-called "Antillean Stream" to which Dr. Schott particularly refers (p. 13). About 6 per cent. of the bottles dealt with in the above tabulated results represent the part played by this subsidiary current in distributing the drift brought by the Main Equatorial Stream to the West Indian region. They are those that are stranded on the northernmost islands of the Lesser Antilles, on the north coasts of Porto Rico and Hispaniola, and on the off-lying Bahamas. An interesting example is afforded in the case of bottle No. 363 in Schott's memoir (p. 13 and map ii.). It was dropped into the sea about half-way between Cape St. Roque and St. Paul's Rocks, and was recovered on Rum Cay in the Bahamas five and a half months afterwards, having accomplished the passage of 3078 miles at a minimum daily rate of $18 \cdot 2$ miles. Another interesting illustration is afforded by a bottle which, after being thrown over about 200 miles off the mouths of the Amazon in $2^{\circ} 36^{\prime} \mathrm{N}$. and $47^{\circ} 6^{\prime} \mathrm{W}$., was picked up near St. Thomas in $18^{\circ} 27^{\prime} \mathrm{N}$. and $64^{\circ} 49^{\prime} \mathrm{W}$. twenty-eight days afterwards, having been carried 1400 miles at a minimum rate of fifty miles a day (U.S. Chart, North Atlantic, May 1909, No. 80). The mingling of the drift of the North and Main Equatorial Currents in the region between the Bahamas and the Greater Antilles is a point of great interest in the distribution of seeds by currents.

The South Equatorial and the Brazil Currents.-Being, as I have shown above, the continuation of the South Equatorial Current that crosses the South Atlantic about the latitude of St. Helena, the Brazil Current proceeds southward, following the trend of the coast, part of its waters reaching the estuary of La Plata, the greater portion, however, being deflected eastward between the 30th and 35th parallels, where they join the South Atlantic Connecting Current that runs eastward to the South African coast. In this way it is possible for drift to make a complete circuit of the South Atlantic, since on approaching the South African coast the materials not stranded would be borne northward in the South African Current, those in the inshore waters ultimately getting into the Main Equatorial Current, and those in the off-shore waters coming within the influence of the South Equatorial Current. The bottle-drift data at my disposal for this ocean are scanty, but they illustrate the circular play of the currents, and they show that whilst extra-tropical South Africa may supply drift to tropical Brazil, it may receive drift from the same region. One of the most interesting records of bottle-drift ever published in this connection is concerned with a bottle that was thrown into the Indian Ocean off the coast of Natal and was recovered on the shores of Brazil in lat. $17^{\circ} 30^{\prime} \mathrm{S}$. The bottle just mentioned must have doubled the Cape, and in its subsequent transport by the South African and South Equatorial Currents we have an illustration of the passage of drift from extra-tropical South Africa to tropical Brazil (further details of this remarkable drift are given a page or two later).

But to understand how tropical Brazil may in its turn supply drift to South Africa it will be necessary to examine the working of 
the Brazilian Current, as exemplified by bottle-drift in the fourth map and on p. 20 of Schott's memoir. It is not a rapid stream, its rate being twelve to twenty miles a day, and in consequence it is liable to a set-back within the tropics during the southern winter owing to the influence of the prevailing South-east Trade. In this manner, no doubt, some of its drift is carried back round Cape St. Roque and mingles with that of the Main Equatorial, an event which actually occurred in the case of some bottles referred to in this memoir. But for this occasional set-back, the current would have a steady flow south. Yet the bottle-drift dealt with by Dr. Schott in this connection only tells part of the story. Though many bottles are cast up on the coasts as far south as Montevideo, we know nothing of those that must have been deflected eastward to be carried across in the South Atlantic Connecting Current to the west coasts of South Africa, where in the great majority of cases they could never be recovered. Their track across the Atlantic would curve south to about the 40th parallel, and would then be represented by that laid down by Dr. Schott in his map for a bottle which, after being cast over in about $41^{\circ} 30^{\prime} \mathrm{S}$. and long. $32^{\circ} \mathrm{W}$., was recovered near the Cape of Good Hope.

The Current-connections of the South Atlantic with the Indian and Pacific Oceans, as Illustrated by Bottle-drift.This is a matter of importance, since upon it depends the possibility of the intrusion of seed-drift into the South Atlantic from the oceans on either side of it. Taking, first, the connection with the Indian Ocean, Dr. Schott gives the tracks of two bottles that doubled the Capes of Agulhas and Good Hope in their passage westward into the South Atlantic. One of them, after being dropped overboard less than a hundred miles south of Port Elizabeth, was cast up on the west coast of Cape Colony in about lat. $33^{\circ} \mathrm{S}$. (maps 4 and 5). The other accomplished a much longer passage. Having been thrown into the sea off the coast of Natal in lat. $29^{\circ} \mathbf{2 4}^{\prime} \mathrm{S}$. and long. $33^{\circ} \mathrm{E}$., it was carried by the Agulhas Current round the southern extreme of the continent, whence it passed into the South African Current and from there into the South Equatorial Current, being ultimately stranded on the coast of Brazil in lat. $17^{\circ} 30^{\prime} \mathrm{S}$. This involved a drift of about 4120 miles, a period of 612 days elapsing between the start and the recovery of the bottle (pp. 19, 27; maps iv. and v.; track 6).

With regard to the connection between the South Pacific and South Atlantic Oceans round the Horn, the data at my disposal indicate that it occasionally occurs. Most of the bottles dropped off Cape Horn are drifted before the Westerly Winds to Australia-as illustrated by the tracks of four bottles mentioned by Schott and others which are specially dealt with in Chapter XIII. In the same chapter allusion is made to the figurehead of a ship burnt at sea in these latitudes which was also recovered in Australia. In none of these cases did the drifting object double the Horn; but Schott gives the track of a bottle in map vi. which was cast over in about lat. $54^{\circ} 20^{\prime} \mathrm{S}$., less than a hundred miles off the west coast of Tierra del Fuego, and drifted in the Cape Horn Current to the Falkland 
Islands. Had the bottle missed these islands, it would have been borne north-east in the same current, and, getting within the influence of the Brazilian Current, as it is deflected eastward, would have entered the circulation of the South Atlantic.

The Difficulties Connected with the Drifting Rates of Bottles across the Atlantic.-We come now to the discussion of the time occupied by the drifting bottles in crossing the Atlantic, either from the American or from the European and African side of the ocean. In the charts the average drift per day is calculated up to the date of the recovery of the bottle. This, as is pointed out by the compiler of the American charts, must be in most cases less than the actual drift-rate, since " no allowance is made for the time, probably often considerable, during which the bottle lay undisturbed on the beach." So also Schott observes (p. 10) that the calculated velocities are merely minimum values, which could only in the rarest cases correspond approximately to the true rate. This naturally introduces an element of great uncertainty; but, if we assume that 20 or 25 per cent. of the bottles were recovered without great delay, it is likely that we shall obtain an approach to the average drift-rate. The results here employed have been calculated on this basis. As before observed, the Prince of Monaco adopted a similar method in estimating the mean velocity of his floats, usually taking the average of the fastest fourth or third, except when the data were few, when he selected the most rapid example.

After handling the data during a long period it is not difficult to recognise sets of results which possess a critical value. One of these is given below in connection with five bottles dropped at the same date into the sea in the vicinity of Cape Hatteras. Here it is not hard to distinguish between the bottles that were quickly recovered and those that had been lying a long time on the shore. It rarely happens that we can exclude the element of uncertainty altogether. But it is manifest, when the bottle is picked up afloat off a coast by fishermen, or when the finder remarks that as it lay on the sand it had all the appearance of having been washed up by the last tide, that we are on relatively safe ground. Instances of both these occurrences are mentioned in the following pages. As an example of the great range of the periods elapsing between the start and the recovery of the bottles I will cite the case of nine bottles which crossed the Atlantic from the Florida region to the coasts of Europe. Since the periods varied between eleven months and three years, it is obvious that a year and more may be spent by a stranded bottle before it is found. However, in the case of some of these belated "finds" one may suspect that there has been a long sojourn in the still waters of the Sargasso Sea, the notable gathering-place of the wreckage of the North Atlantic. As in the instance of some bottles cast up on the Azores, where an interval of several years elapsed, one may seek here for an explanation of the great delay in the recovery. Such a case as is mentioned by Purdy in the Columbian Navigator for 1839, where a bottle dropped overboard off Madeira in June 1825 was picked up ten years after on the Turks Islands, may be placed in this category. The table subjoined is intended to illus- 
trate the critical value of the data supplied by a number of bottles cast into the sea at the same place and at the same time.

Five Bottles put Overboard together from the s.s. "Cheroke " about a hundred miles to the north of Cape Hatteras on December 21, 1905

(Results taken from the North Atlantic Pilot Chart for December 1908, published by the U.S. Hydrographic Office.)

\begin{tabular}{|c|c|c|c|}
\hline Place of Recovery & Interval in Days & $\begin{array}{l}\text { Total Drift in } \\
\text { Nautical Miles }\end{array}$ & $\begin{array}{l}\text { Average Drift in } \\
\text { Miles per Day }\end{array}$ \\
\hline $\begin{array}{l}\text { Bermuda } \\
\text { Bermuda } \\
\text { West coast of Scotland } \\
\quad\left(56^{\circ} 30^{\prime} \mathrm{N} .\right) \\
\text { Shetland Islands } \\
\text { Norway, near the North } \\
\text { Cape in lat. } 70^{\circ} 20^{\prime} \mathrm{N} \text {., } \\
\text { long. } 22^{\circ} 58^{\prime} \mathrm{E} .\end{array}$ & $\begin{array}{l}103 \\
168 \\
\\
390 \\
466\end{array}$ & $\begin{array}{r}520 \\
520 \\
\\
3040 \\
3210 \\
\\
4250\end{array}$ & $\begin{array}{r}5 \cdot 0 \\
3 \cdot 1 \\
7 \cdot 8 \\
6 \cdot 9 \\
\\
10 \cdot 2\end{array}$ \\
\hline
\end{tabular}

Here it is evident that the three bottles with the longest drifts followed the same track until near the Scottish coast, and that the one recovered in the north of Norway must have been found soon after it had been stranded.

The Drifting Rates of Bottles across the Atlantic.--In the following table (p. 66) I have elaborated most of the data at my disposal that concern the drifting rates of bottles across the North and the Equatorial Atlantic. The subsequent remarks relate to the different passages, beginning with the traverse from the Florida Strait and the neighbouring West Indian waters to the coasts of Europe. These are the most interesting of the bottle-drift records, since Europe is here brought into touch with a locality that not only receives drift from the entire West Indian region, but is also the recipient of drift transported by the North and Main Equatorial Currents from tropical Africa, as well as from the coasts of the Guianas and North Brazil. The traverse of the ocean from the European and African side to the New World is then dealt with, and the discussion ends with some general conclusions relating to the average periods taken by bottle-drift in performing the various passages and traverses of this ocean.

The Drift-rates from the West Indies to the Coasts of Europe. - The stages in this traverse of the North Atlantic are indicated in the table given on p. 66, and it has already been established in a previous table that quite four-fifths of the bottles are stranded on the Scottish, Irish, English and French coasts. Whilst the shortest passage was performed in about eleven months, the average period was about fourteen months. The quickest drift was that of a bottle which reached the Irish coast from off the north coast of Hispaniola in $\mathbf{3 3 7}$ days, a passage of $\mathbf{4 1 4 0}$ miles (U.S. Pilot Chart, N. Atlantic, May 1909). It seems unlikely that the traverse from off Cape Hatteras could be often accomplished by a bottle in less 


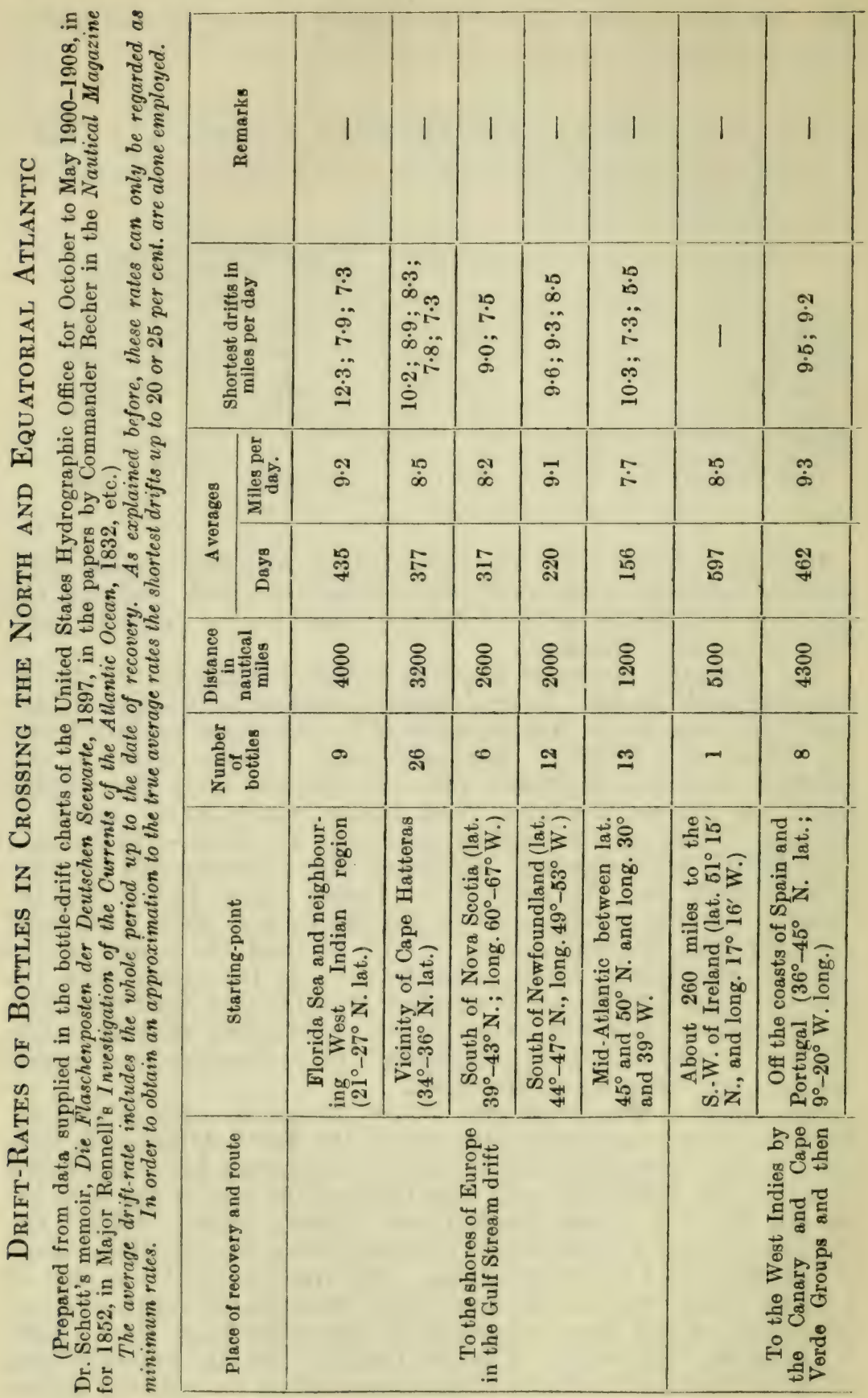




\begin{tabular}{|c|c|c|c|c|c|c|c|c|c|c|}
\hline 1 & 1 & 1 & 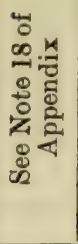 & 1 & 1 & 1 & 1 & 1 & 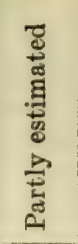 & 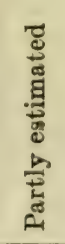 \\
\hline $\begin{array}{l}\dot{\infty} \\
\ddot{\infty} \\
\dot{\infty}\end{array}$ & 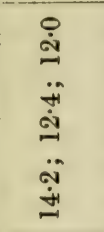 & 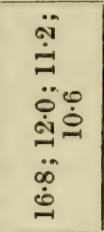 & 1 & 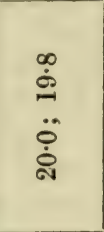 & 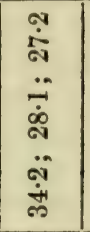 & $\begin{array}{l}\infty \\
\dot{\Xi}\end{array}$ & 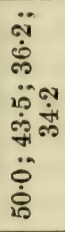 & $\stackrel{\infty}{\dot{\leftrightarrow}}$ & 1 & 1 \\
\hline זे & $\stackrel{\infty}{\stackrel{\infty}{\sim}}$ & ஸ் & ஓ्丶 & ํํํ & ஹ் & ㅇํ & 염 & 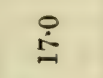 & ஜ & 品 \\
\hline ริ & శ్రి & $\stackrel{\Re}{\varrho}$ & $\stackrel{\overbrace{}}{\varrho}$ & 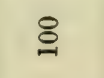 & $\hat{\sigma}$ & is & ลิ & $\stackrel{\infty}{\infty}$ & $\mathscr{\infty}$ & $\stackrel{\infty}{\exists}$ \\
\hline 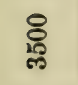 & \&్ట్ర & ఫ్ & శ్టి & ః్ & ஜ్రి & 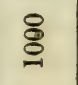 & §్ర & ఫ్ట్ర్ల & 吕 & ‡ి \\
\hline 10 & $\cong$ & สิ & H & $\cong$ & 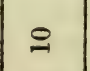 & +1 & $\theta$ & H & 1 & 1 \\
\hline 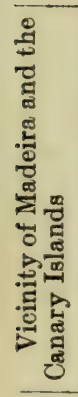 & 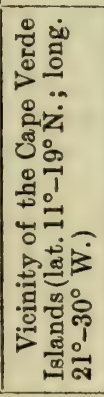 & 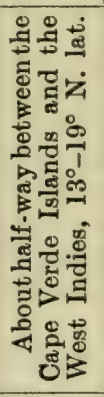 & 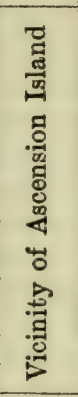 & 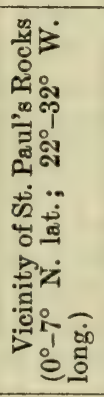 & 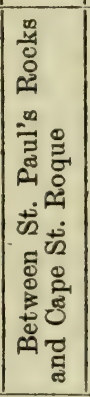 & 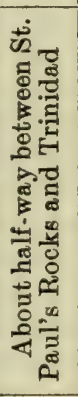 & 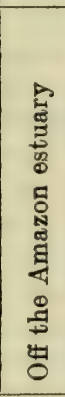 & 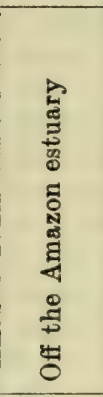 & 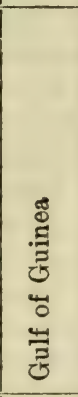 & 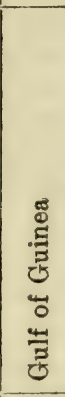 \\
\hline 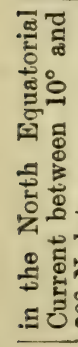 & & & \multicolumn{5}{|c|}{ 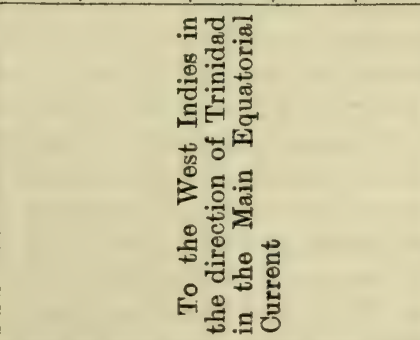 } & 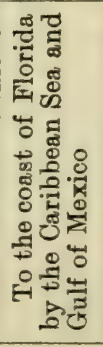 & 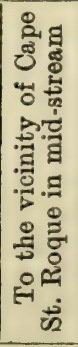 & 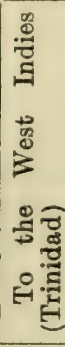 \\
\hline
\end{tabular}


than a year, though the shortest period would be rather over ten months. In Note 16 of the Appendix reference is made to a derelict which drifted from Baltimore Bay to the Hebrides in a little over ten months, but about half the time was spent drifting about within a small area in mid-ocean. A critical value belongs to a rate of eight miles which is given by Schott (p. 11, map ii.) for a bottle that, after bc..g thrown into the sea about 350 miles north-east of Cape Race, was recovered on the Isle of Skye. According to the finder, it appeared to have been thrown up at the last flood-tide.

The uniformity in the average daily rate of eight to nine miles across the North Atlantic is remarkable, and this brings us to record that the average rates computed by the Prince of Monaco for his floats in the eastern half of this ocean are only half this amount. His observations, as we have seen, were made on a line drawn from the Azores to the Banks of Newfoundland, as well as in localities to the east and north of that line; and he places the average drifting rate to the shores of Europe, ranging from Norway to Portugal, at four to five miles a day. This discrepancy, however, is capable of explanation, and I imagine that it may be largely discounted. It is evident that the Prince of Monaco mainly based his rates on the experiments made between June and July 1887, between Newfoundland and the Azores and to the north of that group. On the other hand, the data tabulated above for this traverse are supplied by records that cover a long period of years, and in this manner the disturbing influences retarding the eastward flow of the surfacecurrents during a particular year or season have been eliminated. To such retarding influences experiments made in the same season might be exposed. It is noteworthy that in the experiments of the Prince of Monaco in 1886, when the floats were cast overboard at distances ranging from 400 to 700 miles from the Portuguese and French coasts, more rapid velocities were obtained. The five fastest rates of eleven bottles stranded on the coasts of Portugal and West Spain gave a mean of $7 \cdot 15$ miles a day. So, again, the mean of the seven quickest rates for twenty-four bottles recovered on the west coast of France was 6.67 miles a day. The Prince of Monaco's floats were as a rule deeply submerged, and were thus much less likely to be influenced directly by the wind than the ordinary floating bottle. Yet the retarding effect of contrary winds might be counterbalanced by the acceleration produced by fair winds.

The Drifting Rates from off the Coasts of Europe to the WEST INDIES.-In making this traverse bottle-drift seems to travel at about the same average speed as in the case of that brought to Europe in the Gulf Stream-namely, eight to nine miles a day, the time occupied being usually sixteen to seventeen months. But the rate varies greatly in different portions of the traverse. It is in the passage south from European latitudes to the region of the North Equatorial Current that the slowest progress is made. From the data supplied by a number of bottle-drifts in the American charts it is evident that the average daily rate for this passage is only four or five miles. On the other hand, as shown in the table, bottles starting from the vicinity of the Canary Islands are carried into the 
North Equatorial Current, and accomplish the traverse to the West Indies at an average rate of nearly nine miles a day; whilst farther south, in the latitude of the Cape Verde Group, the trans-oceanic passage is performed at an average speed of nearly thirteen miles a day. These conclusions are confirmed by the results of the Prince of Monaco's experiments in $\mathbf{1 8 8 6}$ opposite the coasts of France and Portugal along the meridian of $17^{\circ} 40^{\prime} \mathrm{W}$. From this region the daily drifting rate to the Canary Islands is placed at four and a half miles and to the West Indies at ten and a half miles. Daussy, whose paper on bottle-drift in this ocean (Comptes Rendus, 1839, p. 81) has before been mentioned, places the daily speed of bottles in the equatorial zone of the North Atlantic at eight to ten miles.

An interesting case is recorded in the table of a bottle which accomplished the whole of the passage from a point about 260 miles off the south-west of Ireland to the south-eastern extremity of the Bahamas in a minimum time of 597 days (U.S. chart, December 1908 , bot. 85). The greatest velocity referred to in the table in connection with the passage in the North Equatorial Current was attained by a bottle that travelled from mid-Atlantic to the West Indian region at an average speed of $\mathbf{1 6 . 8}$ miles a day. It performed the passage from $9^{\circ} 51^{\prime} \mathrm{N}$. lat. and $32^{\circ} \mathrm{W}$. long. to St. Vincent, a distance of 1660 miles, within ninety-nine days (U.S. chart, February 1909, bot. 48). It is worth noting that the derelict American schooner Alma Cummings was drifted at the rate of sixteen miles a day from a position 600-700 miles west of the Cape Verde Islands to the Panama Isthmus (see Note 15 of Appendix). A critical value attaches itself to a bottle that was transported in the North Equatorial Current from a position south of Cape Verde Group (lat. $14^{\circ} 1^{\prime}$ N.; long. $25^{\circ} 2^{\prime}$ W.) to the Grenadines in 169 days, which gives a daily rate of about thirteen miles. There could have been but little loss of time in its recovery, since it was found afloat off the coast (see Nautical Magazine for 1852, bot. 42, and 1853, p. 437).

The individuality of the North Equatorial Current is not always sufficiently recognised. It is something more than the North-east Trade-drift. Between the parallels of $10^{\circ}$ and $20^{\circ} \mathrm{N}$. it is illustrated by about fifty bottle-tracks in Schott's maps and by nearly half that number in the American charts examined, as well as by about a dozen other examples from other sources. The part that it takes in the circulatory movement of the waters of the north Atlantic is strikingly exemplified in the results of the Prince of Monaco's experiments in the temperate latitudes of the north-east Atlantic, almost a tenth of the floats recovered having been found in the West Indian region. All the months of the year are represented in the records at my disposal, and there is not a single instance of a drift to the eastward in these latitudes $\left(10^{\circ}-20^{\circ} \mathrm{N}\right.$.) in the open ocean. Always there is a steady flow to the west, with but little of the "southing" one would expect in a mere trade-wind current.

Drift-Rates from Tropical Africa to Brazil and the West Indian Region in the Main Equatorial Current.-A much greater velocity is regularly displayed by the Main Equatorial Current as it traverses the Atlantic from the Gulf of Guinea to the 
coasts of North Brazil, thence proceeding northward past the Guianas to the West Indies. From the Admiralty Sailing Directions, Laughton's Physical Geography, and other works of reference, it is evident that very high velocities, even of sixty miles a day, are at times attained by this current on its way to Cape St. Roque. It is probable, however, that an average rate of twenty to thirty miles is near the truth. In the latter part of its course, along the coasts of North Brazil and the Guianas, it nearly doubles its speed, flowing usually from thirty to fifty miles a day and occasionally as much as seventy or eighty miles.

The behaviour of the drifting bottle is quite in agreement with the known great speed of this powerful current. In Note 1 of the Appendix the data are discussed; and it is shown that whilst in the slacker water in the vicinity of St. Paul's Rocks and Ascension, that is, in the northern and southern portions of the current, the bottles are carried along at a rate of about twenty miles a day, in the centre of the stream, as it concentrates between St. Paul's Rocks and Cape St. Roque, an average speed of thirty miles is attained. From what has been said it would be expected that during the remainder of the passage along the South American seaboard to the West Indian region the speed of bottle-drift would respond to the increase in the velocity of the current as it sweeps past the coasts of North Brazil and the Guianas. This expectation is fully justified in the facts given in the note, where a daily rate of between thirty and fifty miles, and averaging forty miles, is indicated. It may be inferred from these data that, starting from the Gulf of Guinea, a bottle would require an average period of twelve weeks to reach the vicinity of Cape St. Roque and of seventeen weeks to reach Trinidad. It is, however, not improbable when the current runs with unusually great speed that the traverse to the Brazilian coast may be performed in as little as two months.

The Drifting Rate of Bottles from off the Amazon Estuary to the Coast of Florida.-This establishes an interesting connection, since we already know how long a period is usually required by bottle-drift for the passage from Florida to the shores of Europe, namely, fourteen months; and we shall thus be able to determine the time that would be required for Amazon drift, as typified by the floating bottle, to reach our coasts. As previously remarked, the track assigned in both the American and German charts to bottles that arrive in the Florida seas from latitudes in the tropical Atlantic south of $10^{\circ} \mathrm{N}$. lies across the Caribbean Sea and through the Straits of Yucatan. The data for three bottles that accomplished this passage from off the Amazon to Florida waters are supplied in Note 1 of the Appendix. It is there inferred that this traverse of 3200 miles would be performed in about six months at the rate of seventeen miles a day, from which it may be concluded that as a rule the passage of Amazon drift to Europe would occupy twenty months.

The Drift-Rates in the Brazil Current.-The Brazil Current has been before alluded to as an extension of the South Equatorial Current. Its velocity is usually stated to be from twelve to twenty 
miles a day, which is greater than that displayed by numerous bottle-drifts given by Schott, who says that more than ten miles a day was seldom indicated (pp. 19, 20, map iv.). The longest passage was that of a bottle which was carried about 1600 miles from opposite Bahia to the vicinity of Montevideo at a minimum daily rate of about ten miles. Many of the bottles, however, were stranded on the coasts further north.

General Results of the Bottle-Drift Data for the Atlantic and their Application to the Dispersal of Seeds by Currents.In order to draw from the foregoing discussion some conclusions that may be of practical value in the consideration of the dispersal of seeds by currents in the Atlantic, I have given below a few general results relating to the average periods taken by bottle-drift in accomplishing the various traverses and passages of this ocean.

Rrisults for the Times occupied by the Drifting Bottle in crossing the Atlantic in Northern and Equatorial Latitudes

(A) From the Florida and neighbouring West Indian region to the shores of Europe by the Gulf Stream route.

(B) From off the coasts of Europe to the West Indies (Lesser Antilles and the Southern Bahamas) by the Canary and Cape Verde groups and in the North Equatorial Current.

(C) From the Gulf of Guinea to the West Indies (South of Barbados) in the Main Equatorial Current.

(D) From the Gulf of Guinea to the nearest coast of Brazil in the Main Equatorial Current.

(E) From off the Amazon estuary to Florida by the Caribbean Sea and the Straits of Yucatan in the Main Equatorial Current.

(F) From off the Amazon estuary to the shores of Europe by the Caribbean Sea, the Yucatan and Florida Straits, and the Gulf Stream route.

(G) The circuit of the North Atlantic from the Florida region to the Lesser Antilles and the Southern Bahamas by the Gulf Stream route and in the North Equatorial Current. (For the return to the Florida seas 160 days should be added for the usual completion of the route by the Caribbean Sea and the Gulf of Mexico, and 100 days for its completion by the short passage through the Northern Bahamas.)
4000 miles at $9 \cdot 2$ miles a day in 435 days, or about a year and two months.

4500 miles at 9 miles a day in $\mathbf{5 0 0}$ days, or a year and $4 \frac{1}{2}$ months.

4000 miles at 34 miles a day in 118 days, or a hout 4 months.

2500 miles at 30 miles a day in 83 days or 12 weeks, but under exceptionally favourable conditions in 60 days.

3200 miles at 17 miles a day in 188 days, or about 6 months.

7200 miles at $11 \frac{1}{2}$ miles a day in 623 days, or about 20 months. Calculated from results $\mathbf{A}$ and $\mathbf{E}$.

8500 miles at about 9 miles a day in 935 days, or about $2 \frac{1}{2}$ years. Calculated from results $A$ and $B$.

The first matter in connection with these results that needs further discussion is the time occupied in the circuit of the North Atlantic. 
For obvious reasons it would be very difficult to demonstrate this circuit for any particular bottle. The nearest approach to the complete record is that of the bottle, already alluded to, which was picked up on the west coast of Ireland thirty-four months after it had been cast over to the westward of the Cape Verde Islands. It is easy to construct the circuit piecemeal fashion. A striking instance is afforded by two bottles which in one case reached the Southeastern Bahamas from off the coast of Ireland, and in the other reached the Irish coast from the South-eastern Bahamas, the track of the North Equatorial Current being followed in the first case and the Gulf Stream route in the second case. The data for these observations are given in Note 20 of the Appendix; but it may here be stated that the total period, calculated up to the dates of the recoveries, amounts to 934 days, and the average drifting rate to nearly ten miles a day. This period is identical with that given under $\mathrm{G}$ in the above table, though to that period about a hundred days should be added for the passage from the South-eastern Bahamas to the Florida seas. ... Derelicts would probably perform the circuit of the North Atlantic in a shorter time. Whilst the circuit, beginning and ending with the Florida seas, would require about three years for a bottle, it might not require more than two years for a derelict. The Alma Cummings, when drifting in $\mathbf{5 5 3}$ days from off Cape Hatteras to the Panama Isthmus, nearly described the circle; but since the wreck was deflected south to the westward of the Azores, its passage was somewhat shortened (see Note 15).

The Distribution in the West Indian Region of Seed-drift Brought by the North and Main Equatorial Currents as ILlUStrated BY BotTle-DRIFT.-By following the indications supplied by the floating bottle in this matter we shall be determining the distribution over the West Indian region of the seed-drift brought in the North and Main Equatorial Currents. Bottles arriving in the first-named current strike the South-eastern Bahamas and the Lesser Antilles, in the last locality usually north of Barbados. Of those reaching the south-eastern islands of the Bahamas the great majority are stranded in that neighbourhood; but a few, as is shown in Note 13, are carried in the prevailing westerly drift-current to the Florida seas. However, as is indicated in the table on p. 57, only about 25 per cent. of the bottles brought to the West Indian region in the North Equatorial Current are beached on the Bahamas. About 10 per cent. are carried beyond that group and are thrown up on the north coasts of the Greater Antilles. All the rest strike the line of the Lesser Antilles, but generally north of Barbados, and more than half of them are stranded on those islands. The survivors (about 27 per cent. of the original total) pass between the islands into the Caribbean Sea. Most of them are stranded on the south coasts of the Greater Antilles and on the shores of Central America; but a few (amounting to about 7 per cent. of the original total) are carried through the Straits of Yucatan into the Gulf of Mexico and are ultimately beached on the shores of that gulf and on the coasts of Florida. Several examples are given in the charts of bottles that illustrate this circuitous route from the Lesser Antilles 
across the Caribbean Sea and by the Gulf of Mexico to Florida. The length of the passage is about 2000 miles, and the indications are that about $\mathbf{1 6 0}$ days would be required for its accomplishment.

The distribution over the West Indian region of the seed-drift brought by the Main Equatorial Current is well exemplified by the disposal of its bottle-drift as described on p. 61. After depositing 5 per cent. of its burden on the shores of the Guianas, it leaves 31 per cent. on Trinidad and Tobago and on the neighbouring Venezuelan coasts, and 26 per cent. on the islands of the Lesser Antilles, chiefly in the south, only 2 per cent. reaching the Bahamas. The remainder (36 per cent. of the total) breaks through the islands and passes into the Caribbean Sea, more than half being thrown up on the south coasts of the Greater Antilles and on the shores of Central America, whilst the survivors, after passing through the Straits of Yucatan, are stranded on the shores of the Gulf of Mexico and on the Florida coasts.

The mingling in the Caribbean Sea of drift brought by the North and Main Equatorial Currents is well exemplified in the remarks above made. Whether brought by the one current or by the other, the drift, after it enters this sea, has the same distribution on the south coasts of the Greater Antilles, on the shores of Central America and of the Gulf of Mexico, and on the Florida coasts. But the mingling of the drift begins off the Atlantic coasts of the Lesser Antilles and in the southernmost of those islands. In the first case, the Antillean Stream, referred to on a previous page, commences the mixing process in its north-westerly course towards the Bahamas. In the second case, although the island of Barbados usually divides the main streams of the two equatorial currents, there is not infrequently an overlapping of the currents in its vicinity with, as the result, an intermingling of their drift in the southern islands of the Lesser Antilles.

The meeting in West Indian waters of seed-drift brought by these two great equatorial currents from the North and South Atlantic is a matter of great interest for the student of plant distribution. It is a subject that attracted the attention of Dr. Schott when discussing the bottle-drift data of this region (p. 11). The importance of this fact is obvious. Whilst the North Equatorial Current brings to the West Indies the sweepings of the Atlantic seaboard of North America, and of Southern Europe and North-west Africa, through the respective agencies of the Gulf Stream and of the Portuguese or North African Current, the Main Equatorial Current carries to the same region the sweepings of both sides of the South Atlantic, from tropical West Africa, South-west Africa, Brazil, and the Guianas.

The Burden of the Main Equatorial Current.-This current bears westward not only drift from the shores and great rivers of tropical Africa, but also drift which it has received from the South African Current. This current has previously swept the shores of South-west Africa, and has caught up drift brought across by the South Atlantic Connecting Current from the Brazil Current on the other side of the ocean, materials derived from the Rio de la Plata 
and from the shores and estuaries of Brazil south of Cape St. Roque. The burden carried westward by the Main Equatorial Current must, indeed, be a motley one. The seed-drift of the rivers of two continents, including some of the largest rivers of the world, contribute to its freight. It bears westward towards Brazil drift of the Plate, the Congo, and the Niger; and as it sweeps northward to the West Indian region it gathers materials from the Amazon, the rivers of the Guianas, and the Orinoco.

But the possible sources of seed-drift do not end here, since the Main Equatorial Current may receive accessions from the Indian and Pacific Oceans. The Atlantic is not a closed ocean to the south. It has already been shown that bottle-drift from the east coast of Africa can double the Cape and reach the shores of Brazil, and that materials from the Pacific side of Fuegia can double the Horn and reach the Falkland Islands. In the first case the Indian Ocean is tapped as a source of seed-drift. In the second case we have the possibility that the drift from New Zealand and the islands of the Southern Ocean, after it strikes the coasts of South Chile and the western shores of Fuegia, may at times double Cape Horn and get within the influence of the currents of the South Atlantic. (The bottle-drift of high southern latitudes is dealt with in Chapter XIII.)

The Island of Trinidad as a Centre of Drift Dispersal. Next to the Florida Sea, the gathering-place of much of the floating seed-drift of the West Indian region before beginning its transatlantic passage in the Gulf Stream, there is no locality so interesting as a drift-centre as the island of Trinidad. From the standpoint of the dispersal of plants by currents, it is the connecting centre or junction of the lines of dispersal that converge from the Atlantic side and diverge on the West Indian side. As shown by the floating bottles, it is the Main Equatorial Current that principally piles up drift on its beaches, drift from tropical West Africa and from the north-east seaboard of South America, though at times, as indicated below, drift also reaches it from the North Atlantic through the North Equatorial Current. Whilst materials from the South American mainland north of Cape St. Roque doubtless greatly predominate, including, as they do, the drift of the Amazon, of the rivers of the Guianas, and of the Orinoco, yet materials from the West African rivers, the Niger and the Congo, as well as from the shores of the Gulf of Guinea, must be represented.

The bottle-drift data relating to this locality are worthy of further remark. It has already been shown that about thirty of every hundred bottles recovered after being thrown into the Main Equatorial Current between the coast of North Brazil and St. Paul's Rocks reached Trinidad. Much of the Amazon drift, as observed below, is cast up on the shores of this island. Five out of sixteen bottles, that were recovered after being dropped overboard off the Amazon estuary, were stranded on Trinidad. Dr. Schott (pp. 12, 14) dwells on the very large number of records of drift bottles that were returned to the "Deutsche Seewarte" in Hamburg from the east coast of this island, almost all of them arriving there from the south-east and east-south-east, less than 10 per cent. coming from the east or 
north-east, or from latitudes north of $10^{\circ} \mathrm{N}$. within the zone of the North Equatorial Current. It may be, therefore, truly said that on the beaches of Trinidad we find sampled all the seed-drift that reaches the West Indian region, and, in fact, the New World.

The Transport of Amazon Drift to the West Indian and Florida Regions and Probably also to Europe.- The transport of Amazon drift to the West Indian Islands has long been surmised, and in this connection we may quote the remark of Sir D. Morris that the general characters of the drift on the south coast of Jamaica point to a source in the Orinoco and the Amazon (Nature, January 31, 1889). The vegetable drift brought down in such quantities by the Amazon soon gets into the rapid stream of the Main Equatorial Current and is distributed over the West Indian region. "The waters of the Amazon," writes Laughton in his Physical Geography $(1873$, p. 188), " at first set to the north-east, but they soon incline to the northward, and falling into the strength of the current are swept away to the north-west." Bates observed Amazon drift, more particularly the fruits of Manicaria saccifera, which are so characteristic of West Indian beach-drift, about 400 miles to the north of the mouth of the estuary (The Naturalist on the River Amazons, 1864, p. 461). The American and German bottle-drift charts clearly indicate the mode of distribution of such floating fruits and seeds and the tracks that would usually be followed. I here give the places of recovery of sixteen bottles thrown into the sea between 200 and 400 miles north and east of the Amazon estuary, the data being mainly supplied by the American charts. Three were cast up on the coasts of the Guianas, five on Trinidad, one on the adjacent island of Tobago, one on the neighbouring Venezuelan shores, three on the Lesser Antilles (between Grenada and the Virgin Islands), one on the shores of the Gulf of Honduras, and two on the east coast of Florida after passing through the Florida Straits. One of the records relating to the Florida coast should be specially mentioned here, since my authority is an old newspaper cutting dating back, perhaps, to the closing years of last century. A bottle thrown over from the Prince Eugene on March 11, about 300 miles north-east of the Amazon estuary, was picked up 279 days afterwards on the east coast of Florida, in lat. $27^{\circ} 30^{\prime} \mathrm{N}$. The captain was informed by letter from the Hydrographic Office in Washington that it had performed a passage of $\mathbf{3 3 2 0}$ miles.

In establishing this link by bottle-drift between the estuary of the Amazon and the Florida seas we indicate the probability of fruits and seeds of the Amazon drift being transported to the shores of Western Europe. It is in the neighbourhood of the Florida Straits that West Indian drift gathers before starting northward on its rapid journey through the straits towards Cape Hatteras and thence across the Atlantic. The data enable us to place the period needed for this long passage from the Amazon to Europe at about twenty months, allowing six months for the first stage ending with the Florida Straits, and fourteen months for the Atlantic traverse. It is on the same grounds-namely, that drift from the Main Equatorial Current reaches the Florida coasts and that drift from the Florida 
Straits is stranded on the shores of Europe, that Dr. Schott (p. 13) assumes the presence of water from the southern hemisphere in our northern seas. It is true that no bottle from off the mouths of the Amazon seems to have been found on the coast of Europe; but we have the record of a bottle, referred to on p. 59, that was dropped into the Caribbean Sea about 100 miles from the south coast of Jamaica in the direct track of the Main Equatorial Current and was recovered on the Irish coast. The first part of the passage from the coast of Brazil would be indicated by the track of a bottle that reached the Cayman Islands from Ceara, north-west of Cape St. Roque (Savage English, Kew Bull., 1913, p. 370).

But the demonstration of this link between the Florida Straits and the Amazon estuary may mean even more, since the Main Equatorial Current before quitting the Gulf of Guinea would have gathered drift from the West African coasts and from the estuaries of the Niger and the Congo. It is therefore not unlikely that even West African drift might find its way by this circuitous route to the shores of Europe. The bottle-drift data indicate that if Amazon drift can reach European waters in twenty months that from the Congo would require two years. Reference has several times been made to a bottle which was found on the Irish coast thirty-four months after it had been thrown over to the westward of the Cape Verde Islands, having crossed and recrossed the Atlantic in the North Equatorial Current and in the Gulf Stream. But I possess no bottle-drift data bearing directly on the possibility of drift being carried from the Gulf of Guinea and the two great rivers of equatorial West Africa to the coasts of Europe. There is, however, the extremely interesting observation of General Sabine, where casks of palm oil from a ship wrecked on the borders of this gulf are stated to have been drifted ashore in the following year at the extreme north of Norway, and there is the case of a bottle thrown over from the Lady Montague, two and a half leagues north-east of Ascension, which was found afloat off the coast of Guernsey 295 days afterwards. There are, however, serious difficulties connected with the first case, and as regards the second it seems incredible that a bottle could twice traverse the Atlantic, in equatorial and north temperate latitudes, in less than ten months. Both of these exceptional cases are dealt with in Notes $\mathbf{2 5}$ and $\mathbf{2 6}$ of the Appendix.

The Balance of the Account between the Old and the NEw World.- It is an error to place an equal value, as De Candolle does in his Géographie Botanique (pp. 763-4, 1855), on the work of the Gulf Stream and of the Equatorial Currents in transporting seeds to the Old World and in carrying them to the New World in a suitable condition for germination. He considers that the seeddrift would be carried to the Gulf of Guinea from the tropies of the New World in that portion of the Gulf Stream that bends south past Europe and North Africa to the Canary Islands. There is no support given to this view by the numerous bottle-drift data at my disposal. All such drift, when it approaches the vicinity of the Cape Verde Group, is deflected westward and is borne in the North Equatorial Current to the West Indies. There is no approach to 
an equal value in the reciprocal exchange of seed-drift between the tropical regions on the opposite sides of the Atlantic. When we come to balance the account respecting the interchange of seed-drift between the Old and the New World, we learn that in the "giveand-take " process the gift from the New to the Old World would be slight. All the seeds borne to Europe in the Gulf Stream from the West Indian region would find uncongenial climatic conditions that would deprive the gift of any value. But better prospects would await those that chanced to be diverted south, either in the vicinity of the Azores, or further east in approaching European waters, where they would come within the influence of the Portuguese or North African Current. In both events they might possibly be stranded on the coasts of tropical Africa to the north of the Cape Verde Islands; but, as indicated by the bottle-drift, the chances are that they would not be stranded at all, but would be carried back to the West Indies in the stream of the North Equatorial Current.

It is also highly probable that seed-drift from the Atlantic shores of North America, from Cape Hatteras northward, might be at times transported to the shores of Europe in the Gulf Stream drift, as is indicated in the tabulated results for bottle-drift before given. Such dispersal would be effective for the seeds of a few coast plants of temperate latitudes; but the seed-drift derived by currents from such regions is always small in amount and frequently ineffective for purposes of reproducing the plant. In my book on Plant Dispersal (pp. 429, 434, 438) it is shown that dispersal by currents is mainly restricted to warm latitudes. Whilst in the tropics seed-drift is abundant on the beaches, in the cooler regions of the globe it is usually very scanty and often masked by other vegetable débris.

Another possible way by which the New World might occasionally present seed-drift to the Old World is afforded by the already mentioned westward extension of the Guinea Current at certain seasons of the year so as to constitute a counter equatorial current (see Note 19 of the Appendix). Acting as a "backwater" to the North and Main Equatorial Currents, it would be most effective in returning African seed-drift to Africa; but at times, by extending nearer than usual to the New World, it might pick up a little drift from the north-east coasts of South America. Then again, as before suggested, it is probable that some of the drift gathered by the Brazil Current from the shores and estuaries of Brazil south of Cape St. Roque, as well as from the Rio de la Plata, might ultimately find its way by the South Atlantic Connecting Current into the South African Current and then into the Main Equatorial Current in the Gulf of Guinea. But whether it would be beached on the South African side seems unlikely, though there is an example of bottledrift which might be instanced in this connection (p. 63).

In the above discussion I have made the most of the possible and probable chances of the communication of seed-drift from the New to the Old World. The gifts at most would be unimportant and casual, and when effective of a belated kind. Not for a moment could a comparison be made with the large amount of effective 
seed-drift that must be rushed in a few months across the tropical Atlantic in the streams of the North and the Main Equatorial Currents. It is, as we have seen, only in the tropics that currents play an important part in plant distribution. For ages these two currents have been bearing their burdens westward direct from the African shores. Except for the occasional intervention of a counter-equatorial stream, as before described, there would be no direct return route from the American shores.

Drift carried by Currents round Cape Horn, Cape Agulhas, and the North CAPE.-It is noteworthy that drift has been known to double all the three great headlands which form the extremes of the continents of South America, Africa and Europe, towards the poles. Reference has already been made to this matter in different connections. Thus on p. 63 it is shown that bottles can be carried from off the coast of Natal round Cape Agulhas and across the South Atlantic to tropical Brazil, and from the Pacific side of Tierra del Fuego to the Falkland Islands. In neither case would the connection appear to be a frequent one; but the transference of seeddrift from the Indian Ocean to the South Atlantic would probably be the most effective. With regard to the doubling of the North Cape it is well known that West Indian seed-drift is carried by the Gulf Stream to the vicinity of this headland, and in Chapter II. it is pointed out that it may even double this promontory and reach the shores of the White Sea. I have no example of this having been accomplished by bottle-drift; but that bottles can reach the vicinity of this cape from the other side of the Atlantic is shown in the U.S. Pilot Chart for December 1908, in the case of one dropped overboard off Cape Hatteras.

\section{Summary}

1. As indicative of the track followed by the drifting seed and of the time occupied in the traverse of the Atlantic the behaviour of the drifting bottle affords very important data (p. 46).

2. After dealing with the sources of the materials employed, the value of bottle-drift for the study of the dispersal of seeds by currents is discussed. The small proportion of recoveries is pointed out (p. 48), and it is shown that the difficulties connected with the delays in the recovery are not so formidable as they at first seem (p. 49). The water-logged derelict from off Cape Hatteras, the baulk of mahogany from West Indian islands, the living turtle from the warm latitudes of the New World, the floating bottle containing the record of its start in Cuban waters or in Florida seas, the buoyant seed that could have grown only in the West Indies or on the tropical mainland of America, all tell the same story when they are stranded on our European beaches (p. 48).

3. The treatment of the subject is divided into two parts : in the first place, the tracks followed; in the second place, the time occupied by the drifting bottle; and in order to give method to the inquiry the accomplishment of the circuit of the North Atlantic is first dealt with. It is remarked that the circulatory movements of the currents in this ocean are equally well illustrated, whether the 
circuit is performed by one bottle or piecemeal by a number of bottles (p. 51).

4. The traverse from the West Indies and from the south-east coasts of North America to the shores of Europe in the Gulf Stream drift is then considered. The fan-shaped distribution of bottledrift from the New World is then remarked, since it may be stranded anywhere on the east side of the North Atlantic between the North Cape of Norway and the coast of Morocco, reaching even the Canary Islands. From the results of experiments covering a long period of years it is inferred that drift may reach any given locality on the European coasts from all latitudes on the American side of the North Atlantic between the tropics and the sub-Arctic regions. Thus, bottle-drift is stranded on the Irish coasts from all latitudes between the Caribbean Sea and Davis Strait. The results of the extensive researches conducted with specially devised floats by the Prince of Monaco in the north-east Atlantic are here utilised (pp. 49-56).

5. Having shown that bottles are carried across the North Atlantic to Europe from the West Indies in the Gulf Stream drift, the requisite data are adduced to demonstrate that they can be returned from European waters to the New World in the tropical latitudes of the same ocean by the North Equatorial Current. The facts indicate that from any locality in the Eastern Atlantic between the vicinity of the Irish coast and that of the Cape Verde Group bottles can be transported to any part of the West Indian region north of Barbados. A few of them finally reach the east coast of Florida after traversing the Lesser Antilles and crossing the Caribbean Sea and the Gulf of Mexico. This track must have been followed by a bottle that, after being cast over to the westward of the Cape Verde Islands, was recovered thirty-four months later on the Irish coast (pp. 56-59).

6. After a short reference to the Guinea Current (p. 59), the next point of importance touched upon is the passage of bottles across the tropical Atlantic in the Main Equatorial Current from the Gulf of Guinea to the coast of Brazil. Guided by the bottle-drift data, the writer adopts the view that the two equatorial currents that approach the Brazilian coast north and south of Cape St. Roque are distinct in their origin, their course, and their destination; and he distinguishes them by the names, frequently used by other writers, of the Main and the South Equatorial Currents (pp. 60).

7. It is shown that whilst the mass of the bottle-drift of the North Equatorial Current strikes the West Indian region north of Barbados, most of that of the Main Equatorial Current enters the region in the Trinidad waters to the south of that island. Of a hundred bottles thrown into the last-named current between North Brazil and St. Paul's Rocks nearly forty would be carried swiftly into the Caribbean Sea, to be distributed in most cases around its shores; but sixteen of them would pass through the Straits of Yucatan into the Gulf of Mexico, and of these five would reach the Florida seas. Only a few of them would take the shorter route by the subsidiary Antillean Stream that flows east of the Lesser Antilles to the Bahamas (pp. 60-62).

8. The indications of bottle-drift are then used to elucidate the 
part that would be taken by the South Equatorial Current and its southward extension, the Brazilian Current, in the distribution of seed-drift in the South Atlantic; and the same data are employed to illustrate the current-connections of this ocean with the Indian and Pacific Oceans. It is shown that bottle-drift can pass from the Indian Ocean into the South Atlantic round the Cape and may even reach Brazil, and that it can pass into the same ocean from the South Pacific round Cape Horn (pp. 62-63).

9. The drifting rate of bottles in crossing the Atlantic is then treated; and after showing how the disturbing elements connected with the delay in their recovery may be largely eliminated, a table of general results is given (p. 66). It is inferred that the average time occupied in the passage from the West Indian region to Europe would be about fourteen months at a daily rate of about nine miles, and it is remarked that the average speed during different stages of the traverse is not much less. The fact that much slower rates are indicated by one of the series of the Prince of Monaco's observations in the North-east Atlantic is explained (p. 68). The return passage from European waters to the West Indies usually covers a period of sixteen to seventeen months. But the rate varies in different parts of the traverse. In the passage south to the vicinity of the Cape Verde Islands it would be only four or five miles a day; whilst in the trans-oceanic passage in the North Equatorial Current it would be nearly thirteen miles (p. 68).

10. A much greater velocity is attained by bottle-drift in the swift stream of the Main Equatorial Current-namely, an average daily speed of thirty miles from the Gulf of Guinea to Brazil and of forty miles from off the Amazon estuary to Trinidad. About twelve weeks would generally be occupied in the trans-oceanic passage from the Gulf of Guinea to Brazil (p. 70). The data furnished by bottle-drift indicate that Amazon drift, crossing the Caribbean Sea and the Gulf of Mexico and following the Gulf Stream route, would arrive in European waters in about twenty months (p. 70). The average rate of bottle-drift in the Brazil Current does not exceed ten miles a day (p. 71). It is concluded that the complete circuit of the North Atlantic (from the Florida seas by the route of the Gulf Stream, the North Equatorial Current, the Caribbean Sea, and the Gulf of Mexico) would be accomplished in an average period of just three years (p. 72). The difficulties in demonstrating the completion of the circuit by the same bottle are very great. But it has been almost accomplished by derelicts. The nearest approach to a complete record is that of the bottle which was picked up on the west coast of Ireland thirty-four months after it had been cast into the sea to the westward of the Cape Verde Group (p. 72).

11. Although the indications of the bottle-drift data open up great possibilities for the distribution of seed-drift in the North and South Atlantic, each ocean possessing its own independent circulatory system of currents, it must often happen that the transport of floating seeds from tropical to temperate latitudes, and vice versa, has no effective value. Whilst the North Equatorial Current brings to the West Indies the sweepings of the Atlantic seaboard of North America, 
of Southern Europe, and of North-west Africa, the Main Equatorial carries to the same region the sweepings of both sides of the South Atlantic. The burden borne westward by the current just named is, indeed, a motley one. Some of the greatest rivers in the world, the rivers of two continents, contribute to its freight, the Niger, the Congo, the Plate, the Amazon, and the Orinoco. Great importance is attached to the fact that the drift of the North and Main Equatorial Currents mingles in the Caribbean Sea (pp. 73-74).

12. Attention is drawn to the interest that attaches itself to the island of Trinidad from the standpoint of the dispersal of plants by currents. It is the great centre of connection between the Old and the New World and between the South American mainland and the West Indian islands (p. 74).

13. The probability that Amazon seed-drift reaches the shores of Europe opens up the possibility of West African seed-drift from the Congo and the Niger arriving on these coasts by the same circuitous route-namely, through the West Indies and in the Gulf Stream drift. This track seems to have been pursued by a bottle which was found afloat off the coast of Guernsey, after being dropped overboard near the island of Ascension. Sabine's observation on the transport of casks of palm oil from the Gulf of Guinea to Hammerfest bears on this point (pp. 75-76).

14. When we come to balance the account respecting the interchange of seed-drift between the Old and the New World, we learn that in the give-and-take process the gifts from the New to the Old World would be slight. As a rule they would be unimportant, ineffective, and casual, and even when effective of a belated kind. Not for a moment could a comparison be made with the large amount of effective seed-drift that must be rushed in a few months across the tropical Atlantic in the streams of the North and Main Equatorial Currents (p. 76).

15. In conclusion, it is shown that even the North Cape, Cape Agulhas, and Cape Horn form no insuperable barriers for the passage of seed-drift (p. 78).

\section{WORKS QUOTED IN CONNECTION WITH BOTTLE-DRIFT}

BeCHer, A. B., in Nautical Magazine for 1843 and 1852.

Berghads, H., Allgemeinen Länder und Völkerkunde, i., 1837, and Physikalischen Atlas (Abth. Hydrogr.).

DAUSsy, Sur les observations de courants faites au moyen de bouteilles jetées a la mer, Comptes Rendus, 1839, viii., 81.

KонL, J. G., Geschichte des Golfstroms und seiner Erforschung: Bremen, 1868.

Monaco, Prince Albert of, Sur le Gulf Stream : Paris, 1886 (Gauthier-Villars); different papers in Comptes Rendus, 1885-92, the final summary and tabulation of results in tome $114,1892$.

Nrumayer, G., Petermann's Geographischen Mittheilungen, 1868.

Pagn, J., The U.S. Hydrographic Office, National Geographic Magazine, xii., 337 : New York, 1901.

Purdy, J., in Columbian Navigator, iii., 31, 1839. 
RexnelL, J., An Investigation of the Currents of the Atlantic Ocean : London, 1832. Russwl, H. C., Journ. Roy. Soc. N.S. Wales, 1894, 1896.

Sснотт, G., Die Flaschenposten der Deutschen Seewarte, Archiv der Deutschew Seewarte, xx., 1897, Hamburg.

U.S. Hydrographic Office, Washington, Bottle-drift charts on the backs of the North Atlantic Pilot Charts, October to May, 1900-8.

Wood-Jores, F., Coral and Atolls, London, 1910, pp. 294-5, contains results of bottle-drift experiments in the Indian Ocean. 


\section{CHAPTER IV}

THE SIMILARITY BETWEEN THE WEST INDIAN AND WEST AFRICAN LITTORAL FLORAS AS EXPLAINED BY CURRENTS

The similarity between the West Indian and West African littoral floras has long occupied the attention of botanists, and particularly of the late Prof. Schimper. It is a subject that is intimately bound up with the question of the dispersal of plants by currents; but a little clearing of the ground is first requisite in order to appreciate its true significance.

The Discontinuity of Tropical Genera possessing Littoral SPECIES.-A very noticeable and not infrequent feature in connection with the littoral trees of the tropics of the Old and New World is the discontinuous distribution of the genera as far as all the nonlittoral species are concerned. Though the littoral species is in each case widely distributed in both the western and eastern hemispheres, the genus is also represented by peculiar species in both worlds, and in such a manner that we are often left in doubt whether the shore species has its home in the east or in the west. In all such cases it is only the littoral species spread by the currents that connects the two hemispheres. Otherwise the discontinuity would be complete. As examples we may give Chrysobalanus, Entada, Thespesia, and Ximenia. But this discontinuous distribution raises many difficulties, whilst it removes others.

Thus, as far as the range of the genus is concerned, the New World has as much claim as the Old World to be considered the home of Thespesia populnea, since the six other known species are shared equally by the two hemispheres. But other genera than those named above present new points of difficulty. Thus Symphonia is a genus of twelve or thirteen species, of which nearly all are confined to Madagascar and two occur in Africa. A single estuarine species, $S$. globulifera, which connects West Africa with the New World has apparently no means of crossing the Atlantic. Then we have Terminalia with a large number of species spread over the tropics of both hemispheres; but truly littoral species occur only in the Old World, and there is no species connecting the two hemispheres. Then there is Crudya with nearly all its dozen species American.

This discontinuity presents no great difficulties when it affects genera found in the tropics of both hemispheres which are only connected together by littoral species that are known to be dispersed 
by currents; and the same may be said of those genera without littoral species where there is no connection between America and the Old World, as in the case of Mammea with six known species, of which three are restricted to tropical America and three are known only from Madagascar. Here we are concerned with the original distribution of the genera in the tropical zone, and the presence or absence of any link between America and the eastern hemisphere seems to be a matter of fitness for dispersal by currents. One can also understand cases like Terminalia, where the absence of any species linking the two worlds may be concerned with the circumstance that the littoral species capable of being spread by the currents are not found on the West African coast; but the behaviour of the genera, Symphonia and Crudya, is not easy to comprehend, since there we have one genus almost entirely of the Old World with only a single outpost in America, and another almost entirely American with a distant representative in the Philippine Islands.

The important lesson to be learned from the discontinuity of genera in tropical latitudes is that we can only appeal to the currents in the case of the littoral species, the original distribution of the genus around the tropical zone being quite another matter. Facts of this kind go far to limit the sphere of influence of the oceanic current in determining plant distribution. Currents have done little to confuse the great issues raised by the genera. Whilst they have often effected the mingling of littoral floras of continents, the main facts of distribution are largely undisturbed. With these introductory remarks we will now proceed to discuss the similarity of the West Indian and West African littoral floras, and in so doing we will take up again the story of the beach-drift.

An Appeal to the Oceanic Currents.-Perhaps the most important question raised by the study of West Indian beach-drift is suggested by the fact that more than half of the plants that contribute to it (beach plants, mangroves and their associates, estuarine plants, and inland plants that grow at times at the riverside) occur outside the New World. Almost all of the Old World plants here concerned have been recorded from West Africa; and there can be little doubt that the few exceptions, most of which have been observed on the east side of the continent, will disappear with future inquiry.

This fact at once leads one to investigate the relation between the occurrence of these West Indian plants in West Africa and their suitability for dispersal by oceanic currents. To each of these plants, as well as to those that are restricted entirely to the New World, the question has been put, whether or not its fruit or seed, as the case may be, could be transported without loss of the germinative power in the Main Equatorial Current from West Africa to Brazil. This, as is shown in Chapter III., is the shortest available route between the two Worlds for the transference by currents of floating fruits and seeds. It requires a capacity on the part of the fruit or seed of floating unharmed from two to three months in seawater, and of being able to withstand the ordinary buffeting of the waves. 
The question is put and answered in the table given on p. 86, in the columns of which are embodied the results of the author's observations and experiments, as well as literary research, extending over a period of more than thirty years, and carried out in many localities both in the Old and the New World. There are not more than three or four of the fifty-three plants named in the table with which he is not familiar in their homes, and in all but one he is acquainted with their fruits and seeds, and has investigated their capacity for dispersal by currents.

With the exception of the group of small-seeded plants, which, since they raise other considerations besides those concerned with currents, are not here dealt with and are discussed in Note 21 of the Appendix, we have represented in this table the principal littoral, estuarine, and riverside plants of the West Indies. All offer themselves for the application of the test.

\section{Explanatory Notes of the Following Table}

(a) The results given in the buoyancy column refer only to the period during which the seed retains its germinative capacity whilst afloat. Flotation may continue long after the death of the seed.

(b) The plants marked ? in the West African column occur in all probability in West Africa, though in the works of reference at my disposal that region is not specially particularised, and they are as a rule merely described as found on all tropical coasts. It may be assumed that plants like Suriana maritima and Colubrina asiatica, which are found in the West Indies and in East Africa, also occur in West Africa, though in the case of the Old World they are usually only mentioned as existing on all tropical coasts.

(c) The occurrence of the plants on the Pacific coasts of tropical America is indicated in the table as far as the data at my disposal allow. The distribution is often stated in such a general way in works of reference that it is not possible to learn with certainty whether or not the plant concerned exists on the Pacific as well as on the West Indian side of the New World. This is unfortunate, since the question is one of considerable interest, especially as regards true littoral plants. It is, however, probable in most of the cases where no indication is given in the table that the plant also grows on the Pacific coast.

(d) The list of beach plants restricted to the New World could be considerably extended if buoyancy data were available; but it is very doubtful whether any of them would possess seeds or fruits with great floating powers. One may mention Ernodea litoralis, Rhachicallis rupestris, and Phyllanthus falcatus. Then there are plants of Amarantaceous genera, such as Alternanthera and Lithophila, as well as different sedges, such as Cyperus brunneus, etc., and grasses, such as Uniola paniculata, Cenchrus tribuloides, etc. 


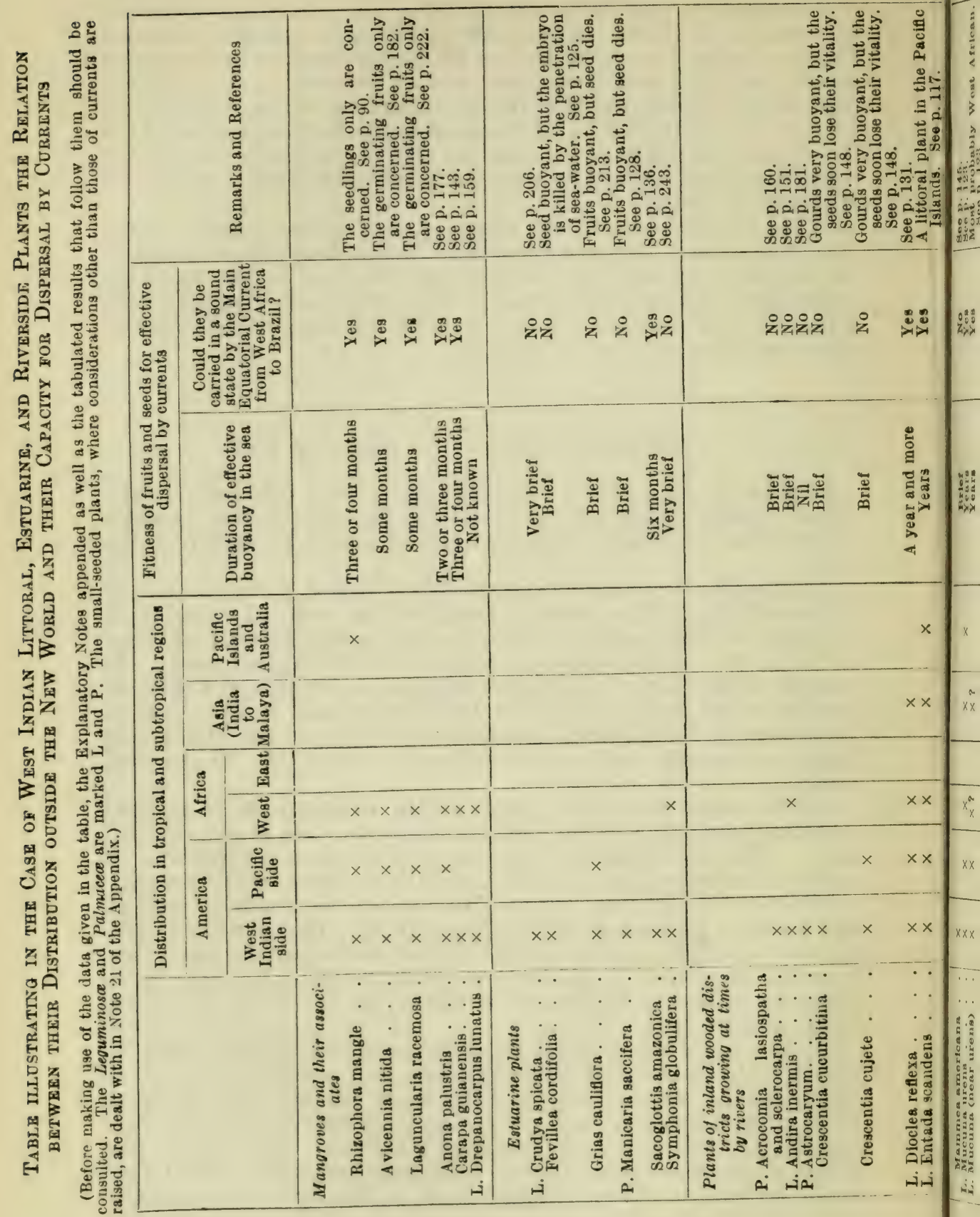




\section{WEST INDIAN AND WEST AFRICAN FLORAS 87}

\begin{tabular}{|c|c|c|c|c|}
\hline 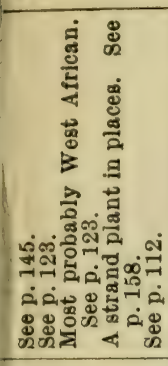 & 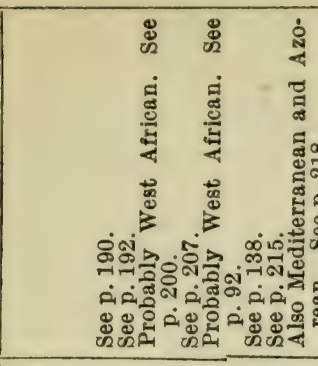 & 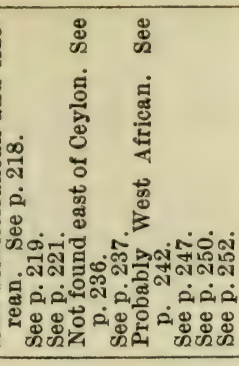 & 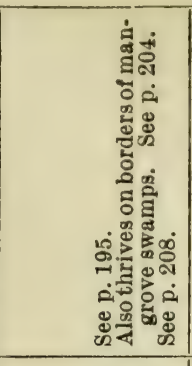 & 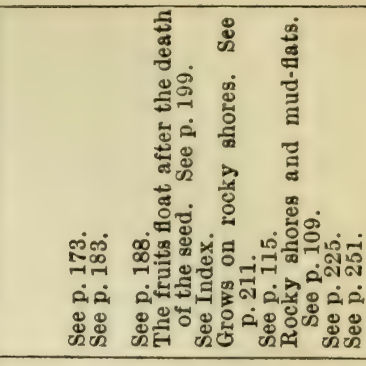 \\
\hline 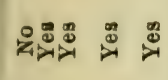 & 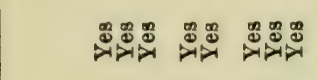 & 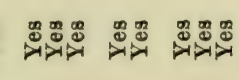 & 悉䍜 & 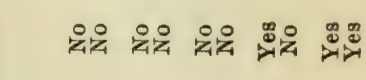 \\
\hline 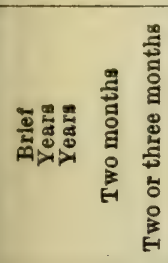 & 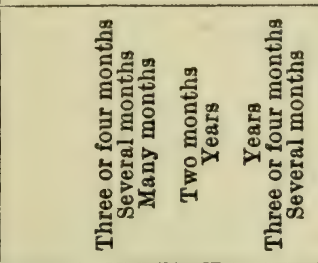 & 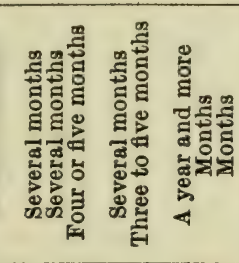 & 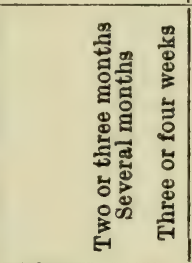 & 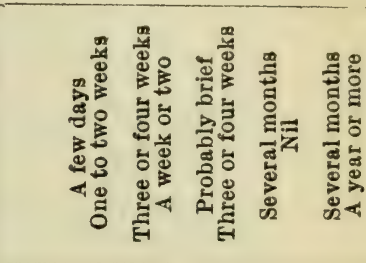 \\
\hline$x$ & $x \times x \quad x x \quad x x$ & $x x \quad x x \quad x x x$ & & \\
\hline$x \ddot{x}$ & $x x x \quad x x \quad x x$ & $x \times x \quad x x \quad x \quad x$ & & \\
\hline & $x x x \quad x \quad x x$ & $x_{x}^{a} x \times x \quad x \times x$ & & \\
\hline$x_{x}^{\tilde{x}} \quad x$ & $x x_{x}^{\tilde{x}} \times x_{x}^{\tilde{x}} \times x_{\ddot{x}}^{\tilde{x}}$ & $\tilde{x}_{x}^{\alpha} \times \tilde{x}_{x}^{\tilde{x}} x x x$ & $x \times x$ & \\
\hline$x \times \times x$ & $x \quad \tilde{x} \quad x x x$ & $x \times \underset{x x}{a-a} \tilde{x} x x$ & $x \times x$ & $\times \ddot{x}$ \\
\hline$x \times x \times x$ & $x x x \quad x x \quad x x x$ & $x \times x \quad x x \quad x \times x$ & $x \times \quad x$ & $\begin{array}{llllll}x x & x x & x x & x x & x x\end{array}$ \\
\hline 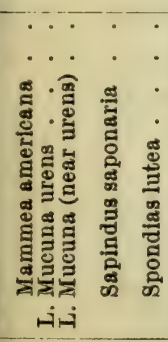 & 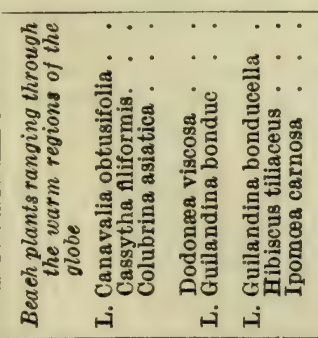 & 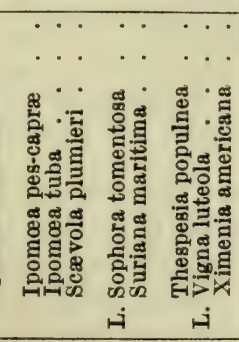 & 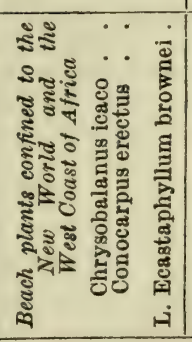 & 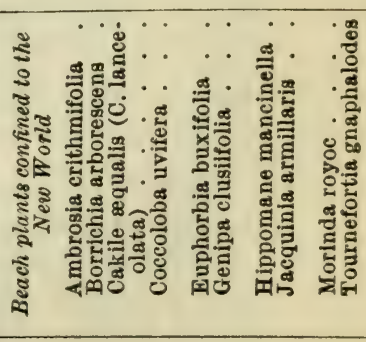 \\
\hline
\end{tabular}


Tabulated Results of the Preceding Table

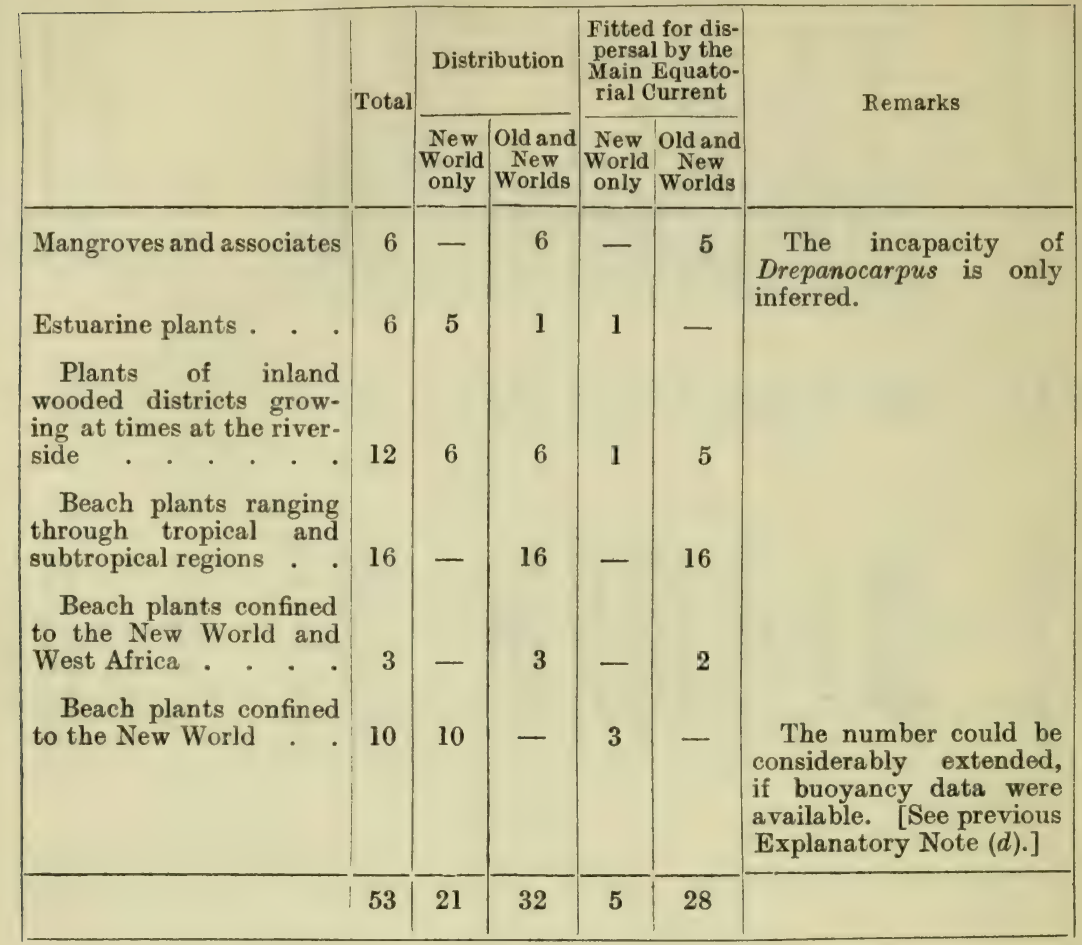

Summary of the above tabulated results.

Of the 53 plants, 32 , or 60 per cent., occur in both Worlds, and 33, or 62 per cent., respond to the current test in their fitness for transport by the Main Equatorial Current.

Of the 32 plants occurring in both Worlds, 28 , or 88 per cent., respond to this test; but only 24 per cent. ( 5 out of 21 ) do so of those confined to the New World, a proportion that doubtless would be considerably lessened if more buoyancy data were available.

The plants that are exceptions to the rules.

The three plants that occur on opposite sides of the tropical Atlantic but could not be floated across the ocean are Andira inermis, Ecastaphyllum brownei, and Symphonia globulifera. Possibly a fourth would be Drepanocarpus lunatus.

The five that are restricted to the New World, yet are able to cross the Atlantic between West Africa and Brazil, are Hippomane mancinella, Morinda royoc, Sacoglottis amazonica, Sapindus saponaria, and Tournefortia gnaphalodes.

The Test of Capacity for Dispersal by Currents.-There are presented in the above table fifty-three West Indian plants of which thirty-two, or 60 per cent., are found outside the New World, and in nearly all cases on the shores and in the estuaries of tropical West Africa. Of these Old World plants all but four, or 88 per cent., give an affirmative reply when interrogated as to the fitness of their 
fruits and seeds for transport across the Atlantic from the Gulf of Guinea to South America in the Main Equatorial Current. We are not concerned just at present with the indications that this test might yield of a West African origin of many of the West Indian littoral and estuarine plants. For the moment we will simply regard this as a proof of capacity for accomplishing the traverse of the tropical Atlantic. When we regard the twenty-one plants that are restricted to the New World we find that only five, or 24 per cent., respond to the test. It should here be repeated that the list of plants confined to the New World could be considerably augmented, and that the effect would be to markedly diminish the proportion of those that respond to the test. With reference to the five plants that are restricted to the New World, notwithstanding their capacity for crossing the tropical Atlantic, we shall subsequently see that in negativing any reciprocal interchange of littoral, estuarine and riverside plants between the Old and the New World they afford a clue to the origin of most of the West Indian plants of these stations that have been found in the Old World.

(A) Its Application to the Plants in the Mass.-The issue may thus be stated. Whilst nearly 90 per cent. of the plants that are common to the West Indies and West Africa possess seeds or fruits that could be transported by the currents from the Gulf of Guinea to Brazil, less than one-fourth of those restricted to the West Indian side possess the same capacity, but have not extended their range outside the New World. The matter thus resolves itself into a question of the opportunities offered by the Atlantic currents, concerning which it has already been brought out in Chapter III. that whilst the Main Equatorial Current offers a ready and rapid means of transport for fruits and seeds from West Africa to the New World, the opportunities of West Africa receiving West Indian seeds and fruits in a sound condition are small. Reference may here again be made to the fact that De Candolle in his work on Botanical Geography (pp. 763-4) places an equal value on the Gulf Stream and the Equatorial Currents of the Atlantic in the reciprocal exchange of drift between the opposite tropical regions. This is a serious error, since the long circuitous route by the Gulf Stream, which would involve a minimum passage of two years, would for all but a very few leguminous plants negative any chance of effective dispersal. The Brazilian Current would not tap the West Indian region at all, and the return of any of its seed-drift to tropical Africa would involve a very lengthy passage and a somewhat complex series of current connections. The only chance would be that offered by the Equatorial Counter Current; but it is shown that the occasions in which it would extend far enough to the west to tap the New World as a source of drift would be few, though not altogether negligible.

(B) Its Application to the Plants according to their Station.-Having applied this test to the plants in the mass we will now apply it to them according to their station.

(a) The Mangroves.-In the first place come the mangroves and their associates, all of which are West African as well as West Indian. 
The true mangroves comprise Rhizophora mangle, Avicennia nitida, and Laguncularia racemosa; whilst their associates at the borders of the swamp include Anona palustris, Carapa guianensis, and Drepanocarpus lunatus. With all of them, except the last, concerning which the requisite data are lacking, it is possible that the Main Equatorial Current could have transported them from the African coast to the shores of Brazil and the Guianas, but it would be under varied conditions. Whilst Rhizophora would arrive in the form of floating seedlings, with Avicennia and Laguncularia the germinating fruits would be concerned. When pointing out in my book on Plant Dispersal the obvious risks to which the seedlings and germinating fruits would be exposed during a long ocean passage, I felt constrained to admit (p. 77) that their capacity for effective dispersal across an ocean must be postulated.

At that time the position adopted was that America had supplied West Africa with its mangroves. This I regard now as untenable, and a later consideration of the current question, as discussed in Chapter III., has convinced me that an average period of only twelve weeks would be required for the transport of seed-drift from the Gulf of Guinea to Brazil, whilst under especially favourable circumstances this period might be reduced to two months. Though the seedlings and germinating fruits of the mangroves could scarcely withstand the wear and tear of an ocean passage of six months, it seems probable that they would survive a passage of half this duration. With regard to the floating seeds of plants like Anona palustris and Carapa guianensis, which are associated with the mangroves, it is likely that they could only accomplish an ocean traverse of from two to four months with sound kernels. For long passages of many months they would be quite unfitted as far as the preservation of their effective condition is concerned.

(b) The Estuarine Plants.-Apart from the mangroves and their associates there are estuarine plants, such as Crudya spicata, Fevillea cordifolia, Grias cauliflora, Manicaria saccifera, Sacoglottis amazonica, and Symphonia globulifera, all of which contribute their seeds or fruits to the floating drift that is borne seaward and distributed by the currents. Whilst all the mangroves and their associates are also West African, five of the six plants just named are confined to the tropics of the New World. With the exception of Sacoglottis amazonica there is not one of them, however, that gives promise of being able to withstand without injury an immersion of months in the sea, and this oddly enough is not the Old World plant. The buoyancy of the seeds or fruits may be so great that as with Sacoglottis amazonica and Manicaria saccifera the fruits have been known to be stranded on the shores of Europe; but the indications plainly show that they would not be in a germinable condition. Yet it is strange that the plant which is least fitted for oceanic dispersal, namely, Symphonia globulifera, is the only one of the six that has been found outside the New World, that is, in West Africa. This plant is one of the puzzles of distribution, and we shall see its riddle repeated in one or two other cases mentioned below.

Whilst in Symphonia globulifera we have an estuarine tree growing 
on both sides of the tropical Atlantic that could not possibly, as far as its seeds or its fruits are concerned, have accomplished the ocean traverse, we have in Sacoglottis amazonica another estuarine tree, which, although it is restricted to the New World, presents in its buoyant fruits some capacity for reaching the Old World. In the first case other influences than those of currents have determined its distribution. In the second case the determining factors have been the arrangement of the currents and the insufficiently persistent vitality of the seeds. Whilst the fruits of Sacoglottis amazonica could perform the two years' traverse to the African coast by the Gulf Stream route in the North Atlantic, the seeds would probably lose their germinative power after six months. Though not impossible, the direct route by the Counter Equatorial Current is largely negatived in this case by the extensive bottle-drift data given in Chapter III.

(c) Inland Plants growing occasionally at the Riverside.-In connection with West Indian rivers there is another group of plants, the fruits of which often fall into the stream from the parent plants growing on the banks beyond the reach of the tide, and are then carried down to the sea to be distributed far and wide by the currents. The distinction, however, is a little artificial, since quite half of the plants would be found at times on the coast; and there are some, like Entada scandens, which, though usually growing inland in the West Indies, are typically littoral in their station in the Pacific islands. This group can be subdivided into $(a)$ those found in tropical West Africa, such as the leguminous climbers, Entada scandens, Mucuna urens, and Dioclea reflexa, and the trees, Andira inermis and Spondias lutea; and $(b)$ those confined to the New World, such as Mammea americana, Sapindus saponaria, Crescentia cujete, C. cucurbitina, and the palms Astrocaryum and Acrocomia.

Here there is a certain relation between distribution and fitness for dispersal by currents. With the exception of those of Sapindus saponaria, none of the fruits or seeds of the purely New World plants could accomplish an ocean traverse of two or three months' duration without loss of the germinative capacity, though capable of floating for much longer periods in an ineffective state. But even Sapindus saponaria may not prove to be an exception, since there are indications dealt with in the special treatment of the plant that it might be regarded as an Old World species. Of the five plants also at home in West Africa all but Andira inermis possess seeds or fruits that could perform in safety the ocean passage from West Africa to Brazil. In the case of the seeds of the leguminous climbers they could do very much more, since these seeds retain their germinative capacity after being carried in the Gulf Stream to the shores of Europe. Andira inermis presents the same difficulty as Symphonia globulifera. Though it occurs on both sides of the tropical Atlantic, it is not able to cross it.

(d) Beach Plants.-We come now to the beach plants, those that border the beaches and thrive on the sandy tracts in the rear. They arrange themselves into three groups: the cosmopolitan plants extending in a general sense over the continental and insular coasts 
of the tropics and subtropics of both hemispheres, those confined to the New World and the west coast of Africa, and those entirely restricted to the New World.

The Cosmopolitan Beach Plants.-In the case of this group we are dealing with plants that have travelled in most instances practically around the globe. They include five leguminous species, Canavalia obtusifolia, Guilandina bonduc, G. bonducella, Sophora tomentosa, and Vigna luteola; two malvaceous species, Hibicrus tiliaceus and Thespesia populnea; three convolvulaceous species, if we include Ipomeea carnosa with $I$. pes-caprae and I.tuba; and six others belonging to as many different orders-namely, Cassytha filiformis, Colubrina asiatica, Dodoncea viscosa, Sccevola plumieri, Suriana maritima, and Ximenia americana. There are a few of these plants that could scarcely be considered as universally distributed in warm latitudes, but the differences that separate them from the others are only in degree. Thus both Scaevola plumieri and Vigna luteola occur on both coasts of the New World and on both coasts of Africa; but since the first extends to India and Ceylon and the second exists in Australia, it would be difficult to exclude them. In giving Ipomœa tuba a very wide distribution I have followed Urban, and the reasons in the case of $I$. carnosa are given in the reference named.

Every one of these fifteen or sixteen widely spread beach plants has buoyant seeds or fruits (in most cases it is the seed that is concerned) which can float for a long time unharmed in the sea; and respecting some, such as the two species of Guilandina and Thespesia populnea, it is known that their seeds can float for a year in the sea without loss of the germinative capacity. A plant has, in fact, been raised from a Guilandina seed cast ashore on the coast of Ireland. But there is not a species in this group of beach plants that would not respond to the test involved in the transport of their seeds or fruits in a sound condition from West Africa to Brazil in the Main Equatorial Current, though in the case of Dodoncea viscosa the minimum limit of flotation-capacity is only just attained.

The Beach Plants restricted to the New World and West Africa.When the test above mentioned is applied to the small group of beach plants that beyond the New World are only known from the shores of West Africa, we find that two out of the three respond to it-namely, Chrysobalanus icaco and Conocarpus erectus. The third, Ecastaphyllum brownei, presents the same problem that was offered by Andira inermis and Symphonia globulifera amongst the riverside and estuarine plants. Here we have three plants that grow on the opposite sides of the tropical Atlantic with to all appearance no capacity for accomplishing the ocean passage. At first sight it would seem that the validity of the current hypothesis is here impugned; but in one case, at least, it is likely that quite other considerations arise. Thus Symphonia globulifera, an estuarine tree, belongs to a genus that is mainly confined to Madagascar, the exceptions being two West African species, one of which, as in the present case, is found in the West Indies. It is obvious that the discontinuous distribution here indicated may not be connected with means 
of dispersal at all. A curious question is raised in the case of Conocarpus erectus, the small seed-like fruits of which possess considerable floating powers. It grows on the Pacific coasts of tropical America, and its absence from the Pacific islands is remarkable, since there seems to be no reason, as far as its capacity for dispersal by currents is concerned, why it should not have reached the eastern islands of the tropical Pacific. The same difficulty is presented by the Manchineel tree (Hippomane mancinella), a matter which is referred to below. When dealing in detail with Conocarpus erectus it will be pointed out that Schimper regarded it as a current-dispersed plant. On the whole it may be considered that the three beach plants of tropical America that are only known outside the New World from the shores of West Africa raise many difficulties.

The Beach Plants confined to the Nerw World.-On the other hand, when we come to the West Indian beach plants that have not been found outside the New World we learn that of the ten plants named in the table the majority do not respond to the test. Whilst most of them possess fruits or seeds that can only float for a few days or weeks, in three cases, those of Hippomane mancinella (the Manchineel tree), Tournefortia gnaphalodes, and Morinda royoc, the floating capacity covers several months and may extend to a year or more.

To illustrate this point I will take the case of the Manchineel tree, the fruits of which are one of the most common constituents of beach-drift in the West Indian region; and there can be no doubt, as shown on a later page, that they can float for many months in the sea with their seeds uninjured. It is a tree that has held its present area for ages. In the hammocks of the Florida everglades there have found a sanctuary many West Indian plants that flourished in the same locality when the hammock-lands represented an ancient system of keys or low islands that rose from the waters at the time that the Gulf Stream flowed across the present peninsula of Florida (Harshberger, p. 230). The Manchineel was one of them. For a long period currents have afforded considerable opportunities for the transference of littoral plants from West Africa to the New World, but very few for a transference from America to Africa. Yet it may be argued that since the Manchineel grows on the beaches of the Pacific coast of the New World its fruits could have reached the Old World across the Pacific. However, the complete traverse of the ocean would occupy a period of two or three years, a subject discussed in Chapter XIII. Yet only about half that time would be required for its fruits to reach the Paumotuan, Tahitian, and Marquesan groups in mid-Pacific, and it is difficult to understand why the tree has not been recorded from the beaches of the Pacific islands.

It is still more difficult to understand, in the case of the tropical Atlantic, why, if the Counter Equatorial Current is an effective agency in seed dispersal, beach plants like the Manchineel, Tournefortia gnaphalodes, and Morinda royoc have not reached West Africa from the New World, and we may say the same of Sacoglottis amazonica among the estuarine plants. The time required for this traverse would be about double that needed for the traverse in the Main Equatorial Current in the opposite direction, and all these American 
plants would be able to withstand the six months' passage, as far as the buoyancy and soundness of their seeds and fruits are concerned. The implication is that the Counter Equatorial Current is ineffective for this purpose, and if it has not enabled these four plants to cross the Atlantic and pass the barrier that divides them from West Africa, it could have offered no opportunity to other American beach plants, such as Coccoloba uvifera, etc., that are far less suited for dispersal by currents.

\section{Summary}

1. Before dealing with the similarity between the West Indian and West African littoral floras, a subject intimately bound up with the dispersal of plants by currents, the ground is cleared by a brief discussion of the discontinuity of tropical genera, with the object of showing that whilst we can only appeal to the currents in the case of the littoral species, the distribution of the genus around the tropics often raises other issues (pp. 83-84).

2. The important conclusions arrived at in the previous chapter that the Main Equatorial Current offers a ready and rapid means of transport for fruits and seeds from tropical West Africa to the New World, and that the opportunity of their reaching West Africa in a sound condition from the tropics of the New World is very slight, are here utilised. Except in the case of the small-seeded beach plants, where other questions than those of dispersal by currents are concerned, the test of fitness for transport in the Main Equatorial Current from West Africa to Brazil is now applied to the littoral, estuarine and riverside plants of the West Indies. In answer to the question whether or not they respond to the test, the following results have been obtained (pp. 84-88).

3. Taking the plants in the mass, nearly 90 per cent. of those found in the tropics of both the Old and the New World and only 24 per cent. of those confined to the New World possess seeds or fruits that would be able to undergo this trial (pp. 89).

4. But this testimony in favour of the currents is not equally provided by the plants when regarded from their different stations. Whilst the mangroves with their usual associates and the numerous cosmopolitan beach plants, all of them typical of both sides of the Atlantic, respond almost without exception to the test, the majority of the beach plants restricted to the New World (seven out of ten) do not comply with it. Similar direct and indirect testimony on behalf of the currents is supplied by the plants that grow often at the riverside, especially in the wooded districts above the estuary. Here the purely New World types are as a rule quite unfitted for effective oceanic dispersal, while those found on both the American and the African sides are in most cases adapted for it (pp. 89-94).

5. On the other hand, the evidence of the six estuarine plants points in the opposite direction, since the only one that occurs outside the New World is quite unsuited for the ocean traverse, while one of those that are peculiarly American is well fitted for it (pp. 90-91).

6. It will be therefore observed that although on the whole the 
general verdict strongly favours the current hypothesis, there are some important exceptions. With the mangroves and their associated plants, as well as with the cosmopolitan beach plants, the vote is practically unanimous. With the American beach plants and with the riverside plants it is a majority vote, whilst with the estuarine plants the evidence is conflicting and at times apparently hostile (pp. 89-94).

7. Yet the ultimate tendency of the qualifying cases may not necessarily be hostile. The implication of the behaviour of such peculiarly American plants as Sapindus saponaria, Hippomane mancinella, Morinda royoc, Sacoglottis amazonica, and Tournefortia gnaphalodes, which possess fruits or seeds well suited for the direct ocean traverse, may be that the currents have given them no opportunity of extending their range eastward beyond the New World, since, as we have seen, the facilities offered by the currents to West African littoral plants of reaching America are very much greater than the opportunities supplied to American tropical shore plants of extending their range to West Africa. But here another difficulty arises in the case of certain of the littoral plants which border the beaches on the Pacific coasts of tropical America. It is not easy to understand why Conocarpus erectus and Hippomane mancinella that are evidently well fitted for oceanic dispersal, have not reached some of the easternmost groups of the tropical Pacific through the agency of the equatorial currents (pp. 93, 94).

8. In the case of plants like Andira inermis, Ecastaphyllum brownei, and Symphonia globulifera, which, although existing on both sides of the tropical Atlantic, have neither fruits nor seeds that could cross the ocean in a sound condition even by the most direct route, it is probable that other considerations arise which are concerned with the original distribution of the genus in both worlds (pp. 92, etc.).

9. Probably the most significant general conclusion in this summary is given in the third paragraph; and it is in this connection essential to remember that if buoyancy data had been available for several plants not included in the list, the proportion responding to the test among littoral plants confined to the New World would in all likelihood have been as low as 15 per cent. 


\section{CHAPTER V}

RHIZOPHORA MANGLE AND THE PLANTS OF THE GREAT MORASS OF THE BLACK RIVER DISTRICT IN JAMAICA

This species of mangrove is so universally spread in the West Indies that there will be no necessity to name the various localities in which I found it. My numerous observations on the plant in Fiji and Ecuador are described at length in my book on Plant Dispersal. Here I will merely add my West Indian observations, contrasting them as occasion requires with the results previously obtained.

ON the Period required for the Growth of Rhizophora Seedings on the Tree.- Reference will first be made to the length of time that elapses in different species of Rhizophora between fertilisation and the fall of the seedling from the tree. In the work above named (pp. 457, 466) it is stated that whilst Jacquin in the West Indies placed this period at eleven to twelve months for Rh. mangle, my own observations in Fiji for the same species gave a result of eight to nine months. The considerable variation in the length that the seedling attains on the tree will explain this difference. For Rh. mucronata in Fiji, I placed the period at about ten months. These results may now be supplemented by those given by Kerner in his Natural History of Plants (Oliver's translation, I., 603) for another Asiatic species, Rh. conjugata. Apparently quoting Ransonnet, he writes that the hypocotyl reaches its full length of 30 to $50 \mathrm{~cm}$. in from seven to nine months. With these results we have now the requisite data for all the three species that are usually recognised as constituting the genus Rhizophora, and the view expressed in my work that a period of nine or ten months is typical of the genus thus holds good.

On the Ability of Rhizophora Seedlings to withstand DRYING.--It is remarked in my previous work (p. 461) that stranded Rhizophora seedlings would be able to withstand drying for months, provided that they were protected by a covering of vegetable drift or of sand; and an experiment in Fiji is described in which two stranded seedlings, kept dry in my room for nine weeks, developed leaves and roots when afterwards planted in the mud of a mangrove swamp. However, the results of a more recent experiment on West Indian seedlings, which are given below, indicate that under favourable conditions seedlings can retain their vitality in the dry state for five months; and one cannot doubt that, if the experiment had been conducted under more natural conditions in the tropics, 
the results would have been still more marked. It is well known that these seedlings readily strike when stranded on a mud-flat, and my observations show that they do the same on a sandy beach, though often abortively. The point here investigated is their capacity of postponing this process.

ON the Vitality of Seedlings of Rhizophora mangle which had been kept Dry for Five Months after being gathered From the Tree

(They varied in length from $6 \cdot 6$ to $12 \cdot 3$ inches (168-312 mm.), and were detached from the fruit-case. The experiment was carried out during June and July in England in a greenhouse, and, therefore, under warm conditions. The measurements were made from the base of the plumule to the tip of the hypocotyl.)

\begin{tabular}{|c|c|c|}
\hline Dried Seedlings & Increase in Weight & Increase in Length \\
\hline $\begin{array}{l}\text { Five seedlings kept afloat between } \\
4 \text { and } 5 \text { weeks in fresh water. } \\
\text { Original length in dry state, } 6 \cdot 6 \text { to } \\
8 \cdot 9 \text { inches. }\end{array}$ & 17 to 25 per cent. & $0 \cdot 2-0.3$ inch $\left(5-7 \frac{1}{2} \mathrm{~mm}.\right)$ \\
\hline $\begin{array}{l}\text { Three seedlings kept afloat be- } \\
\text { tween } 4 \text { and } 5 \text { weeks in sea-water. } \\
\text { Original length in dry state, } 6 \cdot 6 \text { to } \\
12 \cdot 3 \text { inches. }\end{array}$ & 10 to 20 per cent. & 0.2 inch $(5 \mathrm{~mm})$. \\
\hline $\begin{array}{l}\text { Two seedlings kept afloat between } \\
4 \text { and } 5 \text { weeks in sea-water. Original } \\
\text { lengths in dry state, (A) } 8.9 \text { inches, } \\
\text { (B) } 12 \text { inches. }\end{array}$ & $\begin{array}{l}\text { (A) } 54 \text { per cent. } \\
\text { (B) } 48 \text { per cent. }\end{array}$ & $\begin{array}{l}\text { (A) } 0.6 \text { inch }(15 \mathrm{~mm} .) \\
\text { (B) } 1.0 \text { inch }(25.4 \mathrm{~mm} .)\end{array}$ \\
\hline
\end{tabular}

All the seedlings were much shrunken, wrinkled, and blackish along their whole length, with the exception of the lower end, which, for a distance of from one to two inches from the tip of the hypocotyl, retained a bright green hue and was less withered. Evidently the seedlings in fresh-water regained only a part of the water that they held in the living state, and the small increase in length of from 5 to $7 \mathrm{~mm}$. was in the main the result of the swelling process. Three of them placed in sea-water behaved like those in fresh-water, and here it is also apparent that little or no actual growth occurred. However, two of those in sea-water behaved very differently. They absorbed, relatively speaking, twice or three times as much water, and increased their length in the one case by $15 \mathrm{~mm}$. and in the other by $25 \mathrm{~mm}$. The growth was hypocotylar, since the measurements were made from the base of the plumule to the tip of the hypocotyl. Rootlets were not developed. No effort was made to unfold the plumular leaves, nor was there any marked increase in length of the plumule, such as could be attributed to growth.

This experiment is interesting from the fact that it supplied its own "control" in the case of the three seedlings that behaved in sea-water like those in fresh-water and showed no active growth. One of the implications is that Rhizophora seedlings, after falling 
into the sea from the tree, may proceed with the hypocotylar growth whilst afloat, though probably rootlets would not be produced. This growth would naturally be more marked than in the case of the dried seedlings experimented on. We would expect that in ordinary circumstances the floating Rhizophora seedling, if prematurely detached, would add some inches to its length.

However, it does not appear that growth is long continued in the case of fruits, detached in the early stage of germination, which fall into the sea. Germinating fruits, with the hypocotyl protruding half an inch or less, may be at times broken off from the tree through the agencies of storms and animals. Such fruits sink at once, and it was ascertained by experiment in fresh-water that although the germinating process was continued for the first five or six days under water, the protruding portion adding about $3 \mathrm{~mm}$. to its length, the hypocotylar growth was arrested after a week. Fruits of full size, but displaying no protrusion of the radicle, made no attempt to do so whilst lying for a fortnight in fresh-water. The curious appearance of a Rhizophora fruit in the early germinating stage, which had been broken off and was lying in the ooze under the tree, led me to plant a number of such fruits in the mangrove mud with the hypocotyl in the air, thus reversing the normal position. Under these unusual conditions fruits with the seedling protruding between 12 and $18 \mathrm{~mm}$. added from 2 to $3 \mathrm{~mm}$. to the length of the hypocotyl during the course of three weeks and remained in most cases quite healthy.

The Proportion of Germinating Fruits of Rhizophora mangle that display more than one Seedling.- In my book on Plant Dispersal (pp. 449, 466) I deal with the fact that whilst, as a rule, only one of the four ovules in a fruit of Rhizophora becomes a seed, occasionally two seeds and even three seeds are developed. Out of more than 2000 germinating fruits of $R h$. mangle examined in Fiji, mainly in the Rewa delta, about 1 per cent. displayed more than one hypocotyl. In these cases there were usually two and very rarely three hypocotyls, the rate of frequency of fruits displaying three seedlings not exceeding 1 per 1000. These results apply to the total number of fruits observed, but there were localities in which the proportion of fruits bearing more than one seedling amounted to between 2 and 3 per cent.

These observations were extended in the West Indies in the case of the same species, about 1000 germinating fruits being examined, $\mathbf{5 0 0}$ of them in the delta of the Black River, Jamaica, and the rest at St. George's, Grenada. In the locality first named just 2 per cent. displayed two seedlings, no fruit with three hypocotyls being noticed. But considerable variation was exhibited by different trees. Thus, whilst one tree gave a proportion of less than 1 per cent., another gave a value of 6 per cent. In Grenada. I obtained quite phenomenal results, the fruits of five trees examined yielding a proportion of $7 \frac{1}{2}$ per cent. with two hypocotyls, none with three being observed. But the proportions varied greatly, the respective results for the different trees being $16,11,7,3,1$ per cent. The rate of frequency obtained by Baron von Eggers in the tropics of the 
New World was very small, namely, 3 per 1000 (Plant Dispersal, p. 450).

The Length attained on the Tree by Seedlings of RhizoPHORA MANGLE.- In Jamaica, as in Fiji and Ecuador, I found that the average length attained by seedlings on the tree, the measurements being taken from the base of the plumule, was from nine to ten inches. In all three regions, when growing in sheltered situations, they may attain a length half as long again. But it would seem that this maximum is at times greatly exceeded in the New World. Thus I found washed ashore on the weather side of Tobago, mingled with much Orinoco drift, several seedlings sixteen to eighteen inches long, and in one case twenty-two and a half inches in length. It is quite possible, however, if these seedlings had been a long time afloat in the sea, that their hypocotyls may have grown in length, a subject discussed above.

The Absence of Dimorphism in Rhizophora mangle in Jamaica AND OTHER West Indian LOCALITIES.-In different localities in the West Indies, as in Jamaica, the Turks Islands, and Grenada, I endeavoured to ascertain if Rhizophora mangle exhibited the dimorphism displayed by the species in Ecuador. In my book on Plant Dispersal (pp. 445, 487) it is shown that in Ecuador there are two forms: the one " mangle chico," ten to fifteen feet high, growing in the seaward and landward margins of the swamps; the other "mangle grande," which attains a height of sixty or eighty feet and composes the interior of the swamp. The last in some of its characters approaches Rhizophora mucronata, the Asiatic species. However, after careful inquiry in the Black River and Savanna-la-mar districts of Jamaica, I could not discover any persistent evidence of dimorphism. Although there was often a considerable contrast in height and size between the Rhizophora trees fronting the sea and those growing in the midst of the swamp and on the banks of estuaries, the former frequently only ten or twelve feet high and the latter attaining heights of sixty or seventy feet, the floral characters as a rule remained much the same. Only in a few cases did there seem a tendency to the development of the " mangle grande" type in the taller trees. It may be that Rhizophora racemosa (a form of $R h$. mangle where the stalk of the inflorescence branches two or three times), which was long ago differentiated by botanists, may answer to the "mangle grande" type. The two are separated in Hooker's Niger Flora. However, the "mangle chico" is evidently the West Indian form. The plants of the Turks Islands were all of this type, and, as far as examined, those of Grenada and Tobago. On the parts of the coast of Porto Rico visited by Dr. Millspaugh the tree "seldom attains a growth of over ten feet in height" (Plantoe Utowance, Pt. I.). In the West Indies I never came upon any seedless form of Rhizophora, such as I have described in the case of the "Selala" of Fiji (Plant Dispersal, p. 443).

On the Influence of Varying Degrees of Salinity on the Station of Rhizophora mangle.-A promising field of inquiry would lie in the systematic determination with the hydrometer of the influence of varying degrees of salinity on the distribution of 
plants in the estuaries and coast swamps of tropical regions. An investigation on the lines of that pursued by Prof. Harshberger on the salt-marsh and estuarine plants of the New Jersey coast would yield valuable results (vide Proc. Amer. Philos. Soc., Sept. 1911). For such a study the true mangroves of the genus Rhizophora would offer abundant materials. Though I have made observations on this subject with reference to species of Rhizophora, and particularly $R h$. mangle, in different parts of the tropics, they have been discursive in their nature, and, as will appear, they supply rather hints for further inquiry than conclusive and determinate results.

In Fiji, where I made a special study of Rhizophora mangle, the American species, and of Rh. mucronata, the Asiatic species, I found that whilst they both throve at the coast, only the first named was also at home in the brackish water of the estuaries. This double station, in the coast swamp and in the estuary, was displayed by Rh. mangle in Fiji, in Ecuador, and in Jamaica. In all three localities I ascertained that the tree could live in the higher parts of an estuary where the water was at certain states of the tide quite fresh, and at others brackish or slightly salt. But my data showed that however well it might adapt itself to fresh-water conditions for some hours of each day, it would not be able to live in the parts of the estuary altogether beyond the reach of the sea-water. Typically, $\boldsymbol{R}$. mangle is a tree of the coast swamp and of the mouth of an estuary where the sea-water has in a general sense much of its normal salinity. Its seedlings can be transported by the currents to islets in the open sea, where they give rise to mangrove colonies, such as are presented by the Florida sand-keys. If it is able to adapt itself to the slightly salt or even to the fresh water of the interior of an estuary, it is only for a portion of the day. Rh. mangle is primarily a plant of the typical salt-water swamp of the tropical sea border.

Yet its adaptability to less saline conditions invites inquiry. As stated in my book on Plant Dispersal (p. 442), it extends in Fiji to the higher reaches of the estuaries, where the density of the water varies according to the state of the tide between $1 \cdot 000$ and $1 \cdot 010$. Its behaviour is the same in Ecuador. In the Guayaquil River it grows forty miles up the estuary, where the water is potable and has a density of 1.000, except at high water, when it is brackish (Ibid., p. 486). In the channels at the back of the city of Guayaquil, to which the sea-water has freer access, the water at high tide had a specific gravity of 1.014 ; and in response to the increased salinity there was a more typical development of the mangrove formation, $R h$. mangle fronting the water with Laguncularia racemosa and Avicennia in the rear. In the case of the Santa Rosa River, which opens on the Ecuador coast near Puerto Bolivar, Rh. mangle, though abundant at the coast, failed altogether about ten miles from the mouth of the estuary, where the water was quite fresh during nine out of the twelve hours, being salt only in the latter part of the rising tide.

In the Black River of Jamaica I obtained similar results in the month of January. In the company of Laguncularia racemosa this Rhizophora ascends the main channel of the estuary for two and a 
half or three miles; and though it thrives where the water has the density of fresh-water during most of the twenty-four hours, except towards high tide, when the hydrometer indicated 1.002 and 1.003, it disappears when the water is permanently fresh. In the Salt Springs branch of the estuary the same thing occurred. Rhizophora mangle grew on the banks for the first two or three miles of the ascent, when the specific gravity of the water varied between 1.000 and 1.003; but it disappeared altogether from the river-banks a mile or two further up, where the water was permanently fresh. The mode of its disappearance was remarkable, the trees not only diminishing in numbers, but very markedly in size. It is thus described in my journal: "Whilst ascending from Salt Springs to the Blue Hole fine specimens of Rhizophora trees, fifty feet high, lined the banks in places for the first half-mile. After this the trees were scanty, and became smaller and smaller as we penetrated further into the Great Morass, until, at about a mile and a half above Salt Springs, the trees originally fifty feet in height, were reduced to shrubby, sickly-looking growths, and shortly disappeared."

Probable Infiltration of Sea-Water into the Interior of the Great Morass of the Black River.-The name of Salt Springs, which is given to one of the principal branches of the Black River estuary, would seem to indicate that salt water wells up in the midst of the Great Morass in which the place thus called lies. In spite of the name I could learn of no such phenomenon, but it is not unlikely that sea-water does penetrate for some distance through the lower portion of the dense mass of plant-growth that forms the surface of the morass. Beneath the plant-growth lies a platform of the rag-rock of the district, a limestone seemingly composed in the main of old reef detritus, and not infrequently bared to view. The Great Morass, the general vegetation of which is described later in this chapter, extends inland for five or six miles as the crow flies, and is raised but a few feet above the sea. There is some ground for holding, as is explained below, that the salt water ascends much farther up the river along its bottom than is indicated by the density of the surface-water. But, apart from this, it would be strange if the sea-soaked mangrove swamps of the coast, which are physically continuous with the inland swamps of the Great Morass, did not favour the landward infiltration of sea-water.

In the case of the Machala plains on the coast of Ecuador, where low-lying districts extending several miles inland constitute the sea border, I have shown that this takes place on an extensive scale (Plant Dispersal, p. 485). Here there is continuity in the soil-cap between the mangrove belt of the coast and the arid plains miles inland. The rise in level being only a few feet, the effects of the sea-water infiltration are evident on the surface far from the coast in a saline efflorescence on the soil. The stages of the infiltration landward of sea-water are displayed : first, in the mangrove swamps a mile or two in width daily overflowed by the tide; second, in the salt-encrusted mud-flats in their rear, which are overflowed only by the higher tides, and support plants like Salicornia, Sesuvium, and Batis maritima; third, in the vegetated plains still farther behind, 
which extend for miles inland, and, though sufficiently raised above sea-level to be above the reach of the tides, are nevertheless soaked with sea-water, that displays its presence in the salt left by evaporation on the surface of the ground. On these plains, at a distance of four miles from the coast and probably extending much farther inland, there flourishes a dry jungle-type of vegetation of the xerophilous kind, such as Algaroba trees (Prosopis), cactaceous plants, and several sorts of prickly shrubs.

Those who live near rivers in houses built on alluvial soil know that when the river is in flood the water rises through the basements of their dwellings long before the river overflows its banks. This is well illustrated in the delta of the Mississippi, as at New Orleans, where the graves have to be erected on the surface of water-soaked ground. When low-lying districts of alluvial formation front the sea, the salt water must often be found a short way below the surface far inland.

It would, therefore, be a matter for surprise if the subsoil water of the low-lying region of the Great Morass in the Black River district of Jamaica did not often hold in solution much saline material at a distance of two or three or more miles from the sea border of the swamp. But little indication of the infiltration of sea-water in the subsoil might be offered by the surface-waters of the morass; and mangroves, thriving away from the coast in a seemingly freshwater swamp, may actually have their roots immersed in a saltimpregnated substratum.

It is not difficult to show, as I have already done, that on the banks of a river Rhizophora mangle gradually dwindles away, as one ascends the stream, until it disappears altogether when the water is permanently fresh. But away from the streams in the midst of the Great Morass, where the surface water varies in density only between 1.000 and 1.001 , there occur in the Black River delta, a couple of miles from the coast, isolated belts of tall Rhizophora trees, fifty or sixty feet high, which seem strangely out of place in the midst of a dense growth of Typha. I was told by my coloured companions that these inland belts of Rhizophora are situated around shallow pools infested by alligators. I could not do more than examine the margin of one of these belts; but I remarked the relative thinness of the leaves of the trees. They would be worth a careful examination by a resident. It would seem probable that salt water here wells up through the swamp, or at any rate approaches the surface.

The Underflow of Sea-water in Estuaries.-An important factor in influencing the stations of plants in tropical estuaries is to be found in the circumstance that whilst the surface water, more or less fresh in character, is running down, there may be an undercurrent of sea-water running up. Thus opposite Puna, at the mouth of the Guayaquil River, I found on one occasion that while the surface water with a density of 1.010 was running down, my thermometer, when lowered to a depth of two fathoms and more, was carried up-stream by a strong undercurrent, which extended to the bottom at a depth of seven fathoms. Evidently the sea-water 
was making its way up the estuary beneath the down-flowing fresher surface water, but the differences in temperature were very slight. During the two days that we lay in quarantine off Puna the density of the surface water ranged between 1.004 and 1.016, being saltest after the tide had been running up for a while. Some time after the tide had commenced to "flow," the whole mass of the river water turned up-stream. The result of this delay in the backing of the water was that the duration of the up-going tide was shorter than that of the ebbing tide. This contrast increased with the ascent of the estuary, so that at Guayaquil, forty miles from the sea, the reversal of the downward current occupied only a short time.

The undercurrent of sea-water ascending an estuary is a common feature in the régime of a river, and it is one that must have a definite relation with the stations of plants growing at the waterside. With this feature is doubtless to be connected the curious fact that the water may continue to rise after the ebb has begun at the surface. It is apparent that in a tidal estuary a multitude of lines of inquiry offer themselves to an investigator with the hydrometer.

In some cases, however, valuable indications may be obtained from differences in temperature. When one finds in an estuary that the water at the bottom is warmer by some degrees than the water at the surface, the existence of an undercurrent of sea-water may be surmised. Suspecting that there was an up-current of sea-water below the surface fresh-water of the Black River estuary in Jamaica, I made some observations, at noon in the month of January, in the main stream between the bridge opposite the town and the junction of the Salt Springs River, a mile further up, the depth varying from three to three and a half fathoms. Having first ascertained that the temperature of the sea was about six degrees (Fahrenheit) warmer than that of the river, the sea being $80^{\circ}$ and the river $74^{\circ}$, I proceeded to compare the surface and bottom temperatures of the river. A number of observations made in the part of the estuary above stated gave closely similar results, which I may sum up in the remark that whilst the downward surface-current of fresh-water (density 1.001) had a temperature of about $74^{\circ}$, the water on the river bottom showed a temperature of $78^{\circ} \mathbf{F}$. Here it was evident that the salt water was ascending the river beneath descending fresh-water, and that the influence of the dissolved salts in the sea-water was more than sufficient to counteract the decrease in density due to its higher temperature. Within the mouth of the Salt Springs branch of the estuary the difference between the surface and bottom temperatures was only two degrees, and a little higher up there was none at all.

The complicated Problems offered in the Thermometric and Hydrometric Investigation of a Tidal Estuary.-A multiplicity of considerations arise when we regard the influence on plant stations of the greatly varying conditions of temperature and salinity in different parts of a tidal estuary; and their complexity deepens when we contrast the régimes of different seasons. The whole subject of the economy of an estuary, as revealed by the thermometer 
and hydrometer, is here opened up, and it presents many very complex problems. It would be futile, however, to speculate now on the various working values to be assigned to the increase in density due to the fall in temperature and to the increase arising from dissolved saline materials. We will leave the problems offered by this contest between the elements to the future investigator, and will content ourselves with the reflection that much light will be thrown on the conditions which determine the stations of plants in a tidal estuary by such a systematic employment of the hydrometer and thermometer as was exhibited in Prof. Harshberger's investigations on the estuarine plants of the coast of New Jersey.

The Springs of the Black River Morass, as Illustrated by Those of the Blue Hole.--It is likely that the numerous springs of fresh-water which well up in different parts of the Great Morass supply a large proportion of the water that the Black River discharges into the sea. One of the best known of these springs is the Blue Hole, which lies, as the bird flies, four or five miles from the coast, and is reached by way of the Salt Springs tributary, of which it is one of the main sources. These springs, which are distant about a mile from the foot of the neighbouring range of hills, issue in a funnel-shaped, well-like hole about forty feet deep and sixty feet across. The considerable body of water which here escapes is carried away in a stream, the channel of which is almost blocked by aquatic plants, that grow here in great luxuriance. On January 7, 1907, at noon, the temperature of the Blue Hole was $75 \cdot 5-76^{\circ} \mathrm{F}$. at the bottom, and $77^{\circ}$ at the surface, that of the river below, which received

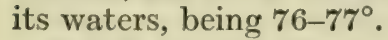

A rich growth of aquatic and semi-aquatic plants is characteristic of the large and copious head-springs of rivers in most parts of the world. Here under comparatively uniform thermal conditions, where the yearly range of the water-temperature often corresponds approximately to the limited range of the monthly means of the air-temperature in the shade, the aquatic plants thrive vigorously throughout the year. For the whole twelve months it is probable that the range of temperature of the water in which the vegetation around the Blue Hole is bathed would be only 75 to $82^{\circ} \mathrm{F}$., which is the usual range of the monthly means of the temperature of the air in the lowlands on the south side of Jamaica. (See a paper by the present writer on the temperature of springs in the Journal of the Royal Meteorological Society, about 1895, and papers on rivertemperature in the Proceedings of the Royal Physical Society of Edinburgh, 1896.)

The plants grow in greatest profusion in the stream leading immediately from the Blue Hole. Largely occupying its channel and often carpeting the bottom are masses of Isnardia palustris, Hydrocotyle umbellata, Potamogeton plantagineus, etc. There also flourish here in the shallows Sagittaria lancifolia and a pretty yellowflowered Utricularia. Pistia occidentalis fills up little recesses in the oozy banks, propagating its kind vegetatively with rapidity. In the river below Ceratophyllum demersum grows in the shallows.

The Vegetation of the Black River District.-This may be 
conveniently described under three heads : $(a)$ the aquatic and semiaquatic plants of the river and the riverside; $(b)$ the plants of the Great Morass, a region of swamp traversed by the Black River and its tributaries; $(c)$ the plants of the mangrove formation.

(a) The Plants of the River and the Riverside.-Lining the banks above the mangroves is a tall reed-growth of Cyperacea (Cyperus elatus, etc.) and Typha angustifolia, with which are associated Sagittaria lancifolia, which attains a height of four or five feet, Chrysodium vulgare (the Swamp Fern), a species of Jussiaca, Pavonia corymbosa (a malvaceous shrub), Polygonum glabrum, etc., all of which grow more or less in the water or in the swampy borders. In the shallows grow the Water Hyacinth (Pontederia) and Nymphoa ampla, the last covering the large expanses of water into which the rivers occasionally broaden out. Amongst the more or less submerged aquatic plants are Utricularia (near U. obtusa), Potamogeton plantagineus, Ceratophyllum demersum, Isnardia palustris, Hydrocotyle umbellata, etc. Pistias grow scantily in the recesses of the banks of the main channels, but are especially abundant in the vicinity of the springs that well up in different localities of the Great Morass, and nestling amongst them little floating masses of Azolla may be at times observed.

(b) The Vegetation of the Great Morass in the Black River District.This broad, savannah-like region, elevated but a few feet above the sea, extends some six or seven miles inland to the foot of the mountains. Looking down upon it from the slopes behind, one would imagine that one was gazing at some arid plain where clumps of tall palms serve to vary the monotony of a landscape in which Nature has been niggard in her ways. This notion would receive fresh colour when we observed the rivers winding through the plain and the dark green belts of trees that in places marked their courses. Yet we are not looking at a waste but at a swamp, where the ground is soaked with water as a sponge, where copious springs well up, and where the alligator finds a home.

The tall palms are the Thatch Palms (Sabal umbraculifera), and they grow in the midst of a swamp-jungle largely composed of a reed-growth of Typha, Cyperacea, and other similar plants. We should often find no footing in the marshy ground; and if we wished to examine the district, we must pole along in a canoe through narrow channels more or less blocked by vegetation. In one place we should be traversing an area of several acres occupied only by Scirpus plantagineus, growing to a height of three feet, and suggestive in its appearance of an Equisetum. In another place we should find the surface carpeted with Herpestis monniera. A third locality would be appropriated by the Swamp Fern (Chrysodium vulgare). But more often the eye would rest on the tall reed-growth of grasses (Arundo, etc.) and sedges (Cyperus, etc.) and bulrushes (Typha) that monopolises most of the surface. Conspicuous amongst the swamp vegetation are the Pavonia trees, or rather shrubs (P. corymbosa); whilst, strangely enough, Conocarpus erectus, a plant typically halophilous in its station, is one of the most frequent among the smaller trees in this fresh-water morass in places where the ground is firmer. 
Coming to the vegetation of the banks of the Black River, as it winds through the Great Morass above the mangrove, the most conspicuous feature is presented by the trees that line its sides in places. This subject is dealt with at length in Chapter I., when discussing the Black River as a source of drift, and I must refer the reader to that description for an account of a character of the Great Morass that was probably much more pronounced before the arrival of the white man.

(c) The Plants of the Mangrove Formation.-The mangroves of the Black River district are mostly confined to the lower part of the estuary and to the part of the Great Morass that lies nearest to the sea. Whether in the swamps or at the riverside, they do not usually extend more than two or three miles inland. In both cases they present the same arrangement, the belt of Rhizophora mangle at the water-front being backed by a growth of Laguncularia racemosa and Avicennia nitida. In localities near the coast Batis maritima and Salicornia flourish on the mud beneath the mangroves. An account of my observations on Rhizophora mangle in this district will be found on an earlier page of this chapter.

The Savanna-la-mar District of Jamaica.-This region includes the Great Morass of Westmoreland, where most of the features of the Black River Morass are reproduced. I will here give the results of observations made during my sojourn of a week or two in the district. One of the most instructive journeys through the lowlying, swampy regions of Jamaica may be made from Savanna-lamar to Negril, a traverse of fifteen or sixteen English miles. For the first third of the distance, where the mangrove-lined creeks run in far from the coast, one's attention is mainly occupied with the inland extension of Rhizophora, Laguncularia, and Avicennia, and with the large tracts of muddy ground exclusively occupied by Batis maritima. In the middle third we have left the salt-water swamps behind, and now traverse a region of fresh-water swamp much like that of the Great Morass of the Black River district. Here flourish Sabal umbraculifera, Typha angustifolia, Sagittaria lancifolia, Cyperacece, and others of the Black River marsh plants. In the last third we encounter the characteristic vegetation of the lower hills, with Grias cauliflora growing at the sides of the streams, but we meet the mangroves again on approaching Negril. Britton, who compares the Great Morass of Westmoreland with the Everglades of Florida, noted the presence here of Crudya spicata (Harshberger's Phyt. Surv. N. Amer., p. 678), which, as observed in the first chapter, is a riverside tree in the Black River Morass.

Among the small rivers that discharge into the sea near Savannala-mar is the Cabarita. Here the mangroves, chiefly represented by Rhizophora mangle, ascend the stream for about a mile from the sea, being associated with Grias cauliflora at their upper limit. In the swampy land bordering the river, where the mangroves fail, flourish Typha angustifolia, Cyperus elatus (a tall, papyrus-like sedge), and Arundo saccharoides; whilst Coix lachryma sometimes covers large surfaces of wet ground. The banks displayed more than one species of Polygonum, including $\boldsymbol{P}$. glabrum, and a species of Commelyna was 
especially frequent. The Water Hyacinth (Pontederia), Potamogeton fluitans, and Ceratophyllum demersum grew abundantly in the stream ; whilst occasional young Pistias and small portions of Azolla were to be observed on the surface.

I ascended for about 100 yards Bowen's River, a small stream twenty-five to thirty fcet across and infested by alligators, which lies about three miles east of Savanna-la-mar. Whilst Typha and Sagittaria grew on the borders, Polygonum glabrum, a pretty blue Commelyna, and Hydrocotyle umbellata flourished at the margins and in the shallows. Ceratophyllum demersum grew in dense submerged masses, and in shallow places near the banks the surface of the water was covered with Azolla.

The Great Lake at Pondside near Black River.-This is a large sheet of fresh-water less than a mile in length and ranging, as I found, between one and a half and two and a half fathoms in depth. Alligators here find a congenial home. They lay almost submerged across the path of the canoe, and sank slowly as we approached. For this reason I could not examine properly the abundant, tall reedgrowth at the margins, my little craft being frail and leaky, whilst my coloured companion was too much scared to be of use to me. Nymphoea ampla grew in abundance, for the most part in the shallows; but even in the centre of the lake solitary plants with very slender stems rose up to the surface from a depth of ten feet. Utricularias, not in flower, were associated with the Nymphæas; and Potamogeton plantagineus thrived in all the shallower waters, with Sagittaria lancifolia at the borders. In marshy places, where springs rose up on the side of the lake, I noticed the Dumb Cane (Dieffenbachia seguine). I visited this lake a few days after the great earthquake at Kingston in January 1907, and was told that "the water rose up in large waves like the sea."

The District of the Salt Lakes near Black River, Jamaica. -Bordering the sea-coast a few miles to the east of Black River lies the district known as the Salt Lakes. Here are a number of shallow salt-water lagoons in the midst of extensive mud-flats and swamps. A detailed topographical description would be here out of place; but one may say that this region of lagoons is backed by the Great Morass, and that it is fronted by the sea-beach. The lagoons vary much in size, the largest being known as the Great Salt Lake, which is nearly a mile in length, and at the time of my visits in January 1907 scarcely a fathom deep, the greatest soundings obtained being usually four or five feet. Separating the lagoons from the sea is a low strip of land varying in width between a few yards and a quarter of a mile. Under ordinary conditions, such as prevailed at the time of my visits, these lagoons are cut off from direct communication with the sea. The Great Salt Lake, it is true, has a narrow, tortuous channel leading to the coast, which is known as the Creek. But at ordinary times there is no passage here through the beach. However, in the rainy months, as in May and October, when much of the Salt Lakes district is submerged by the waters draining coastward from the Great Morass, the waters force their passage and the Creek remains open for a while to the sea. But Nature is sometimes slow 
in giving relief to the submerged region, and the people of the neighbourhood then dig a trench through the beach for carrying off the surplus water.

It is therefore evident that the hydrographical features of the district of the Salt Lakes vary greatly in different seasons. Although the drainage of the waters from the Great Morass is relatively small for most of the year, it is large in the wet months. After the rains the lagoons are greatly increased in size and their water is nearly fresh. During the dry months they shrink considerably and become very salt, the smaller lagoons being sometimes completely desiccated or reduced to scanty lakelets only a few inches deep. This alternation between a state of high salinity and a condition when the water is almost fresh must have an influence on the distribution of the vegetation.

When I visited this locality in the middle of January intermediate conditions prevailed, such as exist probably through the greater half of the year. Some of the lesser lagoons had dried up, being represented by expanses of white mud. Others were reduced to ponds a few inches deep, the water being very warm and very salt. In the case of a greatly shrunken lagoon nearest to Paroti Point, the density and temperature of the water at midday were respectively 1.031 and $88^{\circ} \mathrm{F}$., the values for the sea at the same time being 1.026 and $79^{\circ} \mathrm{F}$. In the larger and deeper lagoons the contrast between their salinity and that of the sea was slight. Under similar conditions of temperature the salinity of the water was 1.028 and that of the sea 1.026. At first sight the Salt Lakes district would appear to be well fitted for the salt-pan industry, but the fresh-water from the great inland swamps, especially after the rains, would probably prevent the success of such an undertaking.

General Character of the Vegetation of the Salt Lakes District.-Avicennias among the trees and Salicornias amongst the lesser plants form the predominant features of the vegetation occupying the extensive expanses of white mud that give the character to the district of the Salt Lakes. Then come the mangroves at the borders of the larger lagoons, and here the same Avicennia ( $A$. nitida) takes its place with Rhizophora mangle and Laguncularia racemosa in the swamp. Around the shores of the Great Salt Lake the Rhizophoras and the Avicennias are, however, the most frequent, sometimes the one, sometimes the other, usurping the lake's margins. All three mangroves thrive in the creek which leads from the beach to the lake. In the smaller lagoons, where the water has been reduced to a depth of a few inches and has a greater salinity, the Rhizophoras disappear from the mangrove belt, leaving the Avicennias and Laguncularias in possession of the borders of the partially desiccated lake. On the expanse of exposed mud-flats Salicornias and Batis maritima thrive. When the water has evaporated away and only a shallow depression indicates the original lagoon, the Laguncularias in their turn disappear, and Avicennias with Salicornias and Batis maritima alone remain.

Avicennias grow in this district under all the various soil-conditions that are presented, whether in the salt-water swamp, in the wet salt 
mud on the margins of the lagoons, in the places removed from the lagoons where the saline mud dries on the surface in the sun, in the neutral ground between the sandy beach and the mud-flat where the soil is loamy and beach plants mingle with those of the mud-flats, or, lastly, on the borders of the great inland fresh-water swamps, where they come in touch with the plants of the Great Morass. In all these stations they have different associates : herding at one time with Rhizophoras and Laguncularias in the swamps; at another growing with Salicornias on the soft mud-flats; at another with Jacquinia armillaris, Conocarpus erectus, etc., where the saline mud hardens on the surface in the sun; at another time side by side with beach plants like Coccoloba uvifera, Dodoncea burmanni, and Ernodea littoralis, where the soil is loamy near the beach; and at another time amidst the tall Sabal palms ( $S$. umbraculifera) and the Cyperacece which mark the outskirts of the inland region of fresh-water swamps. If we except Conocarpus erectus, there is no plant in the Salt Lake district that displays so much adaptability to the various conditions as Avicennia nitida.

Conocarpus erectus is similarly associated here with the mangroves at the borders of the lagoons, with the plants of the exposed mudflats, and with those of the sandy beach; but its powers of adaptation are not so conspicuous on account of its being much less frequent than Avicennia nitida. Its adaptability to different stations is discussed more in detail in the separate treatment of the plant.

Several other plants occur in this district, but they are usually not common enough to give character to the vegetation. One may refer, however, to the Silver Thatch palm (Thrinax argentea), a small palm, three to nine feet high, which is certainly characteristic of the neutral ground between the mud-flats and the sandy beach on the seaward side and the inland swamps in their rear. Portulaca halimoides, an interesting little plant with woolly flowers and only two or three inches high, grows in places on the salt white mud, especially where the ground, though moist beneath, is baked on the surface by the sun's heat. Jacquinia armillaris (L.) is a small tree or shrub that is very common on the saline mud of the flats, growing gregariously and exhaling from its flowers a penetrating odour like that of bitter almonds. This is $\boldsymbol{J}$. barbasco of Mez (Das Pflanzenreich, Theophrastaceo, 1903). It is a littoral plant widely spread in the West Indies. Its hard seeds, which are $5 \mathrm{~mm}$. in length, have no buoyancy, and are probably dispersed by birds, though the dryish berry would not seem to be especially attractive.

\section{SUMmary}

1. As supplementing his observations on Rhizophora in the Pacific islands, the author adduces additional facts from other sources to confirm his previous conclusion that the lapse of a period of nine or ten months between fertilisation and the fall of the seedling is typical of the genus (p. 96).

2. He presents data from his West Indian experiments to show that Rhizophora seedlings, after detachment from the tree, can at times 
retain their vitality in the dry condition for five months, an implication arising from his results being that the seedlings, when they fall into the sea, would often continue their hypocotylar growth in length for an inch or two (pp. 96-98). His observations in the Pacific on the proportion of germinating fruits of Rhizophora mangle possessing more than one seedling, and on the extreme length of the hypocotyl, are here supplemented (pp. 98-99).

3. He was unable to discover in the West Indies any persistent evidence of the dimorphism observed by him in Rhizophora mangle in Ecuador, nor did he come upon any seedless form of Rhizophora corresponding to the "Selala" of Fiji (p. 99).

4. There are next given the results of a number of observations made in the West Indies, Ecuador and the Pacific islands on the influence of varying degrees of salinity on the station of Rhizophora mangle (pp. 99-101).

5. Remarks are then made on the infiltration of sea-water into the interior of the Great Morass of the Black River district in Jamaica, and in this connection is noted the occurrence of colonies of Rhizophora maangle in the midst of this great swamp (pp. 101-102).

6. The underflow of sea-water up tropical estuaries is regarded as an important factor in determining the stations of estuarine plants, and the subject is illustrated by the cases of the Black River in Jamaica and of the Guayas or Guayaquil River in Ecuador (p. 102). In this matter Prof. Harshberger's hydrometric and thermometric observations on the stations of plants in the tidal estuaries of New Jersey afford instructive lessons for similar investigations in tropical estuaries (pp. 103-104).

7. Attention is directed to the numerous large fresh-water springs that well up in the midst of the Black River Morass, and to the rich growth of aquatic plants at their borders (p. 104).

8. The author then deals at length with the vegetation of the Black River district, especially of the Great Morass, as well as of the similar region of swamp around Savanna-la-mar (p. 105). He also describes the vegetation of the Great Lake at Pondside near the Black River (p. 107). The physical and botanical features of the Salt Lakes in the same neighbourhood are treated in detail (p. 107). 


\section{CHAPTER VI}

\section{THE LARGER FOREIGN DRIFT OF THE TURKS ISLANDS}

IN Chapter I. special prominence is given to the analysis of the larger foreign drift of the Turks Islands. It is now proposed to deal with each plant in the order of frequency of their fruits or seeds in the stranded drift of this small group, the several plants being treated often at length, from the standpoint of distribution. This will afford an opportunity of discussing the various interesting problems which these plants raise.

\section{Ecastaphyllum ( ?)}

These legumes, which are amongst the most frequent of the fruits in the larger drift of the Turks Islands, have some of the characters of those of Ecastaphyllum, but are certainly not those of $\boldsymbol{E}$. brownei (Pers.), a common West Indian littoral small tree or shrub. They are $1 \frac{1}{3}-1 \frac{2}{3}$ inch long, broadly oval, compressed, and have a shining reticulate epidermis. The single seed has thin, pervious coverings; but in no case did I come upon one that was sound, all of them being in various stages of decay.

\section{Spondias lutea, Linn. (Hog Plum)}

Few fruits are more frequently represented in the beach-drift of the West Indies and of the Pacific and Atlantic coasts of tropical America than those of this tree. It is not, however, the fleshy drupe but its hard "stone" invested by a thick fibro-suberous covering, that is here found. These "stones," which are oblong in form and usually 1-1 $\frac{1}{2}$ inch in length, float very buoyantly, and in their weatherbeaten condition amongst old drift might be even taken for old corks rounded by the waves.

The trees grow in open wooded districts, both inland and at the coast, and not uncommonly they are frequent at the riverside, as in the case of the Black River in Jamaica, or they grow in numbers on the slopes of a river valley, as I noticed in Tobago, or they may be found amongst the vegetation bordering the beach, as I observed in Grenada and Trinidad. Writing of the tree in Jamaica at the end of the seventeenth century, Sloane says that it was found everywhere in the lowland woods and in the savannahs (II., 127). In Jamaica it is associated in the open inland woods with such trees as Cedrela odorata (Jamaican cedar), Pithecolobium filicifolium 
(bastard tamarind), and Swietenia mahogani (mahogany), and in Cuba it has the same associates in the open forests that grade into the savannah formation. But in Cuba it also grows in the denser forests on the slopes of the river valleys (Fernow, etc., quoted by Harshberger, pp. 675, 676).

The fruit, however, is too coarse to be palatable for man, but it is much appreciated by pigs, and from this circumstance it derives its popular name. As the fallen fruits lie on the ground they lose their fleshy covering; and the air-dried "stones" are so light that in places where the trees abound they may be seen gathered together by the strong winds. On a hillside in Tobago during the heavy rains I noticed that the "stones," which lay in quantities on the ground, were being gradually washed down the slope into the river below. The "stone" usually displays four or five cavities, each containing a seed. The seeds retain their freshness for years in my drift-collection, and this is evidently true of those in the beach-drift. However weather-beaten their appearance, it was never difficult to find "stones" containing some sound seeds in the old drift, whether on a beach in Jamaica, where the trees are abundant, or on the shores of the Turks Islands, where they do not grow.

On account of their great buoyancy the "stones" at first appear well suited for transport across the Atlantic. But the fact that I had found no record of their occurrence amongst West Indian drift stranded on European beaches led me to investigate the matter. As a result, I found that their floating powers were insufficient for the purpose of an Atlantic traverse in the Gulf Stream drift. In addition, it proved to be more than doubtful whether the seeds would retain their germinative powers after a flotation of more than a few months. I made an experiment on a number of drift specimens that preserved their sound condition. The indications were that although about half still floated after seven months in sea-water, they were sodden through their substance, floated heavily, and had decaying seeds. The limit of the period during which the germinative capacity is preserved in a passage across the sea seemed to be two or three months. Although the "stones" would be unable to survive the long passage of a year or more that would be involved in an Atlantic traverse from the West Indies in the Gulf Stream drift, they would, as far as their buoyancy is concerned, be well able to perform the passage of two or three months from the West Coast of Africa to Brazil in the Main Equatorial Current, and the seeds would probably retain their germinative powers.

In the Turks Islands the "stones" were to be noticed, often in numbers, on all the cays where the drift was able to gather. They presented themselves among the drift on almost every beach in the West Indies that I examined, as on the north and south coasts of Jamaica, on the north and south sides of Trinidad, in Tobago, and in Grenada. It is many years since they were identified at Kew in a collection of seed-drift made by Morris in Jamaica (Chall. Bot., IV., 299). They are to be observed in the floating drift of rivers, as in the Black River of Jamaica, or stranded in numbers at their mouths, as in the case of the White River of the same island. It is 
on the beaches that line the coast in the neighbourhood of estuaries that the "stones" of these fruits are most abundant.

On the Pacific shores of tropical America they would seem to be equally abundant, whether afloat in the estuaries or cast up on the beaches. Thus, I found them in the Guayaquil River in Ecuador and on the beaches of the Ecuadorian coast towards the Peruvian border. They came under my notice on the beaches at Panama and afloat in a neighbouring estuary, and it may be added that they were gathered by me from the beach at Colon on the Atlantic side of the isthmus.

The distribution of the tree over the greater part of the West Indian region, as well as on the Pacific and Atlantic borders of tropical America, derives new interest from the circumstance that the tree occurs on the tropical coast of West Africa. As before remarked, the "stones" are fitted for carriage in the Main Equatorial Current from West Africa to Brazil, and the seeds would probably preserve their capacity for germination. The difficulty, however, is that this tree is not a truly littoral plant. It may grow amongst the trees bordering a beach; but it is more at home in an inland station on a hillside or near a river bank. It is, in fact, the river that as a rule brings the floating " stones" down to the coast before giving them over to the agency of the currents.

Although I have gathered a large number of the stranded "stones " on beaches, I have never found one showing germinating seeds. In such an event, however, the young plant would certainly fail to establish itself. The "stones" are so extremely light that, as I have observed in the Turks Islands, the strong winds are able to blow them off the beach into the bush behind, where more favourable conditions might be found, though not in this particular group. Land crabs, also, that frequent the beach, might often carry them off and bury them in their burrows.

It is likely that the spread of this tree within the same land area is assisted by the facility with which it roots when stakes are placed in the ground. The wood is very light, and it is possible that the trunk or a branch floating in a river may on stranding be able to establish itself on the bank. Sloane observes that it "grows easily by the branch" (II., 127). Under the head of Growing Stakes or Live Fences in Jamaica, this tree is mentioned in association with several others in Note 31 of the Appendix to my book on Seeds and Fruits.

\section{Hippomane mancinella, L. (Manchineel)}

Few plants seem to be better fitted for dispersal by currents than this littoral tree, which is widely spread over the tropics of the New World, occurring not only throughout the West Indies and on the Atlantic coasts of the mainland from Mexico to Venezuela, but also on the Pacific side.

Pax, in his recent memoir on the section of the Euphorbiacea, to which this plant belongs (Euphorbiacee-Hippomanea, Das Pflanzenreich, IV., 147, V., 1912), only implies its occurrence on the Pacific side in the case of Costa Rica; but doubtless he includes both coasts 
of Mexico in his statement of the general distribution. Harshberger (p. 229) merely names Mexico, Central, and South America, without particularising the Pacific coast. However, I found it growing at Panama by the beach, and in all probability it is common on many parts of the Pacific coasts of Central America. Grisebach mentions Panama, but without distinguishing locality. It is a native of most of the West Indian islands, large and small, from Cuba to Trinidad, as enumerated by Grisebach and Pax. It extends north to South Florida and to the adjacent islands of the Bahamas, such as Andros and Abaco (Millspaugh), and reaches Venezuela to the south. As Pax suggests, its absence from certain localities may be due to its extermination on account of its poisonous nature.

A few remarks on its station may now be made. Wherever I came upon it, as at St. Croix, Tobago, Grenada, and Panama, it was growing with the trees bordering the beach on sandy soil. Grisebach only refers to its station in the case of Trinidad, where it grows " on the sandy sea coast." Pax characterises it as a plant of the coastlands and as often growing on rocky ground. Millspaugh says that it grows in coppices and on scrubland in the Bahamas. In South Florida, according to Harshberger (p. 230), it grows away from the coast, being one of the trees of the "hammocks." This is the name given to isolated patches of vegetation of varying extent that are scattered as islands in the everglades and pine forests, and are held to represent an ancient system of sea-washed keys, which existed during the later Tertiary and received their plants from the Bahamas. The "hammock," as we learn, is a refuge for nearly all the flowering plants that are common to the West Indies and the North American mainland. Though most of the trees and shrubs named by Harshberger grow in the coastal plains of the West Indies, few seem to be characteristic littoral plants; and for this reason the hammock scarcely appears to have become a sanctuary for typical strand plants in any number.

The very poisonous nature of the milk-sap is well known; yet it is observed by Pax that some men possess an immunity in this respect. When at Panama I experienced severe pain for several hours through allowing the sap of the fruits to come in contact with my bare legs, extensive blistering resulting. It is probable that there is a substratum of truth in the fable that fatal effects arise from sleeping under the shade of this tree. The experiment made in the West Indies by Jacquin, who remained unhurt after standing naked for some hours under a tree, whilst the rain fell through upon him (Hooker's edition of the System of Botany of Le Maout and Decaisne, 1873, p. 697) scarcely seems conclusive. The night dew dropping slowly from the leaves would be much more likely than the rain-wash to produce injurious effects.

I made the acquaintance of this tree in different islands, as in St. Croix, Grenada and Tobago. I did not find it in the Turks Islands, although, according to Dr. Millspaugh, it has been collected there (see reference in the chapter on the flora of this small group). Its place is taken on Grand Turk by a small euphorbiaceous tree or shrub, not unlike it in habit, perhaps a species of Sapium, which has 
the same popular name, and possesses, according to the inhabitants, the same dangerous qualities. The absence from the Turks Islands of the true Manchineel could scarcely be attributed to its extermination by the islanders in the isolated uninhabited cays. Although it grows in Key West, off the Florida coast (Pax), we learn from Dr. Millspaugh's paper before quoted that it was not discovered by Mr. Lansing during his methodical examination of all the sand keys lying west of that island. The vegetation there is mainly littoral, and in many islets it is exclusively so. Several of the keys are little more than sandbanks, and the question of extermination by man could not be raised. It would thus appear that although, as shown below, the fruits of the Manchineel must be amongst the drift first stranded on new land in this part of the world, the tree is one of the last to establish itself. I never remember to have come upon a germinating fruit in the beach-drift of any locality, although examination always showed that some of the seeds were sound. It may be that the intervention of certain land crabs is necessary, and that germination only occurs after the fruit has been stored in their burrows beyond the reach of the sea. Sloane, in the account of his voyage to Jamaica (II., pp. 4,7), throws some light on this point. He says that goats feed on the fallen fruit greedily, and he was shown trees that had grown from seeds dropped in their dung.

I come now to discuss more in detail the fitness of these fruits for dispersal by the currents. (I may add here that the fruits are illustrated in the memoir of Pax before named.) On account of the station of the tree by the beach, the fallen fruits, as I had several opportunities of observing, are liable to be picked up by the waves and carried out to sea. Should the fresh fruit, which is rather like a crab-apple in size and appearance, fall at once into the water, experiments show that it will remain afloat. But more often it loses its soft outer covering whilst lying on the sandy soil ; and in so doing its buoyant capacity is greatly increased. The bared fruit gathered after drying on the ground consists of a hard " stone" deeply grooved and covered with a thick layer of cork-like, air-bearing tissue. Neither the "stones" nor the seeds inside have floating power, the buoyancy being due to the investing material. These dry, bared fruits evidently can float for many months. Some of them kept in seawater for five weeks showed no signs of sinking, all of them floating as buoyantly as when the experiment began. The stone usually has about six loculi, but not more than half contain sound seeds, the others being much contracted in size. Locked up within the woody endocarp, the oily seeds maintain a moist condition for years. After eight years, the seeds of some fruits gathered by me at Panama seemed quite fresh; whilst the fruits of the Turks Islands beach drift, which may in some cases have been lying there for years, as a rule appeared sound.

It is, therefore, not surprising that the stranded fruits of the Manchineel came under my notice in nearly every place where the beach drift was systematically examined. At Panama, in Jamaica, St. Croix, Tobago, Grenada, Trinidad, and in the Turks Islands these fruits formed a regular constituent of the drift, and often in numbers. 
In several cases the tree was growing in the vicinity, but in Jamaica, though the bared fruits were to be frequently nbserved on the beaches, I never came upon the tree, though, according to Grisebach and Pax, it exists in the island. In the Turks Islands, as before remarked, the tree does not grow, yet the fruits occurred on almost every beach, and made up quite 10 per cent. of the larger drift. Wherever in this locality the drift had been able to gather, some of them were to be found, whether on Grand Turk and Greater Sand Cay, lying at the north and south extremes, or at Eastern Cay, the most windward island of the group. As far as I can ascertain, these fruits have not been recorded amongst the West Indian drift stranded on the shores of Europe; but it seems highly probable that they sometimes reach those coasts.

\section{Terminalia catappa, L.}

Since this tree was originally introduced into the New World, I need only refer to the fact that its dispersal by currents has long been known in the tropics of the eastern hemisphere, where it frequents the coasts, both insular and continental. In the writings of Schimper, Hemsley, Ernst, and others (including, I may venture to add, my own), it is frequently referred to in this connection. We learn from the observations of Treub, Penzig, Ernst, and their associates that its drupaceous fruits were amongst the first stranded on Krakatau after the desolation of its surface by the eruption of 1883 , and that its young trees were amongst the earliest to establish themselves near the beach.

In the warm regions of the New World it is now widely distributed, a work originally begun by man but since extended by the currents, especially in those localities, as in the island of Grenada and at Colon, where it has resumed its littoral station. In Grenada I found it bordering the beach in the company of Coccoloba uvifera, Hippomane mancinella, and Hibiscus tiliaceus. According to the data given by Harshberger, in his work on North America (p. 686), it grows characteristically among the trees lining the beach in the Virgin Islands in association with Coccoloba uvifera, Hippomane mancinella, Thespesia populnea, etc.

Its fruits came under my notice in the beach-drift of Jamaica, Colon, and the Turks Islands. In the last-named locality they are abundant and occur on almost every beach where drift collects. always bared of their outer fleshy covering, and nearly always in a much weathered condition, but in most cases containing a sound seed. As is well described by Schimper in his Indo-Malayische Strandflora (p. 170), this drupaceous fruit owes its floating powers to a thick layer of cork-like buoyant tissue that invests the "stone," none of the other materials possessing independent buoyancy. The subject of the floating capacity of the fruits of the genus is fully discussed in my work on Plant Dispersal.

Although Grisebach, Hemsley and other authorities agree in regarding this tree as introduced into the New World, it is remarkable that about a third of the total number of species in the genus, as indicated in the Index Kewensis (132 in all), are confined to America, 
of which by far the greater number are tropical South American. But the endemism displayed in oceanic islands in the Indian and Pacific oceans, as well as in the West Indian islands, is very remarkable. The Mascarene Islands, Mauritius, the Andaman and Nicobar groups, the Fijian, Samoan, and Tongan archipelagos, Cuba, Jamaica, and even the Bahamas (Harshberger, p. 330), all hold one or two peculiar species of Terminalia. If we were to look for the home of Terminalia catappa in a region where the genus is best represented, we should find it in the New World, particularly in South America. The New World, we might imagine, ought to have been able to provide its own wide-ranging littoral species; and it seems strange that human agency should have had to intervene in the matter. However, the distribution of the genus presents many problems that cannot be dealt with here.

\section{Entada scandens, Benth.}

This plant is discussed at length in my two books, Plant Dispersal and Studies in Seeds and Fruits. In the first named it is regarded from the distribution standpoint. In the second, the germination process, the various stages in the maturation of the seed, and the development of its impermeability, are dealt with in much detail.

The great floating powers of the seed have long been known, as well as its ability to retain its germinative capacity after being stranded on the European side of the Atlantic. The white, softish, full-sized moist seeds of the green legume possess no buoyancy. This capacity is acquired during the shrinking and hardening stage, being due to the large cavity produced by the bending outwards of the cotyledons as they dry, the materials of the typical dry seed having no floating power.

The initial buoyancy of the seeds when recently detached from the plant is indicated by the results of experiments made in Fiji and Ecuador (Plant Dispersal, p. 181), from which it is inferred that quite 50 per cent. sink in sea-water and about 70 per cent. in freshwater. In a recent experiment made in Jamaica the proportion of non-buoyant seeds in freshly gathered material was much smaller, only 20 per cent. sinking in sea-water and 30 per cent. in fresh-water. This variation in the initial buoyancy is due to the variation of the conditions attending the shrinking and drying process, which would probably be less complete in shady humid forests than in drier, exposed situations. From curiosity I tested the buoyancy of a hundred seeds with sound coverings that had been brought by currents and stranded on the Turks Islands. Of these, all but five floated in fresh-water and all but one in sea-water, the last named having from some cause lost its buoyancy. In my previous work on Seeds and Fruits it is shown that loss of impermeability may in time be induced through some initial defect in the cuticle.

The seeds form a frequent constituent of beach-drift in the warm regions of the New World. Amongst localities in which $\mathbf{I}$ found them may be mentioned Ecuador, both sides of the Isthmus of Panama, Jamaica, and the Turks Islands, but not in Trinidad, Tobago, or 
Grenada, for reasons given below. In Jamaica I found them at various places, but only on the north coasts; but since they were obtained by Morris amongst the stranded drift near Kingston, it is evident that they may also be thrown up on the south side (Chall. Bot., IV., 302). In the Turks Islands they were frequent on every beach that held drift.

The distribution of the plant in the New World is peculiar. It is found in Jamaica and probably also in Cuba, Haiti, and Porto Rico, and occurs on both coasts of Central America. But it is absent from the Bahamas, and though existing in the northern islands of the Lesser Antilles, as in Guadeloupe, it has not been recorded from the southern islands and from Trinidad. The implication of the absence of its seeds from the beach-drift of Trinidad and the adjacent islands off the Spanish Main is that it is not to be found in the neighbouring portion of the South American continent, that is to say, in the regions drained by the Orinoco and the large rivers of the Guianas. In these continental regions its place, though not its station, is taken by two or three other species.

Of these, probably the most typical is Entada polystachya, a plant which I have discussed at length from a particular standpoint in my Studies in Seeds and Fruits. This species, which has much smaller non-buoyant seeds, has its home, according to Grisebach, in the Lesser Antilles from Dominica to Trinidad, as well as on the adjacent South American mainland, and, strangely enough, also in Panama. It grows away from the beach and often on trees by the side of rivers. It is not represented in the beach-drift, its seeds possessing no floating power, and evidently it could only be dispersed by currents through the agency of the separate joints into which the pod breaks up, the buoyancy of which could not be great.

With regard to the absence of Entada scandens from Trinidad and the neighbouring islands of Tobago and Grenada, I may say that it is not represented in Hart's Herbarium List for Trinidad. Mr. Broadway, who had an experience covering several years of the flora of this region of the West Indies, told me that it has not been found there. The only localities given by Grisebach are Guadeloupe and Jamaica, but the presence of its seeds in such quantities on the Turks Islands beaches indicates that it must be at home in San Domingo and Porto Rico, from which the seeds are in all probability derived. Its seeds occur in the drift on both sides of the Isthmus of Panama and on the beaches of Ecuador, and the plants grow in the woods at the back of the coasts in those regions.

Grisebach, when referring to the station of Entada scandens in Jamaica, says that it is common in mountain woods; and it was usually in that station that I found it. But it may survive on trees beside streams and ditches in districts where the woods have long since been mostly cleared away for cultivation, as at Moneague. The greatest altitudes above the sea at which the plant came under my notice in Jamaica were on the slopes of Mount Diablo at 2000 feet, at Pallet at nearly 2000 feet, and at New Find near Lumsden at about 1500 feet-the two last localities being in the mountains at 
the back of St. Anne's. In the Pacific Islands it is a characteristic plant on the trees lining the beaches and the estuaries.

Two critical facts present themselves in the New World with reference to the distribution of this plant over the warm region of the globe. In the first place there is its occurrence on both the Atlantic and Pacific borders of Central America. As I pointed out in my work on Plant Dispersal, this does not compel us to assume, as in the case of the mangrove flora, that the plant's present distribution in the New World antedates the emergence of the Panama Isthmus. Frequenting, as it does, not only estuarine regions but also mountain woods inland, it can be at once perceived that, given its occurrence in the interior of a region like the Isthmus of Panama, the seeds of plants growing on the same " divide" could be carried by rivers to both the Atlantic and Pacific borders. The seeds are often found in river-drift in different parts of the world. Thus I found them not only in estuaries on both sides of the Panama Isthmus, but also in the Guayaquil River in Ecuador, and in the estuaries of Fiji.

The second critical fact of distribution is that whilst Entada scandens grows on the West Coast of tropical Africa, it is absent from the corresponding portions of South America (Venezuela to Brazil) and from the neighbouring West Indian islands, such as Trinidad and Tobago. It is certainly strange that seeds, which are transported in the Gulf Stream drift to Europe in a sound state, have not been carried by the Main Equatorial Current from the Gulf of Guinea to the South American mainland. As described in Chapter III., this is the direct track of many of the bottles thrown overboard in this current in mid-Atlantic. Whilst a West Indian seed would require a year or more to reach the coasts of Europe, it would accomplish the passage from West Africa to Brazil in the Main Equatorial Current in from two to three months. A great deal, of course, depends on the distribution of the plant on the African coast. If it does not grow much south of Senegal and the Gambia, its seeds would be carried across the Atlantic in the North Equatorial Current, and would not strike the South American mainland. It is pointed out in Chapter III that bottle-drift from the latitude of Cape Verde only reaches the Lesser Antilles and the islands north; and it is not improbable that we have here an explanation of the peculiar distribution of Entada scandens in the New World. In other words, its range in tropical America may prove to be determined through the arrangement of the equatorial currents by its distribution in tropical West Africa.

It may be that Entada scandens has not been for many ages a denizen of the New World. So little does it figure in the floras of the larger West Indian islands that the American botanical explorers, so freely quoted in Harshberger's great work, rarely seem to have recorded it. Yet it probably occurs in all these large islands. It is almost certain that the numbers of these seeds thrown up on the beaches of the Turks Islands are derived from Hispaniola, Porto Rico, and the northern islands of the Lesser Antilles, since the plant is not represented either in the drift or in the floras of the 
southernmost islands and of the adjacent continental regions of South America (Venezuela to Brazil).

Yet a different standpoint may be needed when we come to regard the distribution of the genus. About a score of species are known, of which about a fourth are confined to the New World and about two-thirds to Africa and Madagascar, whilst Burma holds a species of its own. The indications are that, as a genus, Entada belongs to the tropics of both the eastern and western hemispheres, and that, however effective oceanic currents may have been in dispersing a particular species (E. scandens) around the globe, we must look elsewhere for the explanation of the range of the genus. In this respect Entada falls into line with a multitude of tropical genera shared by the Old and the New World.

A word may be said here respecting the spread of Entada scandens to the interior of continents, as, for instance, to the Himalayan region and to the lake district of Africa. It is quite likely that man has often here played a part, but it is probable that large animals have also taken a share in the dispersal. We know that camels and ostriches will at times swallow almost anything; and although such creatures would scarcely frequent localities where Entada scandens is at home, yet it is noteworthy that there is in the Kew Museum an entire seed of this plant, measuring about $1 \frac{1}{2}$ inches across, which was removed from the cæcum of a rhinoceros from Chittagong that died in the Zoological Gardens of London.

\section{Mucuna trens, DC., and an allied species, probably Mucuna altissima, DC.}

Mucuna seeds of two kinds, not very dissimilar in appearance and evidently belonging to allied species, make up 6 per cent. of the larger drift cast up on the beaches of the Turks Islands. Of these about a third belong to $M$. urens, DC. and are not to be distinguished from seeds of the same species collected by me in the Pacific islands (Plant Dispersal, p. 80, etc.). The plant in flower and fruit, as observed by me in Jamaica and Tobago, corresponds to De Candolle's description as given by Grisebach; whilst seeds of the same species gathered by me on the Panama beaches were thus named at Kew. The seeds are semi-globose, nearly an inch across $(20-24 \mathrm{~mm}$.), and have a broad raphe, a fifth of an inch $(5 \mathrm{~mm}$.) wide, that nearly encircles the seed. They are typically greyish black or brownish black, but seeds in the drift may present a lighter hue. The other Mucuna seeds belong to a type often designated as "near urens" in this work. There are reasons for the belief that they are the seeds of $\boldsymbol{M}$. altissima, DC., a species regarded as confined to the New World, and as such they are sometimes referred to in these pages; but, as shown below, this identification requires confirmation. These seeds are twice as frequent as those of $\boldsymbol{M}$. urens on the beaches of the Turks Islands. They are flatter or more depressed and are rather over an inch in diameter (26-30 mm.), and they possess a narrower but similarly encircling raphe $(3-4 \mathrm{~mm}$.). In colour they are usually a dark or a light brown, and when of the lighter hue they sometimes display 
black mottlings. The distinctions, however, especially as regards the width of the raphe in the two species, sometimes disappear. One finds at times drift seeds that might be referred to either kind, and even the seeds of growing Jamaican plants of $\boldsymbol{M}$. urens were not always constant in their characters.

Bentham, when describing Mucuna altissima in the Flora Brasiliensis (Mart. XV., part 1, p. 169, tab. 46, 1859-62), remarks that the fruit is unknown; but he figures with a query under this name a pod with seeds that are very like those designated "near urens" in these pages. Grisebach (1864) describes the legume and seeds of this species. The last are stated to be orbicular, compressed, cight to ten-tenths of an inch in diameter, and almost wholly surrounded by the raphe, a description, which, except for the smaller size, would apply to the drift seeds of the "near urens" type. The last are stated above to be rather over an inch across. The matter, however, requires further investigation.

Authorities are agreed that Mucuna urens is widely spread in the tropics of the Old and New World. In the latter it occurs in all the larger as well as in many of the smaller West Indian islands, and extends south to Peru and Brazil on the Pacific and Atlantic sea borders. There has been apparently some uncertainty about the limits of the species in the Old World, but there is no doubt that it is found in tropical West Africa as well as in the Pacific islands (Hawaii, Marquesas, Samoa) and in other regions. Mucuna altissima, to which the seeds of the other kind probably belong, is, according to Grisebach, a peculiar American species distributed over the West Indies and occurring on Central America and in Brazil.

The same two kinds of Mucuna seeds also came under my notice frequently in the beach-drift of other parts of the West Indies besides the Turks Islands-namely, in Trinidad, Tobago, Grenada, and in Jamaica; and in their association they are evidently very characteristic of West Indian drift. On the beaches of Tobago and Trinidad, where they are numerous and often encrusted with Balani, they occur in nearly equal numbers. As far as I could judge from the Morris collection of Jamaican beach-drift in the Kew Museum, the same two sorts of Mucuna seeds are there represented under the name of M. urens. As occurring in West Indian drift the seeds of both sorts are usually sound and germinable. They are those that are transported across the Atlantic to Europe in the Gulf Stream drift. It may be here stated that Ridley, in 1887, found two seeds of Mucuna urens, D.C., stranded on Fernando Noronha, off the coast of Brazil (Journ. Linn. Soc., vol. 27). The plant grows on the mainland; but it is far more probable that the seeds were brought in the Main Equatorial Current from the Gulf of Guinea.

Peculiar (as far as my experience goes) to the Trinidad and Tobago beach-drift are the seeds of another species of Mucuna readily recog-

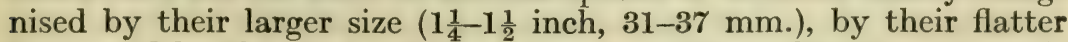
form, and by the great width of the encircling raphe ( 9 or $10 \mathrm{~mm}$.). They are greyish or brownish black, usually sound, and to quite half of them the shells of marine organisms (annelids, cirripedes, etc.) are attached, an indication of a previous flotation of months in the 
sea. Since the drift always reaches these islands from the southward and eastward, it is likely that these seeds were brought by the Equatorial Current flowing northward along the coasts of Brazil, and it is not beyond the limits of possibility that they might even have been brought over from the African coasts.

It is, however, with the two seeds of the "urens" type (Mucuna urens and $\boldsymbol{M}$. altissima?) that we are here concerned. Singular confusion has arisen in the application of the specific name of pruriens DC. to one of these by older as well as recent botanists, a name which is really that of a very different species of Mucuna, a weed of cultivation and quite unsuited for distribution by the currents. The error seems to date far back, perhaps originating with the interpretation of a remark made by Forster, one of Cook's botanists; but the discussion of the matter is reserved for Note $\mathbf{1 0}$ of the Appendix. Both of them came under my notice in a sound condition amongst the West Indian seeds stranded on the Azores. As in the beach-drift of the Turks Islands, those of the true urens type were only half as frequent as those of the other species. It is probable that the drift seeds of this genus which Darwin received with other drift from the Azores (Chall. Bot., IV., 291) belonged to these types. Evidently both kinds are often cast up on European beaches; but it is noteworthy that of the five specimens from those beaches which I have handled-namely, from the South of England, Ireland, and the Shetland Islands, four belong to the "near urens" kind and one to the true urens type. However, both sorts are to be found amongst the West Indian drift seeds picked up in the South of England, as contained in the Kew collection.

Ever since Sloane referred, more than two centuries ago, to the fact that these Mucuna seeds are frequently thrown up on the Orkney Islands, they have been frequently observed on European coasts, and they are often mentioned in this connection in Chapter II. On the Scandinavian beaches they are very commonly noticed according to Sernander (pp. 119, 143), and have even been found on the Baltic shores, being alluded to under the name of M. urens, L., DC. Lindman, who is there quoted, mentions the seeds of yet another species of the genus which have been found on Scandinavian beaches. They are referred with a query to $\boldsymbol{M}$. macroceratoides, DC. In the Index Kewensis, M. macroceratides is accredited to Brazil. It was evidently to $\boldsymbol{M}$. urens that Lyngbye alluded when he identified some seeds picked up by him on the Faroe Islands in 1817 as belonging to Dolichos urentis, a matter already mentioned in Chapter II.

The records of these seeds on European beaches are to be found scattered through Chapter II. In this place they are briefly given together. Next to the record of their occurrence in the Faroe Islands we have that for the Shetland Islands. The specimens sent to me from that group were of the "near urens" type. Mr. Peel refers to seeds probably of Mucuna urens as amongst the West Indian seeds thrown up on the outer Hebrides; and it cannot be doubted that they frequently reach the west coasts of Scotland. On the Irish coast they are regular constituents of the West Indian drift there stranded. For my information relating to this locality I am mainly indebted 
to Miss Knowles. The only Irish seed inspected by me came nearest to the true urens type.

On the beaches of the South of England Mucuna seeds are occasionally found. In the Kew Museum there is a specimen named $\boldsymbol{M}$. urens from Cornwall, and another specimen from the Isle of Wight is named "near M.urens." I found a sound seed of the kind last mentioned on the south coast of Devonshire, and Hemsley names Mucuna seeds (doubtless of one or other of these two sorts) as picked up near Portsmouth (Chall. Bot., IV., 291). Many of these seeds found on European beaches are quite sound. Lindman procured the germination at Upsala of seeds of $\boldsymbol{M}$. urens obtained from the Scandinavian beaches (Sernander, p. 7); and in this connection it is important to note that seeds gathered by me from the plant in the Hawaiian islands germinated and gave rise to healthy plants, after being kept afloat in sea-water for a year (Plant Dispersal, p. 80).

With regard to the buoyancy of the seeds of these two kinds of Mucuna, their frequent occurrence in beach-drift and their ability to cross the Atlantic unharmed are facts of observation above recorded. In my work on Plant Dispersal (pp. 80, 81, 531, etc.) I deal more especially with the seeds of $\boldsymbol{M}$.urens as found in the Pacific islands. Though, as above observed, seeds remained afloat after a year in seawater and subsequently germinated, it was indicated in my experiments that on account of the liability of the seeds to absorb sea-water and swell in the warmer parts of the ocean, a large proportion, at least 50 per cent., would sink in the early part of the transatlantic passage.

As concerns the station of the plants of Mucuna that are most frequently represented in West Indian beach-drift, I have only data for $\boldsymbol{M}$. urens proper; but doubtless the plants yielding the seeds of the other kind are similar in their habits. If, as is not unlikely, the last mentioned prove to be the seeds of $M$. altissima, DC., then we are concerned with a species that grows in mountain-woods in the West Indies and on the tropical American mainland. This species came under my notice as a tree-climber around the lake of the Grand Etang in Grenada, but not in seed. $M$. urens came under my notice in Jamaica climbing on the trees of the wooded slopes of the Black River above Lacovia, and also in the "pen" district around Moneague in the centre of the island, growing on trees by the side of ditches. I also found it hanging from the trees on the banks of Les Coteaux River in Tobago. In such stations the seeds are very likely to fall into streams and rivers, and they may be observed amongst the drift stranded at the mouths of rivers, as in the case of the Black River and of the White River in Jamaica. It is in this manner that the seeds of this plant are generally brought within the influence of the ocean currents, being first carried down by rivers from inland regions to the sea.

However, not all the seeds of Mucuna urens that fall into the rivers reach the sea, since a number of them sink in fresh-water. I did not test the relative buoyancy in fresh-water of seeds gathered directly from the plant; but the seeds of the beach-drift, though they all float in sea-water, not infrequently sink in fresh-water. Ten 
per cent. of the seeds of the Turks Islands beach-drift and 20 per cent. of the drift seeds of Trinidad and Tobago sank in fresh-water. It may be added that of the seeds of the allied species (near urens) found in the beach-drift of the two localities just named, all floated in sea-water, but 20 per cent. of those of the Turks Islands and 9 per cent. of those of Trinidad and Tobago had no buoyancy in fresh-water. In their buoyant behaviour the seeds of these two kinds of Mucuna, so common in West Indian beach-drift, illustrate the fine adjustment, referred to on pages 96 and 181 of my work on Plant Dispersal, that is not infrequently to be observed with the seeds of leguminous plants dispersed by currents. This principle would probably be exemplified in a more marked manner by Mucuna seeds taken direct from the plant, just as has been already described in the case of Entada scandens. An obvious implication of the results of these experiments on the relative buoyancy of such seeds in salt and fresh water is that a good proportion of those found in beach-drift must have grown on coast trees, since they could not have been carried down to the sea from inland districts by a river.

In this connection one may add that of the large Mucuna seeds of the Trinidad and Tobago beach-drift, which are described without a specific name on page 121, 50 per cent. sank in fresh-water, although all floated in the sea.

\section{Fevillea cordifolia, SW. (Antidote Vine)}

This plant belongs to a cucurbitaceous genus holding about six species, all of which are tropical American and West Indian. It is a climber on high trees, and where a river traverses a wooded region the fruits often fall into its stream. It has a wide distribution in the West Indies (Cuba, Jamaica, Hispaniola, Porto Rico, Guadeloupe, Martinique, Trinidad, etc.), and in tropical America.

As in the case of Grias cauliflora (see p. 211) the discussion of its means of dispersal raises some critical questions relating to their connection with the area of distribution. Both are restricted to the tropics of the New World, and both display a general unfitness for dispersal by currents-an unfitness not concerned so much with deficiency in the floating power of the seed (Fevillea) or of the fruit (Grias) as with the loss of the germinative capacity.

I will at first refer to the mode in which the seeds reach the coast in Jamaica, and then to their condition in the beach-drift, where they occur in numbers. The station of the plant as a vine on the trees bordering the Black River is noticed on page 15. The fruit is heavy, rounded, and four to five inches in diameter; and since the plant often grows on the tree-branches spreading over the water the fruits frequently fall directly into the river. Only a few ripe fruits were to be seen on the plants when I examined the Black River in January 1907; but I learned from one of my boatmen, a native of the district, that the "ploom-ploom," as he termed it, of the fruits as they fall into the water is commonly to be heard when ascending the river in March. However, during my ascents I observed both fruits and seeds afloat in the drift, the last being very frequent. 
The ripe fruit, which usually contains about ten seeds, floats when it falls into the water. In course of time it breaks down whilst still at the surface, the seeds escaping and floating away; its buoyancy being due not only to the seeds but also to the floating power of the pericarp. The seeds are flat and round and about two inches across. They are as buoyant in the moist fresh condition when just freed from the fruit as they are in the dry condition. The embryo which forms the kernel has no buoyancy, the seed owing its floating power to the coverings. On first examining it, the seed would seem to be structurally well equipped for transport by marine currents. In the moist fresh state, when the embryo or kernel fills its cavity, the cotyledons are closely appressed; but the embryo is imbedded in spongy cellular tissue, especially aeriferous in its outer part and very buoyant. Outside this tissue is a thin crustaceous shell, which is non-buoyant, but the seed possesses an outer border or edging, 4 to $5 \mathrm{~mm}$. thick, of a brownish suber-like material which is very buoyant. Thus it is that when, as often happens, an empty seed splits into two halves in the manner below described, the two portions float away and occur loose in the drift. In the older seeds found afloat in the river the inner spongy tissue is drier, brownish, and increased in buoyancy; whilst the floating power of the seed is sometimes augmented through an empty space in its interior due to the shrinkage of the embryo.

But there is a weak place in the seed's structure as far as buoyancy is concerned, since water is apt to penetrate the suture between the two halves of the crustaceous shell. This might favour the germination of a seed floating in a river; but it would be fatal to the germinative capacity of a seed floating in the sea. This explains the condition of the seeds found afloat in the Black River drift, many of which must have been a long while out of the influence of the current and doubtless belonged to the previous fruiting season. They were very frequent in the river-drift in January, and I examined a considerable number of them from my canoe, with the following results-

Sound seeds (one or two germinating) 50 per cent. Seeds injured by boring animals or by the nibbling of fish

Seeds empty or with decaying embryo 30 ", ",

Seeds represented by the two separated halves of the shell

$5,,$,

100

Thus, excellent as the provision for long flotation at first sight seems to be, it is really very faulty, and it is doubtful whether effectual over-sea transport is possible for any distance.

Reference will now be made to the testimony of these seeds as they lie stranded on the Jamaican beaches after being brought down by the rivers. I especially studied their condition on the beaches stretching four or five miles on either side of the mouth of 
the Black River, where they occur in numbers, and obtained these results-

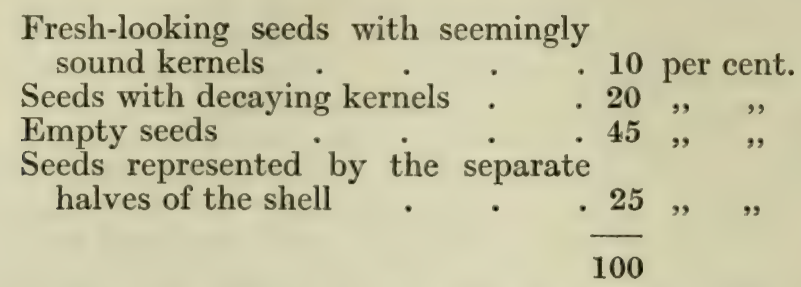

By comparing the above results with those before given for the floating drift of the Black River, we see at a glance that the proportion with sound kernels or embryos has fallen from 50 to 10 per cent., which is by no means a promising sign of fitness for ocean transport.

The seeds came also under my notice on the beaches of other parts of Jamaica, as at St. Anne's Bay and at the mouth of the White River, but with unsound kernels or merely as empty shells. It should be mentioned in this connection that Mr. Hemsley, speaking of the seeds gathered by Mr. Morris on the sea-shore off Kingston in the same island, says that they "look quite sound" (Chall. Bot., IV., 302). It may, however, be surmised that, as the seeds were collected for transmission to Kew, only the soundest specimens would have been selected. Only the empty seeds came under my notice on the Trinidad beaches, the plant according to Hart's list growing on the island.

The next stage in the progress of the seeds in crossing the ocean would be presented in the stranded drift of one of the outlying groups of the West Indies, where the plant does not grow, as in the Turks Islands. To reach these islands the seeds would have to traverse usually some hundreds of miles of sea in their journey by the prevailing surface drift-currents from the islands to the eastward and southward. Now the following was the state in which these seeds presented themselves to me as they lay stranded on the beaches of the Turks Islands, and their testimony goes to emphasise their unfitness for ocean transport.

${ }^{1}$ Seeds with seemingly sound kernels 5 per cent.

${ }^{1}$ Seeds with kernels of doubtful

Seeds with decaying or decayed

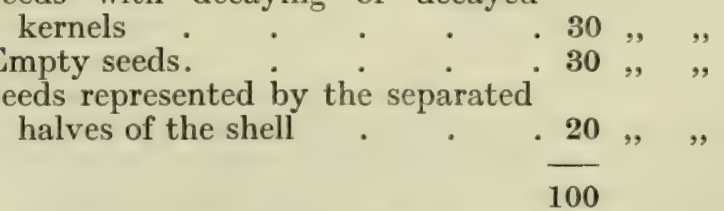

Similar indications were offered in the results of flotation experiments conducted in England during the summer on seeds that had

1 It is extremely doubtful whether any of the seeds were germinable. 
been taken from the ripe fruit in Jamaica five months before. Of four placed in fresh-water one sank in three weeks and displayed on examination a decaying kernel. One sank in seven weeks, and failed to germinate when placed under suitable conditions, the embryo proving to be in a putrid condition. Two remained afloat after two months, and of these one showed a kernel beginning to decay, whilst in the other it was quite fresh and sound. Of four put in sea-water at the same time, one sank in three weeks and another in six weeks, both losing their kernels by decay when subsequently placed in soil. Of two that floated after a couple of months immersion, one showed a putrid kernel and the other a kernel in an earlier stage of decay.

The outcome of all these observations on the seeds of Fevillea cordifolia is that after they have been freed by the breaking down of the fruit floating in river-drift they will float for a long time unharmed in the fresh-water, some of them ultimately germinating at the surface. Of the numbers that would not be detained in the river but would be carried down to the sea, most would soon succumb to the injurious effects of salt water, and probably none would preserve their germinative capacity after floating for several weeks in the sea. A scale of progressive deterioration is indicated by my observations, beginning with those seeds floating in river-drift where 50 per cent. are sound, then taking those stranded on the neighbouring sea-shore where 10 per cent. only are sound, and ending with some sandy islet a few hundred miles away, where only 5 per cent. would be regarded as sound. Seeds that behave in this fashion could never cross an ocean unharmed, though it is quite likely that the empty crustaceous shell, or its separated halves, would be found amongst the West Indian drift stranded on the coasts of Europe.

\section{MANICARIA SACCIFERA}

As it is a little doubtful whether one or more species are included under this name, it is here used in a general sense. The stranded fruits of these palms came under my notice in widely removed localities of the West Indies, as in Jamaica, Tobago, Trinidad, and the Turks Islands, and I may here add Colon. They have long been known as occurring in the beach-drift of Barbados and of other islands of the Lesser Antilles, and in recent years they have been noticed on the Cayman Islands. Yet with the exception of Trinidad, none of the West Indian islands are known to possess these palms. The observant Jamaican native when he picks up on the beach the "sea coco-nut," as he calls it, will tell you that it has been "brought by the waves from a distance." So also the Barbadians, who name it "sea-apple," can have no acquaintance with the palm.

The distribution of these palms is very interesting. Though recorded from the estuaries of tropical South America, as from the Amazon, the rivers of the Guianas, and the Orinoco, Trinidad represents its only known insular habitat. Yet the presence of the drift fruits in such numbers in the Turks Islands at the south-east extremity of the Bahamas seems to indicate that the palms grow in 
the estuaries of the large islands to the southward and eastward, such as Hispaniola and Porto Rico. However, Urban up to recent times did not know of their existence in those two islands, since he refers to their fruits as brought from South America to Porto Rico by the currents (Symbola Antillance, IV., 131, 1903-11). Writing about 1885 Hemsley remarked that it is quite possible that these palms exist in Jamaica (Chall. Bot., IV., 303); but Morris a few years later wrote that on account of their striking appearance and the peculiarity of their entire leaves these palms, if they existed in the island, "could not fail to be noticed" (Nature, January 31, 1889).

Manicaria saccifera is essentially a palm of the Amazon estuary, its native name being Bussú or Ubussú. Spruce tells us that it abounds on both banks of the Lower Amazon (Notes of a Botanist, etc., I., 56). Martius, as quoted by Hemsley (Ibid.), writes that it is abundant on the banks of the Amazon estuaries, but is not known from the interior of the continent. Bates observed many of the fruits afloat in the sea about 400 miles off the mouth of the main estuary of the Amazon, mingled with much drift brought down by the river (The Naturalist on the River Amazons, 1864, p. 461). The Ubussú palm, as he also characterises it, is described by him as growing on land overflowed by the tide in the estuaries of that great river (Ibid., pp. 69, 139). These palms play the same rôle in the Lower Amazon that is taken by Nipa fruticans in the estuaries of tropical Asia and Malaya.

According to Sloane's Natural History of Jamaica (II., 186) these fruits in his time (the close of the seventeenth century) were frequently cast up on the Jamaican beaches, and were amongst the West Indian drift thrown up by the "Currents and Seas" on "the north-west islands of Scotland." He refers to Petiver's description and figure in his Gazophylacium Naturce (tab. 64, fig. 3, p. 6), where it is mentioned as a fruit "from about Cartagena in America." Hemsley quotes Sloane in this connection (Chall. Bot., IV., 303), and reference for further particulars should be made to his pages.

Doubtless the fruits of this palm have since been often found on European coasts, but seemingly they have rarely been identified. There is but little ground for believing that the drifting fruits ever retain the germinative capacity when stranded on the shores of Europe. I became very familiar with these drift fruits in various localities of the West Indies, widely removed from each other, and formed the conclusion that, as far as concerns the disposal of the species, the floating fruit would be quite ineffective except in the case of very short sea traverses.

The fruit is one to three lobed, and has an outer almost woody warty or tuberculate covering, rudely suggestive of some coniferous fruit, a covering that is soon lost in the drift. Plukenet's description, as quoted by Hemsley (Ibid.), of the fruit cast up on the coasts of Barbados-fructum externo cortice denudatum-is true of the great majority of the stranded fruits on West Indian beaches, and would apply to all fruits stranded on the shores of Europe. But at times, as on Jamaican beaches, and on very rare occasions in the Turks Islands, one finds a fruit with its "cortex" more or less intact. 
Plukenet states that Sloane showed him specimens obtained from Jamaica that retained this outer case. I find it difficult to believe that such fruits did not reach Jamaica from some source nearer than Trinidad and the Orinoco and Amazon regions. I only found the fruits retaining the " cortex" on the north side of the island, and it will be pointed out below that it is just on these northern Jamaican beaches that these drift fruits are most numerous and most likely to be at all fresh. The foreign drift on the north coast of Jamaica must be mainly Cuban and Haitian; whilst that on the south coast would be largely brought by the Equatorial Current from Trinidad and the adjoining estuary of the Orinoco, as well as from the Amazon estuaries further south.

On Trinidad, where these palms grow in the swamps, and on the neighbouring island of Tobago, the entire fruits are frequently found in the beach-drift, where they are mingled with others that have lost the outer coverings, and have in some cases come from a great distance, since not a few are incrusted with Balani and similar marine organisms.

Within the common casing are usually two or three (at times only one) globular fruits of the size of a small apple and covered by a hard thin shell, which is somewhat brittle and more or less adherent to the indurated skin of the kernel. The albumen lines a large cavity, as in the coco-nut, and it is to this cavity that the fruit's buoyancy is entirely due. It is the bared globular fruit that is characteristic of beach-drift over much of the West Indian region. Very rarely does one come upon a fruit that is seemingly "germinable," and then, as a rule, only in the vicinity of its home. In Jamaica, where the fruits are more numerous on the northern than on the southern beaches (probably in the first case largely derived from Cuba or Haiti, and in the last case cast up by the Equatorial Current), it is very difficult to find a fruit that could be characterised as sound, and when one is found it is on the north coast. Around the districts of Black River and Savanna-la-mar, on the south-west coasts, all examined had mouldy or unhealthy kernels with embryos gone or in a decaying state. On the north coast, as around St. Anne's Bay and its vicinity, I found that about 20 per cent. were rotting inside, and about 60 per cent. displayed sour-smelling, mouldy kernels and decaying embryos. The remainder were fairly healthy, but the embryos were excessively shrunken, and the albumen was usually hard and dry; but in a few cases the contents were fresh and relatively moist and the embryo was healthy, water still remaining in the seed cavity.

It is noteworthy in this connection that the fruits collected by Morris amongst the beach-drift off Kingston on the south side of Jamaica were found at Kew to possess unsound seeds (Chall. Bot., IV., 303). This is the rule in Jamaica. On the other hand, in an island like Trinidad, where the palm is at home in the coast swamps, fresh fruits are frequent among the stranded drift, 50 per cent. of those observed by me being sound. However, some of these fresh fruits may be derived from a source near at hand, namely, the estuary of the Orinoco. In Tobago, only twenty miles distant from 
Trinidad, the proportion of sound fruits in the beach-drift is nearly as large. This island is not known to possess the palm, and doubtless its drift fruits are principally derived from Trinidad and the neighbouring Venezuelan shores. In both islands we also find old dead drift fruits incrusted with Balani that probably hail from the Amazon.

Of the Manicaria fruits brought by the currents to the beaches of the Turks Islands not more than 1 or 2 per cent. appeared to be "germinable." Out of some scores observed I only found one or two in their cases, all the rest being bared fruits, and possessing in almost all cases either a mouldy kernel with the embryo more or less removed by decay, or a hard and dry kernel with the embryo greatly shrivelled. The stranded fruits occurred on all the larger islands; but they diminished in frequency towards the south, being most numerous on Grand Turk in the north, and least common on Greater Sand Cay in the extreme south, where, however, other kinds of foreign drift abound. The indications are that these Manicaria fruits often arrive at the Turk Islands from Hispaniola, eighty or ninety miles to the southward.

On Grand Cayman, which lies in the track of the Main Equatorial Current between Cuba and the coast of Honduras, quantities of these Manicaria fruits are thrown up. Mr. Savage English in his paper on this island in the Kew Bulletin (1913) remarks that occasionally perfect fruits are found (such as have been already described in a previous page from other localities); but no "sea coco-nut" has ever been known to germinate on Grand Cayman, and "there is not a tree of it on the island." He attributes the loss of the germinative capacity to the long flotation in the sea involved in the transit from Trinidad and South America. In a few cases signs of arrested germination were observed when the fruits were opened. As indicative of the source of these fruits, it is stated that a drifting bottle from off Ceara, to the north-west of Cape St. Roque, was picked up on the Cayman Islands.

On the whole it may be inferred that the floating fruits of Manicaria saccifera, as far as the retention of the germinative capacity is concerned, possess, in spite of their great floating powers, but a very limited capacity for distributing the species over wide tracts of ocean, though able to traverse in an effective condition the narrow seas dividing the West Indian islands, straits that rarely exceed sixty miles across and have usually not half that breadth.

\section{Dioclea reflexa, Hook. f.}

This leguminous tree-climber, which in many respects, as in its distribution, station, habit, general seed-characters, and dispersal by currents, presents much the same features as Mucuna urens, ranges through the tropics of Asia, Africa, and America. From the data given by various botanical authorities, more especially by Urban, it is highly probable that all the larger West Indian islands, and most of the smaller mountainous islands, possess it. Thus, it is already known from Jamaica, Cuba, Porto Rico, Dominica, St. Vincent, Tobago, Grenada, and Trinidad. But judging from my 
own experience, and bearing in mind Grisebach's remark that it is uncommon in Jamaica, it would appear that, widely distributed as it is over this region, it is rarely frequent. Mucuna urens seems to be three or four times as common, and this difference, as we shall see, is reflected in the story of the stranded drift.

In the West Indies it climbs the lofty trees of the inland forests, and especially favours the river-bank and the lake-side in wooded districts, so that its seeds are likely to drop into inland waters and to be carried down to the sea. But it also grows amongst the trees lining estuaries, though it could not in this region be placed amongst the typical coastal plants. The locality in which I especially studied this species was on the forested slopes of the lake and effluent of the Grand Etang in Grenada at elevations of 1800-2000 feet above the sea. Doubtless it finds its station on the densely wooded banks of the great rivers of Venezuela, the Guianas, and tropical Brazil; but it is not easy to find direct references to its station in those regions. However, Bentham, ascribes to it a station in woods near rivers in the Amazon area, and mentions the Rio Negro in this connection (Flora Brasiliensis of Martius, vol. 15, part 1). In tropical West Africa it finds its home near the coast and at the riverside (Hooker's Niger Flora.)

The seeds, though less frequent than those of Mucuna urens, were found by the writer to be characteristic of beach-drift in Jamaica, the Turks Islands, Grenada, Tobago, and Trinidad. They are included in the Morris collection of Jamaican beach-drift in the Kew Museum. Though those of Mucuna have often been recorded from the drift stranded on European beaches, I have found no reference to those of Dioclea reflexa. This is probably due in part to the circumstance that they have often been regarded as Mucuna seeds, a confusion which is apparent in some of the older allusions to West Indian drift on European beaches, and an instance is given below. Except in size, the diameter being about an inch in both cases, the appearance of such Dioclea and Mucuna drift seeds is dissimilar. Whilst the two sorts of Mucuna seeds characteristic of European beach-drift are orbicular in form, dark-grey in hue, and have a black raphe nearly encircling them, the typical seed of Dioclea reflexa shows black mottling on a light-brown ground, is squarish on one side, and its raphe is limited to two-thirds of its circumference.

That the seeds of Dioclea reflexa are to be included amongst West Indian drift stranded on European beaches, will be now established, but they are far less common than those of Mucuna. Probably at least ten Mucuna seeds are washed ashore for each Dioclea seed. Although the writer has not found one himself on this side of the Atlantic, a sound seed of D. reflexa stranded on the Shetland Islands was sent to him by Mr. J. Tulloch of Lerwick for his inspection. Then there is the curious circumstance that Dr. James Wallace, in his enlarged edition (1700) of his father's book on the Orkney Islands (1693), substitutes a figure of a seed of a Dioclea, most probably D. reflexa, for one of Mucuna given in the earlier edition, as though they represented the same seed. Since the seeds of this species of Dioclea are able to reach the Shetland Islands, it would seem highly 
probable that they are cast ashore on the Norwegian coasts; but the name is not included in the list of West Indian seeds and fruits given by Sernander in his account of the Atlantic drift thrown up on those shores. However, one may expect to find these drift seeds also in the temperate latitudes of the South Atlantic. Hemsley records Mr. Moseley's discovery of the seeds of Dioclea reflexa washed ashore on Tristan da Cunha (Chall. Bot., IV., 291).

In my book on Seeds and Fruits (p. 103) allusion is made to the habit of this climber of growing on trees beside streams in the mountain forests of Grenada; and it is there shown how small would be the percentage of seeds that would be fit for attempting the Atlantic traverse. On this ground alone we are thus prepared to expect that the seeds of this plant would not be so frequently observed among the West Indian seeds thrown ashore on European coasts as those of Mucuna. Judging from my results in the Turks Islands, a locality which represents an early stage in the drifting of the seed across the North Atlantic, the seeds of Dioclea reflexa are rather less frequent than those of Mucuna urens and much less common than those of the other species of Mucuna. In the drift of the Trinidad and Tobago beaches all three seem to be of equal frequency. In the Turks Islands the seeds of Dioclea reflexa were generally distributed in the drift, but were most frequent in the southernmost island. It is interesting to note that of the seeds of this plant collected in the beach-drift of this small group, 10 per cent. sank in fresh-water though buoyant in sea-water. This may be compared with the results of a similar experiment on the seeds of the same plant in the beach-drift of Trinidad and Tobago. Here 30 per cent. sank in fresh-water, though floating in sea-water.

No reference has been made to the occurrence of Dioclea reflexa on the Pacific side of tropical America, as I possess no data directly bearing on that point. However, its place is well supplied there by Dioclea guianensis (Benth.), an allied species mentioned by Seemann, under the synonym of $\boldsymbol{D}$. panamensis, as growing by rivers on both sides of the Panama Isthmus (Bot. Voy. H.M.S. Herald, p. 109). This species is stated to be a native both of the Guianas and of Ecuador; and it is not unlikely that numerous Dioclea seeds, which I found afloat in the drift of the Guayaquil estuary in Ecuador and stranded on the beaches near its mouth, belong to this plant.

Doubtless there are several recorded facts illustrating the distribution of the seeds of Dioclea reflexa by currents in the tropics of the Old World, but the following will be sufficient for the purpose. Many years ago they were identified at Kew from collections of drift seeds made by me on the beaches of Keeling Atoll in the Indian Ocean and on the coral islets of the Solomon Group in the Pacific, as well as from another collection of floating drift obtained by Moseley off the coast of New Guinea (Journ.Vic. Inst., London, 1889; Bot. Chall. Exped., IV., 291, 309, 311).

But there is an allied species of Dioclea, $D$. violacea, Mart., which plays a similar rôle in the tropical Pacific. I was familiar with its seeds in Hawaii and Fiji, and frequent mention is made of them in my work on Plant Dispersal. They are commonly brought down by 
the rivers and deposited on beaches in Fiji, and my experiments showed that they can float for a year and more unharmed in seawater. There is, however, a difficulty connected with the distribution of this species. It seems from Hemsley's reference to it (Bot. Chall. Exped., IV., 291) to have been first described from Brazil. Yet if it is so widely distributed by currents in the Pacific, having been recorded from Hawaii, Fiji, Tahiti, etc., it is strange that it should only be confined to Brazil in the New World and that its seeds do not figure in West Indian beach-drift.

Interesting as the genus Dioclea is to the student of distribution, it only repeats the problems displayed by two other genera of leguminous tree-climbers, Mucuna and Entada, all three of them holding species possessing seeds capable of wide dispersal by currents, species that range over the tropics of the globe, and all three of them containing species of more limited range that, certainly in Entada and probably also in the other two genera, are not adapted for this mode of dispersal. These three genera thus behave like other leguminous tropical genera, such as Canavalia, Guilandina, Sophora, etc., that hold littoral species, found round the tropical zone, plants possessing buoyant seeds known to be distributed by currents far and wide over the oceans; whilst they own other species restricted to smaller areas and not capable of dispersal by the currents. In neither case could the agency of the current be appealed to in explanation of the distribution of the genera round the tropics. It is only the species of the estuary and of the beach that offer in the buoyancy of their seeds the opportunity for the currents. Species that habitually grow away from the sea-beach on the river-bank as a rule possess seeds that sink, a fact brought out in my book on Plant Dispersal. These inland species with their limited range largely make up the genus, the distribution of which around the world opens up very different issues.

\section{Sacoglottis amazonica, Mart. (Humiriacex)}

This is one of the most interesting of the West Indian drift fruits that have been found on European beaches. Though characteristic of West Indian beach-drift, this fruit can scarcely be said to belong to a West Indian plant, since the small tree to which it belongs has its home in the Amazon estuary, and is otherwise only known from the island of Trinidad, where it is of very rare occurrence. It is, however, highly probable that the tree will be found in the estuary of the Orinoco, if it has not already there been found. There is no other fruit or seed amongst the West Indian drift of European beaches, about which it may be assumed with such confidence that the original source was one of the great estuaries of the South American mainland between the Equator and the Gulf of Paria, most probably the Lower Amazon.

The story of the mystery that long surrounded the parentage of these drift fruits was told in Nature many years ago (January $\mathbf{3 1}$, 1889; November 21, 1895) by Mr. Morris (now Sir Daniel Morris). Although they had been known for two centuries and more, not only 
amongst the strange constituents of Jamaican beach-drift but in European collections of curious seeds and fruits found on our beaches, it was not until 1889 that the parent plant was discovered. The subject was re-opened when Morris recognised in a drift fruit picked up at Bigbury Bay, South Devon, by Mrs. Hubbard in 1887, the same fruit that he had gathered on Jamaican beaches in 1884. Several botanists aided in the inquiry, Hillier, Oliver, Stapf, Urban and others; but the source was definitely established when Mr. Hart in $\mathbf{1 8 8 9}$ sent from Trinidad to Kew some drawings made by Dr. Crueger in 1861, both botanists that in turn filled the position of Superintendent of the Botanic Gardens of Trinidad.

Much of what follows was written before the author became acquainted with the fact that Morris had made a comprehensive investigation of the subject. The present writer had also dug deeply into the older botanical literature; but here also he has been largely forestalled. Almost all that is of importance to the student of distribution respecting Sacoglottis amazonica was told long ago by Morris. However, as my investigations have been quite independent, and also because my account helps to fill up some of the gaps in the earlier researches, more especially in the handling of the drift fruits over a large area of the West Indian region, I venture to give my results much as they were written out before the papers of Morris in Nature were consulted.

It is singular that Mr. Hart first introduced me to the parent plants of these strange drift fruits, with which I had been previously familiar on the beaches of Jamaica and Colon. Within an hour of my landing at Port of Spain in Trinidad, in December 1908, I was in the Botanic Gardens talking to a stranger about my difficulties in finding the parent plants of some of the seeds and fruits in West Indian beach-drift. He took me into the Herbarium and showed me some specimens. The stranger was Mr. Hart and the specimens were those of Sacoglottis amazonica. From him I learned that the small tree, to which the fruits belonged, grew in the estuaries of the Orinoco and the Amazon, and that if $I$ wished to see it in its home I ought to visit those regions, since it was very rarely to be found on the swampy coasts of Trinidad.

These drift fruits are spread far and wide over the West Indian region. I found them on the beaches at Colon, in Jamaica, and on the Turks Islands, Tobago, and Trinidad. There are specimens in the Kew Museum from Barbados, and Morris refers to one found afloat off an island between Grenada and St. Vincent. As before noted they were found by Morris in 1884 on the south coast of Jamaica, and almost two centuries before, 1688-9, they were observed by Sloane during his residence on this island to be frequently cast up on its shores.

Although, as far as I know, not recorded from any island in the West Indian region except Trinidad, the regular occurrence of its drift fruits on the beaches of the Turks Islands, at the south-eastern end of the Bahamas, renders it highly probable that the plant grows on the large islands to the southward and eastward, such as Porto Rico and San Domingo, since it is from that direction that much of 
the foreign drift reaches this small group. It is a tree of the Amazon delta and of the Middle Amazon, growing in woods on the riverbank. It is accordingly something more than an estuarine tree, since it extends far up the great river and has been found at Teffé some distance above the confluences of the Negro and the Madeira with the main stream. The latest reference I have found to the distribution of this tree is that given by Stapf in Morris's paper of 1895. We learn from the Index Kewensis that the genus holds about ten known species, of which nine are Brazilian and one is found in the Guianas. Probably Sacoglottis amazonica is the only species that is dispersed by the currents; and it is pointed out in Chapter IV. that the limitation of this tree to the New World appears to be entirely a question of the arrangement of the currents, which would readily transport the fruits in a sound and effective condition from tropical West Africa to Brazil, but not from the tropies of the New World to West Africa.

Before dealing with these fruits from the standpoint of their fitness for dispersal by currents, I will observe that they were characterised by Morris as possessing "ideal qualities" as drift fruits, their great buoyancy being due, as he points out, to numerous closed cavities or resin-cysts. The typical drift fruit, as he explains, has lost the outer fleshy covering of the fresh fruit. He found that two of the normal five cells of the fruit were usually suppressed. His account is illustrated by excellent figures of the fruit.

They presented themselves to me in West Indian beach-drift as oblong woody fruits, about two inches long, and usually twoseeded. After the detachment of the ripe fruit from the tree, the outer fleshy covering evidently dries up and forms a dark-brown skin, which is soon lost in the "wear-and-tear" of the drift, and is only to be observed with fruits that have not travelled very far from the parent plant. When stripped of the outer skin the drift fruit presents a remarkable appearance on account of the rounded "bulgings" on the surface, which correspond to the empty resincavities beneath. It is in this bared condition as light-coloured warty ligneous fruits that they generally occur in West Indian beach-drift, the outer dark skin, two or three millimetres in thickness, having been lost, as above stated, in the "wear-and-tear" of sea transport. The two seeds lie in the centre of the fruit. They occupy long cells two-thirds of the fruit's length, but appear to be perfectly protected against the penetration of sea-water. Any weak place in the equipment of the seeds for traversing an ocean unharmed would be expected rather in the inherent inability of the seed to retain its germinative capacity for a period sufficiently long than in any defect in the protection afforded by the fruit-case.

It is only at the extreme south-east corner of the West Indian region, namely, in the islands of Trinidad and Tobago, that these drift fruits present themselves on the beaches in a more or less entire state, that is to say, with the outer skin in a more or less perfect condition. The bared state, as Morris points out, is the typical condition of the drift fruit. In Jamaica they are always bared, and the same may be said of those in the beach-drift of the Turks 
Islands. On the beaches of the south coast of Trinidad these fruits are amongst the commonest constituents of the drift, and the seeds are often fresh. On the south-eastern beaches of Tobago, where the fruits are common, about a third of them contained sound healthy seeds. Since the tree is very rare on Trinidad and does not grow on Tobago, it is obvious that the fruits so characteristic of their beaches belong to the drift of the Orinoco and the Amazon; and it is not surprising that in islands nearest to the true home of the tree the drift fruits should sometimes retain their outer coverings, and that the seeds should be often fresh. In the drift of the Turks Islands only about a fifth possess healthy seeds; but in this small group the seeds do not seem to be able to retain their sound appearance for a long time in the drift. However, though usually in scanty numbers, these drift fruits are to be observed on every beach of the Turks Islands, where the foreign drift collects in any quantity, from Grand Turk to Greater Sand Cay, at the extreme ends of the group.

These fruits float buoyantly for many months. Three fruits from the Tobago beach-drift were placed in sea-water two years after their collection, and all still floated buoyantly seven and a half months later. In two of them the seeds proved to be discoloured and seemingly dead. In the third they appeared to be fairly sound. From the results of this experiment as well as from the indications supplied by the condition of the seeds in the stranded fruits on West Indian beaches as above described, it would seem that although the fruits would be able to withstand the immersion of a year and a half, which would be involved in their transport to the coasts of Europe, the seeds would probably lose their germinative capacity after the first six months. The floating power is to be entirely ascribed to the numerous impervious round empty cavities ( 3 to 5 $\mathrm{mm}$. across) in the substance of the woody case and to the impermeable outer surface of the fruit, when deprived of its skin. Neither the substance of the fruit nor the seeds possess independent buoyancy.

It is apparent that Morris formed a similar estimate of the unfitness of the seeds for reproducing the plant after a prolonged ocean traverse. Though impressed with the ideal qualities of the fruit, as far as buoyancy is concerned, he remarked that there is "no record that the seeds have germinated after long immersion in salt water, or that the plant has established itself in a new locality outside its present area." As regards the last point it may be observed that it would scarcely be possible to discover such a record in the case of any large West Indian island, not even for Jamaica. We could not expect any proof more valuable than that which is supplied by the very scanty representation of Sacoglottis amazonica on the southeast coast of Trinidad.

From what has just been said we would expect to find the fruits of Sacoglottis amazonica on European beaches, though not with sound seeds; and reference has already been made to a specimen in the Kew Museum which was picked up in 1887 by Mrs. Hubbard on the Devonshire coast. But from data given by Sloane in his Natural History of Jamaica (II., 186) it is apparent that these fruits 
have long been known as constituents of the West Indian drift brought by the Gulf Stream to the shores of Europe. Although the parent plant was not known to him, he was able to compare its fruit with the accounts given by Petiver and others. "This is frequently cast up" (thus Sloane writes) "on the shores of this island (Jamaica) by the waves, and is one of those fruits thrown on the northwest islands of Scotland by the seas." He quotes the description given in a work thus designated-J. B. Cat. Jam., p. 214, "Fructus exoticus cinereus, cum lineis et tuberculis duris." He also gives Petiver's description of his drawing of the fruit in his Gazophylacium Naturce (tab. 71, p. 5), "Fructus Jam. ovalis foraminosus," and the same author's account of " a hard oval fruit, with seed-holes round its surface, found on the shores of Jamaica," etc. Petiver's figure and description, which I found in the $\mathbf{1 7 6 4}$ edition of his book (plate 71, p. 7), leave no doubt as to the identity of the fruit mentioned by Sloane as commonly stranded on the north-west islands of Scotland. Probably these fruits were often figured in the works of the early botanists. Thus one is figured and well described by Clusius (Exot. Libr., libr. II., cap. 19, p. 45; 1605) as sent to him by Jacobus Plateau, but nothing more is said of its source.

In the remarks just made I have briefly given the results of my examination of the older literature relating to the strange drift fruits of Sacoglottis amazonica, both on West Indian and European beaches. Since they were written, I have enjoyed the privilege of reading the papers of Sir D. Morris, who, with the assistance of Mr. E. G. Baker, made a more extensive inquiry in this direction, though I am not clear whether either of them noticed Sloane's recognition of these fruits as thrown up on the north-west islands of Scotland. My references to the older literature may now be supplemented from these sources. The description and figure given by Clusius in his work of 1605 were reproduced by J. Bauhin in 1680 in his Historia Plantarum (tom. i., libr. 3, cap. cxi., fig. 1). One of the earlier allusions to this drift fruit is that of Johannes Jonston, who described it in his Historia Naturalis de Arboribus et Fructibus (p. 102), a work published in 1662 . It was mentioned by Sloane as early as 1696 in his Catalogus Plantarum (p. 214); and here one may find an explanation of a reference of his in the preceding paragraph, J. B. apparently indicating J. Bauhin. Its discovery by Mr. E. G. Baker in the Sloane Collection in the British Museum, under label No. 1656, was of much assistance to Sir D. Morris in clearing up the mystery surrounding the origin of these drift fruits. 


\section{CHAPTER VII}

\section{THE LARGER FOREIGN DRIFT OF THE TURKS ISLANDS (continued)}

\section{Guilandina bonducella, L.}

Since this plant and its seeds are discussed at length in my books on Plant Dispersal and on Seeds and Fruits, it is only necessary to repeat here that the seeds are able to float for years unharmed in the sea and that they retain their germinative capacity after being stranded on the shores of Europe. For the last two centuries and more it has been known that the seeds of this plant are frequently cast up on European beaches. This subject is dealt with in Chapter II.; but it may be here observed that the writer himself found a seed, apparently sound, in April 1909, on a beach near Salcombe in South Devon. For many years and in several parts of the tropical zone, he has been familiar with this littoral shrub. Here, however, his remarks will be chiefly restricted to the results of his observations in the West Indian region.

As a coast plant it is generally distributed in the West Indies from Jamaica to Trinidad. It occurs as frequently on small as on large islands; and noteworthy amongst the former are the Cayman Islands where it was found by Millspaugh (Plantee Utowance). In Jamaica it came under my notice on the borders of nearly every beach examined on the north and south coasts. It also came under my observation on St. Croix, Grenada, the Turks Islands, etc., as well as on the Colombian coast near Cartagena. Its seeds form a regular constituent of West Indian beach-drift, and came especially under my notice in this connection in Jamaica and the Turks Islands.

This plant was observed by me only on Grand Turk, the northernmost of the Turks Islands; yet its seeds occur in the drift of the other islands of this small group under circumstances indicating that they formed a part of the general drift brought to these islands from the southward and eastward. Though not very frequent, a circumstance probably due to their often being covered over by the heapedup larger drift materials, a few of the seeds came under my notice on all the Turks Islands where drift had accumulated in any quantity on the beaches. On Grand Turk it thrives in places away from the beach in dry, rocky situations, especially in the northern part; and it only came down to the coast in places where the usual inland vegetation reached the beach. Since the seeds are regularly brought to this small group from outside regions by the currents, the limited occurrence of the plant is remarkable. There is evidently 
some influence that inhibits the establishment of Guilandina bonducella as a littoral plant in these islands. As I found a few seedlings on the beaches of Grand Turk, it is apparent that the excluding cause comes into operation after this stage. It may be that goats and other animals browse on the young plants, since the soft prickles that grow on the stems and on the under surface of the foliage could offer no protection, though when they harden in the older plants such protection would be afforded.

It is probable that the same cause which prevents this plant from assuming its characteristic littoral station on the Turks Islands has operated throughout the Bahamas, an archipelago to which this small group geographically belongs. I did not find it included in the manuscript of Britton's and Millspaugh's Flora of the Bahamas, its place in those islands being taken by the allied species, Guilandina bonduc, which grows in coastal thickets. Neither species was recorded by Lansing in his thorough examination of the Florida keys (west of Key West). It is also apparent that although the seeds must often be stranded on the Bermudian islands, where several West Indian shore plants have found a home, the plant has not succeeded in establishing itself there, since General Lefroy's remark that it has only once been found (Chall. Bot., II., 30, 129) would scarcely justify us in considering it a successful colonist. On account of its cosmopolitan distribution as a littoral plant in warm latitudes we are apt to infer that it could make its home everywhere; but the foregoing negative facts of its distribution will prevent us from forming such a conclusion.

In my book on Plant Dispersal (p. 192) it is stated that almost without exception the seeds of littoral plants of Casalpinia bonducella (Guilandina bonducella) in Fiji floated both in sea-water and in freshwater, whilst in Hawaii the seeds of the same species growing inland all sank. (On consulting my Fijian note-books I find that out of forty-seven seeds from three different coast localities all floated in fresh-water.) I made some additional observations on these two points in the West Indies, that is to say, on the relative buoyancy of the seeds in fresh and salt water, and on the influence of an inland station on the floating capacity. With regard to the first point it may here be said that out of sixty-eight seeds obtained from plants growing by the beach at Savanna-la-mar in Jamaica 75 per cent. floated in fresh-water and 84 per cent. in sea-water. Of eighty seeds from plants growing by the beach near St. George's in Grenada 95 per cent. floated in fresh-water and 98 in sea-water. Out of fourteen seeds collected from the beach-drift near Seville in Jamaica all floated in sea-water, but only twelve or 86 per cent. in fresh-water. It is thus evident that in the West Indies not quite all of the seeds of littoral plants float in sea-water, and that of those that are buoyant in sea-water not quite all float in fresh-water. We should represent a rough average result if we said that of a hundred seeds of plants growing by the beach ninety float in sea-water and eighty in freshwater.

Concerning the effect of an inland station on the buoyancy of the seeds I found that of a hundred seeds gathered from plants growing 
half a mile from the beach in Grand Turk all floated in sea-water and fresh-water. It appears, then, that an inland station does not deprive the seeds of their buoyancy in the Turks Islands, though in the case of plants growing inland on the old lava-fields of Hawaii this effect was produced.

There seems at one time to have been a trade in the seeds of $G$. bonducella and $G$. bonduc between the New and the Old World. Sloane makes the curious observation (Nat. Hist. Jam., II., 41) that those of the grey-seeded "Nicker" plant $(G$. bonducella) were much esteemed for their medicinal virtues by the Turks. Respecting those of the yellow-seeded "Nicker" plant (G. bonduc) of the West Indies he writes that "the seeds are brought very plentifully into Europe for making buttons" (Ibid.).

I am indebted to Prof. Ewart for the record of the occurrence of two stranded seeds of Guilandina bonducella on the shores of South Australia. They were found by Miss M. O'Dowd in 1912. He considers that they may have been transported there from the Queensland coast. They, however, did not prove to be germinable. As far as the current connections are concerned, it seems to me more likely that if brought from a distance these seeds must have hailed originally from Tropical East Africa or Madagascar. In that case they would have been carried by the Agulhas Stream within the influence of the West Wind Drift Current, and then across the Indian Ocean to Australia. This source is distinctly indicated by the tracks of bottle-drift reaching the Great Australian Bight, a subject discussed in Chapter XIII.

\section{HYMENAA}

Amongst the characteristic fruits of the Turks Islands drift occur two kinds of ligneous indehiscent legumes, of which one kind was identified by Prof. Pax as the fruit of Hymencea courbaril, the West Indian Locust-tree, whilst the other he considered to belong to an allied species of the same genus. These drift pods often occur entire with sound seeds; whilst at other times some or all of the seeds are decayed.

Hymencea courbaril is a tall tree found over much of the West Indies and on the Central and South American mainland from Panama to the Guianas. As concerning its insular distribution, the fact that it occurs in Cuba, Jamaica, Porto Rico, Antigua, Dominica, St. Lucia, Trinidad, etc., indicates its wide range. It grows both in inland plains and in river valleys. In Jamaica it flourishes in all parts of the island and especially up the valley of the Black River (Fruits, etc., of Jamaica, by E. J. Wortley, Kingston, 1906). The legumes of this tree, as they occur in the drift of the Turks Islands, are broad, flat, 5 or 6 inches long, and contain about six seeds in a dry fibrous pulp that fills the fruit cavity. The seeds possess no buoyancy, and could only be transported across tracts of sea by the floating pod, which seems stout enough (the thickness of the walls being 3 to $4 \mathrm{~mm}$.) to withstand the wear-and-tear of a passage across the Atlantic, though it is doubtful whether it would retain 
its buoyancy for the many months that would be occupied in the traverse.

The other pods, which are about 4 inches long and roundish rather than flat in section, hold about four seeds, enclosed in a similar dry pulp, of which some float and others sink in sea-water. The remarks above made concerning the fitness for being transported across the ocean apply also to these fruits. As far as I know no Hymencea pods have been recorded amongst West Indian drift on European coasts.

\section{Carapa guianensis, Aubl.}

Carapa as a littoral genus is linked with Rhizophora not only in its present distribution but probably also in its past associations. Carapa, like Rhizophora, with which it is often associated in coastal swamp regions, has only a few species, the first-named possessing only five or six and the last three or four. In both cases the genus is mainly of the Old World, lending a species to the American continent which holds it in common with the African West Coast. In both genera, therefore, the presumption is that the origin is Asiatic.

Many critical questions of great importance are raised when we come to discuss the distribution of these two genera, questions, I may add, that were ably put by Schimper years ago in his study of the Indo-Malayan coast flora. Both, as already indicated, are littoral genera, frequenting in the case of Rhizophora coastal and estuarine swamps exclusively, and in that of Carapa both the swamp and the dry beach. In both cases there are two species that divide the warm regions of the globe between them in the same peculiar fashion, one appropriating America and the West Coast of Africa, the other monopolising the rest of the tropical zone from the East Coast of Africa eastward to the Western Pacific. In the instance of Rhizophora there are not wanting localities where the Old World species (Rh. mucronata) and the New World species (Rh. mangle) meet, as in Fiji, a matter discussed at length in my work on Plant Dispersal. As far as I can ascertain the two species of Carapa that hold the Tropics between them never meet on common ground, $C$. guianensis making its home in the warm regions of the New World and on the tropical coasts of West Africa, and $C$. moluccensis ranging from the Zambesi eastward to distant Fiji. [There is no need to raise the question here whether C. moluccensis, Lam., is distinct from C. obovata, Bl., another Asiatic form, since the distribution is much the same, and the student of dispersal cannot distinguish between the seeds of the two forms (see Chall. Bot., IV., 290).]

Carapa guianensis is one of the features in the estuarine vegetation of the large rivers of Brazil, the Guianas, and Venezuela, and occupies a similar station in the adjacent West Indian island of Trinidad. Its occurrence in the Orinoco estuary accounts for the presence of so many of its seeds amongst the Orinoco drift on the south coast of Trinidad. The tree is abundant in the Lower Amazon, as at Para, and Spruce speaks of it as "met with all the way up the Amazon" (Botanist on the Amazon, etc., edited by Wallace, 1908, I., 480). I have not found, however, any reference to its occurrence 
on the Pacific side of tropical America, and in that respect the comparison with Rhizophora mangle is incomplete.

With the two species of Carapa that between them cover the tropics of the globe the writer is familiar, having studied the trees together with their fruits and seeds in Fiji and in Trinidad, and having gathered their seeds from the floating river-drift and the stranded beach-drift of various parts of the world, as on the south coast of Java, in the Keeling Islands, in Fiji, and in the West Indies. Though it does not seem that Treub found stranded Carapa seeds on the beaches of the devastated island of Krakatau, when he visited it in 1886, nearly three years after the great eruption, those of $C$. moluccensis were observed by Penzig in 1897; and when Ernst and other botanists examined this locality in 1906 they found Carapa trees established. The species was referred by them to $C$. obovata; but there can be little doubt that the trees grew from such stranded seeds as were previously observed by Penzig, the two forms not being distinguishable by their seeds (vide Treub and Penzig in Annales du jardin botanique de Buitenzorg, 1888 and 1902, and Ernst's Nerw Flora of Krakatau, 1908).

Carapa seeds were frequently noticed by me in the floating drift of the Rewa estuary in Fiji, and often in a germinating condition. They must form a feature in the drift of the estuary of the Orinoco, since many more drift seeds are piled up on the southern coasts of Trinidad than could have been derived from the trees in the coast districts of that island. We cannot doubt that they are equally abundant in the floating drift of the Amazon and of the rivers of the Guianas.

But the grave perils that threaten the floating and the stranded Carapa seeds lessen their effective value for oceanic dispersal. In the first place, there is the tendency to germinate when afloat in an estuary before the sea passage begins. Then there is the tendency to germinate prematurely after being stranded on the beach at the completion of a long sea traverse. This, I especially noticed, in the Keeling Islands, where after a drifting passage of at least 700 miles the seeds often sprouted on the beach, the protruding portions either falling a prey to the crabs or being withered up in the sun. Then there is the danger from the attack of boring molluses and other marine creatures during the ocean passage. This presented itself as a very real risk in the case of seeds of Carapa moluccensis that I found stranded in the Keeling Islands and on the south coast of West Java. Here the empty cavity was often occupied by the tubes of the Teredo. As a result of these repressive influences Carapa moluccensis seems never to have been able to establish itself on the Keeling Islands. Yet it may be remarked that the tendency to rapid germination on the part of a stranded seed, whilst usually leading to fatal results on an exposed sandy beach, would be a direct advantage on the muddy shores of a mangrove-fringed coast, where the germinating seed could at once strike into the mud in the shade of the trees.

With respect to the occurrence of the seeds of Carapa guianensis in the beach-drift of the West Indian region, the following remarks 
may be made. They were included in the drift collection made by Morris on the south coast of Jamaica (Chall. Bot., IV., 299), but nothing is said as to their condition. As the plant is not known from this island, the seeds were probably brought by the Equatorial Current in its passage across the Caribbean Sea. The seeds often came under my notice on the beaches of Trinidad, where the tree is at home. On the south coast very few of them were in a sound, fresh condition, many of them showing evidence of prolonged flotation in the sea in the incrusting shells of cirripedes and of other marine organisms, whilst others had been probably brought down by the Orinoco, since they were in a germinating but dried-up condition. On the north coast, as at Grande Riviere, they were more or less fresh, and had evidently been recently brought down by the river. They were frequent on the east coast of Tobago, often incrusted by cirripedes; but as far as I know the plant is not found in the island. In the Turks Islands they mostly came under my notice on the east side of Grand Turk, half of them being empty, whilst not more than one in ten possessed sound seeds.

Of the four West Indian localities above mentioned which displayed the fruits of Carapa guianensis in the beach-drift-namely, Jamaica, Trinidad, Tobago, and Turks Islands, only the second as far as I know owns the parent plant. But from the regular occurrence of the seeds in the drift of the Turks Islands, where the tree certainly does not grow, it may be inferred that the species is at home in the islands to the southward and eastward (San Domingo, Porto Rico, etc.), from which the drift seems to be largely derived. According to the writings of Grisebach, Hemsley, Spruce, and Schimper, the tree grows on the mainland at the coasts and in the estuaries of Central America, Venezuela, the Guianas, and Brazil.

The fact that Carapa guianensis also grows on the coast of Senegambia in West Africa raises the issue as to the seed's capacity of crossing the Atlantic in a germinable state. Although the seeds will evidently float for many months in the sea, from the indications above given it is doubtful whether they would retain their germinative powers for so long a period. The risks, as I have shown, are great and numerous. It is especially questionable whether the seeds would withstand a sea passage of more than two or three months, or, in other words, whether for the purpose of effective dispersal they are fit for much more than distribution by the currents over the islands of the Caribbean Sea. This would quite exclude the possibility of their being able to reach in a sound state the tropical coasts of West Africa from the New World by the Gulf Stream route, which even by the way of the Azores would occupy twelve months and more. But, as we have seen, Carapa is mainly an Old World genus, the New World being presumably the recipient rather than the distributor. In that event it is quite possible that the seeds could accomplish the much shorter ocean passage, occupying only three or four months, in the stream of the Main Equatorial Current from the Gulf of Guinea to the coast of Brazil, a subject discussed in Chapter III. The fact that seeds of Carapa moluccensis are often cast up in the fresh condition on the shores of Keeling 
Atoll, after a drifting voyage of at least 700 miles and a passage that would require at least seven or eight weeks, renders this route across the Atlantic possible for the seeds of Carapa guianensis.

\section{Mammea americana, L.}

This well-known West Indian tree belongs to a small genus which has a remarkable discontinuous distribution. It holds six known species, of which three are tropical American and three are peculiar to Madagascar (Index Kewensis). In belonging to a genus of this description Mammea americana resembles several other trees that are referred to in this work in connection with drift. These discontinuous tropical genera have a great importance.

According to Grisebach and Urban this tree, which is confined to the New World, ranges from Cuba and Jamaica to Brazil, and is widely distributed in the greater and smaller West Indian Islands. It grows in the lower mountain forests of Jamaica, the locality where I made its acquaintance, and it is as a West Indian forest tree that it finds its natural station (see also Harshberger's work, p. 688, concerning its station in the islands of St. Thomas and St. John).

The large russet-coloured drupes, four to six inches across, contain usually two or three large "stones," each consisting of a fibroligneous endocarp encasing the seed. Inside the tough skin of the fruit is a firm fleshy pulp. The fresh "stones" have no buoyancy; but since the pericarp is buoyant, it is probable that the fruit would float at first, though not for long, as the soft coverings would soon decay. The "stones" evidently acquire their floating power when drying on the ground after being freed from the fruit, the buoyancy being due partly to the dried endocarp and partly to the unfilled space arising from the shrinking of the seed. Though edible in a general sense for man, the fruits are more appreciated by animals. In Jamaica, according to Sloane, wild swine feed upon them. When dried after removal from the fruit the "stones" have a rough, pitted exterior; but as they occur in the beach-drift, after undergoing the wear-and-tear of sea transport, their surface is usually smooth and marked by interlacing fibres which give them a peculiar appearance. In this condition the "stones" are generally two and a half to three inches long and ovoid in shape.

I found the "stones" in the beach-drift on the north coast of Jamaica (as at St. Anne's), on the south-east coast of Tobago, on the south coast of Trinidad, and on the Turks Islands. In the group of islands last named they form a regular constituent of the beach-drift, and came under my notice wherever the drift had collected in any quantity, as on Grand Turk, Cotton Cay, Salt Cay, and Greater Sand Cay; but I rarely observed more than two or three on each beach. In all the four West Indian localities above mentioned, the "stones" of the beach-drift gave little promise of being effective agents in the dispersal of the species by currents. Usually in half the cases the seed had decayed away; whilst in the rest, though the seed appeared sound, its hard consistence and deadlooking aspect on section did not indicate the retention of the germin- 
ative capacity. It is thus evident that the tree possesses but little fitness for effective trans-oceanic dispersal by currents; and it may be inferred that if the fruits, in the shape of the "stones," ever reached the shores of Europe, which is unlikely, they would either be empty or would contain decaying seeds.

But we may go further and observe that it is more than doubtful whether the agency of the currents could be appealed to for an explanation of the distribution of this tree over a large part of the tropies of the New World. The reason of its representation in the drift is probably to be found in its station on the forested slopes of river valleys, from which the bared "stones" of the fruits could be swept down into the rivers during torrential rains. If at times they are carried by the sea currents in a sound state from one island to another, the coast would offer a most unsuitable station for the establishment of a typical tree of the inland forests. It is possible that man has aided in its dispersal, since the edible fruit is appreciated by natives; but the main factor is, I think, to be looked for in the past, when the area of its distribution had not been broken up in the great changes which have resulted in the detachment of the large West Indian islands from the South American mainland, a matter referred to on other pages of this work.

In his account of the Cayman Islands, Mr. Savage English (Kero Bulletin, 1913) tells us that the fruits of this tree are occasionally thrown up on Grand Cayman " in a more or less eatable condition "; and he thinks that the tree may ultimately be introduced by the currents. However, it is already included in the flora of the Cayman Islands (Urban, Symboloe Antillance, IV., 412); and if brought from a distance the drift fruits in question doubtless came from the neighbouring shores of Cuba and Jamaica.

\section{Gourds and Calabashes of the genus Crescentia}

In my work on Plant Dispersal (p. 570) it is observed that gourds and calabashes of Cucurbitaceous plants are frequently brought down to the sea in tropical regions and are thus likely to be dispersed by the currents. Floating in the estuaries and stranded on the beaches, the gourds of a Cucurbita came often under my notice in Fiji; and their suitability for dispersing the species was established in one case, where seeds from a fruit that had been floating for at least two months in sea-water germinated in a few days.

Gourds, usually small in size, were frequently observed by the writer afloat in the drift of the estuary of the Guayas in Ecuador, as well as stranded on the neighbouring beaches. Some of them were cucurbitaceous; but others were the wild fruits of Crescentia cujete, the Calabash tree, which belongs to quite a different family, the Bignoniacece. It was not until some years afterwards that he recognised these Crescentia fruits amongst his Ecuadorian driftcollections, having in the interval become acquainted with the tree in the West Indies. However, although the writer was not aware of it, they had long before been identified as gourds of Crescentia 
cujete in a collection of Ecuadorian drift fruits and seeds which he had sent on his return to England to the Kew Museum.

Gourds of sorts have long been known to be thrown up on the coasts of Europe. They are usually referred to as belonging to Lagenaria vulgaris (Cucurbita lagenaria), the calabash gourd of the Old World, and were long ago familiar to Scandinavian naturalists amongst the foreign drift cast up on their shores. Sernander deals with this subject on p. 119 of his work on the Distribution-Biology of the Scandinavian Plant-World (Upsala, 1901), and Hemsley refers to it in his Report on the Botany of the Challenger Expedition (IV., 277). These gourds of the Norwegian beach-drift were first described by Tonning, a pupil of Linnæus. Found by Ström and Gunnerus in the eighteenth century and by Lindman in recent times, they have been in all cases referred to Lagenaria vulgaris. According to Sernander, the gourds stranded on Scandinavian beaches are usually "worked" calabashes; but he alludes to one that was not carved in this fashion, which contained several seeds.

It is highly probable, however, that some of the gourds and calabashes recorded from the Scandinavian beach-drift were fruits of Crescentia cujete which had been brought in the Gulf Stream drift from the West Indies. By all the authors they are placed amongst the Gulf Stream materials heaped up on those coasts and associated with tropical seeds, such as those of Entada scandens and Mucuna urens, which are recognised as commonly brought by the currents to the Scandinavian shores from the West Indies. It will be shown below that gourds and calabashes of the genus Crescentia are very typical of West Indian beach-drift. The reason why their real character has been overlooked in the case of those found in European beach-drift may be found in the circumstance that unless one is familiar with the fruits in their homes, it is necessary to break open the gourd to identify the genus, and the discoverer of such a stranded fruit on a beach in Europe would probably be loth to spoil his specimen.

Crescentia includes five species all confined to the tropical regions of the New World. The most familiar species is $C$. cujete, the Calabash tree, which is distributed over the West Indies, and on the American mainland from Mexico to Brazil. One would be inclined to think that man in the past must have assisted in its distribution, since its gourds are extensively employed as water vessels; but it is noteworthy that another species, $C$. cucurbitina, L., which is referred to below, has a range almost as wide, notwithstanding that its fruits seem to be of little use to man. The Calabash tree thrives in Bermuda with all the appearance of being indigenous; but Rein had grounds for suspecting that it had been introduced, and accordingly Hemsley does not include it in the indigenous Bermudian flora (Chall. Bot., II., 9, 55). The gourds of this tree are those most usually found in West Indian beach-drift. However, another species of Crescentia, C. cucurbitina, as above named, is not infrequently represented in the drift of this region. The tree, according to Grisebach, is distributed over the West Indies from Cuba and Jamaica to Trinidad, and reaches the Spanish Main in Venezuela. Urban, who employs 
for this species the synonym, Enallagma cucurbitina (Baill.), adds Panama to the list of localities (Symb. Antill., IV., 567).

Gourds of Crescentia, more especially of $C$. cujete and C. cucurbitina, characterised the beach-drift examined by me in Jamaica, Turks Islands, and Trinidad. These three localities are sufficiently removed from each other to justify the inference that Crescentia gourds are generally characteristic of West Indian beach-drift. Numbers of fruits both from the living plant and from the drift were examined by me, and all of them belonged to this genus; and the implication arises that the gourds and calabashes carried by the currents from the New World to the shores of Europe would be fruits of Crescentia. The mode in which these fruits get within the influence of the currents is well illustrated in the Black River district of Jamaica. Both the trees named grow there at the riverside above the mangrove formation. Their fruits form regular constituents of the floating drift, and are carried down to the sea in numbers, many of them being subsequently cast up on the beaches in the vicinity of the estuary.

The next matter to be dealt with concerns the station of these two species of Crescentia. The Calabash tree, C. cujete, occurs both wild and cultivated in Jamaica; but the natives distinguish the wild trees at a glance by their smaller fruits and by other characters. Grisebach supplies no station for the species; but Hemsley after giving its general distribution states that it grows commonly in swampy and marshy places (Chall. Bot., II., 55). It was in such stations that I usually found the wild tree in Jamaica; but it also grows there in the open woods of the lower levels. It came under my notice most typically as a tree of the interior of the Great Morass of the Black River district in this island, where it is associated at the riverside amongst other trees with Grias cauliflora (Anchovy Pear tree). Both Grias cauliflora and the Calabash tree, in bearing flowers and fruits on their trunks, exhibit the same feature of "cauliflory." Sloane, writing of the Calabash tree in Jamaica near the close of the seventeenth century, says that "it grows everywhere in the Savannas and woods of Jamaica and the Caribes" (II., 173); but he makes no reference to its being cultivated. Urban, speaking of its general station in the West Indies, states that it grows in woods and is also cultivated (Symb. Ant., IV., 567). That the tree can thrive in dry stations is illustrated in the Virgin Islands, where it is associated with Cactacea and other xerophilous plants (Harshberger's Phytogeog. N. Amer., p. 687).

Crescentia cujete is readily propagated from shoots; and it is on its powers of vegetative reproduction that the Jamaican cultivator seems to rely, the seeds according to common report being useless for the purpose. The fleeting vitality of the seeds is pointed out below. Crescentia cucurbitina, the other species represented in West Indian beach and river drift, is the "Paki" of the Jamaican. It was observed by me as a tall tree growing on the banks of the Black River above the mangroves, and also in wet ground near the coast below the Roaring River Falls on the north side of the island. Grisebach gives its station in Jamaica as the dry rocky coast. This is rather puzzling, since it is essentially a tree that favours moist 
localities. Urban, alluding to its station in the West Indies (Ibid., IV., 567), states that it grows in marshy places, both inland and at the coast.

The suitability of the fruits of these two trees for dispersal by currents was especially studied during a sojourn at Black River in Jamaica. That they could be thus transported across wide tracts of sea soon became evident, and the point to be determined was whether after being stranded on some distant shore they were likely to contain germinable seeds.

The fresh gourd of Crescentia cujete is filled with a white spongy pulp containing numerous seeds. After detachment of the fruit the pulp soon begins to soften and blacken; and a process almost of liquefaction sets in, which seems usually to involve the vitality of the embryos of the inclosed seeds, unless conditions favouring rapid germination intervene. As the fruit dries on the ground, its contents ultimately dry up, and all that represents the original white pulp and its seeds is a loose, rounded, blackened mass, about one and a half inches across, in which the seeds may be observed either empty or with embryos evidently dead, if not actually decaying. This is the condition in which the fruits of the Calabash tree generally are found in the Jamaican beach-drift, and anything less likely to assist dispersal by currents, as far as the propagation of the species is concerned, could scarcely be imagined. In these gourds of the shore-drift, when the embryos of the seeds have not disappeared, they are usually blackened, friable, and dead; whilst only in a few cases are there any signs of vitality; and even then the discoloured appearance and general condition give but little promise of any capacity for germination.

The gourds of Crescentia cujete, as found in the beach-drift of the Black River district, were generally small, three to four inches across, globose, much weathered by exposure, and in half of them the shell was cracked. They were evidently derived from the trees growing wild in the Great Morass by the riverside, and had been washed up on the beaches after having been carried down to the sea. They came under my notice on the beaches near the mouths of rivers in other parts of Jamaica, as near the White River on the north coast. On the beaches of the Black River district they were four times as frequent as those of the Paki tree (C. cucurbitina). Their shells also are thicker $(2 \mathrm{~mm}$. as against $1 \mathrm{~mm}$.), and the fruits generally seem better fitted for withstanding the buffeting involved in sea transport.

The fresh gourds of Crescentia cujete float in water, and in this state they are not uncommon in the floating drift of the Black River; but their buoyancy is principally due to the spongy air-bearing pulp and to the impermeability of the shell, the specific gravity of the last being near that of fresh-water. The fruit acquires increased buoyancy after the pulpy contents have broken down and dried up into a small rounded mass, leaving the greater portion of its cavity empty, such being its condition in the beach-drift. The fresh moist seeds, 9 or $10 \mathrm{~mm}$. long, have an initial buoyancy, a capacity which they owe entirely to the fact that the embryo but loosely fills the cavity within its horny coverings. When dry they at the 
most float for only a day or two. Under any circumstances, however, the seed with its transient vitality, is quite negligible as an independent agent in current-dispersal.

The fruit of the Paki (C. cucurbitina), which displays on its surface numerous pin-point pits, is ovoid or oblong, three to four inches long, with a blunt terminal point, its cavity being filled with a white, spongy pulp containing numerous non-buoyant seeds, 16 or $17 \mathrm{~mm}$. across, and thus much larger than those of the Calabash tree (C. cujete). The seed contains a reddish embryo within a loose, white, membranous, sac-like covering; but as compared with the seeds of the Calabash tree those of the Paki are poorly protected, shrink greatly on drying, and are still more perishable in their nature. The fresh fruit floats, and was not uncommon in the drift of the Black River. As with the gourd of the Calabash tree its buoyancy is due to the air-bearing pulp and to the waterproof shell. Here also the pulp of the mature fruit soon undergoes a softening and blackening process; and here again the pulp and seeds ultimately dry up and cake into a loose, blackened, rounded mass occupying but little space in the fruit cavity, the seeds being dead and their embryos blackened and often friable. The Paki gourds thus appear to be even less fitted for the distribution of the tree through the agency of the currents than those of the other species. But apart from the condition of the seeds the gourd itself is less able to withstand the "wear-and-tear" of oceanic dispersal, since the shell is thinner $(1 \mathrm{~mm}$.) and more brittle than that of the fruit of the Calabash tree. The fruits are also less frequent in the beach-drift of the Black River coast than those of $C$. cujete. Their form, their pin-hole pits, and their blunt terminal point, as well as their large seeds, readily distinguish them from the other gourds in the drift. They are described by Miers in the Transactions of the Linnean Society, Vol. XXVI., 1870.

In the Turks Islands I found these two gourds to be regular constituents of the larger foreign drift of the beaches, as on Grand Turk, Cotton Cay, Greater Sand Cay, etc. Those of the Calabash tree were rather more frequent than those of $C$. cucurbitina in the proportion of three to two. Most of the former were the smaller fruits of the wild tree; but I also found one or two large calabashes six or seven inches across, doubtless the fruit of the cultivated tree. With both species the stranded gourds were much weathered and often cracked; and all that were examined contained the usual dried-up, blackened, loose mass of pulp and dead seeds. A good proportion, however, had entire shells (perhaps half of them), and could have continued their ocean traverse.

Since the plants do not grow in the Turks Islands, which derive their foreign beach-drift from the islands to the southward and eastward, we have here the completion of the first stage in crossing the Atlantic. It is highly probable that some of these floating gourds, more especially those of $\boldsymbol{C}$. cujete, are included at times amongst the West Indian drift stranded on the shores of Europe. But their seeds would be always dead; and it could be only in local distribution, as in inter-island dispersal, that currents could aid in the spread of the species. The occasional presence of a solitary 
wild specimen of the Calabash tree amongst the vegetation bordering the beaches on the Black River coast may be thus explained, the parent gourd having been brought down by the river. My Jamaican companions at once recognised them as wild, self-sown trees.

\section{Andira Inermis, Kth. (Angeleen tree)}

This tree belongs to a genus of the Leguminosa, comprising about twenty species, all of which are confined to the tropical regions of the New World, with the exception of this species, which, according to Grisebach, Oliver, and others, also occurs in Senegambia on the West Coast of Africa. We learn from Grisebach that the Angeleen tree is distributed over the greater part of the West Indies from Cuba and Jamaica to Trinidad, and that it extends from Mexico along the Spanish Main to Guiana.

Generally speaking it is a tree of the lower forests, but with a decided inclination, determined by the buoyancy of its fruits, to gather at the riverside. This preference for a station along the river banks is remarked by Grisebach for the tree in Jamaica; and it was in such localities that I observed it in that island. The places in which it was more particularly studied by me in Jamaica were along the banks of the Black River above the mangroves, extending to the foothills of the central range, and in the hilly country at the back of St. Anne's. Its station by the riverside is the only fact connected with its range that can be brought into relation with its occurrence on the West Coast of Africa; but this does not carry us very far. Although the river could bring the fruits within the influence of the ocean currents, there seems to be but little chance of their ever being stranded on the African coast with their seeds in a germinable condition. Since the genus is American, the New World must have supplied the opposite coast of Africa with this American tree; and that could only happen now along the circuitous Gulf Stream route. That a pod stranded on the eastern shores of the Atlantic could contain a germinable seed, will appear from the following discussion to be most improbable.

The fruit is a leguminous, indehiscent, one-seeded pod, about one and a half inches long, ovoid-globose in form, with (in the dry state) a loosetextured, fibro-ligneous husk 2.5 to $3 \mathrm{~mm}$. thick. In the fresh condition, when it is moist and semi-fleshy, it has but little buoyancy, either sinking at once or floating only for a day or two; and thus the pods form no feature in the Black River drift, though the tree commonly grows on the banks with its branches overhanging the stream. In the dry state they are evidently much more buoyant; but the indications of my observations are that except in interisland dispersal in the West Indian region the fruits would rarely contain a germinable seed when distributed by the currents. The stranded pods did not come under my notice in the Jamaican beachdrift; but I gathered them in small numbers from amongst the foreign drift thrown up on the beaches of different islands of the Turks Group. Such drift fruits sometimes contained a seed; but it was hard, discoloured, and evidently unfit for germination. Since the 
seed had no buoyancy, the pod must have owed its floating power to the light, loose-textured husk. There is little to show that the dry fruit would remain watertight for any length of time when immersed in sea-water. The only protection the seed itself possesses against the influence of sea-water is a thin permeable skin; and I think that the death of the seed of the floating fruit would soon be brought about through this cause. The pods probably reached the Turks Islands after a week or two's drift from the neighbouring coasts of San Domingo.

For the reasons just given it would seem futile to look to the currents for the explanation of the existence of this tree on both sides of the tropical Atlantic. We have seen that since the West African region must have borrowed this species from the New World, we are debarred from appealing to the agency of the Equatorial Current in transporting seeds and fruits from the Gulf of Guinea to the American continent. There remain only the possibilities of its reaching West Africa by the westward extension of the Guinea Current or with the Gulf Stream drift after it has crossed the North Atlantic. As shown in Chapter III., the first route receives but scant support from the evidence of bottle-drift, and the time required (at least six months) would negative its practicability for the effective dispersal of this tree. The objections would be still greater if we appealed to the second route, which would involve an ocean passage of about two years. In addition it is most unlikely, if plants like Sacoglottis amazonica and Hippomane mancinella, which are so much better fitted for the Atlantic traverse, have failed to get away from America, that a plant with the limited fitness for dispersal by currents possessed by Andira inermis should be able to do so.

Thus the currents fail to account for the occurrence of this tree on the coast of West Africa. But it is just possible that the light, empty pod might occur at times amongst European beach-drift, as it would probably continue to float long after it had ceased to be watertight. The great difficulty lies with the ill-protected seed. Under natural circumstances its germinative capacity would soon be lost, since the thin coats offer no protection against excessive shrinkage, and it would seem likely that ordinary air-drying would soon deprive it of vitality.

Birds also fail us, since only a fruit-pigeon could carry such a large fruit, and that would only be possible between neighbouring islands or between adjacent insular and continental coasts. The difficulties here raised resemble in some points those presented in the case of the fruits of Chrysobalanus icaco, a plant also found on both sides of the tropical Atlantic (see p. 193). But there is this important difference in station. With the species of Chrysobalanus the tree.is essentially littoral, and thus the currents when carrying the fruits to a distant coast would be bearing them to a suitable station. With Andira inermis, however, the stranded fruits would lie in most uncongenial conditions, conditions very different from those which the tree favours in inland districts, as in the humid forests of Porto Rico (Harshberger, pp. 685, 688) or by the riverside in Jamaica. 


\section{Cassta fistula, L., and Cassia grandis, L.}

The pods of these two trees, which are often two feet long in the entire state, are characteristic of the foreign drift on the beaches of the Turks Islands, though in a fragmentary condition. I found them on the beaches of all the larger cays, such as Grand Turk, Cotton Cay, Salt Cay, and Greater Sand Cay. Portions of the same two fruits also came under my notice amongst the beach-drift of Trinidad and Tobago. The association of the pods of these two trees in the beach-drift of the West Indian region in localities so far removed from each other is worthy of remark. Those of Cassia fistula were also recorded by Morris from the stranded drift in Jamaica (Chall. Bot., IV., 301). We must therefore regard these singular fruits as regular constituents of West Indian beach-drift. Their occurrence in this connection on the Turks Islands is specially interesting, since the trees do not grow in those islands, and the pods could only have been brought by the currents from the large islands to the southward and eastward. On these beaches the pods of Cassia grandis are more frequent than those of $\boldsymbol{C}$. fistula.

Since Nature associates these two trees in the drift, we will deal with them together. Cassia grandis is indigenous in tropical America and in the larger West Indian islands (Grisebach). It is one of the several species of the genus that represent the remains of the original Antillean flora of the great Caribbean land-mass now in large part beneath the sea (Harshberger, Phytogr. N. Amer., p. 307). But Cassia fistula is usually regarded as introduced to America from its home in the Old World, although the matter is still one for discussion. However, from the facts given by Sloane, to be subsequently noticed, there seems little room for doubt that with Cassia fistula in the West Indies we are concerned with an introduced tree. De Candolle held with Sloane that it was brought by the Spaniards to America (Geogr. Bot., p. 772); and both Bentham and Grisebach regarded it as naturalised in the tropics of the New World. A good deal of interest attaches itself to this point, since the pods of Cassia fistula are amongst those found on the coasts of Europe with other West Indian drift.

But before proceeding further in this discussion I will refer to the condition of the fruits of these two trees as presented on the Turks Islands beaches. The seeds, it should be remarked, have no buoyancy, being transported in the compartments of the buoyant pod; but the long fruits break up in time in the floating drift, and though sea-water then penetrates some of the compartments, the fragments still float, being kept up by the air confined in the other chambers and by the buoyancy of the tissues forming the fruit. It is in this fragmentary state that these pods usually occur in the Turks Islands beach-drift, and also in that of other West Indian islands, the portions varying from four to ten inches in length and being as a rule much "weathered." The smooth pods of Cassia fistula are, however, much better fitted for ocean transport than those of $\boldsymbol{C}$. grandis, which have a rougher exterior and possess two lateral ribs that are very apt to be torn away in the drift, thus exposing the seed-chambers along more or 
less of the fruit's length. Yet most of the seeds are too large to fall out of the pod at first; but the waves would soon complete the process of destruction, and the floating pod, with long rents in its sides, would probably not survive more than a month or two's buffeting in the currents. Only the pods of $C$. fistula would be able to withstand the "wear-and-tear" involved in the passage across the Atlantic to the shores of Europe. It is, therefore, at first sight not surprising that they alone have been found stranded on European beaches.

But before dealing with this matter, I will refer to the condition of the seeds in the fruits thrown up on the beaches of the Turks Islands, which represent the end of an early stage in the transatlantic voyage. Most of the seeds of these two species of Cassia are impermeable to water, and they would withstand for a long time the effects of the penetration of sea-water into the floating fruit, which takes place sooner or later when the long pods, as generally happens, break in two. Those that are permeable would quickly swell up and lose their germinative capacities; whilst in time a number of the impermeable seeds would be also unable to retain their impervious character under the warm, moist conditions of the drift in tropical seas, and they, too, would swell up and become useless for propagating purposes. But a good proportion of the seeds would be able for long periods to resist the penetration of sea-water, and transported in the floating fragments of the pod they would retain their sound state when stranded on some distant coast. Of the seeds found in the fragments of the pods of $C$. fistula and $C$. grandis on the beaches of the Turks Islands, between 20 and 40 per cent. were generally hard, entire, and quite sound on section; the rest had lost their germinative powers, having swelled up after the sea-water had penetrated the drifting fruit.

The fragments of the pods of these two trees that are stranded on the Turks Islands could at the most have only drifted a few hundred miles, and seeing that more than half of their seeds have been killed by the penetration of sea-water, it seems unlikely that many sound seeds would be found in the pods of Cassia fistula that have been picked up on European beaches. I am assuming here that such fruits hail from the New World, which at first appears reasonable, since they are associated in the European beach-drift with seeds of Entada, Guilandina, Mucuna, etc., that undoubtedly come from the American side of the Atlantic.

It would seem, however, that the records of the stranding of the fruits of $C$. fistula on the European side are not numerous. According to Sernander (p. 117) they were found on the Norwegian coasts by Ström and Gunnerus, who flourished about the middle of the eighteenth century. Lindman in recent years has confirmed the identification of the species (Sernander, Ibid.). In this matter Hemsley (Chall. Bot., IV., 277) quotes Tonning, a pupil of Linnæus, through whom the observations of Ström and Gunnerus, as Sernander points out (p. 116), are usually known in the scientific world. Nothing, however, is said by Sernander as to the condition of the pods and of the seeds when gathered on the Scandinavian beaches. 
Much depends on these points, since fruits that were entire and showed but little signs of long exposure to the sea could scarcely have accomplished the passage from the New World.

It is interesting to note the fact referred to by Hemsley (Chall. Bot., IV., 278, 301) that Martins raised plants from seeds of Cassia fistula cast ashore in the pod at Montpellier in the south of France. Hemsley cites this case as one of the instances where plants have been raised in Europe from seeds that have traversed the Atlantic. On this view the pod must have been carried through the Straits of Gibraltar into the Mediterranean after its ocean traverse. Here, again, much would depend on the condition of the stranded fruit when determining its probable source. It would seem safer, indeed, to look for a source much nearer home than the American side of the Atlantic; for instance, in Egypt, where the tree has long been widely spread, since such pods might have been brought down to the sea in the Nile drift. At all events, the observations of Martins at Montpellier and of myself in the Turks Islands indicate that the pods of Cassia fistula can carry sound seeds across considerable tracts of sea; but the data at my disposal, whilst indicating the possibility that the pods can be transported from the New World to the shores of Europe by the currents, leave the question as to the condition of the seeds unanswered. There is a lack of information concerning the actual facts recorded, and for this reason a suspension of judgment may be necessary.

It should be remarked that whilst the pods of Cassia fistula are characteristic of West Indian beach-drift, there seems to be but little mention of their occurrence in the drift of tropical beaches in the Old World. Let us take, for instance, the Indian Archipelago in its most comprehensive sense as including the whole region between south-eastern Asia and Australia. This region is regarded as one of the principal homes of the tree, and yet its fruits seem rarely to have attracted the notice of observers of the drift. Thus they are not named in Gaudichaud's description of the drift of the Molucca Sea as quoted by Hemsley (Chall. Bot., IV., 279). Schimper does not mention them in his account of the drift of the Java Sea and of the coasts of Java (p. 160). In my own paper on the drift of Keeling Atoll and of the south coast of Java no reference is made to them; and the same remark applies to the writings of Treub, Penzig, and Ernst on the new Krakatau vegetation, and to Moseley's account of the drift observed by the Challenger Expedition off the coast of New Guinea, as given by Hemsley (Ibid., IV., 285). It is possible that such fruits may have been at times regarded in the same light as the empty mango stones so frequent in tropical beach-drift, but this seems hardly likely.

The divergence in opinion relating to the claim of Cassia fistula to be ranked as an indigenous American tree is illustrated by Hemsley. Whilst in one place he includes it amongst those plants certainly or probably dispersed by currents, in another place, when dealing with Jamaican beach-drift, he writes that it doubtless owes its present wide area to man rather than to any other agency (Chall. Bot., I., 43; IV., 301). It is odd that its pods are a feature of tropical beach-drift 
in the New World rather than in the Old World; and it would almost seem that Nature in the form of the Gulf Stream drift, stranded on the shores of Europe, makes a silent protest against our viewing this tree as a stranger in America.

There is, however, a way out of the difficulty. It is possible that Cassia fistula may have been the gift of Africa to America through the agency either of the Main or of the North Equatorial Current before the discovery of the New World, but in the earlier period of the European colonisation of West Africa. In the first case the floating pods could have been transported in two or three months from the Gulf of Guinea to Brazil, and no doubt many of the seeds would still be sound. In the second case, where the agency of the North Equatorial Current is appealed to, the floating pods could have been carried in six or seven months from the vicinity of the Cape Verde Islands to one of the Lesser Antilles, and perhaps a few of their seeds would still be germinable. The intervention of the aborigines of the New World would be required; but one can imagine that the discovery of such a singular fruit on the beach might tempt one of the more curious among the natives to plant its seeds. The tree must have been long established on the West Coast of Africa and on the Cape Verde Group. In those two localities in the middle of last century it was beginning to grow wild (Schmidt's Cap Verdische Flora, 1852).

Though it is feasible that Cassia fistula may have been introduced into South America by the currents, assisted, as just suggested, by the subsequent intervention of the aborigines, it can hardly be doubted that the early Spaniards were the agents in establishing it in the West Indies. Sloane in his book on Jamaica (II., 42) quotes Martyr to the effect that it was planted in Hispaniola, Cuba, and Jamaica by the Spaniards. Sloane was writing of his experiences in the latter part of the seventeenth century, when, as he indicates, there was a trade to Europe from the New World in the fruits of this tree, the Brazilian fruits being regarded as superior to those from Egypt. In 1688-9, during his sojourn in Jamaica, the tree was frequently to be met with around houses and on the sites of plantations during the Spanish time. He takes the similar history of the Tamarind (Tamarindus indica), which, having been first planted at Acapulco by the Spaniards, was in his time widely spread over the West Indies. The case of the Tamarind appears to be decisive in this matter.

\section{Calophyllum calaba, Jacq.}

This West Indian and South American tree, with which I made my first acquaintance in the forests of Mount Diavolo in Jamaica, calls for only a few remarks. It contributes scantily to West Indian beach-drift; but it cannot be compared, either in its station or in the buoyancy of its fruits, with Calophyllum inophyllum, the well-known current-dispersed tree of the coral atoll and of the coral-girt shores of the Pacific.

Calophyllum calaba, the familiar Santa Maria tree of the West Indies, is a conspicuous feature of the wet forests of Jamaica and 
Cuba. It would only be found near the beach when forested hillslopes descend directly to the coast. In Jamaica it is certainly not a littoral tree, and this is also the view of Grisebach. However, Descourtilz, as quoted by Hemsley (Chall. Bot., IV., 298), and Schimper (Ind. Mal. Strand Flora, pp. 108, 182) speak of it as a West Indian strand tree.

I found a few of the small globular fruits amongst the beach-drift of the north and south shores of Jamaica, some of them empty and some of them bearing sound seeds. Fruits with sound seeds were picked up by Morris on the south coast of the island (Hemsley, Ibid.). The manner in which its buoyant fruits could reach the sea is indicated in the station of the tree on the banks of a branch of the Spanish River in the mountain forest zone of eastern Jamaica (Forrest Shreve in Harshberger's Phytogr. N. Amer., p. 679). I collected a few of the fruits amongst the foreign drift of the beaches of the Turks Islands, but they were either empty or contained a greatly shrunken dead seed.

If this was a typical strand tree in the West Indies, with its fruits dispersed far and wide by the currents, we should expect it to play the part taken by Calophyllum inophyllum in the Pacific, as above referred to. We should expect to see it establishing itself on the sandy islets thrown up in coral-reef regions, as on the Florida sandkeys, and to find it included amongst the indigenous flora of a group like the Bermudas. Dr. Millspaugh does not mention it in the case of the Florida keys so systematically examined by Mr. Lansing; whilst it is admitted to be an introduced plant in the Bermudas, and apparently it belongs also to the foreign plants of the Bahamas (Chall. Bot., II., 21; IV., 298).

Hemsley regards it as dispersed by the currents (Ibid., I., 42); and this is the opinion also of Schimper, who couples $C$. inophyllum and C. calaba together as possessing a well-developed floating apparatus in the shell of the fruit (p. 182). But whilst Nature has emphatically demonstrated that the first is dispersed by currents far and wide over the insular and continental coasts of the Indian and Pacific Oceans, she gives no consistent indications of the same kind for the second. In Jamaica and Cuba, C. calaba is essentially a tree of the inland forests, and its fruits make a very poor show in the beachdrift. Although it is possible that the currents might carry the sound fruits to a distant shore, it is scarcely likely that a tree accustomed to the humid conditions of an inland forest would be able to establish itself on a beach. However, the germinative capacity of the seeds appeared to be soon lost; and in an experiment on the buoyancy of the dry fruits I found that whilst they all floated for two or three weeks, those that floated for a longer period had rotting seeds. I would imagine that, as compared with the Pacific species, the fruitshell is more pervious to water in prolonged flotation.

\section{Sapindus Saponaria, L. (Soap-berry)}

This is an American tree usually described as confined to Florida, the West Indies, and Venezuela. A specimen obtained by Forster 
from Easter Island about $\mathbf{1 7 7 3}$ was regarded by Seemann in his Flora Vitiensis (p. 47) as belonging to this species; and there would seem to be some reason for believing that the species is indigenous in the Marquesan and Tahitian Groups, in the floras of which it is included by Drake del Castillo in his work on those islands. Both Hawaii and Fiji have each a peculiar species; but I would refer the reader to my book on Plant Dispersal (pp. 325, 332) for an account of the difficulties connected with the distribution of the genus, and to Hemsley's remarks in the Botany of the Challenger Expedition (IV., 304) for an authoritative discussion of this point. If, as Hemsley observes, there are two or three Asiatic species closely allied to Sapindus saponaria, it may be that we are here concerned with one variable plant that ranges through the warm latitudes of the globe. In any case we are here dealing with a plant that is well worth studying from the standpoint of dispersal.

Although, as stated below, the seeds of Sapindus saponaria have been found in the stranded drift of Jamaica, the Turks Islands, the Bermudas, and the Azores, it does not seem to be a littoral tree in the ordinary sense. Schimper (Ind. Mal. Strand Flora, p. 111) remarks that it ought to be a strand plant in the New World; but Grisebach gives no particulars as to its station, and I did not observe it amongst the shore vegetation in Jamaica. Writing of the tree in Jamaica, Sloane observes (II., 132) that it grew in his time in all the "lowland or Savanna woods" of the island. It is, indeed, a tree of the open woods; and this is also the station assigned to it by Millspaugh in the case of the island of Cozumel, off the coast of Yucatan (Plantee Utorwance). From such a station its seeds would at times get into river-drift and be carried to the sea. In those seemingly rare localities, where as an intruder from the inland districts the Soapberry tree grows by the beach, the dispersal of its buoyant seeds by currents would be facilitated. This would be the case in Florida, where, as Prof. Harshberger tells me, the plant grows on the sandy beaches of the peninsula.

An interesting record of the occurrence of the seeds of this tree in beach-drift is that described by Hemsley, on the authority of J. M. Jones, in the case of the Bermudas (Chall. Bot., II., 27; IV., 304). The plant is rare in those islands, having been first raised from seed washed up on the southern shores in 1841. It must thus be viewed only as a recent addition to the Bermudian flora; but the important point is that the seed preserved its germinative powers after a period of flotation in the sea that must have covered several weeks, if not months, though man's aid was necessary to secure the establishment of the species. A few seeds came under my notice amongst the drift stranded at Paroti Point on the south coast of Jamaica. Though the tree is common in the island, this was the only locality in which I found the seeds in the beach-drift. The seeds examined had sound kernels and floated in sea-water. I picked up two others amongst the stranded drift on Greater Sand Cay, the southernmost island of the Turks Group; but they were afterwards mislaid, so that their soundness was not tested. Though occurring in scanty numbers, the seeds of Sapindus saponaria may, I think, be claimed as one of 
the normal constituents of West Indian beach-drift. I found no reference to their occurrence in European beach-drift; but, as stated below, they came under my notice amongst the foreign drift of the Azores.

The modes of dispersal now merit our attention. Although the fleshy pericarp of the fruits might attract birds, the seeds in their hard shells being apparently well able to withstand transport in a pigeon's crop without injury, there is no evidence at my disposal that frugivorous birds distribute the seeds. On the other hand, the indications of West Indian beach-drift and the stranding of the seeds in a germinable condition on the shores of Bermuda point unmistakably to the agency of the currents. Hemsley's view that the seeds are dispersed by the currents (Chall. Bot., I., 43, 48; II., 27; IV., 304) is thus well founded, and the behaviour of the seeds under experiment in part confirms his opinion.

The seeds are black, round, 10 or $11 \mathrm{~mm}$. in diameter, and have a hard, impervious shell about $1 \mathrm{~mm}$. thick. The buoyancy is of the type characteristic of convolvulaceous seeds, neither the shell nor the kernel possessing any floating power of themselves, the buoyancy arising from the fact that the kernel incompletely fills the seed-cavity. When, however, the cavity is entirely occupied, the seed sinks. Thus it happened that in my experiments in Jamaica about half of the seeds sank at once in sea-water, and about threefourths of them sank in fresh-water. Of those that floated in seawater about half floated after a month's immersion, and 20 or $\mathbf{2 5}$ per cent. after six to seven weeks, some of the last being sound, whilst in others it was evident that water was beginning to penetrate the coverings. The weak spot in the hard shell is in the "scar," the umbilical aperture previously closed tending to become patent after prolonged immersion. Water finds its way slowly into the interior, the hard shell softens so that it can be readily cut with a knife, the kernel decays, and the seed sinks. When several seeds are kept in the same vessel the water has to be changed frequently, as the rotting kernels of the seeds that are absorbing water turn it putrid.

I would imagine that few seeds would display sound kernels after more than two months in sea-water. This period, however, might be sufficient for the transport of some of the seeds in a sound condition to Bermuda from the Florida Strait; but it would be insufficient for their passage to the Azores, for which several months would be necessary (see Notes 12 and 14 of the Appendix). Though, as far as I know, the seeds have not been found on European beaches, their occurrence on the beaches of the Western Azores points, in spite of the results of my experiments, to this possibility. I picked up two seeds, both seemingly sound, one at Porto Pym in Fayal, and the other near Magdalena at the west end of Pico. But even the presence of these drift seeds in the Azores is inconsistent with the indications of the experiments. Additional investigations are needed before one can credit these seeds with the capacity of reaching isolated islands like Easter Island through the agency of the currents. 


\section{Drepanocarpus lunatus, Mey.}

This shrub grows in maritime swamps in the tropics of the New World and of the West Coast of Africa, being in both regions often associated with the mangroves, and especially on the African side, where, as we learn from Dr. Vogel's journal (Hooker's Niger Flora, 1849), it is frequent at the coasts and in the estuaries. According to Grisebach it is found on the mainland of the New World from Mexico to Brazil, and he records it from the West Indian islands of Haiti, St. Lucia, and St. Vincent. In West Africa it thrives on the Guinea Coast and in Senegal.

With the exception of a solitary empty pod that came under my notice on one of the beaches of the Turks Islands, I never found the fruit represented in West Indian drift, nor was it represented in the collection of Jamaican beach-drift made by Morris. It is therefore probable that neither the fruits nor the seeds are suited for effective dispersal by currents. Yet the opposite inference might be drawn from the fact that out of about fifteen known species of the genus only one occurs outside the New World, namely Drepanocarpus lunatus, and that is held in common between West Africa and America. De Candolle considered that this littoral species might be spread by the currents, but gives no data. In his Géographie Botanique (1855, circa p. 780) he viewed it as an American plant naturalised in West Africa; and with it he links Ecastaphyllum brownei, another littoral plant that is both West Indian and West African, yet is unsuited for trans-oceanic dispersal by currents (see p. 207). This seems to be an unsatisfactory explanation. If valid, we should have to apply it to other littoral plants, e. g. Symphonia globulifera, which present precisely the same difficulty (see p. 243).

\section{Omphalea diandra, L.}

The seeds of this euphorbiaceous plant must be regarded as typical of West Indian beach-drift. They are black, semi-globose, one to one and a half inches across, and possess a hard, crustaceous shell. Whilst scantily represented in the Turks Islands drift, they are characteristic of the Trinidad beaches; and they are included in the collection of drift made by Morris on the coast of Jamaica (Chall. Bot., IV., 302). But though about half of those collected by me on the West Indian beaches contained kernels, the others being often more or less empty, it is uncertain whether any of them would retain their germinative capacity after prolonged flotation in sea-water, the oily kernel being liable to a degenerative change that destroys its viability after being kept for a year or two. The kernel removed from its impervious hard shell floats in water, its buoyancy being due mainly to the lightness of the albumen, but partly also to a shrinkage-cavity between the cotyledons. It is thus apparent that the seeds, which must often be carried down by rivers to the sea, could be transported by the currents for considerable distances; but it is very doubtful whether this would aid the oversea dispersal of a riverside inland plant such as Omphalea diandra undoubtedly is. 
I am not acquainted with the parent plant; but Hemsley states that it climbs on trees on river banks in Central and South America and in the West Indies (Chall. Bot., IV., 302). Pax, in the Pflanzenreich monograph on the Hippomanece (IV., 147, 1912), to which the genus is referred, states that the distribution of this species extends from the Antilles and Central America to Peru and Brazil. It is found in the Amazon region, and here one may note Spruce's observation of its frequency amongst the riverside vegetation of one of the tributaries of the Marañon branch of the Amazon on the lower eastern slopes of the Ecuadorian Andes (Kew Bulletin, 1909, p. 216).

Omphalea triandra, another species, which is dealt with on p. 226, contributes to local beach-drift in the West Indies. Although the seeds float and illustrate the same type of buoyancy, they lack the hard crustaceous shell of those of $O$. diandra, and are in this respect less fitted for prolonged transport by currents.

\section{Acrocomia}

The empty "stones" of this genus of palms are common in Jamaican beach-drift, and also came under my notice on the beaches of Trinidad, Tobago, and Grenada, being doubtless in the main derived from trees growing in the interior of the respective islands. They may be regarded as characteristic of West Indian beach-drift, though they are very scantily represented in the foreign drift of the Turks Islands. Yet it is not easy to explain at first sight their occurrence on beaches, since the palms especially affect savannas and open woodlands, and seem to have no special preference for the vicinity of rivers, by which the fruits could be conveyed to the coast. However, that they are thus carried down to the sea is very evident. (I have not distinguished here between the fruits of the two most common species of the genus, $A$. lasiospatha and $A$. sclerocarpa).

The moist mature fruits sink in sea-water, but they acquire buoyancy in the drying process. However, experiment shows that the dry fruits will sink in a few days or in a week or so, the outer brittle shell being deficient at the base, which is imperfectly protected against the penetration of water by the small perianth. The history of these fruits in West Indian drift is similar to that of Aleurites moluccana in the drift of the Pacific islands, as described in my book on Plant Dispersal (p. 419). The fallen fruits, having become light and buoyant in the drying process, are washed into the rivers and thus transported to the coast, where they are often stranded on the beaches. Whilst lying there exposed to the sun and rain, they are in time deprived of their outer coverings. The hard black "stones," about an inch across, which are thus exposed, soon lose their seeds through decay, and it is in this condition that they usually occur in the beach-drift. The seeded "stone" has no buoyancy either in the moist or the dry fruit. It is only when it is set free by the removal of its coverings on the beach, and when it has lost its seed by decay, that it is able to float. Each empty "stone" has three lateral perforations, two of which are closed at the bottom, but one is more or less patent. However, the sea-water 
is unable to displace the air within, and the "stone" thus becomes buoyant.

\section{IPOMdeA TUBEROSA, L.}

Much interest is attached to these West Indian drift seeds or fruits, since they remained for nearly three centuries without a botanical name, though often mentioned by the earlier botanists and other contemporary writers as figuring amongst the foreign drift stranded on the Orkney Islands and the Hebrides. Clusius (1605), C. Bauhin (1623), Sloane (1695), Petiver (1702), the two Wallaces in their descriptions of the Orkneys (1693-1700), and Pennant in the account of his tour in the Hebrides (1772), all refer to them, but not one of them was acquainted with their source, although some, like Sloane, make correct surmises. They were content to describe and sometimes rudely figure them. Petiver's use of the name "Faba Orcadensis," though very appropriate in a popular sense, since the earliest recorded drift specimens came from that group, served rather to increase the mystery, which was not solved until Hemsley identified them with Ipomoea tuberosa, L., in his paper in the Annals of Botany for 1892 (Vol. VI.). Superstition played its part in the story of these strange-looking gifts from the sea; and, as we have seen in Chapter II., the women of the Hebrides are stated to have sought relief during the pains of childbirth by clenching one of them in the hand.

These fruits or seeds (their particular designation being uncertain) are about an inch across, depressed-globose in shape, yet slightly squarish in outline. The ebony-black hue, the hard, bony, polished shell, the four-lobed, or rather four-grooved, upper surface, and the large scar underneath, are characters that distinguish them from all other drift seeds and fruits. Grisebach states that Ipomoe tuberosa is distributed over the West Indian islands and occurs on the tropical American mainland (Mexico to Guiana), as well as in tropical Africa and the East Indies. Hemsley in the paper above named remarks that although it is usually regarded as a native of tropical Asia, Africa, and America, its Old World form was separated by Mr. C. B. Clarke under the name of $I$. kentrocaulos. "It is not" (he writes) " essentially a shore plant, but rather a climber of lofty trees." Normally there are four separable seeds as in typical Ipomøas, but they are closely compressed and form a spheroid. Not infrequently, according to Hemsley, only one seed is developed, which "assumes the size and nearly the shape of the four seeds combined," and adapts itself to the size and shape of the seed-vessel, the original complement of four seeds being indicated by four furrows. It may happen, as in the case of one of the typical drift specimens examined by me, that there is an appearance of two cells, each containing an embryo. Here we seem to be concerned with a fruit rather than with a seed. There is evidently much to be learned about the conditions under which this abnormal development takes place. It may be added that Grisebach makes no allusion to it in the description he gives of the species, and that seeds gathered by me from living plants in Jamaica displayed no such peculiarity. 
A remarkable feature is that only these abnormal seeds or fruits show capacity for dispersal by currents, the ordinary separate seeds from Jamaican plants exhibiting little or no buoyancy. The currentdispersed seeds, as we learn from Hemsley, are " not uncommonly met with in the drift of the Caribbean Sea, and are sometimes carried far up into the North Atlantic by the Mexican Gulf Stream." However, only two specimens came under my notice on West Indian beaches, one in Jamaica and the other in the Turks Islands. They are represented in the Kew Museum in the Morris collection of Jamaican seed-drift made in 1884; but they were not mentioned by Hemsley in his account of the seeds and fruits there contained which is given in his report on the botanical results of the Challenger Expedition (IV., 284, 298, 1885). Some years passed before he identified them as the seeds of I pomøa tuberosa.

The botanical name, however, was not known to me until early in 1913, when Dr. Rendle very kindly came to my aid and referred me to Mr. Hemsley's identification. Shortly afterwards I saw them under this name in the Kew Museum, a note on the label stating that they are frequently washed up on the coasts of Cuba and South America. The interesting feature in the story of these West Indian drift seeds is their occurrence on European beaches. In $1908 \mathrm{Mr}$. J. Fox sent one to me from the Shetland coasts, together with seeds of Entada scandens and Mucuna; and there is one in the Kew Museum which was obtained by Colonel Fielden in the Hebrides in 1891. Doubtless these seeds have also been gathered amongst the Atlantic drift on the shores of Scandinavia; but Sernander makes no allusion to them in his account of the foreign seeds and fruits washed up on those beaches. However, it is possible that some large drift seeds discovered there by Lindman in 1880 , which were referred to the Convolvulacea but had otherwise defied determination, may belong to this species.

It came as a surprise to me, whilst looking up some of the early references to Gulf Stream drift in the British Museum library, that these seeds had long been known to the older botanists and to the early writers on the Orkney Islands. In their nameless condition they were almost forgotten until Hemsley wrote his paper in the Annals of Botany. The historical side of the subject did not, howrever, come within the scope of his paper; and this must be my - excuse for dealing here with a matter that could have been handled by him in a far more authoritative and complete fashion. The list of references now given is not at all exhaustive, but it will serve my purpose.

Clusius, in his Exoticorum Libri (libr. II., cap. xvi., p. 41, fig. 9), published in 1605 , described and figured without further comment these fruits amongst some which had been given to him by Jacobus Garetus. C. Bauhin, in his Pinax Theatri Botanici (p. 405), printed in 1623, merely cites the description of Clusius. With the aid of Clusius, Sloane was able to identify the fruit with one of those figured by the Rev. J. Wallace in his book on the Orkney Isles (issued in 1693) amongst other "strange beans" frequently cast up on those islands (Philos. Trans., Vol. XIX., p. 398, 1695-7); 
and he also identified it with others he had often seen in collections of rare fruits. Though, as he says, authors were silent as to its source, and he himself had " never seen it grow," he rightly surmised that the sea had brought it to the Orkneys from the West Indies. The peculiar form of the fruit often tempted the old authors to make a drawing of it. Though the figures are rude, they are accompanied by good descriptions.

J. Petiver, F.R.S., a contemporary of Sloane, described and figured the fruit in his Gazophylacium Naturae, a remarkable work containing 1000 illustrations of objects of natural history, and published with varying form and title from 1695 to 1764. Under the name of Faba Orcadensis, he describes it as " nigra, polita, tetrasulcata, hilo magno," and, like Sloane, he refers to Clusius in this connection. Like Sloane, also, he alludes to its being figured in Wallace's account of the Orkney Isles, though in this case it is the son's enlarged book that is concerned. "My ingenious friend, Mr. James Wallace, Physician " (thus Petiver writes), "hath figured this in his Description of the Orckney Isles, p. 14, from whose shoars Mr. Will. Clerk brought it me. Father Kamel hath also sent me the same from the Philippine Isles." [Petiver's description of the fruit is given in a small octavo volume published in 1702, p. 54; whilst the figure it concerns is to be found in a large folio volume (table 34, fig. 10) issued in 1764, the contents of the first fifty tables being described in the smaller volume. It is ill-figured, but well described.]

It is evidently to this fruit that Pennant alludes in his account of his Voyage to the Hebrides in 1772, which has been already quoted (see p. 32). After naming four kinds of "Molucca Beans" thrown up on this group, he says that " the fifth is a seed called by Bauhin 'fructus exot: orbicularis sulcis nervisque quatuor,' whose place is unknown." He appears to have had access to Sloane's account of the West Indian drift seeds on the Orkney Islands; but there is no reference to it. C. Bauhin's Pinax Theatri Botanici $(1623$, p. 405) is evidently the work quoted by him; but Bauhin, as previously stated, had merely quoted the earlier work of Clusius.

This discussion may be concluded with a few remarks on the nature and cause of the buoyancy of these " composite" seeds, as one might term them. Of the three specimens obtained from the beach-drift of Jamaica, the Turks Islands, and the Shetlands, all floated in sea-water, but two, including the Shetland seed, sank in fresh-water. In other words, all were specifically lighter than seawater, but two were heavier than fresh-water. This behaviour, interpreted in the light of a somewhat extended acquaintance with the subject of the flotation of fruits and seeds where the average specific weight happens to be near that of sea-water, indicates that a large proportion of these "composite" seeds produced by the plant would not possess buoyancy in any sense. As in the case of convolvulaceous seeds generally, the floating power is to be ascribed entirely to the cavities produced by the shrinking of the albumen and embryo during the hardening stage, the separate parts having no independent floating capacity. 
A section of one of the seeds disclosed traces of two cells, each holding an embryo and displaying a large shrinkage-cavity.

\section{Mangifera indica (Mango)}

The empty fibro-membranous "stones" of this fruit are common on the beaches of the Turks Islands and in West Indian beach-drift generally. I would imagine that those washed ashore on the Turks Islands were drifted there from San Domingo or were thrown overboard from passing vessels. Numerous small craft hailing from San Domingo and other islands trade in fruit in these seas. These materials are found all over the tropics on the beaches of countries where the Mango is cultivated. No doubt they often occur on other coasts derived from rubbish thrown over by passing ships. Prof. Ewart tells me that they are cast ashore on the south coasts of Australia; and in Chapter II. reference is made to one that was stranded on the coast of South Wales.

\section{Miscellaneous Materials in the Beach-Drift of the Turks ISLANDS}

Amongst these materials may be specially noticed large spines or prickles, pumice, floating corals, and electric-light bulbs, the second and third named deriving special interest from their suitability for carrying small seeds in their cells or crevices.

The large Prickles of Zanthoxylum.-These large spines or prickles, which are rather frequent in the drift, are conical in form, and are apparently detached from the trunks of two species of Zanthoxylum, a genus including different West Indian trees. The largest prickles have a diameter at the base of two to two and a half inches, and belong perhaps to Z. clara-Herculis, the "Prickly Yellow" of the Jamaican. The smallest kind has a basal diameter of one and a half inch. These prickles would be able to withstand the transatlantic passage, and ought to be found amongst the West Indian drift stranded on European beaches. They are figured by Sloane (Vol. II., table 172), though not in connection with drift, under the name of Euonymus affinis, a tree which, he says, is very common in Jamaica.

Pumice.-The stranded pumice usually consists of small, rounded pebbles, a quarter to a half inch across, which commonly occur amongst the smaller drift sorted out by the waves above the line of the heavier and larger drift. Occasionally one finds large fragments, as in the case of one washed ashore on the east coast of Grand Turk, which was seven and a half inches long and weighed one and oneeighth pound. It was well rounded, and was partially incrusted with large Serpulid tubes, 5 to $6 \mathrm{~mm}$. in diameter, and with other marine organisms. Evidently it had been a year or more afloat, and might well have been transported from the other side of the Atlantic.

Floating Corals.-Fragments of floating corals stranded on the beaches of Grand Turk and of the other cays, as well as on the shores of the neighbouring Caicos Islands, are well known to the residents, and are termed "floating stones." Occasionally they are picked up 
at sea from boats sailing between the islands. They range from five or six inches to a couple of feet across, and all apparently belong to the same kind of Mrandrine massive coral with large convolutions. I picked up some small specimens on the beach, and examined others of large size which a resident had placed in his garden. The largest measured by me was $17 \times 14 \times 5$ inches in size. It floated when placed in fresh-water, and probably weighed forty or fifty pounds. I was informed that larger specimens have been found. Most of the floating corals examined by me floated in fresh-water as well as in sea-water; but in one case the coral floated only in sea-water. Many years ago floating corals of the same character were examined by me on Keeling Atoll in the Indian Ocean, and a description of them was given in a paper contributed to the Scottish Geographical Magazine for 1889. Reference may be made in this connection to Coral and Atolls, by Wood-Jones, 1910.

Electric-light Bulbs.-Amongst the "odds and ends" cast up on the beaches of the Turks Islands are electric-light bulbs. I found three or four of these stout glass globes, which were all quite intact and would seemingly float for years. Mr. Savage English alludes, in his paper on Grand Cayman in the Kerw Bulletin (1913), to the occurrence of these bulbs amongst the " jetsam " of that island. Doubtless they are discarded and thrown over from vessels. They are quite watertight, and suggest useful floats for current investigation, as they are very conspicuous on a beach. 


\section{CHAPTER VIII}

\section{MISCELLANEOUS PLANTS}

IN this chapter numerous other West Indian littoral plants, which are not dealt with in the preceding chapter, are discussed from the standpoint of dispersal. The object has been to treat in this manner all the plants mentioned in the table given in Chapter IV., in which the relation existing among West Indian littoral plants between their distribution outside the New World and their capacity for dispersal by currents is illustrated. The small-seeded shore plants, which raise other considerations, are dealt with in Note 21 of the Appendix.

\section{Acacia farnestana, Willd.}

This plant came under my notice in different parts of the tropics, and I made a special study of its station and modes of dispersal in Hawaii and Jamaica. One may begin the discussion of this widely spread small tree or shrub with remarking that there is some divergence of opinion as to its distribution as an indigenous plant. De Candolle in his Géographie Botanique (pp. 770, 792) viewed it as of American origin and as naturalised in Asia and Africa. Bentham observed that, whilst it was difficult to determine where it was indigenous, it had the appearance of being so in Western America from Texas to Northern Chile, in tropical South Africa, and in Northern Australia, but not in India (Trans. Linn. Soc. XXX., 502). Baron von Mueller speaks of it as native of Southern Asia and the warm parts of Australia, and as growing spontaneously in tropical and subtropical America (Select Extra-Tropical Plants, 1880). The general opinion, however, leans towards an American origin; but at present we will accept three facts concerned with its distribution, as stated by Bentham : $(a)$ that it is widely spread over the tropical and subtropical regions of the New and the Old World; $(b)$ that it has been generally cultivated for the perfume of its flowers; and (c) that it has been frequently established as an escape from cultivation. Further consideration of the matter may throw light on the plant's origin, but since we are dealing with a favourite tropical cultivated plant which also grows wild in nearly all warm countries (Hemsley, Bot. Chall. Exped., IV., 148), the initial difficulties are apparent. It is, however, possible that we may obtain some clue by regarding the outposts of its distribution, as in the case of its occurrence on oceanic islands.

Let us commence with the islands of the Pacific. Wherever this 
plant is found in these archipelagos, whether in Hawaii, Tahiti, the Marquesas, Rarotonga, Samoa, Tonga, Fiji, etc., the botanist refuses it a place in the indigenous flora. Its absence from the native floras of these islands would be readily understood, if it was not at home on the western borders of the Pacific, that is to say, in the regions comprising South-eastern Asia, Malaya, and North Australia, whence the Polynesian plants have been in great part derived. Yet it would be quite consistent if America was the home of the plant, since except in the very distant past there have been very few connections between the American and Polynesian floras. The indications would seem to be, as inferred by Hillebrand in the case of Hawaii, that the tree was introduced by the early Europeans into the Pacific islands.

With the issue thus a little narrowed we will now discuss its distribution more in detail; but numerous difficult questions at once present themselves. Why should this particular species of Acacia, we may ask, wander round the tropics of the globe, when hundreds of others remain restricted to their homes, principally in Australia and South America? Hemsley, writing about thirty years ago, remarked that of the three hundred Australian Acacias, this is the only non-endemic species (Chall. Bot., IV., 148). Found over most of the warm regions of the globe, it so often impresses the botanist with the appearance of being indigenous that, as we have seen, various regions have been assigned as its home. Long ago Willdenow placed its home in the West Indies and particularly in San Domingo (quoted by Schmidt in his Cap Verdische Flora). However, it will be apparent from its behaviour in the Hawaiian Islands, as described later on, that the plant soon adapts itself to a new locality and spreads rapidly. The tendency on the part of many introduced plants to become thoroughly naturalised in a short space of time is well illustrated in this case, and the modern botanist with a larger experience of such cases is better able to discriminate in such matters.

But a further difficulty would present itself in the variety of stations selected by the plant. Though they would be all consistent with the behaviour of a xerophilous plant, their variety would tend to complicate the problem concerned with the home of the species. It is equally at home in the arid plains of the elevated interior of Mexico, at the margin of the sea beaches in the West Indian Islands, and amongst the trees in the loamy soil bordering the mangrove belt in Jamaica and elsewhere. It may cover the low-lying plains of the sea border with an impenetrable bush as on the Gulf margins of Texas, or it may with other trees fringe the dry beds of streams in the prairies of the same region. Such is its behaviour in the New World as indicated by Harshberger and others, but the variety of its stations might be illustrated from other parts of the globe.

Its littoral habit may be first dealt with. Though more typical of the belt of trees that immediately border the sandy beach, it accompanies certain of these trees when they grow at the edge of a coastal or estuarine swamp. In Java, according to Schimper (Ind. Mal. Strand Flora, pp. 67, 122), it is an essential constituent of the 
Nipa formation, a brackish-water swamp association predominantly characterised by Nipa fruticans and stretching inland in the rear of the coastal mangroves. But it is confined to the drier ground, and herds with Cerbera odollam and some other characteristic beach trees of the Barringtonia formation that are equally at home at the beach margin and at the swamp border. In Jamaica I observed it growing in the loamy soil behind the mangrove belt in the company of several other plants, such as Coccoloba uvifera, Conocarpus erectus, Guilandina bonducella, Hibiscus tiliaceus, and Thespesia populnea, that are often associated with it at the margin of the beach. When, as in Jamaica, it appears on the beach, it will usually be found also occupying the low district in the rear. But its behaviour in Jamaica supplies another clue. When one reflects that in the society of the Mesquite (Prosopis juliflora), Cactacece, Yuccas, etc., it thrives in the scrub of the extensive Liguanea plains in the interior (Harshberger, p. 678), the suspicion arises that Acacia farnesiana, being primarily a xerophyte, only presents itself in this island as an intruder on the beach.

We obtain the same clue when we glance over the other parts of the West Indies. Millspaugh found it growing inland on St. Thomas, as well as on the seashore of Porto Rico, and also at Santiago de Cuba (Plantoe Utowance). In the case of Inagua, one of the Bahamas, Harshberger found it associated with Opuntia and Phyllanthus in the low thickets of the strand, and in the same company it came under my notice in the interior of Grand Turk. As in Jamaica, the chaparral formation, a more or less impenetrable scrub of Acacias (including A.farnesiana), Prosopis juliflora, Cactacea, Yuccas, etc., covers the arid plains of the interior of Hispaniola, an island in which Willdenow was inclined to look for the home of the plant we are now discussing. But it is not in the islands that the chaparral is best developed, but on the mainland, as in the arid interior of Mexico, Texas, and the Californian Peninsula as described by Harshberger. Here amidst a motley group of xerophytes, in which Cactacea, Yuccas and Acacias are conspicuous, the plant we are now concerned with is at home; and the ever-prevailing Mesquite (Prosopis juliflora) is its frequent associate. When this scrub descends from the elevated tablelands of Mexico to the plains that border the Gulf and extend along the shores of Texas, Acacia farnesiana accompanies it to the sea-coast. In such situations its claims to be ranked as a strand plant would be no greater than those of the numerous other xerophytes of the chaparral scrub that descend with it to the coast.

If the matter ended here there would be little difficulty in deciding the point at issue. But not uncommonly in the West Indian region and in other parts of the world Acacia farnesiana, as already remarked, discards its associates of the chaparral and takes its place amongst the characteristic littoral trees. Having explained how the plant reaches the coast from the inland regions we have now to ascertain why it remains there. In the answer to this question we may perhaps find a key to its wide distribution over the globe. It associates with quite different plants in the arid regions of America, Africa, 
and Australia. How comes it, we may ask, that the xerophytes with which it grows in those three continents are confined in the main to their respective regions whilst this plant occurs in all of them? What advantage can this species possess over all the hundreds of Australian Acacias that have never wandered far from their home? It is not merely that it is able to adapt itself to a littoral station; for most xerophilous Acacias could do that; but it is able to maintain itself there. A shore station gives it some special advantage over the numerous xerophytic plants of the arid inland regions. They come and go on the strands of all the continents, but Acacia farnesiana remains. Why is that?

It is a matter of dispersal. The number of plants that are dispersed by currents, as I have shown in the eighth chapter of my work on Plant Dispersal, must be very small indeed, almost infinitesimal in relation to the totality of species in the plant world. From a somewhat extensive acquaintance with the buoyant capacities of seeds and fruits I feel on safe ground in assuming that nearly all the species of the chaparral scrub that reach the coast, as on the Gulf shores of Texas and Mexico, possess no means of effective dispersal by the currents. They may hold their own in places by force of numbers, but they cannot extend their range along the coast to localities where the chaparral is absent. In this respect Acacia farnesiana possesses a great advantage, as I found in Hawaii, since its indehiscent pods can float for a month unharmed in seawater. Its maintenance at the coast does not depend on recruits from the inland scrub. It is ensured by the distribution of its fruits by the currents. Though the seeds themselves sink, they are buoyed up by the pod.

A reference may here be made to my experiments in Hawaii, as the details are not given in my previous work, where only the results are stated. The moist green pods either sink at once in sea-water, or float heavily and sink in a few days. They are entirely filled with a kind of pith, the seeds having not yet accomplished their hardening and shrinking stage. When the pod is ready to fall from the tree, it is blackened and more or less air-dried, and the seeds rattle freely inside. Its prolonged buoyancy is due to the cavities produced by the shrinking of the seeds and the drying up of the pith. Of five of these dry pods placed in sea-water, one sank in sixteen days, the next in twenty-three days, and the others in from thirty-two to thirty-six days, the cause of the sinking arising from the decomposition of the pith and the gaping of the valves produced by the penetration of sea-water. This is far, however, from the type of buoyancy one associates with fitness for trans-oceanic dispersal by currents; but it is well adapted for inter-island dispersal in an archipelago and for extension along a continental sea border.

The behaviour of the plant in the Hawaiian Islands is very suggestive. Regarded by Hillebrand as of early introduction it has spread over all the islands, and in places forms extensive coastal thickets. Cattle spread the seeds over an island, and they may often be seen germinating in their dung; but the currents accomplish the interisland dispersal. On some parts of Oahu, where the shrub grows 
abundantly near the sea, the pods are washed up in great quantities on the beaches, and the freed seeds are to be seen germinating in numbers, the seedlings striking into the sand. It occurs as a characteristic beach shrub around the coasts of Hawaii, Oahu, etc., and has been spread by the cattle far inland. Hibiscus tiliaceus is its frequent associate. Spreading up some of the valleys of Oahu Acacia farnesiana forms extensive thickets impenetrable for cattle, typical chaparral scrub but of recent growth. This matter is dealt with at length in my work on Plant Dispersal.

The occurrence of Acacia farnesiana in oceanic islands needs a little further consideration. One may suspect that this shrub or small tree was introduced by man into islands when they lie far from the continents, since its capacity for dispersal by the currents would probably be limited to traverses of tracts of sea not more than 400 or 500 miles across. Cambage ascertained that the seeds preserved their germinative power after an immersion of five or six months in sea-water (Journ. Proc. Roy. Soc. N. S. Wales, XLIX., 1915 , p. 94). But since the seeds had no buoyancy, he appealed to the pods. On finding, however, that a single pod sank in a few days, he inferred that the seeds might be carried for very long distances in drift-wood or pumice. This means of dispersal, however, would be at the disposal of all the species of Acacia that happen to grow near the beach, and would not of itself be sufficient to explain the exceptional range of the species in question. He does not introduce the agency of man, an agency that would at once give the plant a great advantage over other Acacias not so favoured.

One can scarcely doubt that this plant was introduced by Europeans at an early date into the Cape Verde Islands and Madeira, either from the West Coast of Africa or from Southern Europe where it has long been cultivated. It was collected by George Forster on St. Jago in 1778 (1779?), and was regarded by Schmidt in the middle of the last century as truly indigenous in the group (Flora der Cap Verdischen Inseln, 1852, pp. 38, 342). Welwitsch, who was in the islands about that time, refers to it as subspontaneous (Catalogus Herbarii Gorgonii, by Prof. Coutinho, 1914-15). It also seems to have been introduced into Fernando Noronha, though it is now behaving as an indigenous plant. The thorny Acacia bushes that were described by Moseley as abundant on the shore during the visit of the Challenger about 1874 (Chall. Bot., III., 11) were probably of this species. Ridley, who found Acacia farnesiana growing in thickets in the interior of Fernando Noronha in 1887, regarded it as having been introduced (Journ. Linn. Soc. Bot., vol. 27). In 1836 an Acacia was collected by Darwin on Keeling Atoll, which was referred to this species (Chall. Bot., IV., 113). During my sojourn on the atoll in $1888 \mathrm{I}$ did not observe that it formed a feature of the indigenous flora. It was probably one of the numerous plants introduced in the early days of the occupation of the islands.

Of the several authorities on the floras of the oceanic islands of the tropical Pacific, not one includes this species amongst the indigenous plants, that is to say, the plants found in the islands at the time of their discovery. Mann and Hillebrand for Hawaii, Seemann 
and Horne for Fiji, Hemsley and Burkill for Tonga, Reinecke for Samoa, Cheeseman for Rarotonga, Jouan and Drake del Castillo for the Tahitian Group, the Marquesas, and the Paumotus, all in one way or another disclaim the plant. Many of them do not mention it. Seemann, however, remarks that in his time (1860) it was strictly confined to the gardens of white residents in Fiji. Hillebrand, as we have seen, regards it as a plant of early introduction in the Hawaiian Islands. Since he does not include it in his list of plants introduced by the natives in prehistoric times (p. xvi.), we may suppose that he places it amongst "several species of Acacia (that) might well claim a place" amongst plants introduced since the time of Captain Cook. If this was the case, Acacia farnesiana must have quickly become established, since in Hillebrand's time (1851-71) it was "spread over all the islands." Cheeseman, also, made a list of plants probably introduced into Rarotonga by the natives prior to the arrival of the white man; but this plant does not figure in the list. From these data, I think that it is fair to assume that botanists do not credit Acacia farnesiana with a preEuropean existence in the Pacific islands. (With the exception of the writings of Jouan and Mann, which are quoted by Hemsley (Chall. Bot., IV., 148), all the works of the other authorities named are given at the beginning of my work on Plant Dispersal.)

It would be possible to extend this discussion very considerably; but I have gone far enough to show the probability of this plant being indigenous in the New World. Bentham would place South Africa and Australia in the same category. However, Cambage included this plant in his recent studies of the history of the Australian Acacias, as indicated by their seedlings, and he looks rather to America for the home of the plant (Ibid., p. 97). This will remind us that there is another way of approaching the problem. Not the least valuable outcome of the studies of Andrews of the adaptation of plant-forms to the special conditions of Australia will be the sidelight often thrown on problems of this kind. The following considerations respecting this plant have suggested themselves after a perusal of his recent paper on the Leguminosa (Journ. Proc. Roy. Soc. N. S. Wales, Vol. XLVIII., 1914). From his discussion of the Australian Acacias I would infer that although Acacia farnesiana is at home in Northern Australia, it does not display the special Australian impress which attains its maximum expression in the development of the phyllode, a character of Acacias amongst which the plant we are discussing finds no place. The section, Gummifera, to which it belongs, seems to have obtained no secure footing in Australia (p. 395); and the other types of the series, of which it forms one, are endemic in America, in Africa, or in Asia (p. 392). We could, therefore, scarcely regard Acacia farnesiana as a gift of Australia to the littoral flora of the tropical zone. We have pointed out the probability that either directly or indirectly Australia originally supplied species of Scaevola, Dodoncea, and Cassytha, that frequent the shores of the Old and the New World in warm latitudes; but the same, it would seem, cannot be said for Acacia.

I may conclude this discussion with the remark that Acacia 
farnesiana has here been taken as a sample of a small group of cosmopolitan tropical and subtropical plants, including such as Hibiscus tiliaceus and Thespesia populnea, which, though often differing greatly in other particulars, are linked together by the difficulties which their distribution presents. Equally at home at the coast and inland, and all capable, though to a varying degree, of dispersal by currents, there is always more than a suspicion that man has assisted for ages either directly or indirectly in their distribution. Over all of them hangs a doubt as to their birthplace, since they behave as indigenous plants over most of the warm regions of the globe. In their present range they seem to be quite independent of the development centre of the genus. If the botanist places the plant concerned in one hemisphere, the errant species presents itself as to all appearance an indigenous plant in the other. The student of distribution quarrels with all of them in one region or another, since they figure too frequently as disturbing factors in his speculations on the history of a flora.

Both Hibiscus tiliaceus and Thespesia populnea are treated in a later page, but with less detail as the writer hopes to take up the further study of the story of their travels around the globe. Their history is bound up with that of aboriginal peoples, and they raise somewhat different issues than does the species of Acacia with which we have been concerned. The names of Hibiscus tiliaceus and Thespesia populnea are part and parcel of the native languages around the tropics, and we can almost detect a linguistic affinity between those of the New and the Old World. On the other hand, Acacia farnesiana is a nameless plant, as the philologist would express it, around the tropics of the globe. It has names, it is true, but not names that belong to the language of the aborigines in whose country it may now grow. It has been a great traveller, but its story is bound up rather with the continents than with islands, rather with early civilisations than with states of barbarism. From the circumstance that it has been identified with the "Small Acacia" of Dioscorides, and has been even supposed by some to have been represented by its flowers in Egyptian tombs (Von Mueller, Extr. Trop. Plants; De Candolle, Géogr. Bot.), we may have to face quite other issues.

\section{Ambrosia crithmifolia, DC. (A. hispida, P.)}

This composite beach plant ranges all over the West Indies, including the Bahamas and the Florida keys and the continental shores of the Caribbean Sea. Growing prostrate on the sand with its flowering spikes rising six to twelve inches in the air, it gives a peculiar aspect to the surface, reminding one a little, as regards the foliage effects, of an English sand-dune covered with Matricarias. When it carpets extensive tracts of sandy plains bordering the sea, the aromatic fragrance of the plant is often borne far to seaward by the wind blowing off the shore.

Detached from the parent plants the small dry fruits, enclosed in the persistent involucre, occur in numbers in the sand of beaches, 
from which they could readily be swept off by the waves and carried away in the currents. However, my experiments in the Turks Islands indicate that they possess limited floating powers. Picked up by the waves, and washed off the beach, they would sink in from two to four days. Prolonged drying for a year and more adds but little to their buoyancy, half of them sinking in two days, whilst the few remaining afloat after a week are only floated up by adherent air-bubbles. The achene removed from the involucre has initial buoyancy, but sinks within four days. Though unsuited for direct distribution by the currents over broad tracts of sea, these small fruits might be carried great distances in the crevices of a drifting log. They would readily be washed with the sand into the crevices of timber temporarily stranded on a coast.

The achene shut up in the dry involucre would not be likely to tempt sea-birds, and the fruits do not attach themselves to plumage. The achene is 2.5 to $3 \mathrm{~mm}$. in length. The length of the fruit with the persistent involucre is $4 \mathrm{~mm}$.

The genus holds fifteen known species, of which all but one are confined to the New World. The exception is a widely spread Mediterranean shore plant (Ambrosia maritima, L.) which extends to the coast of Senegal. Certain of the species range far and wide as waste plants and weeds in the American continent and in the West Indies. Some North American species frequent estuarine marshes, whilst others prefer the sand-prairies of the interior and the borders of salt swamps in inland regions (Harshberger).

I found Ambrosia crithmifolia thriving on six of the ten cays of the Turks Islands, and reference to it in this connection will be found in the chapter on the flora of these islands. Mr. Lansing's observations on the Florida sand-keys, where he found it growing on five of the nineteen keys examined, indicate that it is one of the earlier plants to occupy land newly gained by accretion from the waves. Yet the fact that it has not been observed in Bermuda, which has received so many West Indian strand plants, militates against the efficacy of the currents in transporting it across broad tracts of ocean.

\section{Anacardium occidentale, L. (Cashew-nut)}

The nuts of this West Indian tree, which is only indigenous in the New World, do not form a feature in the beach-drift of these regions. On one occasion I found a solitary decaying nut on a Jamaican beach; but that alone could not entitle it to be regarded as a drift fruit. Yet it is interesting to note that Gunnerus, who lived in the middle of the eighteenth century, found this fruit on the Norwegian coast; but Sernander in his book on the Dispersal-Biology of the Scandinavian flora (p. 117) tells us that it has not been found since. Hemsley, who quotes Linnæus on this point, says that the seed was in a living condition, and he places the fruit among those certainly or probably distributed by currents (Chall. Bot., I., 43 ; IV., 278, 305).

This Norwegian drift fruit has puzzled me much, since Linnæus gives no other particulars concerning it. The large fleshy peduncle could not possibly be here concerned, unless it was thrown over 
from some vessel near the Norwegian coast; whilst it is scarcely likely that the heavy nut when fresh could have much buoyancy. This is indicated in one of my experiments. I placed in sea-water some sound nuts which had been gathered rather over a year. After a few days the pericarp began to soften, and in ten days all the nuts were at the bottom of the vessel, a week being the average flotation period. Empty nuts are much lighter and might float longer.

\section{Anona palustris, L.}

The genus Anona, or, as it is now usually written, Annona, has been fortunate in its latest monographer, Dr. W. E. Safford, who has recently published in volume 18 of the Contributions from the United States National Herbarium for 1914 a classification of the genus. Here we are mainly concerned with the littoral and estuarine tree above named; but from the distribution standpoint it cannot be treated without some reference to a few of the general features of the genus to which it belongs.

"The genus Annona" (writes Dr. Safford, p. 4) "is confined almost exclusively to tropical and subtropical America. At an early date, however, certain species were introduced into the warmer regions of the Old World for the sake of their edible fruits, and were described as distinct. In addition to these there are a few species endemic in tropical Africa." The author gives no numerical account of the distribution of the genus in his paper. Failing this, a general statement of the results for about 120 species named in the Index Kewensis may be given. Here about 100 species are exclusively American. Of the balance most are tropical African, and the rest occur in Madagascar, the Mascarene Islands, Ceylon, China, and Malaya, with one species, A. palustris, both American and African, the only species common to the Old and the New Worlds. Some emendation is, however, here required respecting the few Asiatic species named in the Index Kewensis, since Dr. Safford informs me that "there is no endemic Anona in Asia. ..." The manner in which the edible species, the Sops, the Custard Apples, the Cherimoya, etc., have been spread over the world by man, not only in recent times but by the early European navigators, suggest that human agency may have been effective in this direction, even in prehistoric times. (Dr. Safford tells me, in a letter since received, that "certain economic species were introduced into India at a very early date.")

It is a significant fact that the only species which links together the Old and the New Worlds, the cultivated species being excluded, is one of the plants of the mangrove association, namely, Anona palustris, a tree that finds its home in estuaries and in coastal swamps. As far as I can ascertain there is no other species that could be regarded as a littoral plant. There are one or two species like A. paludosa, Aubl., that grow in marshy situations at the coast, but they also occur inland. Nor are there any plants that are exclusively confined to the vegetation bordering the sandy beaches. Where such plants grow in sandy plains at the coast they belong 
to an association of inland xerophilous plants that in places descend to the sea-border. We would therefore expect that Anona would illustrate the principle exemplified by many tropical genera, such as Barringtonia, Calophyllum, Clerodendron, Cordia, Guettarda, Morinda, Scaevola, Terminalia, etc., that where a genus comprises both coast and inland species only the coast species possess seeds or seed-vessels adapted for effective dispersal by currents. This principle, which is laid down in the second chapter of my book on Plant Dispersal, might be considerably extended now, and the indications especially concerning Anona will be stated below. But a few remarks on the station characteristics of the genus are first required, as well as some preliminary observations on its means of dispersal.

The capacity of the genus for adapting itself to very different stations is remarkable. Some species are at home in the humid conditions of the dense mountain forests; others thrive in the drier conditions of the open-wooded districts; others grow in the savannas and grassy plains; others are found in the sandy plains near the coast, and others in the desert rocky regions in the company of xerophytic Cactacee, Agaves, and Acacias. A few live in inland and coastal marshy districts, and one is the associate of the mangroves at the borders of estuaries and in the swamps at the sea-coast. Probably the xerophytic habit is most typical of the Anonas of our own day; but as indicative of a tendency to resume, what I would regard as the primeval habit and station of the genus, these plants even in their driest stations tend to gather along the streams, and where the conditions are too arid for permanent streams they may be found in the dry rocky beds of the channels that serve as watercourses only during the rains. I would consider that the genus was primarily a denizen of wet forests in warm latitudes, and that it has often become adapted to drier climates during the differentiation of climate in later ages.

The modes of dispersal of these plants may be now discussed. The question is at once raised when we contrast the distribution of Anona palustris, the only species common to the eastern and western hemispheres, with other species that are restricted to one or other of the two hemispheres. Dr. Safford in a letter to Prof. Harshberger, which is given below, strikes a true note regarding this tree when he writes: "If it were birds that distributed the seeds, why would not the more attractive species be just as widely dispersed? The seeds may possibly be borne by currents." The answer to this query is indicated below, and it would seem, as far as these data can guide us, that although birds and other creatures may be effective agents in local dispersal, the currents come into play when broad tracts of ocean have to be crossed. That Anona seeds are swallowed by fruit-eating birds of the pigeon family is stated by Gosse in his Birds of Jamaica (pp. 308, 315; 1847). Both the Pea Dove (Zenaida amabilis) and the White-belly Pigeon (Peristera jamaicensis) feed upon them. Parrots no doubt feed on the fruits, though I don't know whether they would swallow the seeds. One of the Mexican species is named "the little custard apple of the parrots" (Safford, p. 55). Pigs, iguanas and alligators are also 
stated to be partial to these fruits, one species (Anona palustris) being known in Jamaica as the Alligator Apple.

Since none of the Anona seeds examined by me are impervious to water, it is unlikely that they would be able to withstand the injurious effect of the digestive fluids of birds for more than a few hours. It is quite possible that a pigeon might transport them unharmed across a strait two hundred miles in width, but that would be the limit. We must look for other agencies, therefore, to explain the case or cases where broad tracts of ocean have presumably been traversed by the species; and when the fruit of such a plant is inedible and the species is not likely to have been spread by man we must appeal to the currents. If in addition to these features we find that the plant concerned is a denizen of coast swamps and is associated with mangroves that are well known to be distributed by currents, then the presumption in favour of the current hypothesis becomes very strong, and we would expect to find that the seeds of all other species, where the question of oversea transport is scarcely raised, would be ill-fitted for crossing an ocean in a current. It is not a matter of fruit-buoyancy, since the floating fruit would soon break down, as is illustrated in the case of that of Anona palustris in a later page, and the fate of the species would be ultimately determined by the behaviour of the liberated seeds.

What, therefore, we may ask, is the behaviour of seeds of Anona, when their buoyancy is tested? The answer to this question is indicated on p. ir7; and though the seeds of only five species have been experimented upon, the data go to show that Anona comes into line with many other tropical genera where only the littoral species are adapted for dispersal by currents.

It will be learned from the results tabulated on p. $\mathbf{1 7 7}$ that it is only the littoral species with inedible fruits and seeds capable of floating a long time in sea-water that occurs outside the New World, namely, on the coast of tropical West Africa. This species, Anona palustris (syn. A. glabra), deserves a special discussion.

We may best begin with Dr. Safford's letter to Prof. Harshberger, which is given on p. 155 of the latter's paper on the vegetation of South Florida (Trans. Wagner Free Institute of Science, Philadelphia, October 1914): "A letter of qucry directed to Dr. W. E. Safford, who has monographed the genus Annona, as to the means of distribution of the custard-apple, elicited the following information under date of August 20, 1912 "-

"Dear Sir,

"I have the honour to acknowledge the receipt of your recent letter in which you ask suggestions as to how the swampapple, Annona glabra, is dispersed. This is a question which has perplexed me. The associations of this plant are with species of so-called mangroves of wide distribution. This species itself occurs on both sides of tropical America, the Galapagos Islands, and the West Coast of Africa. It would be interesting to find out whether detached branches take root readily in the mud. The wood is so light, it is called corkwood, and the roots are used for corks and 


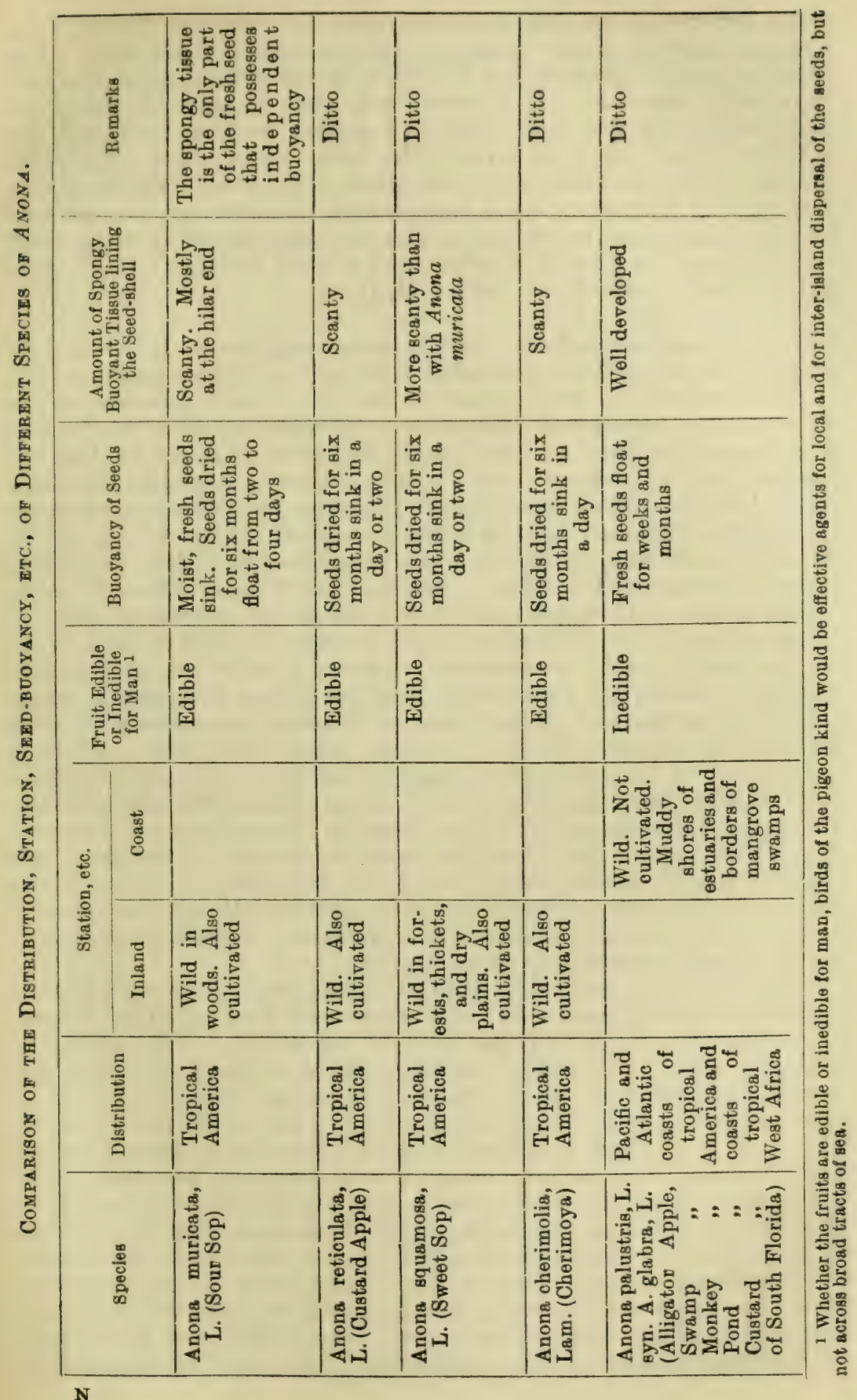


floats for nets. An experiment might be made by breaking off limbs or roots, and after soaking them for a time in salt water plant them in mud. I cannot find that their fruits are any more buoyant than other Annonas. If it were birds that distributed the seeds, why would not the more attractive species be just as widely dispersed? The seeds may possibly be borne by currents. They say that the fruit is eaten by aquatic lizards, or iguanas of the Bahamas. I wonder if they are carried from island to island. . . ." (It may be noted here that according to Fawcett and Rendle in their work on the Jamaican flora the light wood is used for corks, floats, etc., nothing being said of the roots.-H. B. G.)

The ground covered by this extremely suggestive letter will be traversed in the following discussion respecting Anona palustris.

The distribution of this plant in the New World extends on the Atlantic side from South Florida and the Bahamas over the Greater and Lesser Antilles to the South American mainland. On the Pacific side it is at home on the coasts of Central America, the Galapagos Islands, and on the coast of Ecuador, its southerly extension beyond the Peruvian borders being prevented by the aridity of the climatic conditions, which bring the mangroves and their associated plants to a halt in this region. On the West Coast of Africa it grows on the coasts and estuaries of Senegambia and in the Niger region.

Its station is at the borders of the mangroves, and it is at home on the muddy banks of estuaries. I found it to be one of the most frequent trees on the banks of the Guayas estuary in Ecuador, where they were overflowed at high water. Here it was associated with Rhizophora mangle, Hibiscus tiliaceus, and other trees. It is a constituent of the mangrove formation on the coasts of the Virgin Islands in the West Indies and of the island of New Providence in the Bahamas (Harshberger's Phytogr. Surv. N. Amer., pp. 687, 690-1). It does not appear to be frequent now in Jamaica. I did not come upon it myself in the Black River district, though in the recent volume on the Flora of Jamaica by Fawcett and Rendle, where only two localities are given, this is one of them. A fruit was brought to me from the north side of the island.

But one of the most interesting localities where Anona palustris occurs is in South Florida, where, as we are told by Prof. Harshberger, from whose memoir on the region the following details are taken, this tree offers one of the most remarkable formations. In these low-lying levels it occurs thirty to forty miles from the sea in an area which has been for ages undergoing a transition from its condition of submergence beneath the Gulf Stream in later Tertiary times to one of marsh and swamp, and finally of dry land. The greatest development in this region is a forest of "an almost pure growth" of this tree, which, varied by an occasional cypress (Taxodium distichum), forms a band usually two to three miles in breadth for a distance of about thirty miles along the south and south-east shores of Lake Okeechobee, passing on its southern side into the marsh formation of the Everglades. Two or three of the islands in this lake support a dense growth of this tree. In some places 
the Anona trees, when within a distance of five or six miles from the coast, blend with an outer zone of cypress swamp. In other places where they approach the coast they are associated with Rhizophora mangle. In others, again, they largely form hammocks, or groups of trees, that rise up like islands in the midst of the marsh vegetation of the Everglades. One of the characteristic developments of the tree occurs in the Banana Holes, which are shallow depressions or sinks, in which water often collects, where flourish a variety of other plants, Chrysobalanus icaco, Cladium, Phragmites, Sabal, Sagittaria, Salix, Typha, etc.

From what has been said it would thus appear that in South Florida this tree has many associates of a very different kind, and we may regard its behaviour there as the story of a tree of the man- grove formation that has been endeavouring for ages to gain for itself an inland station.

As regards the modes of dispersal of Anona palustris it is likely, as suggested by Prof. Harshberger (p. 116), that the seeds are locally distributed by frugivorous birds. He also adopts the suggestion of Dr. Safford that it is distributed by its light, corky wood, fragments of the tree being carried by water. Observation and experiment will show whether this last mode of dispersal is effectual. However, a very effective method of dispersal came under my notice in the Guayas estuary in Ecuador, a method described ten years ago in my book on Plant Dispersal (pp. 488-9). Very frequent in the floating drift of the river off Guayaquil were the seeds of this tree, often in a germinating condition. The seeds were liberated by the decay of the floating fruit, which was also common in the river-drift. They occurred commonly amongst the materials afloat in the Gulf of Guayaquil, ten to twenty miles off the mouth of the estuary, and were washed up on the beaches thirty miles to the south. Experiments showed that the seeds will float in sea-water until they rot and decay-one experiment covering eleven weeks, none of the seeds sinking, though several had become putrid. Seeds from Ecuadorian and Jamaican trees behaved in the same way.

The tendency of the seeds to germinate whilst afloat in rivers raises an objection against their fitness for dispersal by currents, since sea-water would probably kill the germinating seed. Here a good deal depends on whether the small embryo has begun its growth within the albumen before the seed reaches the sea. In the resting condition the embryo is only about one-sixth of the length of the nucleus of the albumen, which is about $11 \mathrm{~mm}$. long, and the cotyledons are minute. Considerable growth of the cotyledons takes place within the seed at the expense of the albumen before the tip of the radicle protrudes; and ultimately the cotyledons occupy almost the length and breadth of the seed nucleus. It is therefore apparent that a great deal depends on whether the embryo has passed beyond the resting-stage before the seed reaches the open sea. When the embryo is about one-third of the length of the nucleus, the tip of the radicle, which abuts against the pervious hilar end of the seed, has for its sole protection a thin membranous layer of albumen. In the resting seed, the embryo is better protected by the albumen 
for an oversea traverse; yet even here the impervious outer skin is deficient at the hilar or radicular end of the seed.

A curious feature in the buoyant behaviour of the seeds of Anona palustris is that they are, like other seeds of the genus, permeable to water and air. When dry they behave hygroscopically and vary in weight 2 or $\mathbf{3}$ per cent. according to the humidity of the surrounding air. Fresh and moist from the fruit they owe their floating powers entirely to the layer of cellular tissue lining the seed-shell, no other part of the fresh seed possessing independent buoyancy. An examination of seeds that had been afloat some weeks showed that until they became water-logged or saturated with water, there was no soaking of water into the seed substance, but rather a vital process of absorption of water, such as occurs in seeds imbedded in the ripe fruit. Seeds that had been afloat for three weeks, after being placed in a dry state in the water, were found to have taken up water only to the extent that it occurs in seeds in the fruit, the interior of the seed being fairly dry. Sufficient moisture had been absorbed to restore the normal moist condition of the seed as it lies in the fruit, and the embryo had resumed its original full outlines. There were no signs of saturation.

A point of importance is concerned with the degree of salinity that the floating seeds of Anona palustris will withstand without injury to their powers of germination. In the river Guayas the germinating seeds were floating unharmed in brackish water that at high water had a density of about 1.003. From the association of this tree with the mangroves, the germinating fruits and seeds of which are not affected by sea-water, it is probable that its seeds can germinate in brackish water, though it is not likely that they would do so in pure sea-water. Nor do I think that the Anona trees would thrive in pure sea-water. The muddy banks of the Guayas estuary, on which they flourish, are overflowed by brackish water at high tide. But more observations on this point are needed. These trees grow in brackish water in the Bahamas (Harshberger, p. 691); and it is apparent that on the South Florida coasts, where they are associated in the swamps with the mangroves, the water must at least be brackish. But they are only halophilous by force of circumstances. Their great development in the inland regions of South Florida has taken place around fresh-water lakes, and such conditions are evidently the most congenial for their growth.

A singular point arises as to the practical bearing of these observations and experiments on the occurrence of Anona palustris on both sides of the tropical Atlantic. It is just possible that the seeds could safely traverse the Atlantic in the Main Equatorial Current from the Gulf of Guinea to Brazil, a passage which would require a period of two or three months, this being the only available transatlantic route for seeds of their floating capacity. Yet Anona is now almost exclusively an American genus, and if there has been an interchange America has the first claim to be considered the giver. But this would compel us to suppose either that the seeds had been able to withstand the six to eight months' passage involved in the Counter Equatorial Current, or that they could accomplish 
unharmed the long trans-oceanic passage of about two years from the West Indian region in the Gulf Stream drift to the West Coast of Africa. We are here presented, therefore, with a dilemma such as was offered by Chrysobalanus icaco, one that could be evaded only by postulating a common centre of dispersion in high northern latitudes in a warmer geological age. This postulate seems the more probable, since, as Dr. Safford informs me, Anona senegalensis, a typical shrub or tree, that extends from the East to the West Coast of Africa, is " apparently most closely related to certain species growing on the plains of Southern Brazil and Paraguay" (letter cited).

A word may here be said on the synonymy of this species. Dr. Safford conclusively shows (p. 14) that the two plants to which Linnæus originally applied the specific names of glabra and palustris belong to one species. But it is possible that under the same specific type may be also included Anona klainii, Pierre, of the West Coast of Africa, which is at all events "very closely allied to A. palustris, if not identical with it." Dr. Safford, whose work has here been quoted (pp. 5, 15) tells me that the seeds of the two cannot be distinguished. I would point out that whilst on p. 15 this author speaks of these two species as on the West Coast of Africa, he alludes to them on p. 5 as on the eastern coast of the continent. That the West Coast is the true habitat is, however, indicated in his letter to me. Prof. Urban, as he shows, formed the same opinion of the close affinity of the two forms.

In conclusion, reference may be made to a curious abnormality frequent in the seeds of another species of Anona (A. muricata). Here the cotyledons are separated by a thin sheet or film of the endosperm, about half a millimetre in thickness, which occupies the length and breadth of the seed-kernel with the exception of a deep notch in its base for the hypocotyl. It is best examined after the embryo has begun to grow, and is about half the length of the seed.

\section{Astrocaryum}

Empty fruits of different species of this genus of palms were identified at Kew amongst my beach-drift collections from the Pacific and Atlantic sides of the Panama Isthmus. They were also included among the Morris collection of Jamaican beach-drift (Chall. Bot., IV., 304). I found them occasionally on the Trinidad coasts; but they did not come under my notice on the beaches of the Turks Islands. However, since I came upon a typical specimen on the coast of Pico in the Azores, it would seem likely that they would reach the shores of Europe. The drift fruits are always empty. They are rather like miniature coco-nuts, and are usually about $1 \frac{1}{4}$ inch or $31 \mathrm{~mm}$. in length.

\section{Avicennia nitida, Jacq.}

This mangrove is found all over the West Indies and along the continental coasts and estuaries of the warm regions of the New 
World, as well as on those of the West Coast of Africa. There will be no necessity to discuss here the station of this tree in the outer zone of the mangrove swamp, and I will limit my remarks here to the part played by the young seedlings, on being freed from the fruit coverings, in distributing the plant.

In my book on Plant Dispersal (p. 489) mention is made of the abundance of these seedlings in the lower course of the Guayaquil River in Ecuador, and of their being carried out to sea and stranded in numbers on the coasts near the estuary. Germination commences on the tree, and it is in this condition that the fruit usually falls into the water of an estuary. There it floats, and the seedling soon frees itself from its envelopes and floats away. The germinating fruits were to be observed in numbers thrown up on the beaches of Jamaica, Trinidad, Tobago, etc. It is important to note in this connection that sea-water is not injurious either to the germinating fruit or to the freed seedling, and that the seedling could be transported for considerable distances unharmed in the sea. It has been shown by Dr. Millspaugh that with the two cther mangroves, Rhizophora mangle and Laguncularia racemosa, Avicennia nitida is one of the earliest plants to establish itself on the Florida sand-keys. All three mangroves have made their home in the Bermudas.

The germinating fruit and the freed seedling might retain their vitality a considerable time after being stranded on a beach. In Jamaica I took five fruits on the point of falling from the tree. They were on the eve of rupturing, and I inferred from the condition of other fruits in the same stage that each of them contained a dark-green, well-developed seedling. They were allowed to dry in a room, with occasional exposure in the sun, for twenty-five days, during which period three of them opened. They were then placed in fresh-water, and within a week two of them were growing healthily, notwithstanding that they had lost just 50 per cent. of their weight in the drying process.

Avicennia seedlings offer the only means of the dispersal of the plant by currents, and although considerable tracts of ocean might be safely crossed in this manner, it is not at all probable that they could accomplish unharmed the long transatlantic passage in Gulf Stream drift from the New to the Old World. On the other hand, they seem sufficiently hardy to survive the much shorter passage of from two and a half to three months in the Main Equatorial Current from the west coast of Africa to Brazil. Avicennia is regarded as an Asiatic genus, and according to this view the borrowing of its species from the Old World by way of the West Coast of Africa would be quite consistent. As regards the time occupied in the traverse in the Main Equatorial Current, it would be similar to that taken up in the passage from the Florida region to the Bermudas, namely, two to three months, a passage that Avicennia seedlings must have once safely performed previous to the establishment of this mangrove on those islands. (See Note 14 of the Appendix respecting Bermuda bottle-drift.) 


\section{Borrichia ARBorescens, DC.}

This is a maritime Composite shrub, usually two to three feet high, which is very typical of the warm regions of the New World. It belongs to a genus exclusively American and comprising only two allied species, of which the present one ranges over the West Indies and tropical continental America, whilst the second (B. frutescens, DC.) grows in the Southern United States and in Mexico, both species being indigenous seaside plants in Bermuda (Chall. Bot., II., 45). Although we are only concerned here with the wide-ranging species, it is highly probable that the results of my observations on the dispersal capacities will apply to both.

This shrub commonly frequents rocky stations at the coast, but it also grows on sandy beaches and on the dunes in their rear. It often presents in the same locality two forms, one with glabrous foliage and the other with leaves covered by a silvery down; but both kinds of leaves may occur on the same individual. The writer specially studied the plant from the dispersal standpoint in Jamaica and in the Turks Islands. Its most critical habitat is in the Florida. sand-keys, where we see in operation the earliest stage of plant-stocking in these regions, so well observed by Mr. Lansing andi described by Dr. Millspaugh (Field Columbian Museum, publ. 118, Bot. Ser., 1907). After the mangroves it takes a place amongst the first seven or eight strand plants that occupy the newly formed islets in these seas.

The next critical habitat is Bermuda, since the question of the fitness of the fruits for transport by currents across broad tracts of sea is at once raised. The achenes, including the short crown, are from 4 to $5 \mathrm{~mm}$. long; but there are no hairs nor any means of attaching the fruits to plumage. Looking to the currents for a possible explanation of the wide range of the plant, I tested the buoyancy of the fruits both in Jamaica and in the Turks Islands. In my Jamaica experiments they sank after soaking in sea-water for a day or two. In those made in the Turks Islands on the plants: of that group, the fruits floated on the average six or seven days, the limit being ten days; but in a later experiment in England on fruits of the same set, which had been kept for fifteen months, they floated on the average nine or ten days, the limit being seventeen days. In such experiments it is requisite to select the achenes very carefully, since from insects and other causes it is often not easy to find achenes with sound seeds.

In the light of these results it is evident that the original fruits could not have reached Bermuda by their own floating powers, a passage, as shown in Note 14 of the Appendix, that would usually occupy nearly three months. Nor can we appeal to the agency of sea-birds, since the dry fruits would not be likely to be swallowed by them, whilst, as already remarked, they do not adhere to plumage. We are thus driven to conjectures. It may be suggested that the achenes were accidentally introduced into the Bermudas with the salt brought from the Turks Islands in the seventeenth century. In those times there was a regular trade between the two groups in 
this article, as shown by the report of Mr. F. H. Watkins on the salt industry of the Turks Islands (Colonial Reports, Miscell., No. 56, 1908). As the plant thrives around the creeks and ponds that supply the salt-pans on Grand Turk, it is not improbable that the original achenes might have been contained in salt shipped to Bermuda. But against this view there is the fact that the plant was cultivated before 1699 in England at Hampton Court from Bermudian sources (Chall. Bot., II., 45). On the whole it would seem most likely that the original fruits were transported to the Bermudas buoyed up in the miscellaneous Gulf Stream drift that is stranded there in quantities.

\section{Cakile}

My remarks on this genus will be mainly directed to the question of dispersal. The history of the investigation of the genus is symbolical of the history of its specific differentiation as a single wideranging variable type. At first, when the known forms were few, the genus was often regarded as monotypic, or as holding only one species with fixed geographical varieties in the Old and New Worlds and typified in Cakile maritima, the well-known European form. In the next stage each side of the North Atlantic was credited with a solitary species. As the inquiry proceeded, more particularly after Asa Gray had separated the two common American plants from the European $C$. maritima, the balance of distribution was transferred to the American side of the Atlantic. In that direction the later investigations have in the main advanced; and whatever view we take of the limits of the species it cannot be gainsaid that the genus is preponderantly American.

There is, however, a disconcerting lack of agreement amongst later investigators as to the limits of the species. Most of the difficulties seem to be due to the different results obtained from the use of the leaf and fruit characters in the distinction of forms. Having encountered such difficulties, Dr. Millspaugh made a discriminative study of the fruits and seeds of the specimens in the principal herbaria of the United States and defined the relations of the American plants with those across the Atlantic, the results being published under the title of Plantce Utowance (Part I. A) by the Field Columbian Museum (Chicago, 1900). He distinguished ten species, eight being American and two European, no species occurring as an indigenous plant on both sides of the Atlantic. In the Index Kewensis, including the supplements up to 1910 , ten species are enumerated, of which seven are exclusively American; but only six of the species given by Millspaugh are named. The more recent investigators, including Schulz in Urban's Symbola Antillance (1903), seem to have laboured towards the reduction of the species, and I note that Fawcett and Rendle in their Jamaican Flora (1914) speak only of four species in the genus.

However, these differences of opinion concerning the limits of the species do not affect the distribution of the genus, which may be regarded as restricted, with the exception of a representation in the region of the Great Lakes of North America, to the western 
and eastern sea-borders of the North Atlantic in tropical and temperate latitudes and including the West Indian and Caribbean region; but the genus on the eastern side of the ocean does not seem to extend south of Madeira and North Morocco. A curious feature of the distribution is that the genus is not represented by indigenous species on the Pacific shores of the American continent. Harshberger gives no locality on those coasts; and Millspaugh regards the only species which he locates on the Pacific side (C. edentula at Berkeley, California) as introduced.

The uncertainty about the limits of the species does not make my task an easy one. I have made the acquaintance in their homes with three of the species in four different regions, namely, in the south of England, in the Azores, in the West Indies, and on the Pacific Coast of North America. The West Indian species, with which I was familiar in Jamaica and in the Turks Islands is Cakile oqualis (L'Hér.), which has been united by Schulz with two other species (named after Cuba and San Domingo) in C. lanceolata. The fusion somewhat extends the range of $C$. aqualis, which already had the reputation of being the most characteristic and widest spread of the Antillean species. Thus extended, the range covers the Greater and Lesser Antilles, including the Bahamas and the Florida keys, and reaches to the Bermudas. It comprises also the continental coasts of the Mexican Gulf and the Caribbean Sea, past Yucatan to Colombia. It is the species of the Turks Islands; but, except in one island, it is there uncommon. I only noticed it on Greater Sand Cay, where it was represented by a single clump, and on Grand Turk, where it grows in abundance. Since it was found on Grand Turk by Hjalmarsson in 1858, more than half a century before my visit, it would seem that it has long since attained the limit of its colonising powers in the Turks Islands, its scanty distribution over the group being probably due to the havoc executed by the breakers of those tempestuous seas on the shores of most of the islands. In Jamaica I observed it on the north coast and west end of the island, at White River, St. Anne's Bay, Dry Harbour, and Negril; but localities on the south coast are given by Fawcett and Rendle.

The species of the Azores is confined to one locality, Porto Pym on Fayal. It is regarded by Millspaugh as introduced and as belonging to Cakile edentula (Bigel.); but Trelease views it as referable to $C$. americana (Nutt.). From Lowe's description of a common species in Madeira under the name of C. maritima, it would seem to be similar to the Azorean plant. Further particulars concerning this matter will be found in Chapters XVII. and XIX. under the Azores. The species observed by me in 1896 on the Golden Gate beach at San Francisco was probably the same species that, as we learn from Millspaugh, has been introduced into San Francisco Bay (C.edentula). There seems to be no indigenous species on the Pacific coasts of the New World; and this disposes of the statement in my work on Plant Dispersal (pp. 431, 432) that the genus is represented by indigenous species on both sides of North America. My observations on Cakile maritima, the common European species, are given in the work just named. The few notes since made on the coasts of South Devon 
and Cornwall are concerned with its transient occupation of the beaches in places usually within reach of the wash of the waves at the higher tides. A few individuals occupy a beach for a season or two, then disappear, and two or three or more years elapse before the species again gets a footing.

An interesting feature in the distribution of the American plants is the occurrence of two Atlantic coast species (C. americana and C. edentula) on the shores of the Great Lakes. Here in the society of other beach plants of the same Atlantic beaches, such as Lathyrus maritimus, Euphorbia polygonifolia, Psamma arenaria, etc., these maritime species have found a home on the borders of inland freshwater lakes. This invasion of what is now the interior of a continent is regarded by Harshberger (p. 222) as having taken place during the post-glacial submergence of these regions. Such a change of station throws some suspicion on the determining influence of the halophilous inclination when it is so readily thrown off. In this connection one is inclined to recall Kearney's discovery that the amount of salt in sea-beaches is a negligible quantity, and to ask oneself what constant character in the organisation of Cakile plants we can associate with the double station on a sea-beach and on the shores of a fresh-water lake. (For comment on Kearney's discovery see Harshberger in Proc. Amer. Philos. Soc., 1909.)

That the currents are active dispersers of these plants may be inferred from their frequent occurrence in isolated islands, as exemplified below in the case of Cakile lanceolata, though from facts to be subsequently given it may be doubted whether the most buoyant fruits could safely cross a tract of sea more than 300 or 400 miles in width. The difficulties likely to be encountered before a footing can be obtained on an island in the open sea have already been mentioned in the case of the Turks Islands. But they are also illustrated in the case of the Florida sand-keys which are for the most part curving sand-banks, raised three or four feet above the sea. Although Mr. Lansing noted the occurrence of Cakile fusiformis on twelve of the nineteen keys examined by him, the species was as a rule merely represented by a few scattered clumps, and in only two or three instances was it fairly frequent. Always it formed the outposts of the sand-vegetation on the weather side of the key. But Cakile may experience the same difficulties on European beaches in obtaining a footing beyond the reach of the waves in stormy weather. What the waves give, they can also remove, was the lesson taught to me by Cakile on English beaches.

On a long beach on the north coast of Cornwall it would be typically represented by solitary clumps of $C$. maritima lying far apart and all below the highest line of drift. They are derived from stranded fruits that have germinated in the drift, of which results may be seen in the numerous seedlings growing in the midst of the rubbish heaped up by the waves. It is in the upcast wrack of the Norwegian beaches that this species of Cakile flowers and fruits (Sernander, p. 123).

Cakile lanceolata is the West Indian species most characteristic of small isolated island-groups. Thus it occurs in the Cayman 
Islands, on the Alacran Shoals, and in the Bermudas. That the Bermudas received their representatives of the genus through the currents is the opinion both of Hemsley and Millspaugh. Though its capacity for dispersal by this agency is variable, as is shown in the table below, it is significant that the species which has made its home in Bermuda is the plant that may exhibit the greatest buoyancy in its fruits. Yet in this there is a difficulty, since the drifting passage from the West Indies to Bermuda would occupy ten or twelve weeks (see Note 14 of the Appendix); whereas my experiments indicate that under the most favourable conditions the fruits of $\boldsymbol{C}$. lanceolata would on the average float for only three or four weeks.

A similar point is raised by the occurrence of Cakile maritima, the European species, in Iceland. It is shown in my experiments that its fruits are not suited for crossing a tract of sea much over 100 miles in width, whilst the Faroe Islands, the nearest land to the eastward in the direction from which they must have come, are almost 250 miles away, and a drifting passage against the prevailing winds and currents is involved. It would be easier for fruits of West Indian species of Cakile to reach Iceland in the Gulf Stream drift so often cast up on its shores than for those of C. maritima to traverse the distance that separates it from Europe, provided that the fruits possessed in both cases the floating power. But the passage from the West Indies would occupy many months, and the unfavourable climatic conditions would in themselves inhibit the establishment of a West Indian plant. A clue may be offered when we regard the associates of $C$. maritima on the Icelandic beaches, namely, Armeria maritima, Glaux maritima, Lathyrus maritimus, Matricaria maritima, Mertensia maritima and Silene maritima (see Babington in Journ. Linn. Soc., XI., 1871). From the data for five out of these six associates given in my book on Plant Dispersal, it is to be inferred that only two of the plants, Lathyrus maritimus and Matricaria maritima, would have reached Iceland by the currents. In the case of Mertensia maritima, about which I possess no data, dispersal by currents would seem most unlikely. Three or four of the associates, which occur on both sides of the Atlantic and extend into Arctic latitudes, raise quite other questions than those of dispersal. On the whole I am inclined to hold that the Icelandic strand flora, in which the genus Cakile takes a part, mainly reflects the effects of past changes in circumpolar distribution and is but little concerned with the currents.

Taking the case of Cakile lanceolata as representing both potentially and actually the limits of possibilities for the dispersal of the genus by currents, we may, I think, accept the conclusion, which is warranted by the facts given below, that currents may effectually distribute the plants along continental coasts and between islands 100 to 200 miles apart. Currents will not explain the existence of the genus on both sides of the North Atlantic. We must look for the explanation in a common centre of dispersion of the genus in Arctic latitudes when warmer climatic conditions there prevailed. In other words, we must appeal to the theory advocated by Dyer which is discussed in Chapter XV. 
Coming to the mode of dispersal of this genus by the currents it may be at once observed that it is the upper article or joint of the fruit that is alone concerned. It is deciduous and readily detached from the dry fruit, whilst the lower joint remains firmly fixed to the stalk on the plant. The buoyancy arises from the development of spongy air-bearing tissue in the upper article, which is very light when dry and buoys up the enclosed seed which itself sinks in seawater. As shown in the subjoined table, the floating capacity will usually allow the seeds to be carried between 150 and 200 miles. Flotation in sea-water, as indicated by my experiments on the fruits of $C$. lanceolata and C. maritima does not affect the germinative capacity of the seed, nor in fact does prolonged immersion after the fruits have sunk affect it. Martins found that germination took place after fruits of $C$. maritima had been in sea-water for forty-five days, though it is more than doubtful, as is brought out in Note 4 of the Appendix, whether they floated for more than a fraction of this period. In my experiments germination occurred with fruits of $C$. lanceolata that after floating for a week had lain for several days at the bottom of the vessel. The lesson of the experiment of Martins is that a submersion of forty-five days in sea-water will not destroy the germinative capacity of the seeds of Cakile.

The restricted floating capacity arises from a weak point in the buoyancy equipment. The suture between the lateral halves of the joint is exposed in the face of the articulation at its base; and it is here that the water ultimately penetrates into the interior and deprives the article of its floating power. In old weathered fruits this suture becomes more or less patent in the face of the articulation and there is a slit-like opening. From this cause the buoyancy of the joints is not always constant, as is shown in the different behaviour of those of Cakile lanceolata obtained from Jamaica and the Turks Islands.

Nevertheless, although the buoyancy as a rule is limited, there is abundant evidence in the beach-drift of different regions that the currents are effective agents in dispersing the fruits over limited tracts of sea. I found the joints of Cakile to be characteristic constituents of the smaller beach-drift in the south-west of England (Cornwall and Devon), in Jamaica, and in the Turks Islands. Sernander also alludes to them as occurring plentifully amongst the Scandinavian beach-drift (pp. 122, 156, etc.). In all these localities several of the stranded fruits were observed to be in a germinating condition, and not infrequently seedlings were to be noticed growing among the stranded drift-materials.

One may here direct attention to the very interesting suggestion made by Dr. Millspaugh that the differentiation of the species of Cakile is a response to the requirements of dispersal by currents. "The evolution for floatage" (he writes) "seems to have reached its height in the new species growing upon the Alacran Shoals" (C. alacranensis of Millspaugh). Here there is a great development of spongy tissue in the upper joint; and it is argued that "the species-generating force in the genus seems to have been the development of the fruit for disseminating the plants." Prolonged investiga- 
tion and an abundance of fresh materials would be needed before one could discuss this important point.

In the table subjoined are incorporated the results of the author's flotation experiments on the upper joints of different species of Cakile from several regions. It may be inferred from the data there given that the floating powers may vary considerably even in the same species. In two of the columns the results are applied to the transport by currents. A drifting rate of fourteen miles a day, or one hundred miles a week, is taken as representing the usual distance that would be covered under favourable conditions.

\section{Cakile Flotation Experiments}

Results of experiments by the author on the floating capacity in sea-water of the upper joints of the fruits of different species of Cakile. (See explanation above given.)

\begin{tabular}{|c|c|c|c|c|c|c|}
\hline \multirow[t]{2}{*}{ Species of Cakile } & \multirow[t]{2}{*}{$\begin{array}{l}\text { Locality of } \\
\text { Collection }\end{array}$} & \multicolumn{2}{|c|}{$\begin{array}{l}\text { Flotation Period } \\
\text { in Days }\end{array}$} & \multicolumn{2}{|c|}{$\begin{array}{l}\text { Capacity for } \\
\text { Transport by Cur- } \\
\text { rents stated in } \\
\text { miles at the rate } \\
\text { of } 14 \text { miles a } \\
\text { day, or } 100 \text { miles } \\
\text { a week }\end{array}$} & \multirow[t]{2}{*}{$\begin{array}{l}\text { Age of the Fruits } \\
\text { when collected }\end{array}$} \\
\hline & & $\begin{array}{l}\text { Aver- } \\
\text { age }\end{array}$ & $\begin{array}{l}\text { Maxi- } \\
\text { mum }\end{array}$ & $\begin{array}{l}\text { Aver- } \\
\text { age }\end{array}$ & $\begin{array}{l}\text { Maxi- } \\
\text { mum }\end{array}$ & \\
\hline C. maritima . & $\begin{array}{c}\text { Cornwall } \\
\text { Cornwall } \\
\text { Devonshire }\end{array}$ & $\begin{array}{l}7 \\
7 \\
7\end{array}$ & $\begin{array}{r}10 \\
9 \\
10\end{array}$ & $\begin{array}{l}100 \\
100 \\
100\end{array}$ & $\begin{array}{l}140 \\
130 \\
140\end{array}$ & $\begin{array}{l}\text { Recent } \\
\text { Seven months } \\
\text { Recent }\end{array}$ \\
\hline C. lanceolata & $\begin{array}{l}\text { Jamaica } \\
\text { Turks Islands } \\
\text { Turks Islands }\end{array}$ & $\begin{array}{r}25 \\
3 \\
5\end{array}$ & $\begin{array}{r}35 \\
5 \\
7\end{array}$ & $\begin{array}{r}350 \\
40 \\
70\end{array}$ & $\begin{array}{r}500 \\
70 \\
100\end{array}$ & $\begin{array}{c}\text { Recent } \\
\text { Recent } \\
\text { Fifteen months }\end{array}$ \\
\hline C. edentula . & Azores & 9 & 12 & 130 & 170 & Recent \\
\hline
\end{tabular}

The number of fruits experimented on ranged from six to fifteen. The term "recent " is applied to fruits that were experimented on at periods varying from a few weeks to two or three months after they had been gathered in the dry state from the plant.

\section{Additional Experiments.}

The buoyancy in sea-water was also tested in the case of some fruits (upper joints) of the following species very kindly sent to the author by Dr. Millspaugh. As they had been collected several years before, and since only three fruits could be used in each experiment, it seemed best to separate the results from those given above. The maximum results obtained for the flotation period were as follows-

Cakile americana from Lake Michigan 5 days.

C. edentula from Lake Michigan 12 days.

C. alacranensis from the Alacran Shoals 20 days.

C. fusiformis from Dog Key, Mississippi 21 days.

Canavalia obtusifolia, DC.

This creeping or climbing plant has established itself on the beaches of the warm regions of the globe, for instance, on the Pacific and Atlantic coasts of tropical America, on both the east and west shores of 
tropical Africa, in the islands of the Indian Ocean, in the Malayan Islands, and in Polynesia. With the exception of the African coasts, which I have not visited, it came under my notice in all the above regions. It ranks with Ipomoea pes-caproe as one of the most ubiquitous of tropical strand plants.

Yet, in spite of its world-wide distribution in tropical regions and of the fact established by observation and experiment that the seeds are dispersed by currents, the seeds present a strange fickleness of behaviour under the test of experiment. The plant has been discussed in detail in my book on Plant Dispersal; but I will here allude to the results of buoyancy experiments given in that work (p. 579). Of freshly gathered seeds placed in sea-water in Fiji only 10 per cent. as a rule floated after three months. Of seeds which had been kept for three years 50 per cent. floated after eleven weeks. In an experiment on recently collected seeds in Jamaica 40 per cent. floated after a month. The explanation of this behaviour is that on the average only 70 per cent. of the seeds are impervious to water, a result obtained from more recent experiments and recorded in the author's Studies in Seeds and Fruits (p. 94). But the proportion of impermeable seeds varies considerably, being sometimes more and sometimes less; and at any rate the impervious seeds can float for long periods. The impermeable seeds retain their germinative capacity for a long time. Prof. Ewart found that seeds, sixteen years old, were able to germinate, though sulphuric acid was required to start the process (Ibid., p. 96).

The seeds were commonly observed by me in the drift of the Fijian beaches and also on the coast of Ecuador, as well as on both sides of the Isthmus of Panama, the plants being usually noticed in the vicinity. I found them afloat in the drift of the Rewa estuary in Fiji, and they were collected by Moseley amongst a number of other floating fruits and seeds off the coast of New Guinea (Chall. Bot., IV., 291). Though neither the seeds nor the plants were observed by Treub on the shores of Krakatau three years after the great eruption of 1883, the plant was found established by Penzig in $\mathbf{1 8 9 7}$ and by Ernst and others afterwards. I came upon the seeds in the beach-drift of different parts of the Jamaican coast, and they were obtained by Morris from the beaches on the south side of the island (Chall., Bot. IV., 291). They also came under my notice on the beaches of St. Croix, Tobago, and other islands.

The plant is universally distributed in the West Indies, and there were few beaches visited by me that did not display it. It occurs all round Jamaica, and I found it on nearly every beach examined on the north, south, and west sides of the island. It was rarely observed growing away from the coast. However, in Tobago I noticed it a mile inland and about 250 feet above the sea. In the Turks group it is very rare, and was only remarked on two of the ten islands-namely, on Salt Cay on the east side, where a fair-sized colony was thriving on the beach, and on Grand Turk, where it was represented only by a solitary seedling growing in the beach-drift and evidently derived from a seed thrown up by the waves. According to Millspaugh it was recorded by Lansing from seven of the nine- 
teen sand-keys lying west of Key West off the Florida coast; but in all but two cases it was only represented by a single colony. The plant grows commonly on the Bermudian beaches.

It would be unnecessary to give all the data relating to the wide distribution of this shore plant in the warm regions of the New World; but a reference to a few localities which have particular interest may here be made. In the first place, its occurrence on the Pacific coast is not usually stated. However, I found it on the Ecuador coast at Puerto Bolivar and on the beach at Panama. Then, again, Harshberger includes it among the strand plants of the delta of the Mississippi and of the Louisiana coast (Phyt. Surv. $\boldsymbol{N} . \boldsymbol{A}$., pp. 215, 444). In some localities it grows in great profusion. Thus Millspaugh at Santurce, Porto Rico, found it growing on sandy fields near the sea " in great quantity, massing the surface of many acres" (Plantoe Utowana). Amongst interesting insular localities may be mentioned Fernando Noronha. Though it was not recorded by Hemsley amongst the collections made by Moseley during the voyage of the Challenger (1873-76), Ridley observed it growing plentifully in 1887 (Journ Linn. Soc., vol. 27).

It may be remarked in connection with the statement now and then made that the floating pods assist in the dispersal of the species, that this would not happen under normal conditions. The pod dehisces on the plant and often discharges its seeds with some force, a habit common with legumes, where the valves develop a spiral twist when drying. A detached fruit which $I$ had placed in the sun in Tobago burst with an explosion like that of a pistol and threw the seeds ten to twelve feet away. Should an unopened pod be torn from the parent plant and carried off by the waves, the attachment of the valves would soon be loosened and the seeds would soon be liberated and float away.

\section{Cassytha filiformis, Linn.}

\section{Cassytha americana, Nees}

Since Bentham unites the wide-ranging American form Cassytha americana with the widely distributed Old World form $C$. filiformis, we have here a species spread over the warm regions of the globe, in Asia, Africa, America, and Australia, but chiefly, as Hemsley remarks, in maritime districts (Chall. Bot., IV., 185). It is one of the Dodder Laurels, a tropical genus holding at least fifteen or sixteen species, of which two-thirds are Australian. It is noteworthy that this species has been recorded from almost every group of the tropical Pacific, from the Paumotu Archipelago and Tahiti to Fiji and northward to Hawaii. When I met with it in the West Indies I renewed acquaintance with a plant with which I had already been very familiar in Hawaii and Fiji, the results of my numerous observations in the Pacific being given in my previous book on plant dispersal in those regions.

In Hawaii this parasite is occasionally found growing on the beach plants, but it prefers the lower open-wooded region and especially the surface of old lava-flows near the coast. In Fiji it is typically 
a shore plant, but it habitually extends far inland in the savannahlike plains on the dry sides of the islands. It is, however, as a littoral plant that it seems to be most frequently mentioned in the Old World. In the Malay Peninsula, as we learn from Ridley, it is common in open sandy country near the sea (Trans. Linn. Soc. Bot., III., 267 ; 1888-94). On the numerous coral islands of the Jara Sea it grows very luxuriantly, covering the woody and herbaceous plants with a felt-like coat (Schimper's Plant Geogr., p. 341, and Ind. Mal. Strand Flora, p. 188). It is stated below that after the eruption Cassytha filiformis established itself among the strand plants of Krakatau. As Prof. Scott Elliot tells me by letter, it crawls over the low bushes and covers the surface of coastal sanddunes in Madagascar. In the West Indies this plant occupies similar stations. Whilst it is characteristic of the savannahs and lower woods of Jamaica, it is also found at the coast. Millspaugh observed it trailing over the beach sand-dunes on Cayman Brac and in similar situations on Porto Rico (Plant. Utow.). In the Bahamas it grows over the shore plants and is found in the thicket formation inland (Harshberger's Phyt. Surv. N. Amer., pp. 691, 693-4). In South Florida it is a plant of the coastal dunes and of the east-coast pinelands (Harshberger, Trans. Wagner Inst. 1914, pp. 70, 92, 93). Over the West Indian Islands this parasite is widely distributed, and it ranges in the New World from South Florida and Mexico to Brazil.

In the Pacific Islands I found that its small fruits, whether from coast or inland plants, were able to float unharmed in sea-water for months. On the other hand, fruits obtained by me from the moist lower woods of Jamaica displayed no buoyancy, even after being kept for years, the unfilled space in the fruit-cavity to which the floating power is due being absent in this case. The floating capacity is probably as a rule developed in stations where xerophytes thrive, as on the coast and in savannahs.

From its frequent station at the coast, and from its occurrence in small coral islands, it cannot be doubted that the currents take advantage of the buoyancy of the fruits to disperse the plant. As long ago pointed out by Schimper frugivorous birds would also aid in the distribution, the fruits in the moist condition being likely to attract birds. In fact, fruits have been found in the crops of pigeons shot in the Pacific Islands (Hemsley, Chall. Bot., I., 46). Whether birds or currents first carried the fruits to Krakatau after the eruption of 1883 is not known. It appears, however, that the plant was first recognised there in 1897, and that in 1906 it was well established amongst the strand vegetation (Ernst's Nerv Flora of Krakatau).

It seems highly probable that this plant is a gift from the Old to the New World through the agency of the currents. In this respect the behaviour of the genus is closely similar to that of $S$ ccevola as described under the shore plants of that genus. Like Scaevola the genus is predominantly Australian, eleven out of the sixteen known species being peculiar to that region. Of the remainder, three are peculiar to Africa, one is common to Ceylon and Borneo, 
and lastly there is the cosmopolitan species we have been discussing. Fawcett and Rendle, from whose work on the flora of Jamaica these facts of distribution are taken, follow Bentham in regarding Cassytha filiformis and C. americana as one species. The parallel between Cassytha and Scaevola becomes still closer when we reflect that the only species recorded from the New World is in each case the only species that is common to the western and eastern hemispheres, namely, C. filiformis and Sc. plumieri. A somewhat similar parallel is offered by Dodonaea, another Australian genus, which is dealt with under the head of $\boldsymbol{D}$. viscosa.

In their suitability for being dispersed by frugivorous birds there is another point of resemblance between the genera Cassytha and Scaevola. In neither genus, however, could we often appeal to this agency for trans-oceanic dispersal. In this respect $I$ have somewhat changed the point of view adopted in my previous work (p. 71).

\section{Chrysobalanus icaco, L. (Coco Plum)}

This shrub has a special interest, because it is not only widely distributed in the tropics of the New World but also grows in West Africa. It has an edible fruit, and its occurrence on the opposite sides of the Atlantic raises much the same questions that are raised by the Hog Plum, Spondias lutea, which has the same distribution. Both have the reputation of possessing edible fruits, which, however, are not very palatable in the raw state except to animals. With both there is a suspicion that the aborigines may have aided their dispersal, and in both the agency of the currents has been invoked. The efficacy of the last agency is more assured in the case of the Hog Plum, which is discussed at length in Chapter VI.; but for the Coco Plum the ground is not so certain, as is explained below. However, it should be remarked that two eminent botanists, De Candolle and Hemsley, basing their inference on general considerations, regard the plant as dispersed by the currents, though the first named looks upon the interference of man as equally probable (Géographie Botanique, pp. 784, 792; Chall. Bot., I., 43; IV., 279).

From the data given by various authorities it is apparent that Chrysobalanus icaco ranges in the New World from South Florida and the Bahamas through the West Indian region to Trinidad, and from Mexico through Central America by way of Venezuela to Brazil. It evidently grows on all the larger West Indian islands and on most of the Lesser Antilles. In the New World the species may be viewed as possessing two forms, an inland form restricted to that hemisphere and a coast form found also in tropical West Africa. The inland plant, originally differentiated as C. pellocarpus, Mey., frequents moist woods; whilst the coast plant is a typical shrub of the vegetation lining the beach. (I have here followed Fawcett and Rendle in their union of the two species in their Jamaican flora. This was the view of De Candolle, and the exigencies of distribution long since compelled me to support his opinion.)

We must therefore expect to find very different stations assigned to this shrub. This is illustrated in Jamaica, where, according to 
Fawcett and Rendle, it may be found on the seashore and inland at elevations up to 3000 feet. Disregarding its inland stations, I will here refer to my observations on its occurrence at the coast on this island and to those of others in the West Indies and in West Africa. It is instructive to notice its associates, and they are sufficiently varied to cause reflection. At Falmouth (Jamaica) it grew on the drier ground of the coast flats behind the Batis-SalicorniaSesuvium association of the muddy borders of the mangrove belt, and in the company of Guilandina bonducella, Coccoloba urifera, and Borrichia arborescens. On the south side of the island, to the east of the Black River and opposite the Salt Lakes, it grew on a strip of sea-beach fronting the inland marshes in the society of a Pancratium, and served as the host of a conspicuous yellow-coloured Loranth (Phoradendron). In the Virgin Islands it is found amongst the trees bordering the beach, such as Coccoloba uvifera, Hippomane mancinella, and Thespesia populnea; and in the Bahamas it grows on Watling Island behind the Tournefortia-Suriana association in the company of Genipa clusiifolia and Coccoloba uvifera (Harshberger, Phyt. Surv. N. Amer., pp. 686, 690). On the beaches of South Florida and on the dunes in their rear Coccoloba uvifera, the Seaside Grape, is still the constant associate of the Coco Plum, Chrysobalanus icaco, an association on which light may be thrown when we deal with the plant first named (Harshberger, vide infra).

But it is apparent that Chrysobalanus icaco is also a characteristic plant of the great fresh-water morass of the Everglades in the heart of South Florida. There it thrives in the patches of forest, known as the "hammocks," that rise up in the midst of the swamps and serve as sanctuaries for the West Indian vegetation that ages since, when the region of the Everglades was submerged beneath the Gulf Stream, occupied low islands rising up in a shallow sea. It is at home also in this swampy interior at the edge of the cypress swamps and at the borders of streams. In the company of such typical West Indian littoral and estuarine plants as Hippomane mancinella (Manchineel) and Anona palustris, Chrysobalanus icaco has been for ages a denizen of the Everglades (Harshberger in Trans. Wagner Inst., Philadelphia, 1914, pp. 67, 70, 135, 172; and Phyt. Surv. N. Amer., 1911, pp. 230, 698).

In the tropics of the African West Coast, where the Coco Plum is stated to be very common, it figures as a characteristic littoral plant. Writing of the coast near the mouth of the River Nun, Dr. Vogel observed in his journal that "the strand is clothed with jungle close to the sea, consisting of Chrysobalanus icaco and Ecastaphyllum brozonei," the last named being also a West Indian littoral shrub (W. J. Hooker's Niger Flora, 1849, pp. 35, 336).

In the dispersal of this species both birds and currents have played a part. Although its fruit would attract pigeons and birds of similar habit, we could only appeal to such an agency in the case of interisland dispersal. The protection of the relatively thin-walled stone would of itself be insufficient to enable the seed to withstand without injury a sojourn of several hours in a bird's crop, and this unfitness would be emphasised by the imperfectly filled hole at 
one end of the stone, which in time would admit the gastric fluids.

My observations on the suitability of the fruits for transport by currents were made in Jamaica on coast plants. The drupaceous fruits are about an inch long, have a crustaceous fleshy covering, and enclose a prominently ribbed stone (nearly as large as the entire fruit), the walls of which are about $2 \mathrm{~mm}$. thick. Inside is a single seed which does not quite fill the cavity, and it is to this empty space that the buoyancy of the dry fruit is due. But the seeds often fail in a large number of fruits. In one locality I found that only 10 per cent. were seeded. In the case of more or less empty fruits there will usually be found the remains of two seeds, and investigation showed that each of the two ovules, forming the ovular complement of the genus, had developed into seeds, which, after attaining a size of 3 or $4 \mathrm{~mm}$., aborted and shrivelled up. Such empty fruits, though useless for purposes of dispersal, are readily transported by the currents

The fruits in the form of the dry more or less bared stones rarely occur in the Jamaican beach-drift, and when found are usually empty. It was in this condition that I found most of the fruits in the beach-drift of the Black River coast and of the coast near the White River on the north side of the island. The fresh fruit floats at first; but I should not imagine that it would float for a long time, unless the failure of both seeds had resulted in an empty seed-cavity. The dried stones as they lie under the plants are much more buoyant. Four of these selected stones, which had been gathered a few months, were placed in sea-water After two months they were all afloat, and of two cut open one proved to have a sound seed and the other a rotting seed. I should greatly doubt, however, whether the currents, where a period of flotation exceeding two or three months is involved, would prove to be effective agents for the dispersal across an ocean of any sound fruits. A canal, which at one end of the stone leads into the seed-cavity, is merely filled with soft tissue that would in time permit the penetration of sea-water, thus bringing about the death of the seed.

As regards dispersal by currents, the absence of this plant from such a well-examined group of islands as the Bermudas is significant, since so many West Indian strand plants have been carried there through this agency. Nor can we appeal to the presence in the Bermudas of its constant West Indian associate, Coccoloba uvifera, since its indigenous character is doubtful, a matter referred to when dealing with that plant. It is highly improbable that fruits with a sound seed could ever cross the North Atlantic with the Gulf Stream drift, though one might expect to find occasionally on the shores of Europe an empty stone or one with the seed decayed. Nor could the fruits withstand the six or eight months' immersion involved in a passage to West Africa in the Counter Equatorial Current, even if such a traverse was feasible. The chances that the currents could carry the stone with a sound seed from the New World to tropical West Africa may be thus ruled out. On the other hand, a capacity of floating in the sea for two or three months without injury to the 
seed would just bring these fruits within the scope of the agency of the Main Equatorial Current as a carrier of drift from West Africa to Brazil. Though the greater number would probably not survive this test, the few that did so would find on the first sandy coast congenial conditions for establishing the plant. Its spread over the West Indian region through the influence of the same swift current would naturally follow. But before considering the possibility that the New World has derived this species from West Africa, a few remarks may be made on the distribution of the genus.

There can be no doubt that the genus is preponderantly American, whatever view we may take of the limitations of the species. Of the nine species given in the Index Kewensis, five are peculiar to the New World, three to the Old World (mainly Africa), and one is common to both worlds. By some the species are regarded as fewer, but the American preponderance remains. There is thus a basis of support for De Candolle's original contention (Géogr. Bot., pp. 784, 792) that the species common to both worlds, Chrysobalanus icaco, is American in origin. On the other hand, this plant was regarded by J. D. Hooker and Bentham as "possibly introduced" into America from Africa (W. J. Hooker's Niger Flora, p. 336). We are thus on the horns of a dilemma. If De Candolle is right, and certainly the ancient story of the plant in the Florida Everglades gives support to his view, it could not have been a gift from America to the Old World under the present arrangement of the Atlantic currents. If Hooker and Bentham are right, we can appeal to the currents, but we have to face the facts that the genus is predominantly American and that the plant in dispute has been for ages a denizen of the Everglades. Then we have the singular feature, which Chrysobalanus holds in common with several tropical genera existing in both worlds, a feature indicated in the fact that the only species linking the western and eastern hemispheres together are littoral plants that could only cross the Atlantic by the agency of the currents in its narrowest portion between Africa and Brazil, the implication being that Africa would here figure as the giver and not as the recipient. The easiest way out of this disconcerting situation may be to adopt the view that we are not primarily concerned with means of dispersal, and that the original centre of dispersion of the genus lay in the north. In other words, the hypothesis advocated by Dyer may remove most of our difficulties. 


\section{CHAPTER IX}

\section{MISCELLANEOUS PLANTS (continued)}

\section{Coccoloba uvifera, L. (Seaside Grape)}

THIs is one of the most familiar of the trees growing by the seashore in the West Indies. It is able to adapt itself to a variety of stations at the coast. Thus, it often grows among the trees and shrubs lining the sandy beach, when it is associated with Chrysobalanus icaco, Ecastaphyllum brownei, Guilandina bonducella, Suriana maritima, Thespesia populnea, etc. But it is almost as much at home on a low, rocky coast in the company of the Seven-year Apple (Genipa clusiifolia), and may not infrequently be found in the mangroveborder association, growing either with Conocarpus erectus on the flanks of the Laguncularia fringe or with Avicennia on the mud-flats bordering salt-water lagoons. Where low, sandy plains lie behind the beaches, it may extend some distance inland.

It belongs to a genus peculiar to the tropics of the New World and holding a large number of species, 140 and more, that find their principal station in the mountain forests and on the open-wooded plains of the West Indies, Central America, and tropical South America. This shore tree, which varies greatly in size, is spread over the West Indian region, ranging from South Florida and the Bahamas to Trinidad, and extends along the eastern borders of the continent from Central America to Venezuela, the Guianas, and Brazil. It grows in the Bermudas, and, although it now behaves as an indigenous plant on the sandy and rocky coasts (Harshberger, p. 703), it was marked in a list of plants furnished by the Hon. J. H. Darrell about forty years ago to the Governor, Sir J. H. Lefroy, as from the West Indies (Hemsley in Chall. Bot., I., 61). Unlike many other West Indian littoral trees and shrubs it has not been recorded, as far as I know, either from the Pacific coasts of America or from the West Coast of Africa. Fawcett and Rendle, the most recent authorities, restrict it to the eastern side of the New World, and I may add that when examining the shore vegetation on both sides of the Panama Isthmus, I noticed it only on the north side, as at Colon.

As a rule where the plant grows it is found in abundance. In the West Indies I studied it as a shore tree at St. Croix, in numerous places around the coasts of Jamaica, in the Turks Islands, on Grenada and on Tobago. It was observed by Millspaugh in the Cayman Islands (Plantoe Utowanx), and its occurrence there is suggestive; 
but it would seem to belong to a late stage in the plant-stocking of isolated small islands. From the circumstance that Mr. Lansing recorded it from only one of the Florida sand-keys and regarded it as introduced, it would not appear to be one of the early plants that establish themselves on newly formed islets in these seas.

In my notes I have only recorded it from four of the islands of the Turks Group, namely, on Grand Turk, Long Cay, Cotton Cay, and Salt Cay; but where found it is usually abundant. Amongst other localities on Grand Turk it grows in quantity in the interior of the low-lying level region of the southern half of the island, where on a sandy soil it is associated with shrubs or small trees, as the case may be, of Bontia daphnoides, Dodoncea viscosa, Euphorbia vaginulata, Sophora tomentosa, etc.; but here, as in other parts of the island, it extends in places to the beach. It thrives on the edge of the rocky plateau of Long Cay on the leeward side, where it is associated with Genipa clusiifolia, the Seven-year Apple. In Cotton Cay it grows in dense thickets on the rocky surface of the wind-swept eastern extremity of the island, the Seven-year Apple growing under its lee; but the constant exposure to the strong trade-wind has compelled it to assume a semi-prostrate, straggling habit of growth. Its behaviour in the Turks Islands closely corresponds with that in the rest of the Bahamian region, where it grows not only on the sandy and rocky shores, but on the dry plains in their rear, and is often associated in coastal thickets with Genipa clusiifolia (Harshberger, Millspaugh, etc.).

The fruits are of regular occurrence amongst the smaller drift of beaches wherever the plants grow on the coast; and not infrequently they may be found germinating in the drift washed up by the waves, together with seedlings derived from the stranded fruits. The fallen fruits lie in numbers under the trees lining the beach, and they could be easily swept off by the waves at the higher tides. They germinate in numbers on the ground beneath the trees, and numerous seedlings are to be seen striking into the sandy soil. This inclination to rapid germination on the soil would militate against the chances of effective dispersal by currents, since seeds that germinate easily would, as a rule, be imperfectly protected against the penetration of sea-water, and in many cases these fruits, when swept off the beaches by the waves, would be in the early stage of germination.

We come now to the methods of dispersal. The purplish, fleshy fruits, 15-20 $\mathrm{mm}$. long, at once suggest the agency of frugivorous birds; and it is in this fashion that Hemsley considers the overseas dispersal of the plant may be explained (Chall. Bot. Intro., p. 49). In this connection it is noteworthy that Coccoloba laurifolia, one of the species that come next to $C$. uvifera amongst the West Indian species with wide ranges, is known in Florida as the Pigeon Plum (Fawcett and Rendle). Pigeons would probably be effective agents of local dispersal or of inter-island distribution across narrow tracts of sea; but it is very doubtful whether they would be effective for long ocean traverses that could not be accomplished by a bird in a few hours. The defects in structure that unfit the fruit for prolonged flotation in the sea, as below described, would also render 
it less able to withstand the injurious influence of the digestive fluids of a bird for many hours.

Though in appearance drupaceous, the fruit is described by botanists as a nut wholly enclosed in the fleshy accrescent perianth. When the fleshy covering has been removed, the nut is seen to consist of a hard shell containing a kernel enclosing an embryo with foliaceous cotyledons in a ruminate albumen. From the history of such a structure alone, one would be inclined to doubt the impermeability of the seed-vessel. In this case the nut has a thin crustaceous shell with an outer membranous skin, the shell being wanting at the lower end of the fruit, which seems to be a character of the family. The gap in the shell is filled up with softer tissue almost like a plug; and it is here that the place of weakness as regards impermeability to fluids lies.

Neither the entire fruit in its moist, fleshy coverings, nor the freshly removed nut have any floating power; but after the fruit has dried up on the ground it acquires buoyancy. It is in this condition, with the withered outer coverings more or less removed by insects and other agencies, that one finds these fruits under the trees, the floating power being largely due to the fibro-membranous covering investing the shell, and to its association with spongy cellular tissue at the lower end. In Jamaica I made three experiments in sea-water on the dried fruits gathered from under the trees in different localities. In the first experiment half remained afloat after nine days. In the two others 50 and 60 per cent. were floating after a fortnight's immersion. The respective extreme limits of the floating capacity in the three experiments were two weeks, four weeks, and seven weeks. But water had always penetrated into the seed-cavity of the sunken fruits, and as the fruits soon turned the sea-water putrid, it had to be changed daily, results far from indicating any special fitness of the fruits for prolonged transport by the currents. On the whole I would infer that the penetration of sea-water would in the course of a few days or weeks render these fruits quite unsuited for effectual distribution over the ocean, and that although they would float for a few weeks the germinative capacity would be lost, as a rule, in a week or two.

A practical inference from these results is that Coccoloba uvifera could scarcely have reached the Bermudas with the aid of the currents. The same objection on structural grounds must be raised to the view that the fruits could withstand the influence of the digestive juices of a bird during its passage across 800 miles of sea by the shortest route to the Bermudas from the Bahamas. The view of the residents that the tree has been introduced in later years is probably correct.

From the foregoing remarks it would appear that a stretch of from 100 to 200 miles of sea would be all that either the bird or the current could accomplish in aiding the disposal of Coccoloba uvifera. Yet the defects of the fruit that limit its capabilities for dispersal are generic characters. It is, therefore, scarcely likely that any inland species could be better adapted for distribution by birds, whilst in its station alone it would lack opportunities for distribution by currents. We could not go far wrong if we argued that in Coccoloba uvifera 
we see at their best the capacities of the genus for dispersal. Yet measured by the geographical range they have produced effects in some inland species (species that could have owed but little to currents) which give the inland plants a rank near that of $\boldsymbol{C}$. uvifera. Thus, in Jamaica, out of nineteen species enumerated by Fawcett and Rendle eight have been recorded from outside the island. Four of them, excluding $C$. uvifera, are inland, and often mountain, species that have a distribution in the West Indies nearly as wide as the species just named, and three of the four reach the South American continent. It is, therefore, apparent that currents have not endowed $C$. uvifera with a much greater range than is possessed by some inland species that could owe nothing to currents; and it is quite likely that currents have not been the principal agent in its dispersal.

\section{Colubrina asiatica, Brongn.}

This littoral shrub is discussed at length in my book on Plant Dispersal, and I have there dwelt on the suitability of its buoyant seeds for dispersal by currents and on their occurrence in river- and beach-drift in the Pacific islands. It is distributed over the warm regions of the Old World including the African East Coast; but I have found no reference to its occurrence on the West Coast. Grisebach gives it as a West Indian plant, but for Jamaica only. It should, however, be at once observed that not one of the several other authorities consulted (Hemsley, Urban, etc.) mentions it as occurring in the West Indies or in the New World, so that we seem to have here the same difficulty that, as shown in a subsequent page, is presented by Thespesia populnea.

I found it in fruit growing abundantly beside a beach at Dry Harbour on the north coast of Jamaica, where it was associated with such characteristic strand trees and shrubs as Coccoloba uvifera, Conocarpus erectus, Guilandina bonducella, and Suriana maritima, and it was the most frequent of them all. The seeds are indistinguishable from those of the plant in the islands of the Pacific and display similar floating powers.

It may be that the difficulty lies in the species being very rare in the tropics of America. The genus, which consists of twelve to fifteen known species, is mainly American, a fact that in itself should cause us to hesitate in excluding it from the New World, an opinion expressed by the writer in his book on Plant Dispersal (p. 563) before he visited the West Indies. As tested by him in Fiji, the seeds of this species float unharmed in sea-water for many months, and they are even better fitted for dispersal by currents than those of many other littoral plants. There are, at least, two West Indian species, Colubrina ferruginosa and $C$. reclinata, that are widely spread in that region and may be found occasionally in littoral stations (Grisebach, Urban, Millspaugh).

We may add that Colubrina asiatica figures amongst the later accessions to the flora of Krakatau, its seeds being derived from the neighbouring coasts, where it thrives (Ernst). 


\section{Conocarpus erectus, L.}

This small tree, which finds its most characteristic station at the drier borders of mangrove swamps, has the distribution of the American mangrove formation, occurring on the Atlantic and Pacific shores of the New World and on the West Coast of Africa. Though not one of the mangroves, it is a constant associate of those plants and ranges with them throughout the West Indian region, reaching north to South Florida on the Atlantic side and to Lower California on the Pacific side, and following the mainland south to Ecuador on the west and to South Brazil on the east. Its occurrence on the Pacific coasts of tropical America is noted by Hemsley (Chall. Bot., II., 32). It was observed by myself on the coasts near Panama, and also on the shores of Ecuador, where it was also noticed by Baron von Eggers. In my book on Plant Dispersal I omitted, on page 488 , to include it amongst the vegetation of the beach of Jambeli Island off the Ecuadorian coast. Millspaugh (Planto Utorwance) and Harshberger (Phyt. Surv. N. America) give it two localities in Lower California, and the former adds Acapulco on the Pacific coast of Mexico. Its ability to establish itself on isolated island groups is shown by its existence on the Alacran Shoals and the Cayman Islands (Millspaugh), and particularly by its occurrence in the Bermudas and in the Galapagos Islands.

Grisebach includes the Marianne Islands (Ladrones) in his list of localities. Its occurrence there, though far from impossible, is scarcely probable, since it has not been found on any of the archipelagos in the Pacific excepting the Galapagos Islands. Dr. Rendle suggests that there may have been a misreading of the locality, since there is in the Herbarium of the British Museum an old specimen from Menzies labelled "Marias I', San Blas," off the west coast of Mexico (letter cited).

This species is a most variable one, a behaviour which is evidently in response to the different stations in which it is able to thrive, since, as shown below, though most typically at home on the borders of the mangrove it can accommodate itself to almost every kind of station that a coast can offer. It presents all gradations between a prostrate trailing shrub and a moderate-sized tree, usually exhibiting itself as a shrubby tree seven to ten feet high. Grisebach gives three varieties, and Millspaugh makes five (Plant. Utow.); but doubtless there are more. The prostrate forms generally grow on rocks.

All West Indians know the Button-tree, as they call it. In Bermuda it is termed Button-wood and also Wild Mulberry, from the changing colour of its fruits, first white, then reddish, and then brown. But its singular roundish fruits are much more like the cones of the Alder. In fact, Alnus maritimum was one of its earliest botanical names, and Alder-tree is still one of its West Indian names. Grisebach also gives, as another of its appellations, Zaragoza Mangrove, I suppose from some place on the shores of the Spanish Main. I was familiar with it in a number of places, wherever, in fact, the mangroves came under my observation, as on St. Croix, Jamaica, Turks Islands, Trinidad, Colon, Panama, and the coast of Ecuador, etc. 
Though not a mangrove, it nearly always accompanies the formation; yet it can accommodate itself to the dry, sandy beach or to the dunes behind, to a muddy flat, and even to a rocky shore. Its various stations are well illustrated in Jamaica, where it occurs all round the island; but rarely can one dissociate it altogether from the surroundings of a mangrove swamp; and in most cases where it grows on a sandy beach fronting the coast a mangrove swamp lies in the rear of the beach. Though in Jamaica and in other islands it may be found growing on a typical dry, sandy beach and on a rocky coast, it is around the mangrove borders immediately skirting the Avicennia and Laguncularia trees, which form the margin of the formation, that it finds its most typical station. In this connection it often skirts a mangrove swamp on the land side, and when it is found on the seaward side it is usually growing on a thin strip of sandy beach thrown up by the waves. It is often mixed up with Laguncularias and Avicennias on the exposed muddy shores of lagoons communicating with the sea. Quite remarkable is its frequency in the Black River Morass. Here, though it seemed to prefer drier ground, it might be observed two miles inland associated with Typhas and tall sedges. Its variety in coastal stations is well illustrated in Harshberger's work. But it is to its association with the outer mangrove growth of Avicennia nitida and Laguncularia racemosa that he chiefly refers, as in the case of Cuba, the Virgin Islands area, the Bahamas, and the Californian Peninsula, the designation of "Conocarpus-mangrove formation" being employed. Yet he speaks of its growing, either prostrate or in dwarfed condition, on coastal rocks in Bermuda and in the Bahamas; whilst in the locality first named it forms thickets on the dunes.

All its capacities for different stations are displayed in the Turks Islands, and in fact they are all illustrated on Grand Turk; but the destruction of much of the original extensive mangrove formation on the two largest islands, Grand Turk and Salt Cay, has often given prominence to stations away from the mangroves. However, in the first-named island it is still to be seen associated with Laguncularias on the land side of the swamps. On the rocky surface of Long Cay it thrives in association with Borrichia arborescens; but it adapts itself to the great wind-pressure, to which it is there commonly exposed, by adopting a semi-prostrate habit, like several of the shrubs (Tournefortia, Suriana, etc.) on these windward cays. Here it clambers over the rocks, and is not more than one or two feet in height. This is evidently the variety " procumbens " of Jacquin, as given by Grisebach. It thrives on the weather side of Salt Cay, both at the borders of the beach and on the dunes behind in the company of Tournefortia gnaphalodes and Suriana maritima. It may be one of the prevailing small trees or shrubs in the half-stony, half-sandy interior of an island like Cotton Cay, where it is in the company of the Turk's-head Cactus; but even here it may be surmised that its original station was around the central lagoon with the mangroves that have since disappeared. This plant is one of the marginal associates of the mangrove belt that are able by their greater adaptability to survive the destruction of the mangroves at the 
hands of man. Its capacity in this respect is exemplified on Gibbs Cay, where it grows on the dry sandy slopes of the island. On half of the cays that form the Turks Group, namely, on Round Cay, Penniston Cay, Pear Cay, Eastern Cay, and Greater Sand Cay, the plant was not observed.

The observations made by Mr. Lansing (and described by Dr. Millspaugh) on the Florida sand-keys west of Key West, are of interest in this connection, since the method of stocking newly formed islands is there illustrated. Out of nineteen keys examined, five displayed the plant; and it appears that where it is conspicuously absent from a group of the keys, as in the Tortugas, this is to be attributed to the fact that they lack the mangroves with which this tree is usually associated. Yet it is rarely in great quantity on any of these Florida sand-keys. Four out of the five possessing it displayed only one or two moderate-sized colonies, and it was only in the fifth that it was well represented. The station was nearly always the same, namely, at the back of the vegetation of the exposed sandy part of the islet and bordering the Avicennias that fringed the great colonies of Rhizophoras.

Although it would be wrong, as Schimper also observes (p. 64), to number Conocarpus erectus with the mangroves, it would be equally wrong to place it with the typical trees and shrubs that line the sandy beach. From the standpoint of station it comes between the two; but in the matter of its distribution it has the range of the mangroves and accompanies them almost everywhere. When I first met with this plant on the coasts of Ecuador and Panama, its double station appeared very puzzling. But I found that this was recognised by Baron von Eggers, who, whilst studying the Ecuadorian strand plants, placed Conocarpus erectus in different localities in the mangrove formation and in the sandy-beach flora. This is the dilemma in which the plant frequently places the botanist, and it is one from which he can free himself by investigating the stages of the plant-stocking of newly formed islets in these seas. Such an inquiry has been accomplished in the case of the Florida sand-keys by Mr. Lansing and Dr. Millspaugh. The last-named botanist makes a special association for this locality of the plants of the mangrove borders, including Avicennia nitida, Laguncularia racemosa, Conocarpus erectus, etc.; and he shows how in the case of a young Rhizophora colony, recently established on a newly formed sand-key, Conocarpus erectus may take the place of the usual Laguncularia fringe.

The small scale-like achenes, which are gathered together in a rounded cone-like fruit-head, readily become detached when the head dries. They average about $4 \mathrm{~mm}$. across and possess great floating power. Although Schimper did not test their buoyant capacity, he rightly postulated it from their structure (Ind. Mal. Strand Flora, pp. 170, 180), which he compares with that of Terminalia fruits of the same family. Within the thin, impervious, shelllike outer skin there is an extensive development of spongy airbearing tissue, and within this is the seed protected by a hardened layer of the endocarp. No part of the fruit or seed has any floating 
power, except the spongy tissue. A number of the achenes were placed in sea-water in Jamaica, and after two months they all floated buoyantly and contained in some cases sound seeds. Evidently they could float for a long period, and could certainly be carried by the Equatorial Current across the Atlantic from West Africa to Brazil.

But there is an important point to notice in this connection. Although the plant fruits abundantly it oftens matures scarcely any seed. One may examine a number of the achenes and find neither seed nor stone, or at all events only in a few cases, as in a sample from the Turks Islands, where only 3 or 4 per cent. contained a seed. This was remarked by Schimper (p. 171), and he quotes Bentham and Hooker to the effect that this is a frequent phenomenon. But I should imagine that it rarely happens that one meets with the experience of Schimper, who found every fruit examined to be seedless. Thus, whilst writing these lines, I have examined a sample of fruits from Jamaica, and find about 10 per cent. seeded. As a set-off against this defect in seeding one must place the abundant fruiting of the plant. Taking the average number of fruit-heads on a panicle at fifteen, and the average number of achenes per head at thirty-three or thirty-four, then each panicle would contain 500 achenes and, taking the proportion of seeded fruits at 4 per cent., twenty seeds. Each small tree must develop a large number of these panicles in a season. Suppose we place them at fifty, which is probably below rather than above the average, then each plant would mature a thousand seeds, which I imagine would be as many as an ordinary Terminalia tree would mature in a single season.

Schimper undoubtedly regarded this plant as dispersed by the currents, and the same position was taken by Hemsley in his discussion of the Bermudian flora (Chall. Bot., I., 48). Millspaugh, however, in his paper on the Florida sand-keys, regarded it as probably distributed by birds. I think, however, that a good case has been made for the currents. It may be noted in conclusion that there is every reason for believing that it is truly indigenous, and that it reached Bermuda with other West Indian plants characterised by Millspaugh as belonging to the association of the mangrove border. Hemsley recognises this plant as probably one of the four that can be identified from the description of Jourdan, who accompanied the expedition of Sir George Sommers that was wrecked on the Bermudas in 1609. It is noteworthy that three out of these four early Bermudian plants, namely the Prickly Pear (Opuntia), the Juniper (J. bermudiana), and the Palmito (Sabal blackburniana) had evidently been established there through the agency of frugivorous birds (Chall. Bot., I., 49; II., 3).

\section{Crudya spicata, W.}

In its range the leguminous genus Crudya presents most of the difficulties offered by Chrysobalanus (p. 193). Out of fourteen known species all are American with the exception of one African 
and one Philippine species, the most important difference between the two genera being that Crudya, unlike the other genus, has no species common to both the American and African sides of the tropical Atlantic. This difference is associated with the fact that when we compare the two species of these genera that are most likely to be dispersed by the currents, Chrysobalanus icaco of the seashore and Crudya spicata of the fresh-water morass of the lower levels, the only one that could perform an ocean traverse through the agency of its floating fruits or seeds is Chrysobalanus icaco, the West African shore plant. But even here the traverse of the ocean is restricted by the limited floating capacities of the fruit to the passage in the Main Equatorial Current from the Gulf of Guinea to Brazil.

The distribution in the West Indies of the trees of the genus Crudya, as indicated by Grisebach, is very interesting and provokes inquiry. Three species are named, of which two are described as frequenting swampy districts; whilst the station of the third is not mentioned. All occur in the Guianas, one of them (the species under consideration) being found also in Jamaica and the other two also in Trinidad.

It is with the species at home both in Jamaica and Guiana, namely, Crudya spicata, that we are specially concerned, though it is highly probable that the general features of its behaviour will be reproduced by the other two species. This tree raises all the questions presented by Symphonia globulifera (p. 243) and Grias cauliflora (p.211). It is especially comparable with the first named, since both occur in Guiana. All three plants are trees of the riverside. In all three cases the trees add their fruits or seeds to the floating river-drift, and in all three cases the floating fruit or seed is usually found in the germinating condition. In not one of these three trees do the means of dispersal explain the presence of the same, or, as in the case of Grias, of closely allied species in the large West Indian islands and in the South American mainland. All three species are in the same sense "difficult" plants. They are all of the greatest significance to the student of distribution, and in all of them he is forced to admit that " means of dispersal " do not explain " range."

Crudya spicata, according to Grisebach, flourishes in the great morass of Westmoreland in Jamaica, and Britton has more recently referred to it in the same locality (Harshberger, p. 678). I found it in that district on the banks of the Cabarita River in association with Grias cauliflora. It also came under my notice on the banks of the Black River near Lacovia. The flat ligneous legume, which is about $3 \frac{1}{2}$ inches long and tardily dehiscent, contains one or two large seeds which possess only thin, pervious, membranous coverings that afford no protection against drying and but little against the penetration of water. The pods are to be seen afloat in the riverdrift as well as the seeds; the last owing their buoyancy to a large central cavity between the flat cotyledons, the embryo itself having no floating power. When the seeds occur in the floating drift, they look rather like those of Entada scandens, and the Black River people give them the same name of "Cacoon"; but they are readily dis- 
tinguished by their soft coverings. The floating pods are much less frequent.

Quite 80 per cent. of the seeds afloat in the Black River drift were in a germinating condition, a result not to be surprised at when we reflect on the unprotected state of the seed. The germinating seeds when carried down to the sea would soon be destroyed by the salt water; whilst the few that had not begun to germinate would, on account of their unprotected character, meet the same fate. The buoyant capacity would, of course, be limited under any condition, and the tendency of the seeds to germinate afloat would render them quite ineffective for purposes of dispersal by currents. I did not learn how the seeds liberated themselves from the pod, whether on the tree or in the river. But it seems probable that in the last case the pod takes up water, and that this leads to its rupture through the swelling of the seeds. This appears to be indicated by the fact that the seeds afloat in the river are too large for the pod as it grows on the tree. The germinating seeds are thrown up in numbers on the beaches near the Black River estuary, and shrivel up in the sun. The pods were not to be found in the beach-drift, and evidently they do not reach the sea.

Seeds of a species of Crudya are brought down by the Orinoco and deposited in the germinating state with much other drift on the south shore of Trinidad.

Some matters have still to be investigated relating to Crudya spicata; but enough has been said to show that it possesses no effective means for overseas dispersal. We cannot look there for an explanation of its range.

\section{Dodon ea viscosa, L.}

This plant is discussed at length in my work on Plant Dispersal (p. 338, etc.). Here, as there, Bentham is followed in the inclusion within this species of nearly all the extra-Australian forms. In the West Indies I renewed my acquaintance with this cosmopolitan plant, more especially in Jamaica and the Turks Islands. The form that I experimented on in Jamaica was Dodonaea burmanni, DC.; but, as Grisebach observes, both this form and that of $D$. viscosa proper grow on the seashore in that island. Since they occupy the same stations and accompany each other over most of the warm portions of the globe, both as littoral and inland plants, the facts of distribution would in this respect go to support Bentham's view of the comprehensive nature of the species.

The form above named grows in Jamaica among the vegetation bordering the beach and on the drier mud-flats and behind the mangrove fringe of the salt-water lagoons in the Black River district, where it is associated with Conocarpus erectus, Coccoloba uvifera, etc. Millspaugh speaks of Dodoncea viscosa growing on the sandy beach at Grand Cayman (Planta Utowance), and Harshberger mentions it as a dune plant in Bermuda (p. 703).

The dark round seeds, 2.5 to $3 \mathrm{~mm}$. in diameter, float in seawater, their buoyancy being due to the unfilled space in the seed- 
cavity, neither coats nor kernel having independent floating power. Of some tested in Jamaica half were afloat after six and a half weeks in sea-water, most of them with sound kernels. Schimper found that seeds of $D$. viscosa floated from ten to sixty days (p. 165).

In the Turks Islands this plant only came under my notice on Grand Turk. There, in the company of Sophora tomentosa and of plants peculiar to this region, it thrives in the sandy interior of the southern part of the island, but does not appear on the beach.

Dodoncea offers in its distribution much the same problem that is presented by Cassytha and Scarvola as discussed in other pages of this work. Here we have three genera, in great part Australian, which are, however, represented over the warm regions of the globe by one or two species typically littoral in their habit, but able in the case of those of the first two genera to accompany xerophytic plants far inland. Here we have a clue to distribution, which if thoroughly investigated might lead to rich results, though it would require many years of travel and research. It can only be said here that my later inquiries in the West Indies go to confirm the general inference given on page $\mathbf{3 4 1}$ of my previous work, namely, that in the case of Dodoncea viscosa currents alone could not account for its distribution in oceanic islands like Hawaii, and that if we placed the agencies of dispersal in their order of effectiveness they would be, first, granivorous birds, then the currents, and lastly man.

It may here be observed that this plant was found established on Krakatau in 1906, more than twenty years after the great eruption. It was also noticed on the neighbouring coast of Sumatra (Ernst, pp. 17, 40). As one of the plants of the old dunes it is found near the coast all over New Zealand, and has also reached the Chatham Islands (Cockayne's Report on the Dune Areas of Nerw Zealand, 1911, pp. 30, 33).

\section{Ecastaphyllum brownei, Pers.}

This small leguminous shore tree, which is not only widely distributed in the tropics on the American side of the Atlantic, but occurs also on the West Coast of Africa, is one of the commonest plants bordering the beach in these regions. It extends from South Florida through the West Indies to Southern Brazil, and is found on both the Atlantic and Pacific shores of Central America. It is one of the plants that De Candolle regarded as at home in America, but as naturalised in Africa. In West Africa, however, it behaves as an indigenous tree; and when we read in Dr. Vogel's journal quoted in Hooker's Niger Flora, that with Chrysobalanus icaco it forms the jungle that clothes the strand near the mouth of the River Nun, we are reading of the association of two typical West Indian shore trees or shrubs in tropical West Africa. Both of them were viewed by De Candolle as American plants naturalised in Africa (Géogr. Botan., p. 792); yet both of them would be quite unfitted, as regards their fruits, to accomplish in an effective state the long drift involved in the passage from the American to the African continent by the Gulf Stream route. The only Atlantic traverse avail- 
able for them would be the shortest, namely, from the West African coast to Brazil in the Main Equatorial Current.

I was familiar with this shore tree in different places, and especially in Jamaica and at Colon; and its pods were a frequent constituent of the drift on the beaches of those localities. The pods were amongst the collection of beach-drift made by Morris in Jamaica, their seeds appearing quite sound (Chall. Bot., IV., 300). When, however, we examine their capacity for trans-oceanic dispersal by currents, we find it insufficient. They are too fragile for withstanding the buffeting involved in dispersal by ocean currents for more than a few weeks; and they soon begin to decay and to admit water, against which the thin coverings of the enclosed seed could afford no protection. The currents have been effective agents in establishing many of the West Indian plants in Bermuda; but this tree is not one of them. This is very suggestive, because almost all of them are well suited for dispersal by currents; and the inference is that, though the currents could carry these pods unharmed from island to island in the West Indies, they have not been able to carry them in this condition to the Bermudas. The agency of the drifting log could scarcely be invoked, since, as we shall see, the question is not so much one of buoyancy as of the inability of the pod to preserve the seed from injury through the penetration of sea-water, and this danger would still threaten a pod in the crevice of a drifting log. It is significant that these pods did not come under my notice in the stranded drift of the Turks Islands; nor does the plant grow in the group.

The legume is a single-seeded, flat, somewhat oblique, oblong pod, about an inch in length. It floats buoyantly in the dry state; but it owes its buoyancy entirely to the air-bearing tissue in the walls of the pericarp, the seed possessing no floating power and filling the seed-cavity. But for purposes of prolonged oceanic transport the pod is too fragile, and is not sufficiently impervious to water, the thin seed-coverings also offering no protection against sea-water. In appearance the pod does not seem much better fitted for withstanding prolonged sea-water flotation than the dried pod of Pisum sativum. Under the quiet conditions of two experiments made in Jamaica, the pods showed no tendency to sink after a month's flotation, but in some cases water had penetrated and the seed was decaying, and there was little to indicate that the seed would retain its germinative capacity after the pod had been exposed for more than a few weeks to the "rough-and-tumble" of oceanic transport.

\section{Erythrina}

Reference may first be made to the supposed seeds of this genus thrown up on the Orkney Islands and on the coasts of Scandinavia, which are referred to in Chapter II. (pp. 23, 26). The Orkney drift seed figured by the elder Wallace is evidently an Erythrina seed, and the "Bent-stones" (Buesteen) of the early describers of Scandinavian foreign drift may probably be placed here. Tonning, a pupil of Linnæus, includes Piscidia erythrina amongst the plants contributing to the Scandinavian drift (Amœnitates Academicae, VII., 477, as quoted 
by Hemsley in Chall. Bot., IV., 278), and Gumprecht, employing the same reference in page $\mathbf{4 2 0}$ of his paper, observes that Tonning referred the Scandinavian "Buesteen" to Piscidia erythrina. This leguminous tree, as shown below, is not at all likely to have furnished the "Bent-stone" seeds of the Scandinavian beach-drift; and it is noteworthy that Sernander, the most recent writer on this subject, who was doubtless guided by Lindman, excludes it from his list of Tonning's identifications.

Piscidia erythrina, L., is a West Indian tree, the seeds of which, as described in Grisebach's work, are one-third of an inch long, black, sub-compressed, and transversely oblong. They evidently would not be described as "Bent-stones" or "Curved-stones"; and it is very unlikely that they possess buoyancy. Though the tree is common in the West Indies, its seeds have never been recorded from the beach-drift.

There is, however, abundant evidence to show that the seeds of littoral species of Erythrina, to which the name of Bent-stone would apply, are dispersed by currents in the Indian and Pacific Oceans, and I have dealt at length with the matter in my book on Plant Dispersal (pp. 141, 435, 437-8, 489, 577). In those regions they figure in stranded beach-drift and in the floating drift of rivers. In the West Indies the species with buoyant seeds do not seem common enough to enable them to figure in the beach-drift. But on the South American mainland, as illustrated in the case of the estuaries and beaches of Ecuador (Ibid., p. 489), Erythrina seeds are abundant in floating and stranded drift, and may be observed miles out at sea off the river mouths. A systematic inquiry into the buoyancy of the seeds of the New World species of the genus is needed. I experimented on those of Erythrina velutina and E. corallodendron, neither of which are littoral species. In the first case most of the seeds have buoyant kernels, two-thirds floating in fresh-water and nine-tenths in sea-water. Of four seeds that floated in sea-water three were afloat after a month. The seeds of Erythrina corallodendron displayed no floating power and possess non-buoyant kernels.

\section{Genipa clusirfolia, Gr. (Seven-year Apple)}

This remarkable maritime shrub, which attains a height of from four to six feet in the Turks Islands, has a limited distribution, being restricted according to the authorities to Cuba, the Bahamas, and South Florida, though its presence in Hispaniola would seem probable. Although it is well distributed over the Bahamian region, extending to the extreme south-easterly sub-groups, the Inaguas, the Caicos Islands, and the Turks Islands, it has not been recorded from Bermuda. Its absence from the Florida sand-keys west of Key West is of interest, since it grows on the Florida coast; whilst this and the other negative features of its range go to suggest a small capacity for dispersal by currents. It belongs to a genus that is confined to the warm regions of the New World.

Yet there is much to attract the student of dispersal in the "Sevenyear Apple," the name by which it is known all over the Bahamian 
region. The origin of the name is obscure, and it promises to remain in obscurity, since Catesby, who was in these islands about 1725, remarks in his work on the natural history of this region (I., 59): "I know not for what Reason the Inhabitants of the Bahama Islands call it the Seven Years Apple." In this connection it should be noted that in January and February 1911, during my sojourn in the Turks Islands, it was in flower and unripe fruit. Catesby states that it ripens its fruit in seven or eight months. One may notice that the name of "Seven-year Vine" is according to Grisebach applied in the West Indies to Ipomøe tuberosa, a widely distributed plant with an inedible tuber, dealt with in Chapter VI.

I found Genipa clusiifolia growing on four of the ten islands of the Turks Group, namely, Grand Turk, Long Cay, Cotton Cay, and Greater Sand Cay. On Grand Turk individual plants grew amongst the rock masses at the foot of the bluff that rises in the rear of the broad beach at the southern extremity of the island. It also grew on rocky ground in the interior of the island in different localities, as on the low hills around the North Wells; but I never noticed it growing in colonies, as in some of the smaller cays. It composed great thickets on the rocky surface of Long Cay on the lee or southwest side, being associated with Coccoloba uvifera; and it extended to the edge of the low cliffs that form the border of the island. On the eastern or weather end of Cotton Cay a few plants were associated under similar soil conditions with dense thickets of Coccoloba uvifera and a quantity of Phyllanthus falcatus. It occurred probably on other parts of this island. On Greater Sand Cay it was one of the most characteristic plants, especially in the northern half, growing in colonies over the sandy and rocky surface, but not coming down to the beaches. In all these localities the plant in the early part of 1911 was in flower and unripe fruit, the fruiting stage being most pronounced.

This plant is truly littoral in its station. In Cuba, as remarked by Grisebach, it grows on maritime rocks. Millspaugh writes that it occurred on coastal rocks on all the Bahamian islands visited (Pranunc. Baham.). Harshberger includes it in the Bahamian strand formation, assigning it a station not only on the coastal rocks, but also on the sandy ridges and mounds behind the Tournefortia-Suriana association. He writes that it is an element of the sandy strand formaton of South Florida (Trans. Wagner Inst. Philadelphia, Oct. 1914, p. 70; Phyt. Surv. N. America, pp. 690, 692).

The fruit is an egg-shaped berry, $2 \frac{1}{2}$ to 3 inches long, yellowish and hard in the unripe condition, but reddening as it approaches maturity. When ripe, as Catesby tells us, it is pulpy and has the consistence of a mellow pear. (The fruits at the time of my visit to the Turks Islands were full-sized, but still hard.) It possesses a thick rind and a large number of dark-brown, flat crustaceous seeds, one-fifth of an inch $(5 \mathrm{~mm}$.) long and lying horizontally in a relatively scanty pulp. It is a curious fact that I never observed either withered fruits on the plant or fallen fruits on the ground. It is probable that they are much appreciated by the large iguanas found on some of the cays; and it is noteworthy that the two islands most frequented 
by these reptiles, Long Cay and Greater Sand Cay, were the two on which the plant was observed growing in greatest abundance.

To my surprise the fruits approaching maturity, though still hard, floated buoyantly, the floating power lying in the thick rind or pericarp, which is protected by a tough skin. Four of them were placed in sea-water, where they floated for three weeks, when they began to rot and the seeds commenced to fall out and sank. If we allow for the fruits floating in fragments a few days longer, it is probable that a month would represent the limit of the floating capacity. One such fragment I found washed up on the beach of Grand Turk. However, the hard fruits could only be torn off from the plant during hurricanes. The mature soft fruit, if it did not sink at once, would break up afloat in a few days. The plant seems to be quite useless, and could owe but little directly to human agency in its dispersal. However, the present islanders carry the living iguanas from island to island for purposes of food, a practice probably followed by the Caribs, and any of the hard seeds in the stomachs of these reptiles would thus be distributed.

\section{Grias cauliflora (Anchovy Pear tree)}

Known as the Anchovy Pear tree, Grias cauliflora is one of the most picturesque trees in the river scenery of Jamaica; and from many points of view it is amongst the most interesting, its "cauliflory" at once attracting attention. The genus was originally established by Linnæus from this Jamaican tree, as first described under its popular name by Sloane in his book on the natural history of that island (Vol. II., p. 123, etc.; table 216). Unfortunately Miers, when he wrote his monograph on the Lecythidacea (Trans. Linn. Soc., XXX., 1875), to which the genus belongs, was not acquainted with the fruit. Yet the fruit, as will be shown, plays an important part in the distribution of Grias cauliflora along the same river system.

In Jamaica it grows, as Sloane observes, by the riverside. It may be noticed both on the banks and in the shallows and even on the slopes of waterfalls. As observed by me, it thrives on the banks of the Black River and of the Cabarita River above the mangroves and on the sides of streams in the district south-east of Negril, as well as in similar stations on the north side of the island. At the Roaring River Falls it grows not only at the brink of the falls, but in the wash below them, as well as half-way down their face, where the fruits have caught in the crevices of the calcareous tufa encrusting the declivities. Harshberger (p. 678), when in this locality, noted that the trees grew directly in the water, their seeds having germinated in the tufa. It may here be remarked that Sloane's statement that the Spaniards used to eat the pickled fruits as a substitute for mangoes may perhaps supply an explanation of the popular name of the tree. The mature fruits would be singularly unfitted for food, and doubtless the young fruits were thus employed.

Grisebach gives Jamaica as its only habitat in the West Indies, and mentions no other West Indian species. I have not been able 
to find a reference to it in any other island, though Sloane states that it grows all over the West Indies. From the fact that the fruits, which possess considerable floating powers, are significantly absent from the drift heaped up on the beaches of the Turks Islands, it would seem that the tree does not grow in the islands which are the source of much of this drift, namely, San Domingo, Porto Rico, and the neighbouring Leeward Islands. Whilst the fruits are characteristic of the drift of the Jamaican beaches, being thrown back on the coast after being brought down by the rivers, as in the vicinity of the mouths of the Black River, the Cabarita, and the White River, they did not come under my notice in the beach-drift of Grenada, Tobago, and Trinidad. They would, therefore, appear to be unrepresented in the drift of the Orinoco and the Amazon, since it is stranded in quantity on those islands; and one may note in passing that Hart does not mention the tree in his "Herbarium List" of the Trinidad flora. It is, however, shown below that the same tree evidently exists on the upper reaches of the Guayas River in Ecuador, and that an unidentified species of the genus grows in quantities near rivers on the lower eastern slopes of the Ecuadorian Andes.

Whilst its limited distribution in the West Indies may be partly due to the little power of preserving the germinative capacity of the seed in the floating fruit, a matter discussed below, it is evident that questions quite apart from those relating to means of dispersal are here raised. According to the Index Kewensis (up to 1905) the genus holds four species referred respectively to Peru, Panama, the West Indies, and Guiana. But a mere list of species with their habitats conveys no notion of the rôle plants of this genus play in tropical South America. It would appear that these trees are especially at home on the lower slopes of the Equatorial Andes on the Pacific and Atlantic sides, as well as along the upper reaches of the rivers in that region. Spruce found Grias trees in the Chimborazo forests extending up to 3500 feet above the sea (Notes of a Botanist on the Amazon and Andes, II., 286; 1908). Mr. A. R. Wallace, who edited Spruce's book nearly half a century after the traveller returned from South America, subsequently sent to the Kerw Bulletin $(1909$, p. 216) some additional notes made by Spruce on the riverside vegetation of the Upper Amazon. We there learn that a species of Grias almost entirely composed the forest in places on the Pastasa River, a tributary of the Marañon branch of the Amazon, on the lower eastern slopes of the Ecuadorian Andes. The specific identity was not determined in these cases; but I may add that on comparing some of my Jamaican specimens of the fruit of Grias cauliflora with fruits gathered by me some years before from the floating drift of the Guayaquil River in Ecuador, the two kinds could not be distinguished from each other. These floating fruits formed a feature in the drift of this Ecuadorian estuary, and evidently were derived from the upper reaches of the river. Specimens of them sent by me to the Kew Museum have been labelled Grias cauliflora by those in charge.

Looking at the foregoing facts of distribution, it seems fair to assume that this genus was once far more widely spread over the West Indies than it is at present. It is doubtless a remnant of a 
flora that once held the region, now occupied by the Caribbean Sea, which united the Greater Antilles with Central and South America (vide Harshberger, p. 307). From the data given below with respect to the fruits of Grias cauliflora, it would seem that the genus is quite unsuited for dispersal by marine currents.

The fruits readily get into the floating drift of rivers, on the banks of which the tree so often finds its station. They are elliptical, 3 to $3 \frac{1}{2}$ inches long, possess eight prominent ribs, and contain a fleshy though tough seed, $1 \frac{1}{2}$ to 2 inches in length, which is merely, as in Barringtonia, a gigantic hypocotyl, the cotyledons being absent or inconspicuous. The buoyancy of the fruit is entirely due to the husky fibro-ligneous pericarp and to its air-bearing tissue, the seed sinking in water. But though the fruit can evidently float for months, it is far from impervious to water. It soon loses in the floating river-drift the outer thin skin of the living fruit, and water enters freely into the seed-cavity, the membranes investing the seed affording little or no protection. As a result, the floating fruits soon begin to germinate in river-drift. Thus, in one of my ascents of the Black River in January, I estimated that 50 per cent. of the floating fruits were germinating, showing roots up to three inches in length. Forty per cent. had been so long in the water that the seed had disappeared through decay or was in a decaying condition, and there can be little doubt that most of these had originally germinated. Ten per cent. had more or less fresh seeds that had not yet begun to sprout. When the floating fruit reaches the coast, the sea-water kills the seed, whether or not in the germinating state.

Although when stranded on a sea-coast these buoyant fruits would either be empty or would carry a dead or decaying seed, it cannot be doubted that if the trees were at all frequent on the large island of Hispaniola, about $\mathbf{1 0 0}$ miles away, their fruits would be washed up on the beaches of the Turks Islands. Their absence from the drift of these islands indicates the absence or rarity of the tree on Hispaniola, as well as on Porto Rico and in the neighbouring Lesser Antilles, islands which collectively represent the main source of the foreign beach-drift of the Turks Islands. This implication goes to support the view that Grias cauliflora occupies a very restricted area in the West Indies, an area which it has been unable to extend through the agency of the currents. The species would thus appear to be on the road to extinction in the West Indian region.

Yet the fruits, useless as they are for the purposes of oversea distribution, are frequent on the beaches for several miles east and west of the Black River estuary in Jamaica. They are also to be found amongst the shore-drift near estuaries on other parts of the coast of this island, wherever the tree thrives at the riverside. Thus, they were noticed near the mouth of the Cabarita River at the south-west corner of the island and near the estuary of the White River on the north side. As they lie on the beaches several still show the protruding rootlets of the germinating seed, but in a shrivelled state. Several also are empty, or display a seed far decayed.

But when, as not infrequently happens, the seed is still entire, it undergoes a very curious change as it lies within the fruit on the 
beach fully exposed to the sun and weather. The tough, fleshy seed of the living fruit here dries up and hardens until it has the consistence and appearance of a stone, a change affecting both the seed that has germinated and the seed that has not. In this new state, however, the seed retains the normal amount of hygroscopic water, such as we would look for in dead vegetable substances of the same nature. As is pointed out in my book on Seeds and Fruits (p. 232), it loses about 12 per cent. of water when exposed to a temperature of $100^{\circ} \mathrm{C}$., and there is no indication of its having assumed the characters of inorganic substances.

On some beaches most of the stranded fruits contained these hard, stone-like seeds. Thus, on a beach in the Black River district about 25 per cent. possessed either no seeds or seeds far advanced in decay, the rest having dead seeds that had experienced the stony induration above described. Placed in a collection of fossil fruits from some clay formation, one of these oblong, indurated seeds of Grias cauliflora might pass as a fossil fruit, particularly when a longitudinal section had been made so as to expose the central axis in relief. At all events, they might be readily fossilised in ordinary fresh-water deposits, and it is quite likely that some puzzling organic forms in the old plantbeds may be petrified seeds which, as in the Barringtonice and Lecythidece, are merely greatly enlarged hypocotyls.

\section{Hibiscus elatus, Sw. (Paritium elatum, G. Don) and Hibiscus}

\section{tiliaceus, L. (Paritium tiliaceum, A. Juss.)}

At some future time I may publish my notes on the different species of the Hibiscere from the distribution standpoint, a subject already partially dealt with in my work on Plant Dispersal. Here I will endeavour to bring my methods to bear on the elucidation of the causes of the great difference in range between these two allied species, one $(\boldsymbol{H}$. elatus $)$ confined to a relatively small area in the New World, the other $(\boldsymbol{H}$. tiliaceus $)$ occurring all around the tropical zone. Hibiscus tiliaceus is a species with which I have long been familiar in many parts of its range-on the Atlantic and Pacific sides of America, in various Pacific islands, in the Malayan region, and in the Keeling Islands in the Indian Ocean.

On making the acquaintance of Hibiscus elatus in Jamaica I recognised that it gave me an opportunity of comparing two allied species (both of them placed under Paritium) of widely different ranges, and I asked myself whether this great contrast in range could be associated with differences in behaviour, as regards station, means of dispersal, etc., or whether, assuming the intervention of man, it was connected with the utility of one tree and the uselessness of the other. Obviously here was an opportunity of making a flank attack on the problems concerned with $\boldsymbol{H}$. tiliaceus. It soon appeared, however, that the determining factor was concerned neither with man nor with means of dispersal, but with differences of station, and that the same point was raised, to which my attention had been drawn in various genera in the Pacific islands, namely, that in a genus possessing littoral and inland species, the first had often very wide 
ranges and the second very restricted ones (Plant Dispersal, Chaps. XIV., XV.).

In Jamaica, like $\boldsymbol{H}$. tiliaceus its sister species, $\boldsymbol{H}$. elatus is known as the Mahoe; but although when of small size it might easily be taken for the other species without close inspection, it is typically a much more imposing tree. Whilst that of $\boldsymbol{H}$. tiliaceus is usually from ten to fifteen feet in height, that of $\boldsymbol{H}$. elatus is large and spreading and often between thirty and forty feet high. It is also distinguished by its larger flowers, its hairy seeds, and by its deciduous involucel and calyx, the loss of which gives the fruits a very characteristic appearance on the tree. Its distribution in the West Indies is evidently restricted, Grisebach giving only Jamaica and Cuba.

But its station is of peculiar interest, since in the comparison of the two species from the standpoint of distribution it seems to offer the only determining difference that one can connect with the great contrast between the ranges of the two trees. In Cuba its habit is evidently hygrophilous, since Harshberger quotes Fernow (p. 677) as including it amongst the characteristic trees of the "wet" forests on the weather slopes of the island, where "the atmosphere is nearly saturated with moisture." Here it is associated with Calophyllum calaba, a tall tree common in the mountain forests of the West Indies. Grisebach merely states that in Jamaica it frequents the lower hills and plains of the interior districts. I found it growing in young wood in the Moneague district about a thousand feet above the sea and within the zone of heavy rainfall. It came under my notice on the banks of the Black River above Lacovia, where the river traverses the foot-hills, the slopes being well wooded to the waterside with tall trees of Cassia, Ficus, etc. It also extends for some distance on the river border below Lacovia, where the river traverses the Great Morass, a region of fresh-water swamps, where it accompanies on the riverside Grias cauliflora, the Anchovy Pear tree.

In Jamaica this is not a tree that finds a station amongst the strand flora or with the xerophilous plants of the dry coastal plains. In these respects it differs fundamentally from Hibiscus tiliaceus, growing as it does under much moister atmospheric conditions in upland regions and descending along the riverside where the wooded hill-slopes reach the lowlands. It is probable that the station at the riverside is connected with the buoyancy in sea-water of the seeds, a principle enunciated in my previous work. The seeds, as I found, are able to float unharmed for at least several weeks, though their floating capacity is probably less than that of the seeds of $H$. tiliaceus, where my experiments, as well as those of Schimper (Ind. Mal.Strand Flora, p. 165), indicate a floating capacity of from four to six months and more.

Hibiscus elatus yields the celebrated Cuba bast, and is cultivated for that commodity. In this respect it offers another point of resemblance to $\boldsymbol{H}$. tiliaceus, which in its bast was one of the most useful trees for the Pacific islander, supplying the materials for cordage, nets, native cloth, etc. Since both possess seeds that could be dispersed by currents, and since both would be regarded as useful 
trees, it would not appear that either man or the currents would of themselves alone determine the great difference in range. I have shown in my previous work that capacity for dispersal by currents is not of itself sufficient to give a plant a wide range. Behind this capacity must lie a littoral station, and behind that again a xerophilous habit. Whilst $\boldsymbol{H}$. tiliaceus is to be placed with the xerophytes of the sea border and of the dry inland plains, $\boldsymbol{H}$. elatus associates with the hygrophytes of the wet woods of the interior. Though both may be found at the riverside, the first is confined to estuaries within tidal influence, whilst the last frequents the higher reaches where the river traverses wooded districts and where mixture with salt water would not be expected to occur.

These two allied species further illustrate the principle, already alluded to, that whilst coast plants are often spread over a wide area of the globe, inland plants of the same genus are restricted to a limited region. Mere capacity for dispersal by currents would not bring this about unless it concurred with a littoral station. The seeds of Hibiscus elatus, after being carried down by a river from the interior of an island to the sea, would find no suitable station when stranded by the currents on some neighbouring coast. It is the station at the coast that enables the seeds of $\boldsymbol{H}$. tiliaceus to establish the plant when transported to another shore.

I come now to deal more especially with Hibiscus tiliaceus. This is one of the "problem" plants of distribution, which, like Acacia farnesiana, Thespesia popuinea, etc., are found all round the tropics and are as a rule littoral in station. With this tree, as with Thespesia populnea, it is the littoral station that determines the effectiveness of the currents in dispersing the seeds. But other agencies of dispersal cannot be excluded, such as the influence of man, and, for local distribution, the intervention of birds and other animals. Many details of its station, distribution, and dispersal in the Pacific are given in my book on Plant Dispersal. Here I will mainly confine my remarks to its behaviour in the West Indies.

This was one of the plants in which De Candolle took special interest. In his work on geographical botany (p. 769), whilst recognising man's agency in its dispersal, he suspects that currents were originally effective agents in its distribution, and perhaps at a very ancient date. Not knowing whether it was most common in the east or in the west, that is, in the tropics of the Indian Archipelago or in those of America, he does not at first assign it a home in either hemisphere. However, in a later page (p. 792) he places it with Acacia farnesiana amongst plants spread by the currents, but probably American and naturalised in Asia and Africa. I scarcely think that a purely American origin can be sustained. It doubtless attained its present distribution ages ago, and may have witnessed the emergence of primeval man around the tropics of the globe. Under such circumstances speculations as to its home seem futile.

Though found in coast regions in all tropical latitudes, on both sides of the American and African continents, in Indo-Malaya, in Australia, and Polynesia, it seems to be less frequent in the New World; but this is a matter that requires further investigation. It is 
distributed over the West Indian region, extending into subtropical latitudes on the Atlantic coasts of both North and South America. It grows on both sides of Central America, exists in the Galapagos Islands, and was observed by both Baron von Eggers and myself on the seashore and on the banks of estuaries in Ecuador. It was not observed by me in the Turks Islands, and apparently forms no feature either of the Bahamian or of the Bermudian flora. The plants in the Bermudas are stated to have been raised from seed washed ashore by the currents about three-quarters of a century ago (Chall. Bot., II., 128a).

In Ecuador and in the West Indies it presented to me the same variety of stations at or near the coast that it displayed in the Pacific islands. Wherever it grows, it is as much at home on the borders of mangrove swamps and on the banks of estuaries as it is among the trees lining the beach.

It is impossible to deal here with most of the points raised by the consideration of Hibiscus tiliaceus in the New World, a subject to be discussed at some future time. But here I may say that both in the Pacific islands and in the West Indies, as well as in Ecuador, there always seemed to me to be something refractory about its behaviour under the test of experiment and observation. The frequent difficulty in obtaining sound seeds, the difficulty in procuring their germination after prolonged flotation in sea-water, the variety of station, the inability to discover whether natives ever really did aid in the spread of the tree, its capacity for vegetative reproduction, the uncertainty about the agency of birds in its dispersal-these and other considerations often blocked the way when I was on the eve of obtaining a clear issue on some point connected with its distribution.

\section{Ipomca carnosa, R. Br.}

This is an exceedingly interesting beach plant which, according to some authorities, is found over the warm regions of the globe, whilst others would limit its distribution chiefly to the New World with a representation in the Mediterranean and in a few island groups like the Hawaiian Islands and the Azores. When its synonym is freed from confusion, it is highly probable that in its range it will be found to rival the well-known shore species, I pomoea pes-capre, with which it is not infrequently associated on tropical beaches, though very far behind it in its frequency. Following Urban and Millspaugh, etc., who have most recently dealt with the plant, the following are amongst its numerous synonyms: Batatas acetosafolia (Choisy), B. littoralis (Choisy), Convolvulus acetosafolius (Vahl), C. littoralis (L. Syst.), C. repens (Sw.), I pomøe acetosaefolia (R. and S.), I. arenaria (R. and S.), and I. carnosa (R. Br.). It has been confused with Convolvulus soldanella, which may explain how that species has been sometimes accredited to the tropies of the Old World. It has not always been separated from Ipomœa pes-capra, since Seemann includes $I$. carnosa $(\mathbf{R}$. Br.) amongst its synonyms.

Even the more limited conception of its distribution suggests that a plant which could reach islands in the middle of the Atlantic 
and Pacific Oceans might do a great deal more. Though, as is observed below, it is tenacious of locality, there are evidently some deterrent influences which restrict its dispersal, influences, however, that are not concerned with unfitness for dispersal by currents, since my experiments show that in their ability to float unharmed for many months in the sea its seeds are not inferior to those of Ipomoea pes-caprce, one of the most typical beach plants of the tropics.

Let us look at some of the features of its distribution. In North America, according to the data supplied by Harshberger, it grows on the shores of the Mississippi delta, on the Louisiana beaches in association with Ipomøa pes-capree, and around the coast lagoons near La Paz in Lower California. In the West Indies, as we learn from Grisebach, Hart, Millspaugh, and others, it grows on the beaches of Jamaica, the Cayman Islands, Porto Rico, and Trinidad; and it has long been known from the Guianas and Brazil. It is also a Mediterranean plant, and it has been found also in the Azores as well as in the Hawaiian Islands in the centre of the Pacific.

Until recently it was only known from one locality in the Azores, namely, Porto Pym in Fayal, where it was observed by Watson in 1842, by Brown in 1894, and by myself in 1913 and 1914. However, during my stay on Pico I found it thriving on a beach just south of Magdalena at the western end of the island. In Hillebrand's Flora of the Hawaiian Islands it is only recorded from Niihau, an island at the extreme north-west of the group, where it was collected by Remy half a century or more ago.

Its behaviour in the Cayman Islands is characteristic. Mr. Savage English in his account of Grand Cayman (Kerw Bulletin, No. 10, 1913) refers to a small colony which had established itself on the shore in one locality, presumably after the hurricane of 1903 , adding that it was new to the islanders. However, Dr. Millspaugh, who visited the Cayman Islands in February 1899, found it on the beach at Spot Bay in Grand Cayman, as well as on Cayman Brac (Plant. Utor., I., 85). The plant is evidently tenacious of locality, since it still grows in the Azores in the same locality where it was first noticed more than seventy years ago. Unlike its companion beach plant, I pomøa pes-caprce, its stem is mostly buried in the sand, only the leaved and flowering shoots usually showing, a feature described in detail by Dr. Millspaugh. When I visited Porto Pym on March 12, 1913, only a few young leaf-shoots were showing above the sand. A month later they were much more numerous. On July 21, 1914, it was flowering abundantly and in early fruit; whilst numbers of the previous year's seeds bared of their hairy covering lay on the sand. On August 12 many of the capsules had matured and were opening, displaying their hairy seeds.

To test their buoyancy, a number of the hairy seeds of the same year and of the bared seeds of the previous year were put in sea-water a few weeks after collection. After three months 20 per cent. of the hairy seeds and all of the bared seeds remained afloat, and after seventeen months 10 per cent. of the hairy seeds and 90 per cent. of the bared seeds were still floating. The survivors germinated freely, and from them I raised plants. If the currents are responsible 
for the existence of this plant in the Azores, the seeds must have come in the Gulf Stream drift in the company of the other West Indian seeds thrown up on these islands. It is true that the Mediterranean shores would offer a much nearer source; but the current connections do not allow us to appeal to that region. It is, however, possible, as implied by Dr. Millspaugh in the case of Cakile edentula, its companion on the beach of Porto Pym, that it may have been introduced with ballast. But the same suspicion would fall on the other beach plants of this little bay, Polygonum maritimum, Salsola kali, Euphorbia peplis, etc. That West Indian seeds are sometimes stranded there is indicated by my finding on the same beach a seed of Sapindus saponaria apparently in a sound condition.

\section{IPOMGEA PES-CAPRA, SW.}

Since this wide-ranging tropical beach plant has been discussed in detail in my book on Plant Dispersal in the Pacific, I will restrict my remarks mainly to its occurrence in the West Indian region. The circumstance that it came under my notice in Jamaica, Turks Islands, St. Croix, Grenada, and Tobago, as well as at Colon, sufficiently illustrates its general distribution over this area. From the data supplied by Grisebach, Millspaugh, Harshberger, etc., it is apparent that all the larger islands and most of the smaller ones possess this species. Excluding the small sand-keys, a few hundred yards across, I would imagine that this plant has established itself on every small island where there are beaches. Numbers of beaches were visited by me on the north, south, and west coasts of Jamaica, and the species was noticed on nearly all of them. However, certain restricting influences seem in places to affect its distribution. Thus, Mr. Lansing found it on only four of the nineteen Florida sand-keys examined by him, which contrasts with the prevalence there of such beach plants as Cakile fusiformis, Euphorbia buxifolia, and Suriana maritima that occur on most or on nearly all of them.

In the West Indies this plant did not present itself to me far away from the beach, as it did in the dry inland plains of Vanua Levu, in Fiji, where it attained a maximum height of 1300 feet above the sea. The other botanists, whose works are at my disposal, say nothing of its inland extension in this region. In the Turks Islands it usually grows over the sandy and rocky surfaces of the smaller cays, which are often only one or two hundred yards across and display seadrift thrown up by the breakers in the centre. In Gibb Cay, however, which is of greater height, the plants had climbed the sandy slopes to an elevation of nearly fifty feet. On the larger cays they thrive on the dunes behind the beach; but although the conditions in the interior of the islands seem very favourable for their inland extension, I possess no record of their occurrence far from the beach.

As in other parts of the tropics, the seeds are often to be found in stranded beach-drift; and there can be no doubt that the currents are effective agents in dispersing the buoyant seeds over these seas, since a good proportion can float unharmed for six months and more. They came under my notice on the beaches of Jamaica, 
Tobago, etc.; and, as in the Turks Islands and elsewhere, seedlings that had raised themselves from stranded seeds were observed growing in the beach-drift.

I have been obliged to omit, on account of the limits of space, a very long note of many pages on the distribution of this plant in the warm latitudes of the globe as compared with Convolvulus soldanella, which takes its place on the beaches of temperate latitudes. As a rule, I pomøa pes-capra monopolises the coasts between the 30th parallels of north and south latitude, whilst Convolvulus soldanella holds the shores of the temperate zones beyond those latitudes in both the north and south hemispheres, though in the New World wide gaps may separate the two species. As far as I know at present, the ranges of the two species only overlap in Australia. It has long been known from the observations of Cheeseman that the two plants meet in the neighbouring Kermadec Group (lat. $31^{\circ} 30^{\prime} \mathrm{S}$.), and it would, therefore, be expected that the two plants would overlap on the eastern coasts of Australia. Mr. Maiden very kindly looked up the matter in my interests, and the conclusion he formed was that "the two species overlap in northern New South Wales and in southern Queensland for at least 300 miles." Looking at the data which he supplied me it would be fair to conclude that the overlapping takes place between the 25 th and the 32 nd parallels, I pomoea pes-capra reaching south to $32^{\circ} \mathrm{S}$. and Convolvulus soldanella extending north to $25^{\circ} \mathrm{S}$. New Zealand, a home of $C$. soldanella, is well outside the zone of $I$. pes-caprce and does not possess it. Prof. Ewart also supplied me with some valuable information on this point.

The comparison has opened up so many problems of distribution in different parts of the world that it would take more space than can be allotted in these pages to deal satisfactorily with the subject. When I have filled up the numerous lacuna in my research, I hope to publish it in the form of a paper. A short discussion of the question is given in my previous work on Plant Dispersal in Note 49 of the Appendix.

\section{Iтомса тUBA, Don.}

According to the various authorities at my disposal this plant is confined to the warm latitudes of the New World, where it is widely distributed, as in South Florida, the Bahamas, the Greater and Lesser Antilles, reaching south to the Guianas and Brazil. Urban regards it as almost cosmopolitan in the warm regions of the globe (Symb. Antill., IV., 513); but he seems nearly alone in holding this view. Though not known from the Bermudas, it was found both by Moseley and Ridley on the small Fernando Noronha group lying about 200 miles off Cape St. Roque (Chall. Bot., III., 19; Journ. Linn. Soc. Bot., vol. 27).

Particulars as to its station are often lacking; but it is evidently as a rule a maritime plant, and in the manuscript of the Bahamian flora lent to me by Dr. Millspaugh it is described as a denizen of sandy shores in that archipelago; but I do not gather that it ever intrudes on the beach after the fashion of I pomœa pes-caproe. Thus 
in the Florida sand-keys it grows with other littoral plants away from the beach. In the Turks Islands it thrives on both rocky and sandy slopes behind the beach. Dr. Millspaugh, in his paper on the Florida sand-keys, refers to its " often high location on many rocky Antillean islands." In another paper (Plantee Utowance) he alludes to it as growing over low bushes on the shores of Cayman Brac.

The same American botanist shows that this plant, which is referred to under the synonym of Calonyction album (House), grew always towards the centre of the sandy interior of the low islets forming the Florida sand-keys, removed alike from the mangrove border on the lee side and the beach on the weather side. Of nineteen islets examined, it was only found on four.

It was only observed by me on three of the ten islands of the Turks Group, but never on the largest islands. On Gibbs Cay it grew in quantity over the sandy slopes and summit at a height of thirty to sixty feet above the sea, but not on the beach. On Pear Cay, where there is but little beach, it occupied much of the rocky surface, twenty to thirty-five feet above the sea. On Eastern Cay it did not grow on the extensive low sandy flats bordering the sea, but on its stony slopes fifty to sixty feet above the sea-level.

The seeds are well suited for dispersal by currents. Of ten placed in sea-water in the Turks Islands all were afloat after forty-five days, the kernels being sound and quite dry. In a later experiment in England on seeds that had been gathered for fifteen months, 90 per cent. remained afloat after ten weeks, and from their condition they would evidently have floated unharmed for a considerably longer period.

\section{Laguncularia racemosa, G.}

This West African mangrove tree, which finds its most characteristic station, with Avicennia nitida, on the landward side of the mangrove swamp, is generally distributed in the West Indies, and has accompanied the other two mangroves, Rhizophora mangle and Avicennia nitida, in their extension to the Bermudas. It grows on the Atlantic side of the American mainland from Florida by way of Mexico and Venezuela to Rio de Janeiro (Schimper, p. 66), and also on the Pacific side on the Panama, Ecuadorian and Lower Californian coasts (Harshberger).

The tree is dealt with in my book on Plant Dispersal, and here I will chiefly endeavour to supplement those remarks. It will be unnecessary to name the localities in which I noticed it, since it came under my notice wherever I examined the mangrove formation, as in Jamaica, Turks Islands, St. Croix, Grenada, Tobago, Trinidad, Colon, and Panama. According to Millspaugh it grows on ten of the fourteen Florida sand-keys that support mangroves, and is evidently one of the first plants to stock the emerging islet.

Laguncularia racemosa is as a rule merely semi-viviparous. Only in rare instances does one find the radicle protruding from the fruit on the tree. Generally the dark green embryo does not effect more on the plant than the rupture of the thin seed-coats, the protrusion of the hypocotyl taking place shortly after the fruit has dropped 
from the plant, either on the mud or in the water. The enormous number of seedlings, only three or four inches high, that are at times to be noticed under the trees affords evidence of this partial vivipary. They are sometimes crowded together in thousands so as to almost form a turf, and the waste must be tremendous. Should the buoyant fruits drop into the water, whether into a river or into the sea, they quickly proceed with the germinating process, and can be carried in this condition for a great distance. Germinating fruits of Laguncularia are frequent in the floating drift of the estuary of the Guayaquil River in Ecuador, and I noticed them in a healthy state twenty miles out at sea with the protruding hypocotyl between 3 and $12 \mathrm{~mm}$. in length. In another locality, about three miles off the coast of Ecuador, I estimated that 90 per cent. of the floating Laguncularia fruits were germinating. The stranded fruits of $L$. racemosa were frequently found by me on the beaches of Jamaica, Tobago, Trinidad, etc., and they were nearly all germinating.

The capacity of proceeding with the germinating process in seawater has been already implied, and fruits in this condition can be transported far by the currents, more especially since fish do not nibble at the protruding seedling. It is not likely that any floating fruits could remain for more than a week or two in the sea without showing the radicle; and it is quite possible that the germinating fruits would survive the passage of two and a half or three months in the Equatorial Current from the West Coast of Africa to the shores of Brazil. That the New World derived its species of Laguncularia from the West Coast of Africa before the emergence of the Panama Isthmus seems probable.

The fruits can withstand drying when detached from the tree in the entire condition. Five green non-germinating fruits were placed in sea-water in Jamaica after being allowed to dry in the air for nearly two weeks. A fortnight afterwards three were germinating healthily afloat.

Comparison of the Shape and Dimensions of the Froits of Laguncularia racemosa of the West Indian Region and of the Panama Isthmus with those of the Laguncularia of the Estuary of the GUAYAQUIL RIVER AND OF THE NEIGHBOURING COASTS OF ECUADOR.

\begin{tabular}{|c|c|c|c|}
\hline & Form, etc. & Length & Breadth \\
\hline $\begin{array}{l}\text { Laguncularia racemosa } \\
\text { of the West Indies, etc. }\end{array}$ & $\begin{array}{l}\text { Broadens out into } \\
\text { shoulders near the top. } \\
\text { Ribs and wings more promi- } \\
\text { nent. }\end{array}$ & $17 \mathrm{~mm}$. & 8 to $9 \mathrm{~mm}$. \\
\hline $\begin{array}{l}\text { Laguncularia of Ecua- } \\
\text { dor. }\end{array}$ & $\begin{array}{l}\text { Becomes narrower near } \\
\text { the top. Ribs and wings } \\
\text { less prominent. }\end{array}$ & 18 to $19 \mathrm{~mm}$. & 6 to $7 \mathrm{~mm}$. \\
\hline
\end{tabular}

In my book on Plant Dispersal (p. 498) reference is made to the circumstance that the Laguncularia tree of the Guayaquil estuary and of the neighbouring coast swamps of Ecuador has a fruit differ- 
ing somewhat in form from that of the Laguncularia (L. racemosa) found on both coasts of the Panama Isthmus, and, I may here add, in the West Indies generally. Whether the difference is specific is doubtful. The fruit of the Ecuadorian tree is more symmetrical, longer and narrower, and does not broaden out into two shoulders near the top as in the case of the typical $L$. racemosa.

\section{Limnanthemum humboldtianum, Gr.}

This aquatic plant is distributed over the warm regions of the American mainland and in the West Indies. As observed in Jamaica it was equally at home on the exposed muddy borders of ponds and in the water. The moist seeds are globose, hairless, smooth, and $1.5 \mathrm{~mm}$. in diameter. In the wet state about sixty-three seeds go to a grain; but in the dry state at least double that number would be required to make up that weight. On account of their oily surface the seeds float on the surface of a pond by throwing off the water, but when completely submerged they sink. They would thus be able to float for a long time in dry weather, and this would aid their early germination; but the raindrops would soon sink them. The seeds of our English species behave in a similar way, but here the flotation is assisted by a marginal fringe of hairs. These seeds are oval, flat, 4 to $5 \mathrm{~mm}$. long, and have an oily surface, which enables them to repel the water; but they can be sunk by dropping water on them. I observed the germinating process in both the English and West Indian species. Germination usually takes place in the case of sunken seeds, since from one cause or another the floating seed would soon be sent to the bottom in a pond. After the process is well advanced the seedling floats up and continues its growth at the surface.

The general subject of the distribution of the genus is discussed in my work on Plant Dispersal. I have been familiar with these plants in England, Fiji, and Jamaica, and have formed the conclusion that in the tropics aboriginal man has often unintentionally assisted in their dispersal. He cultivates many of his edible tubers (Colocasia, Alocasia, etc.) at the borders of ponds and ditches where Limnanthemums thrive.

\section{Luffa acutangula, Roxb.}

This is an introduced Asiatic species to which I refer here merely in connection with the slight floating power of its seeds. The seeds, as tested in the well-dried condition in Jamaica, sink in a day or two. Seeds of another cultivated introduced species were experimented on in Fiji, and found to sink after a few days in sea-water. The interest of these results lies in the circumstance that the seed of Luffa insularum, A. Gray (a maritime form of L. cylindrica), which grows in the Pacific islands on the shore and in the plains behind, are able to float in sea-water unharmed for months, and are doubtless often dispersed by currents. This subject is dealt with on p. 426 of my book on Plant Dispersal. This bears on the question of the connection between seed-buoyancy and a littoral station. 


\section{The Turk's-head Cactus (Melocactus communis) of Turks} ISLANDS

This plant, which figures on the farthing stamps issued in recent years for this colony, has a fancied resemblance to a man wearing a fez, and has given its popular name to the islands. It is still abundant on Eastern Cay and Cotton Cay, and, though now infrequent, was originally common on Grand Turk. The Rev. J. H. Pusey, for many years a Baptist minister in these islands, says in his handbook (Jamaica, 1897) that " it lasts a great number of years without the support of any earth whatever." Small specimens brought by me to England proved their capacity of surviving several weeks in a packing-case. At present there is a risk of this interesting plant being exterminated. I met a planter from the Caicos Islands in 1911 who was taking several cases of them to the United States to test the market for their sale. This cactus is usually designated in general literature as Melocactus communis, DC., a species found also in Jamaica, Haiti, Antigua, etc. But in Britton's and Millspaugh's manuscript of the Bahamian flora it was regarded under the name of Cactus bahamensis as a plant restricted to the southern Bahamas (the Inaguas, Turks Islands, Caicos Islands, etc.).

The small red juicy fruits, about $16 \mathrm{~mm}$. long, contain minute black seeds rather over a millimetre in length, and well suited for dispersal by frugivorous birds. Another smaller cactus of similar habit of growth, which I take to be Mamillaria simplex, is associated with it on Grand Turk. It possesses seeds of the same size. The seeds of the common Opuntia tuna measure $5 \mathrm{~mm}$. across. 


\section{CHAPTER $\mathrm{X}$}

\section{MISCELLANEOUS PLANTS (continued)}

\section{Morinda Royoc, L.}

According to the data supplied by Grisebach, Hemsley, and Millspaugh this plant has a wide distribution in the warm regions of the New World, principally at or near the coast, or, as Hemsley puts it, "usually growing in maritime districts" (Chall. Bot., II., 38). The following are the insular and continental localities given: Bermudas, Florida, Bahamas, Cuba, Isle of Pines, Cayman Islands, Jamaica, Haiti, Honduras, and Panama.

I was only familiar with it in Jamaica, where it was noticed in different localities near the beach on the north coast. Grisebach states that it was found by all collectors along the sea-coast of that island. But here it may also grow inland. Thus it was observed by me at the roadside a mile or two at the back of St. Anne's, and 600 or 700 feet above the sea. In South Florida, according to Harshberger, it is an inland plant of the "banana holes" and of the " hammocks" (Trans. Wagner Inst., Oct. 1914). Millspaugh says that it occupies scrublands and pine-barrens in the Bahamas (Pronunc. Baham.), and doubtless it often grows a considerable distance from the coast. According to the same botanist, it is known as "rhubarb" in the Caymans and in the Bahamas. In the first-named islands it is employed medicinally in the place of that drug, and it furnishes a yellow dye. In its use as a dye plant it resembles Morinda citrifolia jn the Old World, which has long served this purpose in the East.

Its usual maritime station also links it with Morinda citrifolia, but there are other important similarities from the standpoint of dispersal. The Asiatic plant and the genus as a whole are dealt with from this point of view in my work on Plant Dispersal. It is there remarked that though the fruit of $\boldsymbol{M}$. citrifolia soon decays when afloat, the woody, hard pyrenes possess great buoyancy, which they owe to a large bladder-like cavity, probably, according to Schimper, a modified seed-chamber. Though the pyrenes of $M$. royoc are smaller, they have the same characters and behave in the same way, their great floating capacity being connected with precisely the same structure. Some of them which I placed in seawater were all afloat and sound after five weeks, and gave promise of floating unharmed for many months. It is probably to this floating capacity of the pyrenes that the species owes its station at the sea-coast; and in this respect it is to be placed in the same 
category as $\boldsymbol{M}$. citrifolia, the pyrenes of which are often dispersed by currents.

It is shown in my previous work that the fleshy fruits of this genus must often attract birds, and that the pyrenes could be readily transported by frugivorous birds across tracts of ocean. Nearly all of the fifty known species are inland plants; and the indications are that only the littoral plants possess buoyant pyrenes, the bladderlike cavity being either absent or but slightly developed in the pyrenes of inland species. From its range over the warm regions of the globe Morinda is a very interesting genus for the student of distribution. Very noteworthy is it that quite 60 per cent. of the species are confined to islands, large and small, in Malaya and in the Indian and Pacific Oceans.

Though this is predominantly an Old World genus, not more than 15 per cent. of the species being restricted to America, the peculiar New World species have originated in several localities, as in Mexico, Guatemala, Yucz tan, Panama, Venezuela, Haiti, and Cuba. Nearly all these localities are given in the Index Kewensis. Urban has described a new species from Haiti under the name of $\boldsymbol{M}$. buchii (Symb. Antill., I., 481); and Dr. Greenman has in recent years distinguished a new species, $M$. yucatanensis, which had been previously referred to $M$. royoc. It is found in brushlands and forests in the interior of Yucatan (Publication 126, Botanical Series of the Field Columbian Museum, Chicago, 1907). Nothing, however, is said of the distinctive structure of the pyrenes. The plant is known in Yucatan under the Mayan name of "Joyoc" (Hoyoc). If, as seems probable, this is a plant of the Royoc series, then we might here be presented with the case of a derivation of an inland species from a littoral species, a subject generally discussed in my book on Plant Dispersal.

As regards the history of the American representatives of Morinda, I venture to hold, in spite of the numerical superiority of the genus in the Old World, that, like many other genera common to the western and eastern hemispheres, it originally spread from a common centre in high northern latitudes during one of the warm geological periods in those regions.

\section{OMphalea triandra, L.}

This tree, the " cobnut" of Jamaica, is interesting from the standpoint of dispersal by currents, since its seeds float buoyantly and occur occasionally in the drift on Jamaican beaches. The tree grows in hills behind St. Anne's in that island, and it was in this neighbourhood that I found the seeds on the beaches. The seeds are globose, about an inch in size, brown-coloured, and not unlike chestnuts in look. The buoyancy arises from a large internal cavity and also from the independent floating power of the kernel, portions of the albumen floating in water. The brown covering is seemingly waterproof, and no doubt the seeds would float for some time. It is, however, very doubtful whether they could find their way to a suitable inland station when stranded on a coast. Since the seeds 
of Omphalea diandra owe their floating power to the same causes, it is probable that this type of buoyancy is characteristic of the genus (see p. 159). According to Grisebach and Pax (Pfanzenreich, IV., 147, V.), Omphalea triandra has been found in Jamaica, Haiti, and the Guianas.

\section{Scevola Plumieri (Vahl) and Sc. Koenigir (Vahl)}

One of the most characteristic of the littoral plants of the West Indies is Scavola Plumieri. It is especially interesting from the standpoint of distribution, since, as in the case of other genera represented by littoral plants in this region, such as Rhizophora (p. 141), Tournefortia (p. 247), and Carapa (p. 141), it divides with a sister species the tropical shores of the world. In this case, however, there has been unfortunately some confusion between the two species, Sccevola Plumieri of the beaches of tropical America and tropical Africa, and Sc. Konigii of the beaches of tropical Asia, Australia, and Polynesia, a subject discussed in Note $\mathbf{5}$ of the Appendix. But the matter has been cleared up by Krause in his recent monograph on the Goodeniacexe (Das Pflanzenreich, IV., 277; 1912). The confusion in the synonymy quite obscured the issues raised in the matter of their areas of distribution. Now, as far as littoral plants are concerned, Scavola comes into line with the other three genera above referred to. It puts much the same questions and raises much the same issues; yet the differences that occur are in themselves full of suggestion for the future investigator.

These two species, as I have said, occupy between them the beaches of the warm regions of the globe, both insular and continental. As limited by Krause on pp. 18, 120, 121 of his memoir, Scarvola Plumieri occupies the shores of the West Indian islands and the eastern coasts of the American mainland from Florida by way of the Bay of Honduras to the shores of Brazil, reaching as far south as Rio de Janeiro. It extends northward to Bermuda. He does not give any station on the Pacific coast of America; but Grisebach and Hemsley record it from the Galapagos Islands (Flora Brit. West Ind.; Chall. Bot., IV., 161); and according to Baron von Eggers it is one of the "West Indian strand plants" that make up the "sand-flora" of the coasts of Ecuador (Deutsche Geogr. Blätter, heft 4, band 17, Bremen, 1894). Harshberger also gives La Paz (lat. 24. N.) on the coast of Lower California as a habitat (Phytogr. Surv. N. America, p. 639). Krause does not give many localities for the West Indian side of Central America; but the Caribbean shores of Mexico may here be mentioned as indicated by Britton and Millspaugh in the manuscript of their Flora of the Bahamas, and the last named specially records it for the shores of Yucatan, near Progreso (Plantoe Utowance, pt. I.). It is also implied by Grisebach as existing on the Caribbean coasts.

According to Krause, Sccevola Plumieri ranges along the West African coast from Senegal to Benguela, or through nearly thirty degrees of latitude $\left(16^{\circ} \mathrm{N}\right.$. lat. to $13^{\circ} \mathrm{S}$. lat), and along the whole coast of East Africa from Somaliland to the Cape. Further east- 
ward it intrudes into the area of Sccevola Konigii, attaining its limits in this direction in Southern India, Ceylon, and Mauritius; and at times both species are recorded from the same limited area, as in Mauritius.

Generally speaking, the domain of Sccevola Konigii begins where that of $\boldsymbol{S}$ c. Plumieri ends. It is not recorded either from the Pacific side of America, or from the East Coast of Africa, which in a general sense represent the limits of the area appropriated by its sister species. But between those continental coasts it ranges through the tropical zone, and sometimes extends beyond. Thus we find it on the beaches of the Pacific islands from Rarotonga to Hawaii and from New Caledonia to Liu-Kiu, in the northern part of Australia, in New Guinea and throughout Malaya, in South-eastern Asia, and in the islands of the Indian Ocean. It finally reaches its westward limits on the Malabar coast, in the Seychelles, and in Madagascar, but apparently not reaching the East Coast of Africa.

It has already been said that these two interesting species of Scaevola, in dividing the coasts of the warm regions of the globe between them, raise the same issues as those presented by Carapa, Rhizophora, and Tournefortia, where in each case two sister species similarly divide the world; but there are important differences. Although one of the two littoral plants of each genus is widely spread in the New World, it is confined there in the case of Tournefortia. With Carapa and Rhizophora the American shore plant extends to the African West Coast, but is not found on the east side of that continent; whilst the American Rhizophora meets the Asiatic species in the Pacific islands, as in Fiji.

Before going further something may be said of the genus to which the two littoral species of $S$ caevola, which are here compared, belong. Of eighty-three species recognised by Krause, fifty-eight, or 70 per cent., are confined to the Australian region. The rest are nearly equally divided between the Malayan region (including New Guinea) and the Pacific islands, excepting the two shore species with which we are specially concerned.

Looking at the facts of distribution relating to the Goodeniacexe given in this monograph, one becomes conscious, as regards Sccevola, that one is dealing with a modification of a geographical type rather than with a genus as usually understood, since it is pointed out by Krause (p. 14) that of the thirteen genera in the family ten are confined to Australia and Tasmania, and that of the total of 291 species only twenty-seven, or 9 per cent., are found outside this region, the bulk of the species being restricted to the western half of Australia. It is of importance to note that of these twenty-seven species all but two species belong to $S$ caevola, a very significant indication that this genus has been especially favoured in its means of dispersal.

Scaevola, therefore, is not only in the main an Australian genus, but it belongs to a family that is also chiefly Australian. It is a member of a family that thrives where the physical conditions often determine the xerophilous habit in plants, and, as I have before observed, this habit is the first requisite for a littoral station. It is, therefore, in this connection of special interest to refer to the remark of Krause 
(p. 19) that $S$ caevola as a genus has a characteristic inclination for a littoral life (" neigung für das Litoralleben"). This inclination is well illustrated in the circumstance that many of the Australian species are equally at home in arid inland districts and at the coast, though very few are exclusively littoral in their station. The adoption of a station at the coast does not necessarily involve a wide range for a plant, the acquirement of buoyant qualities by the fruit or by the seed being as a rule needed for a wide distribution. In other words, the littoral plant must be suited for dispersal by currents to ensure a wide range. Thus it may be safely assumed that the five other species of Scarvola named by Krause (p. 19) as the most typical strand plants have but slight capacity for distribution by currents, since they are all confined to Australia, and four of them are only known from West Australia. The origin of buoyancy in seeds is dealt with in detail in my book on Plant Dispersal. Buoyancy whether of seed or fruit is quite accidental as far as adaptation to dispersal is concerned. It is just as likely to be developed in inland plants, especially where dry conditions prevail ; and it is shown that in such cases, where the plants are xerophytes, they tend to gather at the coast. But it is only the littoral station that determines its utility for dispersal, since it brings the plant with buoyant seeds or fruits within the influence of the currents.

In many strand floras there is an element composed of local inland xerophilous plants, which, being at home in the neighbouring dry districts of the interior, encroach in places on the beach, but through lack of fitness for dispersal by currents do not accompany the other beach plants with buoyant seeds or fruits that extend their ranges across the sea far beyond that particular locality. With the exception of Sccevola Konigii, it is probable that nearly all the Australian species of the genus that find their homes more or less frequently on the beach belong to this category. The littoral flora is liable to receive numerous accessions from the inland flora, where the conditions of the interior favour the growth of xerophilous plants. This I found to be especially the case in the Turks Islands, where the plants growing away from the beaches are mostly xerophytes. So also on the Chilian beaches I found that the strand flora contained numerous intruders from the neighbouring dry inland regions (Plant Dispersal, p. 478). Schimper lays stress on the inclusion in the Indo-Malayan strand flora (p. 197) of colonists from sandy or stony places inland. Harshberger tells us how the numerous xerophytes of the chaparral scrub of the arid interior of Mexico and Texas descend to the plains that border the sea and extend along the shores of the Gulf of Mexico (p. 660, etc.).

I have here gone far enough to indicate the nature of the problems opened up when we recognise in Scavola a genus eminently suited for supplying strand species. We are now in a better position to understand how the genus has come to furnish two of the limited number of strand plants that are cosmopolitan, or semi-cosmopolitan, in the warm regions of the globe, a considerable proportion when we reflect that even including the plants of the mangrove formation the total number would probably not exceed fifty. 
Before dealing with the means of dispersal of the wide-ranging littoral species, Scavola Plumieri and Sc. Konigii, reference may be made to the genus in this connection. When in the Pacific the writer formed the opinion that the inland species, though not fitted for dispersal by currents, were well suited on account of their fleshy drupes for dispersal by birds, his observations and experiments indicating that only a littoral station was associated, as in the case of $S c$. Konigii, with the capacity for distribution by currents (Plant Dispersal, p. 135, etc.). In this way, it was held, the range of such a shore species was enormously extended as compared with the inland species, nearly all of which were restricted to a particular group of islands or were confined to small areas.

Krause (p. 14) deals with the subject; but his inferences were based entirely on the structural characters of the fruits. He considers that the fruits of Sccevola are adapted for two methods of dispersal-one by birds and other animals when the fruit has a fleshy covering and a hard endocarp, the other by currents where the endocarp has a cork-like outer layer suggestive of buoyancy in the fruit. In illustration of dispersal by currents he takes four West Australian species of dune plants growing on and near the coast, as well as Sccevola Kønigii, the widely ranging strand plant of the Old World; but no results of experiments are given and none are referred to, since they did not come within the scope of the work. Amongst examples of dispersal by birds he mentions the strand plant of the New World and of both the African coasts, Scaerola Plumieri, for the fruits of which only dispersal by birds seemed possible, the agency of the currents being excluded. I formed the same opinion on first examining these fruits in the West Indies, but experiments showed that they are also well fitted for distribution by the currents.

The two modes of dispersal of the fruits of Scaevola have long been established by Schimper, myself, and other students of distribution. They may be combined in the same species, as with the two worldranging beach plants $S c$. Kœnigii and $S c$. Plumieri, the juicy exocarp attracting the bird, and the buoyant stone fitting the fruit for transport by the currents. Schimper first apportioned their true values to these two capacities in the same species when in the case of $\boldsymbol{S c}$. Konigii, in his book on the Indo-Malayan strand flora (p. 156), he regarded the fruits as fitted for dispersal over long distances by the currents and for short distances by birds. The fruit is specially described and figured in his work (p. 172).

Yet it is evident from the treatment of $\boldsymbol{S c a v o l a}$ by Krause in this monograph that the greater number of the species have dry or hard fruits that would not be especially attractive for birds. In this connection it is very significant that the two sections, Sarcocarpoea and Xerocarpoea, which derive their names respectively from the fleshy and from the dry character of the fruits, include in the case of the first named the species that are established in localities farthest away from the Australian home of the genus, and in the case of the second named nearly all the species of the genus that are confined to Australia. The section Sarcocarpaea includes not only the inland species that have established themselves through the agency of 
birds in distant islands of the tropical Pacific, as in Hawaii and Fiji, but the two world-ranging shore plants, Scavola Konigii and Sc. Plumieri, which owe their wide dispersion mainly to the currents, but also to some extent to birds. The great increase in the range due to the capacity for dispersal by currents is well illustrated by these two strand species of Sccevola, there being but little probability that other species of the genus possess fruits capable of floating unharmed for long periods in the sea.

It is not likely that the buoyancy which Krause assumes on structural grounds for the fruits of four littoral Australian species of Scaevola can be very marked, since none of them are known from outside regions and three are confined to West Australia. Yet the principle involved may be correct, and we may have here reproduced the behaviour of Terminalia, as described by Schimper in his book on the Indo-Malayan strand flora (p. 180). In this genus, although the fruits of several inland species possessed floating powers associated with buoyant tissue in their coverings, the fruits with by far the greatest floating capacity and with the greatest development of buoyant tissue were those of Terminalia katappa, the only characteristic shore species and the one most widely spread.

I will now deal more especially with the American and African shore plant, Sccevola Plumieri, contrasting it as regards its modes of dispersal with the Asiatic and Pacific littoral species, Sc. Konigii. Having been for many years familiar with the Asiatic species, in Java, Polynesia and the Keeling Islands, I have been at length able to compare its behaviour with its sister species of the Atlantic region. This was accomplished in the Turks Islands at the southeast end of the Bahamas, where I enjoyed abundant opportunities of studying the plant.

As regards its distribution in the West Indian region the data show that Scavola Plumieri is spread over the Bahamas and the Greater and Lesser Antilles; but apparently it is absent from Trinidad. It extends north to South Florida and reaches Bermuda. In the Florida sand-keys it does not seem to be at all frequent, since Mr. Lansing found it on only four of the nineteen keys examined, and in only one of them did it exist in any quantity. The shrub, it may be added, is much less hardy than that of Sc. Konigii, and it evidently has greater difficulty in establishing itself on a fresh coast. It is noteworthy in this respect that in March 1895 Dr. Millspaugh found only a single individual on the Alacran Shoals (Plantoe Utorvance).

In the Turks Islands, where it attains usually a height of from two to two and a half feet, it is known as the Ink-berry plant, on account of its black, juicy fruits of the size of a large cherry. Its distribution in this small group is irregular and varies from year to year, a result due to the destructive action of hurricanes in the smaller keys or cays, and to its being much appreciated by cattle and goats in the larger islands, the whole plant being often devoured. I was informed by a resident that it thrives only on beaches to which animals cannot get access. Compared with the more woody plants of the beaches, such as Tournefortia gnaphalodes and Suriana maritima, these more 
or less fleshy shrubs cannot withstand the hurricanes and gales. They are not able, as in the cases of the two plants just named, to maintain their position by at first growing prone and sending down secondary rootlets into the sand. On the southernmost and most exposed island of the group, Greater Sand Cay, an island that is wind-swept to a degree not easily realised without a sojourn in these tempestuous seas, and one that is often breached by the breakers in several places during storms, this plant was scarcely represented when I visited it in March 1911. A few young plants grew on the weather side, and there were some seedlings growing amongst the stranded drift. The presence of a few goats on the island may partly explain this; but, as shown below, the much hardier bushes of Suriana maritima have suffered severely in recent storms, and much of the vegetation growing on the beaches was swept away under the combined influence of wave and wind during the last hurricane.

On Grand Turk, the largest island of the group, the plant was common in places on both coasts. It was thriving on Gibbs Cay, ascending the sandy slopes some twenty or thirty feet; but I did not observe it on Round Cay. On the rocky islands of Long Cay, Pear Cay, and Penniston Cay, where beaches are absent or scanty, it did not come under my notice at all; and the same may be said for Eastern Cay. On Cotton Cay I did not see it; but only a portion of its coast was examined. On Salt Cay it did not often present itself; but I found it flourishing near its southern extremity. On Greater Sand Cay, as already observed, it barely existed. This completes the list of the islands of this small group.

We come now to discuss the dispersal of this plant by birds and by currents, and in these respects we will compare it with Scaevola Konigii. There is no doubt that the fruits of both plants can be distributed by birds as well as by the currents; but, as has already been pointed out, whilst the bird would be an effective agent in local dispersal, as from island to island within the same group, it is to the current that we must look for the agency concerned in distribution over the breadth of an ocean. The importance of the bird in the case of Scavola Plumieri is emphasised by Dr. Millspaugh in his paper on the Florida keys, where he remarks that "the black, pulpy fruits of this plant form a very attractive food for land birds ; it thús becomes scattered far throughout the Antillean region" (p. 240). This is also the opinion of Krause, who would exclude the possibility of current agency altogether (p. 14). However, neither Millspaugh nor Krause refer to the results of any flotation experiments, and the former was surprised when I showed him in the Turks Islands a cup of sea-water in which the "stones" of Sccevola Plumieri had been floating for several weeks. The bird for local distribution and the current for oceanic transport: this was the conclusion formed concerning Sccevola Konigii by Schimper and myself. It applies also, as my West Indian results indicate, to Scavola Plumieri.

In both cases the fruits, or rather their "stones," are able to float in sea-water for months, and in that of Sccevola Konigii for a year or more, the seeds remaining fresh and, when tested, retaining 
their germinative capacity. Yet, strange to say, the fruits of these sister species, so similar in station and in habit, exhibit very different types of buoyancy. In both cases the maintenance of the floating powers depends on the "stone" ; but there the similarity ends. In both plants the fresh drupe floats in sea-water, and the buoyant stone is freed in a few days by the decay of the fruit. This, however, is not the usual course of events in nature, since the fallen drupe generally loses its soft parts whilst lying on the sand beneath the bush, and it is the more or less dry stone that is swept into the sea. The stones form a regular constituent of the smaller beach-drift in the different parts of the tropics where the two plants grow.

I will first take the West Indian species, Sc. Plumieri. Should the fresh black drupes get into the sea, experiment shows that they will sink in two days, the buoyant stone, on being freed from the decaying fruit, soon floating to the top. But, as just remarked, it is the more or less bared stone that is usually picked up by the wave from the beach. These stones, ovoid in form, prominently tubercled on the surface, and 9 or $10 \mathrm{~mm}$. in length, do not possess buoyant tissue of any sort, neither the hard material of the stone nor the seed within possessing any floating power. The outer cork-like covering, which, as described below, endows the stones of $\boldsymbol{S} c$. Konigii with buoyancy, is not here represented. The floating capacity of the stone of $\boldsymbol{S c}$. Plumieri is due to the circumstance that only one of its two cells holds a seed. The empty cell, which is water-tight and usually contains the seed envelopes, gives floating power to the stone. This can be proved in different ways. The most striking proof is this. If we take a buoyant stone and remove the portion containing the empty seed-cavity, it sinks at once. But if we remove the portion holding the seed, it floats still more buoyantly, almost like a piece of cork. It does not follow that the two-celled stones of this plant never have both cells filled with a seed. My observations, however, indicate that stones with one cell empty predominate. In fact, two-seeded stones very rarely came under my notice.

Though it is usually the bared stone of Sccevola Konigii that is picked up by the waves as it lies on the beach, the fresh drupe may at times be carried off by the sea. In that case it floats buoyantly, and when after a few days' immersion it loses its white, fleshy covering, the stone remains at the surface. As studied in the homes of the plant by Schimper (p. 172) and myself, the cause of the buoyancy lies in a layer of cork-like, air-bearing tissue investing the stone proper. If this covering is removed the stone sinks, neither the hard material composing it nor the seeds possessing any floating power; and I may add that the two cells of the stone in each case hold a seed, so that the question of buoyancy of the type presented in the instance of $S c$. Plumieri is not raised. It may be remarked that the stone proper of Sc. Konigii is much smaller than that of the West Indian species, being rounded, about $5 \mathrm{~mm}$. across, and slightly tubercled.

The stones of the drupes of these two species of $S$ caevola represent two quite different types of buoyant fruits, types that are described 
in Chapter XII. of my book on Plant Dispersal. Those of Sc. Kœnigii, which are described and figured by Schimper in his work on the Indo-Malayan strand flora (p. 172, pl. vii.), belong to a type that includes many of the characteristic littoral plants of the Indian and Pacific Oceans, the buoyant tissue forming part of the fruit-coverings. Since the question of adaptation was raised by Schimper in their case I termed them the "adaptive" group, though not myself in agreement with him on that point.

However, the interesting thing is that the type of buoyancy represented by the stones of Sc. Plumieri is offered by plants where this question of adaptation could not be raised. It corresponds with the Premna type, which is discussed at length on pp. 112 and 561 of my book above quoted. The behaviour of the small drupes of a littoral species of the genus is exactly that of the West Indian Scaevola Plumieri. The Premna drupes floated at first, but the buoyant stones are soon freed by the decay of the soft parts. Neither the seeds nor the substance of the stone are buoyant, the stone deriving its floating power from the fact that three of its four cells are usually empty. The importance of the bearing on the question of adaptation to dispersal by currents of the contrast presented by the two shore species of Sccevola is obvious. If the buoyant quality is accidental in its origin in one species, it is not reasonable to assume that it is adaptive in the other.

The results of my experiments on the floating powers of the stones of the drupes of these two species of Scaevola now require a few remarks. As long ago as $1888 \mathrm{I}$ tested the buoyancy of those of $S c$. Koenigii on Keeling Atoll, the results being given in my paper on the plants of that locality which was published in the journal of the Victoria Institute of London in 1889. Ripe fruits gathered from the plant continued to float buoyantly after fifty days' immersion in sea-water, losing during the early days of their flotation their white fleshy covering. Subsequently three of the stones were sown out by Dr. Treub at Buitenzorg, and out of the six seeds that they contained five germinated in the course of the next two months. Twenty-one months afterwards I put in sea-water in England two fruits gathered on Keeling Atoll. Both floated after a year's immersion, the seeds proving to be quite sound (see Plant Dispersal, p. 531, and Note to the Keeling Atoll paper).

My first experiments on the fruits of Scavola Plumieri were carried out in the Turks Islands in 1911, the average result being that about 70 per cent. remained afloat after sixty-three days in sea-water. The stones that had lost their soft coverings whilst lying under the bushes on the beach sand were the most buoyant. About 60 per cent. of the fresh stones and about 80 per cent. of the old dry stones floated after six weeks. In all cases the seeds of the floating stones proved to be sound and healthy at the close of the experiments. It was ascertained that the sinking was due to water penetrating the empty cell, the cell containing the seed being usually quite dry. In later experiments made in England on stones that had been collected ten months and still possessed sound moist seeds, I found that 66 or 67 per cent. floated after eighteen weeks in sea-water. 
But only half of the survivors proved to have been quite impervious to water. In the other half, water had begun to penetrate into the empty cavity as well as into the cavity containing the seed; and as they all sank in fresh-water the limits of their floating powers had evidently been nearly reached. The upshot of the experiments was that only a third of the stones were in a sound germinable condition after eighteen weeks' flotation in sea-water; and I would imagine that a period of five to six months would represent their flotation capacity.

On the whole the results of experiments on the capacity for dispersal by currents possessed by Sccevola Plumieri and Sc. Konigii go to show that although in both cases the stones will float unharmed for months in the sea, the advantage is certainly on the side of the plant last named. We would expect that floating capacity dependent on the existence of buoyant tissue in the fruit-coverings would be more effective than when determined by the failure of seeds and the resulting empty cavity. Whilst the stones of Sccevola Konigii will float in sea-water for a year or more, those of Sc. Plumieri will on the average float in a sound condition for only four or five months. Those of the first-named species could very well be drifted across an ocean as broad as the North Atlantic; but this would not be practicable for those of $\boldsymbol{S} c$. Plumieri, their floating powers only allowing them to reach Bermuda from the Florida coasts, the transatlantic traverse, occupying twelve months and more, being impracticable. But although the transference of Sc. Plumieri from the New World to West Africa by the only available route in the Gulf Stream drift would be impossible, the passage from tropical West Africa to Brazil in the Main Equatorial Current would be quite within the floating capacity of its fruits, since, as shown in Chapter III., it could be performed in three months. I have not here referred to the possibility of a passage to West Africa in the Counter Equatorial Current, since there is little to indicate that it is an available route for seed dispersal.

When, therefore, we discuss from the standpoint of dispersal by currents the question whether Sccevola Plumieri has reached the West Coast of Africa from America, or the Atlantic coasts of America from Africa, we have to exclude the long easterly passage in the Gulf Stream drift in preference for the westerly passage in the swift Main Equatorial Current from the Gulf of Guinea to the coasts of Brazil. From the standpoint of distribution a consideration of the same question leads to the same results. There is no probability that the American region could have received this plant from across the Pacific. Although Australia is the home of the genus, $S c$. Plumieri does not occur there, or, in fact, anywhere in that region of the globe. We have, therefore, to choose between America as the birthplace of the species or America as its recipient from the African West Coast. Although in the Index Kewensis America is credited with two endemic species of Sccevola, one in Trinidad and the other in Central America, these are both disregarded by Krause, who includes the species of the second locality (Sc. cumana) amongst his doubtful species (p. 168). No species of the genus is mentioned in Hart's list of the Trinidad flora. There is, therefore, little reason 
for supposing on the grounds of the distribution of the genus that America is the birthplace of this species. All the indications favour the view that it has received it from the shores of the nearest portion of Africa.

In the case of Sccevola Plumieri another difficulty presents itself in connecting its ranges on the East and West Coasts of Africa. Though it reaches the Cape or its vicinity on the east side of the continent, there seems to be a gap of about twenty degrees of latitude on the west side between the Cape and Benguela, where, according to the data supplied by Krause, it is next found. Probably future records will bridge over this broad gap; and we can only suppose that the species originally found its way north along the African West Coast through the combined agencies of birds and of inshore northerly currents. That it reached this coast from the eastern side of the continent is very probable. This involves the doubling of the southern extremity of Africa; but it has been shown in Chapter III. that this has been performed by bottle-drift.

Tabulated Results of the Comparison of Schrola Plumieri, Vahl, AND SCAVOLA KENIGIT, VAHL.

\begin{tabular}{|c|c|c|}
\hline & Scævola Plumieri & Scævola Kœnigii \\
\hline Distribution. & $\begin{array}{l}\text { Pacific coast of tropical } \\
\text { America and the Galapagos } \\
\text { Islands. } \\
\text { East coasts of tropical } \\
\text { America from Florida to Rio } \\
\text { de Janeiro, including the West } \\
\text { Indies and Bermuda. } \\
\text { West Coast of tropical Africa } \\
\text { from Senegal to Benguela. } \\
\text { East Coast of tropical Africa } \\
\text { from Somaliland southward } \\
\text { and extending to the Cape. It } \\
\text { reaches eastward to Southern } \\
\text { India, Ceylon, and Mauritius. }\end{array}$ & $\begin{array}{l}\text { Islands of the Indian Ocean } \\
\text { extending westward to the } \\
\text { Malabar coast, the Seychelles } \\
\text { and Madagascar, but not re- } \\
\text { corded from the east coast of } \\
\text { Africa. } \\
\text { South-eastern Asia, extend- } \\
\text { ing north to the Liu-Kiu } \\
\text { Islands and eastward through } \\
\text { Malaya to New Guinea and the } \\
\text { northern coasts of Australia. } \\
\text { Islands of the tropical Pacific } \\
\text { as far east as the Low Archi- } \\
\text { pelago and as far north as the } \\
\text { Hawaiian Islands. }\end{array}$ \\
\hline $\begin{array}{l}\text { Characters of } \\
\text { fruit. }\end{array}$ & $\begin{array}{l}\text { Black juicy drupe. Stone } \\
\text { ovoid, markedly tubercled, } 9 \\
\text { to } 10 \mathrm{~mm} \text {. long, no covering } \\
\text { of buoyant tissue, two-celled, } \\
\text { one cell empty. }\end{array}$ & $\begin{array}{l}\text { White fleshy drupe. Stone } \\
\text { roundish, slightly tubercled, } \\
5 \mathrm{~mm} \text {. across, possessing an } \\
\text { outer covering of cork-like } \\
\text { buoyant tissue, two-celled, } \\
\text { both cells holding a seed. }\end{array}$ \\
\hline $\begin{array}{c}\text { Buoyancy of } \\
\text { fruits in sea-water. }\end{array}$ & $\begin{array}{l}\text { Stones float for four or five } \\
\text { months with seeds sound. }\end{array}$ & $\begin{array}{l}\text { Stones float for twelve } \\
\text { months and more with seeds } \\
\text { sound. }\end{array}$ \\
\hline $\begin{array}{l}\text { Cause of the } \\
\text { floating capacity. }\end{array}$ & $\begin{array}{l}\text { Buoyancy of stone is en- } \\
\text { tirely due to the empty cell. }\end{array}$ & $\begin{array}{l}\text { Floating power of stone is } \\
\text { entirely due to the buoyant } \\
\text { tissue investing it. }\end{array}$ \\
\hline $\begin{array}{l}\text { Agents of dis- } \\
\text { persal. }\end{array}$ & $\begin{array}{l}\text { Currents across tracts of } \\
\text { ocean. } \\
\text { Frugivorous birds for local } \\
\text { dispersal. }\end{array}$ & $\begin{array}{l}\text { Currents across oceans. } \\
\text { Frugivorous birds for local } \\
\text { dispersal. }\end{array}$ \\
\hline
\end{tabular}




\section{Sophora tomentosa, L.}

This littoral shrub, which ranges over the warm parts of the globe, is discussed at length in my book on Plant Dispersal. My remarks here will be accordingly restricted to some supplementary observations made in the West Indian region. Though widely distributed in the West Indies and extending to South Florida and Bermuda and along the Caribbean shores of Central America to Brazil, it does not appear to be of frequent occurrence. Whilst typically at home on a sandy beach, it may also grow on rocky shores, as occasionally happens in Jamaica and, according to Harshberger's work (p. 674), also in Cuba.

The plant came under my notice more particularly on the north coast of Jamaica, in the Turks Islands, and on the Colon beaches. In the Turks Group it only came under observation in one island, namely, on Grand Turk; and there it was frequent in the interior of the low, sandy southern third of the island, where it grew in the company of Coccoloba uvifera, Dodoncea viscosa, and other plants, but was never observed amongst the vegetation immediately bordering the beach. The beach conditions are, however, reproduced in the plains of the interior, where the plant thrives at distances never exceeding half a mile from the beach. It appears to have a difficulty in establishing itself on low, sandy islets in these seas on which many characteristic shore shrubs find a home. Thus, Mr. Lansing did not record it on the Florida sand-keys, of the vegetation of which he made a most methodical investigation. As illustrating its transient sojourn on small isolated island groups one may refer to a note on this subject by Mr. Savage English in the Kerw Bulletin for 1913. He refers to a solitary specimen on the shore of Grand Cayman which was washed away in the hurricane of 1912.

In the district of St. Anne's on the north side of Jamaica I had an opportunity of observing the influence of an inland station on the buoyancy and size of the seeds. The seeds of the strand plant, as is shown in my previous work, are able to float in sea-water unharmed for several months, and even after twelve months' immersion. It is also established in its pages that with the seeds or fruits of typical beach plants like Ipomoea pes-capro, Sccevola Konigii, etc., the buoyant capacity is as a rule maintained when the plants have extended inland several miles from the coast. This conclusion is generally supported by the behaviour of Sophora tomentosa in Jamaica; but at the same time it was elicited that although the seeds of the inland plants floated in sea-water as long as those of the beach plants they did not do so in the same proportion, a greater number of them sinking during the experiment-a result, however, that is to be connected with the moister climatic conditions of the inland station.

I found the plants well established at the roadside and on the hillslopes just below "Sussex," which lies at the back of St. Anne's about two miles inland and about 700 feet above the sea. Their seeds were compared with those of shore plants growing at the St. Anne's coast on Priory Islet. The estate known as "Sussex" 
lies a little below the zone of heavy rainfall; but the climatic conditions there are far more humid than on the coast beneath. This distinction is important, because it is bound up with different degrees of shrinkage of the coast and inland seeds, and with the consequent different degrees of impermeability. As indicated below, the coast seeds are smaller and lighter, contrasts which my observations on seed-impermeability enable me to connect with a greater degree of imperviousness resulting from more complete shrinkage of the seedcoats. The coast seeds were 5.5 to $6 \mathrm{~mm}$. in size and averaged $1 \cdot 3$ grains in weight; whilst the inland seeds measured 6.5 to $7 \mathrm{~mm}$. and had an average weight of $\mathbf{2}$ grains.

The difference in behaviour is at once shown in an experiment in sea-water commenced by me in Jamaica, continued there by Mrs. H. B. Warde after I had left for England, and concluded by me on my return to the island about half a year afterwards. Of the coast seeds, 95 per cent. were afloat after seven and a half months, and no more sank when the experiment was extended to nine months, the seeds being still hard and sound. Of the inland seeds some began to swell and sink after two months; but 60 per cent. were afloat, and hard and sound, after seven and a half months. Some of the sunken inland seeds germinated in the sea-water and plants were raised from them. In another sea-water experiment carried out by me in Jamaica the contrast in behaviour was greater. After a month all the coast seeds were afloat in their normal state; but several of the inland seeds began to swell in a few days, some of them germinating in the sea-water, and only 10 per cent. remained afloat in a hard, sound condition after a month. In a third seawater experiment conducted in England in the same year, under warm conditions imitating those of the tropics, all the coast seeds were afloat and normal after four months, whilst 69 per cent. of the inland seeds alone floated; the rest, having absorbed water, swelled and sank. All the seeds employed in these experiments were of the previous season's growth. It appeared in the course of this inquiry that the "scar" was the place of weakness in the inland seeds as regards the penetration of water.

The seeds experimented upon were gathered from the well-dried pods hanging on the coast and inland trees at the end of March 1907. In both localities the previous year's pods were hanging in bunches from the trees. In neither locality were the trees then in flower; and whilst the coast plants were leafless, the inland trees displayed abundant foliage, a contrast connected with the prevalence of more humid conditions in the inland station.

The bearing of these Jamaican experiments may be thus stated. My experiments in the Pacific on the influence of an inland station on the buoyancy of the seeds or fruits of typical shore plants were concerned with plants that had extended miles inland in dry districts where plants of the xerophilous habit prevailed. Here in Jamaica we had typical shore plants invading the fringe of the lower forest zone, where more humid conditions determined the hygrophilous habit. The results obtained in Fiji and those obtained in Jamaica are therefore in one sense not strictly comparable. In the first 
case, the xerophyte of the beach found conditions suited for xerophilous plants in the dry inland districts; whilst the fruits matured and the seeds underwent the shrinking and hardening process under somewhat similar circumstances in both stations. In the second case, the xerophyte of the beach was placed under different climatic and soil conditions in the lower forest zone. The fruits matured and the seeds hardened in a moister climate, and we have seen how the whole plant responded, since the inland plants were in full leaf in the spring whilst those on the beach were leafless.

The conclusion to be drawn from these experiments is, that whilst the buoyancy of the seeds of littoral plants is retained when the same plants grow inland, whether in moist or dry conditions, it is less persistent when the inland plants grow in the humid conditions of the lower woods than with those growing in plains or open-wooded districts where drier xerophytic conditions prevail. The buoyancy is retained, therefore, when the xerophytic conditions of the coast are preserved in inland plains. It tends to disappear under the moist conditions of the inland forests. We have here indicated how it comes about that in a genus holding both littoral and inland species the seeds or fruits of the former float and of the latter sink. This is illustrated in the case of Sophora in the Pacific islands, where the seeds of the wide-ranging shore species, $S$. tomentosa, float, and those of the inland species, as exemplified by $S$. chrysophylla of the Hawaiian forests, sink.

It is probable that Sophora tetraptera, a tree of New Zealand and South Chile, which grows at the coast but also grows inland, would display buoyant seeds only when growing at or near the coast. In an experiment on the seeds of the tree that I collected on the Chilian coast it was found that half of the seeds floated in sea-water after seven months' immersion. Two of them placed in soil germinated and produced healthy plants. This is an extension of an experiment described on p. $\mathbf{5 8 0}$ of my work on Plant Dispersal.

A word may here be said about the source of Sophora tomentosa in the New World. As far as the currents are concerned, it is far more likely that its floating seeds reached Brazil by the short route in the Main Equatorial Current from the Gulf of Guinea than that they were carried in the Gulf Stream drift from the West Indies to Africa. Yet the genus holding some thirty species is spread over the warmer regions of both hemispheres. North America has its own species that flourish in the prairie districts, in the North Mexican highlands, and in the Rocky Mountains (Harshberger's Phyt. Surv. N. America).

\section{Suriana maritima, L.}

This shrub, the sole species of the genus, is one of the most widely spread of tropical strand plants. It occurs in the Pacific islands, on the northern coasts of Australia, in Malaya, in the islands of the Indian Ocean, on the shores of the Asiatic mainland, on the East Coast of Africa, but not, as far as I know, on the West Coast of that continent, though its occurrence there is extremely probable. In the New World it is widely spread over the West Indies, occurring 
even on such isolated groups as the Cayman Islands and the Alacran Shoals (Millspaugh). It is also a Bermudian plant. On the American mainland it is found on the coasts of South Florida and on the shores of the Gulf of Mexico. I have no record of its occurrence on the Pacific coasts of that continent, but it ought to grow there.

There are, however, some curious gaps in the distribution of a plant that Nature evidently intended to be universal on tropical shores. For instance, its distribution in the Pacific is freak-like. It has been recorded from Tonga, but not from Fiji or Samoa. Yet it occurs in the Melanesian archipelagoes of the Western Pacific. Though found in the Tahitian Group and in the Paumotu Islands, it has not been observed in Hawaii. We have here, it would seem, an outcast in the plant world, friendless, without kith or kin, and claimed by nobody, since botanists are undecided in what order to place it. It would be futile to seek for its home. It is probably coeval with man in the tropics, and he has evidently been its greatest foe.

Its suitability for firewood no doubt explains its otherwise unaccountable absence from some of the Pacific archipelagoes. One of the first things a Pacific islander does, when he lands on an uninhabited shore, is to gather fuel for cooking his yams or his taroroots; and if, as often happens on coral islands, fishing parties make a sojourn there of some weeks, the wood of this shrub would be burned in quantities. This inimical influence would not be an affair of to-day but of the ages. It goes to explain why the plant was not recorded by botanists from Keeling Atoll before my visit in $\mathbf{1 8 8 8}$ (vide Keeling Atoll paper), since long before the white man's occupation of the islands they had probably been visited from time to time by Bugis traders.

Though typically a plant of the borders of the sandy beach and of the sand-dune, it may also grow on coastal rocks as in Bermuda and in the Bahamas (Harshberger). I came upon this shrub growing on the north coast of Jamaica at St. Anne's, and at Dry Harbour and on the south coast at Paroti Point. But it was in the Turks Islands at the south-east end of the Bahamas that I paid especial attention to it. However, before proceeding to refer to its occurrence in that small group I will notice its distribution in the sand-keys of Florida, as observed by Mr. Lansing and described by Dr. Millspaugh. Out of nineteen keys examined westward of Key West this plant was noted in all but two; but usually it was infrequent and represented by only one or two small colonies growing in its natural station on the sandy soil to the rear of the mangrove belt. Only in four keys was it at all frequent, and in two of these it occupied most of the surface of the islet. In the past, no doubt, man did much to disturb the distribution of this plant in the Florida keys by utilising it for firewood

In the Turks Islands, though a characteristic strand plant, it as a rule presents itself in the rear-line of the beach vegetation when any arrangement can be detected. But it is equally at home on the sand-dunes behind the beach; and in the smaller cays, when sand has been spread over the island, it also occupies the interior 
in association with other plants from the beach. It grows, often in abundance, on nearly all the islands; but it did not come under my notice either on Round Cay or on Eastern Cay. Its absence from the last-named island, which is the most weatherly of the group, may be partly due to its use for firewood by visiting parties, either from Grand Turk or from passing schooners, since it thrives on the neighbouring Pear Cay, which from the difficulty of landing is much less frequently visited. But it may be that hurricanes have assisted in its banishment from this cay, as is illustrated by the destruction executed amongst its numbers on Greater Sand Cay, as noticed below. On Pear Cay it displayed a singular adaptation to the wind-pressure, the trunk and primary branches being prone and rooting in the sand, whilst the leafy branches alone rose erect three or four feet into the air. On Greater Sand Cay I found it fairly well distributed in February 1911; but my boatmen told me that before the last hurricane of 1908 it was much more frequent-a statement confirmed by the number of dead prostrate trunks still to be seen on the surface over the island, the material being utilised for firewood by small sailing craft trading in these seas. The shrub is frequent around the coasts of Grand Turk, and in places where the beach vegetation borders on the mangrove belt one may sometimes see a curious intermingling of the plants of the two formations, Suriana maritima with other beach plants growing amongst the mangroves. Though preferring a sandy soil, where it grows in colonies, the plant also grows well on rocky ground, but only as individuals.

On the Turks Islands there is evidently from some cause or another great loss of seeds. In two localities I found that 95 per cent. of the seeds or seed-like fruits gathered from the plants were empty, whilst of those picked up from the sand beneath the bushes 30 to 40 per cent. had sound kernels. The seeds, which are about $3 \frac{1}{2} \mathrm{~mm}$. long and broadly conical, have a dark wrinkled hairy skin, which, however, they soon lose in the beach-drift, and then they are about $3 \mathrm{~mm}$. in size and have a smooth reddish surface. In appearance they look a little like grape-seeds, and no doubt their hardness might fit them for dispersal in the stomachs of birds; but their great floating powers offer a much readier explanation of the worldwide distribution of the species. Dr. Millspaugh regards the seeds as dispersed through the medium of the feet of sea-birds; but the currents aided by the drifting log and floating pumice have doubtless done most of the work of distribution. There is nothing in the character of the dryish fruits on the plant to attract frugivorous birds.

Hemsley in his list of plants dispersed by oceanic currents includes this species (Chall. Bot., I., 42, 48); and Schimper, who especially investigated the buoyancy of the seeds, came to the same conclusion. I may add that the term " nucule " is applied to the seed-like fruits; but they are for purposes of distribution "seeds," and I will follow Schimper in this respect. They lie in numbers on the sand near the shrubs; and in the Turks Islands they are prominent amongst the small drift derived from local plants and sorted out on the beach by wind and wave. In this fine drift the seed-like fruits of Suriana 
maritima are associated with the pyrenes of Tournefortia gnaphalodes, the seeds of Ipomøa, the "stones" of Scaevola Plumieri, and wellrounded small pumice pebbles, 5 to $12 \mathrm{~mm}$. in size.

These seeds, as I have said, could readily be carried in the crevices of floating logs, or in the cavities of floating pumice, such as is stranded on the beaches of tropical regions all over the world. But it is on their great floating powers, which fit them for dispersal by currents, that we must mainly rely. Neither the kernel nor its hard covering has any buoyancy, the floating power arising, as also ascertained by Schimper (p. 163), from the unfilled space in the seedcavity. In my paper on the plants of Keeling Atoll I refer to some experiments there made which only indicated a capacity of floating between two and six days in sea-water; but as the seeds are described as rather soft, it is evident that they were immature. Schimper in an experiment made at Bonn (p. 165) kept the seeds afloat in saltwater for nearly five months (143 days); and my experiments in Jamaica and the Turks Islands point in the same direction. Thus in Jamaica some seeds which had been floating in sea-water for seven weeks were quite sound at the close of the experiment. In the Turks Islands I placed sixty seeds in sea-water and after nine weeks forty-five were floating buoyantly, and would evidently have floated for a much longer period. Of the seeds that sank nearly all were empty; whilst of those that remained afloat nearly all had dry sound kernels and dry cavities.

\section{Swietenia mahagoni, Jacq. (Mahogany)}

In one's inability to explain its mode of dispersal over the West Indian area and the mainland of tropical America, this tree must be typical of many other trees of the forests of this region. Having made a special study of the fruit in Jamaica, the results of which are given in my work on Seeds and Fruits, I here give a few remarks on the plant from the standpoint of dispersal.

Belonging to a genus of only three or four species that are restricted to the tropics of the New World, this tree does not raise awkward questions, such as are presented by genera common to the eastern and western hemispheres. Yet queries almost as difficult to answer are implied in its occurrence in the larger West Indian islands. Its distribution in South Florida, Mexico, Central America, and Peru may be a matter of the continuity of the land-surface, and there is much, as far as the plants of the Greater Antilles are concerned, to support the contention of the geologist that with those large islands in past ages distribution was also a matter of the continuity of the land-surface. The occurrence of the Mahogany tree in the Greater Antilles and in most of the larger islands of the Bahamas suggests questions that are concerned with former continental connections rather than with means of dispersal.

The large winged seeds, two and a quarter inches in length, that are freed by the dehiscence of the capsule, are quite unfitted for transport by the currents. In experiments they can float a week or two; but they absorb sea-water and become sodden and dead, 
and they are much too fragile for transport over the sea. It is possible that strong winds might carry the seeds some distance; but experiment showed that this would not be greater than 100 feet in a moderate gale.

\section{Symphonia globulifera (L. fil.)}

\section{(syn. Moronobea coccinea, Aubl. Mart.)}

This West African tree of Upper and Lower Guinea is found in the New World in Jamaica, Dominica, Trinidad, Guiana, North Brazil, Panama, etc. Its station is by the riverside in mountain woods, and in the swampy ground bordering estuaries, but above the mangrove formation. In Jamaica I observed it flourishing at the waterside on the banks of the Black River estuary; and according to Forrest Shreve, as quoted by Harshberger (p. 679), it grows in the forests of the Blue Mountain Range, forming with Calophyllum calaba and other trees closed arches over the rivers. The genus has a remarkable distribution, though it may be in part explained by our better acquaintance with the floras of some localities than of others. Of its dozen or more known species nearly all are peculiar to Madagascar; but two are West African, and one of these, $S$. globulifera, is the widely spread New World species that we are now considering.

Its germinating seeds occurred in abundance in the floating drift of the Black River estuary. In Jamaica it is known as "Hog-gum " or "Boar-wood." Its softish, baccate fruits, which have a yellow juice, are one-and-a-half to one-and-three-quarters of an inch long, and hold from one to three seeds, one to one-and-a-quarter inch in length, which are at first fleshy and afterwards tough and flexible. The mature seeds, when freed by the decay or breaking down of the fruit, are not in any way protected by their coverings against drying or against the penetration of water; and when removed from the fruit they shrink greatly. Their readiness to germinate, whilst afloat in the Black River, is thus explained; and I may state that quite 95 per cent. of the seeds there observed were germinating.

The seed presents the structure characteristic of several other genera of the Guttiferce, a structure also illustrated in the Barringtonice. There is a central axis separated from the outer thick portion by a thin layer of vascular tissue (Mirbel's membrane), which becomes wavy or crumpled in the drying seed. The cotyledons are either absent or are represented by minute scales, the seed being, therefore, merely an enlarged hypocotyl.

When we reflect on the unprotected condition of the fruit and its seeds, on the fleeting vitality of the seeds, on their readiness to germinate when afloat in river-drift, and on the fate that must await them when they reach the sea, it is not possible to find an explanation of the plant's distribution on the opposite sides of the Atlantic in dispersal by currents; and it would be equally futile to look to the agency of birds. We may even go further and hold that the seeds are not even suited for inter-island dispersal by either agency in the West Indian region. Taking the arrangement of 
land and sea as it is at present, the distribution of this tree offers one of the most difficult problems dealt with in these pages.

\section{Thespesia populvea, Corr.}

This tree has presented itself to me as a littoral plant in several parts of the tropical zone, namely, in Hawaii, Fiji, the Solomon Islands, Keeling Atoll, and in different islands of the West Indies. Its distribution over the tropics of the Old World and its mode of dispersal by currents are discussed in my book on Plant Dispersal; but I did not there regard it as belonging to the New World, being guided in this matter by Bentham, who in his Flora Australiensis regards it as introduced into America. However, there can be little doubt that it behaves in the West Indies as an indigenous plant; and, considering its great capacity for dispersal by currents, there seems in the light of more recent investigations but small reason for the refusal of its proper place in the flora of the New World. "Quod credere vix possum " is Lrban's opinion concerning the belief of botanists that it has been introduced into America (Symb. Antill., IV., 401). If the distribution of the genus given in the Index Kewensis offers a clue, the New World can almost make an equal claim to be the home of this tree. Of the seven other species there named, three are peculiar to Mexico, the West Indies, and Brazil, respectively; one is only found in Africa; and three are confined to Malaya. It is, howerer, quite possible that in some distant age the tree reached the New World from tropical West Africa, where it is now at home, since the seeds could have been readily carried across to Brazil in the Main Equatorial Current.

It is distributed over the Greater and Lesser Antilles and is found in Trinidad (Hart). I especially observed it in St. Croix, Jamaica, Grenada, Tobago, and the Turks Islands. In order to prove that it behaves as an indigenous shore tree in the West Indies it is of importance to name its associates. I found it thriving at the beach border on St. Croix in the company of such characteristic littoral trees and shrubs, as Coccoloba uiifera, Guilandina bonducella, and Hippomane mancinella. Harshberger states that on St. Croix and the Virgin Islands it is one of the Coccoloba-Hippomane association, the formation of trees and shrubs that immediately lines the beaches (p. 686).

Grisebach speaks of it as growing along the sea-coast of Jamaica, and I made notes of its associates in different localities on the shores of that island. On the beaches of the Black River district it was associated with Coccoloba ui ifera, Ecastaphyllum brownei, and Guilandina bonducella. In the Savanna-la-mar district a mangrove fringe often skirts the low sandy shores, and on the beach behind it this tree thrives in the society of Guilandina bonducella, Coccoloba urifera, and Conocarpus erectus, one of the most typical strand shrubs of the West Indies. It is associated with the same three plants on the borders of the beaches on the north side of the island, as at St. Anne's Bay and at White River, and to them we may add Sophora tomentosa, another characteristic beach shrub. With Coccoloba uivera it is one of the commonest of the plants bordering 
the beaches along the east coast of Tobago; and in the company of the same plant together with Guilandina bonducella and Hippomane mancinella it grows at the margin of the beach south of St. George's Harbour in Grenada.

There can, therefore, be but little doubt that Thespesia populnea behaves like an indigenous strand plant in the West Indies. If its exclusion from the proper flora of the New World is based on the assumption that the genus has its home in the eastern hemisphere, then we should have to exclude such a typical West Indian beach plant as Scavola Plumieri and such representative West Indian swamp plants as Rhizophora mangle and Carapa guianensis.

Against the view that it is truly American are to be urged the facts that the tree has not established itself amongst the new vegetation of the Florida sand-keys and is regarded as introduced into Bermuda (Chall. Bot., II., 22). It is, however, widely spread over the Pacific, occurring in some of the most remote islands; and it is difficult to imagine how a characteristic shore tree that is of no great use to man and is exceptionally suited for dispersal by currents could owe its wide distribution, except in a secondary sense, to human agency.

In the Turks Islands the tree gave me the impression of being indigenous, though now it could merely be viewed in the light of a survival, since it came under my notice only in the northern part of the island of Grand Turk. Here it grows gregariously inland on one side of the hollow known as the North Wells, but it also grows on the borders of the neighbouring coast. I should imagine that originally the tree thrived around the lagoons on the beach behind the mangroves, as it often does in the Pacific. In Grand Turk and Salt Cay the salt industry has led to the destruction of most of the original vegetation on the lagoon shores, and Thespesia populnea was probably involved in this clearance.

In the West Indies one not uncommonly finds Nature engaged in distributing this plant. The dried baccate capsules and the seeds are not infrequent in beach-drift, the fruits liberating by their decay the buoyant seeds, which are readily swept off by the waves. In some localities in Jamaica I noticed seedlings growing freely in the stranded drift.

It is strange that notwithstanding its capacity for dispersal by currents this tree is stated by Lefroy to have been introduced by man into the Bermudas (Chall. Bot., II., 22). In this matter it is in the same category as Hibiscus tiliaceus, which, as before pointed out, is not included in the indigenous flora. In many respects, as in its general distribution as a littoral tree in the warm regions of the globe, in its fitness for dispersal by currents, and in the wide prevalence of the same native name in the Pacific islands, it raises the same issues as Hibiscus tiliaceus; but there is this difference, that it is not of such great use to man, at least among the Pacific islanders, and the uncertainty whether it owes much to human agency in its distribution, a matter to which Hemsley refers (Chall. Bot., IV., 235), is for this reason more pronounced than with the other tree.

Since I did not deal connectedly with this tree in my previous 
work on the Pacific, I will go briefly over the ground there traversed as regards its distribution and modes of dispersal, supplementing my remarks with additional observations and reflections and directing them towards the elucidation of the problem connected with the intervention of man. It resembles Hibiscus tiliaceus closely in its general distribution, accompanying it as a common seashore tree throughout the archipelagos of the tropical Pacific, in North Australia, in Indo-Malaya, in the islands of the Indian Ocean, on both coasts of Africa, and in the West Indies; but, as far as I know, only Hibiscus tiliaceus has been recorded from the Pacific coasts of America, though it is very probable that Thespesia populnea also grows there.

The testimony of botanists in the Pacific islands as to its claim to be indigenous, that is to say, to have existed there at the time of their discovery in the eighteenth century is practically unanimous. It was found during Cook's voyages by Banks and Solander in the Society Islands and by Forster in Easter Island (Seemann, p. 18); whilst Hillebrand, the authority for the Hawaiian Islands, places it with the plants that were introduced by the natives in prehistoric times. Hemsley, Burkill, and Reinecke in the case of the Tongan and Samoan floras, Cheeseman as concerning Rarotonga, and Seemann in respect of Fiji, include the tree amongst the indigenous plants without any comment.

If as Hillebrand claims, and his opinion is always weighty, the Polynesians have carried these seeds about with them during their oceanic migrations, what, we may ask, were the inducements for them to do so? Though like Hibiscus tiliaceus the tree yields bast fibres which are used for cordage in other parts of the world, it does not seem, according to Cheeseman, Hillebrand, Reinecke, Seemann, etc., that the Polynesians and Fijians utilised it for this purpose. In fact, it was for the durability and hardness of its timber that the Fijians, Rarotongans, and Samoans chiefly prized it. Hillebrand, however, finds sufficient explanation of its wide distribution in the Pacific in the veneration paid by the Tahitians and other islanders to the tree.

I am inclined to consider that the Pacific islanders may have assisted in the distribution of this tree, but not to the extent in which they aided the dispersal of its frequent associate on the seashore, Hibiscus tiliaceus. But whatever was accomplished in this direction by man was probably carried out ages ago. Oliver, in his Flora of Tropical Africa (1868-77), considered it as probably distributed through cultivation. It is worth noting that another species of the genus, Thespesia danis, from east tropical Africa was held sacred in the Galla country (Hooker's I con. Plant., ser. iii., Vol. IV.). Though doubtless its presence on isolated oceanic islands in the Pacific is usually due to currents, I am inclined to hold that in the case of Easter Island, where it was found by Forster in 1773, during Cook's second voyage, its existence should be attributed to man.

We pass on to advocate the claims of the currents in explaining the wide range of this coast tree. Hemsley, though regarding it as introduced into the New World, ascribes to currents a share in its distribution (Chall. Bot., I., 42 ; IV., 125, 235). My first experiment 
on its fitness for dispersal by this agency was made in the Solomon Islands in 1883. Since that time I have tested the capacity in the Keeling Islands, in Hawaii, Fiji, and other localities (Solomon Islands, 1887, p. 305; Journ. Vict. Inst. London, 1889; Plant Dispersal, 1906, p. 531), all the experiments giving the same indications and culminating in one where, after floating a year in sea-water, a see -germinated and developed into a plant. The dried fruits, which lie in numbers under the trees, are, as already observed, very likely to be swept off the beach by the waves. They float, but in time break down, thus liberating the buoyant seeds on which the dispersal by currents eventually depends. In the West Indies the dried fruits, seeds, and seedlings produced from stranded seeds are characteristic of the beach-drift, and the same may be said of the Hawaiian Islands. In the Solomon Group I found that this was one of the early plants that established themselves on the low sandy islets of the coral reefs (Chall. Bot., IV., 309). In the Marquesas, according to Jouan, it is only found on the seashores in places to which the waves could have conveyed the seeds (Ibid., IV., 125). In my Victoria Institute paper above quoted good reasons are given for the belief that the Keeling Islands possessed the tree at the time of their first occupation by white men about 1825, and that they received it with many other of their shore plants through the instrumentality of the currents.

The indications of the foregoing discussion are that whilst, as with Hibiscus tiliaceus, man and the currents have each played their part in distributing the species, the currents have perhaps had a rather more important share in the process than in the case of Hibiscus tiliaceus. However, I hope at some future time to discuss the distribution and dispersal of Thespesia populnea in greater detail.

\section{Tournefortia gnaphalodes, R. Br., and Tournefortia Argentea, Linn. $\mathrm{f}$.}

The distribution of these widely spread littoral species of Tournefortia raises several of the questions presented by the two shore species of Scaevola before dealt with, Sc. Plumieri and Sc. Kønigii. One of them, $T$. gnaphalodes, is found over the West Indies including the Bahamas, in South Florida and the adjacent keys, in Bermuda, and on the coasts of Mexico and Yucatan, but not apparently on the Pacific coasts of the New World. The other, T. argentea, is spread over most of the continental and insular coasts of the Indian and Pacific Oceans in warm latitudes. It has also extended from the East African to the West African coast, being found on the shores of Lower Guinea (Oliver's and Dyer's Flora of Tropical Africa, Vol. IV., sect 2, p. 29). Unlike Sccevola, however, the two species never meet, being separated from each other by the breadths of the Atlantic and Pacific Oceans. We have here also a New World and an Old World species dividing the tropical beaches of the globe between them, but the American species of Tournefortia is appro. priated by the New World, whilst the American species of Scarvola 
occurs on both coasts of Africa. We are thus face to face with problems of a different nature.

This is seemingly not such a well-defined genus as $\mathbf{S c c e v o l a . ~ I t ~}$ holds more than 120 species, distributed over the tropics and subtropics of the globe; and since the New World possesses its own peculiar species, it may be inferred that Tournefortia gnaphalodes could have had an independent origin on this continent. Hemsley states that there are several littoral species. One of these, as I infer, is T. sarmentosa, Lam., which extends from the Philippines to North Australia and occurs also in Mauritius and in the Seychelles (Bot. Chall., IV., 168).

Like the two shore species of Scaevola, those of Tournefortia possess fruits endowed with great floating powers, and are thus well fitted for dispersal by currents. However, they differ from the Sccevola plants in that the fruits of both species exhibit the same type of buoyancy. There is a much greater resemblance, both in habit and general appearance, between the two shore species of Tournefortia than in the case of the other two plants. Covered with hairs, which give them a silver-grey hue, these shrubs form a conspicuous feature in the shore landscape, their height ranging usually up to five or six feet, but much reduced in exposed situations.

I will now deal more in detail with these two species of Tournefortia from the standpoint of dispersal by currents. Both of them possess dry drupaceous fruits, measuring about seven millimetres in the case of $T$. gnaphalodes and somewhat less in the case of $T$. argentea. When naturally dried, these fruits separate with a little pressure into two hemispherical pyrenes, and it is in this condition, but bared of their outer dark skin, that they usually occur in the old drift of beaches. Each pyrene displays a suber-like exocarp, in which lies imbedded a small two-celled stone, each cell usually containing a seed. Deprived of its outer covering the stone sinks.

[Particulars relating to $T$. argentea will be found in Schimper's work on the Indo-Malayan strand flora (p. 174), in my Plant Dispersal (p. 108, etc.), and in my paper on Keeling Atoll in the Journal of the Victoria Institute (1889)].

A familiarity with both species in their homes enables me to treat them together here. The fruits of both plants, entire and in halves, are of common occurrence in the smaller drift of beaches on which they grow. They cover the sand in quantities beneath the bushes, and the strong winds scatter them over the beach. So frequent were they on some of the beaches of the Turks Islands that they were to be noticed in every handful of sand. Under the shrubs they are apt to germinate, as was often indicated on Grand Turk by the shrivelled projecting radicles that had withered up before they could establish themselves in the sand. I noticed both on Keeling Atoll and on Grand Turk that the pyrenes are at times mixed with the sand washed into the crevices of stranded logs. This matter is especially discussed in my paper on Keeling Atoll; and it is there shown that floating pumice must also often assist dispersal in the same manner. But although drifting logs and floating pumice often aid dispersal, they do not determine it, since the buoyant fruits of these two 
species of Tournefortia are of themselves able to cross the broadest ocean.

Whilst my first sea-water flotation experiments, carried out on Keeling Atoll and in the Turks Islands, were limited in duration, they established the great buoyancy of the fruits of both species of Tournefortia, none of them sinking during a period of forty days in the case of $T$. argentea and of sixty days in that of $T$. gnaphalodes. In a subsequent experiment made in England four fruits of $T$. argentea that had been gathered twenty-one months were placed in seawater, all of them floating and displaying sound seeds after a year's immersion. In the same way I made a later experiment in England on fruits of $T$. gnaphalodes collected twelve months before. All remained afloat and retained sound seeds after six months in seawater. They were sown out, and after a couple of months several germinated and produced healthy seedlings. The delay in the subsequent germination conveys a warning against expecting quick results when testing the germinative capacity of seeds after prolonged flotation in sea-water. There was also delay in the case of the fruits of $T$. argentea which had been forty days afloat in sea-water on Keeling Atoll. Dr. Treub, Director of the Botanic Gardens of Buitenzorg, Java, sowed seven of them in one of his houses, and all germinated in the course of two months (Journ. Vict. Inst. Lond. 1889).

However, the dispersal of the fruits of Tournefortia by currents is not always so simple as it appears to be. In the case of T. gnaphalodes it was necessary to employ a good number of fruits in my experiments, since about half of them had no seeds, the contracted seed-cavities indicating their early failure. Another influence that goes towards reducing the number of fruits effective for dispersal is the tendency of the fallen fruits of this plant to germinate unsuccessfully on the sand beneath the shrub, a matter already mentioned. It is thus likely that a large number of the fruits swept off a beach by the waves and carried off by the currents may be ineffective for purposes of dispersal.

With reference to the distribution of Tournefortia gnaphalodes in the ten islands of the Turks Group, it may be said that the plant came under my notice on all of them except Cotton Cay; but it is highly probable that it occurs on that island also, as my examination of it was incomplete. In the two largest islands of Grand Turk and Salt Cay it grows in quantity, both on the edge of the beaches and on the sandy belts in the rear. On Grand Turk it grows around the greater portion of the island, and is especially abundant along the length of the weather or east side. But it thrives almost as well on the rocky surfaces of small cays, such as Penniston, Long, and Pear Cays, where sandy beaches are either scanty or absent. Whilst it grows over the surface of such small rocky cays, which are from fifty to a hundred yards in width and from twenty-five to thirty-five feet in height, it rarely strays far from the vicinity of the beach in the larger islands, and does not usually climb far up their slopes. However, it grows on the sandy top of Round Cay, which, though fortyfive feet in height, is the smallest of the islands. In islands, like 
Pear Cay and Eastern Cay, which are exposed to the full force of the strong winds, the main stem lies prone and roots in the sand, only the primary branches rising erect into the air (see Note 3 of the Appendix).

From Mr. Lansing's methodical examination of the Florida sandkeys west of Key West, we are able to form an idea of the relative abundance of Tournefortia gnaphalodes in comparison with the other plants, the flora being almost entirely littoral and in many respects identical with the shore flora of the Turks Islands. Of the nineteen keys described, those occupied alone by mangrove colonies being excluded, nine possessed this plant, which, though nowhere abundant, is evidently fairly well distributed over this region. Yet, although better represented than Scaevola Plumieri, which was found on only four of the keys, in no single key did it form a predominant feature of the vegetation. In five cases it was either scanty or very scanty, and in the other keys it grew in moderate amount.

From the data given by Grisebach, Harshberger, Millspaugh, Urban, and others, it is evident that the currents have distributed Tournefortia gnaphalodes all over the West Indian islands, both large and small, from Cuba, Jamaica, and the Bahamas to Barbados and St. Vincent. I have no information relating to its occurrence on the mainland of South America; but its ability to establish itself on the most isolated islands is indicated by its existence on Grand Cayman and the Alacran Shoals (Millspaugh). Though most characteristic of the vegetation bordering the sandy beaches, it is frequently to be found on a rocky shore of calcareous formation. It is a plant that prefers coasts fully exposed to wind and wave, and I have shown in Note 3 of the Appendix how well it adapts its growth to the wind-pressure. Dr. Millspaugh, who had an extensive acquaintance with it in the West Indies, states that it prefers a station "on the beach line facing the open sea" (Plant. Utorv.). In this respect it resembles $T$. argentea its sister species of the Pacific islands, both plants on account of their hardy nature being amongst the first shrubs to establish themselves on a newly formed coral-sand key.

Some of the results of the foregoing comparison of these two shore species of Tournefortia are tabulated in the table on p. 251.

\section{Vigna luteola, Benth.}

In my volume on Plant Dispersal I deal with Vigna lutea, A. Gray, a common strand species in the tropies of both hemispheres, but, as it would appear, most characteristic of the Old World. I was familiar with it amongst the beach plants of Hawaii and Fiji. Its small seeds, 5 or $6 \mathrm{~mm}$. long, were frequent in the beach-drift of those groups, and also in the floating drift of Fijian rivers. Experiments showed that they can float for months unharmed in sea-water.

Widely spread in the warm parts of the New World is a sister species, Vigna luteola, Benth. In its littoral station, in its general habit, and in the buoyancy of its seeds, its behaviour is similar to the other species. It has a very wide distribution in the New World. According to Hemsley and Grisebach, it ranges from Carolina and 
Texas to Peru and Chile on the Pacific side and as far south as Buenos Ayres on the Atlantic side; and in the Old World, as we learn also from Hemsley (Bot. Chall. Exped., II., 29) as well as from Oliver (Flora of Tropical Africa, II., 206), it is found on both coasts of Africa and in Australia. It is widely dispersed in the West Indies. Grisebach gives Jamaica, Antigua, Dominica, and St. Vincent as its homes. Millspaugh (Plant. Utow., I., 53) gives Porto Rico, Jamaica (Port Antonio), and the Cayman Islands. In Jamaica I noticed it at Port Antonio, St. Anne's Bay, and at Black River. It is not

Tabulated Results of the Comparison of Tournefortia gnaphalodes, R. Br., AND TOURNEFORTIA ARGENTEA, Linn.f.

\begin{tabular}{|c|c|c|}
\hline & Tournefortia gnaphalodes & Tournefortia argentea \\
\hline $\begin{array}{l}\text { Main facts of } \\
\text { distribution. }\end{array}$ & $\begin{array}{l}\text { American shores of the } \\
\text { tropical and subtropical At- } \\
\text { lantic, including the West } \\
\text { Indies, South Florida, and the } \\
\text { Bermudas. }\end{array}$ & $\begin{array}{l}\text { Tropical, continental, and in- } \\
\text { sular shores of the Indian and } \\
\text { Pacific Oceans, excluding the } \\
\text { Pacific coast of America; also } \\
\text { on coast of tropical West } \\
\text { Africa. }\end{array}$ \\
\hline Fruit-characters. & $\begin{array}{l}\text { Dry drupaceous fruit, about } \\
7 \text { mm., separating into two } \\
\text { hemispherical pyrenes, each } \\
\text { pyrene displaying a small } \\
\text { two-celled stone (a seed in } \\
\text { each cell) imbedded in a cork- } \\
\text { like exocarp. }\end{array}$ & $\begin{array}{l}\text { Similar to the other species, } \\
\text { except that the fruit is rather } \\
\text { smaller. }\end{array}$ \\
\hline $\begin{array}{r}\text { Buoyancy of } \\
\text { fruits in sea-water. }\end{array}$ & $\begin{array}{l}\text { Float for months with seeds } \\
\text { unharmed, none of them sink- } \\
\text { ing. }\end{array}$ & $\begin{array}{l}\text { Float for months without } \\
\text { injury to the seed, none of } \\
\text { them sinking. }\end{array}$ \\
\hline $\begin{array}{l}\text { Cause of the } \\
\text { floating capacity. }\end{array}$ & $\begin{array}{l}\text { The buoyancy is due to the } \\
\text { cork-like exocarp, the stone } \\
\text { having no independent float- } \\
\text { ing power. }\end{array}$ & $\begin{array}{l}\text { The same as with the other } \\
\text { species. }\end{array}$ \\
\hline $\begin{array}{l}\text { Probable home } \\
\text { of the species be- } \\
\text { fore buoyancy was } \\
\text { acquired. }\end{array}$ & $\begin{array}{l}\text { In the tropics of the New } \\
\text { World. }\end{array}$ & $\begin{array}{l}\text { In the tropics of the Old } \\
\text { World. }\end{array}$ \\
\hline $\begin{array}{l}\text { Subsidiary dis- } \\
\text { persal agencies. }\end{array}$ & $\begin{array}{l}\text { Birds, drift-wood and pum- } \\
\text { ice. }\end{array}$ & $\begin{array}{l}\text { Birds, drift-wood and pum- } \\
\text { ice. }\end{array}$ \\
\hline
\end{tabular}

mentioned in Hart's "Herbarium List" for Trinidad; but I found it on the south coast of that island. It is also included in the Bermudian flora.

Hemsley says that it frequents brackish marshes on the seashore, and Grisebach states that it is common in Jamaica in this station. At Port Antonio I found it thriving in wet places on the beach. At St. Anne's Bay it grew on the beach; and at Black River it was scrambling over the reeds and other vegetation within the mouth of the estuary. On Porto Rico, Millspaugh described it as "rising free among high reeds and grasses" (Ibid.). In Trinidad I found 
it on the beach. In the delta of the Mississippi it grows in great luxuriance, giving its character and name to the plant-association that clothes the higher portions of the alluvial banks between the "passes" or mouths of that river : here, clambering amongst the canes of Phragmites communis it forms an almost impenetrable thicket (Harshberger, Phyt. Survey, N. America, pp. 216, 444, under Vigna glabra, a synonym).

The seeds of Vigna luteola, which are rather smaller than those of $\boldsymbol{V}$. lutea, float for a long time in sea-water. Some, which had been seven weeks afloat in one of my experiments, germinated freely afterwards. They help to form the smaller drift of beaches, as I noticed at Trinidad. Amongst the floating drift of the estuary of the Guayas River in Ecuador, I collected a number of sound seeds of a species of $V i g n a$, apparently those of $V$. luteola.

The cause of the floating capacity of the seeds of both Vigna lutea and $V$. luteola lies in a large central cavity between the cotyledons, the materials composing the seed having no independent buoyancy, a matter dealt with for the first species in my previous book (p. 106). The genus holds about fifty known species, spread over the warm regions of the Old and New World; and it would be important to determine whether it follows the rule laid down in my earlier work, that when a genus possesses both littoral and inland species only the seeds or fruits of the shore species float. In the case of the Hawaiian representatives of the genus the possibility was there pointed out (p. 139) that the two endemic inland species were derived from the coast species $(\boldsymbol{V}$. lutea $)$. The genus, it may be added, offers many interesting problems for the consideration of the student of distribution.

\section{Ximenia americana, L.}

The writer made the acquaintance of this shrub or tree amongst the littoral plants of Fiji, where its means of dispersal were investigated, the results being given in his previous work on the Pacific. Like the species of Sccerola and Cassytha that figure in the strand floras all round the tropics, it can be dispersed in two ways, by birds and by currents. Its drupaceous fruits are known to be distributed by fruit-pigeons (Chall. Bot., I., 46); whilst the stones are able, as $I$ ascertained, to float in sea-water for months. But since the fruits were rarely represented in the beach-drift, it was assumed that bird agency has been predominant in the Pacific (Plant Dispersal, p. 113).

Although, as Hemsley observes (Chall. Bot., IV., 132), it is a maritime shrub throughout the tropics of both hemispheres, it may extend inland-a behaviour which it most frequently exhibits in the New World. It has been recorded from Tahiti, Samoa, Tonga, Fiji, from the islands of the Western Pacific, from North Australia, Malaya, both coasts of Africa, and both coasts of the New World. Its usual place among the trees and shrubs lining the beaches of the Old World seems often to be abandoned, as just remarked, for an inland station in the tropics of America. Though it is frequent in the interior of South Florida, it has not established itself amongst the characteristic littoral vegetation of the coasts or of the sand-keys. 
Whilst it is a plant of the beach and of the dunes on the coasts of Cuba (Harshberger, p. 673), it seems to be most characteristic of inland districts in Jamaica, occurring, as we learn from the work of Fawcett and Rendle, at heights of from 2000 to 3000 feet. Seemann, however, observes that it is common on the sea-beach on the Pacific side of the Panama Isthmus (Bot. Voy. H.M.S. Herald). Whilst its range is said to cover the region between South Florida and Buenos Ayres, its distribution seems to be fitful in the West Indies, and I find no reference to it in my notebooks.

It would seem that in the New as in the Old World the fruiteating pigeons have taken a more active part in its dispersal than the currents. Reference may here be made to the fact that this is one of the plants that established themselves on Verlaten Island after the complete destruction of its vegetation by the great eruption of the neighbouring island of Krakatau in 1883. It was found there by Ernst and his party in 1906 (Ernst's New Flora of Krakatau, p. 37).

The distribution of the species of Ximenia, only five being known, is suggestive of a genus that owes its representation in both the New and the Old World to its original dispersion from a common centre in high northern latitudes in an age when warm climatic conditions prevailed in those regions. It seems difficult to look for any other satisfactory explanation in the case of a genus which has one species that is found round the tropical zone, a second confined to Mexico, a third to Brazil, a fourth to South Africa, and a fifth to New Caledonia. Yet alternative explanations are possible, though not necessarily hostile to Dyer's hypothesis, even though we cannot regard them with approval. Thus, one may regard all the localised species as derivatives of the plant that ranges round the tropical zone. From this point of view it might be supposed that Ximenia americana, in dropping species, so to speak, in different parts of its range, has played on a large scale the rôle of a highly variable polymorphous species in the Pacific archipelagos. Here a solitary species, the sole representative of its genus and ranging over the tropical Pacific, becomes ultimately in each group of islands the parent of a number of peculiar species, the same process being also exemplified in the individual groups (Plant Dispersal, p. 333, etc.). Nevertheless, such an explanation would not account for the original occurrence of the parent species in the ocean-severed regions of the tropics. Either we must regard it as having travelled from its birthplace in the tropics around the globe through the agency of birds and currents, or we must view it as having been originally spread over the diverging land-masses of the globe from a common centre in the north. 


\section{CHAPTER XI}

THE GENERAL CHARACTERS AND GEOLOGICAL STRUCTURE OF THE TURKS ISLANDS 1

The Turks Islands, well known on account of the salt industry that has been long established there, are situated on one of the level summits of a great submarine mountain range rising up from depths of 2000 fathoms and over. The long and narrow bank on which the ten islands lie is about thirty-seven miles long, as limited by the 100-fathom line. The depth of water covering the bank does not generally exceed ten or eleven fathoms, and is often only three or four fathoms; and so rapid is the submarine slope that, if limited by the fifteen-fathom line, the bank would possess much the same dimensions.

Geographically this group forms the south-eastern extreme of the Bahamas. Botanically it belongs to the Bahamian region, and geologically its structure is that of the same archipelago, the familiar æolian formation of the Bahamas here prevailing. The islands or cays are low in elevation, none of them reaching 100 feet in height, the highest (Eastern Cay) being ninety-six feet, whilst the lowest (Long Cay and Penniston Cays) do not exceed thirty feet. They are usually long and narrow, and vary in length from five and a half miles in the case of Grand Turk to less than 200 yards in that of Round Cay.

The general characters of this small group are those of the numerous islands of the great archipelago of the Bahamas, all of which rise from banks that are covered by a few fathoms of water. These banks are the flat summits of a lofty range of submarine mountains which terminate abruptly near the surface. Rising from the ocean's depths of 2000 fathoms and more at the eastern end, the banks are separated at the western extremity from the Florida coasts by depths of about 400 fathoms. The 100 -fathom line surrounds the islands and reefs of the Little Bahama Bank, and a similar line includes those of the Great Bahama Bank, with intervening depths of less than 300 fathoms, the isolation of the banks increasing as we go east, depths of 1000 to 2000 fathoms dividing those from which

1 This chapter was mainly written nearly four years ago, when the author was only acquainted with the monograph of A. Agassiz on the Bahamas. Since it has been in type he has enjoyed the privilege of communication with Dr. Vaughan, who has recently investigated the western Bahamas. His conclusions are of great importance; but the writer has been obliged to deal with them in Note 39 of the Appendix. 
2015

2037

1975

1950<smiles>[Mg][Mg]</smiles>

\section{TURKS ISLANDS}

(Adapted from Admiralty Chart 1266)

Heights in feet thus..

(40)

Soundings in fathoms thus . .... 40.

When no bottom was found, thus ito

Scale of Sea Miles

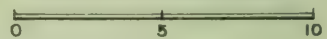

12

9

1043

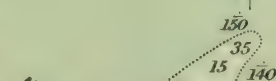

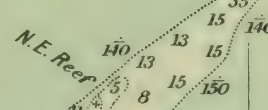

707

765

$$
{ }_{8} 15150
$$

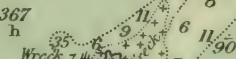

Wreck $74,39+7+7$

$40]+30^{++}++$

40.) H tookitio (75)

1011

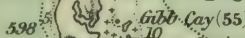

TURKS ISIANDS

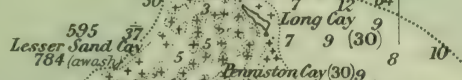

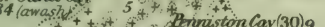

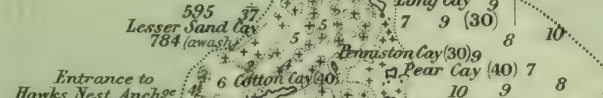

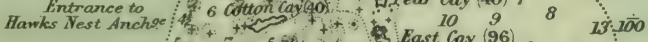

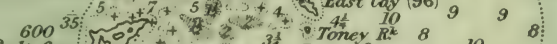

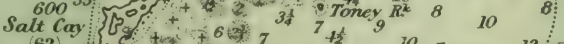

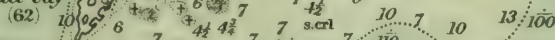

$$
\begin{aligned}
& 978
\end{aligned}
$$

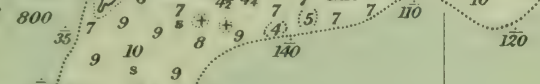$$
810 \text { 30: } 10 \quad 9 \quad 9
$$

903

$$
\begin{array}{cll}
212 & 112
\end{array}
$$

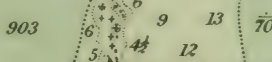

$$
5.42
$$

* Greater Sand $\operatorname{Cay}(40)$

865

872

$\operatorname{lin}^{2}{ }^{6}{ }^{6} 13$

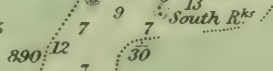

$12^{7}$

Endyimion $R^{k}$

$6817^{+15}$

$$
12217
$$

617

$16 . \ldots 70$

180

224

50

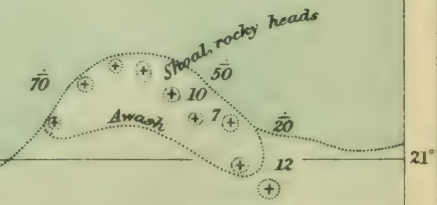

MOUCHOIR

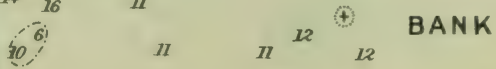



the eastern islands rise. All the islands are of moderate elevation, Cat Island displaying the greatest height of about 400 feet; but their average height would not amount to half this elevation, and large areas of some islands are not removed many feet above the sea.

Whilst viewed orographically the Bahamian banks are connected at their western end with the Florida region and project at their eastern end into the ocean's depths, they present a similar relation with the Greater Antilles. This connection becomes more and more dissevered as we proceed from west to east, depths of rather under 300 fathoms dividing the Great Bahama Bank from the north coast of Cuba, whilst depths of $\mathbf{2 0 0 0}$ fathoms and over separate the eastern banks, on which the Turks and Caicos Islands lie, from the north coast of Hispaniola. Trending eastward from the Turks Bank is the line of the Mouchoir, Silver, and Navidad Shoals, which are surrounded on the north, east, and south sides by depths of 2000 to 3000 fathoms. On the north side of the Bahamian archipelago the submarine slopes descend to depths of 2000 fathoms a few miles from the shore.

Some curious considerations offer themselves when we reflect on the present and past conditions of the Bahamas, of which the Turks Islands form a part, considerations that have a bearing on the origin of the geological structure and of the floral characters of the whole region. It may be that in Miocene times, when the Florida peninsula was under the waves, the Bahamas were the Laccadives and the Maldives of the coral-reef region of the Atlantic. Dana in his Corals and Coral Islands (p. 213) gives vent to a suspicion of this kind; but he did not follow it up, and contented himself with noting the analogy between the eastern and western ranges of land on the Great Bahama Bank and the opposite sides of the Maldive Group. However, the coral reef makes a peremptory demand to be called as a witness in this connection, and for this reason. Only in coralreef regions could we find the conditions that have produced an archipelago, several hundred miles in length, consisting of relatively low islands that are entirely composed of reef débris and calcareous æolian rocks. In a geographical sense the analogy with the abovenamed archipelagos of atolls in the Indian Ocean is closer than would at first appear. The Laccadives would represent the western portion of the Bahamas, where the islands come into relation with the adjacent continent, and the Maldives would stand for the free oceanic eastern portion that protrudes into the ocean's depths.

In the Bahamas we have an archipelago possessing hundreds of islands, large and small; and yet along its length of 600 miles and more there is not an island that is more than 400 feet above the sea, the majority of them not exceeding half this elevation. Several of the eastern islands rise from banks that are the flattened tops of submarine mountains starting up some 12,000 feet above the ocean's floor. Yet there is relatively little difference in the elevation of the islands, and we find this small range in height along the length of the archipelago. We have here the anomaly that so exercised Darwin's mind in the case of the lines of living atolls in the Indian and Pacific Oceans; that is, a lofty range of submarine mountains, 
rising from the ocean's depths, which along a length of several hundred miles exhibit a line of peaks that in all cases end abruptly at or near the ocean's surface. The implication is that atolls originally crowned the summits of these submerged peaks in Bahamian seas, atolls long since overwhelmed by the shifting sand-dune, the work of which is presented in the æolian sandstone of our own day. But, as in the line of atolls formed by the Laccadive and Maldive archipelagos, there is a "continental" end, where the Bahamian archipelago abuts on the adjacent continent, and an "oceanic" end, where it projects into the ocean's depths.

The standpoint adopted with regard to the problems offered by the Bahamas would, I think, largely depend on whether the investigator was familiar with the western or " continental " portion or with the eastern or "oceanic" portion. The points of view might differ materially. Politically as well as geographically the western area is by far the most important; and from the time of Catesby, nearly 200 years ago, to that of A. Agassiz in our own day, the experience of the west has largely coloured the views of the majority of investigators. Agassiz, it is true, made a general examination of the archipelago; but his acquaintance with the west principally determined his views. On the other hand, the present writer's experience was limited to a three months' sojourn in the Turks Islands at the extreme eastern end of the archipelago, during which period he made a fairly detailed examination of all the islands of the little group. He may thus claim to be an exponent of the "oceanic" standpoint.

Much mystery surrounds the history of the Bahamas. The view that there are atolls buried beneath the xolian deposits does not involve any change of level, since the sand-dune could have effected all that we see at present without the assistance of a movement of upheaval. When, as with the Turks Islands Bank, the original bank was long and narrow, the atoll form of reef would be replaced by a reef of similar shape. But on a broad platform, like that presented by the neighbouring Caicos Bank, a typical atoll might have been formed, of which we may discern the remains now in the broken margin of islands and in the extensive flats in the interior of the bank that are now covered by only a few feet of water. However this may be, all that we see at present could have been produced at the existing sea-level. Different periods of upheaval and subsidence of the Bahamian area have been postulated by geologists and zoologists; but, without entering into matters that are mainly inferential, I will at once proceed to refer to the account of these islands given by A. Agassiz in his Reconnaissance of the Bahamas (Bull. Mus. Comp. Zool. Harvard, 1894), a work from the hand of one of the foremost investigators of our time.

A. Agassiz on the Formation of the Bahamas.-After remarking that the islands of the Bahamas are from end to end all of æolian origin, he thus proceeds-

"They were formed at a time when the banks up to the ten-fathom line must have been one huge irregularly shaped mass of low land, the coral sand beaches of which supplied the material that must have built up the successive ranges of low hills which we still find in 
New Providence, and which are so characteristic of all the ridges of the islands of the group. After the formation of the islands came an extensive gradual subsidence, which can be estimated at about 300 feet, and during this subsidence the sea has little by little worn away the xolian hills, leaving only here and there narrow strips of land in the shape of the present islands."

Before I proceed to give in detail the results of my observations in the Turks Islands some discussion of the views of Agassiz is necessary. He considers that the disintegration of the original landsurface is still in progress; but this would be under present-day conditions, which would be quite other than those which prevailed when the land was being broken up during the movement of subsidence, and could not safely be employed in illustration of it. In this connection he regards the strips of land on the Caicos and Turks Banks as representing the last stages in the process of destruction, the original condition of those banks being exemplified in the neighbouring large island of Great Inagua, where the whole area of the bank is occupied by land; whilst the intermediate stage is presented in the island of Andros. Another point is that this investigator lays no stress on the operation of reclaiming agencies at the present time. Here and there a bight or a cove may have been filled in; but the prevailing tendency in our own day, as in the past, is (he holds) one of destruction. However, as he himself shows, a large portion of the island of Grand Turk has been reclaimed by coralgrowth at the present sea-level; and in general terms he describes the islands of the Turks Group as formed in part of æolian rock and in part of shore coral-rock.

Then again, when he describes the Bahamas as representing the results of the breaking up, during a movement of subsidence amounting to $\mathbf{3 0 0}$ feet, of one huge mass of low land, he could have had in his mind only the western portion of the archipelago. The banks from which the eastern islands rise must have been isolated through the ages. So rapidly do they plunge down into the great depths dividing them that an upheaval of 300 feet would add but little to their size, and would be far from establishing any connection between them.

Let us take the adjoining banks from which the Turks and Caicos Islands rise. They are united under the sea by a "col " covered by about 250 fathoms of water, and lying a few miles to the south of them. This "col" is the head of a deep submarine valley, running north between the two banks along their whole length, which is at least about 1500 fathoms deep opposite Grand Turk and about 2000 fathoms where it debouches on the ocean's floor. A subsidence of 300 feet (fifty fathoms) could not have effected the separation of these two banks, seeing that the "col" was some 1200 feet under the sea before it commenced. Moreover, isolated as the two banks are from each other, this "col" is in relatively shallow water as compared with the ocean depths around them. The great hollow that separates them on the south from Hispaniola is 2000 fathoms and more in depth. Similar depths of 2000 fathoms isolate the Caicos Bank from the neighbouring island of Mariguana, and prob- 
ably also from Great Inagua. To the north of the two banks lies the open ocean with a depth of 2000 to 3000 fathoms.

No soundings in which bottom was obtained are given in the Admiralty chart (1266) for the seas dividing the three great banks stretching south-east from the Turks Islands, namely, Mouchoir, Silver, and Navidad Banks; but it is not improbable that they are connected by deeply submerged " necks." Except probably on the Turks Island side these three great banks rise up from the ocean depths around them. The trench separating them from Hispaniola is 2000 fathoms deep, whilst to the north is the open sea, where soundings of 3000 fathoms have been obtained. To the east this line of banks plunges down in a few miles to depths of over 2000 fathoms, which increase as we go eastward some forty miles towards the Brownson Deep, where depths of 4000 to 4500 fathoms occur. From what has been said above it is apparent that the eastern extremity of the Bahamian area, including the Caicos and Turks Banks with the islands rising from them and the Mouchoir, Silver, and Navidad Banks that carry no islands, has been isolated from the rest of the region by deep-sea conditions through the ages. As we proceed westward the connecting seas become shallower and the banks and islands larger; but the process is gradual, and even immediately west of the Caicos Bank depths of 1200 to 1800 fathoms separate banks and their islands.

I come now to the reasons assigned by A. Agassiz for assuming a subsidence of $\mathbf{3 0 0}$ feet. They are based on the existence of " oceanholes" in the banks. These holes have been sounded to a depth of thirty-four fathoms (204 feet); and it is to be supposed that in estimating the total depression at $\mathbf{3 0 0}$ feet he allowed for the depth of water covering the banks. He considers that they were formed in the æolian rocks, before the subsidence, by the same agencies that produce the present caverns, sinks, blow-holes, etc., in the xolian sandstone of the hills. We learn from his maps that these "oceanholes " may pierce the banks to a depth of 200 feet and may be 200 yards or so in width. I venture to think that this evidence in support of a depression of 300 feet is a little hypothetical. In any case, the decision must lie with the student of land forms and submarine contours, the interpretation of which has become an important branch of geological science in recent years.

The subject of these "blue" or "ocean" holes has evidently received much attention from American geologists. Dr. Vaughan has recently procured additional information concerning them in the North-west Bahamas, and he writes that "on the assumption that these holes were subaerially formed, parts of Andros must have once stood 192 feet higher than now." Similar but smaller holes, as he states, exist in the Miami coast region of Florida. They penetrate to a depth of over thirty-five feet a rock floor of oolite lying ten feet below low tide, and are regarded as "indicating the presence of solution wells" in that formation (Year Book of the Carnegie Institution of Washington for 1914 and 1915, No. 13, pp. 227-33; No. 14, p. 234).

This subject raises another important point. An implication of 
the theory of Agassiz is that the foundations of the æolian sandstone would lie far beneath the surface of the sea. I find no reference in his pages to the exposure of any base-rock in this region, and his views would expressly exclude the idea of the existence of a foundation of "reef-rock" at or above the sea-level. In the case of the same xolian formation in the Bermudas, Professors Heilprin and Rice lay stress on the exposure of a foundation of reef-rock; but Agassiz rejects their interpretation. Naturally, if, as I hold, the xolian deposits of the Bahamas were formed with the sea at its present level there would be a base-rock composed of coral-reef débris; and it ought to be exposed during the retreating tide, where cliffs front the sea. But a little reflection will show that situations favouring its exposure would be usually inaccessible on account of the breakers and the rollers ever dashing against the base of the sea-cliffs. Such an examination would be hazardous in the Turks Islands, for the sea is rarely sufficiently quiet on the weather coasts of the islands where these sea-cliffs exist. In those places where the cliffs lie a little inland, being cut off from the sea by the growth of a fringing reef, extensive beaches with the sand piled up against the foot of the cliffs would effectually prevent observation. The most favourable localities would exist where a line of cliff washed by the waves abuts on a beach. Even these do not always permit one's approach; but I found such an accessible spot in the Turks Islands, and there was exposed, underlying the æolian sandstone, a reef-rock containing large fragments of corals.

There are two points connected with these xolian sandstones to which A. Agassiz makes no allusion. The first is that this formation seems to be peculiar to the Bahamian and Bermudian regions. Calcareous sandstones, formed by the consolidation of wind-blown sand derived from coral-reef beaches and composing entire islands, are unknown in the great coral-reef regions of the Indian and Pacific Oceans. The second point is concerned with the conditions under which these æolian rocks were formed. Their absence, more or less complete, from other great coral-reef areas would seem to imply that unusual conditions, mainly climatic, prevailed during their formation in the Bahamas and in the Bermudas. Both these matters are dealt with at the close of the chapter.

The Author's Observations on the Geological Characters of the Turks IsLands.- The results are given here exactly in the form in which they were written before the author had read the memoir of A. Agassiz on the Bahamas. The remarks suggested by the perusal of that work have since been intercalated. The sojourn of the American naturalist in this group probably did not cover more than a week or two; but he seems to have visited all the islands, including those that are most isolated, such as Eastern Cay and Greater Sand Cay. Though few details are given by Agassiz, it will be seen that the results obtained by the present writer are in general agreement with his conclusion that the islands are formed in part of æolian sandstone and in part of shore coral-rock. However, the distinction has to be made between the work of the past and of the present in describing the formation of these islands. Whilst the 
extensive low sandy tracts, overlying old reef-rock, belong to the present, the " nuclei" of æolian sandstone, around which they have been formed, belong to the past, a past when probably almost the whole of the Turks Bank was occupied by land of æolian formation, four-fifths of which have disappeared at the hands of the marine and aerial eroding agencies.

All the ten islands or cays are composed either entirely or in part of the rolian sandstone, the growth in size in later times by the development of low land around "nuclei" of the æolian rock being chiefly characteristic of the larger islands.

The Eolian Sandstone.-This is a white calcareous sandstone of the Bahamian oolitic type. Whilst on the exposed surface the materials are often cemented into a hard crust, which is some inches thick and possesses an almost flinty fracture, they are usually loosely compacted beneath, so that the rock readily breaks down between the fingers. The crust, however, is generally broken up into slabs, as explained below, thus exposing the less consolidated rock which, readily disintegrating, has furnished much of the loose sand that occurs on the surface of the interior of the larger islands. It is as a semi-compacted sandstone that the rock typically presents itself; but in the smaller low flat cays it is the hard crust that attracts most notice, and one might imagine that one was dealing in the mass with a hard, honeycombed limestone, if the attention was confined only to the surface characters. It is in the face of the line of bluffs on the east side of Grand Turk and in the coast cliffs of the other large cays that this formation is best exposed; but one may find good exposures at times in the smallest of the islands when they possess any elevation, as on Round Cay.

This formation sometimes offers itself in thick beds of loosely compacted sandstone composed of usually well-rounded grains varying from 0.5 to $1.5 \mathrm{~mm}$. in size. At other times the rock is made of finer materials, between 0.3 and $0.5 \mathrm{~mm}$. in size and rather more consolidated. Such finer sandstones often display a laminated structure, the layers being usually horizontal; but they are occasionally inclined, in which case cross-bedding may at times be observed. The hard crust exhibits scattered grains in a compact matrix, and has the appearance of a consolidated calcareous ooze; but, as is shown below, it has a very different history. All these rocks dissolve readily in acid, leaving scarcely any residue.

Nowhere did I find any marine shells or other marine remains in the rolian rocks. However, on the sandy slopes of Gibb Cay I found gathered together on a ledge great numbers of old Bulimoid shells of a large species of land-mollusc. Whether they had been freed by the disintegration of the sandstone from which the loose sand was derived, or whether they represented a molluscan fauna that had subsisted on vegetation which had been destroyed by the goats, I could not determine. The first explanation seems to be most probable, since A. Agassiz (p. 20) remarks that land-shells similar to those now living on the islands occur in the æolian rocks of the Bahamas.

We come now to the consideration of the hard surface-crust of the 
æolian sandstone, a discussion that will lead up to the treatment of the causes of the consolidation of the rock in the mass. The hardening process of the crust extends to a depth varying usually from three to twelve inches. When, as often happens on the lesser cays, large level surfaces of the hard crust are fully exposed to the sun's heat, the rock becomes fissured in all directions, and the ground looks as if it had been irregularly paved. With the continuation of the fissuring process and the constant widening of the cracks through the weathering agencies, the ground is ultimately strewn with slabs of all sizes that generally vary in thickness between three and twelve inches and lie in confusion around. All over these islands we find in the interior and even at the coast, both on level ground and on the tops of the more barren ridges, this slabby broken ground in all stages of disruption. The hard crust separates readily in large slabs from the underlying loose sandstone. On Penniston Cay, a low flat island only thirty feet in height, the hard surface crust is in places so much honeycombed and broken up that walking is difficult. In other places, again, we have large slabby undulating surfaces only in the early stage of the disrupting process, and looking more like the top of a lava flow. This hard crust of the xolian sandstone has often been described. Alluding to this sandstone, A. Agassiz remarks that it is " covered with a hard ringing crust when exposed to the action of the sea or the rains." In this connection we can here appropriately introduce the fact that it is to his celebrated father, L. Agassiz, that we are indebted for the clue to the nature of the hardening process that affects the surface of the rock.

The Observations of L. Agassiz on the Salt Key Bank.But the observations of the elder Agassiz, which were published about half a century ago in the first volume of the Bulletin of the Museum of Comparative Zoology, go further, since they also throw light on the conditions under which the consolidation of the mass of the formation takes place. They were made on the keys or low islands of the Salt Key Bank, which lies between the Great Bahama Bank and the coasts of Florida and Cuba. After describing the oolitic rock (as he terms it) formed by the consolidation of the calcareous sand of the high dunes gathered by the wind, he alludes to its being very hard and to its ringing under the hammer, the weathered surface being implied. But the clue is afforded in his reference to "thin layers of very hard compact limestone, alternating with the oolitic beds, which have no doubt been formed in the same manner as the coating of the pot-holes."

These pot-holes are described as of two kinds, those of recent and those of ancient origin. The first, lying near the water's edge, are " mostly clean excavations," being either empty or containing a little loose sand or pebbles. The second, ordinarily beyond the reach of the tides and the waves, have often been "gradually filled with materials identical with those of the older (oolitic) deposits." They are "generally lined with coatings of solid, compact, and hard limestone, varying from a thin layer to a deposit of several inches in thickness. . . I It is plain from their structure that these coatings 
are a sub-aerial formation, increasing by the successive accumulations of limestone particles left upon the older rock by the evaporation of water thrown upon the Key when the ocean is so violently agitated as to dash over the whole Key. Frequently the hollow of these coated pot-holes is further filled with consolidated oolite; or thin layers of fine-grained oolite alternate with a coat of compact limestone, throughout the excavation, which has often been filled in this way up to the general level of the surrounding surface. ..." The structure and the mode of filling of these ancient pot-holes are, as Agassiz goes on to say, distinctly exhibited in the cases of those that have been partially cleared out by the action of storms.

The account of the keys of the Salt Key Bank is given in full by Dana in his Corals and Coral Islands (1872 p. 213,). The elder Agassiz supplies an illuminating description of the history of the formation of these æolian rocks on these islands. The bank, covered by from four to six fathoms of water, is formed of the "oolitic" grains of coral materials mingled with broken shells. Its margin is encircled in some places by rocky ridges and in others edged by sand-dunes. "A close examination and comparison of the different Keys show that these different formations are in fact linked together, and represent various stages of the accumulation, consolidation, and cementation of the same materials." That the rolian rocks have been formed by the consolidation of the sand-dunes, he has no doubt. The sand composing them "must have been blown up by the wind, and accumulated in the form of high dunes before it became consolidated." This dune-sand is still loose, but, as on Salt Key, it shows " here and there a tendency to incrustation at the surface." Then in the case of another key, where the æolian sandstone prevails, he says: "It is evident that what is beginning on Salt Key has here been completed." All this, it should be noted, has been accomplished with the sea at its present level, a matter that is dealt with again below. Different localities have their individual lessons, and I may here remark that though sand-dunes occur in places near the coasts of the larger islands of the Turks Group, they very rarely exhibit a tendency to surface-consolidation.

The Basement of the Eolian Sandstone.-For reasons before explained, underlying rocks of a character different from that of the æolian rock are rarely exposed. It has already been observed that the claim made by Professors Heilprin and Rice for the existence of a basement of old reef-rock in the Bermudas is disallowed by A. Agassiz, who regards it as the effect of the action of the sea in cementing the strata together and destroying their xolian structure. But the weightiest evidence against him is supplied by his father in the case of the islands of the Salt Key Bank. Their foundation is not æolian sandstone, but " a conglomeration of coarser oolitic grains, rounded fragments of corals, or broken shells, and even larger pieces of a variety of corals and conchs, all the species being those now found living on the Bank." Stratification is displayed, the beds dipping towards the sea at an angle of about seven degrees. This foundation never rises above the level of high-water. It is, as the present writer will show, but a coarse kind of the "beach-rock" that is 
exposed between the tide-marks on the sandy islets of coral-reef regions all round the tropies, and forms the basement of the islet. Upon this foundation are heaped up by the waves, as is described by L. Agassiz, masses of sand, broken shells, and fragments of corals, which in their turn are covered by the finer sand driven by the wind and forming sand-dunes. He does not refer to any exposure of an actual contact of the xolian rock with its foundations; but we may infer that they would be the materials heaped up by the waves, but more or less consolidated and cemented, and passing downward below the high-water level into the basement rock, similarly composed of sand, broken shells, and coral débris, that constitutes the foundation of the islands.

It was only in one locality in the Turks Islands that I found a good contact-exposure of the rocks underlying the xolian sandstone. This was on the east coast of Greater Sand Cay near its southern end. Here, about two or three feet above the high-water level, the xolian rock sometimes passed down into a coral-rag, composed of large fragments of massive corals imbedded in a matrix of compacted coarse sand, and at other times into an ordinary coarse beach sandrock such as is described below.

"Beach sand-rock" came under my notice in different islands of the Turks Group, as on Grand Turk and Salt Cay. It is characteristic of low coral islands all over the tropical Pacific, and doubtless is common enough in the Bahamas. It is well described by Dana in his Corals and Coral Islands (1872, pp. 152, 184), and I have dealt with it in my Geology of the Solomon Islands (1887, p. 84). It is a very coarse white sand-rock, and is stratified, the beds dipping seaward with the slope of the beach at an angle usually of seven or eight degrees. It is composed of coral and shell débris; but many characters distinguish it from the æolian sandstone or drift sand-rock, notably the larger proportion of coral débris, the coarseness of the constituents, and their great irregularity in size. Sometimes the materials forming the beach sand-rock are imperfectly consolidated. At others they are firmly cemented into a hard rock with a metallic ring; and when, as is not infrequent, large fragments of corals and dead shells are enclosed in the hard matrix it might be termed a coral-rag, though reef-rock would perhaps be a more appropriate name. The typical rock is exposed between the tide-marks. But it is a formation that is only exposed by the removal of the overlying loose sands by the waves. Wherever exposed, it is always in process of destruction through the action of the sea. I have never seen it in process of formation. The conditions under which the stratification and consolidation take place are obscure. Evidently, whether as sand-rock or reef-rock, it forms the platform on which islands and islets are thrown up by the waves; and it would be on such a foundation that the subsequently produced æolian deposits would be based.

The upshot of the foregoing remarks would appear to be this. If there has been an extensive subsidence of $\mathbf{3 0 0}$ feet in the Bahamian region since the formation of the rolian sandstone, as is assumed by A. Agassiz, the foundations of the æolian rock ought to lie far beneath 
the waves. As far as the Turks Islands supplied direct evidence on this point, it was to the effect that the æolian rocks passed downward into consolidated reef débris, consisting of coarse sand, dead shells, and coral fragments, which had been thrown up on reef-rock at the present sea-level. The same inference is to be drawn from the observations of L. Agassiz on the islands of the Salt Key Bank.

The Evidence supplied by Charts of Recent Changes in Level iN the BaHAMas.-Fortunately this matter has received considerable attention in one way or another. Looking at the evidence supplied by the examination of old maps, particularly that obtained by Mr. Tillinghast which is mentioned below, and having regard to the unimportant changes that occurred between the careful survey of 1834 and the time of his visit in 1893, A. Agassiz concludes that "we are warranted in assuming that the configuration of the Bahamas, as we now know them, does not differ materially from that of the $\boldsymbol{Y}^{\text {as }}$ de los Lucayos as they were first discovered by Columbus." From this we may infer that during a period of 400 years no great change has occurred in the relations between land and sea in this region.

Mr. Tillinghast carried out his investigations with the idea that " an examination of old maps" might reveal a change in the zondition of the Mouchoir, Silver, and Navidad Banks since the tince of the discovery of the Bahamas "which might be of importance in the disputed question of the landfall of Columbus." As a result he formed the conclusion, after examining a large number of old charts going back to the beginning of the sixteenth century, that "they throw more light on the condition of the cartography of the West Indies than on any physical change among the islands" (see Notes on the Historical Hydrography of the Handkerchief Shoal (Mouchoir Bank) in the Bahamas, in the "Library of Harvard University, Bibliographical Contributions," No. 14, 1881).

In this connection A. Agassiz lays stress on the difficulties surrounding such investigations, and notably the rarity of actual surveys of these regions. He points out (p. 14) that in the chart of the first survey of these three banks at the south-east end of the Bahamas, that of Count de Chastenet-Puységur (1784-7), only shoals and banks are drawn. This is interesting as showing that the three banks (Mouchoir, Silver, Navidad) bore no islands then as they bear no island now. Their stationary condition during the last 200 years is also indicated by the fact that their shoals and rocks were as dangerous to the navigator in the early part of the eighteenth century as they are now. The site of a wreck, named "Plate Wreck," is marked in some of the old charts on one or other of these three banks. Thus it is shown in one of the maps given by Catesby in his work on the natural history of Carolina, Florida, and the Bahamas (Vol. I., 1731).

In the British Museum library I came upon an old chart of the Turks Islands, which is not included in Tillinghast's extensive list of the early maps of this region. It describes itself as constructed from " a survey made in 1753 by the sloops $L '$ Aigle and $L ' E m e r a u d e$ by order of the French Governor of Hispaniola with improvements 
from observations made in $\mathbf{1 7 7 0}$ in the Sir Edward Hawke, King's Schooner." Further details are given in Note 32 of the Appendix; but I may say here that it represents the results of a regular survey, the three main positions being fixed by astronomical observations, the error in longitude being about forty minutes and the errors in latitude not exceeding two miles. But, as will be noticed below, when discussing the effects of the reclaiming process in these islands, the period for comparison is very limited, since the latest Admiralty chart of this group is mainly based on the survey of 1830 . It is, however, permissible to infer on grounds given in the Note that there has been extensive shoaling between the islands since the French survey, though the depths on the open bank clear of the islands experienced but slight change in the interval between the middle of the eighteenth and the middle of the nineteenth century. Lesser Sand Cay, a sandy islet lying between Cotton Cay and Grand Turk, on which plants obtain at times a scanty hold, evidently did not exist at the time of the French survey.

The Degradation of the Eolian Sandstone in the Turks Istands.--Just as L. Agassiz in the case of the æolian rocks of the islands of the Salt Key Bank lays stress on the extensive disintegration they are experiencing at the hands of the atmospheric and marine agencies, so we may lay emphasis on the same process of destruction in the Turks Islands. If Nature busied herself in producing these deposits ages ago, she is not doing so now. There is nothing about these formations that is modern. For ages they have been exposed to great degradation; but, as we shall see, Nature by setting up a reclaiming process is now doing her best to save the pieces. In those localities where there is no protecting beach, as in the case of the smaller rocky cays and of some of the headlands of the larger islands, the full force of the breakers of the open ocean is spent in the destruction of the æolian sandstone. Long narrow rocky islands, such as Long Cay and Penniston Cay, where there is no protection against the breakers, have already been cleft through near their extremities. Toney Rock, which lies near Eastern Cay and receives the whole brunt of the breakers, represents the last stage in the process of destruction. When a beach protects the coast, the atmospheric agencies are active in degrading the clifffaces that once were buffeted by the waves. The bluffs, so conspicuous on the eastern side of Grand Turk, are from this cause in full retreat landwards.

The Modern Process of Reclamation of Land from the Sea In the Turks Islands.-As already observed, A. Agassiz lays no stress on reclaiming agencies in the Bahamas. L. Agassiz, who rightly includes the Salt Key Bank in the Bahamian region, refers to the "very instructive combination of the phenomena of building and destruction" in its shoals and keys. In the Turks Islands there exists, side by side with the process of degradation of the original land-surface of æolian rock, a process of renovation that will ultimately prevail. It is unfortunate that a comparison of the old French chart of 1753 with that in present use covers too short a period to be of much service to us. The Admiralty chart (No. 1441) 
of the Turks Islands is based on Captain Owen's survey of 1830 , with additions to 1845 and corrections to 1898; whilst the French chart is emended from observations made in $\mathbf{1 7 7 0}$ in an English survey; so that the period for comparison is limited to sixty years. However, as will be shown below, the changes that can be established are all on the side of "gain." The reclaiming process is indicated:-

(a) By the shoaling of the Bank.-Whether we referred to the French chart or to the later chart, we should be equally correct in saying that the bank from which the Turks Islands rise is covered by from ten to eleven fathoms of water in the deeper parts. But more than eighty years have elapsed since the last survey, and it is evident that the whole bank is shoaling through the growth of coral and the accumulation of reef débris. Sandbanks are forming in the shallows and are endeavouring to give rise to new islands. One such islet, known as Lesser Sand Cay, lies half-way between Grand Turk and Cotton Cay. Though well exposed at low-water, it is ever shifting its site and changing its form. At times vegetation, derived from drift seeds, begins to appear on its surface; but before long this is washed away by the waves. When I knew it in the early part of 1911, it was a bare bank of sand not 100 yards in length. Yet in time a permanent islet will be established, and a century hence it will be well stocked with littoral plants.

(b) By the throwing up of Protective Beaches and Sandbanks around and between the nuclei of EEolian Sandstone.-Yet Nature has other ways of reclaiming land from the sea on the bank. After the waves have been battering for ages one of these islands of æolian sandstone, she often sets herself to work to save the pieces through the growth of corals and the heaping up of sand and other reef débris. Let us take the case of Greater Sand Cay, which is about one and a half miles in length and elevated some forty feet above the sea. We can read its history as we approach it from the northward. In the distance it appears as a group of four islets. But as we get nearer low connecting strips of land rise above the horizon, and we discover that the four islets, as they seemed, form the hummocks, or low, mound-like hills, of a single island. The hummocks are made of the xolian sandstone, and the low necks that unite them are banks of sand. Here it is evident that a long strip of land of æolian rock was first broken up by the action of the sea. But in later times, whilst the waves were wearing away the islets, the water was shoaling around. Ultimately the energy of the waves was chiefly occupied in throwing up protecting beaches and in joining the islets by sandbanks. In this way the remains of the original island have been preserved, and doubtless the present island will continue to increase in extent. The process of joining up the islets has evidently been in operation in relatively recent times. In the French chart (1753-70) the northern third is represented as separated from the rest of the island by a channel 250 or 300 yards wide and two feet deep. The extensive shoal or patch of reef that runs north from this island seems to be in much the same condition now as it was a century and a half ago, except that there appears to have 
been a northward extension of a few hundred yards since that date.

The original length of Greater Sand Cay is indicated by the shoal, from which some rocky points protrude a few feet above the sea, that stretches nearly two miles to the north of the island. Originally there was a long narrow island, quite three miles in length, of which the northern half has been swept away; whilst the southern was broken up into fragments that have since been joined together by the reclaiming agency of the waves. This process of reclamation will continue, and a low sandy tract will occupy the place of the shoal extending to the north; while the island will add to its breadth on its western side. The process of preserving the remains of the original island is, however, not yet completed at the southern extremity, where the æolian rocks form a steep promontory that is still exposed to the full force of the breakers in the open ocean.

The opposing forces of destruction and reclamation are in operation all over the Turks Group. Where the tendency to protectivebeach formation is slight, as with Long Cay, we see a long strip of æolian rock being broken into fragments by the waves. We see in Pear Cay and in Eastern Cay two islands that were once one, but are now separated by a rock-studded channel, half a mile in width, that has been the scene of more than one of the shipwrecks in this locality. Pear Cay seems likely to disappear altogether in the course of time. Eastern Cay, however, has since doubled its extent by the formation of a broad sandy tract on its west side; and while the breakers are ever pounding away against the precipitous cliffs of æolian sandstone on the eastern side, the waves are ever adding to its area on the west.

The Composite Structure of the Larger Islands of the Turks Group.-In the larger islands the process is a little more complex. The extension of sandy flats from different "nuclei" of xolian rock here led to the enclosure of mangrove-fringed lagoons, which are now in various stages of silting up and of being cut off from the sea. Thus the lower levels of these islands are sandy where they have been heaped up by the waves, and loamy where they have been reclaimed by the silting of the lagoon.

We will begin with Grand Turk, an island about five and a half miles long and averaging rather over a mile in breadth. A ridge of æolian sandstone runs along the eastern border of the island, attaining a height of seventy feet along much of its length, the greatest elevation being seventy-five feet. In addition there are low hills and rising ground of lesser elevation in the north-west, south-west, and centre of the island. But the greater portion of its surface is raised only a few feet above the sea, being no higher than the waves could have elevated it. Two large lagoons, the North and South Creeks, originally penetrated nearly to the centre of the island. Both were lined by a dense growth of mangroves, which are now almost entirely confined to the South Creek; and both occupied depressions that were below the sea-level.

The ridge and lesser elevations of Grand Turk once formed islands of æolian sandstone representing a large land-mass of the same 
formation that had been broken up by the waves. The growth of coral and the heaping up of reef débris led to the development of extensive sandy flats which reconnected the islands and enclosed the lagoons. The reclaiming agency of the mangroves regained large loamy tracts at the borders of the lagoons; whilst the sandy tracts were ever increasing by accretion through the materials heaped up by the waves. One of these methods of reclamation is well displayed at the southern end of the island, which, according to the residents, has extended considerably in recent years through the formation of successive lines of sandbanks. It is strange that the significance of the great recovery of land from the sea that is involved in the building-up of Grand Turk did not present itself to A. Agassiz, since he states that whilst the eastern border of the island is formed by " a narrow ridge of æolian hills," the breadth of the island in its centre consists of "flats" formed by the recent growth of shore coral-rock Indeed, everything that is of importance to man on Grand Turk, and particularly its salt-pan industry, is due to the fact that it has been largely reclaimed from the sea.

A word may be said about the two lagoons of Grand Turk. The South Creek was doubtless originally far more patent than it is at present. It is covered during the higher part of the tide; but at low-water it is exposed, and extensive mud-flats monopolise its area. Salt-rakers have been busy here for over two centuries, and have evidently largely transformed this part of the interior of the island. It is likely that the "salinas" or salt-ponds represent the original extension of the South Creek into the centre of the length of Grand Turk. The North Creek is a clear sheet of water about one and three-quarter miles long and 600 to 700 yards broad. It is credited with a depth of four fathoms in the Admiralty chart, and is now nearly silted up at its mouth. These matters are also referred to in the remarks on the topography of the island in Chapter XII. The delineation of the two creeks in the Admiralty chart (No. 1441), which dates back to 1830 and 1845 , is puzzling. The details of the interior of the island are given in a large-scale map (three inches to a mile) based on a survey executed in 1902-4 by J. F. Osborn (Colonial Surveyor) and on the Admiralty chart just mentioned. The depths of the sea around, that are given in this map, are merely taken from the soundings in the chart.

Salt Cay reproduces all the features of Grand Turk, and it has had the same history Though about three miles in length and about one and a half miles in breadth, its surface is for the most part elevated only a few feet above the sea, the low ridges and hummocks of æolian sandstone, that rise in places to heights of sixty feet, having served as "nuclei" for the growth of extensive low flats of coral and reef débris. Here also there were lagoons communicating with the sea, their shores lined by mangroves that have been almost entirely cleared by the labours of the salt-rakers, who, in making their "salinas," have transformed the interior of the island. Apart from the salt-ponds and the shallow ponds scattered about, a large creek, still communicating with the sea on the south-east coast and bordered in 1911 in one or two places by mangroves, recalls the original 
condition of the island when large lagoons occupied its interior. Whilst a region of sand-dunes lies behind the beach at the north end of the island, illustrating the constructive action of the waves and of the winds, extensive bare rocky surfaces in the interior represent the work of the coral reef. The same features are presented by Cotton Cay. Here again islets of æolian sandstone, now existing as elevations, thirty to forty feet high, at its two extremities, have been joined by the reclaiming agencies of the waves and of coralreef growth; but the lagoons have long since been cut off from the sea, and are now represented by shallow ponds in the centre of the island.

No Recent Change of Level in the Turks Islands.-Of changes in level, whether of elevation or of subsidence, I found no evidence in this region. No old erosion lines came under my notice, except in one or two places where it was apparent that they had been merely cut off from the sea by the intervention of a beach or of a reef-flat. That the level of the sea has remained much the same for a long period is indicated by the circumstance that the platform of reef-rock and ordinary beach-sandstone, on which the rolian sandstone reposes, has been formed with the sea at its existing level.

Probable Destruction in Great Part of the Original Islands of THE Turks Group.-There must have been great destruction of the original islands of æolian sandstone before the modern process of reclamation was made possible by the shoaling of the great bank from which the present islands rise. The low hills and ridges of the larger islands and the small rocky cays are but the scanty remains of what may have been two or three large islands of æolian rock that occupied almost all the bank. At a uniform depth of nine or ten fathoms the bank extends seven or eight miles eastward of Eastern and Pear Cays, and then plunges down into the depths. All this submerged area was once covered by land of æolian formation. The same may be said of the two long tongues that extend north and south from the opposite extremities of the group at a depth of about ten fathoms for about seven miles in each case. The same is also true of the inter-island tracts of shallower water. All this land has disappeared.

The same has been inferred by A. Agassiz for the whole Bahamian Region.-All the questions raised by the consideration of the Turks Islands are issues raised in connection with the æolian rocks of the Bahamas as a whole. The original much greater extent of the land-surface of rolian rocks, which has been postulated by me in the case of the Turks Islands, was assumed twenty years ago by A. Agassiz for the whole of the Bahamian archipelago. Before the last subsidence of 300 feet, which, as he infers, affected the whole region (a point on which the present writer, as already shown, is not in agreement with him), the present banks were occupied, as he holds, by " one huge irregularly shaped mass of low land." However, as I have pointed out, several of the eastern banks are now separated by passages 1000 to 2000 fathoms deep. We cannot, therefore, postulate for that period a continuous land-surface over 
the area occupied by the present archipelago; but, judging from the size of the larger banks, several of the islands must have been as large as an ordinary English county. In addition to the original islands of æolian formation, of which fragments still remain, there were several others, of which no trace now remains beyond the submerged bank that has been generally worn down to the lower limit of breaker-action, except where it displays a few " rocks awash." Probably none of the islands exceeded 500 feet in elevation, and their average height must have been less than half this amount. Their entire surfaces were covered by wind-blown sand; and, in fact, their entire thickness was the work of the drifting dune. The compacted æolian formations, of which they are now composed from top to bottom, plainly tell the story of the building up of these islands; and there is little to indicate that there was any covering of vegetation of any extent.

The History of the Bahamas is the History of the SandDUNE.-These large islands were built up under the sway of the shifting sand-dune, and must have offered a spectacle not to be found on the same scale in any insular territory in the present era, not even in the great coral-reef regions of the Indian and Pacific Oceans. These unusual formations, unusual in the sense just defined, required unusual conditions; and we have now to ask ourselves what exceptional conditions offered the opportunity for the dominion of the dune.

They must have been the conditions that prevail on the sea-board of those great continental masses where the dune holds its sway. At the present time the most insignificant sandbank in coral seas becomes the home of the mangrove, and numerous other plants establish themselves as the bank emerges from the waves. We do not read in our own day of islands in coral seas that are swept clean by ever-shifting sand-dunes. The Turks Islands lie in a region of storms and gales; and if ever strong winds could restore the original sterility of these islands we might look for their work here. Yet, what do we find? In an island like Salt Cay, where the sand-dunes are well developed in places, they make but little effort to overrun the surface. The conditions of the present are confessedly not those of the past; and in what, we may ask, has been the change?

Before answering this question, let us picture to ourselves the conditions that once prevailed over insular land-areas, fifty to a hundred miles across, where the drifting sands reigned supreme, conditions that, as above remarked, are now only found on the sea-board of great continents. The coast regions of Peru are the home of the shifting sand-hill, or " medano," so graphically described by Dr. von Tschudi in his Travels in Peru (London, 1847, p. 243). A fine light yellow drift-sand here covers hill and dale, and when driven by violent winds the medanos pass rapidly over the sandy plains. The smaller ones, though moving quickly forward before the larger ones, are soon overtaken and overwhelmed by them. At one time they cover the plain. At another they move across its breadth in rows. The whole face of the landscape may in this manner be transformed in a few days, and the traveller who had previously lost his way 
amidst a labyrinth of sand-hills may on his return traverse a cleanswept plain where not a single medano obstructs his view. Though the sand is not formed of calcareous materials, but is derived from the disintegration of andesitic rocks, the lesson will be the same.

In February 1904 I spent several days in examining the medanos of the Ancon coast-region north of Callao. Since the details are given in Note 34 of the Appendix, I will confine myself here to a few general remarks. Sand covers the broad plains and the lower hill-slopes and completely hides the crests of hill-spurs, 400 feet in height, as they descend to the coast. At the time of my visit these crescentic mounds, usually six to ten feet high and twenty-five to thirty feet across, formed a line, or rather a column, of two or three irregularly abreast traversing a sandy waste of hill and plain for a distance of from four to five miles, and crossing ridges and spurs 300 or 400 feet in height. I watched them as they came into being near the beach and as they died away miles inland a few hundred feet up the slopes of the main range in their fruitless endeavour to scale the mountains. I spent hours in watching them dribbling over the sharp crest of a mountain-spur that descends to the coast immediately south of Ancon. They had reached the crest after a climb of about 350 feet from the beach below, and as I sat on the ridge-top observing them, they peppered my face with their finer sand with each fresh gust of wind. The sand usually formed a continuous slide during the descent of the steeper northern slopes of the ridge, the medanos shaping again when the sand reached the plain; but where there was a gentler gradient they re-formed halfway down the slopes. During my sojourn the prevailing winds were light, and, as measured by me, the medanos moved forward only a few inches a day; but before a fresh wind they would advance yards daily. Before a gale they would move rapidly across the plains, and a strong wind blowing athwart their line of advance would in the course of a day or two level them with the ground. Von Tschudi also describes medanos with immovable bases formed around blocks of rocks that are scattered about the plain. While the sand is heaped up by the wind on one side, it descends on the other; and there is nothing permanent about this type of medano but its site and its conical shape. The moving medano, however, is the great distributor of sand over the arid wastes of the sea-board of Peru. Sterility reigned over the sand-covered plains and hill-slopes of Ancon. Only occasionally one came upon patches of a little bromeliaceous "tumble-weed" (Tillandsia), which, however, became more frequent as the plains approached the foot of the mountains.

But, to return to the large islands of the Bahamas, as they originally were, covered with and built up by drifting sand, with little or no vegetation to compete with the dominion of the sand-dune, the conditions of the present are confessedly not those of the past, and in what, we may again ask, has been the change? I would suggest with some diffidence that the climatic régime which now prevails on the sea-borders of North Chile and Peru once existed in the Bahamian region. Just as the cold waters of the Humboldt or Peruvian Current determine the relative sterility of that continental 
sea-border by causing the precipitation of the moisture carried by the prevalent south-west winds before they reach the land, so in the past a cold current from the north swept along the northern shores of the Bahamas and cut off the moisture carried by the northeast trade-winds. From this point of view the æolian formation of the Bahamas represents the New World's response in ancient times to the influences producing arid sea-borders in warm latitudes (cold currents and drying winds), but in a region of calcareous sands and under insular conditions, an association of circumstances not repeated on the same scale in any other part of the globe.

At present, as Commander Campbell Hepworth informs me, the influence of the Labrador or Arctic Current as a surface-stream may be traced along the shores of the United States as far as the Florida Straits during most of the year. But how little do we know of the arrangement of the surface-currents in earlier times; and what, we may also ask, would be the behaviour of the Arctic Current if the great Equatorial Current, from which the Gulf Stream takes its rise, flowed in mass, as it probably once did, across the site of the present Panama Isthmus into the Pacific? The effect of the emergence of this isthmus was the birth of the Gulf Stream, and the effect of the Gulf Stream was the dissipation to a large extent in tropical latitudes of the cold current from the north, so that the Bahamian region would no longer come under its influence. Before the change we had here the same association of aridity with a cold current that exists on the sea-border of Peru and also on the seaborders of South California and North Mexico, where the moistureladen winds, by passing over the cool waters of the Californian Current, become drying winds when striking the continent and produce the aridity of its sea-border. In the cases of the South African Current and the west coast of South Africa and of the West Australian Current and Western Australia we seem to have the same association of conditions. [For further particulars of the writer's views on the influence of the Humboldt Current on the climate of the Pacific border of South America reference should be made to pp. 490-6 and 500 of his work on Plant Dispersal (1905)].

I may add that the association of the birth of the Gulf Stream with the elevation of the Panama Isthmus is by no means a new idea. The various rearrangements of the land-areas in the tropics of the New World adopted by some botanists, zoologists and geologists often involve the shutting off of the Gulf Stream from the North Atlantic. However much Darwin's great authority may have weighted the scale against them, the "extensionists" have obtained results in these tropical regions that call for a re-valuation of their testimony.

The Standpoint of the Exterisionists.-Reference may again be made to the relations between the western Bahamas and the adjacent islands of the Greater Antilles. Though depths of 2000 fathoms divide the eastern Bahamas from Hispaniola, much shallower submarine connections exist between the Great Bahama Bank and Cuba, and the possibility of a Cuban land-connection in times that are past cannot be ignored. This leads one to refer to an alternative 
explanation of "things Bahamian," which, although based mainly on zoological evidence, makes a serious claim on some of the geological testimony that the "anti-extensionist " is wont to regard as peculiarly his own.

The remarkable similarity in geological structure between the Bermudas and the Bahamas is rightly emphasised by Scharff in his Distribution and Origin of Life in America (1911, p. 185); and he is justified in doing so, since the peculiar æolian formation of these two regions cannot be matched on the same scale in any insular region of the globe. Should the same formation exist in Florida, the point would acquire yet more importance. Laying stress on the zoological argument that we are not concerned here with land-areas stocked with "waifs and strays," but with ancient land-surfaces possessing faunas often peculiar in their character, he advocates the hypothesis that in Tertiary times the Bahamas and the Bermudas were included in a land-area that joined together the Greater Antilles and was connected with Florida (p. 186, and maps facing pp. 280, 294).

He points out (pp. 288-9) that although displaying affinities with neighbouring regions, the Bahamas possess reptilian, amphibian and molluscan faunas that are often largely their own. In this connection Dr. Scharff could have also summoned to his aid the witness of the plants. In the tropical Pacific, low islands, like those of the Bahamas, would have been stocked through the agencies of birds and currents with cosmopolitan and wide-ranging plants, and would have displayed little or no endemic element. On the other hand, the plants of the Bahamas, as shown in Chapter XII., exhibit a marked Bahamian impress; and present characters that could only have been developed during ages of isolation from other regions.

Note added August 2, 1916.-It will be shown in one of the last notes of the Appendix that according to Dr. Vaughan and other American geologists the similarity in geological structure between the Bermudas and the Bahamas extends to the æolian origin and calcareous character of the deposits, but not to their mechanical condition. A reply will there be made to the query concerning the occurrence of this formation in Florida.

\section{Summary}

1. The low islands of the Turks Group, which belong geographically and botanically to the Bahamas, possess the geological features so characteristic of that archipelago. They are composed in their higher parts of æolian sandstone, which is made of consolidated calcareous drift-sand, and in their lower parts of coral-reef débris thrown up under the existing conditions of sea-level. They possess all the other general characters of the Bahamian Islands, which are situated on banks that at the eastern extremity of the archipelago rise from the ocean's depths and at the western end have shallower connections with the North American continent and the island of Cuba.

2. It is pointed out that only in coral-reef regions could we look for the conditions that have produced a great archipelago with such 
uniformity in characters as found in the Bahamas; and it is urged that the coral atoll makes a peremptory demand to be called as a witness in this connection. It is suggested that the Bahamas were in ages past the Laccadives and Maldives of the Atlantic. The implication is that atolls originally crowned the summits of the ranges of submarine mountains that are now represented by the banks of the Bahamian seas, atolls long since overwhelmed by the shifting sand-dune, the work of which is presented in the æolian sandstone of our own day. But, as in the linear grouping of atolls, formed by the Laccadive and Maldive archipelagos, there is a "continental " end, where the Bahamian archipelago abuts on the adjacent continent, and an "oceanic " end, where it projects into the ocean's depths; and it is hinted that the standpoint adopted concerning Bahamian problems largely depends on whether the investigator was familiar with the continental or the oceanic portion (pp. 255-6).

3. Then follows a discussion of the views of Alexander Agassiz on the formation of the Bahamas. The present writer's detailed examination of the Turks Islands, during a sojourn of three months in the group, enables him to approach the problems from the "oceanic" standpoint; but, although at one with the eminent American investigator as regards the leading structural features of the group, he ventures to differ from him on some points of interpretation. Thus, there can be little doubt that the existing Bahamas are the remains of great tracts of low land of æolian formation that have been in great part destroyed by the waves; but the writer holds that the degradation occurred under the present conditions of sea-level, and not during a subsidence of $\mathbf{3 0 0}$ feet as is assumed by Agassiz. Then, again, the writer emphasises the great work of the reclaiming agencies under present conditions, a matter on which Agassiz lays little stress. Amongst other incidental points of difference are objections that he does not attach sufficient importance to the isolation of the eastern islands by the ocean's depths, and that the foundations of the xolian formation lie near the existing sealevel, and not far beneath the waves as is implied by his subsidence hypothesis (pp. 256-9).

4. The author then gives the results of his observations on the Turks Islands. The formation of the æolian sandstone is first discussed, and the absence of marine remains is pointed out. In this connection the results obtained by Louis Agassiz on the Salt Key Bank are utilised. It is remarked that if Nature busied herself ages since in producing the æolian rocks, she is now actively engaged in their destruction. Yet there is a process of reclamation at work that will ultimately prevail, and new land has been, and is being, formed around the remnants of the early islands. Disconnected islets of æolian rock, that are the fragments of a large island, have been, and are being, joined together again into one island by the growth of coral reefs and the formation of sandbanks. In this manner the destructive action of the waves has often been stayed; and in the larger islands, while the more elevated "nuclei" of æolian sandstone belong to the past, the low tracts of land that have been formed around them belong to the present (pp. 259-262). 
5. The question of the foundations of the xolian rock is then dealt with, and the reply is that in the Turks Islands the rolian sandstone passes down into consolidated reef débris, consisting of coarse sand, dead shells, and coral fragments, which have been thrown up on reef rock under the existing conditions of sea-level (pp. 262-4).

6. Whilst discussing the modern process of reclamation in the Turks Group, the structure of the islands is treated in detail ; and it is shown that in the case of the larger islands, where lagoons have been usually enclosed during the development of the new land, the mangroves have been an important reclaiming agency (pp. 265-9).

7. The comparison of old and recent charts of the Turks Islands, and of the Bahamas generally, does not often yield definite results; but we may quote the conclusion of Alexander Agassiz, who paid considerable attention to the matter, that the configuration of the Bahamas has not been materially changed since their discovery by Columbus, a conclusion that involves the implication that during a period of 400 years no great change has occurred in the relations between land and sea in this region (pp. 264-5).

8. All the questions raised by the consideration of the Turks Islands are issues raised in connection with the Bahamas as a whole. The original much greater extent of the land of xolian origin, which is postulated by the author in the case of the Turks Islands, was assumed twenty years ago by A. Agassiz for the whole Bahamian region. Although we cannot assume that in distant ages a continuous land-surface occupied the area of the existing archipelago, it is probable that several of the islands were as large as an average English county and that their maximum elevation did not exceed 500 feet. They were completely covered by wind-blown sand, and in fact their entire thickness was the work of the drifting dune, there being little to indicate that there was any covering of vegetation of any extent (pp. 269-270).

9. The history of the Bahamas is the history of the sand-dune. The original islands must have offered a spectacle not to be found on the same scale in any insular territory in the present era, not even in the great coral-reef regions of the Indian and Pacific Oceans. These unusual formations require unusual conditions, and the author looks for them in the conditions that prevail on the sea-board of a great continent where the dune holds its sway. The conditions of the present in the Bahamian region are confessedly not those of the past; and in what, we may ask, has been the change (pp. 270-1)?

10. Before answering this question, the author describes the sandwastes on the sea-board of Peru, where the shifting sand-hill reigns supreme, and here he draws in part on his own experiences. He then replies to the query above put, and suggests that just as the cold waters of the Peruvian Current determine the aridity of the seaboards of North Chile and Peru, so in ancient times a southward extension of the Arctic or Labrador Current would have produced similar effects on the Bahamas (pp. 271-2).

11. Not to be ignored, however, is the view of the "extensionist" school based on zoological evidence that the Bahamas and the 
Bermudas were in later Tertiary times included in a land-area that extended to Florida and united the Greater Antilles. It indicates that the last word has not been said in this matter (pp. 272-3).

12. Some conclusions arising from the recent work of American geologists in the western Bahamas with additional remarks on the question of the "ocean-holes" will be found in one of the last notes of the Appendix.

\section{LIST OF SOME OF THE WORKS QUOTED IN THIS CHAPTER}

Agassiz, A., A Reconnaissance of the Bahamas, Bull. Mus. Comp. Zool. : Harvard, Vol. XXVI., 1894.

Agassiz, L., The Bahamas and Salt Key Bank, Bull. Mus. Comp. Zool., Vol. I. Quoted at length by Dana in the work below named.

DANA, J. D., Corals and Coral Islands, 1872.

Timlinghast, W. H., Notes on the Historical Hydrography of the Handkerchief Shoal (Mouchoir Carré) in the Bahamas, Library of Harvard University, Bibliographical Contributions, No. 14, 1881.

VAUGHAN, T. W., Geological Investigations in South Florida and the Bahamas, Year Book of the Carnegie Institution of Washington, Nos. 13 and 14, 1914, 1915.

Watkrns, F. H., Turks and Caicos Islands, Report on the Salt Industry, Colonial Reports-Miscellaneous, No. 56, 1908.

Old Chart of Turks Islands, from a survey made in 1753 by the sloops L'Aigle and $L$ 'Emeraude, by order of the French Governor of Hispaniola, with improvements from observations made in 1770 in the Sir Edward Hawke, King's Schooner : Laurie and Whittle, 53, Fleet Street, London, 1794. 


\section{CHAPTER XII}

\section{THE FLORA OF THE TURKS ISLANDS}

WE come now to an account of the flora of the Turks Islands. The vegetation is generally sparse and may be described as "scrub," the soil being sandy and loamy and containing usually but little humus. Different "cultivations" have been from time to time carried on in the larger cays, especially on Grand Turk. But the cultivated plants are few that will thrive in a sandy and often saline soil, and, except for the clearances of the mangroves bordering the lagoons and creeks in the construction of salt-pans, the botanist will not find great difficulty in restoring much of the indigenous flora of the large inhabited islands. In this he will be assisted by the examination of the smaller uninhabited cays, and it is to these smaller islands that my remarks will at first apply. Though goats have been allowed to run wild on most of them at one time and another, this practice had been largely discontinued at the time of my visit in 1911. Their presence might account for small-seeded weeds like Portulaca oleracea, etc., and might explain to some extent the scarcity of fleshy beach plants like Scavola plumieri on the lesser cays; but otherwise I should not imagine that through their agency the original features of the flora, as presented in the smaller islands, have been much obscured.

In an extract from the Annual Register of 1764 given by Commissioner Watkins in his report on the history of the salt industry of these islands, we read that they are " sandy and barren with very little, if any, fresh-water, without any vegetables except low shrubs, or any animais except lizards, guanas, and land-crabs." Though this reference was made more than a century after the Bermudian salt-rakers began to visit the group, it was not until about 1678 that they commenced systematic salt-raking during their annual sojourns from March to November. It is a testimony to the obdurate nature of the soil and to the difficulty of Nature's task in stocking these islands with plants that so little has been effected since they were first occupied by Europeans. Of course, in the larger inhabited islands of Grand Turk and Salt Cay man has done something to alleviate these conditions. But still their soil is not fit for raising much else than sweet potatoes, guinea corn, and plants that thrive in poor ground. For their fruits and vegetables the Turks Islanders are almost entirely dependent on outside supplies. Yet, notwithstanding the provision of government-ponds and tanks to hold the rain-water, great inconvenience is often experienced during the dry 
hot season. In the not infrequent droughts cattle die in numbers, and the gardens of the inhabitants lose most of their plants.

My principal object being to study the process of stocking the small islands of these seas with plants, I was content to largely limit my observations to such an inquiry. But it was also necessary to obtain some acquaintance with the more extensive flora of the largest island (Grand Turk); and though there are gaps in my knowledge of its plants my remarks will, I trust, enable the reader to form some idea of the peculiarities of its flora and of the general facies of the vegetation. Dr. Millspaugh, who studied the plants of this group with the eye of a systematist of great experience in these regions, will be able to give a far more authoritative and complete account. I looked at matters not with the discriminative eye of the systematist, but from the standpoint of dispersal. This position was rendered comparatively easy in the case of the plants of the smaller cays, since they were largely stocked with widespread strand plants that had long been familiar to me in tropical regions.

The flora of the smaller cays is, as I have just said, chiefly a strand flora. Characteristic West Indian littoral plants have often taken charge of these small islands. In my description I will begin with the smallest uninhabited cays that are formed almost exclusively of æolian sandstone with but little beach or fore-shore. Next I will take those larger in size, where low-lying, littoral tracts have been added to the nucleus of æolian rocks, and will then pass on to the large inhabited islands where man has exercised a greater disturbing influence.

Pear Cay, which derived its name from the abundance of Prickly Pear, is, according to the chart, about forty feet high and about 600 yards long. It is entirely formed of æolian rock; and, since it possesses scarcely any beach, landing is not practicable when the sea is rough. Much of the lower levels are strewn with sand supplied by the disintegration of the sandstone, and here flourish Tournefortia gnaphalodes, Suriana maritima, Ipomœa pes-caprce, Sesuvium portulacastrum, and Corchorus hirsutus with a little Heliotropium curassavicum. I have referred in Note 3 of the Appendix to the manner in which the species of Tournefortia, Suriana, and Corchorus adapt themselves to the wind-pressure in this wind-swept cay, and I need not particularise it here. On the upper portion there is little or no sand and the rocky ground is almost exclusively occupied by I pomoea tuba, which largely conceals the broken slabs of sandstone that lie about. In addition there was a Cyperus (C. brunneus?), which is common on all the small cays.

The Cactuses of the genus Opuntia, that occur here and on most of the small cays and larger islands, are not differentiated in my description. They form a feature of all the islands, and include two common species, Opuntia tuna, the Prickly Pear, which is the most frequent, and another with very long spines, locally known as "Dildo," perhaps 0 . triacantha, Haw.

Penniston CAY is a long flat strip of æolian sandstone, twentyfive or thirty feet high. According to the Admiralty chart it would 
be about 800 yards long and a cable (200 yards) broad; but these dimensions appear to me rather excessive. Its surface, which is largely of bare rock, much honeycombed in some places and slabby in others, is scantily vegetated. Having no beach worth mentioning it receives the full brunt of the breakers, which have forced a passage near its southern end where there is a natural arch. In rough weather the seas deposit drift in the middle of its breadth. The principal plants growing on it were Tournefortia gnaphalodes, Borrichia arborescens, Suriana maritima, Portulaca oleracea, Sesuvium (two species), and a little Euphorbia buxifolia. On the lee side in its southern portion there was a large patch of Opuntia, where Frigatebirds were nesting in numbers.

LoNG CAY, like Penniston Cay, is a long and narrow flat strip of æolian sandstone, raised twenty-five or thirty feet above the sea and possessing one or two small beaches. It, however, receives the full force of the breakers on its north-eastern side, and portions of the original island now form islets at its extremities. As delineated in the Admiralty chart its length would be about a mile and its maximum breadth about 400 yards. However, I paced its width in the broadest portion and did not make it much over 120 yards. The surface is mainly of bare rock, covered, however, with sand thinly in places.

Though much of its area had no covering of vegetation there were considerable portions occupied by plants, especially on the lee or south-western side, where there were extensive thickets, four to six feet high, of the Seven-year Apple (Genipa clusiifolia), both in fruit and in flower, mingled in places at the seaward margin with Coccoloba uvifera. Next in frequency, growing semi-prostrate, or clambering over the rocks, was a variety of Conocarpus erectus. This is probably the form "procumbens" of Jacquin; but its occurrence is chiefly limited to the weather or eastern extremity of the island, to which the epithet "wind-swept" fitly applies; and doubtless it is a station variety. Millspaugh found this form in the Bermudas and on the coasts of Yucatan, and describes it in his Plantoe Utowance (Field Columb. Mus. publ.). Borrichia arborescens should also be reckoned as one of the most frequent of the plants on this cay. Most of the common beach plants of these islands are here represented, sometimes on the rocky portions, sometimes on the sandy parts, such as Tournefortia gnaphalodes, Suriana maritima, Ipomøa pes-capra, Euphorbia buxifolia, Sesuvium portulacastrum, etc. But Scaevola plumieri, which never came under my notice on these small wind-swept cays, was not observed. Where a thin covering of sand lies on the rock, the surface is almost carpeted with Ambrosia crithmifolia associated with Cyperus brunneus. Near the north-west end of the island Rhachicallis rupestris forms an extensive patch of scrub one and a half to two feet in height. We learn from Dr. Millspaugh (Pronunc. Baham.) that this plant grows on maritime rocks throughout the Bahamas and is "often the only vegetation on many of the sea-washed islets."

We now pass from our description of the small rocky cays of æolian sandstone possessing but little beach, and swept over a large portion 
of their surfaces by the sea in stormy weather, to the other small uninhabited cays where the waves have thrown up more or less extensive tracts of low-lying land fronted by beaches around a nucleus of æolian sandstone. Here the strand plants that mainly stock these small cays find congenial conditions on the sandy tracts behind the beaches as well as on the æolian rocks of the higher levels. The cays concerned include Eastern Cay, Greater Sand Cay, and Gibb Cay, with Round Cay adjacent to it. Both as regards the stage in the history of island formation and as concerns the conditions for plant growth, they present an intermediate state between the small rocky cays above described and the large inhabited islands to be subsequently noticed. Here, as in Eastern Cay, the Turk's-head Cactus (Melocactus communis) first appears, which is, or was, more at home in the large islands. Here also, as in Gibb Cay, are found plants, like the Burnt-bush (Euphorbia vaginulata) and Phyllanthus, that abound on the large cays, as on Grand Turk.

EAstern $\mathrm{CAY}_{\mathrm{y}}$, as delineated in the chart, is about 1800 yards long and has a maximum breadth of nearly 800 yards. On its northwest side there is a broad sandy plain elevated a few feet above the sea and running back between 400 and 500 yards to a stony ridge, which attains an elevation of ninety-six feet and forms the backbone of the island. Near the ridge the sandy plain gradually rises until it reaches half-way up its slopes. Characteristic littoral plants such as Tournefortia gnaphalodes, Euphorbia buxifolia, Ipomoea pes-caprce, Sesuvium portulacastrum, Portulaca oleracea, and Borrichia arborescens grow at the border of the sandy beaches and on the ground in their rear on both sides of the island. Apart from the plants growing on the beaches the three most conspicuous features of the vegetation of the island are (1) the abundance of Ambrosia crithmifolia which covers the sandy plains and the lower sandy slopes on both sides of the island with a dense carpet, (2) the frequency of Borrichia arborescens which mainly occupies the upper stony slopes, (3) the prevalence of the Turk's-head Cactus (Melocactus communis), which, though growing on the lower sandy slopes is most abundant in the higher part of the island.

Corchorus hirsutus is also common on the lower levels, growing semi-prostrate on the sandy plains and associated in places with Sesuvium. I noticed two or three fair-sized colonies of Ipomøa tuba on the stony ground fifty or sixty feet above the sea. Cactuses of the Opuntia type are common in the island, especially at and near the summit. During my two visits I failed to find either Suriana maritima or Genipa clusiifolia or Sccevola plumieri.

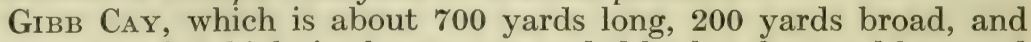
about sixty feet high, is almost surrounded by beaches, and has sand strewn nearly all over its surface. Much of this sand is evidently derived from the disintegration of the æolian sandstone which is more friable than usual. The beach plants, which include Tournefortia gnaphalodes, Scavola plumieri, Suriana maritima, Conocarpus erectus, Euphorbia buxifolia, Sesuvium portulacastrum, I pomoea pes-caprce, and the tall reed-grass, Uniola paniculata, extend with the usual exception of the first named some distance up the slopes and reach 
often the higher levels. Leaving the beach behind we find Ipomoa tuba growing nearly all over the undulating sandy summit, but with numerous associates, sometimes Ipomœa pes-caproe, Ambrosia crithmifolia and Sesuvium, at other times Phyllanthus epiphyllanthus, Euphorbia vaginulata, and Borrichia arborescens. The steep sandy slopes are preferred by Scavola plumieri. The Cyperus of the other smaller cays also occurs, and I noticed an amarantaceous herb by the beach. Goats and other animals have often been kept on this island, and no doubt have affected the relative prevalence of the different plants.

Round $C_{A Y}$ is an islet lying about two cables or 400 yards from Gibb Cay, of which it doubtless originally formed a part. It is composed of the same friable rolian sandstone, the disintegration of which has supplied the sand that covers its surface. Its length is about $\mathbf{1 5 0}$ yards or so, and its height forty-five or fifty feet. On its flat summit thrive Tournefortia gnaphalodes, Sesuvium portulacastrum, and Euphorbia vaginulata, with a little Euphorbia buxifolia and Portulaca oleracea. Cyperacece and grasses are common.

Greater Sand Cay, the most isolated island of the Turks Group, is of especial interest to the student of the dispersal of plants in this region. In sailing amongst the other islands one is in more or less protected waters, but to accomplish the six and a half miles that separate this island from Salt Cay the open ocean has to be traversed. As a result one may have to wait for days and weeks before suitable weather presents itself for reaching it, and on arrival it is not always easy to land, whilst there is always a risk of being detained there for some days by bad weather. The author spent two days on the island. Dr. Millspaugh, who visited it a few weeks afterwards, had difficulty in landing, the boat being turned over on top of him. It would seem that we were amongst the first to investigate its flora. This island is the first to catch the drift from the large West Indian islands to the southward and eastward, and quantities of seeds and fruits are stranded on the beach on its eastern side. Isolated as it is, the disturbing influence of man and animals cannot be excluded. Fishing-parties make a sojourn of a week or two, once or twice during most summers. The small sailing craft of these seas anchor occasionally on its west side to procure firewood, etc. Goats, again, have been kept on the island, one or two being still there when I visited it in March 1911.

The island is about one and a half miles long, 500 or 600 yards in maximum breadth, and forty or fifty feet high. It is principally made up of two main masses of xolian sandistone, connected by a low neck of sand raised ten to fifteen feet above the usual highwater level, but breached by the sea during the hurricanes. Each of these principal portions is again subdivided, the two parts being connected by a low sandy neck which is also breached in stormy weather. During hurricanes the three necks are washed clean by the breakers and largely stripped of their plants. At such times the four nuclei of æolian sandstone are isolated by the waves. Greater Sand Cay is in truth one of the most wind-swept and sea-swept islands of these regions, and it is exposed to the whole force of 
the breakers of the open ocean. Plants with difficulty establish themselves on the beaches and on the necks, being liable to be swept away in the storms. When they take refuge on the more elevated portions of the island they are exposed to the violence of the hurricanes. Numbers of dead prostrated trunks of Suriana maritima lay on the surface over the island during my visit, the victims mainly of the last hurricane two or three years before.

Yet, with the exception of the low connecting sandy tracts, where plant growth is scanty or almost absent, the surface is fairly well vegetated. Owing mainly to the extensive disintegration of the æolian sandstone the surface of the more elevated portions is largely covered with sand which is not less than seven or eight feet in depth in places, and thus affords a good burrowing ground for the large iguanas which abound. But the vegetation is what is termed of the scrub kind. If we were to give a brief description of the plantarrangement we should say that the sandy soil is carpeted with Ambrosia crithmifolia, Cyperi, and coarse creeping grasses (Cenchrus echinatus, etc.), whilst clumps of Suriana maritima and thickets of Genipa clusiifolia frequently dot the surface. Borrichia arborescens also grows in numerous colonies on the sandy portions and as individual plants where the ground is rocky, as on the southern headland. Cactuses of the Opuntia type abound, but the Turk's-head Cactus did not come under my observation.

All the above-named plants come down to the beach in places; but the most characteristic beach plants are Tournefortia gnaphalodes and Euphorbia buxifolia, species that seem able to hold their own on the most exposed beaches in these islands. Other typical beach plants such as Sccevola plumieri, Ipomoea pes-caprce, and Cakile lanceolata appear to be not so well adapted in this respect. The two first-named species were only represented by a few young plants growing amidst the beach-drift and a little above it on the east side of the principal isthmus. Of Cakile lanceolata I only found a solitary clump in the same locality. When the seas break across the low sandy necks during heavy weather most of the beach plants that have obtained a temporary footing are washed away. Sesuvium portulacastrum, a plant that is usually characteristic of beaches in this group, only presented itself in a solitary patch on the eastern beach. Uniola paniculata was scantily established on the lee or western side of the island.

CotTon CAY.-Coming to the larger inhabited islands I will first allude to Cotton Cay. There is a house on the island, but it is not permanently occupied. However, sheep roam over most of its area, and "cultivations" of different kinds have been from time to time established and abandoned. I was not therefore disposed to take a special interest in this Cay, and limited my examination to a traverse across its centre and to a visit to the wind-swept eastern extremity where the original vegetation promised to be least disturbed. The island is about one and one-third miles long, 700 yards broad, and about forty feet high in the "rises" of æolian sandstone. But much of its area is low, the surface being in places rocky and around the two small central lagoons loamy and sandy. These lagoons are 
merely shallow ponds, which seem to have shrunk considerably in modern times.

Conocarpus erectus was by far the most frequent constituent of the bush in the interior of the island, and the Turk's-head Cactus (Melocactus communis) was there not uncommon. Batis maritima and Salicornia ambigua covered the muddy borders of one of the lagoons that I passed near. On the beach on the south side were observed Suriana maritima, Borrichia arborescens, Ambrosia crithmifolia, and I pomcea pes-caproe. On the rocky eastern extremity were dense thickets of Coccoloba uvifera, the plants, owing to the exposure to the strong trade-winds, growing semi-prostrate or low and straggling. Here also Phyllanthus was common, and a few specimens of Genipa clusiifolia found shelter from the wind in the Coccoloba thickets.

SALT CAY, the second largest island, is triangular in form, about three miles long and about one and one-third mile in greatest breadth. It reproduces the physical features of Grand Turk. With the exception of an elevated ridge of æolian rock, sixty feet in height, near its northern border and an isolated hill of the same height and composition towards its centre, most of it is raised only a few feet above the sea; and in the areas occupied by several lagoons and ponds, now shut off from the sea, its level must be below that of the ocean. There are extensive beaches backed by sand-dunes on the north, but bare rocky surfaces prevail over most of the rest of the island except around the lagoons where the ground is loamy or sandy. The salt industry has been pursued here with greater energy than in Grand Turk, and no doubt the establishment of salt-pans has quite changed the character of the vegetation in the interior. The mangroves have been nearly banished; but in places around a large creek that communicates with the sea on the southeast side Rhizophora mangle, Avicennia nitida, and Laguncularia racemosa still survive, with extensive Salicornia colonies on the bordering mud-flats.

Strand plants exist in profusion on the north and north-east sides of the island, both at the borders of the beaches and on the sandy dunes behind. Here flourish Suriana maritima, Tournefortia gnaphalodes, Conocarpus erectus, Euphorbia buxifolia, Ambrosia crithmifolia, and Ipomcea pes-caproe. Sccevola plumieri is scanty in the island, but I found a fairly extensive colony on the beach near the southern point. A solitary patch of Canavalia obtusifolia was observed in the middle of the east coast. In the interior occur plants characteristic of Grand Turk, such as the Burnt-bush (Euphorbia vaginulata), Phyllanthus, etc.

Grand Turk.-The flora of Grand Turk, the largest island of this small group, was first systematically examined by J.A. Hjalmarsson, who spent a fortnight there in 1858, as I learned from Dr. Millspaugh's manuscript, on his return from a botanical expedition in Haiti. Various new species from the interior of this island were described by Grisebach from Hjalmarsson's collections in his book on the West Indian flora. Their number has been increased in later years through the investigations of American botanists; but most 
of them exist on the adjacent islands of the Caicos Group and of the two Inaguas; and I should imagine that the south-eastern extremity of the Bahamian archipelago, consisting of the Turks, Caicos, and Inagua islands, will prove to be a subdivision of the floral region of the Bahamas. For years botanists from the United States have worked this region, and an authoritative discussion from the pens of Britton, Millspaugh, and others is to be expected, if it has not already been published.

Generally speaking the flora of Grand Turk may be regarded as displaying a Bahamian impress in its interior and a West Indian impress at the coast. In other words, we can distinguish between the inland plants that give character to the larger islands of the group as a part of the Bahamian floral region and the strand plants, often monopolising the smaller cays, that are not only widely spread in the tropics of the New World, but are in not a few cases dispersed over the shores of the warm regions of the globe. Whilst the systematist will be mainly attracted by the Bahamian facies and by the more specialised local features of the flora, the student of dispersal will be mainly interested in the plants of the strand. If the group consisted only of the small wind-swept and sea-swept cays a few hundred yards in length, its flora would have been almost entirely littoral and its general facies would be West Indian. It is the nonlittoral vegetation of a large cay like Grand Turk that gives it its Bahamian impress and its still more localised characteristics.

The topography of Grand Turk is also described in the chapter on the geology of the group. Here I will deal with it afresh, since it is necessary to bring into prominence features of more special interest in connection with the flora. The island is about five-and-a-half miles long and one to one-and-a-half miles broad, and attains a maximum height of about seventy-five feet. But much of its area, especially in the southern half, is raised only a few feet above the sea; and there are extensive portions below the sea-level that are occupied by the salt-ponds and the creeks which represent lagoons that once penetrated to the heart of the island.

Two creeks communicating with the sea penetrate the north and south portions of the island. Both of them were doubtless at one time well lined by mangroves, which, however, have been largely cleared away from the North Creek, whilst in the South Creek they are still well displayed. North Creek, though nearly silted up at its mouth, is a clear sheet of water, about one-and-three-quarter miles long and 600 yards wide. South Creek is much smaller; but doubtless it originally extended much farther into the island, as indicated by the "Great Salina" and other salt-ponds which reach to the centre of the island's length. The dams and other works carried out in connection with the salt industry have greatly changed the surface-conditions of the central part of Grand Turk; but it seems probable that originally South Creek extended as a chain of lagoons to the Town Pond in the middle of the island, and that the two creeks were only separated at their heads by a neck, not over a quarter of ' a mile broad, which is now represented by the low ridge dividing the Town Pond from the head of North Creek. 
Perhaps the most singular surface-feature of Grand Turk is the ridge of low hills of æolian sandstone, usually elevated fifty or sixty feet above the sea, that runs along the eastern border, completely obscuring, as the Rev. J. H. Pusey remarks in his handbook of the group, the eastern coast from the town or western shore. There are, however, other elevated portions or "rises," as in the northwest, south-west, and central districts of the island.

The ground is occupied by open scrub all over the island, except in the parts where old or present attempts at cultivation have exercised disturbing influences, or where cattle have introduced new plants when brought to the island. Much of the surface, however, still illustrates the original condition of the open scrub vegetation that clothed it at the time of the first occupation by Europeans. The soil is loamy and sandy in the flats or lower levels, sandy on the gentle slopes of the hills, and rocky on the crests of the hills and on their steeper sides. The glaring whiteness of the sandy and loamy surface of the plains is often but partially relieved by the scrub that grows upon it. The soil is calcareous all over the island, and the proportion of humus is usually small.

The Vegetation of Grand Turk. - I will deal in the first place with the plants of the sandy plains, then with those of the rocky upland districts and of other rocky localities, and lastly with the strand vegetation.

1. The Plants of the Sandy Plains.-The scrub vegetation of the sandy plains and of the gentler hill-slopes in the interior of the island extends to the summit of the hills when the surface is sandy. Euphorbiaceous and Composite shrubs, with bushes of Lantana involucrata, and a pretty heath-like rubiaceous shrub, Borrera thymifolia, often form the greater part of the scrub. The Composite plants include Baccharis dioica and, as I was informed by Dr. Millspaugh, species of Pluchea. Amongst the Euphorbiacee the Burnt-bush (Euphorbia vaginulata) is the most conspicuous; but Croton hjalmarssonii, the Fire-shrub, and a Phyllanthus, probably $\boldsymbol{P}$. epiphyllanthus, grow in quantities. Where the plains merge into the loamy flats bordering the salt-ponds and creeks Statice bahamensis thrives. The type of scrub vegetation as displayed on Grand Turk has a very peculiar aspect when the Burnt-bush abounds. Its dark hue, inconspicuous leaves, and black glands give this plant a sombre appearance, so that one might almost imagine that a fire had scorched the ground. If it were not for the variety afforded by the Borrera heath, the Lantana bushes, and the pretty Statice, the scrub of this island would present a very gloomy aspect in places where the Burnt-bush predominates.

Although some of these scrub plants, like the Baccharis, the Phyllanthus, and the Lantana range widely in the West Indian region, several of them are purely Bahamian; and it is remarkable that this scrub flora of Grand Turk derives its special impress from species first described from this island, though but few of them have proved to be restricted to it. Thus, Euphorbia vaginulata, Croton hjalmarssonii, Borrera thymifolia, and Statice bahamensis were first described by Grisebach from specimens obtained by 
Hjalmarsson in the Turks Islands in 1858. Yet the first has since been gathered by Nash and Taylor (1904) in the two neighbouring islands of the Inaguas; the second by Britton, Millspaugh, and Hitchcock on Great Guana Cay and Fortune Island towards the middle of the Bahamas; whilst Borrera thymifolia and Statice bahamensis have probably been since found in the adjacent islands. It is, however, noteworthy that Dr. Millspaugh has described a new species of Euphorbia (E. lecheoides) from the sandy scrub-land of Grand Turk and Great Inagua (Pronunc. Baham.). It would therefore seem that the endemism which the Turks Islands appeared at first to display in the scrub plants of the sandy plains is often shared with the adjacent islands, the Inaguas and probably also the Caicos Islands.

Quite a character is given to the scrub vegetation of the plains in the southern part of Grand Turk by the strand plants that long ago deserted the beach and permanently established themselves inland. Here thrive amongst the ordinary scrub such typical shore shrubs and small trees as Dodoncea viscosa, Sophora tomentosa, and Coccoloba uivera, of which only the last appears occasionally at the border of the beaches. It is not the occurrence of these plants in the sandy inland plains but the desertion of the shore that is difficult to understand. However, this matter will be mentioned again. Here one may notice that the Barbadoes Olive (Bontia daphnoides), which has probably been introduced, is one of the shrubs that are frequent in these southern plains.

Another littoral plant frequent on the sandy soil of the interior, especially on the elevated northern end of the island, is Corchorus hirsutus. Borrichia arborescens, also a typical plant of the strand, often thrives at the foot of the hill-slopes, where they come down to the creeks and salt-ponds or descend to the beach. A small shrubby tree, known locally as the Manchineel, is also frequent on the lower slopes of the ridge bordering North Creek. It has the habit of the true Manchineel (Hippomane mancinella) and also several of the seed and fruit characters; but its fruit is almost pyriform with pointed apex, and differs in other respects from the depressed globose fruit of the genuine species. The Manchineel proper, such as often came under my notice in other parts of the West Indies, did not present itself to me either on Grand Turk or in any of the other islands of this small group, though its fruits are one of the commonest constituents of the stranded drift. Dr. Millspaugh characterises it as a scrub-land plant widely spread in the Bahamas, including Grand Turk, where it was collected by Nash and Taylor in 1904 (Pranunc. Baham., I.). It is noteworthy that the Manchineel fruit of the Bahamas is described by Catesby as "shaped like a pear or rather a fig" (Nat. Hist. Carolina, Florida, and the Bahama Islands, II., 95, 1743). He saw very few of the trees and observed "none growing on the Sea-Shore." He attributes to them the usual qualities of the Manchineel proper; but it is evident that as in the case of the Grand Turk plant we are here dealing with quite another tree.

2. The Plants of the Rocky Slopes and Ridges in the Interior of Grand 
Turk.-We are still concerned with scrub, but with scrub of a very different character from that found on the sandy plains, and with scrub that is in some localities almost arborescent. Many of the plants were strange to me. Probably the hilly district near the North Wells is most typical in these respects, and here the botanist would find his most interesting specimens. Here plants of the Cactus kind flourish, particularly Opuntia tuna and another species of the genus with very long spines, known as "Dildo." In such localities the Turk's-head Cactus (Melocactus) is at home, though now infrequent, together with a smaller Cactus of similar form, perhaps a kind of Mamillaria. A species of Echites clambers over the rocks, and the Seven-year Apple (Genipa clusiifolia) grows sporadically on the stony crests of the ridges. The plant last named is also found amongst the detached rock-masses at the base of the bluffs facing the beach on the south-east coast. A fan-palm, perhaps a species of Thrinax, once grew as I was told in the north part of the island. Millspaugh in his Pronuncice Bahamenses names several Bahamian plants of the Rubiacece collected by Nash and Taylor in the scrub of this island, such as Catesboea campanulata, C. foliosa, Randia aculeata, Guettarda krugii, etc.; and he describes a new species of the Euphorbiacea, Argythamnia argentea, which had been only found in the scrub-land of Grand Turk. Harshberger in his general work (p. 694) refers to a shrubby Pithecolobium, ten to fifteen feet high, as growing on this island.

Spiny Acacia trees and shrubs, including Acacia farnesiana, $A$. acuifera, and one or two other species, grow in places, as on the lower ground of the North Wells district. Acacia farnesiana may have been introduced by cattle. $A$. acuifera was first described by Bentham from Hjalmarsson's collections in the Turks Islands. I gathered from Dr. Millspaugh's manuscript that it is peculiar to the Bahamas, being found also on the islands adjacent to the Turks Group, namely, the Caicos Islands and the two Inaguas. Here and there amidst the rocks of the ridges thrives Guilandina bonducella, which on Grand Turk has practically abandoned its customary station amongst the vegetation bordering the beach. Thespesia populnea is another plant that has to a great extent deserted its littoral station on Grand Turk. One side of the North Wells hollow is bordered by a copse of these trees situated about a third of a mile from the beach, where they are still scantily represented.

I have now gone far enough to illustrate the general character of the flora of the sandy plains and rocky slopes and ridges in the interior of Grand Turk. We find here plants that the Bahamas hold in common with other West Indian localities, plants that are widely spread over the Bahamas but are confined to that archipelago, plants restricted to the extreme south-eastern islands (the Caicos and Turks Islands and the Inaguas) and held in common by them, and plants found only in the Turks Islands, as represented by Grand Turk. Though the endemism of the Grand Turk plants is probably not very great, it is sufficient to convince us that we are concerned here with ancient conditions of isolation.

3. The Strand Plants of Grand Turk.-We are concerned here with 
plants, most of which the writer was familiar with in the West Indies and in other parts of the tropies. The question of endemism is not here raised, as all of them occur outside the Bahamian area. But two points require a preliminary notice. In the first place, as already remarked, a number of the plants have largely deserted the beach, though they are typical shore species in other regions. In the second place, the littoral flora often receives accessions from the scrub of the interior. The shore plants that are rare on the beach and are found thriving in the scrub of the interior are Coccoloba uvifera, Dodoncea viscosa, Guilandina bonducella, and Sophora tomentosa, and to these may be added Thespesia populnea, as it grows around the North Wells. When they appear at the beach-border it is only as representatives of the seaward extension of the plants of the plains and of the hill-slopes. Of the characteristic plants of the interior that at times establish themselves on the beach, Euphorbia vaginulata, the Burnt-bush, is the most conspicuous. But amongst the other plants of the scrub of the inland plains that are not infrequently to be observed mingled with the true beach plants on the sandy tracts that lie in the rear of the beach are Borrera thymifolia, Lantana involucrata, and Phyllanthus epiphyllanthus. Whether the typical shore plant penetrates into the plains or whether the characteristic plant of the inland scrub intrudes on the beach, it is merely a matter of xerophytes seeking another suitable station. The influences that tend to keep apart the xerophytes of the plains and the xerophytes of the beach are concerned rather with the plant's capacity for dispersal than with differences in station.

The beach that extends for miles along the eastern border of the island affords excellent opportunities for the study of the arrangement of the strand plants. A sandy, dune-like tract, usually about fifty yards in breadth, separates it as a rule from the line of bluffs of æolian sandstone that runs along the length of Grand Turk. At times, however, the bluffs advance to the beach-margin; and again, as in the south, they may recede 100 yards or more inland. Although it is often easy to detect a method in the arrangement of the plants of the beach and of the dune-belt behind, the plants mingle together as one approaches the bluffs, and at the foot of these cliffs they grow side by side with the scrub plants of the inland plains.

Walking inshore from the high-water level we first meet with Ipomcea pes-caprce and Sesuvium portulacastrum, which soon give place to clumps of Euphorbia buxifolia and Cakile lanceolata. A few paces back, where the beach proper joins the duny sand tract, we notice that the foremost mounds are held by the silver-grey shrubs of Tournefortia gnaphalodes and the bright-green plants of Scoevola plumieri. Dark clumps of Suriana maritima with its broom-like habit cover the mounds behind, and the ground we tread upon is carpeted with Ambrosia crithmifolia. Such is the usual order in which the plants present themselves as we walk in from the beach; but they all mingle together as we cross the rolling, sandy tract towards the inland bluffs, at the foot of which they intermingle with the scrub vegetation of the interior as before described, and make but scanty efforts to ascend the sandy and rocky slopes. 
One may notice here an interesting plant which, though not strictly a shore plant, is most at home when clambering over the shrubs in the broad, rolling, sandy belt that lies behind the beach at the south end of the island. This is Passiflora pectinata, which was first described by Grisebach from Hjalmarsson's collections on Grand Turk. It is apparently restricted to the Bahamas. Though at first sight the fruits of Passiflora would not appear suitable for distribution by currents, it is evident that they can be carried short distances, and reference is made in Chapter II. to their occurrence amongst the beach-drift on the south coast of England in different years. However, the seeds have no buoyancy except when airbubbles adhere to them in the dry state, or when the nucleus is decaying or has decayed. But the fruits would not long endure the "roughand-tumble" of an ocean traverse. They owe their floating power to the buoyancy of the thick rind, which is covered by a tough skin. It is also possible that birds might aid in the oversea transport of the seeds, which are sufficiently protected by their crustaceous shells to be able to withstand a passage in a bird's stomach or intestines. In this connection it is noteworthy that Mr. Savage English remarks in the case of the island of Grand Cayman that "Passiflora cuprea, L. (a Bahamian, Cuban, and probably also a Jamaican species), has apparently been brought by a bird within the last few years, and is certainly being rapidly spread (in the island) by this means" (Kerw Bulletin, 1913, p. 368).

The Mangroves of Grand Turk.-In the development of the salt industry, which has been established here since the seventeenth century, there has been a great clearance of the mangroves. Whilst in the case of Salt Cay the mangroves have been from this cause nearly banished from the island, there is a considerable remnant in Grand Turk of the extensive mangrove belt that must have originally lined all the creeks and lagoons. It is well represented in South Creek; but most of the mangroves there appeared of recent growth, and I was told that up to late times there have been large clearances made here. But the mangrove belt soon grows again. However, in 1911 its appearance in South Creek gave one an idea of its original condition. Near its mouth South Creek is fringed by a dense belt of Rhizophora mangle backed on the landward side by Laguncularia racemosa, Avicennia nitida, and occasionally Conocarpus erectus. However, isolated patches of mangrove here extend into the heart of the island on the shores of shallow lakelets, which no doubt at times are in communication with South Creek. In North Creek at the opposite end of the island mangrove is very scanty. There are patches of Rhizophora and Avicennia at its mouth, with some Avicennia trees on the west shore and one or two at the head. Laguncularia is very rare at North Creek. I only saw one tree.

A curious mingling of mangroves with the beach flora and with plants of inland plains is to be noticed occasionally on Grand Turk, where the sea-beach and the lagoon borders meet at the foot of a slope. Here Rhizophora mangle, Laguncularia racemosa, Avicennia nitida, Suriana maritima, Coccoloba uvifera, Borrichia arborescens, and Euphorbia vaginulata grow together on the loamy mud-flat. 
Halophytes grow in abundance on the muddy shores of the creeks and salt-ponds of Grand Turk. The most frequent are Batis maritima, Salicornia ambigua, and a species of Sesuvium, with a species of Suceda in places, and Borrichia arborescens at the landward border of the flats.

The Introduced Plants of Grand Turk.-I need only refer here to the plants of waste ground which the white man has spread over the tropics, such as Argemone mexicana, Datura stramonium, Ricinus communis, and Vinca rosea. One of the first things to attract the notice of the stranger when he lands at the town is an extensive bank of Calotropis procera on the sea-front.

Endemism and Isolation in the Turks Islands.-The data at my disposal only allow of a brief reference to this subject and in a tentative fashion. The bathymetrical surroundings of the Turks Islands are discussed in the chapter on the geology of this small group. It is highly probable that as a unit in the great Bahamian archipelago the Turks Bank has always maintained its isolated condition. North and south the submarine slopes descend to depths of 2000 fathoms and over. The broad trench dividing the Turks Bank from the Caicos Bank on the west must be about 1500 fathoms deep opposite the two banks; but they are connected to the southward by a " col " covered by 1500 feet ( 250 fathoms) of water. Yet this is the only evidence of a former possible connection with existing land-surfaces, since away to the eastward stretch three submerged banks which, except on the Turks Group side, are surrounded by the ocean's depths. In these respects the isolation of the Turks Islands is typical of the eastern Bahamas, where the banks on which the islands rise may be separated by depths of 1000 to 2000 fathoms. Endemism ought, therefore, to be well displayed in the Bahamian archipelago, more especially in the east; but it would be kept in check by the monotony of the climatic, geological, and soil conditions. It is exhibited in the plants, the land-molluses, and the reptiles, but with a special Bahamian impress. Several of the plants first described from the Turks Islands have been found in the neighbouring islands, and it seems likely that the leading feature of the endemism of this small group is that which it shares with the Caicos Islands and the two Inaguas. There has been constant intercourse between them for the last two centuries and more, and it may be that the aborigines during earlier periods aided in bringing about the mingling of their respective floras.

The Flora of the Turks Islands from the Standpoint of Dispersal.The plants fall conveniently into two groups, those of the shore and those of the inland scrub. The former are not only found over the West Indian region, but often also in the Old World. The latter are all plants of the New World, some occurring also in the other West Indian islands, others widely spread over the Bahamas and confined to that archipelago, others confined to, but held in common by, the Turks and Caicos Islands and the two Inaguas, and a few restricted to the Turks Group.

The shore plants found in the Old World includeAvicennia nitida (Currents). 
Canavalia obtusifolia (Currents).

Cenchrus echinatus (Birds, in plumage).

Conocarpus erectus (Currents).

Corchorus hirsutus (Drifting logs and man).

Dodoncea viscosa (Currents, man, etc.).

Guilandina bonducella (Currents).

Heliotropium curassavicum (Floating logs, pumice, man).

Ipomcea pes-caprce (Currents).

Laguncularia racemosa (Currents).

Portulaca oleracea (Floating logs, pumice, man).

Rhizophora mangle (Currents).

Scaevola plumieri (Currents and frugivorous birds).

Sesuvium portulacastrum (Floating logs, pumice, man).

Sophora tomentosa (Currents).

Suriana maritima (Currents and floating logs).

Thespesia populnea (Currents and man).

The shore plants confined to the New World, and as a rule widely spread over the West Indies, include-

Ambrosia crithmifolia (Drifting logs and man).

Batis maritima (Currents and man).

Borrichia arborescens (Drifting logs and man).

Cakile lanceolata (Currents for a few hundred miles).

Coccoloba uvifera (Currents and frugivorous birds for distances not exceeding 200 miles).

Cyperus brunneus (Birds, per pedes et intestina, Millspaugh).

Ernodea littoralis (Frugivorous birds; capacity for dispersal by currents not tested).

Euphorbia buxifolia (Attached to feet of birds, Millspaugh; probably also drifting logs and man).

Genipa clusiifolia (Currents to a small extent, iguanas, frugivorous birds, and man).

Ipomcea tuba (Currents. It is regarded by Urban as also an Old World plant).

Rhachicallis maritima (Means of dispersal unknown, but probably not by currents).

Salicornia ambigua (Currents, feet of birds, man. By some regarded as a form of $\boldsymbol{S}$. fruticosa, an Old World species).

Tournefortia gnaphalodes (Currents).

Uniola paniculata (Regarded by Millspaugh as dispersed by currents; but no experiments have been made, and prolonged floating powers seem unlikely).

(Most of these plants are specially discussed in other pages of this work. Some of the small seeded species are dealt with in Note 21 of the Appendix, and others like Batis maritima in my work on Plant Dispersal.)

The association of considerable powers of dispersal by currents with existence in the Old World is especially noteworthy. Threefourths of the littoral shore plants that occur not only all over the 
West Indian region but also in the Old World possess this capacity, the others being mostly small-seeded plants, where the seeds are non-buoyant. In the case of the shore plants confined to the New World there are only four that could be transported over great distances by the direct agency of the currents, namely, I pomøa tuba, Salicornia ambigua, Batis maritima, and Tournefortia gnaphalodes ; and it is remarkable that in the first two plants their restriction to the New World is disputed, their fitness for trans-oceanic dispersal making a silent appeal against the narrower view of their range. For the other plants we have to invoke a variety of agencies, such as birds in different ways, floating logs, pumice, and man.

Of the capacity for dispersal by currents possessed by the plants of the scrub in the interior of the islands I have very few direct data. The few that were in immature seed gave little promise of such a capacity; but from my extended experience of the buoyant behaviour of seeds it may be inferred that as in other localities the inland plants have in the mass been brought here by other means. Neither the grasses nor the sedges would, it is probable, have been aided in this way, and doubtless they have often been brought by birds. It is most likely that frugivorous birds would account for the presence of Lantana involucrata, Melocactus communis, and Pithecolobium; whilst the small seeds or seed-like fruits of the other plants are probably indebted for their presence here to granivorous birds. The species of Compositoe (Baccharis dioica and Pluchea) may possibly have been aided by the strong winds, their fruits being provided with a pappus. I have no data relating to the genus Phyllanthus, of which two species ( $P$. epiphyllanthus, L., and $P$. niruri, L.) are known from the islands (Millspaugh's Pranunc. Baham.).

(Particulars of the works quoted in this chapter will be found in the list of references at the beginning of this volume.)

\section{Summary}

1. The vegetation of the Turks Islands, apart from the littoral plants, is generally sparse and of the scrub type, the soil being usually sandy.

2. Beginning with the smaller cays, they are described as mainly occupied by West Indian strand plants, the true scrub-land species presenting themselves in the larger islands. Amongst the islands, Greater Sand Cay is regarded as of special interest, since it is the first to catch the floating drift and illustrates a stage in the plantstocking intermediate between that indicated in the small cay a few hundred yards in length and that exemplified in Grand Turk, which is five to six miles long (p. 278).

3. After referring to the work of American botanists (p. 283), the plants of Grand Turk are dealt with more in detail. Its flora derives its Bahamian impress from the plants of the inland scrub, and its general West Indian impress chiefly from the plants of the strand (p. 284).

4. Having described the topography of the island (p. 284), the author deals with the scrub vegetation, first of the inland sandy plains 
(p. 285) and then of the rocky upland and the rocky lower levels (p.286). It is, however, shown that in the southern end of the island quite a character is given to the vegetation of the sandy plains by the abundance of a number of shore shrubs that have largely deserted the beach (p. 286).

5. As far as the data at the writer's disposal enable him to form an opinion, they indicate in the case of the inland scrub flora that whilst some species occur in other parts of the West Indies, others are restricted to the Bahamas as a whole. Some, again, are confined to the Turks Islands with the neighbouring Caicos and Inagua groups, and, lastly, a few are peculiar to the Turks Islands (p. 287).

6. With regard to the strand plants of Grand Turk, it is remarked that the question of endemism is not here raised, since practically all of them occur outside the Bahamas and not infrequently also in the Old World, a conclusion which applies to the true littoral flora of the Turks Group as a whole (p. 288). Whilst not a few of the shore plants invade the inland plains, some of them having almost deserted the beach, the plants of the inland scrub may in their turn intrude on the beach, mingling there with the characteristic strand flora. Here the xerophytes of the plain and the xerophytes of the strand experience little difficulty in exchanging their stations, the influences that tend to keep them apart being more concerned with fitness for dispersal by currents than with station (p. 288). The general arrangement of the plants on the beach-border is then described (p. 288).

7. After mentioning the occurrence of a peculiar Bahamian species of Passiflora in the dune district behind the beach (p. 289), the halophytes of the muddy shores of the creeks and lagoons are named (p. 290).

8. The mangroves, which once formed extensive swamps on Grand Turk, Cotton Cay, and Salt Cay, and are still fairly represented on Grand Turk, are described. The clearings connected with the establishment of the salt-ponds have almost banished them from the other islands (p. 289).

9. It is argued that the endemism favoured by the great depths between and around the Bahamian islands would be checked by the monotonous character of the climate, geological structure, and soil conditions over the archipelago (p. 290).

10. With regard to the means employed by Nature in stocking the Turks Islands, it is observed that two-thirds of the littoral plants that are found in the Old World could have been directly brought there by the currents. For the shore plants confined to the New World, we have usually to appeal to the bird, to the drifting log, and to man. In the case of the inland scrub plants birds are probably the chief agents of distribution. 


\section{CHAPTER XIII}

\section{THE CURRENT-CONNECTIONS IN THE SOUTHERN HEMISPHERE}

IN this chapter are discussed the current-connections between the three great land-masses of the southern hemisphere, South America, Africa, and Australia. The matter is scarcely germane to the subject proper of this work; but, in the light of my own consideration of the problems involved, I will briefly state the results obtained from the bottle-drift data supplied by Schott's memoir and from other sources.

The Relationship Between the Southern Floras.-It is well known that there is a very interesting relationship between the floras of these three widely separated regions, a subject which has occupied the attention of Hooker, Grisebach, Engler, Drude, Schimper, Hemsley, and many others. One of the most important of recent contributions to the literature of the matter, though more concerned with animals than with plants, is Mr. Hedley's paper on the palæogeographical relations of Antarctica (Proc. Linn. Soc. Lond., June 6,1912 ).

A common source in the northern hemisphere would explain the presence in these land-masses of the south of several of the genera, such as Fagus, Podocarpus, Araucaria, etc.; and here we are simply assuming that the same principle which has been at work in recent times within the lives of existing species of Sphagnum and Carex (see Chapter XVI.) operated also in past ages. Birds would explain the occurrence of the same species of Accena, Cotula, Nertera, Uncinia, etc., in the extra-tropical portions of these areas; and currents would account for the existence of the same littoral plants, such as Sophora tetraptera, Convolvulus soldanella, and perhaps Sicyos angulatus, in regions separated by thousands of miles of ocean. It would, however, be in the tropics that the currents would be most effective in accounting for the occurrence of the same species of shore plants on the opposite sides of the oceans.

The Drift round the Globe in High Southern Latitudes.Before dealing with the current-connections of the southern hemisphere I will refer to one of the most interesting phenomena concerned with the currents of the globe, namely, the drifting round the earth in high southern latitudes of bottles and wreckage. The subject is one that could be treated in great detail. Here, however, it will be only dealt with in an illustrative fashion, and the leading considerations that arise will be presented in a general way, thus introducing the discussion that follows. 
On the southern and south-eastern coasts of Australia, and even on the north-east shores of the island continent, there are stranded bottles and wreckage from off Cape Horn and from the vicinity of the islands of the Southern Ocean lying north of Kerguelen, such as the Crozets, St. Paul's, and Amsterdam. Roughly speaking, between the parallels of $40^{\circ}$ and $60^{\circ} \mathrm{S}$. lat. the never-failing westerly winds establish a surface current around the globe, known as the West Wind Drift Current. Of some sixteen bottles referred to in Schott's memoir which performed long passages of from 3500 to 8500 miles in these latitudes, all took an easterly course before the winds of the Roaring Forties. There is not an exception; and the same remark applies to numerous bottles in Australian waters south of the 40th parallel, for the particulars of which we are indebted to Russell, whose " current papers" in the Journal of the Royal Society of New South Wales for 1894 and 1896 are utilised by Schott.

The average minimum drift-rate up to the dates of the recovery of the bottles is eight to nine miles a day. The quickest rate is concerned with one that covered the distance of about 4500 miles between a locality to the north of Kerguelen and its place of arrival in New Zealand at a speed of at least $\mathbf{1 0 . 6}$ miles a day. If in order to allow for the delay in the recovery we take the average daily rate at ten miles, then a bottle drifting round the globe, so as to clear Cape Horn, would accomplish the circuit of about 12,000 miles in rather over three years. At this speed a bottle starting from off the Horn would reach South-eastern Australia in about two and a third years, a passage of about 8500 miles. Two mentioned by Schott actually accomplished this traverse, the minimum daily rates up to the dates of recovery in South-east Australia being 8 and $\mathbf{9 \cdot 2}$ miles. One, referred to by Page, even extended its drift around the east coast of Australia to Cape York, performing a passage of some 10,500 miles in nearly three years at a minimum rate of about ten miles a day, one of the longest drifts known.

But the important point is that during the easterly drift across the Southern Ocean there is a continuous slant to the northward. Drift always decreases its latitude during long passages in the belt of the "brave west winds"; and its general course from off Cape Horn towards Australia would be about E. by N. and from New Zealand eastward about E. $\frac{1}{2}$ N. Thus it is that bottles and wreckage from off the Horn in about lat. $57^{\circ} \mathrm{S}$., from the vicinity of the Crozets and northward of Kerguelen in lat. $44^{\circ}-46^{\circ} \mathrm{S}$., and from the seas to the south-west of Cape Leeuwin in lat. $42^{\circ} \mathrm{S}$., in all cases cross the 40th parallel before reaching Australia. The same northward deflection is to be noticed in drifts across the Pacific in high latitudes, but the amount is less, the displacement being from two to five degrees of latitude.

Schott (p. 22) emphasises this northerly slant of the drift in the Southern Ocean. The result is that Fuegian drift reaches the south coasts of Australia and the north extremity of New Zealand, which lie fifteen to twenty degrees further north. Of four bottles cast overboard off Cape Horn, three of which are referred to by Schott and one by Page, one reached South-west Australia in the vicinity 
of Albany, two reached South-east Australia to the eastward of Melbourne, and one, already mentioned, rounded the south-east corner of the island continent and reached Cape York, the most northerly point of Queensland. The figurehead of the Blue Jacket, a ship that was burned between the Falkland Islands and Cape Horn in lat. $53^{\circ} \mathrm{S}$. and $60^{\circ} \mathrm{W}$. in March 1869 , was recovered at the beginning of 1872 at Fremantle in West Australia. This is the only "drift record" at my disposal that illustrates the branching north from the West Wind Drift Current, as it approaches Cape Leeuwin, of the West Australian Current. It is quoted by Schott (p. 23) from the Melbourne Argus for March 28, 1872.

Fuegian Drift.-If it were possible for Fuegian drift to be carried round the earth and back to the western side of South America, it would strike the coast about twenty degrees north of its original starting-place. A bottle commencing its voyage round the globe from Cape Horn would under these conditions be ultimately stranded on the shores of the same continent somewhere between Valdivia and Valparaiso. If practicable, this passage of about 15,000 miles at an average speed of ten miles a day would occupy about four years. However, Russell's numerous observations in Australian waters demonstrate its impracticability. Fuegian drift after brushing past the coasts of South-eastern Australia and Tasmania would, if it escaped stranding on the north end of New Zealand, be carried to the north-east for a short distance. It would then come within the influence of currents setting to the westward and northward that would sweep it back on the coasts of Queensland, of which an actual instance has before been given as supplied by Mr. Page. The westerly set of the currents between Fiji and the Kermadec Islands would effectually block the passage of Fuegian drift across the Pacific, and it would similarly prevent the passage eastward to South America of any Australian drift. This point is well illustrated in one of Schott's bottle-drift charts (Table 6).

It is apparent from the tracks of bottles laid down in Schott's charts that whilst Fuegia could distribute drift to South Africa, the Crozets, St. Paul, and Amsterdam Islands, the southern coasts of Australia, Tasmania, and the northern extreme of New Zealand, it could do little more, since the rest of the materials would be swept back to the Queensland coasts. On rare occasions by making an unusually wide detour some Fuegian drift might be stranded on Norfolk Island and New Caledonia before it was turned back by the Southern Equatorial Current; but that would be the extent of its invasion of the Pacific Ocean.

The only drift that could reach Fuegia from the west would be derived, as will subsequently be shown, from the southern end of New Zealand, from the Antarctic islands lying south of it, from Kerguelen and the islands to the south of it, from the distant South Shetland and South Orkney Islands, and from the coasts of the Antarctic continent adjacent to the two groups just named. None of the drift from the vicinity of Cape Horn could ever return to the South American continent; and if any floating objects ever performed the circuit of the globe in these high latitudes it would be south 
of the 60th parallel. The bearing of these considerations on the distribution of littoral plants in the Southern Ocean will be subsequently discussed.

The Current-Connections of Australia.-I will now deal separately with the current-connections of the great land-masses of the southern hemisphere as far as they throw light on the distribution of littoral plants in those regions; and in the first place I will take Australia. The island continent is peculiarly situated in these respects. Whilst from its tropical north-west shores it would distribute drift across the Indian Ocean to the East African coasts, on its south-west border and along the whole length of its southern coasts it would receive drift, occasionally from South Africa, but more usually from Fuegia and the intervening islands of the Southern Ocean. From its south-eastern coasts it would supply materials to the northern end of New Zealand; whilst on its middleeast and north-east coasts would be stranded drift from the islands of the tropical South Pacific and from Equatorial South America. The only materials it could receive from New Zealand would be derived from the vicinity of the North Cape. Such drift, as is shown below, would be thrown up on the coasts of Queensland, where it might even be associated, as previously implied, with drift brought from Fuegia by the West Wind Current.

Dealing first with the eastern coasts of Australia, the data in Schott's memoir indicate that we are more especially concerned with the shores of Queensland along its length and with the transporting agency of the South Equatorial Current. Bottles have been recovered on the Queensland coasts not only from the region between and including Fiji, Tonga, and Norfolk Island, but from off the distant coast of Ecuador on the other side of the Pacific; and it may be safely assumed that the eastern archipelagos of the South Pacific, the Marquesan, Paumotuan, and Tahitian groups, which lie athwart the track of the trans-Pacific traverse, would also supply drift to the Queensland coasts.

The principal data, on which the remarks just made are based, may here be given. A bottle cast overboard about 250 miles from the coast of Ecuador in lat. $3^{\circ} 52^{\prime} \mathrm{S}$. and long. $85^{\circ} 38^{\prime} \mathrm{W}$. was recovered 966 days afterwards near Cooktown in North Queensland, the traverse of 7620 miles, as estimated by Schott, having been accomplished at a minimum rate of $7 \cdot 9$ miles a day (Schott, pp. 24, 27, Chart 6, No. 33). The same traverse was in part accomplished in mid-ocean by three bottles mentioned by Schott (p. 24, Chart 6, Nos. 6, 7, 40), which were found in the Paumotus after covering distances of from 1600 to 2100 miles, having been dropped overboard in the Eastern Pacific between the parallels of $10^{\circ}$ and $12^{\circ} \mathrm{S}$. These bottles, being outside the swiftest part of the current, gave a drifting rate of only five miles a day. An interesting traverse in mid-ocean, but more to the north and near the axis of greatest velocity of the South Equatorial Current, is mentioned by Page. Here a bottle, dropped overboard on January 23,1897 , in lat. $4^{\circ} \mathrm{N}$. and $168^{\circ} \mathrm{W}$. was found on the Gilbert Islands forty-two days afterwards, having drifted 1100 miles at the rate of twenty-six miles a day, the fastest 
record for its distance known from this part of the Pacific. Had this bottle pursued an uninterrupted course, it would probably, after traversing the Solomon and Lousiade Archipelagos, have been stranded on Cape York Peninsula. The last part of the oceancrossing was effected by four bottles which reached the coasts of South Queensland and those of New South Wales, just across the border, from the region of the Western Pacific comprised between the Fijian and Tongan Groups and Norfolk Island (Schott, p. 24, Chart 6, Nos. 8, 9, 18, 25).

The evidence afforded by the nine bottle-drifts above dealt with is clear and consistent. All tell the same story and indicate in no doubtful manner the probability of drift seeds from tropical South America reaching the tropical and subtropical shores of Eastern Australia. The extent to which the distribution of littoral plants in these two widely separated areas responds to the influence of the South Equatorial Current will be subsequently noticed. But the east coast of Australia has other possible current-connections which have been before mentioned. It is evident from the data supplied by Russell and Schott that the branch of the West Wind Drift Current which proceeds through Bass Straits on its way towards the North Cape of New Zealand is deflected to the northward and westward, sometimes before and sometimes after passing that headland; and the bottle-drift tracks indicate that materials washed off the North Cape would be stranded in the vicinity of Brisbane. It would thus appear that the coasts of Queensland would be the recipient of drift from the extreme north of New Zealand. It would also, as shown by the stranding of the bottle from Cape Horn on the Cape York Peninsula, receive Fuegian drift.

Coming to the southern sea-borders of Australia, we have already referred to the fact that bottle-drift and wreckage from Fuegia, from the Crozets, and from the islands north of Kerguelen may be thrown up on these shores. But the south coasts of Australia may also at times receive drift from South Africa. A bottle cast over about seventy miles south-east of Cape Agulhas was recovered on the coasts of the Great Australian Bight (Schott, Map 5, No. 31). The tropical north-west sea-borders of the island continent have doubtless received many of their littoral plants from the neighbouring Malayan region through the agency of the currents. They would, as is shown on a later page, distribute drift through the South Equatorial Current to the coasts of tropical and extra-tropical East Africa. It is possible that materials would be also received from the branch of the West Wind Drift Current proceeding north from Cape Leeuwin, which is known as the West Australian Current. But from the standpoint of distribution any seed-drift from high latitudes on the Southern Ocean would be ineffective in those warm regions. It is, however, likely that seed-drift from this source would be effective on the coasts of extra-tropical Western Australia, and we have already seen, in the case of the stranding near Fremantle of the figurehead of a ship burned at sea between Cape Horn and the Falkland Islands, that drift may reach those shores from the southern extreme of South America. 
New Zealand as a Receiver and Distributor of Drift.This subject has already been several times mentioned in this chapter. Whilst its north-west shores would receive drift from Southern Australia and Tasmania, they would also receive the tailings of drift from Fuegia and the islands of the Southern Ocean (north of Kerguelen) that had slipped past the Australian and Tasmanian coasts. On its south-west shores would be stranded materials from Kerguelen and the islands south of it, and perhaps also some occasional drift from the islands (South Shetlands and South Orkneys) and the adjacent coasts of the Antarctic continent south of the Horn.

Russell, as quoted by Schott (p. 23), gives a number of examples to show that bottles thrown over south of the 40th parallel between Tasmania and New Zealand arrive in almost every case at the western shores of New Zealand. Some longer drifts, as supplied by Schott in his charts (5 and 6) and as mentioned in his text, are worth remarking. Thus, a bottle (No. 17) thrown over to the S.S.W. of Cape Leeuwin in about lat. $41^{\circ} 30^{\prime}$ was stranded close to the North Cape. Another (mentioned by Russell) thrown into the sea more to the south-west in about lat. $46^{\circ} \mathrm{S}$. and long. $103^{\circ} \mathrm{E}$. was recovered on the south-east coast of New Zealand, after doubling the South Cape. A third (No. 21) from a position about 200 miles north-east of Kerguelen and near the 46th parallel was beached at the entrance to Cook Straits.

That the southern extremity of New Zealand may receive drift from higher latitudes is indicated by the record of a cask which is noted by Schott on p. 23. Derived from the whaler Ely, which was lost on the Macdonald Islands to the south of Kerguelen in about lat. $53^{\circ} \mathrm{S}$., it was ultimately found on the Chatham Islands, a period of $\mathbf{5 1 0}$ days having passed since the loss of the ship. As a distributor of drift to the Pacific coasts of extra-tropical South America, New Zealand plays an important part, a matter that is discussed below. The possibility of drift washed off its northern extremity being carried to Queensland has already been noticed.

South America and its Current-Connections.-The circumstance that South America reaches south to the 56th parallel, whilst New Zealand extends to about the 47th and Africa only to the 35th, has been a determining feature in plant distribution in this part of the globe. To this factor in the dispersal of plants by currents must be added another determining influence due to the northern slant of the easterly drift in the higher southern latitudes. For this reason Australian drift could never be carried to corresponding latitudes on the Pacific side of South America; and, as we have seen, its traverse of the Pacific Ocean would under any circumstances be impossible on account of the working of the currents to the north of New Zealand as interpreted by the bottle-drift data.

On the other hand, materials from the southern end of New Zealand and from the Antarctic islands to the south of it would be stranded on the shores of South Chile between Valdivia and the island ${ }^{\prime}$ of Chiloe, $40^{\circ}-43^{\circ} \mathrm{S}$. The course that such drift would take is exemplified by the track of a bottle, which, after being cast overboard 
in the middle of the South Pacific in about lat $46^{\circ} \mathrm{S}$. and long. $135^{\circ} \mathrm{W}$., was picked up on Chiloe (Schott, p. 22, Map 6, No. 38). Materials from the islands south of New Zealand, such as Auckland and Macquarie Islands, from Kerguelen and the islands south of it, and from perhaps the distant South Orkney and South Shetland Islands and the neighbouring shores of Antarctica, would be beached further south on the coasts of Fuegia and on the islands reaching north from Cape Pillar to the 50th parallel. A very interesting driftrecord was published in the London Times for April 17, 1912. A bottle thrown over by Captain Wilkes of the Tyser Line nearly a thousand miles east of Kerguelen (lat. $51^{\circ} 38^{\prime} \mathrm{S}$. and long. $96^{\circ} 15^{\prime} \mathrm{E}$.) on November 17, 1908, was recovered about three years afterwards by Maurice Deffarges on the coast of South Chile in lat. $49^{\circ} 42^{\prime} \mathrm{S}$. and long. $74^{\circ} 25^{\prime} \mathrm{W}$.

Doubtless drift materials brought from high southern latitudes by the "west wind drift current" to these shores of South America would sometimes be carried north by the Humboldt or Peruvian Current and distributed along the Pacific coasts. It is also possible that such drift might ultimately be carried past the Galapagos Islands into the stream of the South Equatorial Current and in this manner be returned to the north-east coasts of Australia. But since at least six years would be taken up in the double traverse from New Zealand to South America and back to Australia, it is for several reasons doubtful whether as far as seeds are concerned it would be of any effective value.

One must not ignore the possibility of seed-drift being carried round the Horn from the west to the east side of Tierra del Fuego. Not all of that part of the great "west wind drift current" which strikes the west coast of South America south of the 37th parallel is deflected north in the Peruvian Current. It gives rise south of the 50th parallel to a small stream that doubling Cape Horn joins the Antarctic Current, which proceeding northward meets the Brazilian Current off the estuary of the Plate. Schott lays down the track in Map 6 of a bottle which, after being dropped overboard off the west coast of Fuegia in about lat. 54. $\mathrm{S}$. was recovered in the Falkland Islands (see p. 22 of his text).

The probability of tropical South America supplying tropical North-east Australia with littoral plants through the agency of the South Equatorial Current will be subsequently discussed. On its eastern tropical coasts South America would receive drift from tropical West Africa through the Main Equatorial Current, as explained in Chapter III.; whilst the South Atlantic Connecting Current would carry materials from its extra-tropical eastern shores to South Africa. The fact that drift can double the Horn in the Antarctic Current and be transferred from the west coasts of Fuegia to the eastern side of the continent is noticed in the same chapter. But it is as a distributor of drift to Southern Australia, Northern New Zealand, the islands to the north of Kerguelen, and occasionally to South Africa that Fuegia plays the most important rôle.

Africa and its Current-Connections.- The last of these southern continental land-masses to be here dealt with is Africa. 


\section{CURRENT-CONNECTIONS IN S. HEMISPHERE 301}

Its opposite shores display the same reciprocity in the exchange of drift that is exhibited by South America. Whilst on the west the tropical borders would distribute drift to the New World through the agencies of the equatorial currents, those on the east would be the recipients of drift from tropical North-west Australia and from Malaya. So also the western extra-tropical coasts would receive drift from high latitudes in South America, and the corresponding eastern coasts would distribute it to the southern borders of Australia.

The part taken by the equatorial currents of the Atlantic in transporting drift to America is dealt with elsewhere (Chapter III.). We are here principally concerned with the materials transported from the Gulf of Guinea to the coast of Brazil by the Main Equatorial Current, the time occupied in the passage being only three months. The western shores of South Africa would receive drift from extratropical South America that had been brought within the influence of the South Atlantic Connecting Current by the Brazilian Stream from the north and by the Antarctic Current from the Horn. The course taken would be that followed by a bottle dropped overboard in the middle of the South Atlantic in about lat. $42^{\circ} \mathrm{S}$. and long. $32^{\circ}$ W., which was stranded near the Cape of Good Hope (Schott, Table 4, No. 97). The indications of bottle-drift data are that drift could not be carried direct from the tropics of the New World to those of West Africa in the Counter Equatorial Current, except under exceptional circumstances (Chapter III.).

To the eastern coasts of Africa, from the equator southward, tropical drift would be brought across the Indian Ocean by the South Equatorial Current from Malaya and North-west Australia; and its destination on the African coast would depend on whether it took the direct course north of Madagascar, or passed south to get within the influence of the Mozambique and Agulhas Current. It is also highly probable that the West Australian Current, which represents the northern offshoot of the West Wind Drift Current of the Roaring Forties, would after striking the south-west corner of Australia carry with it not only West Australian drift-materials, but also South African drift, which, brought by it within the influence of the South Equatorial Current, would be ultimately returned to the continent from which it hailed. It is even possible that Fuegian drift may be carried into the West Australian Current and thence into the Equatorial Current, finally reaching tropical East Africa in the company of South African, Australian, and Malayan drift. During its traverse of the Indian Ocean this equatorial stream would deposit samples of its gatherings from four continents on Keeling Atoll, the Chagos Islands, the Seychelles, the Mascarene Islands, and Madagascar.

Let us look a little more closely into the play of the currents in the Indian Ocean from the equator southward, as exemplified by the tale of the drifting bottle. It is suggestively illustrated in Schott's maps and in his text; and by adding a few other data we shall obtain a fair representation of the work of the currents in distributing drift in these seas. However, to quote from the American bottledrift charts for the North Atlantic, "it should be noted that the in- 
dividual drifts as laid down upon the chart, do not necessarily represent the actual surface currents of the ocean, but the resultant effect of all the forces to which the bottle was exposed during its drift."

The bottle-drifts of the Indian Ocean are grouped by Schott into (a) those of the region of the monsoon currents, that is, north of $5^{\circ}-10^{\circ} \mathrm{S}$. lat.; (b) those of the belt of the South-east Trade between $10^{\circ}$ and $30^{\circ} \mathrm{S}$. ; (c) and those of the region of the Roaring Forties or " braven Westwinde." It would appear from his chart and his remarks (pp. 20-22) that the northern part of the Malayan region is more likely to receive drift from the westward than to distribute it in that direction. Thus we should expect to find drift on the beaches of the west side of Sumatra and of the Malay Peninsula from Southern India and Ceylon and from the shores of the Arabian Sea. On the other hand, the bottle-drift data also indicate that drift may at times be carried from the west coast of Sumatra to the Maldives and even to the shores of Equatorial Africa. This direct communication between North-west Malaya and the African east coast under the equator is exemplified by a bottle thrown over in about lat. $2^{\circ} \mathrm{N}$. some 400 miles west of Sumatra, which was recovered 160 days afterwards under the equator on the East African coast, having crossed the Indian Ocean at a minimum rate of 18.7 miles a day, the distance covered being about $\mathbf{3 0 0 0}$ miles (Schott, p. 21, quoted from the American Pilot Chart for June 1895).

In the case of Southern Malaya, meaning thereby the islands east of Java that face Australia, there would be a regular supply of drift to the East African coasts through the South Equatorial or Southeast Trade Current. This is illustrated in part by the track of a bottle which was cast over about mid-way between the island of Sumbawa and North-west Australia in about $15^{\circ} \mathrm{S}$. and long. $116^{\circ} \mathrm{E}$. and was recovered in the Chagos Islands (Schott, Table 5, No. 23). Its track represents the first half of the passage taken by drift in crossing the Indian Ocean from the seas between the Malayan Islands and North-west Australia. The course followed by the bottle lies close to Keeling Atoll, and thus enables us to appeal to a witness who particularly interested himself in these matters during his sojourn in this part of the world, viz. Mr. Wood-Jones. As a spectator of the actual start in these Malayo-Australian waters of Malayan drift on its passage across the Indian Ocean to Equatorial Africa he thus writes in his Coral and Atolls (p. 295): "During a stay of a fortnight in October 1906, in a ship lying on cable ground some twenty miles south of Sumbawa, the current flowed constantly westward at the rate of about one and a half knots; and the waters were carrying all sorts of drift wrack in their stream."

But Wood-Jones aids us still further in this matter. By adding experiment to observation he enables us to complete the traverse across the Indian Ocean which was performed in part by the bottle above alluded to. He had especially in his mind the subject of the transport in the South-east Trade Current of Malayan drift, whether plant or animal, to Keeling Atoll; and, as already indicated, the track of the bottle cast over beween Sumbawa and North-west Australia is laid down by Schott as passing close to Keeling Atoll on the way 


\section{CURRENT-CONNECTIONS IN S. HEMISPHERE 303}

to the Chagos Islands. It was from this atoll that Wood-Jones made numerous experiments with bottles, the results of which are specially important in this connection. Although only two were recovered, both were found on "exactly the same spot" at a place called Ras Day at Brava $\left(1^{\circ} 6^{\prime} \mathrm{N} ; 4^{\circ} 2^{\prime}\right.$ E. $)$ in Italian Somaliland. Both of them, strange to relate, were dispatched on the same day, November 15, 1905, and in both cases the record was returned by the same person, Captain Piazza, Resident of Brava. The first was found on May 27, 1906, an interval of 193 days, which gives a daily drift of not less than seventeen miles over a distance of about 3300 miles. The second was not recovered until July 11, 1907, the cause of the great delay being not explained. Wood-Jones (p. 295) considers that drift would require from forty to sixty days to reach Keeling Atoll from the Malayan Islands to the eastward. By piecing the data together we may assume that the whole traverse from south of Sumbawa to Equatorial Africa would be accomplished in not more than eight months, the distance being about 4500 miles.

As an agent in carrying drift from tropical Africa to Malaya the Indian Counter Current, which courses eastward along equatorial latitudes, seems to be ineffective. It is scarcely illustrated in Schott's maps, and, as in the Atlantic and Pacific Oceans, we may be permitted to doubt whether any purely compensating current could, except on very rare occasions, transport drift across an ocean. In the case of this particular counter-current floating materials would be driven out of its influence, southward during the north-east monsoon and northward in the south-west monsoon.

Summing up the effective current-connections between Africa and Malaya, as far as they are reflected in bottle-drift, we may infer that Malaya is the giver and Africa the recipient. But it would seem that whether it came from Sumatra or from the islands east of Java, Malayan drift reaching East Africa would be mostly gathered under the equator. This was the opinion also formed by Wood-Jones when he reflected on the two facts $(a)$ that crocodiles and large snakes have been stranded alive amongst the Malayan vegetable drift that is regularly floated to Keeling Atoll, and $(b)$ that bottles thrown into the sea by him from this atoll had been stranded at Brava on the coast of Equatorial Africa. "I would dearly love" (he writes on p. 294) "to examine the coast-line of Italian Somaliland in the region of Ras Day (Brava) to see if there was not some waif that had succeeded in making a new home there, and that could clearly tell of a Malayan or an Australian origin. I do not doubt that some such colonist would certainly be found-some typical Asiatic or Australian intruder on the African fauna and flora."

In the westerly traverse of the Indian Ocean in equatorial latitudes by Malayan drift much would depend on the season of the year. The bottles dispatched from Keeling Atoll by Wood-Jones in November were impelled westward during the period of the north-east monsoon which probably came to their assistance when the Southeast Trade failed. Had they been sent off in May, they would, when near the Line in mid-ocean, have been diverted north towards India, and when the south-west monsoon gave place a few months 
later to the north-east monsoon they would have been carried to the south-west, and might have been the sport of the currents for years. This seems to have been the fate of a bottle cast over in May in lat. $6^{\circ} \mathrm{S}$. to the south-east of the Seychelles, which was recovered two and a quarter years after in the Chagos Islands, 800 miles to the eastward (Schott, p. 21, Map 5, No. 8). So again the bottle before mentioned which was found on the shores of Equatorial Africa 160 days after it had been dropped into the sea in $2^{\circ} \mathrm{N}$. lat., some 400 miles west of Sumatra, began its passage in January, that is, in the height of the north-east monsoon. Had it started in July during the height of the south-west monsoon, it would have been carried back to Northern Sumatra or the Malay Peninsula, as is well brought out in Schott's map in the case of other bottles.

The general effect of the alternating influence of the surface drift currents set up in the equatorial waters of the Indian Ocean by the monsoons would be to restrict the arrival on the coasts of Equatorial Africa of drift from Malaya and North-west Australia to the half of the year corresponding to the period of the north-east monsoon. In the other half of the year, if it did not become the sport of the currents between Ceylon and Madagascar, it might be stranded almost anywhere on the shores of the northern half of the Indian Ocean.

This leads us to consider the current-connections of the east side of Africa with Western Australia, and in so doing we shall be compelled to cover old ground. Here the South Equatorial Current, or the South-east Trade Drift, is the direct transporting agency, and Africa thus figures as the recipient. The track that seeds from the tropical coasts of North-west Australia would take is indicated $(a)$ by the bottle, already alluded to, that after being dropped into the sea about half-way between Sumbawa and the opposite Australian shores passed close to Keeling Atoll and was stranded on the Chagos Islands, (b) by the two bottles before mentioned that were carried from Keeling Atoll to Brava on the African coast in $1^{\circ}$ N. lat. Such seed-drift would presumably, therefore, reach Equatorial Africa. It would be derived from the adjacent coasts of North-west Australia and Malaya and from the shores of the Arafura Sea.

But drift from Western Australia in the vicinity of and to the south of the North-west Cape would also come within the influence of the South-east Trade Current. With the same northerly slant that is exhibited in the track of the drift from the Timor and Arafura Seas, it would arrive at a point in mid-ocean-about the 15 th parallel of south latitude and the 75th meridian of east longitude - where it would have to choose between a course lying north of Madagascar bringing it to the vicinity of Zanzibar, and a course south of Madagascar bringing it into the Natal Current and resulting in most cases in its being stranded on the shores of Cape Colony. The probable determining cause would lie in the indirect influence of the monsoons some degrees further north, the northern course being taken during the south-west monsoon and the southern course in the north-east monsoon.

The sequence of events is clearly shown in No. 5 of Schott's charts. 
A bottle (No. 37), which was dropped over in about lat. $16^{\circ} \mathrm{S}$. and long. $98^{\circ}$ E., nearly 1000 miles north-west of the North-west Cape of Australia, was recovered on the south-east side of Madagascar. Presumably it represents the course taken by drift from the vicinity of this corner of Australia. After a drift westward of about 1100 miles, it crossed in about lat. $15^{\circ} \mathrm{S}$. and near the 80th meridian of east longitude the starting-place of two bottles (18 and 38 of Schott's Chart 5, and mentioned on p. 22) only 120 miles east and west of each other, one of which was stranded on the African coast immediately north of Zanzibar, whilst the other was thrown up on the south-east shores of Madagascar. Schott lays down the tracks of bottles from the southern end of Madagascar and its vicinity, which, after getting into the Natal Current, were beached on the south coast of Cape Colony east of Cape Agulhas. We thus perceive how seed-drift from Western Australia may be distributed on the East Coast of Africa from Zanzibar to the southern extreme of the continent.

But as regards Australia, Africa may be a giver as well as a receiver. Drift from the southern extreme may be carried by the Agulhas Current into the West Wind Drift Current and thus to the south coasts of Australia. Of this a suggestive example is afforded by a bottle, thrown overboard about seventy miles south-east of Cape Agulhas, which was stranded on the shores of the Great Australian Bight (Schott, Map 5, No. 31). However, the Agulhas Current has a subsidiary branch that doubles the Cape, and as indicated by the bottle-drift data (see p. 63), may bear drift from the shores of Natal and from the south-east coasts of Cape Colony to the African West Coasts. Though the event is probably infrequent, seeds could be transferred in this way from the east to the west side of the continent. It is even possible that drift from Western Australia, after traversing the Indian Ocean to the south of Madagascar might in this manner reach the South-west Coast of Africa.

It is likely that drift in its passage from South Africa towards Australia may at times perform the circuit of the Indian Ocean. South African drift, after crossing the ocean in the West Wind Current, may be carried north in the West Australian branch of the current into the South-east Trade belt, and thence across the ocean to Africa, thus completing the circuit of the Indian Ocean. Wood-Jones (p. 295) refers to a bottle "launched in Mauritius" that is said to have reached Keeling Atoll. No other data are given; but he is quite justified in assuming that it " almost certainly came to the atoll from the eastward, after completing an enormous circuit of the Indian Ocean." This bottle would have followed the track, above indicated, to the south of Madagascar and towards the southern extreme of Africa, subsequently crossing the Indian Ocean in the belt of the Roaring Forties, and turning north in the West Australian Current to meet the South Equatorial Current (South-east Trade Drift) that flows past Keeling Atoll. It would have accomplished about 10,000 miles in about three years.

The Influence of the Current-Connections in the Southern Hemisphere on the Distribution of Littoral and Estuarine 
Plants.-Seed-drift travels west in tropical latitudes and east in temperate latitudes, from which it follows that whilst in the temperate latitudes of the southern hemisphere we look to the west for the source of the littoral and estuarine plants that are dispersed by currents, in the tropics we look to the east. On account of the usual slant of the trans-oceanic traverses of the drifting bottles there is, however, generally a marked shifting of the latitude either to the north or to the south. But, apart from this, the general effect would be that in the tropics we should look for West African affinities on the eastern shores of South America, for South American affinities on the coasts of Malaya and Australia, and for Malayan and Australian affinities in East Africa. So also in temperate latitudes we should look for South American relations in South Africa, Australia, and New Zealand; for South African affinities in Australia; and for Australian and New Zealand relations in South America.

Although the general principle, just enunciated, still applies, some important modifications are necessitated on account of the usual northward and southward slant of the currents, as evidenced by bottle-drift. Except within the narrow limits of the equatorial Atlantic the shifting in the latitude generally amounts to several degrees. We have seen that Fuegian drift when it reaches Australia has diminished its latitude by about twenty degrees. On the other hand, New Zealand drift when crossing the Pacific to South America is deflected only four or five degrees to the north. Bottles from off the equatorial coasts of South America would strike the shores of North-east Australia a dozen degrees farther south. This southerly slant of drift in the South Equatorial Current is continued right cross the Pacific, and may be even greater than is just indicated. A bottle thrown into the sea on the 10th parallel of south latitude in the meridian of the Galapagos Islands would be stranded on the east coast of Australia on about the 30th parallel of latitude. The effect of this slant, as already shown, is the throwing back of East Australian drift on the shores of that island continent, so that Australia is in this manner unable to contribute drift to South America. The only drift that could reach South America from these longitudes would be from higher latitudes, namely, from the southern end of New Zealand and the Antarctic islands to the southward.

In the southern tropics of the Indian Ocean drift carried along in the South-east Trade or South Equatorial Current is inclined to the north, so that bottles dropped into the sea about the 16th parallel of south latitude between Java and North-west Australia would be beached on the East African coast under the equator. It is remarkable, as shown by the tracks of bottles laid down in Schott's Chart 5, that drift from the southern extreme of Africa, which is carried by the Agulhas Current into the West Wind Current, is transported across the Indian Ocean without much change of latitude, being ultimately thrown up on the south coasts of Australia.

In applying, therefore, to the southern hemisphere the principle that in the case of littoral and other plants dispersed by currents we should in temperate latitudes look to the west for their source and 
in the tropics look to the east, we have often to make a correction for change in latitude. The problem, when re-stated, would be as follows. In the tropics of the Pacific we should expect to find plants of Equatorial South America in Melanesia and North-east Australia; in those of the Indian Ocean plants of Malaya and North-west Australia on the equatorial coasts of East Africa; and in those of the Atlantic, West African plants on the shores of Brazil and of the Guianas. In the temperate latitudes we should look for Fuegian plants in Cape Colony, Southern Australia, and the northern end of New Zealand; for South African plants in Southern Australia; and for plants of the south part of New Zealand in South Chile. We should not look for Australian littoral plants in South America. We will now deal more in detail with these matters :-

(A) As illustrated in Temperate Latitudes.-When the same littoral plants occur in the cooler latitudes of two of these southern landmasses we are guided by the currents in determining which of the two is the source. Thus, there are two littoral plants, Sophora tetraptera and Convolvulus soldanella, which occur alike in New Zealand and South Chile. This singular distribution is one of the mysteries of the Southern Ocean. Both of them possess buoyant seeds capable of dispersal over an ocean by the currents. Thus, according to my experiments on the seeds of Sophora tetraptera, which I gathered on the Chilian coast, half of them remained afloat after seven months in sea-water and retained their germinative capacity. From results for the seeds of Convolvulus soldanella, which are given in my book on Plant Dispersal (p. 542), it appears that 30 per cent. remained afloat after eighteen months in sea-water and subsequently germinated when sown out. Both of these plants are confined to the west side of temperate South America. Since they occur in latitudes north of $42^{\circ} \mathrm{S}$. (Ibid., pp. 476-9) they would come within the influence of the northward flowing Peruvian Current and would have no opportunity of doubling Cape Horn. They are found just in those South Chilian latitudes which, as before remarked, would receive New Zealand drift; and we can have no hesitation in regarding them as introduced into South America from New Zealand by the currents. (Both of these plants are treated in detail in my book on Plant Dispersal. The experiments on $S$. tetraptera were continued after the publication of the earlier work.)

Yet on the part of Sophora tetraptera there has been an effort to recross the Pacific in warmer latitudes. Not only does it grow in the Juan Fernandez Islands, whither the seeds were probably brought from the southward by the Peruvian Current, but it has been found on Easter Island (lat. $27^{\circ} \mathrm{S}$.) in the open ocean. In this last case it would seem that the seeds, after being carried north in the Peruvian Current, came within the influence of the South Equatorial Current. It is not a plant of the tropies, and Easter Island seems to be the northerly limit of its effective dispersal by currents.

The data indicate the little likelihood of seeds from the temperate or extra-tropical western shores of South America being able to arrive in similar latitudes on the Australian side of the Pacific in an effective condition. Even if the current-connections permitted the 
transport, it is doubtful whether either the seeds of Convolvulus soldanella or those of Sophora tetraptera would be able to withstand the three-and-a-half years' immersion in sea-water that would be involved in the passage. Effective dispersal of temperate shore plants by the currents in the Southern Ocean could only be brought about by the easterly drift in the latitudes of the Roaring Forties. Very instructive is the caution given to mariners in the Admiralty chart of the west coast of South America (No. 786). It warns the navigator against an easterly current setting directly on the coast between the latitudes of $37^{\circ}$ and $50^{\circ} \mathrm{S}$. At the southern limit, as we have seen, would be stranded drift from the seas around Kerguelen and from the islands south of New Zealand. Towards the northern imit would be found drift from the southern part of New Zealand.

(B) As illustrated in Tropical Latitudes.-As I have observed in my previous work, dispersal by currents in tropical seas is a far more effective agency than in temperate regions. The westerly set of the equatorial currents is responsible for much that is held in common among the rank and luxuriant vegetation of coasts and estuaries in warm latitudes. The principle of looking to the east has an important application when we are concerned with the existence of practically the same littoral and estuarine flora on the opposite sides of the same ocean, as in the cases of the Atlantic and Indian Oceans. Thus, in the tropical Atlantic we should speak, not of American plants in West Africa, but of West African plants in America. So again in the Indian Ocean it is tropical East Africa that derives its littoral flora from Malaya and North-west Australia. It would be incorrect to speak of East African plants in Malaya. The position adopted by Mr. Wood-Jones as regards the dispersal by currents of tropical plants in the Indian Ocean has been already stated. His bottle-drift experiments led him to look for Malayan and Australian intruders in the African flora, or, in other words, to look to the east and not to the west in order to explain the influence of the currents on distribution.

In the case of the Pacific it would be useless, for reasons before given, to seek for tropical Australian plants on the west coast of equatorial South America. Whatever similarities exist in the littoral floras of these two regions would result from the transport of seeds of South American plants westward across the ocean in the South Equatorial Current. On account, however, of the great breadth of the Pacific Ocean and the numerous perils to which the floating seed would be exposed in an ocean traverse of from 7000 to 8000 miles, the Asiatic littoral plants hold the field in tropical Australia. If we exclude the cosmopolitan beach and estuarine plants, such as Ipomøe pes-caprae and Entada scandens, that occur round the tropical zone, it is only occasionally, as with the American species of Rhizophora (Rh. mangle) in Fiji, that we can find direct evidence of the extension westward across the Pacific of the estuarine and coast plants of the west side of equatorial South America. Island groups in the track of the currents, that would be adapted to serve as stepping-stones for the westward extension of the South American mangrove flora, are few. 
Tropical littoral plants, both strand and estuarine, divide the warm latitudes of the globe into two great regions, the New World region including both sides of America and also West Africa, and the Old World region excluding West Africa and including Polynesia. Whilst several beach plants range through both regions, more are restricted to only one. Amongst the mangroves and their associates, the genera Rhizophora, Avicennia and Carapa occur in both regions, but represented by different species; whilst Brugiera and Lumnitzera are confined to that of the Old World and Laguncularia to that of the New World. The contrast between the two regions is best shown in the mangrove flora, and nowhere is this better displayed than on the opposite sides of tropical Africa, all the plants concerned being known to be dispersed by currents.

Looking at the current-connections between Australia and New Zealand on the one side and South America on the other, we may infer that whereas New Zealand in its relation with South America appears both as a giver and a recipient, Australia would receive South American plants but could make no return. In New Zealand there is a singular reciprocal relation, the northern island receiving littoral plants from Fuegia and the southern island returning shore plants to South America, some nine or ten degrees north of the Straits of Magellan. It is remarkable that concerning the general relations of the faunas and floras of these ocean-parted regions of the southern hemisphere Mr. Hedley arrives at a very similar conclusion in his discussion of "the community of austral life "given in his paper on the palæographic relations of Antarctica (Proc. Linn. Soc. Lond., June 1912, p. 88), the chief point of difference being that he considers the transference to have taken place by way of the Antarctic continent. "Whereas New Zealand" (thus he writes) " in its relation with South America, via Antarctica, appears both as a giver and a receiver, Australia, on the contrary, seems to have made no return to South America, but to have received all and given nothing." It is not without significance that if the questions of the relations between the faunas and floras of these ocean-parted regions had been entirely one of currents, Mr. Hedley could not have employed different language.

One may conclude this chapter with the remark that as far as the currents are concerned many of the same principles would apply, with limitations, to the northern hemisphere. Thus we have in the north the same rule, with the same implications, that drift travels east in temperate and west in tropical latitudes. This is abundantly illustrated for the North Atlantic in Chapters III and IV, and it would also be true of the North Pacific Ocean.

\section{Summary}

1. The matter of the current-connections of the southern hemisphere is dealt with here only in so far as it can throw light on the dispersal of seeds in the Southern Ocean, and the operations of the currents are discussed only in so far as they are reflected in the track of the drifting bottle, itself "the resultant effect of all the 
forces to which the bottle was exposed during its drift." Even in this respect the field of inquiry is restricted, since it is chiefly littoral and estuarine plants that are distributed by currents.

2. The author at first refers to one of the most interesting of these phenomena, namely, the drifting of bottles and wreckage round the greater part of the globe before the westerly winds in relatively high latitudes. However, since the easterly drift across the Southern Ocean displays a continuous northerly slant, the circuit could not be accomplished by the same bottle unless it started some distance to the south of the Horn, that is, beyond the 60th parallel as from the South Shetland Islands. Fuegian drift would be largely intercepted by Australia, Tasmania, and the northern part of New Zealand; whilst the tailings that slipped past the North Cape would be thrown back on the Queensland coasts through the westerly set of the currents. Drift from the southern extreme of New Zealand would be stranded on the shores of South Chile, and only drift from the southernmost of the Antarctic islands would be likely to clear the Horn. The uninterrupted circuit of the globe in these high latitudes would take up rather over three years (pp. 294-6).

3. The current-connections of the great land-masses of the south are then separately dealt with, and Australia is first discussed. Whilst from its tropical north-west shores it would distribute drift across the Indian Ocean to the coasts of tropical East Africa and from its extra-tropical western shores to Cape Colony, it would receive along the whole length of its southern coasts drift from Fuegia and the intervening islands of the Southern Ocean, as well as from South Africa. From its south-eastern coasts it would supply materials to the north end of New Zealand; whilst on its middle-east and northeast coasts would be stranded drift from the islands of the tropical South Pacific and from equatorial South America. The only materials it would receive from New Zealand would be derived from the vicinity of the North Cape : through the westerly set of the currents between that headland and Fiji they would be carried to the Queensland coasts, and the same currents would effectively block the passage of Australian drift across the Pacific (pp. 297-8).

4. In the case of New Zealand a curious reciprocal relation is noticed. Whilst its northern end would receive drift from Tasmania, from the south coasts of Australia, and tailings from Fuegia and the intervening islands of the Southern Ocean north of Kerguelen, its southern end would distribute drift to South Chile. Drift from the vicinity of the North Cape would be carried back to the coasts of Queensland; whilst its south-west coasts would receive drift from Kerguelen and the islands south of it, as well as from the distant South Orkney and South Shetland Islands and from the shores of the Antarctic continent adjacent to them (p. 299).

5. South America is then dealt with. Whilst, as above explained, it could receive nothing from Australia, there would be stranded on its shores south of the 40th parallel drift from the south end of New Zealand as well as from the islands in the higher latitudes to the westward as named in the preceding paragraph. Drift from its equatorial Pacific coasts would reach North-west Australia through 


\section{CURRENT-CONNECTIONS IN S. HEMISPHERE 311}

the agency of the South Equatorial Current. To its tropical Atlantic coasts the Main Equatorial Current would bring drift from tropical West Africa; whilst in the stream of the South Atlantic Connecting Current would be carried materials from its extra-tropical shores to South Africa (pp. 299-300).

6. With regard to Africa it is shown that its opposite coasts display the same reciprocity in the exchange of drift that is exhibited by South America. Whilst the tropical borders on the west would distribute drift to the New World through the agencies of the equatorial currents, those on the east would be the recipients of drift from tropical North-west Australia and from Malaya. So also the western extra-tropical coasts would receive drift from high latitudes in South America, and the corresponding eastern coasts would supply it to the southern borders of Australia. The connections across the Indian Ocean with Malaya and Australia are then discussed. In the first case it is shown that Malaya is the giver and Africa the recipient, the drift being transported in the South-east Trade Current to equatorial East Africa. The general effect of the alternating influence of the monsoons would be to restrict the arrival of Malayan drift to the period of the north-east monsoon. In the other half of the year it might be stranded almost anywhere on the shores of the northern half of the Indian Ocean. As regards Australia, it is shown that whilst drift from its north-west shores would reach tropical East Africa, drift from its extra-tropical western coasts might reach Cape Colony. But as concerns Australia, Africa may be the giver as well as the receiver, since South African drift may arrive on the south coasts of Australia by the way of the Agulhas and West Wind Drift Currents (pp. 300-305).

7. In applying these principles to the distribution of littoral and estuarine plants in the southern hemisphere it is observed that seed-drift travels west in tropical latitudes and east in temperate latitudes. Whilst in the temperate zone we look to the west for the source of plants that are dispersed by currents, in the tropics we look to the east. In the tropics we look for South American plants in North-east Australia, for Malayan and Australian plants in East Africa, and for West African plants on the shores of Brazil and of the Guianas. In the temperate zone we look for Fuegian plants in South Africa, Southern Australia, and the northern end of New Zealand; for South African plants in Southern Australia; and for plants of southern New Zealand in South Chile. Though there is often a marked change in latitude, the rule holds good that for the source of the elements common to littoral and estuarine floras on both sides of an ocean we must, as far as the agency of the current is concerned, look to the east in the tropics and to the west in the temperate zone (p. 306).

8. In illustration of these principles in the temperate zone the instances of Convolvulus soldanella and Sophora tetraptera are taken. In the tropics, it is shown that whilst in the Indian and Atlantic Oceans the littoral and estuarine floras on the opposite sides are closely similar, the fusion has been retarded in the Pacific on account of the great width of the ocean and the paucity of suitable stepping- 
stones in the form of islands that would support a mangrove flora (pp. 307-309).

9. The inference that New Zealand in its relation with South America figures both as giver and receiver, whilst Australia merely receives South American plants and makes no return, though here concerned only with coastal plants, is the identical conclusion framed by Mr. Hedley with respect to the general relations between the faunas and floras of these ocean-parted lands (p. 309).

\section{LIST OF THE PRINCIPAL WORKS QUOTED}

GUPpy, H. B., Observations of a Naturalist in the Pacific, Vol. II., Plant-Dispersal, 1906.

Hedley, C., The Palæographical Relations of Antarctica, Proc. Linn. Soc. London, 1911-12.

PAGE, J., on the bottle-drift observations of the U.S.A. Hydrographic Office, National Geographic Magazine, Vol. XII., 1901, New York.

Russelt, H. C., Current papers in Journ. Roy. Soc. N.S.W., 1894 and 1896. (Quoted in these pages from Schott's memoir.)

Scнотт, G., Die Flaschenposten der Deutschen Seewarte, Archiv der Deutschen Seewarte, XX., 1897.

Wood-Jones, F., Coral and Atolls, 1910, p. 294. 


\section{CHAPTER XIV}

\section{DIFFERENTIATION}

The author approached the study of plant-distribution through his investigations into the agencies of dispersal, the results of which are given in his book on Plant Dispersal. At first inclined to attach undue importance to these agencies, the effect of his special inquiries concerning littoral plants and insular floras, he came to learn that, however efficacious they might be in stocking islands with their plants, they acquired a diminished significance in continental regions. We are there brought face to face with problems concerned with past changes in the history of climate, with the relations of land and sea in the lapsed geological ages, and with those mysterious revolutions in plant-forms that have affected the whole world. It was the behaviour of the polymorphous or highly variable species in the Pacific islands, differentiating as it does in every group, that first drew his attention towards the real meaning of distribution, a matter discussed in the work above named.

The Differentiation Theory and its Limitations.-The view that the history of our globe, as far as secondary causes are in operation, is essentially the history of the differentiation of primitive world-ranging generalised types in response to the differentiation of their conditions, is far from being a novel one. It has been independently acquired by a number of investigators; and, indeed, many lines of inquiry affecting the great groups of animals as well as plants converge towards this conclusion. It does not, however, attempt to explain the origin of types, nor does it account for evolutionary progress, processes which are considered to be under the sway of other influences that are not at present within our field of cognition. It is concerned only with the response of organisms to the demands of their environment, and all that seems purposive in the animal and plant worlds, all that is bound up with the great scheme of progressive evolution, is viewed much as the old naturalists were wont to regard it.

The Author's Association with the Theory.-In the last chapter of his Plant Dispersal, which was published in 1906, the theory is referred to in different connections. Thus the loss of the viviparous habit, that is assumed to have been characteristic of primitive plants under uniform climatic conditions, and the consequent development of the rest-period of the seed, are ascribed to the differentiation of climate and to the resulting seasonal variation. But attention is especially paid to the concurrent differentiation of 
climate, bird, and plant, the range of the bird being largely controlled by the climate, and the range of the plant being mainly dependent on the bird. In all cases there was the conception of a primal world, where uniformity of conditions prevailed, and of primitive generalised types that in their differentiation responded through the ages to the diversification of their conditions. These views were considerably extended in a paper on "Plant-Distribution from an Old Standpoint," read before the Victoria Institute of London in April 1907, when it was contended that the differentiation theory presents us with a good working hypothesis for the age of the flowering plants. They were further emphasised and enlarged in a paper on "The Distribution of Plants and Animals" in Petermann's Mitteilungen for 1910 (Heft II.). The paper was produced in a German translation by one of his staff through the courtesy of the editor; and although printed in a somewhat abbreviated form there was no impairment of the general line of the argument.

But in all these statements of his views the author failed to recognise that although the differentiation theory explained the diversity of forms, there was much in distribution that it did not of itself account for. What was lacking was the proper appreciation of the part played by the arrangement of the continents in determining during secular variations of climate plant-distribution. The deficiency he has endeavoured here to supply; and whilst devoting this chapter to the discussion of the differentiation theory, he will deal with distribution as an expression of the geographical and climatic conditions just mentioned in the chapter succeeding it.

Statement of the Theory.-Natural families, as at present recognised, seem to fall into two groups, the primitive and the derivative, the first world-ranging and the second restricted in their area. The primitive family as differentiation proceeds may give rise to $(a)$ zonal families, as in the case of the two closely related families, the Primulacea of temperate latitudes and the Myrsinacea of the tropical zone; $(b)$ continental families, where they are restricted to a continent, as in the cases of the Tropcoolacece and Sarraceniacece to America; and regional families that are confined to a more circumscribed region, as in the case of the Goodeniacece to Australia and its vicinity.

That differentiation and decrease of range go together is a principle that seems to prevail through the whole plant-world. It is seen in its last stages in the rôle of the polymorphous or highly variable species, which, whilst giving birth to varieties and local races in different parts of its range, still covers most of the area of the genus or sub-genus, as the case may be. It is seen even in the behaviour of the variety so produced; and thus the process goes on until, as in Hawaii, different valleys and hill-tops may possess their own peculiar forms. But this is a subject that has been already discussed by the author in his work on the Pacific. Here he wishes to emphasise the point that the behaviour of a polymorphous species represents, though on a far smaller scale, the behaviour of the primitive generalised family types that once ranged the globe. The successive stages in the differentiation of a world-ranging family 
type are regarded as a response to the stages in the differentiation of the conditions.

Although there are still primitive families, like the Compositoe, the Cyperacea, etc., that occupy most of the globe, there are others where differentiation has proceeded so far that the original family type is lost. The lost type is then only represented in the characters that join together a number of families in a great plant-group, which, though they hold the world between them, respectively characterise different regions of it. There are several such alliances, and some are referred to in this connection in the author's Victoria Institute paper. Reference has already been made to the closely related families of the Primulacea and the Myrsinaceae that between them range the globe, the first in the temperate regions and the second in the tropics. A similar example is offered by the Geranial alliance, of which the two oldest families, the Geraniacexe and the Oxalidaceoe, divide the world between them, the first being most characteristic of the temperate zones and the last of the warmer regions of the globe. The great Scitamineous alliance illustrates the same principle in the warm regions of the world. Though there is no generalised type now known, we find it represented in the characters common to the four closely connected families that range over warm latitudes : the Zingiberaceo mainly in the Old World, the Cannaceo and Marantacece mainly in America, and the Musaceae fairly well shared between both hemispheres.

But the recognition of this principle is not always easy, especially in those cases where, as in the $\boldsymbol{P}$ andanaceo, we have a family restricted to the tropics of the Old World with no very near relations in the New World. Though kindred families are not altogether wanting, it would be justifiable to presume that the families originally associated with it disappeared long since in the differentiating process. Where special influences have been at work rapidly disguising the characters of the primitive family, as in the case of the alliance of the insectivorous families, Sarraceniaceo, Nepenthaceo and Droseraceo, it would seem that a wide gap must separate them from families of the same parentage that never acquired this habit. It would not appear that we could establish any direct connection between the cosmopolitan Droseracexe as the mother family and the closely related American Sarraceniacea and Asiatic Nepenthacea as the offspring.

In the family, in the tribe, in the genus, in the species, and in the variety and local race, we see the same principle at work; and to illustrate it we will draw nearly all our examples from the same plant-type. We see it in the fact that the Geraniacea which has given its name to an alliance of families, still holds most of the area of the primitive world-ranging type. We see it in the behaviour of the tribes within the family. Here the tribe Gerania, which comes nearest to the primitive form, has by far the greatest range, covering as it does nearly the entire area of the family. We see it in the genera of this tribe, where Geranium, the most primitive of all, the genus that lies farthest back in the line of descent, is the genus most widely distributed, occupying as it does nearly the range of the tribe. 
We see it again in the species within a genus; but in a large genus like Geranium, which holds about 270 known species and has been subdivided by Knuth in his monograph in the Pflanzenreich series into thirty sections, we are restricted by the plan of that work to an appeal to the sections. Small genera are best suited to illustrate the principle, and in my book on the Pacific it is discussed in the case of Dodoncea, Metrosideros, and several others. However, its operation within the sections of Geranium is often clearly exhibited. In such cases the parent species, or the type around which the other species group themselves, is highly variable, and has the largest range, covering the whole or the greater part of the area held by the section.

Lastly, we see this principle at work within the limits of a species, and it is especially well exhibited in the varieties and local races of some of the species of Geranium. Thus, there are species which, whilst possessing a number of local varieties or races, have a parent form that includes within its range all the homes of the varieties and races. The behaviour of G. mexicanum, as indicated in Knuth's monograph, is very typical. It has the range of the section Mexicana, to which it belongs, all the other species of the section being confined to limited areas. It has a number of local forms, all of which group themselves around a variety that has the range of the species.

Antiquity and Change.-There is not infrequently an obsession in these matters that time goes with change; and we are now and then apt to look upon some highly differentiated and rare plantorganism as far more ancient than some simple plant-type that abounds around us. This is a dangerous view to hold respecting family types, concerning which it can be contended with much better reason that the contrast is merely a matter of varying rates of differentiation. The scores of American genera of flowering plants that have remained unchanged since Cretaceous and early Tertiary times show clearly enough that antiquity by no means connotes change. The only valid explanation of the fact that in one continent a family may be more differentiated than in another, that is to say, that it is farther from the family type, is to be found in the more rapid operation of the process.

Whilst we should expect to find a primitive family represented on all the larger continental tracts, the absence of some of the derivative families springing from the primitive type is often to be looked for. The differentiation theory takes the world as it is. If we find an explanation of the almost exclusive possession by South America of the Tropceolacea (one of the Geranial alliance) in the relative isolation of that continent, it would surely be inconsistent to postulate, as Knuth does (p. 38), a connection between South America and South Africa in order to account for the occurrence of Geraniacece in both continents. We must begin with the universal distribution of the primitive parent type of all the families of the alliance, and allow the extent of the differentiation to be determined by the arrangement of the land-masses and their internal conditions. The earlier stages of the process of change would be on similar lines, whilst the later changes would diverge widely. 
The Australian Flora.-To illustrate the argument reference may be made to the Australian flora, where we find world-ranging families with a special Australian impress, such as the Leguminosa and the Proteaceoe, associated with families of later development and of purely Australian origin which represent, as in the Goodeniacea, a regional modification of a primitive widely distributed family type, the modification of which has been so extensive that the connections with the other descendants of the same family type in other parts of the world have been lost in the differentiation process. After I had elaborated this argument in some detail for this chapter I found that the whole matter had been treated on similar lines, but on a far more extensive scale, by Mr. E. C. Andrews. Working in Australia, with abundant material at his disposal and with the willing aid of some of the foremost of Australian botanists, he has endeavoured to co-ordinate the evolution of the Australian flora with the development of the physical conditions, and it is with his papers on this subject that I will now deal.

Mr. Andrews had for years devoted himself as a geologist to unravelling the history of Australia as a land-mass, and he found in the development of the present land-forms and in the conditions in which they were produced a key to the various stages in the building up of the island continent. Whilst thus engaged, his attention was drawn to a remarkable relation existing in New South Wales between the arrangement of the purely Australian and extra-Australian plants and the physical, geological and climatic features of the region. This led him to reflect on the manner in which the Australian flora as a whole had responded to the different stages in the development of the continent, and he was induced to look to the Myrtaceae and Leguminosa as orders especially well fitted for the investigation of this subject.

In December 1913 his paper on "The Development of the Natural Order Myrtacex" was issued in the Proceedings of the Linnean Society of New South Wales. For him in this paper the predominant influence in plant-evolution has been neither Time, nor Heredity, nor Variation, nor Selection, but geographical environment. The evolution of floras represents the response of plant-life to variations in climatic and soil conditions during ages of changing geographical surroundings. Taking the position that cosmopolitan and genial climates at different geological periods tended to produce cosmopolitan or widely ranging floras, whilst variation in climate in the past tended to produce differentiated and localised floras, he applies this view to the differentiation of the Myrtacece from deduced generalised primitive forms of the Cretaceous age. It is argued that at this period the family, responding to the relatively uniform conditions of a mild and moist climate that prevailed over much of the globe, had a much wider range than it now has, and that it then covered the tropics as well as a large part of the present temperate regions.

The manner in which the primitive types differentiated in response to the differentiation of climatic and other conditions since the late Mesozoic is then indicated. The early types would become more and more restricted to the regions that preserved their original 
environment, that is to say, to the present tropical latitudes. With the marked diversity of conditions characterising the later periods, local differentiation of the floras took place in such regions as Australia and South America, which became more or less isolated from neighbouring tropical areas. The Myrtacea underwent " divergent transformations." The fleshy-fruited forms, which, as it is presumed, were nearest to the original types, became characteristic of the warm regions of the globe. Their characters were those common to the numerous genera to which they have given rise, the Eugenias, the Myrtles, the Psidiums, etc. The capsular-fruited forms mark a later adaptation of the fleshy-fruited types to less genial conditions, to poverty of soil and to aridity of climate. They are for the most part Australia's response to the influences working out the differentiation of the Myrtacea, and we see them now in the genera Breckia, Melaleuca, Eucalyptus, etc. In the successive differentiation of tribe and genus Australia, he holds, has played a great part in the history of the Myrtacea.

There has been no attempt here to summarise a paper which bristles with so many points that it is difficult to handle it. But not the least important part of it is that in which Mr. Andrews throws down the challenge with regard to the older determinations of Eucalyptus in the Cretaceous and Tertiary formations of the northern hemisphere. After pointing out that the history of Eucalyptus is conveyed in the two kinds of leaves which characterise the genus, the earlier opposite leaves telling a story of the warm genial climates that prevailed during the Cretaceous and Tertiary periods, and the later alternate leaves with twisted stalks one of subsequent adaptation to the harsher and more arid conditions of Australia, he observes that "it is exactly the later more or less xerophytic and unstable form which has always been reported as existing in the Cretaceous and Tertiary beds of the northern hemisphere, beds strongly suggestive of moist, genial climates." Mr. Deane's paper on the "Tertiary Flora of Australia" (Proc. Linn. Soc. N.S.W., 1900) is quoted in this connection, and we are referred to Mr. Cambage's presidential address before the Royal Society of New South Wales in 1913.

We have to face this objection, which, until it is sufficiently answered, will weigh heavily against our belief in the fossilised Eucalyptus leaves of the north. Yet it would not be antecedently improbable that Eucalyptus should repeat the story of two hemispheres, whether in the east and the west or in the north and the south, which is told in varying forms by Liriodendron, Liquidambar, Persea, Sassafras, Libocedrus, Sequoia, and other plants. When one reflects, as Wallace and many others insist, that ancient and once widespread groups may in our time maintain themselves only in a few widely separated localities, it is not easy for the west and the north to abandon their ancient claim to Eucalyptus.

In the following year (1914) Mr. Andrews issued a paper written on the same lines concerning the Leguminosa, a paper read before Section $\mathrm{E}$ of the British Association in August of that year and before the Royal Society of New South Wales in the following November, and here as in his paper on the Myrtacea he expresses his great 
indebtedness to Mr. R. H. Cambage. Like the Myrtacex, the Leguminosce are regarded as descended from a few uniform primary types widely diffused through the world in Cretaceous times and differentiating in later geological ages in response to the differentiation of conditions. We have here in geological time the same associated processes of differentiation of conditions and of differentiation of types. The Upper Cretaceous period, when the primary type had a wide range over the globe, was characterised by low-lying lands and by a mild, moist and genial climate extending from the tropics to the polar regions. Progressive differentiation of climate in later geological times, when high mountains, large continents, and great deserts came into existence, found a response in the differentiation of the types, many of them responding in the present temperate latitudes to the changes in their environment by the development of large and important groups of xerophytes, the evolution taking place along divergent lines in different regions.

In discussing the principles of distribution he lays stress on the probable great age in Australia of the "pantropical" genera and on the relative youth of the endemic genera. It is shown that in Australia the plants which respond to the xerophytic conditions that prevail there, such as the Eucalypti and the phyllodineous Acacice, have only in recent geological times assumed their present leaf-forms. They represent Australia's response in the differentiation of plant-types that were originally widely spread in the tropics; and the more recent development of such generic forms in comparison with their parent pantropical types illustrates a principle that has long been recognised as a corollary of the theory of differentiation. If the theory is true, this is its natural consequence; and the principle involved, namely, that antiquity does not connote change, has been already discussed in an earlier page of this chapter.

Mr. Andrews returns to the attack on those who would deny to Australia the right to the sole possession of Eucalyptus. "The evidence" (he says) "is overwhelming against the probability of any dicotyledonous genus which is endemic in Australasia having existed in any other continent in either Cretaceous or Tertiary time." $\mathrm{He}$ maintains, and this is a strong point, that if xerophytic types, like those of Eucalyptus, the phyllodineous Acacias, Banksia, etc., had gained access to the waste areas of the other southern land-masses, and particularly South Africa, they would have found a congenial home. His general position as regards Australia may be thus summed up. He would hold that whilst the endemic vegetation of Australia has been developed within its limits as the result of its special conditions, the source of its affinities with South Africa and South America must as a rule be looked for in the common home of the type in the tropies. Differentiation of types in response to differentiation of conditions is evidently, to use my own language, the bed-rock of the views advocated by Mr. Andrews. To employ his own words : "Traced backward far enough, geographical environment appears to be the key to evolution."

The Natural Order and Darwinian Evolution.- It follows from the foregoing remarks that no plant-groups, in the sense of the 
great orders, could have been produced on the evolutionary lines implied in the Darwinian theory. To lay down, as the evolutionist does, that the order of development begins with the variety, varieties diverging into species, species into genera, and genera into natural orders, is to reverse the method followed in nature, since it implies that the simpler, least mutable, and least adaptive characters that distinguish the great orders are the last developed. This could never have been. Nature has ever worked from the simple to the complex, from the general to the particular. Had she followed the lines laid down by the Darwinian school of evolutionists, there would be no systematic botany. All would be confusion. There would be no distribution in the sense in which the term is generally understood, and the plant-world would be a world of monstrosities.

In the differentiation of a generalised type by which natural orders break up into tribes, the tribes into genera, and the genera into species, our systematists have symbolised the process of progressive differentiation of conditions which has taken place in the physical world, and this is the result we should expect in a world where adaptivity reigns supreme. Though we signify our approval of these systems by our daily use of them, we employ language and adopt lines of reasoning that are utterly opposed to all that these systems of classification stand for. In these respects our practice and our theory are as far asunder as the poles-our practice good, our theories indifferent.

There lies beside me a very useful little book, written by a botanist of authority and intended for the use of students. In keeping with the teaching of the day, it is there explained how in the evolutionary process the natural order is built up by the varieties diverging into species, the species into genera, and the genera into groups of genera or orders, the species being taken as the unit of origin. Yet if we put this theory into practice in our plant-systems it would spell chaos. No typical natural order could be produced by such a method of evolution. The usual process of change in the plantworld, as in the physical world, has been from the general to the particular, and we should be quite as illogical in reversing the process for the plant as we should for its conditions.

Let the reader take a natural order and endeavour to build it up from one of its own species on the lines suggested by the evolutionist. With the goal before him of the generalised type of the systematist, his theory would desert him at the start. What he would attain, if he persisted in his plan, would be something very different from our natural orders, a highly specialised type of organism nearing its extinction. In these respects our practice belies our theory. Were it not so, our studies of the plant-world would be profitless indeed.

Yet it is not to be supposed that such a process is not in active operation in nature. Unfortunately for the systematist it is, and all the oddities in the plant-world are to be placed to its credit. But the point emphasised is that this is not the process that has given its impress to the plant-forms of the globe. We live in a differentiating rather than in a specialising world; and although specialisation is common enough, it is very far from being the prin- 
cipal determining cause of the diversification of plant-forms. Let us look a little further into this matter. Nature displays in the island and in the continent the two influences of specialisation and differentiation at work. We should look rather for specialised genera in islands and for differentiated genera in continents. In the first instance we have illustrated the Darwinian view, where a species becomes so modified that it is given a generic rank; but there is much evidence to show that this is a road which leads to extinction, the specialised genus having, as a rule, a limited range and a limited duration. In the case of the differentiated genus of a continent we have a broad range and a promise of eternity. It is of such that the plant-world was mainly formed in the past, is largely composed in the present, and will be made in the future. Specialised genera may figure conspicuously in localities; but their corpses strew the path that nature has chiefly followed in the development of the plant-world.

The great trouble is that we give the same value to products of very different origin and of very different standing; the one transient and limited in range, the other permanent and wide-ranging; the one representing nature's failures and the other her successes in stocking the world with its plants. Whilst specialisation means extinction, differentiation means a permanence of floral types that will hold the world as long as there are conditions for plant-life. Take, for instance, the monstrosities of the Tree Lobelias of Hawaii, of which some half a dozen genera have been developed in that group. They were born there and they will die there, and they have been unable to extend their range. These specialised genera make no effort to conquer the globe; yet we place them in a list of campanulaceous genera side by side with such a world-ranging primitive genus as Campanula.

It would seem that monographers of orders may create their own difficulties by not recognising this difference between specialised and differentiated genera in a family. All their difficulties begin when they try to bring them into line. The specialised genera should be set apart and treated independently.

\section{Summary}

1. The general nature and limitations of the differentiation theory are briefly discussed, and the author's connection with it is described. Stress is laid on his failure to recognise in his previous writings that although it explains the diversity of plant-forms there is much in distribution that it will not account for, distribution being also an expression of the influence of the arrangement of the continents during secular fluctuations of climate. The two subjects are accordingly individualised and treated separately, under the heads of Differentiation and Distribution, in this and the following chapter.

2. The differentiation of a world-ranging generalised family type is regarded as a response to the differentiation of originally uniform conditions. The existing families are viewed as primitive and widely distributed and derivative and relatively localised. It is considered 
that in the derivative families the process of differentiation has often proceeded so far that the original family type is lost, being only now represented in the characters uniting in one great plant-group a number of families, which, although they hold the world between them, respectively characterise different portions of it. In the family, in the tribe, in the genus, in the species, in the variety, and in the local race, we see the same principle at work, the process being illustrated in its last stage in the rôle of the polymorphous or highly variable species (pp. 313-14).

3. Whilst we should expect to find a primitive family represented in all the continents, the absence of some of the derivative families is often to be looked for. To illustrate the argument we may take the flora of Australia, where there are world-ranging families, bearing a special Australian impress, associated with families of later development and of Australian origin, which represent an extensive regional modification of a primitive world-ranging type that has been lost in the differentiating process (pp. 315-16).

4. In this connection attention is drawn to recent papers by Mr. E. C. Andrews on the development of the Myrtacea and Leguminosa with special reference to Australia. Adopting the view that the evolution of floras represents the response of plant-life to its physical environment during ages of changing geographical surroundings, he applies it to the differentiation of these two families from wide-ranging primitive forms of the Cretaceous period when relatively uniform climatic conditions prevailed. He challenges the correctness of the older determinations of Eucalyptus remains in the Cretaceous and Tertiary deposits of the northern hemisphere, and claims the genus as Australian-born (pp. 317-19).

5. With this digression the author goes on to show that if the differentiation hypothesis is correct no natural order could have been developed on the lines implied in the Darwinian theory, which, as interpreted in recent works, begins with the variety and terminates with the order, a process that reverses the usual method of nature (pp. 319-20).

6. Yet such a process, as is there implied, is common enough in the plant-world; but it accounts not for natural orders, but for all the oddities of plant-forms. It is here termed a specialising process in contrast with that of differentiation; but it is the differentiating process that has been the principal determining cause of diversification in plants (p. 320). 


\section{CHAPTER XV}

\section{DISTRIBUTION}

THE differentiation theory could of itself explain distribution only where a continuous land-area not affected by unstable climatic conditions is concerned. As our globe presents itself, three factors control and direct the operations of the differentiating agencies : (1) the divergence of the land-masses from the north; (2) the secular fluctuations of climate; (3) the barriers lying athwart the line of march of migrating plants.

(1) The Divergence of the Land-masses.-Although the differentiation theory explains the diversity of plant-forms, it does not of itself account for their present distribution. It might do so if this were a comparatively orderly world with stable climatic conditions, and if the plants had differentiated in situ over a continuous landsurface. But a uniformly constituted plant-world of this description does not exist, since differentiation is intensified as one recedes from the northern polar area, until in the southern lands of South America, South Africa, and Australia it displays its most pronounced effects. That floras become more and more dissimilar with distance from the pole is the result of the continuity of the land-masses in the north and their disseverment by broad oceans in the south. In other words, the continuity of the floras of the north and their discontinuity in the south represent the response of the plant-world to the arrangement of the great land-masses.

(2) The Secular Fluctuations of Climate.-If the first factor alone prevailed, distribution would not be such a very complex matter, since we could express it as the effect of the differentiating process controlled by the divergence from a common centre in the north of the great land-masses of the Old and the New World. But in so doing we should be ignoring a very important disturbing factor, namely, the secular climatic changes. During much of geological time there have been fluctuating conditions of climate which have produced a series of advances and retreats to and from the north polar area of the plants of the warm regions of the globe, regions that have ever been the great home of plant-life.

At a time when a genial climate prevailed over the northern or land hemisphere the plants now represented in type in the warm latitudes occupied the regions beyond the Arctic circle. When this period gave place to cooler conditions the retreat to the south began; and the plants, as the diverging continents pulled them more and more asunder, became more and more distinct from each other as a 
result of the varying differentiating influences of the hemispheres of the east and the west. When the warm conditions returned, the plants advancing northward met again in the common gatheringground around the pole, but modified by their different experiences in southern regions lying oceans apart. There they mingled together, the eastern and the western floras; and when with the next climatic change they began again to retreat to their ancient home in the warm latitudes of the south, the east had borrowed from the west and the west from the east. The secular climatic changes have, therefore, tended in this way to mix together the floras of the globe.

(3) The Barriers athwart the Course of Migrating Plants. -But another factor has intervened to disturb the effect of the influence of the divergence of the land-masses and of the secular fluctuations of climate on the operation of the differentiating agencies. The contrast between the plants of the eastern and western hemispheres may be, and has been, intensified in an irregular fashion by the presence in one and the absence from the other of obstacles in the line of retreat. During their sojourn in the north a huge Himalayan range, or a large Mediterranean sea, or a great Sahara desert, may have been developed and lie athwart their line of march; or a lofty Cordillera, running with the meridian almost from pole to pole, may aid the migration between the north and the south. But always there will have been the great preponderance of land in the north, and always those two great diverging land-masses of the east and the west, ocean-parted in the south and meeting in the north. Thus the distribution of plants may now be expressed as the effect of the operation of the differentiating agencies under the control and direction exercised by the divergence of the land-areas from the north and by secular fluctuations of climate, the resulting migration of plants to and from the north being checked or aided in different degrees by the surface-configuration of the continents.

The Views of Sir W. T. Thiselton-Dyer.-How the author came to recognise that distribution is something more than the work of the differentiating and dispersing agencies is stated in a later page. But it should be at once observed that the controlling influences, as above described, are those which Thiselton-Dyer has for years emphasised in his writings on distribution. Hooker's and Bentham's well-known views on the spread of the Scandinavian flora over much of the globe acquired increased significance in the author's mind when employed by Thiselton-Dyer in his essay in Darwin and Modern Science, as illustrating a general principle applicable to plant-distribution in geological time.

Distribution, a Problem of the Northern Hemisphere.-In the following pages the present author has endeavoured to give in his own words the views stated by Thiselton-Dyer in this essay. In the tropics, which have ever been the great home or " the area of preservation" of plant-life, the continents are separated by broad oceans. In the extreme north, where a permanent home has been rendered impossible through climatic conditions, the continents meet. With the land mostly in the north and the sea mainly in the south, 
with huge land-masses radiating southward and wide oceans stretching northward, distribution becomes chiefly a problem of the north. We cannot get over this fact by raising problems in the south. They could only be subsidiary. The increasing differentiation of floras with distance from the Arctic pole leave us no choice in the matter. It cannot, therefore, be a subject for surprise that of the great landmasses of the south each tells its own story, and that the discontinuity between genera and species, so frequent in the south, diminishes as we approach the Arctic area.

Any theory of distribution will have to explain the abandonment of share in the struggle on the part of whole groups of plants and animals that found a sanctuary long ago in the southern lands of South America, South Africa, and Australia. It will have to face the fact that these three extremities of the great land-masses diverging from their common centre in the north have become for plants and animals " cul-de-sacs," as Thiselton-Dyer terms them, from which there is no escape. It will have to explain why South America, South Africa, and Australia have become the abodes of lost causes, of causes that have been fought for and lost in the north.

The Zoological Standpoint.-Zoologists have often appealed to the hypothesis of a north polar centre of dispersal in explanation of their difficulties. Dr. Scharff, in his recent work on The Distribution and Origin of Life in America (pp. 23, 427), refers in this connection to the views of Allen, Dahl, Haacke, Tristram, and Wilser, only to reject them as untenable. "There have been" (he contends) " scores of great centres of dispersal in the world, and from them streamed forth new forms in every available direction. Northern animals advanced southward and southern forms northward, aided, no doubt, by the ever-changing conditions of climate and the gradual evolution of oceans and continents."

Yet, if we allow for the occurrence of subsidiary centres, it can be scarcely said that these views are radically inconsistent with those advocated in these pages. Standing by themselves they can hardly do other than make the investigation of distribution a study of tangled results which may lead us anywhere. The method of reconstructing the land-surface from the facts of distribution is the least promising of all the modes of attacking the problem. The opposite plan is here followed. The very thoroughness of Dr. Scharff's work appears to me to emphasise the hopelessness of ever solving problems of distribution by taking up the ends of the tangled skein. We must begin with a few general and simple premises that are beyond dispute, and work forward. Working backward seems to be the method least likely to evoke order out of the reigning chaos, and for one among many reasons that we do not yet know the real significance of many of the lesser facts of distribution, being often utterly at variance with one another in our interpretation of them.

The Geological Standpoint.--Let us for the moment forget much about distribution, and start with the fact that there existed in Tertiary times in the Arctic regions a subtropical climate and a subtropical vegetation. Let us add to this the second fact that this vegetation is not to be found within the Arctic Circle now, but in 
southern regions separated by broad oceans from each other. Let us connect with these two facts a third, that this migration south has been associated with a secular change from warm to cold climatic conditions. The conclusion to which they inevitably lead is rejected by Dr. Scharff in the case of animals (p. 428) mainly on account of the absence of geological evidence. But we have the geological records on our side for the plants; and if we hold the belief that the great change both in climate and in flora which has come over the north since Tertiary times has been repeated in the earlier ages of the world's history, we stand on much safer ground than if we were to assume that we are here face to face with a change unprecedented in the story of our planet. We are not concerned with the north polar regions as an evolutionary centre, but as the great mixing ground through the ages of the plants of the eastern and western hemispheres.

Discontinuous Distribution.--Let us glance at the facts of discontinuous distribution. Whether we take a genus (A) which, although represented in the Tertiary deposits of the common meeting ground of the continents in the north, is now divided by the oceans in the south, or a genus (B) that is now hopelessly sundered and isolated in tropical regions and has, as far as is yet known, left no trace of its original existence in the north, or a genus (C) that is now restricted in the main to the continents of the temperate latitudes of the south, the lesson is the same. For discontinuity forms the essence of the problem, the error lying in treating extreme cases, like that of Ravenala, as things apart that require a special explanation. Such cases raise not side-issues, but the main question, the whole history of distribution being concerned with the effects of discontinuity increasing with distance from the north polar area.

The simplest cases of discontinuous distribution are those illustrated by such genera as Quercus, Fagus, Acer, Juglans, Tilia, etc., all represented in the Tertiary deposits of the extreme north, and now found on both sides of the great oceans to the south, reaching in some instances, as in that of Fagus, New Zealand and Fuegia. Less simple cases are those so frequently illustrated among tropical genera where the geological record, as at present known to us, is silent as to their original occurrence in the north. But it is legitimate to assume that the same principle has been at work here, and to infer with Thiselton-Dyer in his Philadelphia address that during the warm periods of the Miocene and earlier ages purely tropical types would have extended north to latitudes where the interchange between the Old and the New World would not be impracticable. The behaviour of Ravenala, which is represented by only two known species, one in Madagascar and the other in tropical South America, is repeated, though in a less striking degree, by numbers of tropical genera. We have, for example, Thespesia (Malvacea), mainly American and Malayan, and Mammea (Guttiferee), equally shared by the New World and Madagascar. Then there are Chrysobalanus (Rosacece) and Crudya (Leguminosa), which are chiefly American, two genera that are only known in the Old World from Africa and Malaya. Then there is Desmanthus, a leguminous genus, of which 
only one of the ten species occurs outside the New World, namely, in Madagascar. The number of genera mainly American which have one or two solitary representatives in the Old World is remarkable. Several remarkable cases of discontinuity could be cited from the tropics of the Old World. For instance, Canarina (Campanulacea) holds three species, found respectively in the Canary Islands, tropical Africa, and the Moluccas.

Whether in the family, in the tribe, or in the genus, discontinuous distribution is a familiar feature in the plant-world of the southern hemisphere. A very ancient history is implied in the representation of the Proteacece by different genera in Australia, South Africa, and South America. Students of fossil botany are persistent in claiming a home for the family in Europe and North America in Cretaceous and Eocene times; but Thiselton-Dyer, with much to gain from such a valuable witness on behalf of his views, does not accept the evidence. As an example of a tribe we may quote his reference to the Mutisiacea, a tribe of the Compositoe, characteristically southern in its distribution in South America, South Africa, and Australia. For the genera we may cite Libłocedrus and Podocarpus of the Coniferce. Both of them are indicated amongst the fossil Tertiary remains of Northern Europe and North America, the first-named even in Spitzbergen; and both reach extreme southern lands-in the case of Podocarpus, Southern Chile, South Africa, and New Zealand, and in that of Librocedrus, New Zealand and Chile.

In the foregoing remarks I have very inadequately illustrated the important subject of discontinuous distribution. Many of these genera are now restricted to tropical regions, and the geological record, as so far interpreted, tells no story of a sojourn in the north. But many of the genera of trees now confined to temperate latitudes of North America and Eurasia grew in Miocene times within the Aretic Circle, and the implication is that in the case of the dissevered tropical genera they also long ages ago were denizens of the north. The history of Sequoia, now restricted to California and its vicinity, but growing in Tertiary times in Arctic latitudes around the pole, is the story of a genus that has failed. So also there may have been a similar failure with some of the tropical genera that are now found in only one of the two hemispheres, either in the Old or in the New World.

The Centrifugal Dispersion from the North DURing the LAST ICE AGE.- The associated processes of centrifugal dispersion from the north and of differentiation with distance from the pole are well described by Prof. Harshberger in his Phytogeographic Survey of North America (p. 181); but he limits its operation to the last of the great migrations that was connected with the Glacial Period. As the herd of glacial plants moved south from the far north into each one of the continental masses, America, Europe and Asia, they were subjected (thus he writes) to a great variety of conditions, "the outcome being great differentiation of form and the development of new species." This dispersion from the north during the last great Ice Age has been the theme of Darwin, Asa Gray, Bentham, Hooker, and many other eminent men of science, a fact to which allusion will again be made at the close of the chapter. 
Application of the same Principle to Geological Time.-It is, however, the feature of the theory advocated by Thiselton-Dyer that this process of differentiation during the centrifugal dispersion of plants from the north has affected not merely one migration from the polar area, but those of all geological periods during which the land-masses have preserved the main characters of their present arrangement. Thus he would extend it to the Mesozoic Conifers, and even suggests it in the case of the Glossopteris flora of PermoCarboniferous times. There is this to be said, however, in this last connection, that we here open up questions relating to the Antarctic continent, which Seward, in his recent monograph on the fossil plants collected during the recent expeditions, believes to have been the centre of the differentiation of the Glossopteris flora (see Brit. Mus. publications, 1914). But the occurrence of this flora in the Upper Palæozoic beds of Russia and Siberia has been established, and there is something to be said in support of Thiselton-Dyer's contention in his Philadelphia address that " an economy of hypothesis is best served by assuming a northern origin and a dispersal southward than by calling into existence a vast territory from the Indian Ocean."

The Views of some Australian Naturalists.-A view, which is the very opposite of that advocated by Thiselton-Dyer is held by some Australian naturalists, who consider that " the community of austral life is explicable only by former radiation along land-routes from the south polar regions." Hedley, whose important paper on the palæographical relations of Antarctica is here quoted (Linn. Soc. Lond., June 1912), calls as witnesses two genera, Fagus and Araucaria, the distribution of which in the past and in the present is usually regarded as indicating their home in the north. Fagus and Araucaria, however, cannot be treated together in this connection, the first named belonging to the age of the Angiosperms, the second to the Mesozoic Conifers. Though Antarctica apparently does not share in the history of the plant-world since the appearance of the Dicotyledons in force in the Upper Cretaceous age, it took a part in the earlier periods, and whilst prevented from figuring in the history of the Angiosperms, it may have preserved a record of world-ranging Conifers.

Let us take the case of Araucaria. In his Philadelphia address Thiselton-Dyer observes that if we go back to the Jurassic age, and turn to Coniferæ, the structures of which lend themselves to recognition in the fossil state, "we find in Araucaria, a genus now represented by a few species in both divisions of the southern hemisphere, abundant evidence that it was once widely dispersed in the northern." In this connection one may remark that four species of Araucaria are included in Knowlton's list (quoted by Harshberger, p. 176) of Cretaceous and Tertiary plants of North America known up to 1898. In the case of Fagus it will be sufficient to note that eleven species are referred to it in the list of fossil North American plants just mentioned. But the linking together of this genus with Araucaria in support of the Antarctic hypothesis raises another point. One might admit the presence of a Mesozoic flora of Conifers in the 
Antarctic continent without committing oneself to the view that Antarctica was a Tertiary abode of the flowering plants. Before quitting this subject it may be added that Mr. Hedley's treatment of the matter is mainly zoological, and that his arguments can only be fairly met in their complete form by one who is similarly skilled as a zoological investigator.

Re-statement of the Views of Sir W. T. Thiselton-Dyer.The position adopted by him in his contribution to Darwin and Modern Science may be again stated before we bring this chapter to a conclusion. He contends that by postulating the permanency of the general configuration of the earth's surface, and by assuming that fluctuating conditions of climate have supplied an effective means of propulsion from the north, a continuous and progressive dispersal of species from the land-centre in the north polar regions is inevitable. One may extend these remarks and say that if it can be shown, as undoubtedly the general trend of the facts of distribution does show, that the divergence of plant-types responds to the divergence of the great land-masses from the north and that dissimilarity is intensified with distance from that pole, any evidence for a Tertiary Antarctic centre for the flowering plants would be discounted in advance. On this view the plant-types most differentiated would be those that had met most rarely in the common gathering ground of the north; that is, those of the tropics and of the southern hemisphere.

It was the recognition by Bentham and Hooker of the continuous southward migration of the Scandinavian flora over a great part of the globe that supplied the key for this interpretation of distribution; and it was, as Thiselton-Dyer remarks, from the geological researches of Heer that it received early powerful support as a general explanation of the geographical distribution of plants. Long ago, as is again shown, Asa Gray held that the preservation of fragments of the Cretaceous flora in Asia and America had its explanation in their having had a common source in the north. As shaped and promulgated in Darwin and Modern Science this theory removes more difficulties from the path of the student of distribution than any previous hypothesis. But it does even more, since in clearing the road it opens a field of investigation which will take many years to explore. How distribution may appear when regarded from this standpoint is exemplified in the comparative study of Carex and Sphagnum in the next chapter.

\section{Summary}

1. The differentiation theory could of itself explain distribution only where a continuous land-area not affected by unstable climatic conditions is concerned. As our globe presents itself, three factors control and direct the operation of the differentiating agencies : the divergence of the land-masses from the north, the secular fluctuations of climate, and the barriers lying athwart the line of march of migrating plants. The effect of the first is seen in the increasing differentiation of floras with distance from the pole, that of the 
second in the migration of plants to and from the common meeting ground of the eastern and western floras in the north, and that of the third in its isolating influence varying in degree on the South American, South African, South Asian, and Australian floras (pp. 323-4).

2. The views of Thiselton-Dyer are here adopted. They embody those of Bentham, Hooker, and Asa Gray in a general principle applicable to plant-distribution in geological time. From this standpoint distribution becomes a problem of the northern hemisphere, and we cannot get over this fact by raising problems in the south (pp. 324-5).

3. After remarking that zoologists have often appealed to the hypothesis of a north polar centre of dispersal, it is observed that the method of reconstructing the land-surface from the facts of distribution is the least promising of all modes of attacking the problem. The geological record is on the side of the views adopted in this chapter; and if we hold that the great change in climate and in flora which has come over the north since Tertiary times has been repeated in the earlier ages of the earth's history, we stand on much safer ground than if we assume that we are here face to face with a change unprecedented in the story of our planet (pp. 325-6).

4. It is observed that discontinuous distribution, which is then briefly dealt with, is the essence of the problem; and it is remarked that the error lies in regarding extreme cases, like that of Ravenala, as requiring special explanation (pp. 326-7).

5. The important feature of centrifugal dispersion from the north is again alluded to, in order to emphasise the point that the southward migration generally recognised as resulting from the last glacial period illustrates a principle that has been in operation through the ages. The opposing view, which is supported by some Australian naturalists and has been very ably advocated mainly on zoological grounds by Hedley, is then discussed. It holds that the community of austral forms of life is the result of radiation along former landroutes from the south polar region (pp. 328-9).

6. A restatement of the position adopted by Thiselton-Dyer is then given, and it is urged that his views remove more difficulties in the study of distribution than any previous hypothesis (p. 329).

\section{LIST OF SOME OF THE WORKS QCOTED IN THIS AND IN THE PRECEDING CHAPTER}

Andrews, E. C., The Development of the Natural Order Myrtaceæ, Proc. Lirn. Soc. N.S. Wales, December 1913.

The Development and Distribution of the Natural Order Leguminosæ, Journ. Proc. Roy. Soc. N.S. Wales, November 1914.

Cambage, R. H., Presidential Address, Roy. Soc. N.S. Wales, 1913.

Acacia Seedlings, Proc. Roy. Soc. N.S. Wales, July 1915.

Dyer, W. T. Thiseltor-, Geographical Distribution of Plants, Seward's Darrin and Modern Science, 1909.

On the supposed Tertiary Antarctic Continent, Journ. Acad. Nat. Sci. Philadelphia, XV., ser. 2, 1912. 


\section{DISTRIBUTION}

GUPPY, H. B., see list at the commencement of this volume.

Harshberger, J. W., Phytogeographic Survey of North America: Leipzig and New York, 1911.

Hedlex, C., The Palæographical Relations of Antarctica, Proc. Linn. Soc. Lond., 1911-12.

ScharfF, R. F., Distribution and Origin of Life in America, 1911.

Seward, A. C., Antaretic Fossil Plants, Brit. Antarc. Exped., 1910 : Nat. Hist. Rep., British Museum (Nat. Hist.), 1914. 


\section{CHAPTER XVI}

THE INFLUENCE OF THE DIVERGENCE OF THE CONTINENTS ON THE DISTRIBUTION OF SPHAGNUM AND CAREX

THE predominance of Sphagnum on the middle slopes of Pico and on the higher parts of San Miguel and Terceira in the Azores first directed my attention to the distribution of Peat-mosses. Whilst subsequently studying the matter in Warnstorf's recent monograph on the Sphagnacea (Das Pflanzenreich, 1911), I became much impressed with the fact that the Sphagnum floras of the eastern and western hemispheres became more and more unlike as one receded from the Arctic regions. This led me to realise that I had completely ignored in my previous inquiries one of the most important factors in shaping distribution, namely, that concerned with the divergence of the two great land-masses of the globe from the north polar area.

From the Peat-mosses I turned to the Carices, another worldranging group of plants, and from them received the same reply. It came as a surprise to me that two groups, so far removed from each other in the scale of plant-life and differing so greatly in their capacities for dispersal, should respond in the same way to the arrangement of the two great land-masses of the Old and the New Worlds. It was a relief to learn that some months had not been spent in vain in the comparison of dissimilar things. From the standpoint of distribution their behaviour proved to be the same, the differences being only in degree. But perhaps the most welcome revelation of all was that many of the difficulties associated with the distribution of the higher plants, such as concern insular floras and the floras of South America, Africa, and Australia, reappeared, though in a less intense form, in the distribution of the humble Peatmosses. Such uniformity of behaviour, independent as it is of degree of organisation and of dispersing capacity, deeply impressed me, and led to my reading over again Dyer's essay in Darwin and Modern Science on the geographical distribution of plants, the result of which is shown in the preceding chapter.

Both Sphagnum and Carex respond to the same Law but in Different Degrees.-From the tabulated results for Sphagnum and Carex given below, a few general inferences may be drawn. In the first place, both groups of plants respond to the law involved in the increase of dissimilarity between the east and the west as one recedes from the Arctic regions, their differentiation intensifying with the divergence of the land-masses from the north. Another 


\section{DISTRIBUTION OF SPHAGNUM AND CAREX 333}

Table Illustrating the Effect of the Divergence of the Land-masseg from the North Polar Area on the Distribution of Sphagnum and CAREX.

(The limits of the regions employed are as follows:-As Arctic and Subarctic are included Scandinavia, North Russia, Siberia, Canada, Labrador, and lands north; as Temperate, the rest of Europe and Mediterranean Africa, extra-tropical mainland of Asia excluding Japan, North America between Canada and the subtropical region next described; as subtropical North American, Georgia, Florida, the Gulf States, and Mexico; as South American, the mainland only, Central America and the West Indies being excluded; as African, all except the Mediterranean province; and as Australian, also New Zealand and Tasmania.)

\begin{tabular}{|c|c|c|c|c|c|}
\hline & \multirow[t]{2}{*}{ Regions } & \multicolumn{2}{|c|}{$\begin{array}{l}\text { Percentage of Species } \\
\text { occurring in both } \\
\text { the East and West } \\
\text { Hemispheres }\end{array}$} & \multirow{2}{*}{\multicolumn{2}{|c|}{$\begin{array}{l}\text { Data and Remarks } \\
\text { (The denominator of the fraction } \\
\text { equals the total number of species in } \\
\text { that region. The numerator equals } \\
\text { the number occurring in both hemi- } \\
\text { spheres) }\end{array}$}} \\
\hline & & Sphagnum & Carex & & \\
\hline \multirow{4}{*}{$\begin{array}{l}\text { A } \\
\text { East and West } \\
\text { Hemispheres }\end{array}$} & Arctic & 100 & 80 & S. $\frac{22}{22}:$ C. $\frac{42}{53}$ & \\
\hline & Subarctic & 89 & 29 & S. $\frac{46}{52}:$ C. $\frac{60}{211}$ & \\
\hline & $\begin{array}{l}\text { Temperate lati- } \\
\text { tudes }\end{array}$ & 59 & 11 & S. $\frac{51}{87}:$ C. $\frac{54}{502}$ & \\
\hline & $\begin{array}{c}\text { South America, } \\
\text { Africa, Australia }\end{array}$ & 2 & 4 & S. $\frac{3}{180}:$ C. $\frac{6}{175}$ & $\begin{array}{l}\text { Africa and Australia } \\
=\text { East Hemisphere }\end{array}$ \\
\hline \multirow{4}{*}{$\begin{array}{c}\text { B } \\
\text { West } \\
\text { Hemisphere }\end{array}$} & $\begin{array}{l}\text { Arctic and Sub- } \\
\text { arctic }\end{array}$ & 90 & 52 & S. $\frac{46}{51}:$ C. $\frac{102}{195}$ & \\
\hline & $\begin{array}{l}\text { Temperate lati- } \\
\text { tudes }\end{array}$ & 70 & 24 & S. $\frac{52}{74}:$ C. $\frac{54}{221}$ & \\
\hline & $\begin{array}{c}\text { Subtropical North } \\
\text { America with } \\
\text { Mexico }\end{array}$ & 34 & 11 & S. $\frac{12}{35}:$ C. $\frac{7}{62}$ & \\
\hline & $\underset{\text { mainland }}{\text { South American }}$ & $3(5)$ & $8(16)$ & S. $\frac{3}{110}:$ C. $\frac{6}{79}$ & $\begin{array}{l}\text { South America is here } \\
\text { compared as before } \\
\text { with Africa; but if the } \\
\text { Eurasian species are } \\
\text { inciuded, the percen- } \\
\text { tages would be in- } \\
\text { creased as indicated } \\
\text { by the figures in } \\
\text { parentheses. }\end{array}$ \\
\hline \multirow{5}{*}{$\begin{array}{c}\text { C } \\
\text { West } \\
\text { Hemisphere }\end{array}$} & Arctic & - & 93 & $\frac{42}{45}$ & \multirow{5}{*}{ Carex only } \\
\hline & Subarctic & 一 & 40 & $\frac{60}{150}$ & \\
\hline & $\begin{array}{l}\text { Temperate lati- } \\
\text { tudes }\end{array}$ & - & 24 & $\frac{54}{221}$ & \\
\hline & $\begin{array}{l}\text { Subtropical North } \\
\text { America with } \\
\text { Mexico }\end{array}$ & - & 11 & $\frac{7}{62}$ & \\
\hline & $\begin{array}{l}\text { South American } \\
\text { mainland }\end{array}$ & - & $8(16)$ & $\begin{array}{l}6 \\
79\end{array}$ & \\
\hline
\end{tabular}

Note-The cases are very few where the species do not occur in corresponding latitudes in the two hemispheres. Since some of the species occur in more than one zone, the same species may figure more than once in the results for the northern hemisphere. In the southern hemisphere Africa and Australia together represent the eastern hemisphere. The South American results refer only to the southern hemisphere. If those held in common with Eurasia were added, the percentage would be increased as shown above. 
important principle is probably concerned in the fact that the more lowly organised Sphagna do not respond to the law to the same extent as the Carices. It may be that this arises from the greater capacity for dispersal of the spores of Sphagnum than the fruits of Carex; but all such advantages would, I think, be discounted in the run of the ages. If we look at the table we notice that the northern hemisphere is almost large enough for the complete differentiation of Carex, but it is too small for Sphagnum; and it would seem that the lower plants need a larger area for evoking the full effects of the differentiating process than the higher plants. It might even happen that the world is not large enough for a particular group of plants, and that a chaotic confusion of affinities in a geographical sense would arise which would disappear in a world twice the size. This involves the principle that lowly organised plants would be less plastic than higher plants in the same area, or, in other words, they would respond less to changes of conditions. The point that our world may not be large enough for the lower plants should not be forgotten, and some interesting deductions could be drawn from it.

It will be seen from these pages that free use has been made of the materials supplied by Warnstorf and Kükenthal in their monographs in the Pflanzenreich on the Sphagnaceoe and the Caricoidece. Buried deeply in the mass of data contained in this splendid series of publications there lies the romance of plant-distribution, which the diligent student can unearth, should he possess the inclination and the patience. If any success attends my efforts to present as illustrating real living problems the facts so laboriously collated by the German investigators, I shall have paid back a little of my debt to the authors of these monographs.

Explanation of the Table.- Though the table is mainly selfexplanatory, it should be remarked that the materials as arranged in the monographs do not always lend themselves for precisely the same treatment, which explains the varying treatment in the columns. In the first place (A) all the species of North America and Eurasia are dealt with, excluding those of the subtropical and tropical zones. In the second and third places (B and $\mathbf{C})$ only those of the west hemisphere are utilised.

The insular factor comes so much into operation in the northern tropics, and there are so many disturbing influences affecting a comparison between the tropical mainlands of the east and the west in the northern hemisphere, that, except in the mainland of North America, the warm latitudes have been disregarded. Islands, large and small, introduce the effects of isolation in a way not presented by a continent; and the disturbing influences of the insular factor are again referred to in a later page of this chapter. The necessity of excluding the island from this table is well exemplified in the case of Sphagnum. If we were to include Japan in the Eurasian region and the Malagasy province in Africa, we should find that half of the endemic Eurasian species (thirty-three in all) did not extend outside Japan, and that one-third of the African endemic species (fortyseven in all) are restricted to Madagascar and the Mascarene Islands. 
The general principle that the farther the continents recede from the north the fewer are the species common to the east and the west is strengthened by including in the table South America as representative of the west hemisphere and Africa and Australia with New Zealand as representatives of the east. But numerous other considerations arise; and in fact the subsequent discussion is mainly occupied with the distribution of Sphagnum and Carex in the southern hemisphere. Here, since the source of these floras is one of the principal points dealt with, the islands are often permitted to tell their story.

Comparison of the East and West Hemispheres in the North. - It is legitimate, in a sense, to compare the endemism of the large land-masses of the southern hemisphere, South America, Africa, and Australia, since they are widely separated and independently situated; but it would be worse than useless to contrast the great land-masses of the north in their entirety, diverging as they do from a common centre in the polar area. I will take the case of Sphagnum. In the combined area of the North American and Eurasian landmasses there are, excluding the islands, 110 species, of which fiftythree are found in both hemispheres. A little consideration will show that the mere statement that 48 per cent. of the North American and Eurasian species are held in common, however true it may be, becomes pointless after an analysis of the details of distribution. Thus, of the fifty-three species held in common, forty-six are Arctic and Subarctic species, and twenty-two are practically circumpolar. Since, therefore, the species held in common between Eurasia and North America mostly congregate in the north, we would expect that the species held separately by these two great land-masses would gather in the south. This is indeed the case. Of thirty-nine species confined to North America, only two are found in Subarctic latitudes. The rest belong to the south, being especially numerous in the Southern United States. Warnstorf, who had no theory to support, is emphatic on this point. Whilst, as he says (p. 38), there is great agreement between the species of the Arctic, Subarctic, Atlantic, and Pacific regions of North America and Europe, in the Southern States of the Union and in tropical America endemism prevails. The rule in North America that the species it holds in common with Eurasia belong to the north, whilst those peculiarly its own belong to the south, is also illustrated in Eurasia. Of the seventeen species restricted to that continent only one is found in the cold latitudes of the north.

It would be equally futile in the case of the Carices to employ any common value when contrasting the endemism of Eurasia and North America. This is sufficiently illustrated in the fact that the number of species which North America shares with Eurasia gradually decreases from 93 per cent. in the Arctic latitudes to as little as 11 per cent. in the Southern United States and in Mexico.

The Connections of the South American Sphagnum and Carex Floras.- The parallelism between Sphagnum and Carex is strikingly illustrated in the case of the connections of South America with the rest of the globe. In both genera the predominance of North 
American species tells a story of the stream from the north; and, since nearly all of them are also Eurasian, we find a noticeable proportion of Old World forms amongst the species migrating south. In both there is a connection with Africa of the slightest kind. In both also there is apparently an Australian and a New Zealand connection.

The links of South America with the outside world, as exemplified by the Peat-mosses and the Carices, are here tabulated in a general way. There are about 110 species of Sphagnum and rather over eighty species of Carex known from this continent, of which in the first case eleven species and in the second case twenty-nine species occur outside it. Since the same species is usually recorded from more than one region, the totals here given exceed the number of species concerned.

The Distribution of the non-Endemic Sotth American Species of SPHAGNUM (11) AND CAREX (29)

\begin{tabular}{|c|c|c|c|}
\hline & Sphagnum & Carex & \\
\hline North America & 7 & 18 & \\
\hline Eurasia & 6 & 11 & $\begin{array}{l}\text { Sphagnum-6 in Europe, } 4 \text { in Asia. } \\
\text { Carex-10 in Europe, } 11 \text { in Asia. }\end{array}$ \\
\hline Central America & 5 & 11 & \\
\hline $\begin{array}{l}\text { Australia and New } \\
\text { Zealand }\end{array}$ & 2 & 6 & \\
\hline Africa & 1 & 1 & $\begin{array}{l}\text { The Sphagnum species occurs in } \\
\text { Central Africa. The Carex species } \\
\text { occurs in South Africa. }\end{array}$ \\
\hline
\end{tabular}

The facilities offered to migration from the north to the south by the great mountainous backbone of the western world and the results arising have often supplied themes to the botanist. An almost unbroken chain of mountains and highlands, connecting Arctic and Antarctic lands, is to be found in the American continent, and there alone on our globe. The only break of importance in this great continuous mountain chain lies, writes Harshberger (p. 191), in the Isthmus of Panama, where there is a distance of about 300 miles occupied by rugged forest-clad hills, between the lofty peaks of Veragua and the northern extremity of the Andes in New Granada. We should accordingly expect, as this writer proceeds to say, that this great chain would form the most effective agent in aiding the southward migration of the Arctic and north temperate vegetation. In other words, the plants of the north would have often followed this route southward along the lofty mountains and elevated uplands; and "we do find," as the same author continues, " not only that a large number of northern genera and many species are scattered along this route, but at the end of the long journey, in Southern Chili and Fuegia, they are found in numbers sufficient to form an element in the 


\section{DISTRIBUTION OF SPHAGNUM AND CAREX 337}

flora of those countries." Doubtless birds have played the principal part in the dissemination of species along this route; but the highlands of the Greater Antilles evidently serve as halting-places in the track of migratory birds across the Caribbean Sea. In his description of the dispersal of Uncinia by birds, which is quoted in Note 37 of the Appendix, Morris states that migratory birds on their way north and south between North and South America rest on the highlands of Jamaica at elevations of 5000 to 6000 feet above the sea; and so exhausted are they that they can be caught with the hands (Nature, December 16, 1886).

The Stream of Plants from the Far North down the Andes To CAPE Horn.- - The stream of species from high northern latitudes in North America down the Andes to Cape Horn is well illustrated both by Sphagnum and Carex. They are all species that are distributed round the pole in the Arctic and Subarctic regions, both of America and Eurasia. Half of the species of Sphagnum and a third of the species of Carex that have been found south of the Straits of Magellan, that is, in Fuegia, are thence derived. Whilst the main stream from the north follows the line of the Andes, the outside regions have caught the eddies; and, as in the case of Sphagnum in South Brazil, where only 3 per cent. of the species occur outside South America, the endemism is intense. Some of the principal conclusions here drawn with reference to the southward trend of Sphagnum and Carex in South America are exemplified in the following table; but naturally there is much that can be substantiated only by reference to the original memoirs of Warnstorf and Kükenthal.

Table illostrating the Concentration in the Southern Part of South America of ARCtic and Subarctic Species of Sphagnum and Carex that are both Eurasian and North American

\begin{tabular}{|c|c|c|c|c|c|c|}
\hline & \multirow{2}{*}{\multicolumn{2}{|c|}{$\begin{array}{l}\text { Total number of } \\
\text { known Species }\end{array}$}} & \multicolumn{4}{|c|}{ The North American and Eurasian Species } \\
\hline & & & \multicolumn{2}{|c|}{$\begin{array}{l}\text { Number and Per- } \\
\text { centage }\end{array}$} & \multicolumn{2}{|c|}{ Distribution in the North } \\
\hline & Sphagnum & Carex & Sphagnum & Carex & Sphagnum & Carex \\
\hline South America & 110 & 81 & $6=6 \%$ & $11=14 \%$ & \multirow{3}{*}{$\begin{array}{l}\text { Five species } \\
\text { are Arctic } \\
\text { and Sub- } \\
\text { arctic and } \\
\text { one is } \\
\text { Temperate }\end{array}$} & \multirow{3}{*}{$\begin{array}{c}\text { Eight } \\
\text { species are } \\
\text { Arctic and } \\
\text { Subarctic } \\
\text { and three } \\
\text { are Tem- } \\
\text { perate }\end{array}$} \\
\hline Andes only & 25 & 51 & $4=16 \%$ & $11=22 \%$ & & \\
\hline $\begin{array}{l}\text { Patagonian } \\
\text { Andes and } \\
\text { Fuegia }\end{array}$ & 8 & 30 & $4=50 \%$ & $11=37 \%$ & & \\
\hline
\end{tabular}

(A) As illustrated by Sphagnum.-Let us begin with the South American species of Sphagnum. Out of about 110 species, at present known, only six have been found outside the New World. They are $S$. fimbriatum, plumulosum, mexicanum, pulchricoma, torreyanum, and medium; and of these five are Arctic and Subarctic species, found in all cases both in Eurasia and North America. Four of them reach the Patagonian Andes, and three extend across the Magellan 
Straits into Fuegia. They may, like $S$. medium, follow the great mountainous backbone of the New World from the Arctic Sea to Cape Horn. This species after extending through the length of North America, from Alaska southward, reappears in the larger West Indian islands, and then travels along the Columbian, Bolivian, and Peruvian Andes at elevations of 10,000 to $\mathbf{1 1 , 0 0 0}$ feet, finally reaching Patagonia and Fuegia. Others, like S. fimbriatum, plumulosum, and torreyanum, may skip the tropical regions, and after leaving North America reappear in the Chilian and Patagonian Andes, or not present themselves again until they arrive in Tierra del Fuego. Some, like $S$. mexicanum, though they may not reach farther than the tropics of South America, exhibit a behaviour very suggestive of their future discovery far south. At home near the sea-level in Subarctic latitudes, this species attains an elevation of from 3000 to $\mathbf{3 5 0 0}$ feet in the West Indies and Central America, and altitudes of from 7000 to $\mathbf{1 0 , 0 0 0}$ feet in the Equatorial Andes.

(B) As illustrated by Carex.-All that has been said respecting the streaming of species of Sphagnum down the Andes from high northern latitudes can be paralleled in the case of Carex. Thirteen of the eighty-one species described as South American occur outside the New World. Of these eight are Arctic and Subarctic plants that are found in all cases in those latitudes, not only in North America, but: also in Eurasia. All of the eight have reached Patagonia and Southern Chile, and six have crossed the Magellan Straits into Fuegia; and it will be seen from the table that, as in the case of Sphagnum, these species from the far north form a considerable proportion of the Carex flora of Antarctic South America. Some, like C. macloviana, may travel with relatively little interruption from the shores of the Arctic Sea down the line of the Rocky Mountains to the Mexican highlands, where this species has been found at an altitude of 14,000 feet, and then along the Bolivian and Chilian Andes to Fuegia. Others, like $C$. goodenoughii, may extend in North America as far south as Colorado, reappearing in the southern tropics in Bolivia, before proceeding down the Chilian and Patagonian Andes. Some, like $C$. capitata, range southward from the North-West Territory down the Rocky Mountains, next appearing in Central America, and following the Argentinian and Patagonian Andes into Fuegia. But others, like C. microglochin, C. magellanica, and C. canescens, display great gaps in their passage south from high northern latitudes to the Fuegian islands, since they skip the tropics altogether and after following the Rocky Mountains to Colorado next appear in Patagonia and South Chile. The streaming southward is equally well illustrated by species confined only to the New World. Thus C. gayana, after following the whole trend of the Rocky Mountains from Canada to New Mexico, reappears in the Chilian Andes at elevations of 8000 to $\mathbf{1 0 , 0 0 0}$ feet before it crosses the Magellan Straits and enters Fuegia. Notwithstanding the gaps, which doubtless will in some cases be filled up by the future investigator, we have here suggestively illustrated the streaming of the Carices down the great backbone of the New World from the shores of the Arctic Sea to Cape Horn. 
The Connections between South America and the Australian REgION.- This discussion of the route followed by both Sphagnum and Carex in reaching Antarctic South America from high northern latitudes raises the question in both cases of the Australian and New Zealand connections with Fuegia and the Southern Andine region. In both some of the species have established themselves either in Australia or in New Zealand; and the point at issue is the significance of this fact.

We will first take the case of Sphagnum. Two species that have reached Fuegia from Arctic and Subarctic latitudes, namely, S.medium and $S$. fimbriatum, are also found in South-east Australia and in New Zealand. There are no other connections between these two regions as respects Sphagnum, and it might at first appear that one region had received its species from the other. But a glance at the distribution of both species makes it clear that just as they have traversed the whole length of the New World from Alaska to the Straits of Magellan and beyond, so they have reached Australia from its own side of the globe, or, in other words, from high latitudes in Asia by way of the Himalayas, in which last-named area they both exist.

It can be similarly shown in the case of the Carices that four out of the six species, which the Australian and New Zealand regions hold in common with the southern part of South America (South Chile, Patagonia, and Fuegia), must have been derived from the same side of the globe by the way of Central and South-eastern Asia. The occurrence of these four species (C. canescens, cederi, pseudo-cyperus, pumila) in Kashmir, Turkestan, South China, etc., renders needless any appeal to South America as their possible source. It can also be claimed for South America that the first three of the four species named were derived overland from the north. Although they have not been recorded from the tropics of the New World all three are characteristic of temperate latitudes in North America; and in postulating for them a southern route by the way of the Mexican highlands and the Equatorial Andes, we should be merely assuming that they have done that which has already been shown to have been accomplished by $C$. macloviana and other Arctic species. An objection might be raised in the case of $C$. œederi, which is represented by a variety peculiar to New Zealand, South Africa, and extratropical South America; but this is met in the subsequent discussion.

The Case of Carex pumila.-Yet, although the evidence is sufficiently convincing that South America did not receive these three species of Carex across the Southern Ocean from the Australian and New Zealand region, in the case of the fourth species, C. pumila, there is a distinct suggestion that it performed the ocean traverse from New Zealand to Southern Chile. This Carex has only been recorded in the New World from Chile; whilst it has an extensive range in Eastern Asia from Manchuria to Formosa and Hongkong, whence its extension to Queensland and over the eastern portion of the Australian continent to Tasmania, and thence to New Zealand, could be readily assumed. Since, therefore, it would be highly improbable from the facts of distribution just given that Carex 
pumila reached the Australian and New Zealand region from Chile, there is good foundation for the view that it is a gift from either Australia or New Zealand, preferably the latter, to South America. Accepting that inference, the fact that it has been recorded only from the western side of the continent, namely, from Chile, clearly indicates the route taken in its ocean passage, that is, from the west, which is under the circumstances the only route rendered practicable by the winds, the birds, and the currents.

The indications supplied by Carex pumila derive fresh interest from those offered in the cases of the two other species, $C$. darwinii and $C$. trifida, which, with the four before named, make up the six species held in common between southern South America and the Australian and New Zealand region. These two Carices have been found nowhere else on the globe than in the southern extreme of the American continent, in New Zealand, and in the islands near and to the south of it. Presumably there has here been some communication between these two widely separated regions; and the question that at once presents itself is whether South America supplied these two species to the New Zealand region, or whether it received them from that source. In either case it must be assumed that the sea-bird that transported the seed followed the westerly winds in its ocean traverse. This being granted, the case of $\boldsymbol{C}$. darwinii raises a curious point. Since this species is well distributed over the Southern Andine region and in Fuegia, and since it occurs only in the Chatham Islands in the New Zealand and Australian region, the seed must have been carried eastward from Cape Horn. This route involves an ocean passage twice as great as that which would be implied in the passage westward against the westerly winds from Cape Horn to the Chatham Islands. But it would be assisted by the several islands in the Southern Ocean that serve as restingplaces for the sea-birds that are ever flying round the globe in the latitudes of the Roaring Forties. The evidence of the other species, Carex trifida, is indeterminate, since it is well distributed in South Chile and the Falklands Islands in the one region, and in New Zealand and the neighbouring Antarctic Islands in the other.

The direct Sphagnum and Carex Connections between Fuegia and the New Zealand and Australian Region.-From the above remarks it may be inferred that the parallel already traced between Sphagnum and Carex may be further extended to the species common to the southern extreme of South America and the Australian and New Zealand region. But the parallel is not complete. Whilst it has been shown that the two species of Sphagnum common to these widely separated regions must have been derived in each case from northern latitudes on the same side of the globe, South American from North America and Australian from Asia, this applies to only three of the six Carices common to the two regions. In the case of the others a communication across the Southern Ocean is implied, in one species from Australia or New Zealand to Chile, in another from Fuegia to the New Zealand area, whilst in the third there is nothing to indicate which region was the giver and which was the recipient. 
The South American and African Connectron.-Before leaving the subject of South America reference may be made to another point of similarity between Sphagnum and Carex, which concerns the scanty connection with Africa in the sense below defined. With both genera the two continents hold but a single species in common, namely, Sphagnum pulchricoma and Carex oederi. The first named, which is characteristic of the Southern United States and of tropical South America, has only been recorded from one locality outside the New World, namely, in the Lake District of Central Africa. The second is a typical North American and Eurasian species of Carex that has extended south as far as Tasmania and New Zealand and South Africa in one hemisphere, and as far as Patagonia in the other, being represented in all three regions by the same peculiar variety. For reasons to be now given it is held that this variety originated independently in South America and New Zealand, but was supplied from Patagonia to South Africa. Concerning the parent species there is no necessity to appeal to any transference across the Southern Ocean between extra-tropical South America and the Australian and New Zealand region, since the two regions could have derived it from northern latitudes on their own sides of the globe, the species being widely distributed in North America and in Northern and Central Asia. As regards its occurrence in South Africa, however, the indications are that this region received the variety across the ocean from Patagonia, as it is not recorded from any part of the African continent except from the high mountains of Basutoland, a matter dealt with in a later page. Reference will also be made below to the significance of the existence of the New World species of Sphagnum (S. pulchricoma) in Central Africa.

The African Peat-mosses and Carices.--This brings us to the discussion of the representation of the Peat-mosses and Carices in the African continent; and here again the behaviour of the two genera, offers a striking parallel, since they illustrate in a similar way that remarkable isolation which Africa so often exhibits in its flora as well as in its fauna. By Africa, we mean Africa with the Mediterranean Littoral excluded. This Mediterranean province of the European region receives from Europe species of Sphagnum and Carex that as a rule have failed to penetrate farther south. Thus species of Sphagnum, like $\boldsymbol{S}$. rufescens and $\boldsymbol{S}$. turgidulum, which are widely distributed over Europe, cross the Mediterranean only to reach Tunis and Algeria. However, although the great majority of the European Carices have been compelled to halt in North Africa after crossing the Mediterranean, a few have penetrated to the south of the continent.

The Check to the Southward Advance of the Carices into Africa.- - Just as in the New World the Carices from the north have been ever pressing south, so in the Old World the northern Carices have been ever endeavouring to reach the interior of Africa; but they have in nearly all cases been rolled back by the obstacles presented by the Atlas ranges and the sandy wastes of the Sahara and of Libya. Not more than 13 per cent. of the European species of Carex that have established themselves in the southern region 
bordering the Mediterranean have been able to penetrate the continent and to reach South Africa, the oases of the Desert and the northern slopes of the Atlas representing as a rule their southernmost outposts. Thus of about thirty European Carices that have spread to North Africa only four (C. divisa, vulpina, extensa, acutiformis) have reached South Africa by travelling along the length of the continent. There is no prospect with any of the four species that South Africa received them across the Southern Ocean, either from South America or from Australia and New Zealand, since they have not been found there as indigenous plants. All the others, including species like C. pendula, sylvatica, pseudo-cyperus, vesicaria, halleriana, and diluta, have either been checked on the Mediterranean border, or have come to a standstill on the slopes of the Atlas, or have made their last halt in the Libyan oases.

The Isolation of Africa.-The isolation of Africa, excluding the Mediterranean province which belongs botanically to Europe, is well displayed in the behaviour of the genera Sphagnum and Carex. Though, considering the great area concerned, the representation is poor, Africa holding about 9 per cent. of the known species of Sphagnum and only 4 per cent. of the Carices, yet the species are fairly well distributed. Thus in both cases about half are found in the tropical portion of the continent, and about a third in the southern part. The degree of endemism displayed is also very similar, since both groups of plants are represented by thirty-one species, and of these six extend outside the continent in the case of Sphagnum and seven with the Carices.

In the following table Africa is compared with the other two great land-masses of the southern hemisphere, South America and Australia, as regards the proportion of its Sphagnum and Carex floras that is not confined to the continent. As far as South America is concerned,

Comparison in the case of South America, Africa, and Australia, of the Proportions of non-Erdemic Species, that is, of Species extending OUTSIDE THESE REGIONS

\begin{tabular}{|c|c|c|c|c|c|c|c|}
\hline & \multicolumn{3}{|c|}{ Sphagnum } & \multicolumn{3}{|c|}{ Carex } & \multirow{3}{*}{$\begin{array}{l}\text { Islands excluded as } \\
\text { below named }\end{array}$} \\
\hline & \multirow{2}{*}{ Total } & \multicolumn{2}{|c|}{$\begin{array}{l}\text { Extending out- } \\
\text { side the region }\end{array}$} & \multirow{2}{*}{ Total } & \multicolumn{2}{|c|}{$\begin{array}{l}\text { Extending out- } \\
\text { side the region }\end{array}$} & \\
\hline & & Number & Percentage & & Number & Percentage & \\
\hline $\begin{array}{l}\text { South } \\
\text { America }\end{array}$ & 110 & 11 & 10 & 81 & 29 & 36 & $\begin{array}{l}\text { Falkland Is., Juan } \\
\text { Fernandez, Gala- } \\
\text { pagos, etc. }\end{array}$ \\
\hline Africa & 31 & 6 & 19 & 31 & 7 & 23 & $\begin{array}{l}\text { Madagascar, Masca- } \\
\text { rene and Atlantic } \\
\text { Is., etc. }\end{array}$ \\
\hline Australia & 24 & 11 & 46 & 28 & 19 & 68 & $\begin{array}{l}\text { Tasmania, New Zea- } \\
\text { land, etc. }\end{array}$ \\
\hline
\end{tabular}




\section{DISTRIBUTION OF SPHAGNUM AND CAREX 343}

these results can only be considered as approximate; but it is probable that the effect of future discoveries will be to make the endemism yet more pronounced. The figures, as far as they go, indicate that the intensity of the endemism is greatest in Africa for the Carices and in South America for the Peat-mosses. But by taking other matters into consideration Africa gives promise of standing first also. with Sphagnum. Thus, whilst the species connecting both South America and Australia with the outer world often range over much of the globe, most of the African Peat-mosses that extend beyond the limits of the region, as here defined, do not reach farther than Madagascar and the Mascarene Islands. Africa owns not one of the ten or a dozen world-ranging species of Sphagnum. These facts distinguish the continent in a conspicuous manner from both South America and Australia.

The Necessity of excluding the Insular Element when comparing the Sphagnum and Carex Floras of Continental Regions.-The insular element is removed from this table. The island by the intensity of its endemism is always a disturbing influence in discussions regarding the floras of continental regions. The effect of linking New Zealand with Australia, Madagascar with Africa, and Japan with Eastern Asia, is to produce results quite out of proportion to the size of the disturbing area. It has already been pointed out in the case of Sphagnum that if we included Japan in Asia and the Malagasy province in Africa half of the known Eurasian species would be recorded only from Japan, and one-third of the species peculiar to Africa would be found only in Madagascar and the Mascarene Islands. So also with the African Carices peculiar to that region, their number would be increased from twenty-five to forty if we added those restricted to the Malagasy province. As shown in the table for the Australian region given on a later page, the effect of adding the New Zealand Carices to those of Australia would be to double the number of species. To have employed the combined results for Australia, Tasmania, and New Zealand, in making the above comparison with South America and Africa, would have caused a drop in the percentage of non-endemic species from forty-six to nineteen in the case of Sphagnum and from sixtyeight to thirty-four in the case of Carex.

Then it should be remembered that with oceanic archipelagos, like the Azores, it may make a great difference in the connections of a whole continental flora if we link them to a continent with which they have little in common (see Note 22 of the Appendix). The insular factor, in truth, raises considerations other than those specially dealt with in this chapter. It may, however, be remarked that both Sphagna and Carices respond in a similar way to the isolating influences at play in oceanic islands. We find peculiar species of both genera associated on islands in all the oceans, as in the Azores and St. Helena in the Atlantic, in Bourbon in the Indian Ocean, and in Hawaii in the North Pacific.

We will now look a little closer into the behaviour of the genera Sphagnum and Carex in Africa, more especially as regards the connections established by the non-endemic species with regions outside 
the continent, North Africa being regarded as European in a floral sense. These are indicated in the table below given.

The Distribution of the non-Endemic African Specizs of Sphagnum (6) $\triangle N D C_{A R B X}(7)$

\begin{tabular}{|c|c|c|c|}
\hline & Sphagnum & Carex & \\
\hline North Africa & - & 4 & Included in the European floral region. \\
\hline Eurasia & - & 6 & For Carex, Europe, 5; Asia 5. \\
\hline North America & 1 & 1 & \\
\hline South America & 1 & 1 & \\
\hline $\begin{array}{l}\text { Australia and New } \\
\text { Zealand }\end{array}$ & - & 2 & $\begin{array}{l}\text { For Carex, Australia, 1; New Zea- } \\
\text { land, } 1 .\end{array}$ \\
\hline $\begin{array}{l}\text { Madagascar and the } \\
\text { Mascarene Islands }\end{array}$ & 5 & 1 & $\begin{array}{l}\text { For Sphagnum, Madagascar, } 3 \text {; and } \\
\text { Mascarene Is., } 4 .\end{array}$ \\
\hline Amsterdam Island & 1 & - & \\
\hline Teneriffe & 1 & 一 & \\
\hline
\end{tabular}

The outside Connections of the African Peat-mosses.-The Sphagnum connections beyond the continent first claim our attention. Of thirty-one species recorded from Africa, as geographically here defined, only six form connections with the outside world, four-fifths of the species being endemic. Of the six concerned, four merely link the continent with Madagascar and the Mascarene Islands (Bourbon, Mauritius, and Rodriguez); one of them, S. pappeanum, occurs on Bourbon and Rodriguez, on Teneriffe, and on Amsterdam, an island in the centre of the Indian Ocean; whilst the sixth, S. pulchricoma, is a characteristic North and South American species that has only been recorded in Africa from the Tanganyika district. The limited nature of the external connections of the African Sphagnum flora is thus apparent; and it serves to emphasise the view that Africa stands first among all the great continents as respects the isolation of its Peat-mosses as well as of its Carices.

It is noteworthy that eighteen of the thirty-one African species of Sphagnum belong to the subsection Subsecunda, the largest and most differentiated of all the ten subsections of the genus and holding one-third of the species. Though it has active centres of differentiation in all the great continents and is more uniformly spread over the world than the other subsections, these centres are not connected by world-ranging species. Not one of the ten species of Sphagnum possessing the widest ranges belongs to the subsection $S u b s e c u n d a$, and not one of them is African. This isolation of Africa must be associated with the circumstance that the majority of its species belong to a subsection that is practically closed to the outside world. A further implication of this fact will be noticed below. It will be 
sufficient here to restate our present position that in its limited connections Africa offers a great contrast with South America and Australia, which are in both cases linked by a number of species with the great land-masses of the north. Africa, it would seem, is a lonely continent as far as the Peat-mosses are concerned.

The outside Connections of the African Carices.-Coming to the African Carices, we find that although the proportion of those that extend beyond the limits of the continent, as here defined, is about the same as in Sphagnum, the genus is brought by the connections of its outside species more in touch with the rest of the world. The seven species concerned, Carex divisa, vulpina, cernua, extensa, cederi, acutiformis, boryana, are, with the exception of the last, wide-ranging Eurasian species that in one or two cases include Australia and sometimes even North and South America in their range. The only special connection is that of $C$. boryana, which extends merely to Madagascar and the Mascarene Islands.

But in one respect the African Carices repeat in a remarkable way the behaviour of the Peat-mosses. In view of its isolation one would have expected Africa to be the home of the older types of these genera. But the contrary seems to be the case. Just as with Sphagnum nearly 60 per cent. of the African species belong, as already shown, to the largest and most vigorous subsection of the genus, so with Carex more than half of the species belong to the youngest, most vigorous, and most generally distributed of all the four subgenera, namely, Eucarex, a subgenus holding two-thirds of all the known species of Carex, 800 in all. It is remarkable that Primocarex, the oldest subgenus, almost fails in Africa. It would thus seem that the invasion of Africa by the Carices and the Peatmosses took place during the later stages in the history of the two genera, and that the occupation of the continent has been followed by a period of isolation extending to our own times. This similarity in behaviour on the part of two groups of plants so divergent in character is a fact of importance.

In the case of Carex the limitation of the species to the continent often seems to be unaccountably abrupt. Thus, there are four species (C. echinochlö̈, boryana, longipedunculata, and simensis, that are evidently distributed over the highlands of tropical Africa from the Cameroons to Abyssinia and have been found on Ruwenzori and Kilimanjaro at altitudes of 7000 to $\mathbf{1 0 , 0 0 0}$ feet. Though they extend practically to the eastern and western limits of the continent only one of them, C. boryana, passes beyond them; but it does not travel farther than Madagascar and the Mascarene Islands. In two of the islands just named, Bourbon and Mauritius, this species meets C. brunnea, one of the most widely distributed of the Carices in warm latitudes. Ranging far and wide over Asia, it reaches Australia across the Malayan region, and finally establishes itself on the Hawaiian Islands in mid-Pacific. Yet there is no record of $C$. brunnea from the African mainland. There must be some important principle involved in the circumstance that Carices find it so difficult to enter the African continent, and so difficult, when there, to leave it.

Sources of South African Carices and Peat-mosses.-An 
interesting question presents itself in connection with the sources of the Peat-mosses and Carices of South Africa, since there are two alternatives. Their ancestors may have come from the north, overland across the continent, or they may have traversed the Southern Ocean in their passage from either the South American or the Australian region. Here an appeal must be made to the connections of species outside the continent.

(A) The Carices.-In the case of Carex the question has been already raised and answered with respect to four species, $C$. divisa, vulpina, extensa, and acutiformis, which are European species that having reached North Africa extended their range to the southern part of the continent, not one of them having been found either in South America or in the Australian region. Neither of the two other species concerned, C. cernua and C. cederi, gives a decisive reply. Thus the first named is a wide-ranging species, which, in the form of a fairly well-distributed special variety has obtained a slight hold in Australia in a single locality in New South Wales, a somewhat better footing in New Caledonia, and a secure establishment in South Africa. Here the indications are indeterminate; but the scale turns against the trans-oceanic hypothesis, since it seems more feasible that Asia served as the common focus of dispersal. The testimony of the second species, C. cederi, is also uncertain. Found in North America, Europe, and Asia, this Carex is represented by a special variety, cataractoe, in different localities in South Chile and Patagonia, in a single locality in South Africa (Basutoland), and in various localities in Tasmania and in the Alps of New Zealand. Here it would seem most likely that whilst South Africa derived the variety across the ocean from Patagonia, the species reached Chile overland from North America, and Tasmania from Central Asia, and that it underwent the same varietal change in both those southern regions.

The conclusions to be formed from the outside connections of the six South African species of Carex here concerned, are that four only could have been derived overland from Europe, that one of them probably hailed across the South Atlantic from Patagonia, and that the sixth was perhaps Asiatic in origin. On the whole, it would appear that South Africa has mainly derived its Carices overland from the northern hemisphere.

(B) The Peat-mosses.- The South African Peat-mosses tell the same story. Of the five species found outside the continent none occur in either South America or in the Australian and New Zealand region. Evidently South Africa has been stocked with its species of Sphagnum from the north. Of these five species Madagascar and the Mascarene Islands hold all. One of them, $S$. pappeanum, which occurs on the mountains of East Africa, as on Ruwenzori, has a most remarkable distribution. Outside the continent it has been recorded only from the islands of Teneriffe, Bourbon, Rodriguez, and Amsterdam.

The Mystery of Sphagnum pulchricoma.-Before quitting this subject allusion should be made to the solitary Sphagnum connection between the continent of Africa and the New World. This is the more strange, since Africa, if we exclude the Mediterranean 


\section{DISTRIBUTION OF SPHAGNUM AND CAREX 347}

Littoral, has no connection through the Peat-mosses with either Europe or Asia. The species concerned is $S$. pulchricoma, which is widely spread in America (United States, Equatorial Andes, Brazil, Paraguay, etc.), and occurs also on the west side of Lake Tanganyika in Central Africa. With the exception of its single African habitat it is, as far as is known, exclusively a New World species. Evidently before full weight can be attached to its sporadic occurrence in Africa, the matter would require further elucidation.

Sphignum and Carex in Australia and New Zealand.-There is a good deal of parallelism between the behaviour of Sphagnum

\section{Distribution of the Australian, Tasmanian, and New Zealand Species of Carex aNd SPHAGNUM}

\begin{tabular}{|c|c|c|c|c|c|c|c|c|c|c|c|c|c|}
\hline & \multirow[b]{2}{*}{ 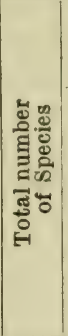 } & \multicolumn{2}{|c|}{$\begin{array}{l}\text { Endemic } \\
\text { Species }\end{array}$} & \multicolumn{6}{|c|}{$\begin{array}{l}\text { Distribution of the non- } \\
\text { Endemic Species }\end{array}$} & \multicolumn{4}{|c|}{$\begin{array}{l}\text { Species common to } \\
\text { Australia, Tasmania, } \\
\text { and New Zealand }\end{array}$} \\
\hline & & $\begin{array}{l}\text { 岕 } \\
\text { है } \\
\text { 艺 }\end{array}$ & 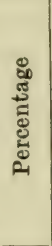 & $\frac{. \frac{5}{2}}{4}$ & 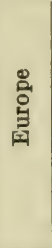 & 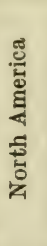 & 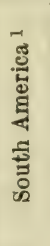 & 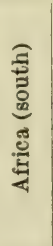 & 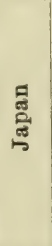 & 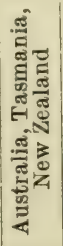 & 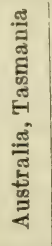 & 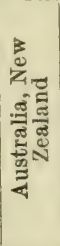 & 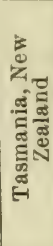 \\
\hline CAREX:- & & & & & & & & & & & & & \\
\hline Australia . . . & 28 & 9 & 32 & 15 & 5 & 5 & 3 & 1 & 13 & 7 & 1 & 3 & 一 \\
\hline Tasmania . . . & 9 & - & - & 5 & 3 & 2 & 3 & 1 & 5 & 7 & 1 & - & 1 \\
\hline $\begin{array}{c}\text { New Zealand with } \\
\text { the islands . }\end{array}$ & 42 & 27 & 64 & 10 & 6 & 6 & 5 & 1 & 9 & 7 & - & 3 & 1 \\
\hline New Zealand alone & 41 & 24 & 59 & 10 & 6 & 6 & 4 & 1 & 9 & 7 & - & 3 & 1 \\
\hline Combined region & 61 & 40 & 66 & 18 & 8 & 8 & 6 & 2 & 15 & - & - & - & - \\
\hline \multicolumn{14}{|l|}{ SPHAGNUM:- } \\
\hline Australia . . . & 24 & 13 & 54 & 6 & 5 & 5 & 1 & - & 6 & 3 & 2 & - & 一 \\
\hline Tasmania $\cdot \cdot \cdot$ & 12 & 5 & 42 & 2 & 2 & 2 & - & - & 2 & 3 & 2 & - & 一 \\
\hline $\begin{array}{c}\text { New Zealand with } \\
\text { the islands }\end{array}$ & 19 & 11 & 58 & 5 & 5 & 5 & 1 & - & 5 & 3 & - & - & 一 \\
\hline New Zealand alone & 17 & 9 & 53 & 5 & 5 & 5 & 1 & - & 5 & 3 & - & - & - \\
\hline Combined region . & 42 & 34 & 81 & 8 & 7 & 7 & 2 & - & 8 & - & - & - & - \\
\hline
\end{tabular}

The above table illustrates three of the main features of the Carex and Sphagnum floras of the Australian and New Zealand region-

(1) The degree of endemism;

(2) The distribution of the non-endemic species outside the area concerned;

(3) The connections between Australia, Tasmania and New Zealand, that is to say, the number of species they have in common. 
and Carex in the region of Australia and New Zealand, and there are also some instructive differences. The principal features are shown in the table given above. If we first take the combined region we notice that whilst only 7 per cent. (three out of forty-two) of the species of Sphagnum occur in both Australia and New Zealand, with Carex 18 per cent. (eleven out of sixty-one) are recorded from both regions. This would seem to indicate that Sphagnum has yielded more than Carex to the differentiating influences; but the opposite tendency is brought out in the table as respects New Zealand, where Carex would appear to have a slight advantage in this respect. There is little, therefore, to be gained by dwelling on this point.

In the case of New Zealand it makes no material difference whether we include or omit the islands lying to the east and south (Chatham, Antipodes, Campbell, Auckland, etc.). It should, however, be noted that, as far as is shown in Kükenthal's monograph, these off-lying islands, as a rule, contain no species of Carex which does not exist in New Zealand, the only exception being the Chatham Islands, which alone in this region hold the Fuegian Carex darwinii. These out-lying islands, therefore, are not known to possess any peculiar species of Carex. It is different with Sphagnum, since Antipodes Island and the Chatham Islands hold in each case a peculiar species of the genus. In one or two cases the New Zealand Carices have spread to Norfolk and Lord Howe Islands, thus indicating a tendency to extend to Australia.

The column that is devoted to Japan in the table is merely intended to emphasise the Asiatic connection. It is brought out in the text that both Japan and Australia derive most of the species held in common by them from the Himalayan region.

The Geographical Covnections of the Australian and New Zealand Peat-mosses and Carices.-But the difference between Sphagnum and Carex in the Australian and New Zealand region is only one of degree, since the geographical connections are closely similar. Whilst with Sphagnum all of the eight species found outside the region are Asiatic, seven being European, and seven North American, with Carex eighteen of the twenty-one non-endemic species are Asiatic, eight are European, and eight North American. There is seemingly in both cases a connection between the Peatmosses and Carices of this region and those of the southern extremity of South America. There is only a very slight connection with South Africa in the case of Carex and none for Sphagnum. For genera so unlike there is, therefore, at first sight a close correspondence between their relations outside the Australian and New Zealand region, a correspondence which is not lessened by an examination of the details. Before discussing the predominant Asiatic connections, a feature common to both genera, I will deal with the South American and South African relations.

In the first place there is the South American connection, apparent or real. As already shown in the case of Sphagnum, the two Australian and New Zealand species ( $S$. medium, fimbriatum) which occur in Fuegia are widely spread Eurasian and North American species that could have reached their present homes in the south 
from Asia and North America, the postulate of a traverse of the Southern Ocean being quite unnecessary. It has also been before pointed out that of the six species of Carex, which Australia and New Zealand possess in common with the southern part of South America, four could have been derived from Central and Southeastern Asia, and that the question of a South American origin could only be raised concerning two species, $C$. darwinii and $C$. trifida. Whilst it is highly probable, as previously shown, that the Chatham Islands, its only locality in that region, received the first species from Fuegia, the evidence respecting the second is indeterminate.

The connection between the Australian and New Zealand region and South Africa is not illustrated by Sphagnum, and it affects only two species of Carex (C. cernua and C. œederi); but it has already been indicated that the evidence, though not decisive, tells more against than in favour of a trans-oceanic connection, since the original forms of both species could have reached the Australian and New Zealand region from Asia.

The Asiatic Connections of the Australian and New Zealand Regron.-By far the most important are the Asiatic connections of this region. As before remarked, all the species of Sphagnum and nearly all the Carices that occur outside its limits are found in Asia. There is no special connection with either Europe or North America which is not also Asiatic, all the species so concerned being widely distributed in the northern hemisphere. Asia, therefore, represents the immediate source of the Australian and New Zealand species of Sphagnum and Carex, since derivation from southern South America and from South Africa is altogether excluded for the Peat-mosses and for all but $\mathbf{3}$ or $\mathbf{4}$ per cent. (two or three out of sixty-one) of the Carices.

When we examine the matter more closely, we find that all of the outside species of Sphagnum and that fifteen of the twenty-one outside species of Carex occur in Japan, a fact that merely indicates a common centre of dispersion in Central Asia for the representatives of the genera reaching Japan and the Australian and New Zealand region. Of the Himalayan region as the centre of departure from which the same species has often travelled north-east to Japan and south-east to Malaya and Australia, more will be said. The route is determined in each case from the distribution of the species of Sphagnum and Carex that are concerned. In the case of Sphagnum there are four species-S. fimbriatum, papillosum, cymbifolium, medium - that have found their way to either Australia or New Zealand from South-eastern and Central Asia. All of them are spread far and wide over the northern hemisphere in North America and in Eurasia, and all have spread from the same Asiatic centre to Japan as well as to the Australian and New Zealand region. The two first named, however, present great gaps between their occurrence in the Himalayas and Burma and in New Zealand. The third shows a similar hiatus between Southern China and New South Wales, and the fourth between the Bhutan Himalayas and the Blue Mountains in South-east Australia. But these gaps can be filled up by other species that reach Japan and Malaya from the Himalayan 
region, but fall just short of Australia. Thus Sphagnum junghuhnianum is a Himalayan species that has arrived at Japan to the north-east and at New Guinea to the south-east after halting in the last case on the mountains of Java and Celebes. (On account of its convenience the term "Malaya" is applied in this chapter to all the region between South-eastern Asia and Australia.)

Bridging over the Gap in Malaya by the Carices.-The more numerous data supplied by Carex enable us to bridge over the gap usually presented by Sphagnum in the Malayan region, since onethird of the eighteen Asiatic species found in the Australian and New Zealand region are there represented. If we look at the twelve Carices that jump over the Malayan Archipelago, we find that eight are wide-ranging North American and Eurasian species; and, as indicative of their capacity to reach as far as they can get, we notice that all but one have traversed Eastern Asia and reached Japan, four or five of these being recorded from the Himalayas.

The six Australian and New Zealand Carices that fill up the gap in Malaya (C. rara, indica, rafflesiana, maculata, breviculmis, brunnea) are purely Asiatic, none being recorded from either Europe or North America. They are most at home as denizens of warm latitudes in southern and south-eastern Asia; but they also illustrate in the case of three of them (C. rara, breviculmis, brunnea) how the same species of Carex from a centre in the Himalayan region can reach Japan in the north-east and Australia in the south-east. The distribution of $C$.indica is illustrative of the track pursued by one of these Himalayan species in reaching Australia. We can connect its habitat in Sikkim and in Northern Australia with records from Assam, the Malay Peninsula, Borneo, Java, and New Guinea. The case of C. breviculmis is also interesting and suggestive. From an altitude of 10,000 feet in the North-west Himalayas it passes across Assam to Tonkin and appears on Mount Scratchley in New Guinea at an elevation of 12,200 feet before making its way south to South-eastern Australia and New Zealand.

These half a dozen Carices that halt in the Malayan region on their way to Australia from South-eastern Asia include, as has been said, three Himalayan species; and in this connection it should be noted that several other Himalayan Carices accompany them as far as the highlands of Sumatra, Java, and Borneo, but no farther. I have made from Kükenthal's monograph a list of fourteen purely Asiatic species (ten Himalayan and four from Southern India and Assam) that have had their passage to the south-east arrested in Malaya. They were, however, more successful in their passage to the northeast, since half of them have reached Japan. But the point to be specially noted here is that the Carices from the Himalayan heights select similar great altitudes in Malaya. Thus $C$. filicina and $C$. fusiformis, which have been recorded from elevations of 8000 to 12,000 feet in the Himalayas, have been collected on Mount Kinabalu in Borneo at altitudes of from 9500 to 11,500 feet. So again, C. teres, which occurs on the Sikkim Himalayas at an elevation of 8000 to 9000 feet, has been gathered on the slopes of the volcanic mountain of Papandayan in Java. 


\section{DISTRIBUTION OF SPHAGNUM AND CAREX 351}

Comparison of tile Sphagnum and Carex Floras of Australia and New Zealand.- These remarks on the combined Australian and New Zealand region may be supplemented by a reference to the separate Sphagnum and Carex floras of the two subregions, as exemplified in the table before given. As respects Sphagnum, Australia and New Zealand when contrasted present much the same degree of endemism. With Carex, however, the New Zealand endemism is much more pronounced. As might be expected, the Asiatic connections of the Australian Carices are more evident than in the case of those of New Zealand; whilst the South American connections are more apparent in New Zealand. But it will be brought out below that these South American relations, as indicated in the table, cannot be taken at their face-value, either for Australia or New Zealand.

The Asiatic Connections of the New Zealand Carices.Of the ten New Zealand species displaying Asiatic connections, seven are also known from Australia, viz. C. pyrenaica, stellulata, gaudichaudiana, breviculmis, brownii, pseudocyperus, and pumila. Three of these, the first, second, and sixth, are wide-ranging North American and Eurasian species. The others are purely Asiatic, except the last (C. pumila), which, though spread over Eastern Asia from Manchuria to Hongkong, occurs sporadically in the New World in Chile. It is discussed on p. 339. One of the most interesting of these seven Carices is $\boldsymbol{C}$. breviculmis. It is the only one of them that breaks its journey from South-eastern Asia to Australia by halting, as already observed, on Mount Scratchley in New Guinea at an altitude of 12,200 feet above the sea.

Of the three Asiatic New Zealand species which have not yet been found in Australia, Carex diandra, C. lagopina, and $C$. oederi, the last named is recorded from Tasmania; and it seems not unlikely that one or more of them will be discovered in the highlands of Eastern Australia. All of them seem to pass from Southern Asia to Australia without halting in the Malayan region; but one may expect that some future explorer of the peaks of Sumatra, Java, and Borneo will aid in filling up this gap. Of the three, perhaps $C$. lagopina is the most interesting. This Arctic and Alpine species of North America and Eurasia is a characteristic sedge of the Southern Alps of New Zealand. The nearest Asiatic locality from which it has been recorded lies in the Khasia Hills of Assam. No question of a South American origin arises, since New Zealand exhibits its only known habitat in the southern hemisphere. Carex diandra has a similar distribution in the northern hemisphere; but it does not occur in such high latitudes. It exists in both the North and South Islands of New Zealand; but there are great gaps separating it from the Eastern Himalayas and Japan, its nearest recorded habitats. Carex oederi is another North American and Eurasian species, which, however, as already noticed, has a special variety (var. cataractoe) peculiar to New Zealand, Tasmania, South Africa, and extra-tropical South America. The wide gaps separating New Zealand from the nearest Asiatic habitats of the parent species in Kashmir and Japan seem at first sight to point to a derivation across the Southern Ocean, 
a view supported by the distribution of the special variety above mentioned; but this subject is further noticed in the next paragraph. The South American Connections of New Zealand and Australian Carices.-With regard to the apparently greater connection with South America which is displayed by the New Zealand Carices as contrasted with those of Australia, there is this to be said. Of the five New Zealand species concerned, two, C. pseudocyperus and $C$. pumila, are Queensland plants, which are found, the first in Kashmir and the second in South China, so that it is scarcely requisite to look to the southern part of South America for their source. Of the other three species, $C$. darwinii, trifida, and oederi, it has already been said that the question of derivation from South America is only imminent with respect to the first two, since they are found nowhere else than in the New Zealand region and in the southern part of South America. Whilst with $C$. trifida the evidence is indecisive, the probability is that the Chatham Islands received $C$. darwinii from Fuegia. The special variety of $C$. œderi, which has often been mentioned as occurring in New Zealand, South Africa, and southern South America, lends support at first sight to the trans-oceanic hypothesis; but it is shown that if put at all the question should be narrowed down to the issue whether New Zealand or South America is its original home, and preference is given to the view that each of these regions derived the parent form from the northern hemisphere, a corresponding varietal modification subsequently taking place in each region.

However, to be on the side of safety we will assume that two of the fifteen New Zealand species which are found outside that region could have been derived from Fuegia. It is different with the three species ( $\boldsymbol{C}$. canescens, pseudocyperus, and pumila) that apparently connect Australia with southern South America. It has above been shown that the two last named probably reached Queensland from Asia. As respecting $C$. canescens, the direct South American connection is also excluded. It has been found in the mountains of South-eastern Australia, though not in New Zealand. Like C. lagopina it is an Arctic and an Alpine species of the northern hemisphere, both in America and Eurasia. Just as Fuegia received it from the north by the way of the Chilian and Argentine Andes, so Australia has received it either from Japan, or from the highlands of Kashmir, where it has been found at an altitude of 12,000 feet. Looking at all the facts concerned with the streaming of Carices to Australia from Asia, it would be hazardous to assume that the mountains of New South Wales and Victoria received Carex canescens across the breadth of the South Pacific Ocean. On the whole, we may infer that whilst New Zealand has derived two of its Carices from South America, Australia has received none.

Similar Rôle of a Sphagnal Subsection in the Australian and New Zealand Region ANd in Africa.-A supplementary remark may here be made on a curious point of resemblance between Africa and the Australian and New Zealand region. It has already been noticed in the case of the African species of Sphagnum that the isolation of the continent is to be associated with the fact that the 
majority of species belong to the subsection Subsecunda, which possesses no world-ranging species. But this is not only a closed subsection for Africa, it is the same for Australia and New Zealand. Although it holds one-fourth of the Australian and New Zealand species, they are all confined to the region, the species connecting it with the outside world belonging to other subsections.

The Behaviour of Sphagnum and Carex and the Theory of Differentiation.--If I were to endeavour to show how the behaviour of the Carices and the Peat-mosses, as discussed in this chapter, fits in with the general theory of differentiation adopted in the two preceding chapters, it would be, as briefly expressed, somewhat to this effect. The Carices represent one of the results of the differentiation of a generalised cyperaceous type originally spread over the globe; whilst the Cyperi represent another result. These two genera largely compose the family, the second being as characteristic of warm latitudes as the first is of the cool regions of the north. Whilst the distribution of Carex has been mainly determined by the divergence of the land-masses from the north and by the secular changes of climate, that of Cyperus has been affected to a much less degree by these influences. While the tide of the Carices has ebbed and flowed in the north, the Cyperi could have reached the common focus of dispersal in the Arctic polar area only when exceptionally warm conditions reigned at the pole. Cyperus ought to represent to some extent the attitude of relative passivity adopted by typical plant-groups in the tropics. Its efforts to penetrate the cooler regions of the globe have not been very successful; whilst its sister genus, Carex, has only been able to reach the temperate regions of the south by halting on the tops of the mountains during its traverse of the tropics.

It is the same with Sphagnum, since it is at home in the moors of the north and occurs at high altitudes on the mountains of the tropics. But there is evidence, as we learn from Ule as quoted by Warnstorf (p. 33), that these plants are adapting themselves to a low-level station in the tropics in the coast-plains of South Brazil. We seem to know but little of the evolutionary history of a genus which was raised by the elder Schimper to the rank of a separate family; and it would be useless to evoke a differentiating process that would involve the common origin from a generalised type of the Peat-mosses, the Mosses proper, and the Liverworts.

One great lesson supplied by the striking parallelism of two planttypes so widely divergent as Carex and Sphagnum is that time has long since discounted any especial advantage which the one might possess over the other as regards facilities for dispersal. In both cases their distribution has been largely determined by the arrangement of the land-masses and by the alternations of climate. Yet such a parallelism would acquire but little importance, if it was merely concerned with these two plant-groups. It indicates a principle enunciated by Dyer as affecting a host of other plants of the north, plants that are often strangely contrasted in almost everything but their response to the principle of distribution so well illustrated in the behaviour of Carex and Sphagnum. 
The last great lesson it presents is shown in the support it gives to the views of Bentham and Hooker on plant-distribution. It is not easy to be original in any field where they have laboured. Though the ground has been "pegged out " by them and others, the "claims" are often still unworked.

\section{Supplementary Note on the means of dispersal of the Carices and the Peat-mosses:-}

The Distribution of the Carices by Birds.- - It will have been noticed in the previous discussion that it has been assumed that species of Carex and Sphagnum can follow along the length of the continents from the north polar regions to Fuegia, South Africa, and Australia. In the case of Carex it is well known that the hard seed-like fruits occur in birds' stomachs, and it has been shown that the smaller fruits can be carried in dried mud adherent to their feet and legs; but the question arises whether birds do actually travel along the routes that have been taken by these plants. It has before been observed that certain South African Carices must have been derived from the northern hemisphere, the possibility of their having come across the ocean from South America, or even from Australia, being excluded by their absence from those regions. This offers a critical case, and to some extent we are able to meet it.

Thus, three instances have lately been recorded of swallows captured in Natal and in the Orange Free State, which had been "ringed" in Great Britain (Staffordshire and Ayrshire) nineteen, nine, and four months previously (Scotsman, November 8, 1913; Times, March 12, 1915). In the Times of the same date reference is made to a Sandwich tern, "ringed" in England in July, which was found on the Ivory Coast, West Africa, in the following February. Then we have the numerous examples of storks marked in East Prussia and the neighbouring provinces which were recovered in the Transvaal, Natal, Basutoland, and Cape Colony. I am quoting here from a paper by A. L. Thomson, who discusses in the Proceedings of the Royal Physical Society of Edinburgh for March 1911, the results of the German and Hungarian inquiries. Doubtless these facts could toe largely increased; but they are sufficient to show that birds do :actually make periodical migrations from Europe to South Africa.

The Distribution of the Peat-mosses by the Winds.- It is not unlikely that the spores of Sphagnum would be sometimes carried in the dried mud adhering to migratory birds; but here the wind presents itself as probably a more effective agent. This being so, we are at once met with the question whether islands like the Hawaiian that lie in mid-ocean some 2000 miles from the nearest continental coast, would have received their Sphagna through this agency. The subject of the transport of seeds and spores by wind is discussed at length by Mr. Lloyd Praeger in a recent paper in the Proceedings of the Royal Irish Academy (1911), and I have dealt with it in this work in connection with the Azores (Chap. XIX). Here it may be stated that, as indicated by his experiments on the falling rate of seeds, even the dust-like seeds of orchids could not be carried to Hawaii by a wind moving fifty miles an hour unless they were raised at the start 
to an altitude of fifteen or twenty miles. Although, therefore, this would exclude all the flowering plants,even those with plumed seeds, the matter assumes a different aspect in the case of the spores of cryptogams. Small as it is, the orchid seed may fall fifty times as fast through the air as the spore of a mushroom; and an initial elevation of at most 3000 feet would be needed for a successful traverse by a mushroom spore of 2000 miles of ocean before a wind blowing with a force of fifty miles an hour. This is the maximum altitude; but the average elevation required, as indicated by Buller's falling rates given in the table in Chap. XIX, would be only half this amount. Though I have no direct data for the Peat-mosses it is not probable that their spores would require an initial elevation exceeding the average height of a lofty mountain-range like that of the Andes, up the slopes of which the ascending currents of air would be able to carry cryptogamic spores to a suitable starting-level several thousands of feet above the sea. (If the spores of Polytrichum could serve us as a guide, the falling rates of which are given in the same table, the initial altitude requisite for Sphagnum would not far exceed 1000 feet.) The occurrence of these up-draughts on the sides of high mountains is well known, and the matter is dealt with afterwards. In this manner the spores of cryptogams would be brought within the influence of the upper air-currents and distributed far and wide.

\section{Summary}

1. On finding that the Sphagnum floras of the eastern and western hemispheres become more and more differentiated as one recedes from the north polar region, the author turned to the Carices and received the same reply. It was at the same time discovered that in their distribution both genera reproduce many of the problems which the plant-world presents in the case of islands and in the floras of the great land-masses of the southern hemisphere. It also appeared from the behaviour of Sphagnum that the lower plants require a larger area than the higher plants for evoking the full effects of the differentiating process, and that in this respect our globe may not be large enough for lowly organised plants (pp. 332-4).

2. A table is given illustrating the effect of the divergence of the land-masses from the north on the distribution of Sphagnum and Carex. A comparison is then made of their behaviour in the North American and Eurasian land-masses, and it is shown for both genera that whilst the species common to both gather in the north, those separately held congregate in the south. Thus it is indicated for Sphagnum that 87 per cent. of the species common to both North America and Eurasia are Arctic and Subarctic species. Of the species separately held very few are found north of the temperate zone. Thus in both the east and the west only 5 or 6 per cent. of the species confined to the respective hemispheres occur in Arctic or Subarctic latitudes. The Carices tell the same story in both hemispheres, the proportion of species which North America holds in common with Eurasia being 93 per cent. in the Arctic regions, 40 per cent. in the Subarctic regions, 24 per cent. in temperate lati- 
tudes, and 11 per cent. in the southern portion of the continent (pp. 333-5).

3. The parallelism between Sphagnum and Carex is strikingly illustrated in the connections of South America with the rest of the globe. In both genera there is the streaming of species from the cold latitudes of the north along the line of the Rocky Mountains, across the highlands of Central America, and down the Andes, reaching to Fuegia (pp. 335-8).

4. The connections of South America with the Australian and New Zealand region may thus be summarised. With both genera a few of the species, that have reached the Southern Andes and Fuegia from high northern latitudes have been found also either in Australia or in New Zealand or in both. But whilst the two species of Sphagnum concerned must have been received by each region from northern latitudes on the same side of the globe, this can only be inferred for three of the six Carices involved. The other three species probably crossed the Southern Ocean, one from Fuegia to New Zealand and another from Australia or New Zealand to Chile, the data for the third being insufficient for the purpose of distinguishing between the giver and the recipient (pp. 339-40).

5. The Carex and Sphagnum connections between South America and Africa are of the slightest. A single South American Sphagnum, found also in North America, occurs in Central Africa; whilst a single Carex, also North American and Eurasian, connects South America with South Africa (pp. 341).

6. The African Sphagnum and Carex floras are then discussed; and here again the behaviour of the two genera offers a striking parallel, since they illustrate in a similar way that remarkable isolation which Africa so often exhibits both in its flora and in its fauna. Whilst the European species of $\boldsymbol{S}$ phagnum have crossed the Mediterranean only to reach Tunis and Algeria, the Carices from the north have in nearly all cases been rolled back by the obstacles presented by the Atlas and the Sahara, only a few penetrating to the south of the continent (pp. 341-2).

7. Both genera display a like degree of endemism in Africa, exclusive of the Mediterranean province, only about 20 per cent. of their species occurring outside the continent. But in the case of the Peat-mosses (Sphagnum) this cannot be taken at its facevalue. Whilst the Sphagna connecting South America and the Australian region with the outer world range over much of the globe, most of the African Peat-mosses that extend beyond the continent, as here defined, do not reach further than Madagascar and the Mascarene Islands. Africa possesses only one other link with the other continents in a solitary North and South American species that has apparently a limited distribution in the Lake District. As far as the Peat-mosses are concerned, Africa compared with South America and Australia is a lonely continent. As regards the African Carices, although the proportion of species found outside the region is about the same as in Sphagnum, the continent is brought more in touch with the outer world by its connections, nearly all the species concerned being wide-ranging Eurasian species that may in rare cases 
include Australia and even North and South America in their range (pp. 342-4).

8. With both Sphagnum and Carex more than half of the African species belong to the youngest, most vigorous, and largest of the subdivisions of the two genera. Primocarex, the oldest subgenus of the Carices and the nearest to the parent-type, fails altogether in Africa. The facts indicate that the invasion of Africa by the Carices and the Peat-mosses took place during the later stages of the differentiation of those genera, and has since been followed by a period of isolation extending down to the present time (pp. 344-5).

9. The sources of the Peat-mosses and Carices of the southern part of the African continent are then considered, and it is concluded that South Africa has derived all its Sphagna and most of its Carices from regions north, it being shown that one of the last named was probably brought across the ocean from Patagonia (pp. 345-6).

10. The parallelism between Sphagnum and Carex presented in Africa and South America is also displayed in the Australian and New Zealand region, the differences in the behaviour being only in degree. Taking first the combined area and its connections with South America, we find that the Sphagna concerned and most of the Carices could have been derived from northern regions on the same side of the globe (p. 347). The connection with South Africa is not illustrated by Sphagnum and very doubtfully by two species of Carex also found in Asia, which is probably their source (p. 349). By far the most important are the Asiatic connections, which are treated in detail; but it may be here observed that all the Sphagna and nearly all the Carices which are found outside the limits of the combined area occur in Asia. There is no connection either with Europe or North America that is not also Asiatic, all the species so concerned being widely distributed in the northern hemisphere. It is shown that derivation from South Africa and South America is altogether excluded for the Peat-mosses and for all but 3 or 4 per cent. of the Carices, New Zealand having received two species from South America and Australia none. Asia, therefore, represents the immediate source of the Australian and New Zealand Sphagna and Carices (pp. 349-50).

11. The Sphagnum and Carex floras of Australia and New Zealand are then compared; and it is elicited that whilst the degree of endemism in each region is apparently similar in the case of Sphagnum, it is much more pronounced amongst the New Zealand Carices. The respective connections are then discussed (pp. 351-2).

12. The similarity in the rôle played by a Sphagnal subsection (Subsecunda) in the African and Australian regions is noted (p. 352).

13. An endeavour is then made to show that the general behaviour of the Carices and the Peat-mosses is in agreement with the views of distribution adopted in the two preceding chapters. The close parallelism between genera so unlike in their rank, so remote from each other in their histories, and so different in their modes of dispersal, is a pregnant fact in distribution. It indicates a principle affecting a host of other plants of the north that are often strangely 
contrasted in everything but in their compliance with the laws of distribution so well illustrated by Carex and Sphagnum (pp. 353-4).

14. Amongst subsidiary matters mentioned in connection with the Carices and the Peat-mosses are those related to the insular factor (p. 343) and the modes of dispersal (p. 354). The insular factor raises other considerations than those specially dealt with in this chapter, but it is observed in passing that both genera respond in like fashion to the differentiating influences that are often intensified in oceanic islands.

Note.-With reference to trans-oceanic dispersal in high southern latitudes reference should be made to Note 37 of the Appendix, where the distribution of Uncinia, a genus allied to Carex, is dealt with. 


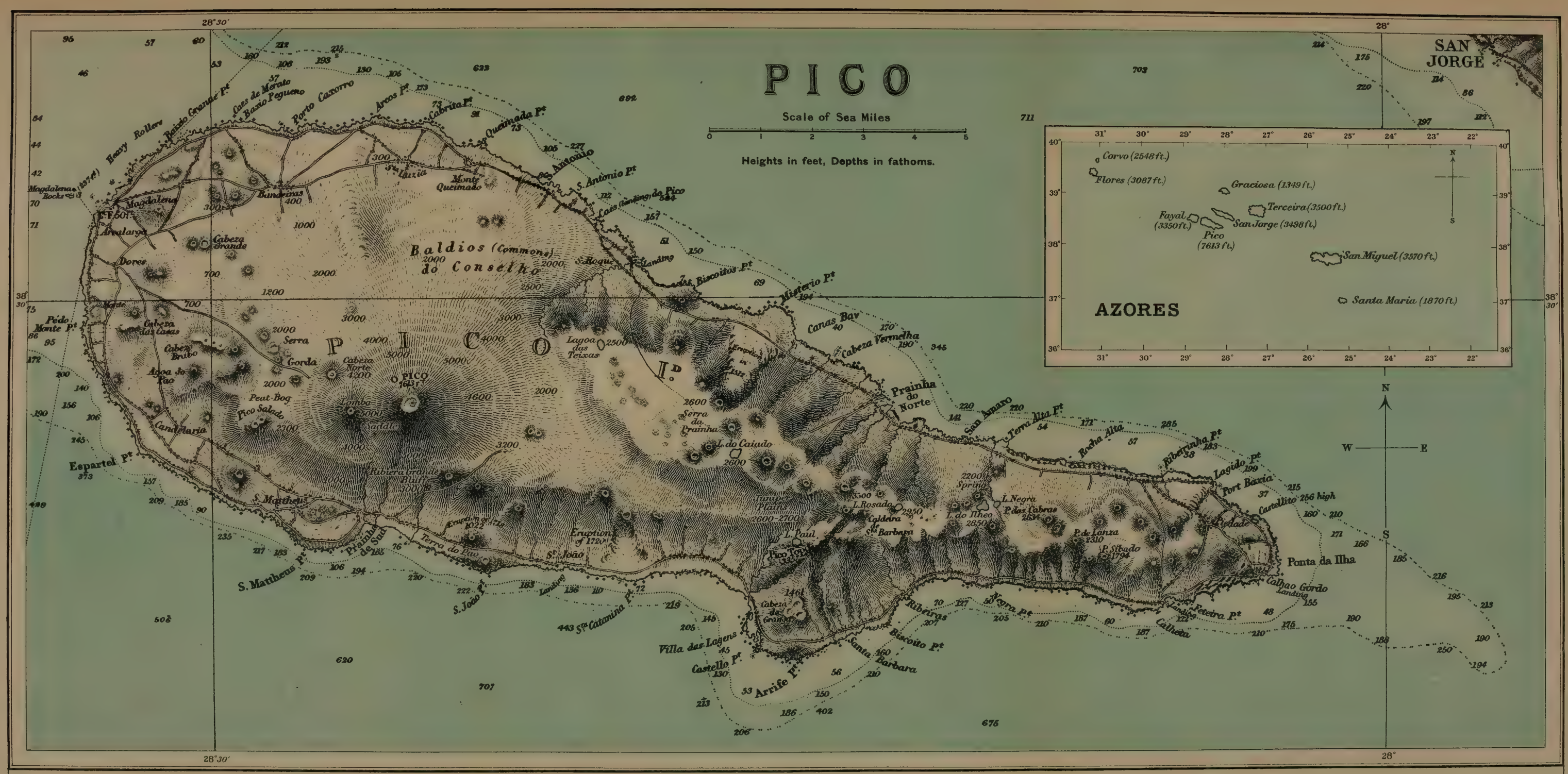

From the Admiralty Chart, No. 1865, based on the survey of Captain Vidal in 1844, with small corrections to September 1913 as there stated. There 1 , however, a more recent correction of 1914 , the height of Pico Topo being given as 3357 fest instead of 5357 feet as in previous Charts. Amongst the adaptations and additions made by the author are the inset plan of the Azores, the deletion of numerous soundings, the insertion of the approximate positions of the six fresh-water lakes, and several approximate elevations.

NOTE.-Hydrographeslly Pico and Fayal are one, since an upheaval of 3000 fect

Whist soundings of 900 fathoms are obtained about five miles off their southern side, they are conneeted with the Azore Banh to the south-west by a ridge covered by a maximum depth of 300 to 400 fathoms. 


\title{
CHAPTER XVII
}

\author{
THE AZORES
}

Is the autumn of 1914, after my return from a second sojourn in the Azores, it was my privilege to communicate to the Kero Bulletin a short general description of the native vegetation of those islands as illustrated on the slopes of the mountain of Pico. Here it is proposed to considerably extend that paper, using it as a framework for the author's detailed account of his observations in the group.

It is not at all easy to obtain a general notion of the original flora of these islands. Much as has been written on the Azorean plants, it is difficult to procure many data concerning the relative frequency, the mode of occurrence, and the associations of the native plants, except from the earlier writings of Seubert, Hochstetter, Watson, Drouet, and others, the later works being mainly concerned with catalogues of the species. Yet it is on the labours of the systematists that we rely for all safe progress in these matters. The monographs of Seubert in 1844, of Watson in 1870, and of Trelease in 1897, form landmarks in the history of the investigation of the flora. But many have laboured to supply the materials, and here we may mention Guthnick, the Hochstetters (father and son), Godman, Hunt, C. S. Brown, Sampaio, Carreiro, Machado, and Chaves.

The Author's Sojourns in the Group.-During his two visits to the Azores, from the middle of February to the end of April 1913, and from the middle of June to the middle of August 1914, the author was principally engaged in investigating the altitudinal ranges of the plants. After familiarising himself with the flora during a stay of about three weeks on San Miguel, when he ascended the principal mountains of the island and enjoyed the privilege, so courteously extended to him by the officials of the Municipal Museum at Ponta Delgada, of consulting the herbarium, he visited Pico and remained on its great mountain from the second week of March to the second week of April 1913. During his second sojourn in the group in 1914 he stayed on the island of Pico from the end of June to the second week of August, a period of six weeks, of which the first four were passed on the mountain, and the last two in the district of Caes-oPico and Praynha do Norte, lying off its slopes. The only other island examined botanically was Terceira; but this visit was confined to a single ascent of Santa Barbara, its principal summit. His intention to spend some time on San Jorge, the only one of the larger 
islands of the group of which the botany is little known, was frustrated by the outbreak of the war.

His Ascents of the Cone of Pico.-Two ascents were made of the summit of Pico, 7613 feet above the sea, namely, on April 1, 1913, and on July 16, 1914; whilst several ascents to altitudes of between 5000 and 6000 feet were accomplished during both visits on the north, east, south, and west sides of the peak, as well as numbers of excursions on the lower slopes. A few words may be said here on the best plan of exploring the mountain. The usual route to the summit from Magdalena by the Serra, past the Lomba (5000 feet above the sea), and up the south-west side of the cone, is the worst that could be chosen by the botanist, since it does not bring him into contact with the upper woods and provides insufficient opportunities of examining the upland moors. The constant employment of this route has been unfortunate for the botanical exploration of the mountain, and largely explains how it came about that it was left for the author to be the first to discover one of the most interesting plants in the Azorean flora, in the form of Arceuthobium oxycedri, a parasite on the Junipers all around the mountain. It also accounts for the fact that certain plants, such as the Laurestinus (Viburnum tinus), Hydrocotyle vulgaris, etc., which are rarely to be observed along this route, were never accredited to Pico until his visit.

All routes to the peak from the west and south sides meet near the Lomba, a prominent hill situated at the south-west angle of the foot of the cone proper. It is from this corner that the easiest ascent to the summit is made. But the top of the mountain can also be reached from the east side. Though more difficult, this ascent was effected, as I was told, by a man of San Joao many years ago.

For the botanist the best plan is to examine the southern slopes from San Mattheus, the western slopes from Magdalena, and the northern slopes from Bandeiras and Caes-o-Pico; whilst the easiest way to explore the eastern, and especially the south-eastern slopes, where the upper woods attain their greatest development, is to avail oneself of a house used for cheese-making which is situated about 2500 feet above the sea between Caes-o-Pico and San Joao. The shortest route to the summit is from San Mattheus, and it is one that does not involve a night spent on the mountain. By starting in the early morning the traveller can reach home the same evening after a prolonged stay on the top. Parties of young men of San Mattheus make the ascent during the short summer nights, and after viewing the sunrise return to their homes in time for their day's work.

Though summer is naturally the most appropriate season, much can be done by the botanist on Pico in the winter months, since the woods are composed of evergreen shrubs and trees, and the usual lower snow-limit encroaches but slightly on the wood-zone. But in the winter half of the year, especially when snow lies on the peak, it is difficult to procure guides to take one to the top. The bitterly cold north winds, the heavy rains, and the prevailing cloud-cap, are the chief obstacles at this season. I had to wait for several days before I was able to induce my man to complete the last two 
thousand feet on April 1. Without informing him of my intention to seize the first opportunity when we were exploring the lower slopes of gaining the summit, I coaxed him on this occasion to an altitude of 6000 feet, and the weather proving fine I completed the ascent with the man following very unwillingly behind, the snow offering but little difficulty.

It is the lack of warm clothes that mainly accounts for this unwillingness on the part of the Pico islanders to make the ascent in winter. Captain Boid observes in the work quoted below that in winter the peak is "positively inaccessible on account of the snow." This is incorrect. Occasionally in mid-winter a man is sent up by a doctor to procure ice for some sick patient in the coast towns and villages, but he generally returns with a tale of woe that for a long time prevents others from attempting the venture. As a fact, the ascent can often be made in winter; but both the mountain and the weather have to be carefully watched, the greatest danger to guard against being the dense driving mists, when, as so often happens, clouds gather on the higher slopes. Progress then becomes impossible, and shepherds who have been tending their sheep have perished from exposure.

I have never heard of any visitor to Pico making the ascent before the month of May. Godman attempted it about the second week of May after waiting for some days, but the weather prevented his succeeding (Natural History of the Azores, p. 15). Though the Bullars ascended on May 12 ( $A$ Winter in the Azores), that month is usually regarded as too early in the year. Indeed, Boid, who was in this locality in May 1831, states that he was prevented from ascending the peak as he was informed that " the road to the summit was quite inaccessible until June" (see his Description of the Azores).

Sketch - of the Botanical Investigation of the Azores.Apparently, long 'before any systematic investigation of the flora of the Azores, several of its characteristic plants were introduced into the gardens of Europe, more particularly those of Portugal and England. In southern Portugal Myrica faya is now "almost indigenous" in the mountains of Algarve and in other localities, and must have been brought from the Azores long ago, a matter referred to in a later page. We learn from Aiton's Hortus Kewensis (1789) that this tree, with other plants from these islands, was introduced in the Kew Gardens through the agency of Francis Masson in 1777 and 1778. Although Masson was one of the first English visitors to the Azores to display an active interest in the flora, a paper by him in the Philosophical Transactions for 1778 on the island of San Miguel contains but little botanical information. In the middle of July 1775 George Forster took several excursions on the island of Fayal during a stay of four or five days made by the Resolution under Captain Cook. He gathered a small collection, mainly consisting of weeds of cultivation and of other plants introduced by man, the list of which is given in the Commentationes Societatis Regiax Scientiarum Gottingensis for 1787 (Vol. IX.). Further reference will be made to this list when dealing with the introduced plants. It is given in Note $\mathbf{3 3}$ of the Appendix. 
On April 24, 1838, there reached San Miguel a party of scientific men, which included Guthnick, a native of Berne, Hochstetter and his son Charles, and Gygax, a Swiss mineralogist. From the account which Seubert gives in the preface of his Flora Azorica it appears that Guthnick, after forming the project of investigating the littleknown flora of this group, received the advice of De Candolle, and that the Hochstetters were his associates in the botanical exploration. The party afterwards visited Terceira and Fayal, and here they parted, the Hochstetters proceeding to Flores and Corvo in a vessel placed at their disposal by Mr. Dabney, the American Consul-general, whilst Guthnick during their absence returned to Europe. The Hochstetters subsequently visited Pico and ascended the mountain, and left the islands in August. I have not been able to discover whether Guthnick published an account of his visit to the islands. Some of his descriptions of new Azorean species are given in Seubert's work. Among the botanical papers accredited to him in the Royal Society Catalogue of Scientific Papers none are concerned with the Azores. As regards the Hochstetters, it may be said that their collections and notes formed the basis of Seubert's Flora Azorica (1844). They worked out the zones of vegetation on the great cone of Pico; and it is to their labours that the scientific world was first indebted for an accurate knowledge of the Azorean native flora. Some of their principal results were first published in a sketch of the flora entitled "Ubersicht der Flora der azorischen Inseln" by Seubert and Hochstetter, which is given in Wiegmann's Archiv für Naturgeschichte, Berlin, 1843, a paper mentioned but not consulted by either Watson or Trelease. It contains a large coloured plate illustrating the zones of vegetation on the cone of Pico, the plants characteristic of each zone being named. But the bulk of the work of the Hochstetters was incorporated in Seubert's Flora Azorica, which was issued in the following year, a work which held the field until Watson's monograph appeared in $\mathbf{1 8 7 0}$ in Godman's Natural History of the Azores, and one that still stands foremost as an account of the native flora.

H. C. Watson was the next botanist to visit the group. His stay in the islands covered four months, from May to September 1842, during which time he occupied a cabin in H.M.S. Styx, then engaged in the survey of the archipelago. The exigencies of the survey rendered the conditions by no means favourable for his purpose; but he obtained collections from Corvo, Flores, Fayal, and Pico. His examination of the mountain of Pico was restricted to an ascent of the summit with the surveying party from the ship, and to two other excursions on the lower slopes; but he expressly states that the conditions did not allow him to obtain exact information concerning the vertical range of the plants on the mountain. This regret was expressed in a paper in the botanical publication below named for 1843; and it is a pity that in his memoir in Godman's work, published many years after, he depreciates the work of his predecessors in this respect. In his criticism (p. 114) of Seubert's Flora Azorica he gives as an instance of the "guesses that might prove only erroneous records" the " alleged ranges of altitudes at 
which various of the species are stated to occur; but" (he continues) " it is asserted here with some confidence that the stated altitudes must too often have been merely rough guesses by somebody not sufficiently informed about the true heights of hills and places in the Isles." Seubert's data were supplied by Hochstetter and his son, and were by no means guesses. As shown in my notes on the Azorean plants in Chapter XIX., they conform as a rule very closely with my own independent observations, the methods of obtaining the altitudes being there stated.

The results of Watson's investigations were first given in the London Journal of Botany, 1843-7, and finally in 1870 in the botanical section of Godman's general work. In the last case they were greatly extended by a large amount of materials supplied chiefly by collections made in 1844-8 by Mr. Carew Hunt, British Consul for the Azores, and to a less extent by those made by Godman in 1865 . It may be added here that the Journal of the Royal Geographical Society for 1845 contains a paper on the islands of San Miguel and Santa Maria by Mr. Hunt. There is, however, not much in it of botanical interest.

In 1857 there visited these islands Drouet and Morelet, two French zoologists, and Hartung, a German geologist, of whom the two first specially interested themselves in the botany of the group. Drouet and Morelet were more or less associated in their travels, and they remained in the islands from April to September. Morelet accomplished the ascent of Pico and made valuable observations on the vertical distribution of the plants. Drouet attempted the same ascent; but his strength failed him, and he turned back when about half-way up the mountain. Morelet published his notes in his Iles Açores (L'Histoire Naturelle) in 1860. Drouet was rather more ambitious, since he published in 1866 a list of the plants of these islands in his Catalogue de la Flore des Iles Açores. But, as Watson points out (p. 119), his enumeration suffers from defects that were to be expected in a work written by one whose chief speciality was zoological. Yet with Drouet's book in his hands the botanist visiting these islands for the first time would be well provided, and the mistakes arising from lack of familiarity with synonyms and "name-changes" would be more than counterbalanced by the valuable notes relating to the plants. Hartung, whose work on the geology of the islands (Die Azoren, Leipzig, 1860) has long been the principal authority on the subject, remained in the group until the end of August. He seems to have made but a short examination of Pico, and, though he visited all the islands, San Miguel and Terceira occupied most of his attention. His book is chiefly of interest to us from the observations it contains on the ancient trunks of Juniper buried in the volcanic tuffs of San Miguel. He devotes about forty pages to the flora, but he depends entirely on Seubert and Watson, and in his comparison of the Azorean, Madeiran, and Canarian floras he relies principally on Heer. It does not appear that he made many observations on the living plants.

Excluding the Portuguese investigators, to be subsequently referred to, the next person to interest himself in the vegetation of 
the Azores was Godman, who, although his special mission was concerned with zoology, made extensive plant collections during his stay in the group, March to May 1865. These materials were in part worked up by Watson in his monograph in Godman's book on the natural history of the islands. In $1894 \mathrm{Mr}$. C. S. Brown made considerable collections, chiefly on Fayal, Pico, and San Miguel. They were utilised by Trelease in the work to be immediately mentioned. Three months in the summer of 1894 and a shorter period in 1896 were occupied by Trelease, Director of the Missouri Botanical Garden, in making collections in these islands. They were worked up by him and the results incorporated with those of his predecessors in his Botanical Observations in the Azores, published in 1897 in the Eighth Report of the Missouri Botanical Garden. The general remarks are limited; but as a catalogue of the plants this monograph is the most complete and authoritative of the works on the Azorean flora that have been published up to the date of my writing. In March 1909, G. C. Druce made a brief stay on San Miguel, which supplied materials for short papers in the Journal of Botany for January 1911, and in the Chemist and Druggist.

The last to be mentioned, but not the least important of the investigators of the Azorean flora, are those resident Portuguese gentlemen who in bygone and in recent times made numerous private collections and built up the herbarium in the Municipal Museum at Ponta Delgada. Much of the work of Dr. Bruno T. Carreiro, Dr. C. Machado, Dr. J. A. N. Sampaio, and others is utilised by Trelease in his monograph; but there must be many whose labours have contributed to our knowledge of the plants of these islands, though their names are no longer remembered. An account of those of the earlier Portuguese residents, who in the long years since the occupation of the islands have paid attention to the plants, would come fitly from the pen of a Portuguese botanist. In 1852 there was published at Lisbon a list of plants introduced into the Botanic Garden of the Medical School of that city from various parts of the world, the authors of which were B. A. Gomes and C. M. F. da Beirão (Catalogus Plantarum Horti Botanici Medico-Chirurgica Schola Olisiponensis). Azorean plants are here included. In conclusion one may observe that in addition to his special studies on the general zoology and fossil diatoms of the group, Colonel F. A. Chaves, the head of the Meteorological Service of the Azores, has done much not only in collecting flowering plants, but in assisting botanists visiting the islands.

The Heights of the Azores.-The great volcanic cone of Pico, 7613 feet in altitude, is by far the highest mountain in the group, none of the other islands attaining half its height. There are eight other islands, and it is very remarkable that the three largest and most elevated of them have practically the same elevation, San Miguel 3570 feet, Terceira 3500 feet, and San Jorge 3498 feet; whilst the two islands next in size, Fayal and Flores, are not much lower, their respective heights being 3351 and $\mathbf{3 0 8 7}$ feet. This is a physical feature of importance, since Pico loses the advantage of its much greater elevation on account of the predominance of lava and cinders 
in its upper portion; and for purposes of comparison, as concerning the average soil-conditions suitable for vegetation, we may regard only its lower 4000 or 4500 feet. Taking the whole island of Pico, the same rule applies, since with the exception of the peak none of the other mountains exceed 3500 feet in height. It is true that Pico Topo, lying behind Lagens, is credited in the Admiralty chart and in the accompanying "Sailing Directions" with an altitude of 5357 feet; but there is an error here, the true elevation, as the writer ascertained by aneroid, being about 3300 feet. This mistake doubtless dates back to the time of the survey of the archipelago by Captain Vidal, 1842-4. The author spent some days in the vicinity of this mountain, which does not exceed the average height of the peaks of this part of the island, the great cone towering far above them all. He learned from Colonel Chaves that up to 1914 the Admiralty chart of the island was the only available map. (In the latest issue of this chart (No. 1855) the correction has since been made, the height of Pico Topo being there reduced to 3357 feet, as indicated in the map of the island accompanying this work.)

Comparison of the Conditions of Forest-Growth in the Azores, Madeira, and the Canaries.-From what has been said above we should be safe in assuming that the soil-conditions for typical forest growth in the Azores, as a whole, cease usually at altitudes between 3000 and 4000 feet. It would seem from the early accounts of Madeira that the original forests must have extended nearly to the summit of the island, and we will take their average limits as between 5000 and 6000 feet. In the Canaries, as illustrated by Teneriffe, this limit would be generally about $\mathbf{7 0 0 0}$ feet. After applying to these values for the three Macaronesian groups the correction for the difference in latitude and for the associated differences in climate, we should expect to find in the Azores only the Canarian forest vegetation of between 2000 and 5000 feet, or, in other words, the evergreen shrubs and trees of the Laurel-belt. We could scarcely look for more, since the higher Pine-belt of Teneriffe could not exist on the lava and cinders of the higher levels of the cone of Pico; whilst the lower Canarian coast-belt with all its strange African plants would be unrepresented for want of the warm climatic conditions. In Madeira, intermediate in latitude and in climate between the other two groups, we should expect to find an intermediate condition of things. The lower African zone, so well developed in the Canary Islands and absent from the Azores, ought to be considerably restricted in Madeira; and, since this island barely emerges from the cloud-belt, its forest vegetation of the Canarian type might be expected, subject to soil-conditions, to reach the summit. In this correlation of the three floras, the writer, as far as the Azores and the Canaries are concerned, was long ago forestalled by Hochstetter and Morelet. Its significance will be made more apparent in a later page.

The General Profile of the Cone of Pico.-The characteristic appearance of the great cone of Pico is that of a mountain rising with easy slopes for its lower two-thirds, and then ascending precipitously to the summit. Except on the southern side it rises 
gently up to between 2000 and 2500 feet; after which there is a steeper gradient to between 4500 and 5000 feet; and then it ascends rapidly to the top. Yet it would be difficult to find a lofty volcanic mountain rising from the sea with such a steep slope as is presented by the great mountain on its south side. It attains its maximum elevation of 7613 feet at a distance of 2.42 geographical miles from the coast, which represents an average angle of slope of about $27^{\circ}$. Mr. Samler Brown rightly says in his guide-book to these islands (edit. 1905, p. 7) that it rises more abruptly from the sea than the Peak of Teneriffe. Taking the shortest distance from the coast at seven and a half miles and the altitude at 12,180 feet, the Peak of Teneriffe rises from the sea on its north side at an average angle of about $15^{\circ}$.

There is some excuse for those who have coasted along the south side of the island of Pico, or who have lived for weeks, as I have done, on the south coast under the shadow of the peak, if at times they carry away the exaggerated impression of a great cone rising in places almost sheer from the sea. There lies before me a chart of the Azores by Wm. Heather, dated 1822, drawn, revised, and corrected by J. W. Norie, hydrographer. In a profile sketch of the peak, bearing E. $3^{\circ} \mathrm{S}$. by compass, the mountain is represented as pinnacle-formed and rising from the sea to its summit at an angle of about $60^{\circ}$. This, of course, is very far from being the case, as may be seen from the profile sketches given in the Admiralty chart from Captain Vidal's survey in 1842-4. Yet, as will now be shown, there is a tremendous drop in a limited region on the southern slopes.

The Bluffs of the Ribiera Grande.-Due south of the peak and opposite the coast villages of Praynha do Sud and Terra do Pao, the mountain in its lower half drops about $\mathbf{3 0 0 0}$ feet in a thousand yards, giving rise for a mile or two to a line of huge bluffs, the precipitous faces of which are deeply scored by gorges and gulleys forming dry river-beds, the largest of them being known as the Ribiera Grande. Their steep sides, carved out into spurs and buttresses, are usually well wooded, except in the gulleys and gorges, and they terminate abruptly in the low and narrow strip of coast on which the two villages lie. These bluffs constitute the most precipitous portion of the lower slopes of the mountain and present one of its chief spectacular features. The winding paths used by the shepherds tending their sheep ascend what looks from a distance like an impossible precipice. Yet with a guide the ascent, though tedious, is not difficult. Tiny white specks, which dot the upper declivities, mark the sheep, and bring home to the climber the great height of the bluffs.

Above the higher edge of the bluffs the steep upper slopes of the mountain are streaked by "slides" of boulders and loose blocks of lava, where no vegetation obtains a hold, localities that my guides were very unwilling to approach. Not infrequently a huge boulder is set in motion, and rolling down the slide it leaps over the upper edge of the bluffs, and bounding down their precipitous sides at tremendous speed, ultimately plunges into some field or garden at 
their base and comes to rest. To the people of the coast villages, especially of that of Terra do Pao, which lies immediately beneath the bluffs, the bombardment by boulders is a matter to be reckoned with. They pointed out some to me which they declared had come from the upper slopes of the peak. One of them was about three feet high, and I was told that this size may be much exceeded. These rockmasses, after leaping and bounding for at least 4000 or 5000 feet down the steep mountain sides, sometimes come crashing down into the precincts of the village in the middle of the night.

The Extent of the Vegetation on the Mountain of Pico.The impression formed at a distance that the lower two-thirds of the mountain are vegetated and that the lava slopes of the upper third are barren, is verified only in a relative sense when the observer ascends the mountain. Godman (p. 15) remarks that " in winter the extreme cone is frequently covered with a thin layer of snow, and is destitute of vegetation with the exception of a few lichens." Ogilvie-Grant, speaking of the Magdalena side of the mountain, states that on the higher slopes "desolation and lava covered with grey lichen and moss hold undisputed sway" (Nov. Zool., Jan. 1905). Impressions of this kind are often acquired by those who have not made the complete ascent.

The lower slopes are generally well vegetated up to altitudes of 4500 to 5000 feet, moor and grass land predominating in their higher levels, that is, above 2000 feet. Woods are well developed in places, the lower woods on the western side and the upper woods on the south-eastern side. On the north-west side there is an almost continuous band of wood, which extends from the vicinity of Bandeiras, about 400 feet above the sea, right up the mountain slopes to over $\mathbf{5 0 0 0}$ feet, where the trees and shrubs are dwarfed. The woods are essentially formed by evergreen shrubs and trees; but on account of the persistent agency of the woodcutter through centuries the trees, except when specially preserved, rarely exceed twenty feet in height, and are usually not more than fifteen or sixteen feet. Dwarfing of the trees and shrubs begins as a rule at about 4000 feet as the effect of deficient soil and of exposure to the prevailing strong winds; but it is likely that in the early times forests of considerable height existed at this altitude.

Above the level of 5000 feet the sparse vegetation of the precipitous upper third of the mountain presents a great contrast to the grassy and wooded slopes below. On the crumbling lava and on the beds of cinders and coarse ashes that form the surface plants for the most part obtain a scanty hold. It is true, however, that dwarfed trees and shrubs climb the steep slopes for a few hundred feet, the scrub failing at levels short of 6000 feet; but above that height vegetation is sparse, and the plants become scarcer and scarcer as one nears the summit, about half a dozen species reaching in much diminished numbers the terminal crater and its small cone.

The Zones of Vegetation on the Mountain of Pico.-When the writer visited Pico with the object of determining the altitudinal arrangement of the plants, he was only acquainted with Watson's and Trelease's monographs, issued respectively in 1870 and 1897. 
In the first-named work the subject is hardly mentioned, whilst in the second it is not alluded to. After he had made his study, he was surprised to find that excellent accounts of the vertical distribution of plants on the mountain are to be found in the writings of Hochstetter (1843), Seubert (1844), and Morelet (1860), and that Drouet (1866) gave many details of importance. However, it is to the Hochstetters that we are most indebted for information on the subject. It was with mingled feelings of satisfaction and disappointment that the writer discovered that his main results were in close agreement with those of the German investigators and of their later French fellow-workers in this field.

In the vertical range of the plants there are few material differences between the writer's results and those of the previous investigators. In the actual arrangement of the zones the differences are also few, and in the main the suggested zones either confirm or amplify the writer's own arrangement.

The zones on Pico, as first described in the conjoint paper by the elder Hochstetter and Seubert in Wiegmann's Archiv (1843), were as follows :-

I. The cultivated or Mediterranean zone, extending from the coast to an altitude of $\mathbf{1 5 0 0}$ feet and characterised by Mediterranean and European cultivated plants, weeds, and shore plants.

II. The Canarian zone, or belt of the Laurel woods, extending from 1500 to 2500 feet.

III. The Azorean zone, or region of shrubs, 2500 to 4500 feet, where many of the species peculiar to the Azores occur.

IV. The bush or scrub region, 4500 to 5000 feet.

V. The peak region, above 5000 feet to the summit (7600) feet.

There are one or two conspicuous defects in this arrangement. In the first place, the Canarian zone extends considerably above 2500 feet. Then, any scheme that ignores the vegetation of the upland moors, so prominent a feature on the slopes of the mountain, between 2000 and 4000 feet, would be incomplete. The data, again, scarcely justify our regarding the region between 2500 and 4500 feet as characterised principally by shrubs, or as being the special home of peculiar Azorean plants. The coast, the lower woods, and the upland moors, all present some of these endemic plants, which number only about thirty in all, several of them having been not yet recorded from Pico.

In Seubert's Flora Azorica, published in the following year (1844), zones II. and III. are named respectively, the regions of the lower and the upper mountain woods, a correction which makes the arrangement closely similar to the one independently adopted by the present writer, the characteristic plants of each zone being in close correspondence. Here again, however, the belt of the upland moors is not recognised. The arrangement, as given by Seubert, is based on Hochstetter's notes, and is as below given.

I. Region of cultivation, coast to 1500 feet.

II. Lower mountain woods, 1500 to 2500 feet. 
III. Upper mountain woods, 2500 to 4500 feet.

IV. Region of bushes, 4500 to 5200 feet.

V. Highest zone, above $\mathbf{5 2 0 0}$ feet, mostly lava, etc.

Morelet, in his work on the natural history of the Azores (1860), adopts three zones of vegetation for the islands generally, namely:-

I. The zone of cultivation to 500 metres (1640 feet).

II. The middle zone, or the zone of woods, extending up to 1500 metres (4920 feet), and corresponding in the laurels and other evergreen trees and shrubs to the laurel-belt of the Canary Islands.

III. The superior zone, $\mathbf{1 5 0 0}$ metres to the summit. Here the trees and shrubs become less vigorous and give place to the pastures and the heaths. Only represented on Pico.

This is a good arrangement, though it is an error to place the pastures in the third zone, the upland moors, to which he evidently refers, belonging to his second zone.

The Zones of Vegetation on the Mountain of Pico as Determined By the Author.-We now come to the zones adopted by the writer. As regards their limits there is a very close similarity with those framed by Seubert from the notes of the Hochstetters and given in his Flora Azorica. They were determined under the belief that the present writer was the first to make this inquiry, and their close correspondence with those adopted by Seubert enables him to tread on firm ground in this matter. Before the occupation of the islands the lower woods must have usually extended to the coast, as they do now in places. Since it is with the native flora and the original condition of the island that we are here concerned, the region of cultivation is omitted and the belt of the upland moors has been added. The list of plants, below given as most characteristic of each zone, include all those named for the same zone by Seubert and Hochstetter, with the addition of others.

I. The Lower Woods or the Faya zone, extending from the coast to between 2000 and 2500 feet above the sea. The most abundant trees are Myrica faya, Erica azorica, and Laurus canariensis (Persea azorica). Next in order of frequency come Ilex perado, Rhamnus latifolius, Persea indica, and Picconia excelsa, the last two being now rare. Taxus baccata, at present almost extinct, found its home in the higher levels of this zone. The most characteristic shrubs in their order of frequency would be Myrsine africana, Vaccinium cylindraceum, Hypericum foliosum, and Viburnum tinus. Hedera canariensis and a species of Smilax represent the climbers, and Rubus fruticosus occurs in the undergrowth. Osmunda regalis is the most conspicuous of the ferns. Doubtless in the original forests this zone was divided into two sub-zones by the distribution of the two laurels, Laurus canariensis (Persea azorica) characterising the upper half and Persea indica the lower half.

II. The Upper Woods or the Juniper zone, between 2000 and 4500 feet for the woods proper and from $\mathbf{4 5 0 0}$ to $\mathbf{5 5 0 0}$ feet for the scrub. There is often a neutral area between 2000 and 3000 feet, where 
the plants of the Faya and Juniper zones intermingle; but as a rule the Juniper begins where the Faya ends. The three most distinctive trees and shrubs of this zone are in their order of frequency, Juniperus oxycedrus (var. brevifolia), Daphne laureola, and Euphorbia stygiana, the Tree-Euphorbia. But Erica azorica (Tree-Heath), Laurus canariensis, Myrsine africana, Ilex perado, and Vaccinium cylindraceum, all of the lower woods, are here also abundant; and characteristic among the ferns are Dicksonia culcita and Acrostichum squamosum, with Woodwardia radicans on the sides of the gulleys. A common parasite on the Juniper trees is Arceuthobium oxycedri. In the original forests Taxus baccata thrived in the lower levels of this zone.

III. The Calluna, Menziesia, and Thymus zone, 5500 feet to the summit (7600 feet), the cone proper. Mats of Calluna vulgaris and of Thymus serpyllum (var. angustifolius) and tufts of Menziesia polifolia predominate on these scantily vegetated steep slopes of lava and cinders. Polygala vulgaris also occurs with one or two grasses, such as Agrostis castellana.

There is a close agreement between my predecessors and myself as to the five plants that exist in the higher levels of the peak. All of us, Hochstetter in 1838, Watson in 1842, Morelet in 1857, and the writer in 1913 and 1914, record the Ling (Calluna vulgaris) and the Thyme, and three of us the Polygala, the Menziesia, and the Agrostis. The strangest reference is to the Polygala, which owes its occurrence at this elevation to the protection it finds in the beds of Ling. A solitary specimen was found by Watson in this locality (Lond. Journ. Bot., II., 394); but the plant is frequent enough to be regarded as one of the characteristic terminal species, and as such it was rightly viewed by Seubert and Hochstetter.

Though the number of terminal species does not seem to have increased in the interval between 1838 and 1914, it is likely that the Ling, the Thyme, and the Menziesia have considerably extended the area occupied by them on the level shoulder on the south side of the mountain between 6500 and 7000 feet above the sea. With the exception of Polygala vulgaris, all the plants of the highest levels on Pico are widely distributed over the group. They are not necessarily summit plants, but have found a home in the highest levels because they alone of the plants of the lower levels, more especially of the moors, have been able to establish themselves there. Polygala vulgaris has been only found on the island of Pico, where it was collected on and near the summit of the great mountain by Hochstetter in 1838, by Watson in 1842, and by myself in 1914; but as below observed I found it also on the moors below, as well as in those of the lake district to the eastward. Agrostis castellana, as we learn from Trelease, is a polymorphous Spanish species that is widely distributed in the Azores, being the most abundant of the native grasses. It is important to note that all the plants that have reached the top of the great cone of Pico have climbed the slopes from the moors below. There is no peculiar summit flora.

IV. The Upland Moors, 2000 to 4000 feet. This zone has been formed at the expense of the Juniper zone around much of the moun- 
tain. Though doubtless greatly extended by the destruction of the forests since the discovery of the islands, the moors have probably always formed a conspicuous feature of the mountain of Pico around the base of the steep-sided central cone. Without differentiating here between the drier and wetter areas, the most striking features are the bracken (Pteris aquilina), the large tussocks of Polytrichum, and the beds of Sphagnum. Their general characters are often those of a Devonshire moor, as on Dartmoor; and most of the characteristic species exist in both regions. Amongst the most frequent flowering plants are Anagallis tenella, Calluna vulgaris, Erythrcea massoni, Hydrocotyle vulgaris, Luzula purpureo-splendens, Lysimachia nemorum (var. azorica), Menziesia polifolia, Polygala vulgaris, Potentilla tormentilla, Sibthorpia europcea, Thymus serpyllum (var. angustifolius), Viola palustris, and among the sedges, Carex flava. Lycopodium selago is common, and Blechnum spicant also occurs. Water-holes exist in the more boggy ground, and around the edges and in the water of these pools grow Callitriche aquatica, Carex stellulata, Littorella lacustris, Peplis portula, Potamogeton polygonifolius, Scirpus fluitans, $S$. multicaulis, etc.

The Prevailing Climatic Conditions on the Upper Slopes of the Mountain of Pico.-With regard to this point it may be stated that the cloud-belt or rainy zone, 2000 to 5000 feet, corresponds roughly to the Juniper zone and to the belt of the upland moors. The " region of clouds," as Watson terms it, is suggestively described by him as the region of boreal and marsh plants (Lond. Journ. Bot., II., 394). With reference to the higher levels between 6000 feet and the summit (7600 feet), although the nature of the surface of crumbling lava and cinders would primarily determine the type of plants adapted for growing on steep slopes of this character, the choice would be further restricted to plants capable of withstanding in such an exposed situation the relatively dry atmosphere, the fierce rays of the sun in summer, the frost and snow of winter, and the stormy winds that buffet these heights during much of the year.

Whilst the rainfall would be much less on the high levels than in the cloud-invested Juniper zone and upland moors below, its deficiency would be partly compensated for by the heavy dews. The amount of sunshine must be considerably greater here than in the zones of the woods below. The mere concealment of the peak by clouds, when viewed from the coast, by no means always implies that the summit is cloud-capt. Not infrequently, when the writer had reached the upper limit of the cloud-belt through a driving wet mist, he found the upper third of the mountain exposed under a clear sky to the full glare of the sun and rising out of a billowy sea of clouds of dazzling whiteness, like an island in the midst of Arctic snows.

Although the daily range of temperature would be greater, it is very probable that the monthly means of the temperature of the air in the shade on the higher slopes of the mountain would approximate those for the elevated region of Dartmoor in the south-west of England, between 1500 and 2000 feet above the sea, a range, let us suppose, of from $33^{\circ}$ in January to about $58^{\circ}$ Fahr. in July. Snow comes and 
goes on the peak at intervals during the winter and may lie for some time; but it is rarely of any great depth except in the drifts. As a rule it disappears finally during May. Godman (p. 10) speaks of the snowy top of Pico peeping out from the clouds in the last week of April (1865). The statement of Captain Boid (pp. 307-9) that snow lies on the mountain nearly eight months of the year gives an exaggerated notion of the permanency of the snow-cap on Pico. Watson observes that snow may lie under the shade of rocks, and (one may add) in cracks and fissures, until May, but no longer. $\mathrm{He}$ states that six weeks before his ascent on July $1 \mathrm{Mr}$. Dabney had sent a party up to procure snow for a sick friend, "and they got some" (Lond. Journ. Bot., II., 394).

The lower limit of the snow is generally about 4000 feet; and in this connection it should be noted that on the summits of the other large islands, all of which reach a height of about 3500 feet above the sea, snow rarely lies. It is always winter for the people of the Western Azores, whilst Pico wears its white cap. During the writer's stay on the mountain, from the second week of March to the second week of April 1913, snow fell on at least three occasions, and for most of the time the peak was white with it. Different ascents were made up the snow-covered slopes, and in one of them (April 1) he gained the summit.

General Account of the Vegetation of the Mountain of Pico.-Coming to a general account of the regetation of this great volcanic cone, and reversing the customary order of description, we will imagine a botanist who, after alighting on the top of the mountain, descends to the coast. Upon the summit, not only at the borders of the small crater, but also on the sides of its little cone (200 feet in height), he would observe in the crevices of the bare lava surfaces small stunted growths, only a few inches high, of Calluna zulgaris and Menziesia polifolia, with small patches of Thymus serpyllum (var. angustifolius), and here and there a tuft of Agrostis castellana. Proceeding to descend the lava slopes on the south side he would very soon notice specimens of Polygala vulgaris growing for protection in the patches of Ling (Calluna rulgaris). He quickly reaches the shoulder of the mountain, a more or less level stretch of lava and "lapilli," 6500 to 7000 feet above the sea, where the Ling and the Thyme grow in dense mat-like beds, almost carpeting the surface in places, the first named only a few inches high and scarcely higher than the Thyme beds. In the middle of July the Ling shows only the evidence of the last season's flowering and fruiting, whilst the Thyme beds present a mass of bloom. It is on this shoulder of the mountain that St. Dabeoc's Heath (Mensiesia polifolia) is most abundant, and flowers copiously in July.

[The above description applies to the plants of the summit as observed by the writer in the middle of July. When he ascended to the top on April 1 of the previous year, the peak was largely covered with snow; but the beds of Ling and Thyme were easily recognised, the former plant displaying the bleached sepals of the last season's flowering and the latter retaining in abundance the empty fruiting calices.] 
From the edge of the shoulder one looks down a precipitous slope of lava-flows, loose stones, and ashes, covered in places by large patches of the Ling, Thyme, and St. Dabeoc's Heath. One instinctively treads on the mats of Ling and Thyme, since they give a firmer foothold during the steep descent. There are few other flowering plants, except the half a dozen above named, that grow on these arid slopes above 6000 feet.

Very rarely one comes upon some straggler from the woods below growing from seeds dropped by birds in the crevices of a bare lavacliff. Situated far above the ordinary upper limit of the rain-belt, exposed to the frosts of winter, and unprotected against the intensity of the sun's rays in summer, such a plant has a hard struggle to hold its own. It was under such conditions, at an altitude of 6300 feet, that the writer found in the middle of July a few scattered individuals of the Azorean Holly (Ilex perado). Though they were scarcely over a foot in height, their thick woody stocks indicated that they had been established for some years. They were in bloom; and it was interesting to notice how the axillary flowers were protected against the scorching heat of the sun's rays by the raising of the leaves, which had assumed the vertical position and lay with appressed faces close to the stem. The expanding terminal leaf-buds were shielded by the same device; but more often than not it had proved to be ineffectual, and the buds were blackened and dead.

Our botanist has now descended to an altitude of about 6000 feet. Before he gets off the steep upper-third of the mountain on to the wooded and grassy slopes of gentler gradient below, he has yet to clamber down another thousand or fifteen hundred feet over old lava-flows, beds of cinders, and loose stones and boulders that when displaced bound for hundreds of feet down the mountain's side. But, as he descends, the conditions become a little more favourable for plant growth. For a minute or two a driving mist envelopes him and shuts all out from view. He has been in a wisp of cloud and is approaching the upper limit of the rain-belt.

Should he descend on the western side he will make but few additions to his list of plants, until, at a level of about $\mathbf{5 5 0 0}$ feet, he comes upon the outposts of the woods in the form of stunted bushes of the Tree-Heath (Erica azorica). On the eastern slopes of the mountain, where for some reason more humid conditions prevail, as soon as he passes below 6000 feet he will find that the beds of Ling (Calluna vulgaris) afford protection to a variety of different plants. On these wind-swept slopes the Ling beds are only four or five inches high; and in them nestle dwarfed specimens of Juniperus oxycedrus, flowering and fruiting, though not over six inches in height, as freely as the trees of ten and twelve feet in the woods below. On exposed peaks in this group, as may be observed on the summits of San Miguel, Terceira, etc., one often finds a dense spreading growth of stunted Junipers rising only two feet from the ground, a feature also observed and well described by Watson (p. 224); but nowhere did the present writer notice the dwarfing process so pronounced as in the case of these tiny Junipers fruiting in the Ling beds on the bleak heights of the great mountain 
of Pico. Amongst the other flowering plants that find a sanctuary in these Calluna beds at altitudes of 5000 to 6000 feet are delicate herbaceous plants, like Polygala vulgaris, Erythroea massoni, and Lysimachia nemorum, and a hardy plant like $V$ accinium cylindraceum, which, however, instead of growing nine or ten feet high, as in the woods, is here reduced to five or six inches. Of the ferns and lycopods that are able to hold their own at these high levels of 5000 to 6000 feet, Blechnum spicant takes refuge in the Ling beds, whilst Lycopodium selago seeks a shelter in the hollows of the lava.

The impression one forms while descending these steep lava slopes of the upper-third of the mountain is that many of the plants characteristic of the lower levels would reach the summit, if the soil-conditions allowed it. This was also the opinion of Morelet, the French zoologist, who ascribed the penury of the higher levels to the nature of the surface and to the steep angle of the slopes. The repressive influence of the fierce winds that blow around these heights during much of the year would be mainly found in the dwarfing of the trees and shrubs. That several of the plants which are at home in the upper woods between 2000 and 4000 feet ean grow at levels between 5000 and 6000 feet is shown in their readiness to seek shelter at these heights in the small craters and gulches, in the broken-down lava caverns, and in the numerous fissures, cracks, and holes. Here we find the Tree-Euphorbia ( $E$. stygiana), the Azorean Holly (Ilex perado), Daphne laureola, Myrsine africana, Laurus canariensis, etc., species that are not to be seen on the windswept slopes near-by; whilst the Juniper and Vaccinium may be observed growing four or five feet high in a pit and only four or five inches high when exposed at its borders.

But apart from these sanctuaries on the higher slopes for the more adventurous plants of the woods below, stunted specimens of the Tree-Heath (Erica azorica), which form the outposts of the woods, sometimes ascend, as already observed, the lower slopes of the steep upper-third of the mountain to between 5500 and 6000 feet. When we get off these steep slopes at a level of from 4500 to 5000 feet, the soil-conditions become more favourable. Here the Tree-Heath begins to assert its arborescent habit, and it is associated with Juniper trees of fair size, the Juniper growing well on suitable ground at these altitudes.

We now enter the cloud-belt, or rainy zone, which in its limits of 2000 to 5000 feet rudely corresponds to the upper mountain woods. Amongst the trees, Erica azorica is often predominant, attaining its greatest development in the middle of the belt and growing, when left undisturbed, to a height of fifteen, eighteen, and even twenty feet; while in the open woodland bushes of Calluna vulgaris may be nearly as abundant. It is between 3000 and 4000 feet that the upper woods display their best growth, and this is well seen on the south-east slopes of the mountain. Although on account of the woodcutter's destructive influence, exercised through centuries, the wood is small, the height of the trees not usually exceeding fifteen or sixteen feet, several of them when left alone can attain, as below shown, twice this height. Among the other characteristic 
trees and shrubs of the upper woods are Laurus canariensis, Myrsine africana, Ilex perado, Daphne laureola, Vaccinium cylindraceum, etc.; and here thrive as solitary specimens, or in twos and threes, the Tree-Euphorbias (E. stygiana).

Indications of the prevailing humidity in the upper woods are displayed in the filmy ferns (Hymenophyllum tunbridgense) growing on the trunks of the large Junipers and Tree-Heaths. In the rank. undergrowth flourish ferns like Dicksonia culcita, Acrostichum squamosum, and the Bracken (Pteris aquilina), lycopods like Lycopodium complanatum, and flowering plants, such as the beautiful Euphrasia grandiflora and Carices, among which we may mention Carex stellulata. Woodwardia radicans is conspicuous amongst the ferns that drape the sides of the gulleys; and clothing the moist and shady banks of the small stream-channels are the fronds of Trichomanes speciosum. Covering the walls of the lava caverns are Selaginellae and Hepaticae.

When long undisturbed these upper mountain woods form dense thickets difficult to penetrate. Here thrives on the branches and trunks of the Juniper trees the Loranth, Arceuthobium oxycedri, a parasite that grows commonly on these trees all round the slopes of this mountain at elevations of from 2000 to 4000 feet. One little plant not yet mentioned is Sibthorpia europcea. It abounds in shady spots.

One of the most interesting of the plants in the upper woods is: Daphne laureola, which is usually restricted to levels between 3500 . and 4500 feet. In the woods and thickets it displays a loose straggling habit; but when, as on the northern side of the mountain, it grows exposed on the moors near their upper limits, it presents itself as rounded dense bushes three or four feet in height. Yet it is a plant that even here seeks protection, and it selects the dips and hollows of the moors and gives a singular appearance to the: landscape.

Numerous small craters and gulches in the zone of the upper woods afford refuge to plants that under ordinary circumstances are confined to the lower woods. The vegetation of the small craters on the slopes of this mountain is often especially luxuriant. When, as sometimes happens, the crater or gulch is inaccessible, the plants attain unusual heights, protected against injury from men and animals. Here in a limited space, at altitudes of about $\mathbf{3 5 0 0}$ feet, one may observe nearly all the trees and shrubs of the slopes of Pico from the coast up to 5000 feet, not only those of the upper woods, but such as Myrica faya, Rhamnus latifolius, and Viburnum tinus, that are ordinarily restricted to the lower woods. In these refuges the Tree-Euphorbias are especially at home, and there flourish here many herbaceous plants of both wood zones, such as Euphrasia grandiflora, a tall Verbascum, Sanicula azorica, and species of Habenaria.

The dominant trees of the lower woods, that is, below 2000 feet, are Myrica faya, Erica azorica, and Laurus canariensis. The dominant shrub is Myrsine africana. But Rhamnus latifolius, Vaccinium cylindraceum, and Ilex perado are also frequent. The 
Laurestinus (Viburnum tinus) is absent in some places and fairly represented in others. The "Pao branco" (Picconia excelsa) is now very rare, its timber being much appreciated by the islanders. However, single trees may occasionally be noticed in the woods; but as a rule it finds a refuge in some inaccessible gulch or small crater. Osmunda regalis may be observed at levels exceeding 1000 feet in moist surroundings at the margin of the woods. Amongst the tree-climbers are a Smilax and Hedera canariensis, the undergrowth being generally formed by species of Rubus, Myrsine africana, the Ivy just named, and Pteris aquilina. In the open districts Calluna vulgaris is abundant.

But the lower woods are essentially the zone of the Faya tree, and here, as in the case of nearly all the most conspicuous features in the vertical distribution of plants on this mountain, we have the corroborative testimony of the Hochstetters. Just as the Junipers are restricted to the upper woods, so Myrica faya is characteristic of the woods below, and rarely extends much above 2000 feet, except when it finds shelter in some gulch or small crater as before described. The trees of the lower woods that reach the coast are mainly the Faya and the Tree-Heath (Erica azorica). Two plants range through the whole height of the mountain, Calluna vulgaris and the narrowleaved variety of Thymus serpyllum. They grow not only on the old lava-flows as they reach the coast, but also on the lava surface of the summit, and on various kinds of soil, both rich and poor, in the intervening levels.

The Vegetation of the Upland Moors of the Mountain of Pico.-There remains for consideration the vegetation of the upland moors, which are generally confined between the levels of 2000 and 4000 feet. The moors form a belt around the greater part of the mountain, but are crossed at intervals by broad strips of woodland. Lying as they do within the rainy zone, their conditions are nearly as moist as those of the upper woods, and they largely usurp their place. They are used as pasture-land for cattle, the lower portions being under private ownership, while the upper parts marked off by a high wall, usually about 3000 feet above the sea, are known as the Baldios or Common-lands. These upland moors, which doubtless have been greatly extended by deforestation since the colonisation of the group, are characteristic of all the larger islands. In their general features and in the association of their plants they often display, as already observed, a striking resemblance to Dartmoor.

Their surfaces on the slopes of this mountain are often marked by linear copses of the Tree-Heath, which present a variety of strange patterns, that look from a distance like huge hieroglyphs on a light green ground. Two objects have here been served. In availing himself of the natural growth of the trees, the land-owner has so trimmed and directed the growth of the original copse, that at the expense of as little ground as possible he obtains shade for his cattle in summer and shelter from the cold winds in winter. In the other case, whilst clearing his land he has preserved the heath trees, when they are frequent, near his boundary lines, and has allowed them to propagate themselves only on the borders of his property, 
the result being that his land is partially enclosed in a living tree-fence.

Except on the south side, where the mountain rises steeply from the coast to its summit, these upland moors have generally an easy slope. The bracken (Pteris aquilina) and the tussock of Polytrichum give a character to their rolling grassy surfaces. It is pleasant to tread their springy turf after the rough descent of the precipitous and scantily vegetated lava slopes above; and, if it is summer, the multitude of herbaceous plants in bloom will delight the eye. One may on the western side distinguish between the boggy lower areas, where Sphagna flourish, and the relatively drier upper levels, where Peat-mosses do not live; but more often this differentiation is not to be made, and one may stumble on a bed or a pocket of Sphagnum without much warning.

On the drier ground thrive Erythroe massoni, Lysimachia nemorum (var. azorica), Luzula purpureo-splendens, Menziesia polifolia, Polygala vulgaris, Potentilla tormentilla, and Thymus serpyllum (var. angustifolius). Calluna vulgaris forms an occasional scrub, whilst Sibthorpia europae conceals with its foliage the shady side of pits and holes, though with the species of Lysimachia it is almost as common in the wetter areas. Terrestrial orchids (Serapias, Habenaria) are not infrequent, and the turf is dotted with single tufts of Lycopodium selago, while Blechnum spicant grows in the higher levels.

The wetter areas, when of any size, are essentially Sphagnum moors, and the Polytrichum tussocks are here more numerous and larger, and measure one and a half to two feet high and two to three feet across, the Peat-mosses being often closely associated with them in their growth. Anagallis tenella, Hydrocotyle vulgaris, and Viola palustris grow in great abundance, and among the Carices, Carex flava is the most common and sometimes almost monopolises the ground. It may be doubted whether the Bog Pimpernel (Anagallis tenella) exists in greater profusion in any part of its range than on the island of Pico. The writer has walked for miles on the mountain moors to the east of the peak, treading on its flowers at nearly every step. In the tussocks, or rather hummocks, of Polytrichum, almost all the flowering plants of the wet moor in turn find a home; but Hydrocotyle vulgaris is most frequently to be noticed growing in their midst. The tussocks, by becoming confluent, form in places dense beds nearly appropriating the ground. This is to be observed at altitudes of 5000 feet on the north side of the mountain, where the moor vegetation begins to ascend its steep upper-third.

The Sphagnum growth is in some localities very extensive, as on the south-west side of the mountain between the Serra Gorda and San Mattheus. For one and a half or two miles from the Serra the soil is stoneless and peaty, and Sphagna form dense growths, a foot high or more, around the bases of the shrubs of Erica azorica that here clothe the surface. The bushes, in fact, seem to grow out of Sphagnum tussocks. The signification of this association is not very obvious. Tansley in his Types of British Vegetation (1911, p. 235) describes similar growths of Sphagna around the bases of bushes and on the stools of Phragmites in the fen formation of East Norfolk, 
and he considers that the acids secreted by the Peat-mosses would be neutralised by the alkaline ground-waters. In the coastal swamps of the Carolina region a large fern, Woodwardia virginica, grows out of low Sphagnum tussocks which are surrounded by standing water (Harshberger's Phyt. Surv. N. Amer., p. 441). The Pico locality, it should be noted, lies in the midst of a district of basic lavas, rather over 2000 feet above the sea. In midsummer its surface is but slightly moist, and large masses of dead Peat-mosses are seen. In winter the ground would doubtless be very wet.

Here and there water collects in depressions of the boggy ground on these upland moors. Around the edges of the pools grow Littorella lacustris, Peplis portula, Carex stellulata, and Scirpus multicaulis, the last in proliferous condition. In the water thrive Callitriche aquatica, Potamogeton polygonifolius, and Scirpus fluitans. Watson, in his paper in the London Journal of Botany for 1843, gives a list of the plants growing in and around some of these pools on the upland moors which he passed on his way to the summit. They include Callitriche verna, Carex stellulata, Peplis portula, Potamogeton natans (subsequently referred to $P$. polygonifolius), Scirpus fluitans, and Sc. savii. Further remarks on the aquatic and sub-aquatic plants of the island of Pico will be found in the following chapter.

The Secondary Cones on the Slopes of the great Mountain of Pico.-Reference has more than once been made to the craters of these numerous small cones as sanctuaries for plant life. They vary usually from $\mathbf{5 0}$ to $\mathbf{2 5 0}$ feet in height, and as far as could be gathered show no signs of volcanic heat, their interior as well as their exterior slopes being either grassy or wooded. Many of them are situated in the upland moors or in the zone of the upper woods, that is to say, at elevations of from 2000 to 5000 feet above the sea. In some instances the craters are inaccessible, and in one case, where a narrow gap led into the crater, the interior was once used as a corral for cattle. I ascended many of them, and the vegetation of their outer slopes depends on whether they rise up in the moors or in the woods. Their craters are usually dry, and only in the case of the smallest cones do they hold shallow ponds, the abode of aquatic plants. In one such crater pool Potamogeton polygonifolius grew in the water and Scirpus multicaulis at its sides, there being a growth of Sphagnum at its border. (In the case of the numerous crater lakelets, that occur off the great mountain in the eastern part of the island, a few remarks will be made later on in this chapter.) Some of the cones are very regular in form, and one may mention in this connection the Cabeza Norte, which lies at the foot of the cone proper on its W.N.W. side about 4000 feet above the sea. It has a height of 200 feet, and its crater, which is remarkably symmetrical in shape, is $\mathbf{5 0 0}$ feet across and is as deep as the hill is high. Its interior is partly clothed with shrubs, mostly Erica azorica, with a little Ilex perado.

The Lake District of the Island of Pico.-This region is separated from the eastern slopes of the great mountain by a broad saddle, or elevated plain, which is raised not less than 2000 feet above the sea. The plain is dotted with small volcanic cones, and 
is in part grassy and in part boggy, cattle grazing here in numbers. To the east of it lies the mountainous eastern part of the island, with which I became acquainted as far as Santo Amaro on the north coast and Ribeiras on the south coast. The general level of this upland region is 2500 to 2800 feet, and from it rise abruptly several isolated peaks, the highest having an altitude of about 3500 feet. Numerous large mountain lakes lie interspersed among the peaks at elevations of 2500 to 2900 feet. They are evidently shallow, and are usually $\mathbf{3 0 0}$ to $\mathbf{5 0 0}$ yards in length. With the exception of the "Lagoa Rosada," not one of them could be regarded as occupying old crater cavities. They are :-

1. The "Lagoa das Teixas," behind San Roque.

2. The "Lagoa Paul," at the foot of Pico Topo.

3. The "Lagoa Caiado," lying W.S.W. of Praynha do Norte.

4. The "Lagoa Rosada," in the Caldeira de Santa Barbara district.

5. The "Lagoa do Ilheo," behind Santo Amaro.

6. The "Lagoa Negra," behind Santo Amaro.

The peaks are mostly bare of trees and shrubs, and on their steep slopes sheep browse in numbers. The only one of them that I ascended was Pico Topo, which lies behind Lagens, and proved to have an altitude of only about 3300 feet instead of 5357 feet as stated in the Admiralty chart. It is a long, ridge-shaped, hog-backed mountain, which rises precipitously from the coast on the southern and eastern sides, but is elevated only about 700 feet above the plains on its north side.

Very moist conditions prevail in the elevated plains between the mountains amongst which the lakes lie. In this upland region, 2500 to 2800 feet above the sea, there are extensive wet moors, where Sphagnum, Polytrichum, Carices, Anagallis tenella, Hydrocotyle vulgaris, etc., thrive, as well as large areas covered with wood and bush, where the Juniper is at home, and where filmy ferns (Hymenophyllum and Trichomanes) abound. The humidity of this region affords a great contrast to the relatively dry conditions prevailing at similar altitudes on the slopes of the great cone of Pico. Even in fine August weather the grass and herbage in the trails remained wet during most of the day, and one's boots and leggings quickly became soaked through even late in the morning. It is the land of the Juniper and of the plants of the boggy moor; and though drier bracken moors are frequent, where, besides Pteris aquilina, there grow Calluna vulgaris, Erythroea massoni, the Azorean variety of Lysimachia nemorum, Lycopodium selago, Polygala vulgaris, Potentilla tormentilla, etc., it is to the two first-named features that the lake region between the mountains owes its most conspicuous characters.

In the woods the Junipers attain a much larger size than on the slopes of the great mountain of Pico, their height being often fifteen or sixteen feet, and their diameter fifteen to eighteen or even twenty inches. Here the Loranth, Arceuthobium oxycedri, flourishes in places on the Junipers. The other components of the bush are the Tree-Heath (Erica azorica), the Tree-Euphorbia (E. stygiana), 
Laurus canariensis, Myrsine africana, the common species of Smilax, Vaccinium cylindraceum, etc., and among the ferns, Acrostichum squamosum, Dicksonia culcita, and Osmunda regalis, and we may here add Lycopodium complanatum. The Vacciniums come next to the Junipers in frequency, and grow so rankly that they may reach a height of from twelve to fifteen feet, thus becoming arborescent. At one time Taxus baccata flourished in this region, and its name is still preserved in the name of the lake behind San Roque, "Lagoa das Teixas"; but it is rare in that locality now, and seems mainly to survive in the gulleys, about 2000 feet above the sea, on the mountain slopes behind that village. I come now to the description of the lakes.

The Lagoa das Teixas (Lake of the Yews), located as just stated, is a shallow lake, 350 to 400 yards in length, and half that in breadth. It is elevated about 2500 feet above the sea. It is also known as the Lagoa do Capitão Alexandre, after a former governor of the island and owner of the property. The shallows are largely occupied by Potamogeton polygonifolius, which covers no small part of its surface. A broad margin of Scirpus fluitans, so dense in growth that one can walk upon it, skirts the water's edge. Outside this is a boggy belt where thrive Sphagnum, Scirpus multicaulis, Carex flava, Hydrocotyle vulgaris, Anagallis tenella, etc. Flourishing in places on the south and west sides, and mainly covering the soppy marginal flats, is the large form of Littorella lacustris, with long cylindrical leaves measuring six to nine inches.

The Lagoa do Caiado lies, as the crow flies, about three miles W.S.W. from Praynha do Norte, in the district known as the Serra da Praynha. Elevated about 2600 feet above the sea, it is about 500 yards long and 400 yards broad. Like the Lagoa das Teixas, it occupies a shallow basin between the hills and cannot be very deep. At its north-east end the banks holding back the waters are so low that apparently it would not be very difficult to make a cutting and drain its waters down the mountain sides. Sphagnum thrives in the boggy margins, and here grow Carices, such as Carex Alava, Scirpus multicaulis, Anagallis tenella, Hydrocotyle vulgaris, etc., whilst Peplis portula is common at its muddy edges. Littorella lacustris and Isoetes azorica flourish at the borders, both displaying two forms, the dwarfed form of the mud-flat and the large, longleaved form of the watery mud or of the deeper water. Some of the deep-water plants of Isoetes, that were washed up on the banks, had leaves eighteen to twenty inches in length. (Further details relating to the mode of occurrence of these two interesting plants are given a few pages later.) Potamogeton polygonifolius covers extensive areas of the shallows of this lake. In one or two places, where the bush growth of the surrounding district descends to its borders, Osmunda regalis may be observed close to the water's edge.

The Lagoa Paul, lying just under Pico Topo on its north-west side, was dry when I visited it on July 30,1914 . When full of water it would be smaller than the Caiado Lake. On the surface of the exposed mud-flats, which were still moist, grew in quantity the 
dwarfed forms of the species of Isoetes and Littorella above named; the latter formed almost a turf.

The Lagoa Rosada, or the Rosy Lake, is situated in the middle of the island between Ribeiras and Praynha do Norte and near the Caldeira de Santa Barbara, indicated in the chart. Elevated about 2950 feet above the sea, it occupies the bottom of a broad basin, which may possibly be of crateral origin, and it is the only one of the large mountain lakes that could be so regarded. It is oval in shape, and is between 200 and 250 yards long, and from 100 to 150 yards broad. Viewed from the slopes above in the late afternoon, its waters had a beautiful inky-blue hue, so that "Lagoa Corulea" seemed a more appropriate name. Besides Potamogeton polygonifolius, the two forms of Isoetes azorica and Littorella lacustris here thrived.

Lying close together in a level district on the top of the mountains behind Santo Amaro, and elevated between 2800 and 2900 feet above the sea, are the Lagoa do Ilheo (Lake of the Isles) and the Lagoa Negra, or the Black Lake. The Lake of the Isles is about the size of the Caiado Lake, if not larger. It contains two islands, and is half-covered by the Potamogeton so common in these mountain lakes; whilst a tall form of Scirpus palustris, two feet in height, is not uncommon in the shallows. The Lagoa Negra is about 300 yards in length and oval in shape. Here were to be seen the species of Potamogeton, Littorella, and Isoetes above named.

A number of small, circular, shallow lakelets, twenty-five to fifty yards across, fill the bottom of the craters of the numerous small cones dotted about this elevated lake region. Occasionally in midsummer they are almost dried up, when the still moist muddy surface may be covered by a turf of Scirpus fluitans, which doubtless resumes its usual aquatic habit when the lakelet refills in the rainy season. More often they are appropriated by the ubiquitous Potamogeton polygonifolius, or, when the surface is clear, plants of Isoetes azorica and Littorella lacustris in their two forms thrive in their waters and at their borders. It may be here added that almost all the aquatic and sub-aquatic plants previously mentioned in connection with the island of Pico flourish in one or other of the numerous small crater lakes of the island, Sphagnum often growing at their borders.

In the vegetation around the large lakes of this region one can sometimes recognise a succession of formations. Whilst the Potamogeton before named occupies the shallows, Scirpus fluitans monopolises the soppy ground at the lake's border, and outside this is a broad belt of Sphagnum, where Scirpus multicaulis, Carex flava, Anagallis tenella, and Hydrocotyle vulgaris thrive.

With regard to the occurrence of Littorella lacustris and Isoetes azorica in this region of the mountain lakes, some further remarks may here be made. Both display two forms, a dwarfed form on the exposed mud-flats, and a large form with long cylindrical leaves growing in the deeper water, as in the case of Isoetes, or where the water just covers the ooze at the lake's margin, as with Littorella. Whilst the dwarfed plants of Littorella lacustris were well in flower at the end of July, the large plants were only showing the flower- 
buds; the latter possess cylindrical leaves, six to nine inches long, which lie prostrate in the water, and are not erect, as has been sometimes described. It was evident that the floating growths of Potamogeton polygonifolius were inimical to the growth of the large forms of Littorella and Isoetes. They are rapidly extending in the ponds, and not improbably will ultimately exterminate the last-named plant.

The Uplands of the Island of San Miguel.-The great upward extension of the cultivated zone, and the large intermingling of foreign trees and shrubs with the indigenous trees and shrubs of the lower slopes up to 2000 feet, will cause our interest to be mainly centred on the upland regions as best illustrated in the mountainous eastern portion of this island. It may, however, be observed that on the lower slopes of San Miguel, as far as they are still held by the indigenous flora, occur the characteristic trees and shrubs of the lower woods of Pico, such as Erica azorica, Laurus canariensis, Myrica faya, Myrsine africana, Viburnum tinus, etc., the last named being more generally distributed over the island than it is on Pico.

Without further remark I will proceed with my notes on the ascents of the Pico da Vara Range in the eastern part of San Miguel, a range that culminates at an altitude of $\mathbf{3 5 7 0}$ feet in the peak of that name, the highest point of the island. My ascents were made in the latter part of February; but it is evident from Drouet's account of the vegetation of the higher slopes of the range in May, that except for the plants in bloom my notes will give a fair idea of the general characters of the larger vegetation in that weather-beaten region.

Pico da Vara, the highest peak of the range, rises abruptly about 600 feet at the eastern extremity of a long, flat-topped, wind-swept ridge that forms the mountainous backbone of the eastern part of San Miguel, and attains a general level of about 3000 feet above the sea. It is a cloud-begirt, wind-buffeted region of heavy rainfall, and it receives the full force of the Atlantic gales. One may walk for three miles along the flat crest of this ridge from its western end without changing one's level more than 200 feet. The soil there is derived from the prevailing coarse, andesitic, pumiceous tuffs; but the materials are only partially disintegrated, so that one crunches underfoot the loose, sodden, pumice gravel that strews the surface. On the crest of this mountainous backbone occur stunted growths of Juniperus oxycedrus and Laurus canariensis (Laurel), mingled with Myrsine africana, Vaccinium cylindraceum, and the Culcita fern (Dicksonia culcita); and in response to the prevailing moist conditions there are tussocky growths of Polytrichum. At the western end of the range, where the ridge broadens out into a kind of table-land, the surface is in places boggy, and in the pools grow Potamogeton polygonifolius and Callitriche aquatica, with Sphagnum and Juncus at the borders.

But the stunted growths of the Juniper and the Laurel largely monopolise the higher slopes of this mountain ridge, the Laurel reaching to the top of the ridge and the Juniper extending to the summit of the eastern peak. In this wind-swept region their height is usually between two and three feet; but where the exposure is 
greatest the Juniper grows semi-prostrate on the ground. Besides the Juniper, Dicksonia culcita also reaches the very top of the island, being accompanied by dwarfed growths of Myrsine africana and Vaccinium cylindraceum.

Yet this is but a winter view of the vegetation of the higher levels of the Pico da Vara Range. In summer, when picnicking parties from the Furnas Valley ascend these mountains, herbaceous plants in abundant bloom adorn the slopes; and, if the weather is fine, there would be little in these breezy heights, with a magnificent panorama at one's feet and a clear sky overhead, to suggest that any risks would attend an ascent in winter. But the little stone crosses on the top of the ridge tell another story. Shepherds, overtaken by the blizzard in mid-winter, have lain down and died; and under conditions that were certainly elemental the writer had an experience on these storm-swept levels of the influences that have oppressed the Junipers and Laurels through the ages. He was overtaken by a succession of squalls from the north-west. For nearly an hour, enveloped in the clouds and without any shelter, he was exposed to a pitiless storm of wind and rain. Subsequently, on reaching the summit of the peak, he found Sibthorpia europoea in foliage in the shelter of a small pit, the sides of which were lined by Liverworts (Hepatica) ; but with the exception of the narrow-leaved variety of Thymus serpyllum, in leaf only, there was little else in the lesser vegetation of these heights to remind one of the summer dress of the slopes of Pico da Vara.

Judging from Drouet's reference to his ascent of this range, the general extent of the larger vegetation at the top was much the same in 1857 as it was in 1913. But the tale of the pumice-strewn soil of the upper slopes is fairly clear. The interval that has elapsed since the great eruption of the Furnas Valley in 1630, when, according to Walker, all the vegetation in the eastern part of the island was overwhelmed by ashes and covered to a depth of many feet, has not been long enough for the restoration of the original forests on these mountain slopes. The struggle of the plants to regain their own has been rendered still more difficult by the repressive influence of the winds on these stormy heights.

Ascent of Santa Barbara, the highest Mountain of Terceira, 3500 Feet above the Sea.-My ascent was made from Angra in the middle of April. Although the zone of cultivation extends up to about a thousand feet, that does not represent the limits of man's destruction of the original forests, since on the higher slopes, where doubtless these forests once grew, scrub is now only to be found. The scrub is formed chiefly of Juniper and Calluna vulgaris (Ling), with Myrsine africana in places. The Ling occupies the lower slopes below 2200 feet where the ground is dry and the soil poor and stony, and it is accompanied by Thymus serpyllum in its densegrowing, trailing, narrow-leaved Azorean form. The Juniper predominates on the higher slopes, where the ground is wet and often boggy, and where Sphagnum and Polytrichum thrive. The higher parts of this mountain are much wind-swept and often cloud-invested, and on account of the clouds, rain, and wind I was unable to make 
a long stay on the summit. But the ascent is by no means an interesting experience for the botanist, since his thoughts are more likely to dwell on the lost forests than on the surviving vegetation.

The Characteristic Coast Plants of the Azores.-Though my experience was mainly confined to the island of Pico, it can be supplemented by notes made on Fayal and San Miguel. The coasts of the islands of the Azores are mostly rock-bound and often precipitous, beaches of any size being, as a rule, infrequent. The most typical plants include the following, which are more or less generally distributed over the group-Beta maritima; Crithmum maritimum; Euphorbia azorica, regarded by some as a variety of the South European E. pinea, L.; Euphorbia peplis; Hyoscyamus albus ; Juncus acutus ; Plantago coronopus ; Polygonum maritimum ; Salsola kali ; Silene maritima; Spergularia marina, probably far more widely distributed in the group than is admitted by later authors; and Statice limonium.

One of the most interesting localities for beach plants that I came upon was the sandy beach of Porto Pym, in Fayal. In their order of frequency the plants were Ipomœa carnosa, R. Br., Salsola kali, Euphorbia peplis, Cakile edentula, and Polygonum maritimum. Some of them, such as the species of Ipomoe a and Cakile, are known to have been growing on this beach for more than seventy years, having been found there by Watson in 1842, and collected since by other botanists, as by C. S. Brown in 1894. It is probable that Cakile edentula was originally introduced with ballast, a matter discussed in the general treatment of that plant.

The most frequent plant on the rocky coasts of Pico is Euphorbia azorica; but Plantago coronopus and Juncus acutus are also common. On the sandy beaches grow in places Polygonum maritimum, often in association with Hyoscyamus albus; whilst Salsola kali occurs scantily. Silene maritima and Spergularia marina grow both on the sand and on the rocks, and sometimes in sandy pockets in the lava rock. Crithmum maritimum (Samphire) is found here and there on the rocks, as at Praynha do Norte; but it is much appreciated by the inhabitants for eating with fish, and it is likely that its relative scarcity on the Pico coasts is due to this cause. On the beach just south of Magdalena I found Ipomcea carnosa, previously only known in this group from the island of Fayal.

On the rocky coast at San Mattheus and at Magdalena there exists a peculiar plant, concerning the identity of which I am in doubt. It is a very fleshy plant, of which unnamed specimens from San Jorge in the herbarium of the Ponta Delgada Museum are enclosed in a Mesembryanthemum cover, having been collected in 1905 and 1908, or ten or twelve years after Trelease's visit. The plants grow prostrate on the lava rocks, and have purplish terminal flowers. They exist in quantity on the rocky flat close to a windmill just north of the town of Magdalena. The species comes nearest to Mesembryanthemum ; but it has a four-valved capsule that dehisces loculicidally, leaving the axis in the centre of the fruit. The seeds have the appearance of Stellaria seeds, and are round, blackish, scrobiculate or warty, about a millimetre across, and have an embryo 
curved around a mealy albumen. In another cover in the herbarium were specimens of quite another plant, labelled Tetragonia expansa, from the Azores, the island not being named. I find no reference to any of these plants in the pages of either Watson or Trelease.

Another Azorean shore plant is Solidago sempervirens, an American littoral species, which, as we learn from Seubert, extends inland to a height of 1000 feet above the sea. Campanula vidalii, which is peculiar to the Azores and occurs principally on the sea-cliffs and coast rocks of Flores, is specially discussed in the notes on Azorean plants at the end of Chapter XIX.

\section{SUMMARY}

1. During his two sojourns in this group the writer was principally engaged in investigating the altitudinal ranges of the indigenous plants; and with this object the vegetation of the great cone of Pico, by far the loftiest mountain in the archipelago, was especially studied. His ascents, and the best methods to be followed in examining the higher slopes of the mountain, are first described (pp. 359-61).

2. A sketch of the history of the botanical investigation of the Azores is next given. This exploration, which commenced with a small collection of dried plants made on Fayal in $\mathbf{1 7 7 5}$ by George Forster, one of Cook's naturalists, and with collections of living plants made for Kew Gardens by Masson a year or two later, has since been carried out by a number of botanists and naturalists of various nationalities-American, English, French, German, Portuguese, and Swiss. We may mention here Guthnick and the Hochstetters in 1838; Watson in 1842; Carew Hunt during 1844-8; Drouet. (zoologist), Morelet (zoologist), and Hartung (geologist), all in 1857; Godman (zoologist) in 1865; Brown in 1894; Trelease in 1894 and: 1896 ; and last, but by no means least, resident Portuguese botanists, such as Carreiro, Machado, and Sampaio. The works that form landmarks in the investigation of the flora are those of Seubert (1844), Drouet (1866), Watson (1870), and Trelease (1897) (pp. 361-4).

3. Before dealing specially with the vegetation of Pico, allusion is made to the heights of the islands of the Azores (p. 364). This leads one to compare the conditions for forest growth in this group with those in the Canaries and in Madeira, a comparison that supplies an opportunity of forecasting the correlation of the three floras, and leads us to look for in the Azores only the evergreen shrubs and trees of the Canarian Laurel woods (p. 365).

4. The general profile of the great mountain of Pico is then described (p. 366); and in this connection the bluffs of the Ribiera Grande are mentioned as presenting one of its principal spectacular features (p. 366).

5. After disposing of the not uncommon error that the higher slopes of the cone are barren, the author deals with the extent of the vegetation on the mountain. The lower slopes are generally well vegetated up to 4500 or 5000 feet, moor and grass land predominating in their higher levels between 2000 and 4000 feet. But woods are well developed in places, the lower woods on the western

c. C 
side and the upper woods on the south-eastern side. They are essentially formed of evergreen shrubs and trees; but on account of the persistent agency of the woodcutter through centuries the trees, except when specially preserved, rarely exceed twenty feet in height, and are usually not more than fifteen or sixteen feet. Dwarfing begins, as a rule, at about 4000 feet, as the effect of deficient soil and of exposure to strong winds. Above 5000 feet are the sparsely-vegetated, precipitous lava slopes of the cone proper; but in spite of the conditions five or six kinds of plants, usually as stunted and creeping growths, reach the summit (p. 367).

6 . The writer then comes to his special study, the zones of vegetation on the great mountain of Pico. This subject is not dealt with in the later works on the flora, which are almost exclusively devoted to the systematic treatment of the plants, and were the only sources of information accessible to him at the time of his visits. The result was that after he had completed his study he found that in the main he had long before been anticipated by the earlier German and French investigators, particularly by the Hochstetters (p. 368). The zones of vegetation adopted by the writer for this mountain do not differ very materially from those of his predecessors. They are as follows :-

I. The Lower Woods, or the Faya zone, Myrica faya being one of the most characteristic of the trees. The zone extends usually from the coast up to $\mathbf{2 0 0 0}$ feet. Besides the Faya, the other trees peculiar to the zone are Rhamnus latifolius, Persea (Laurus) indica, and Picconia excelsa. Among the trees that are abundant in both the Upper Woods and the Lower Woods are Ilex perado, Erica azorica, and Laurus canariensis. Of the shrubs the Laurestinus (Viburnum tinus) is restricted to the zone; whilst Vaccinium cylindraceum and Myrsine africana, abundant here, are equally common in the Upper Woods.

II. The Upper Woods, or the Juniper zone. Juniperus oxycedrus (var. brevifolia), Daphne laureola, and Euphorbia stygiana are the most distinctive of the trees and shrubs; whilst Erica azorica, Ilex perado, Laurus canariensis, Myrsine africana, and Vaccinium cylindraceum are as characteristic of this as they are of the zone below. Taxus baccata, now almost extinct, thrived originally in the lower levels of the Upper Woods and in the higher levels of the Lower Woods. The Loranth, Arceuthobium oxycedri, is a frequent parasite on the Juniper trees. This zone extends usually from 2000 to 4500 feet, but is continued as a scrub up to 5500 feet.

III. The highest zone of the cone proper, 5500 to 7600 feet. All the plants growing on these scantily vegetated, steep, lava slopes have climbed up from the lower levels, principally from the moors, as described below. They include Calluna vulgaris, Menziesia polifolia, Thymus serpyllum (var. angustifolius), Polygala vulgaris, and Agrostis castellana, all of which reach the summit.

IV. The zone of the Upland Moors, 2000 to 4000 feet, which has been formed at the expense of the Upper Woods around much of the mountains. Here we find many of the features of a Devonshire moor, as on Dartmoor. The most striking general features are the 
Bracken (Pteris aquilina), the large tussocks of Polytrichum, and the beds of Sphagnum. Among the most frequent flowering plants are Anagallis tenella, Calluna vulgaris, Carex flava, Erythrcea massoni, Hydrocotyle vulgaris, Luzula purpureo-splendens, Lysimachia nemorum (var. azorica), Menziesia polifolia, Polygala vulgaris, Potentilla tormentilla, Sibthorpia europoea, Thymus serpyllum (var. angustifolius), and Viola palustris. In and around the pools grow Callitriche aquatica, Carex stellulata, Littorella lacustris, Peplis portula, Potamogeton polygonifolius, Scirpus fuitans, S. multicaulis, etc. (pp. 368-71).

7. After discussing the prevailing climatic conditions on the upper slopes of the great mountain (p. 371), the writer gives a general account of its vegetation, commencing at the summit; but only some of the special features can be here alluded to. Thus it is noted (p. 373) that occasional stragglers from the upper woods reach far up the mountain, stunted specimens of Ilex perado having been observed at 6300 feet. Then it is remarked that on the scantily vegetated lava slopes, between 5000 and 6000 feet, a number of herbaceous plants find a sanctuary in the beds of Ling (Calluna vulgaris), and that even the Juniper, as dwarfed specimens only six inches high, finds protection there (p. 373). The prevalence of filmy ferns: such as Hymenophyllum tunbridgense, on the tree-trunks of the upper woods indicates the humidity of the conditions in that zone, the limits of which roughly correspond to those of the rainy belt (p. 375). Two plants range through the whole height of the mountain, namely, Calluna vulgaris and the narrow-leaved variety of Thymus serpyllum (p. 376). Special reference is made to the unusual development of Sphagnum on the south-west side (p. 377).

8. The manner in which small craters and gulleys on the higher slopes serve as refuges for plants of the lower slopes is then treated. In this way plants of the lower woods find a home in the upper woods, and plants of the upper woods in the slopes above (pp. 374-5).

9. The mountain-lake district of the island of Pico is next described. Here several lakes occur at altitudes of 2500 to 3000 feet in the midst of a region of extensive wet moors and of large areas covered with wood and bush. Very moist conditions prevail in the woods, and here the Junipers attain their largest size, the component trees being those of the upper woods of the great cone. Yews (Taxus baccata) were once frequent in this locality, but are now rare. The lakes are described in detail; and in the account of the vegetation growing in and around them the frequent association of Littorella lacustris with a species of Isoetes is noticed (pp. 379-82).

10. Some remarks are then made on the vegetation of the island of San Miguel. On the lower slopes, so far as they are still held by the indigenous flora, occur the characteristic trees and shrubs of the lower woods of the mountain of Pico. The writer describes his ascent in winter of Pico da Vara, the summit of the island, and he observes that stunted growths of Juniper and Laurel (Laurus canariensis) largely monopolise the higher levels of this mountain ridge (pp. 382-3). A short account is given of his ascent of Santa Barbara, the highest summit of Terceira, an ascent that is deprived of much of its interest through the destruction of the forests (p. 383). 
11. Then follows a short discussion of the seashore plants of the Azores, of which the most characteristic seem to be-Crithmum maritimum, Euphorbia azorica (perhaps a form of E. pinea of South Europe), Euphorbia peplis, Hyoscyamus albus, Juncus acutus, Polygonum maritimum, Salsola kali, Silene maritima, and Spergularia marina (p. 384). ${ }^{1}$

12. Under the head of "The Wells of Pico," in Note 36 of the Appendix, the extensive soakage seaward of underground waters is noticed; and evidence is adduced to show that this is a common phenomenon in large islands, and that sometimes fresh-water thus derived issues as submarine springs off the coast. On the great cone of Pico there are no permanent streams and no springs, the poorer inhabitants of the coast towns and villages mainly depending on the slightly brackish water of wells sunk in the rubble behind the beaches. Off the cone, in the eastern part of the island, perennial springs occasionally exist high up the slopes of the mountains.

I Frankenia pulverulenta is also an Azorean shore plant which, however, rarely came under my notice. 


\section{CHAPTER XVIII}

\section{THE AZORES (continued)}

The Proportion of Native or Indigenous Plants in the Azores.-In these pages we are concerned only with the native flora, and it may at once be remarked that it was in all probability extremely limited. The matter of the introduced plants cannot therefore be dealt with here in any detail; but, from what follows, it will be evident that in restricting the field of discussion to the native plants, we assume a very great reduction in the size of the present flora, a flora which has often been erroneously described in general references to the archipelago as in the mass indigenous. The very opposite is, indeed, the case; and if we wish to obtain a sense of proportion in this respect we cannot do better than go back to the writings of the earlier botanists interested in the flora, those who, like Seubert and Hochstetter, employed only the truly indigenous plants to characterise their zones of vegetation above the region of cultivation.

The islands have been colonised for more than four centuries, and during that period multitudes of species have been introduced, either by accident or by intention. Without discrimination, it would be possible to make an extensive collection at the present time that would include hardly any of the native flowering plants, and the same could have been done a century or two ago. In fact, a small collection of about twenty-seven species, gathered by George Forster on Fayal in 1775, was almost entirely composed of plants that had been introduced since the discovery of the islands (see Note 33 of the Appendix). Trelease, the most authoritative of recent investigators of the flora from the standpoint of the systematist, finds no difficulty in seeing how " most of the existing species may have been introduced by ordinary means, largely through human agency, since the discovery of the islands" (p. 67); and one cannot be many weeks in the group without recognising the correctness of this opinion. Watson's total of 439 flowering plants is increased in Trelease's pages to about 560; but I should imagine that the original flora did not comprise 200 species, and that the plants which gave their impress to the vegetation did not amount to a hundred.

Watson makes but little effort, as he himself admits, to distinguish the introduced plants in his catalogue. His position with regard to alien plants is not easy to appreciate now. The old Forbesian hypothesis of a great continental extension of Europe westward would, if applied to the Azores, scarcely raise the question of introduced plants. Watson was aware of this, and although taking a 
neutral attitude in the matter he adopted the implication as regards alien plants. He considered that all " recorded constituents" of the Azorean flora should be taken into our "statistical reckonings" (p. 264), and he made a numerical analysis (p. 272) without any further differentiation than one based on geographical considerations. The results were used by Godman, with no comment on the predominant proportion of alien plants, in his concluding general remarks on the natural history of the islands ( $\mathrm{pp.} 332,334)$, and, as is noted below, by other writers on insular floras.

The effect has been unfortunate, since these writers have treated Watson's catalogue of 439 plants as a list of native plants. He himself remarks (p. 262) that his catalogue includes many species that have been introduced into the Azores; but evidently it did not fall within the scope of his work, as he viewed it, to discriminate to any extent between the natives and the aliens among the plants. To take one instance, Watson's list includes about two dozen species in all of Medicago, Trifolium, and Lotus, of which the majority must have been introduced since the discovery of the islands; yet there is nothing to indicate it. Then again, of the fifty-one grasses named he only particularises three as possibly introduced. So also of the six species of Geranium and Erodium, almost all of them common ruderal species, of the sixteen species of Labiato, which include many roadside and waste plants spread by cultivation, and of such familiar world-ranging weeds as Oxalis corniculata, Plantago major, $P$. lanceolata, Rumex crispus, etc., nothing is said of their alien origin.

The outcome of this will now be shown. When Godman in his book on the group (p. 342) compared the proportion of peculiar Azorean plants with those for birds, insects, and land-molluses, he was employing Watson's entire list of plants as though all were natives of the islands. Then again there was little in Watson's work to guide Wallace in discriminating between native and foreign flowering plants, when he made an analysis in his Island Life of the 439 Azorean species based on their capacity for dispersal. Yet he was fully sensible of the difficulty involved. "There can be" (he writes, edit. 1892, p. 260) " little doubt that the truly indigenous flora of the islands is far more scanty than the number of plants recorded would imply, because a large but unknown proportion of the species are certainly importations, voluntarily or involuntarily, by man. . . . It is almost impossible now to separate them, and Mr. Watson has not attempted to do so." He goes on to say that even if only half of the species are truly indigenous there would remain a wonderfully rich and varied flora to have been carried by the various means of dispersal. But apart from this, the danger of treating all the plants in Watson's list as native plants has not always been avoided. Thus, in comparing the endemic element in insular floras, Watson's total for the Azores has been sometimes utilised as if it were composed entirely of native plants. This is the case in a list given in the Introduction to the Botany of the Challenger Expedition (p. 33). Then again in works of reference the same thing is done. Thus in the article on the Azores in the 9th edition of the Encyclopadia Britannica, which was written before 1875, all the 478 flowering plants, ferns, and lycopods, etc., of Watson's list are characterised 
as "generally considered as indigenous." Yet Watson's attitude reflected the prevailing opinion among botanists in this matter. Hooker, in his famous lecture on Insular Floras in 1866, a lecture which has formed the foundation of all later studies of these floras, would almost seem to imply that the $\mathbf{3 5 0}$ species of flowering plants then known were all natives.

It is not easy for us now to grasp the pre-Darwinian conception current in the middle of last century. It was the period of change between two eras, and it was left to Trelease in recent years to recognise the limited character of the true native flora of this group. The flowering plants designated by him as introduced since the occupation of the islands, including weeds, escapes, casuals, etc., number in all nearly 200; but even Trelease omits to mark as alien to the native flora a considerable number of species, such as Lamium purpureum, Stachys arvensis, Oxalis corniculata, Geranium molle, G. robertianum, G. dissectum, Galium aparine, etc., amounting probably to almost another hundred, which must be regarded as having been introduced since the discovery of the archipelago.

One way of testing this matter, as suggested to me by Mr. Hemsley, is to take the case of the New Zealand flora, where the introduced plants have been carefully discriminated by Cheeseman. This, however, would probably develop into a much larger undertaking than I could begin now, since numbers of collateral questions would arise, and the area of comparison would certainly require to be greatly extended as the inquiry proceeded. Unless some abler worker takes up the subject, I hope to begin the task some day. It would be important to eliminate the agency of man, direct and indirect, from every flora, and to apply the same method to all. Such an inquiry might be almost as ruthless in its effects on the British flora, as it would undoubtedly be in the case of that of the Azores. As applied to the group just named, the term " native flora" denotes the plants in the islands before their occupation by man. It has in practice a widely different meaning in the case of the British Isles, and includes a host of ruderal plants. Yet if a weed had been present here for half a million years, it would still be a weed and never a part of the native flora.

Whatever the antiquity of the weed, its differentiation from the native plants of a flora, or, in other words, the disentanglement of man's influence in the history of the plant-world, becomes the first requisite for the proper study of distribution. Whether a region was first occupied by man 400 or 400,000 years ago matters little. The weed of to-day is the weed of prehistoric ages, and its story is bound up with the story of man on this globe. Results, both unexpected and important, would be the outcome of such an investigation.

Probable Composition and General Characters of the Original Forests of the Azores.-Although he did not see his way to assist us in the differentiation of the weeds, Watson (p. 268) gives some valuable suggestions that enable us to form a mental picture of most of the general characters of the dense woods that covered these islands at the time of their discovery. We may here emphasise his opinion that evergreen shrubs and trees, with ferns and mosses, formed the principal feature of the vegetation, and that 
" a close forest of evergreens must have formerly covered the ground." After a few weeks in the islands the present writer found himself unconsciously restoring the evergreen woods that once predominated in the group. All the trees and shrubs indicated by Watson as composing the original forests are named below, with one exception, Myrtus communis, the indigenous character of which has not always been admitted. Four others have been added in my account, namely, the species of Taxus, Euphorbia, Smilax, and Rhamnus, of which the first has been recognised by Trelease and others as originally native, whilst the other three are peculiar Macaronesian species (Macaronesia comprising the Azores, Madeira, and the Canaries) that are held by Watson as well as by Trelease as truly indigenous Azorean plants. All were evergreens, even Prunus lusitanica.

Amongst the trees, Erica azorica, Laurus canariensis, Myrica faya, and Juniperus oxycedrus (var. brevifolia), would have been most frequent. Ilex perado would have been well represented, together with Picconia excelsa and Taxus baccata. Rhamnus latifolius, a sub-evergreen, doubtless took its share, together with Prunus lusitanica, the latter being now only known from San Miguel. The Tree-Euphorbia (E. stygiana) was probably more frequent than it is at present. Among the evergreen shrubs, Myrsine africana, it is likely, took a leading part; Vaccinium cylindraceum was abundant; and whilst Daphne laureola flourished in the upper woods, Hypericum foliosum was common in the lower woods. The Laurestinus shrub (Viburnum tinus) was well represented in places; and climbers like Smilax canariensis and Hedera canariensis were conspicuous. One cannot, however, pursue this subject here, and reference will now be made to another feature of the original evergreen forest, of which mention has not yet been made.

The Large Size of the Trees in the Original Forests.-One can scarcely be surprised that authors, judging the past from the present, should write depreciatingly of the original forests of the Azores. Godman (p. 4) characterises them as "underwood"; and Watson (p. 268), when alluding to their features, speaks of the "frutescent and sub-arborescent" species, and of the "shrubs and small trees," of which they were composed. Hartung, who spent four months as a geologist in these islands in 1857, takes the same view in his book; but he depended mainly on Watson and Seubert for his botanical information, and made but few original observations except in the case of the buried Junipers. He was anxious to labour the point that the plants which are trees in the Canaries and Madeira become shrubs in the Azores; and he even rejected the adverse testimony of his buried Juniper trees, a subject discussed in a later page. A juster appreciation is given in Seubert's work, which is based on the observations of the Hochstetters, where it is stated that plants such as Erica azorica, Laurus canariensis, and Myrica faya, which form bushes in the higher zones, grow as true trees in the lower woods.

Deforestation at the hands of the woodcutters has been in progress for centuries, and in no localities more than in the woods bordering the roads or tracks, where only young trees grow. Visitors following the ordinary routes would thus only see young wood; and the trees 
growing in the woods farther back, often rendered difficult of access by a dense growth of brambles, would not come under their observation. This matter is discussed later; and it will be sufficient to point out here that in an ordinary traverse of the woods the trees would not be seen at their best. This is illustrated in Watson's conception of Myrica faya as a dense bush (p. 224); whereas, when allowed to grow undisturbed it becomes a tree of respectable size, thirty-five to forty feet high.

Yet it is abundantly evident from the old Portuguese and other authorities of the sixteenth century quoted by Walker, such as Fructuoso, Cordeiro, and Linschoten, that the islands were once heavily timbered. In the middle of that century, according to Fructuoso, there were dense and lofty woods of Cedars (Juniperus), Fayas (Myrica faya), and Laurels (Laurus canariensis) on the slopes of the valley of the Furnas in San Miguel. Linschoten was resident in the group in the latter part of the sixteenth century. I have consulted his account as given by Purchas (edition of 1905). Writing of Terceira, he says that " the island hath great store and excellent kinds of wood, especially Cedar (Juniper) trees, which grow there in so great numbers that they make Scutes, Carts, and other grosse workes thereof." Of Pico he writes that it had " great store of wood, as Cedars and all other kinds, and also the costly wood Teixo (Taxus baccata). There they build many Carvels and small Ships; and from thence, by reason of the abundance of wood, they serve the other Islands with wood." It cannot, therefore, be doubted that Pico, as Walker observes (p. 84), was " at one time densely covered with timber of large size."

In the early history of the Azores the timber of the Juniper trees, the "cedro" of the islanders, was extensively employed in building the churches. Walker (p. 252) quotes an early Portuguese authority to the effect that Terceira, when first discovered, was densely wooded with heavy timber, all the old churches and other buildings being roofed with "cedar" wood. Tradition has it that the immense beams even now in the roof of the cathedral at Angra were cut from trees that flourished as late as 1570. According to the same authority, the "last authentic record " of these " magnificent" Azorean Cedars being still in a flourishing condition relates to their use to repair a church at Villa Franca, in San Miguel, which was much damaged by the earthquake of 1630 . In the church at Magdalena, on the island of Pico, which is said to have been built in 1710, a good deal of Cedar has been employed in the chancel, but it is now often gilded over. I learned from the priest that according to popular belief the wood came from Pico. It would seem from Walker's pages that most of the old timber trees in the group had disappeared before the close of the seventeenth century.

Large Trunks of Trees buried in the Ashes of Ancient Volcanic ERUPTIONS.- The trunks of trees overwhelmed in the early volcanic eruptions give similar testimony of the large size of the trees of the original forests. Frequent reference has been made by writers to their occurrence in the island of San Miguel. "From the boles occasionally unearthed at the Seven Cities and Furnas" (thus writes Walker, p. 25) " there is little doubt that these splendid 
trees, on its first discovery, inhabited a high belt of country extending east and west along the island." But very large trunks of other existing species of trees are also found buried in the volcanic tuffs of this island. Thus Walker (pp. 219, 220) refers to trunks of the Tree-Heath (Erica azorica) and of the Faya (Myrica faya) of giant proportions, which have been exposed in a state of lignite (?) in the ravines of San Miguel. So again, Carew Hunt, for years British Consul in the Azores and the principal source of Watson's later collections, when writing of San Miguel in the Journal of the Royal Geographical Society for 1845, states that there had been found in the tuffs trunks of the Faya, Juniper, and Tree-Heath, the Juniper with stems three feet in diameter.

Most of the data concerning these buried trees relate to the Juniper or " cedar." When at Furnas in 1857, Drouet was shown an enormous semi-carbonised (?) trunk of Juniper oxycedrus, which indicated that formerly the trees attained a far greater size than they do to-day. It may here be said that this statement about the carbonisation of the wood is probably incorrect. In a letter to me Colonel Chaves emphatically denies the assertion of Walker, as above quoted, that buried trees in a state of lignite have been unearthed in San Miguel. The most important observations on these buried trees are, as he points out, those of Hartung, who says nothing about such a condition of the wood. It may be here apposite to give the results obtained by the German geologist as stated in his Die Azoren, Leipzig, 1860. He describes large trunks of the Juniper, that still grows on the island, as buried beneath great thicknesses of volcanic materials (blocks of tuff, pumice, and lava) heaped up during the later eruptions in the regions of Sete Cidades and the Furnas Valley in San Miguel (pp. 168, 200). In the Furnas Valley the thickness of the overlying material is stated to be about 400 feet, the date of the last eruption in that locality being 1660 . The buried trunks of Juniper of the Sete Cidades are characterised as "mächtige Baumstämme"; and the diameters of two of them are given as two and an eighth and one and a half feet. In this connection Colonel Chaves writes to me saying that the biggest trunk of "cedar" (Juniper) found in the Azores is the trunk still remaining in the Grotta do Inferno at Sete Cidades. When referring to the Azorean Juniper, Trelease (p. 169) remarks that "large logs, apparently of this species, occur deeply buried under secondary volcanic débris in the Grotta do Inferno of the great crater known as Sete Cidades."

I am indebted to Miss S. Brown, of "Brown's Hotel," Ponta Delgada, for some particulars relating to the buried "cedars" of Furnas, where she long resided with her father and brother. These buried trees were not uncommonly to be seen in the Furnas Valley; but her father would never believe that trees of the large size indicated by the logs existed there, until he found the stump of one of these buried "cedars" showing the bases of the roots. It was found at a place called Alegria, at the north-eastern end of the valley. In a little sketch kindly supplied to me by his son, who was present at the time, this tree-stump is described as forty to forty-six inches high, with a diameter of twenty-four inches at its upper end, which apparently (as far as the sketch indicates) projected 
originally about two feet above the ground. Miss Brown was good enough to send me a picture frame, made from one of these " cedar" logs, which her father had purchased. I sent it to the Kew Museum, and received through the kindness of Sir D. Prain the following report by Mr. Boodle, who examined the wood with care: "The wood appears to be that of a species of Juniperus, perhaps the same species as the block of wood in the Kew Museum, also dug up in the Azores. According to a label on this block, Masters states that Señor Henriques showed that this wood is identical with that of Juniperus brevifolia." In his letter to the author Sir D. Prain says : "I am prepared to accept his verdict as at any rate definite proof that the wood cannot be identified with anything but that of a Juniper."

These buried Juniper trees have been also found in other islands of the group. When at Horta I was told by Mr. Keating that up to recent times the trunks were often dug up on Flores, and were used for building the small sailing craft trading between the islands. Writing of Terceira, Walker (p. 253) states that in various parts of the island " are occasionally found immense cedar trees embedded in deep ravines and valleys, still in perfect preservation." An unearthed log sometimes proved to be a godsend to the islanders, who promptly cut it up for firewood.

The whole subject of these buried trees of the Azores requires systematic investigation; but there can be little doubt that the group possessed an abundance of excellent native timber in the early centuries of its occupation, and that it has none now. We would be unable in our days to find any native trees large enough to supply timber for the beams of the roofs of churches. Men, goats, and cattle have been active agents in deforesting these islands for four hundred years and more. Except when specially preserved, it would be difficult to find on Pico trees more than twenty feet high and more than thirty years old at the present day; and the same remark would apply to the native trees of the other islands.

The Greatest Size attained by Existing Trees on the Azores.-Facts of the kind just given led me to inquire into the maximum size that the existing trees can acquire when unhindered in their growth; and it will be seen from the data to be now given that they can attain quite respectable dimensions, although falling far short of those indicated for the trees of the original forests. I took up the matter on the island of Pico. Land is there valued for the wood upon it, and it is profitable for the owner to leave his land undisturbed for many years. The great demand for wood for firing and other purposes usually prevents this being done; but in two of these " preserves" at the back of Magdalena opportunities were afforded me of investigating the subject. Here the larger wood was made up entirely of Myrica faya, Laurus canariensis, and Erica azorica. The two first-named trees commonly attained a height of from thirty-five to forty feet and a diameter of from twelve to fifteen inches, and those of Erica azorica a height of twenty-five feet and a diameter of eleven or twelve inches. The Faya trees occasionally exceeded forty feet, the maximum being fifty feet. In the gardens around Ponta Delgada they grow to a height of from thirty-five to 
forty feet. The Erica trees evidently need the protection of a wood to attain their maximum size. Though a few of them in these preserves must have measured between thirty and thirty-five feet, it was apparent from the number of leaning and fallen trees that this was their limit.

It does not seem, however, that the present Juniper trees anywhere approach the size attributed to the " cedros" of the original forests. On Pico a height of fifteen or sixteen feet and a diameter of fifteen to eighteen inches (in very rare cases twenty inches) represent my maximum measurements. Rarely does the Azorean Juniper grow straight, the trunk being twisted and bent. It is likely that the finest specimens exist on the uplands of San Jorge. Judging from a photograph kindly taken in my interest by Colonel Chaves, they might there attain a height of eighteen or twenty feet. Mr. OgilvieGrant mentions the "grand old Juniper trees" in the higher levels of the same island (Novitates Zoologicoe, XII., 1905).

The Causes of the Destruction of the Original Forests.That the volcanic eruptions of early times played an important part in the destruction of forests in the Azores is highly probable. The old timber trees, as before described, are now found buried beneath their ejectamenta. In the early part of the occupation by man, namely, in the fifteenth and sixteenth centuries, the devastation of the forests from this cause must have been tremendous, and it is likely that the older outbreaks produced similar results. Since pumiceous tuffs strew the surface of San Miguel and are often exposed in sections a hundred feet in thickness, both in the high and in the low levels, we cannot help reflecting that the land-surface at such times must have been largely deprived of its covering of vegetation. The outbreak that occurred in the valley of Furnas in 1630 well illustrates what must have often taken place before. For three days and nights the ashes fell over all the island of San Miguel, covering the surface to a depth ranging from seven to twenty feet, and in many places destroying all the vegetation (Walker, pp. 61, 214). Even greater desolation must have resulted from the eruption of 1445 , when the highest eminence of the island at its western end was destroyed, leaving the great crater of the Seven Cities as its mark (Ibid., pp. 51, 57, etc.). The adjacent seas were covered with fields of floating pumice and immense trunks of trees, through which Cabral, the Portuguese navigator, made his way when approaching the island. It is probable that in the relatively recent activity of the volcanic forces in the Azores we have an explanation of the curious fact referred to in a later page of this chapter, that of the three Macaronesian groups, the Azorean, the Madeiran, and the Canarian, it is the group that is farthest from the mainland, namely, the Azores, that displays the least evidence of differentiation in its flora.

Yet it is likely that the plant world would have of itself regained much of its hold on the Azores, if it had not been for the arrival of the European. Man and his animals have completed the destruction of the original forests. In fact, Colonel Chaves, whose opinion would carry the greatest weight, seeks for the exclusive factor in the disappearance of the forests in "the destruction made by the inhabitants for constructions, fire, and exportation" (letter cited). 
The islands were discovered between 1432 (Santa Maria) and 1452 (Flores), and the early settlers displayed much energy in clearing the forests. Goats, hogs, and cattle were soon introduced, and they doubtless effectively assisted man in " the rapid and total extinction of these grand denizens of the forest, and with them probably of interesting plant and insect life" (Walker, p. 25). It is stated that as early as $\mathbf{1 5 2 6}$ the coasts of San Miguel were all under cultivation, and that sixteen parishes and six villages had been founded. According to the Traveller's Guide to Michael's, by F. S. Mayor (pp. 18, 19, Ponta Delgada, 1911), from which the facts just quoted have been taken, the earliest cultivation was of cereals and sugar-cane, the latter succumbing in 1560 to disease. From 1520 to 1640 great quantities of the Woad plant (Isatis tinctoria) were raised and exported; and, as we learn from the same authority, flax was cultivated between 1750 and 1764. In Linschoten's time (about 1589) the inhabitants of San Jorge, as they do at present, chiefly raised cattle and conveyed their produce to the islands near (see Purchas). One can imagine the extensive importation of weeds that must have been involved in the endeavours of the earlier colonists to develop the resources of the group.

In the course of time, so rapidly was the clearing of the woods effected in the more populous islands, like San Miguel and Terceira, that they began to look to the other islands for their timber. Thus Flores supplied Terceira with " cedars," and Pico seems to have been from the earliest days of the occupation a source of timber for the neighbouring islands. Some of the most valuable woods were sent to Portugal in these early times. Thus Dr. Webster, whose descriptions of St. Michael was published in 1821, states that considerable quantities of "the wood of Pico," apparently a species of yew, were formerly sent to Lisbon, where it was manufactured into worktables, desks, etc.

Whilst the earlier colonists despoiled their timber forests for erecting their houses, churches, and for similar purposes, they also employed the timber for firewood. Linschoten writes that in his day, namely, in the latter part of the sixteenth century, the wood of the "cedar" (Juniper) "is the commonest wood that they use to burne in those Countries, whereby it is the wood that with them is least esteemed, by reason of the great quantity thereof " (Purchas, vol. 18, p. 366). This practice has continued down to more recent times. The Bullars state that the "small stunted cedars" were so common on Flores in their time (1839) that their wood was used for heating the ovens, the pleasant smell from the cedar smoke of the cottage fires being noticeable outside the houses. In Pico at the present day the wood of the Juniper is extensively employed for the staves and bottoms of the milk buckets.

The need of fuel through the centuries and the requirements for fruit-boxes in later times have sealed the fate of the original forests. The demands of the fruit-trade were so great that at the time of which Walker wrote, about 1880, trees fifty years old were seldom met with on San Miguel. Those demands have passed away with the trade; but the need for fuel is of course insistent. Pico has been for generations the principal source of fuel for the neighbouring 
island of Fayal. At present a regular trade in Pico firewood exists between Horta and the towns and villages on the Pico side of the straits. There is but little attempt in the way of re-foresting the island of Fayal. Writing of a time so long ago as 1839 the Bullars remarked that " to such an extent has this short-sighted destruction been carried in Fayal that, with ample room for plantations, the principal supply of fuel is derived from Pico " (II., 8).

Firewood is the eternal question with these people; but it is only used for cooking their food, the foliage serving as fodder, the leafy branches as litter in their stables, and the branches of the Ling (Calluna vulgaris) and the Tree-Heath (Erica azorica) as brushwood. The procuring of these materials seems to be one of the principal occupations of their lives. On the lower slopes of the great mountain of Pico one meets all through the year a constant string of men, women, and bullock-drawn carts carrying loads of Erica azorica, Calluna vulgaris, Myrica faya, Laurus canariensis, Ilex perado, etc., the foliage of the last-named plant being cut in quantity for mule fodder. Withal, there is no attempt at renovation of the sources of supply. The land is allowed to remain undisturbed for several years, and the owner makes considerable profit by selling it with the wood standing, receiving it back when the wood is all felled. Faya trees attain a diameter of five or six inches in from eight to ten years, so that the growth of one of the most abundant and most useful of the trees can scarcely be said to be very rapid.

The lower wooded slopes of the mountain of Pico reaching to the government lands, 3000 to 4000 feet above the sea, are all private property. Low walls of loose lava blocks separate the different ownerships, the poor man having a small patch and the rich man a large one. These properties are handed down from parents to children, and the rights are rigidly observed. They may remain in the same family for generations. A bequest of a small patch of woodland for some poor widow is as much a necessity of her existence as a dwelling, and willing hands help her to bring the faggots down the mountain side, if she is old and feeble. A large amount of the carrying is done by the women, whilst the men do the felling. Coal at my time was only used by some of the better-class Picoese. The poorer people of the larger coast towns, like Magdalena, usually purchased their wood off the land from the owner, felled it themselves and carried it home, about six dollars' worth lasting them a year.

The Affinities of the Native Flora of the Azores.- The characteristic flowering plants of the woods, of the moors, of the ponds and lakes, and of the coast, exhibit in a progressive scale a gradually extending connection with the outer world. This is well brought out in the tables following these remarks. Whilst the shrubs and trees of the woods are for the most part non-European, and either exist in the other two Macaronesian groups (the Canaries and Madeira) or are represented there by closely related species, the plants of the upland moors and of the ponds and lakes are nearly all European species, that rarely occur either in the Canaries or in Madeira. The shore plants on their part are fairly well distributed, both in Europe and in the other two groups; and nearly half of them are also North American. The North American connections 
of the native flora are almost all of them European species; and, as might be expected from what has been said above, they are least evident with the plants of the woods and most pronounced amongst those of the sea-border and of the ponds and lakes.

The restrictions of most of the characteristic plants of the woods to the Macaronesian islands, the extension of nearly all those of the upland moors to Europe, and the common dispersion on both sides of the Atlantic of the plants of the seashore and of the ponds and lakes, illustrate a principle of wide application to insular florasa principle, however, that is often best exemplified in tropical regions. The varying degrees of isolation thus implied reflect, as will be shown later on, the differences in the histories of the dispersing agencies in stocking with their plants the woods, the moors, the ponds and lakes, and the seashores. The currents have been for ages unceasingly at work, directly and indirectly, in carrying seeds from one coast to another; and as a rule in tropical latitudes the specific connections kept up between the shore floras of different regions can be mainly ascribed to their influence. In a similar manner migrant waterfowl have sustained the connections of the plants of the river, the lake, and the pond, over great areas of the globe. In a like fashion, though to a less extent, birds of the grouse family have kept the plants of the mountain moors of distant regions in touch with each other. On the other hand, the dispersing activities of forest-frequenting birds, as far as oceanic islands are concerned, have been more and more restricted in the course of ages. The bird finally comes to stay, and both plant and bird differentiate together.

The foregoing subject is dealt with in the penultimate chapter of my book on Plant Dispersal ; but it is one, the importance of which was long since recognised by Godman in his work on these islands (p. 339). The principles involved have been unable to find their full expression in the islands of the Azores by reason largely of the lesser antiquity of those islands as compared with such an ancient group as that of the Hawaiian Islands in mid-Pacific. There, the impress of a far greater antiquity lies on the flora, and where species have been differentiated in the Azores genera have been developed in Hawaii. As shown in the work above named, it is on the forested mountain slopes of the Hawaiian Islands that most of the peculiar genera and peculiar species, both of plants and birds, are to be found. Here the agencies of trans-oceanic dispersal have long since ceased to act. A later suspension of these agencies is indicated by the plants of the mountain moor, which are generically connected with regions on both sides of the Pacific, but are usually specifically distinct. Yet, unless within recent times, there has been no suspension in the activity of migrant waterfowl as seed-carriers to the Hawaiian group, and as a result we find in the waters and at the sides of ponds and rivers plants that are widely distributed over the world. Lastly, there are the beaches, where, through the action of the currents in the run of the ages, we find several of the littoral plants characteristic of the tropical shores of Malaya, continental Asia, Africa, and America. We thus perceive that the Azorean and Hawaiian floras exhibit the same progressive scale of connections with the outer world, which are least with the plants of the woods, 
freer with the plants of the upland moor, and more or less unrestricted with the aquatic plants and with the plants of the seashore.

Though the contrasts in the differentiation of the Azorean and Hawaiian floras are largely bound up with the differences in the antiquity of the two archipelagos, the much greater isolation of the Hawaiian group, which lies some 2000 miles from the nearest mainland, has doubtless had a potent influence. Yet antiquity alone may largely counteract the effects of contiguity to a continent. The Canaries, for example, are evidently of much greater age than the Azores, and to this circumstance we might attribute the fact that as many as $\mathbf{3 0}$ per cent. of their native plants are peculiar, whilst only 10 per cent. are endemic in the Azores. Yet only fifty-five miles of open sea separate the Canaries from the African coast, whilst about 800 miles intervene between the Azores and the nearest mainland, the coast of Portugal. So with the Galapagos Islands, which are removed about $\mathbf{5 0 0}$ miles from the coast of Ecuador, half of the native plants are endemic. It is therefore evident that an influence more potent than that concerned with distance from the mainland may affect the endemism of some insular floras. Presumably this is often that of antiquity.

Before proceeding with the discussion of the affinities of the native flora of the Azores, I will give in tabulated form the distribution of the most characteristic plants grouped according to their station. The affinities of the individual groups will then be dealt with, and this will be followed by a comparison of the Azorean, Madeiran, and Canarian floras, as far as it can be focussed in a contrast of the vegetation of the Peak of Teneriffe and of the great mountain of Pico.

Distribution of Characteristic Native Flowering Plants of the AZORES OUTSIDE THE GROUP

I

Plants of the Woods

\begin{tabular}{|c|c|c|c|c|c|c|}
\hline & 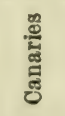 & 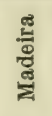 & 总 & 密 & 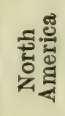 & Remarks \\
\hline $\begin{array}{l}\text { Hypericum foliosum } \\
\text { (Ait.) }\end{array}$ & & & & & & $\begin{array}{l}\text { Probably allied to a } \\
\text { species of Madeira, } \\
\text { H. grandifolium. (See } \\
\text { Watson.) }\end{array}$ \\
\hline Ilex perado (Ait.) & + ? & + & & & & $\begin{array}{l}\text { Allied to a Canarian } \\
\text { species, if not in the } \\
\text { group (Watson). }\end{array}$ \\
\hline $\begin{array}{c}\text { Rhamnus } \\
\text { (Hérit.) }\end{array}$ & & + & & & & $\begin{array}{l}\text { Lowe is the authority } \\
\text { for its Madeiran habitat. }\end{array}$ \\
\hline Prunus lusitanica (L.) & + & + & & + & & \\
\hline Rubus fruticosus (L.) & + & + & + & + & & $\begin{array}{r}\text { A segregate species } \\
\text { usually named discolor } \\
\text { by English botanists } \\
\text { (Watson). (See Trelease.) }\end{array}$ \\
\hline
\end{tabular}


Plants of the Woods (cont.)

\begin{tabular}{|c|c|c|c|c|c|c|}
\hline & 离 & 䒿 & $\stackrel{3}{\frac{3}{4}}$ & 总 & 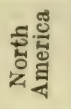 & Remarks \\
\hline $\begin{array}{l}\text { Hedera canariensis } \\
\text { (Willd.) }\end{array}$ & + & $+?$ & & & & $\begin{array}{l}\text { Near H. helix (Wat- } \\
\text { son). }\end{array}$ \\
\hline $\begin{array}{l}\text { Arceuthobium oxy- } \\
\text { cedri (M.B.) }\end{array}$ & & & + & + & + & $\begin{array}{l}\text { The authorities for its } \\
\text { distribution are the In- } \\
\text { dex Kewensis and Arc- } \\
\text { angeli's Flora Italiana. }\end{array}$ \\
\hline Viburnum tinus (L.) & & & + & + & & $\begin{array}{l}\text { Trelease describes the } \\
\text { Azorean form as a } \\
\text { variety of } V \text {.tinus under } \\
\text { the name of subcordatum. }\end{array}$ \\
\hline $\begin{array}{l}\text { Vaccinium cylindra- } \\
\text { ceum }(\mathrm{Sm} .)\end{array}$ & & & & & & $\begin{array}{l}\text { Closely allied to a } \\
\text { Madeiran species } V \text {. } \\
\text { maderense. (See Wat- } \\
\text { son.) }\end{array}$ \\
\hline $\begin{array}{l}\text { Erica azorica } \\
\text { (Hochst.) }\end{array}$ & & & & & & \\
\hline $\begin{array}{l}\text { Picconia excelsa } \\
\text { (DC.) }\end{array}$ & + & + & & & & $\begin{array}{l}\text { Notelaea excelsa (Webb) } \\
\text { is a second name. }\end{array}$ \\
\hline Myrsine africana (L.) & & & + & & & $\begin{array}{l}\text { Widely distributed in } \\
\text { Africa and Central Asia. }\end{array}$ \\
\hline Daphne laureola (L.) & & & + & + & & \\
\hline $\begin{array}{l}\text { Laurus canariensis } \\
\text { (Webb) }\end{array}$ & + & + & & & & $\begin{array}{l}\text { The Persea azorica of } \\
\text { Seubert. }\end{array}$ \\
\hline Persea indica (Spr.) & + & + & & & & $\begin{array}{l}\text { Laurus indica in } \\
\text { Lowe's work. }\end{array}$ \\
\hline $\begin{array}{l}\text { Euphorbia mellifera } \\
\text { (Ait.) }\end{array}$ & + & + & & & & $\begin{array}{l}\text { The Azorean variety } \\
\text { is Stygiana (Watson). }\end{array}$ \\
\hline Smilax & + & & & & & $\begin{array}{l}\text { Trelease divides the } \\
\text { Canariensis of Watson } \\
\text { into Excelsa, L., and } \\
\text { Divaricata, Sol. }\end{array}$ \\
\hline Myrica faya (Ait.) & + & + & & & & \\
\hline $\begin{array}{l}\text { Juniperus brevifolia } \\
\text { (Hochst.), a var. of } \\
\text { J. oxycedrus (L.) }\end{array}$ & + & + & + & + & & $\begin{array}{l}\text { Seubert's view that } \\
J . \text { brevifolia stands to } \\
J . \text { oxycedrus as } J . \text { nana } \\
\text { to J. communis is } \\
\text { adopted. The distri- } \\
\text { bution given is that of } \\
J . \text { oxycedrus. }\end{array}$ \\
\hline Taxus baccata (L.) & & + & + & + & + & $\begin{array}{l}\text { Lowe is the authority } \\
\text { for its being Madeiran. }\end{array}$ \\
\hline
\end{tabular}




\section{Distribution of Characteristic Native Flowering Plants of the Azores oUtside the Group (cont.)}

II

Plants of the Upland Moors

\begin{tabular}{|c|c|c|c|c|c|c|}
\hline & 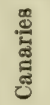 & $\frac{\mathscr{m}}{\frac{\mathscr{m}}{0}}$ & 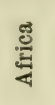 & 芯 & 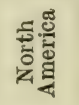 & Remarks \\
\hline Viola palustris (L.) & & & & + & + & \\
\hline Polygala vulgaris (L.) & & & & + & & \\
\hline $\begin{array}{l}\text { Potentilla tormen- } \\
\text { tilla (Wats.) }\end{array}$ & & + & & + & & \\
\hline $\begin{array}{l}\text { Hydrocotyle vulgaris } \\
\text { (L.) }\end{array}$ & & & & + & & \\
\hline Calluna vulgaris (S.) & & & + & + & + & \\
\hline $\begin{array}{c}\text { Menziesia polifolia } \\
\text { (Sm.) }\end{array}$ & & & & + & & \\
\hline $\begin{array}{l}\text { Erythræa massoni } \\
\text { (Sw.) }\end{array}$ & & & & & & $\begin{array}{c}\text { Connected by some } \\
\text { with a Canarian species. }\end{array}$ \\
\hline $\begin{array}{l}\text { Sibthorpia europæa } \\
\text { (L.) }\end{array}$ & & & + & + & & $\begin{array}{l}\text { Occurs in the Abys- } \\
\text { sinian highlands } \\
\text { (Hooker's Marocco, p. } \\
\text { 422). }\end{array}$ \\
\hline $\begin{array}{l}\text { Thymus serpyllum } \\
\text { (L.), var. angusti- } \\
\text { folius (Bois.) }\end{array}$ & & + & + & + & & $\begin{array}{l}\text { The distribution re- } \\
\text { fers to the species. }\end{array}$ \\
\hline $\begin{array}{l}\text { Lysimachia nemo- } \\
\text { rum (L.) }\end{array}$ & & & & + & & $\begin{array}{l}\text { The separation of } L \text {. } \\
\text { azorica (Hornem.) is not } \\
\text { here adopted. } \\
\text { Though regarded as } \\
\text { distinct species by both } \\
\text { Watson and Trelease, } \\
\text { they are united in the } \\
\text { Index Kewensis and by } \\
\text { Seubert as well as by } \\
\text { Pax and Knuth in the } \\
\text { Pflanzenreich. }\end{array}$ \\
\hline Anagallis tenella (L.) & & & + & + & & \\
\hline $\begin{array}{c}\text { Luzula purpureo- } \\
\text { splendens (Seub.) }\end{array}$ & & & & & & \\
\hline Carex flava (L.) & & + & & + & + & Also Asiatic. \\
\hline
\end{tabular}


Distribution of Characteristic Native Flowering Plants of the Azores odtside the Group (cont.)

III

Plants of the Ponds and Lakes

\begin{tabular}{|c|c|c|c|c|c|c|}
\hline & 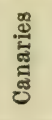 & 恚 & $\frac{\mathrm{m}}{4}$ & 总 & 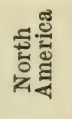 & Remarks \\
\hline $\begin{array}{l}\text { Callitriche aquatica } \\
\text { (L.) }\end{array}$ & & + & + & + & + & World-wide. \\
\hline Peplis portula (L.) & & & + & + & & \\
\hline $\begin{array}{l}\text { Littorella lacustris } \\
\text { (L.) }\end{array}$ & & & & + & & \\
\hline $\begin{array}{l}\text { Potamogeton poly- } \\
\text { gonifolius (Pourr.) }\end{array}$ & & & + & + & + & Also Asiatic. \\
\hline Scirpus palustris (L.) & + & & + & + & + & Also Asiatic. \\
\hline $\begin{array}{c}\text { Scirpus multicaulis } \\
(\mathrm{Sm} .)\end{array}$ & & & & + & & \\
\hline Scirpus fluitans (L.) & & & & + & & \\
\hline $\begin{array}{l}\text { Scirpus savii (S. and } \\
\text { M.) }\end{array}$ & & & + & + & & $\begin{array}{l}\text { Watson is here fol- } \\
\text { lowed. Ball gives it as } \\
\text { on the Great Atlas. }\end{array}$ \\
\hline $\begin{array}{l}\text { Carex stellulata } \\
\text { (Good.) }\end{array}$ & & & & + & + & $\begin{array}{l}\text { Also Asiatic, Aus- } \\
\text { tralian, etc. }\end{array}$ \\
\hline
\end{tabular}




\section{Distribution of Characteristic Native Flowering Plants of the AZORES OUTSIDE THE GROUP (cont.)}

IV

Plants of the Sea-coasts

\begin{tabular}{|c|c|c|c|c|c|c|}
\hline & 总 & 莺 & 总 & 总 & 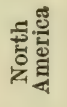 & Remarks \\
\hline$\underset{\text { (Bigel.) }}{\text { Cakile edentula }}$ & & $+?$ & & & + & $\begin{array}{l}\text { For Madeira see page } \\
\text { 185. Probably intro- } \\
\text { duced into Azores in } \\
\text { ballast. }\end{array}$ \\
\hline $\begin{array}{l}\text { Silene maritima (B. } \\
\text { and } \mathrm{H} \text {. Handbook) }\end{array}$ & + & + & & + & & \\
\hline $\begin{array}{r}\text { Spergularia marina } \\
\text { (Watson) }\end{array}$ & + & $+?$ & & + & + & Also Asiatic. \\
\hline $\begin{array}{l}\text { Mesembryanthe- } \\
\text { mum ? }\end{array}$ & & & & & & See page 384 . \\
\hline $\begin{array}{l}\text { Crithmum mariti- } \\
\text { mum (L.) }\end{array}$ & + & + & + & + & & \\
\hline $\begin{array}{l}\text { Solidago sempervi- } \\
\text { rens (L.) }\end{array}$ & & & & & + & $\begin{array}{l}\text { Also indigenous in } \\
\text { Bermuda. }\end{array}$ \\
\hline $\begin{array}{r}\text { Campanula } \\
\text { (Watson) }\end{array}$ & & & & & & See page 427 . \\
\hline $\begin{array}{c}\text { Erythræa maritima } \\
\text { (Pers.) }\end{array}$ & + & + & & + & & \\
\hline $\begin{array}{l}\text { Ipomœea carnosa (R. } \\
\text { Br.) }\end{array}$ & & & & + & + & $\begin{array}{l}\text { Occurs also in the } \\
\text { Hawaiian Islands. }\end{array}$ \\
\hline $\begin{array}{l}\text { Hyoscyamus albus } \\
\text { (L.) }\end{array}$ & + & + & + & + & & \\
\hline $\begin{array}{l}\text { Plantago coronopus } \\
\text { (L.) }\end{array}$ & + & + & + & + & & \\
\hline Salsola kali (L.) & & & + & + & + & Also Asiatic. \\
\hline Beta maritima (L.) & + & + & + & + & & \\
\hline $\begin{array}{c}\text { Polygonum mariti- } \\
\text { mum (L.) }\end{array}$ & + & + & + & + & + & \\
\hline $\begin{array}{c}\text { Euphorbia } \\
\text { (Hochst.) }\end{array}$ & & $+?$ & $+?$ & $+?$ & & $\begin{array}{l}\text { In De Candolle's Pro- } \\
\text { dromus regarded as a } \\
\text { variety of E. pinea, } \\
\text { L., which occurs in } \\
\text { South Europe, North } \\
\text { Africa, and Madeira. }\end{array}$ \\
\hline Euphorbia peplis (L.) & + & & & + & & \\
\hline Juncus acutus (L.) & + & + & & + & + & \\
\hline
\end{tabular}

Note.-With one or two exceptions the African localities are North African, though several of the plants have a wider distribution in the continent. 
Summary of the results given for the characteristic plants of the Azores in the foregoing tables.

\begin{tabular}{|c|c|c|c|c|c|c|}
\hline & \multicolumn{2}{|c|}{$\begin{array}{l}\text { Macaronesian } \\
\text { exclusively }\end{array}$} & \multirow{2}{*}{ 总 } & \multirow{2}{*}{ 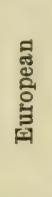 } & \multirow{2}{*}{ 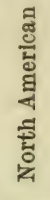 } & \multirow{2}{*}{ Remarks } \\
\hline & Total & 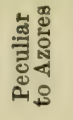 & & & & \\
\hline $\begin{array}{l}\text { Plants of the woods } \\
\text { (total 20) }\end{array}$ & 12 & 3 & 7 & 7 & 2 & $\begin{array}{l}\text { Two of the peculiar } \\
\text { Azorean species are } \\
\text { closely allied to Ma- } \\
\text { deiran species. }\end{array}$ \\
\hline $\begin{array}{l}\text { Plants of the upland } \\
\text { moors (total 13) }\end{array}$ & 2 & 2 & 4 & 11 & 3 & \\
\hline $\begin{array}{l}\text { Plants of the ponds } \\
\text { and lakes (total 9) }\end{array}$ & 0 & 0 & 5 & 9 & 4 & \\
\hline $\begin{array}{l}\text { Plants of the sea. } \\
\text { coast (total 15) }\end{array}$ & 1 & 1 & 7 & 13 & 6 & $\begin{array}{l}\text { The species of Cakile } \\
\text { and the doubtful species } \\
\text { of Mesembryanthemum } \\
\text { are not included. }\end{array}$ \\
\hline
\end{tabular}

Note.-Macaronesia is here taken as comprising the Azores, the Madeiras, and the Canaries. The total under this head includes not only the Azorean plants occurring in the Canaries and Madeira (one or both), but also the peculiar Azorean plants which are indicated in the next column.

With one exception the African localities are North African, though several of the plants have a wider distribution in the continent.

(A) The Affinities of the Characteristic Plants of the Woods.-Although the ancestors of the non-European species were in all probability originally derived from Europe, they doubtless belong to an early period in the plant-stocking of the group, the connection with their home having been long since broken off. But this rupture has only affected the majority of the plants, about a third of those named in the foregoing list being European species. Three of them, Daphne laureola, Viburnum tinus, and Juniperus oxycedrus, grow on the slopes of the Great Atlas at altitudes of 4000 to 6500 feet (Ball), whilst Taxus baccata is at home in the mountains of Algeria (Arcangeli).

The possibility thus presents itself that the Azores derived some of their European plants by way of the mountains of North-west Africa. But there is reason for the belief that the other two Macaronesian groups, the Canaries and the Madeiras, have received similar accessions to their floras from the Atlas Mountains. Thus, to take the Canarian forest flora, we have in Daphne gnidium a European species that is associated on the slopes of the Great Atlas with Daphne laureola, and in Viburnum rigidum a species which from its resemblance to the Azorean variety of $V$. tinus might be by some regarded as possessing the same parentage (see on this point Trelease, p. 118). Then again the Canarian flora owns in 
Juniperus oxycedrus a Great Atlas tree. Not more than 250 miles separate the western extreme of the Atlas Mountains from the Canary Islands, and it would be strange if the woods of that archipelago had not received important accessions from that elevated region. Much of what has been said of the Canarian forest flora would apply also to Madeira. In this case the Yew (Taxus baccata) and the Juniper ( $J$. oxycedrus) could have found their nearest source in the Western Atlas.

As regards the possibility of the Azorean woods having received some of their European species from North-west Africa as well as from South-west Europe, one may be prepared for much when we reflect on the very singular African connection displayed by one of the most predominant of the shrubs, namely, Myrsine africana. It is a native and often a mountain plant of Inter-tropical and South Africa, Arabia, and Central Asia. It is not even at home in Madeira and the Canary Islands, its nearest known habitats being in Angola and Abyssinia. Its small berries are well suited for dispersal by frugivorous birds; but its isolated occurrence in the Azores is one of the puzzles of the flora.

But by far the most important feature in the affinities of the characteristic plants of the Azorean woods is indicated in the fact that, whilst mainly non-European, they are largely Canarian and Madeiran. We are not so much concerned here with statistical results, such as are presented at the end of the previous table, but with the fact that with one exception, that of Myrsine africana, all the trees and shrubs that are most abundant are either Canarian or Madeiran, or are presented in one or both of those two groups by closely allied or similar species. They are Canarian in a special sense, since they are for the most part confined to the middle zone or Laurel belt of Teneriffe, which lies between the levels of 2000 and 5000 feet. That their general facies was Canarian was recognised by the writer when exploring the Azorean woods, after a previous acquaintance on Teneriffe with the woods situated between 2000 and 3000 feet above the sea in the Laguna and Taganana districts. In these Canarian woods flourish the same two Laurels, Laurus canariensis and Persea indica, the same species of Myrica (M. faya), a similar Tree-Heath (Erica arborea), a Holly closely allied to or identical with the Azorean Ilex (I. perado), allied species of Rhamnus, Vaccinium, and Viburnum, and among the climbers the same species of Hedera and Smilax. Excluding the special Canarian element, the list given by Christ of the characteristic trees and shrubs of the Laurel woods of Teneriffe might in most respects pass for one of those of the Azorean woods on the slopes of the great cone of Pico; but this is a subject that will be again noticed when we compare the zones of vegetation on the slopes of these two great volcanic mountains.

The Madeiran aspect of the Azorean woods is seen in many ways. Here again, after excluding the special Madeiran element, the principal indigenous trees and shrubs named by Lowe for the lower woods and for the Laurel and Heath zone, 2500 to 5500 feet above the sea, include many of those that give character to the Azorean woods. 
Here in the lower woods are Myrica faya, Rhamnus latifolius (now very rare), and Euphorbia mellifera, as well as a representative species of Hypericum ( $H$. grandifolium). In the upper woods grow Laurus canariensis, Persea indica, Ilex perado, Picconia excelsa (now very rare), a representative Tree-Heath (Erica arborea), and a species of Vaccinium ( $\boldsymbol{V}$. maderense) closely allied to the Azorean species. The thickets of Tree-Heath and of Vaccinium, in which thrive the two Madeiran Hollies (Ilex perado and I. azevinho), must together with the Laurels and the Fayas often give an appearance very Azorean to the remains of the original Madeiran woods. We will now proceed to discuss briefly the affinities of the other groups of characteristic Azorean flowering plants.

(B) The Affinities of the Characteristic Plants of the Upland Moors.Of the thirteen plants named in the list eleven are European and two are endemic. There is no African or North American connection that is not also European. There are seemingly hardly any of these plants in the Canaries and not many in Madeira; and when we reflect that only Thymus serpyllum appears to be represented on the Great Atlas range, namely, on the higher slopes, we are driven to the conclusion that the Azores derived their moor plants from Southern Europe.

(C) The Affinities of the Characteristic Plants of the Ponds and Lakes.-The conclusion formed for the plants of the moors applies; here with greater force. All the species are European, and this disposes of any special connection either with Africa or North America. Then, again, few of them have been found either in Madeira or in the Canaries. We must therefore look to South-western Europe for the source of the Azorean aquatic and subaquatic plants.

(D) The Affinities of the Characteristic Plants of the Sea-coast.Here, though predominantly European, the species are well represented in North America as well as in the Canaries and Madeira, though, if we exclude Cakile edentula, which was probably introduced in ballast, the only North American species that is non-European is Solidago sempervirens. The case of Campanula vidalii probably raises other issues. As concerns Euphorbia azorica it would be safer to give it a varietal value than to regard it as a distinct species.

A Comparison of the Zones of Vegetation on the Great Cone of Pico with those on the Peak of Teneriffe and on the IsLAND OF MADEIRA.- The contrasts between the zones of vegetation in the Azores and the Canary Islands can be focussed in a comparison between the great mountain of Pico and the Peak of Teneriffe. The differences between the zones on Teneriffe are so striking that all observers agree fairly well in their accounts of them, whether in the case of Von Buch in the early part of last century or in that of Christ in the latter part of it; and since the present writer made acquaintance with the plants of the lower two zones during a short visit to the island in the month of February, he is able to approach the subject with some confidence.

The lowest zone on Teneriffe, the region below the clouds (as Christ designates it), reaches up to 2000 or 2500 feet. It is the African zone with all its strange-looking plants, the region of steppe 
vegetation. On its rocky slopes bushes prevail. Here we see the Cactoid Euphorbias, the curious rubiaceous Plocama pendula with the habit of a Casuarina, many shrubby Composita, such as Kleinia neriifolia, as well as several kinds of boragineous plants of the genus Echium and a score of species of Statice. Here the Canarian palm (Phoenix canariensis) is at home; but probably next to the Cactoid Euphorbias the Dragon-trees (Dracana draco, dealt with in Note 31 of the Appendix) gave most character to the larger vegetation in the early days. Amongst the most conspicuous and interesting of the lesser plants are the fleshy-leaved Crassulacea. On the steep slopes of the barrancos and on the faces of the lofty coast-cliffs they present themselves often as large flat rosettes that may measure as much as twelve or even fifteen inches across. Nowhere else in the world, writes Hemsley in his account of Christ's investigations, is there such a concentration of this class of plants, no fewer than fifty-two species having been enumerated by Christ, mostly belonging to the genus Sempervivum.

Then follows, between 2000 and 5000 feet, the region of clouds and of rains, the zone of the Laurel forests, where we notice several Azorean trees and shrubs, such as Laurus canariensis and Persea indica among the Laurels, as well as Myrica faya, Picconia excelsa, a similar Tree-Heath (Erica arborea), and the same or allied or representative species of Ilex, Rhamnus, Smilax, Viburnum, and $\boldsymbol{V}$ accinium. Amongst the several trees and shrubs that are not found in the Azores are the two Laurels, Oreodaphne foetens and Phoebe barbusana, a species of Arbutus, and a species of the American genus, Clethra. The American elements in the Canarian flora will be again alluded to.

Above the Laurel woods we enter the Pine belt, which is most characteristic of the levels between 5000 and 6500 feet. This was also the zone of the Juniper, now, as Christ remarks, almost exterminated on Teneriffe. It is highly probable that the Juniper (Juniperus oxycedrus) was once associated with the Pine (Pinus canariensis) in considerable quantity; but the value placed on its timber, not only by the colonists but also by the aborigines, has resulted, according to Christ and others, in its practical extinction. However, scattered individuals still exist in the upper portion of the Pine belt; but it is extremely probable that it had originally much the same range as the Pine. It would seem that it still rexists at altitudes of about 4000 feet on Palma, another island of the group, and that it once grew near the summit of one of the highest peaks of the island, the Pico del Cedro, which rises 7470 feet above the sea (see Bolle as quoted by Christ, and Samler Brown's Guide to the Canary Islands, 1905, pp. 1, 10). We might expect that the original vertical range of Juniperus oxycedrus on Teneriffe was about a thousand feet higher than it is on the slopes of the Great Atlas, about three degrees farther north, where it was placed by Hooker and Ball (p. 433) at 4000 to 6500 feet.

Beyond the Pine belt is a belt covered with the "codeso" (Adenocarpus viscosus), a leguminous shrub that extends to about 7000 feet. This plant then gives place on the pumice-stone plains of the Canadas 
to the "retama" (Spartocytisus nubigenus), a broom, which with occasional herbs reaches to nearly 11,000 feet. So characteristic is the broom of this elevated region that the pumice plains are known as the "Llano de la Retama."

Before contrasting the zones on Teneriffe with those on Madeira and in the Azores, we will first determine what we ought to expect, having regard to the difference in latitude (Teneriffe, $28^{\circ} 17^{\prime} \mathrm{N}$.; Madeira, $32^{\circ} 44^{\prime}$; Pico, $38^{\circ} 28^{\prime}$ ) and the associated differences in climate. From the data given below it will be apparent that in response to the cooler climatic conditions we should expect in the case of Pico no African zone, and in its place the extension of the Laurel woods to the coast. In the case of Madeira we should look for intermediate features in the vertical range of the zones. The African zone would be considerably restricted, and the lost ground would be occupied by the Laurel woods in their descent towards the coast.

Taking the rate of change of the mean temperature at rather over three degrees, Fahrenheit, for each thousand feet, the difference in the annual mean temperature near the sea-level at Teneriffe and Pico, which is about seven or eight degrees (69-61), would represent some $\mathbf{2 0 0 0}$ or $\mathbf{2 5 0 0}$ feet. From this it follows that the warm climatic conditions that prevail below 2000 or $\mathbf{2 5 0 0}$ feet on Teneriffe, or, in other words, those of the African zone, would not exist on Pico; whilst the Laurel woods, which succeed the African zone on Teneriffe, would on Pico descend to the coast. In the case of Madeira, where the mean annual temperature near the sea-level (about $66^{\circ} \mathrm{F}$.) is some three or four degrees lower than at Teneriffe, the corresponding difference in altitude would be 1000 or 1200 feet. As the result, the upper limit of the African zone in Madeira, instead of lying 2000 or 2500 feet above the sea, as on Teneriffe, would only attain half that elevation on the Madeiran slopes, and the Laurel woods would descend to a similar extent.

When we come to the facts, and compare in the first place the zones of vegetation on Teneriffe and on Pico, the results may soon be stated. Pico owns no African zone. Where the cultivator has allowed it, its lower woods so Canarian in their character, in their Laurels, their Fayas, and their Tree-Heaths, instead of lying some 2000 or 2500 feet up the slopes, as on Teneriffe, descend to the vicinity of the coast. So also its upper woods, where the Azorean representatives of the Canarian Juniper ( $\boldsymbol{J}$. oxycedrus) give character to the vegetation, indicate a similar downward displacement of some 2000 feet or more, as compared with the elevation of the original Juniper zone on Teneriffe. The Canarian Juniper zone evidently lay above 4000 feet; whilst the Azorean zone of Junipers descends to 2000 feet.

But there is no belt of Pines on Pico. It cannot be argued that the suitable soil-conditions and the requisite elevation for the genus would not be found on the barren slopes of lava and cinders on the higher levels of the mountain, since from the association on Teneriffe of the Canarian Pine with Juniperus oxycedrus it is apparent that the place of the Pine on Pico would be at elevations 2000 or 2500 
feet lower than on Teneriffe, that is to say, between 2500 and 4500 feet above the sea. Here, usually under good soil-conditions, the Juniper is at home on Pico, but there are no Pines. The absence of the Pine from Pico, and from the Azores as a group, is a very pregnant fact in the history of the plant-stocking of the archipelago. A brief comparison of the summit vegetation of the great volcanic mountains of Teneriffe and of Pico, as well as of Madeira, will follow the description of the zones of vegetation on the last-named island.

In the case of Madeira, sufficient materials for the comparison of its zones of vegetation are supplied by Lowe. The lowest or tropical zone, corresponding to the African zone on Teneriffe, extends according to this authority only $\mathbf{7 0 0}$ feet up the slopes. He names it the Cactus and Banana zone, and names among its indigenous plants Draccena draco and Euphorbia piscatoria (the Dragon Tree and arborescent Euphorbia of the lowest Canarian zone), with species of Sempervivum, and the sapotaceous tree, Sideroxylon mermulana; but we may infer that both in its extent and its characters the lowest Madeiran zone is a poor representative of the Canarian zone. From the data given by Lowe we can infer that the woods which originally clothed the slopes of Madeira from five or six hundred feet above the sea to within a few hundred feet of the summit, the altitude of which is about 6100 feet, were in the main the representatives of the Laurel woods of Teneriffe, which there exist at levels of 2000 to 5000 feet. In their lower levels flourished, as in the Azores, the Faya tree (Myrica faya), and in the upper levels the Azorean Laurels Laurus indica and $\boldsymbol{L}$. canariensis), all characteristic of the Canarian woods. They were associated with the Tree-Heath (Erica arborea) of Teneriffe, Rhamnus glandulosa of the same island, the Tree-Euphorbia ( $E$. mellifera), and Picconia excelsa of the woods of Pico and Teneriffe, besides shrubby species of Hypericum and Vaccinium, representing predominant plants of the Azorean and Canarian woods. But a feature of the Madeiran as well as of the Canarian woods, a feature not possessed by those of the Azores, is the presence of shrubs and trees of the American genera, Clethra, Cedronella, and Bystropogon, etc., to the significance of which allusion will subsequently be made.

There was originally a Juniper zone in the higher levels of the Madeira woods, such as there was once on Teneriffe, and such as exists now on Pico. Though now nearly exterminated on account of the value set on its timber, Juniperus oxycedrus, as Mr. Johnson tells us (Encycl. Brit. 9th edit. XV., 180), was formerly abundant, and grew to a height of forty or fifty feet. Its lower limit was probably intermediate between that of the Juniper zone on Pico (2000 feet), and on Teneriffe (4000 feet), so that probably it would have flourished at levels above 3000 feet. Walker, in his book on the Azores, speaks of this Juniper as growing to a stately size in the mountain fastnesses of Madeira. Indigenous Pines are absent from Madeira as well as from the Azores, and the same difficult question is here raised. Since Pinus pinaster has been extensively planted on the Madeiran slopes, the absence of the genus cannot be due to unsuitable conditions.

It is remarkable that whilst the woods of Pico, Madeira, and 
Teneriffe possess many features in common, the plants that have found a home on their summits differ greatly. We have seen that the plants which have reached the summit of the great cone of Pico, the Heather (Calluna vulgaris), the Heath (Menziesia polifolia), the Thyme (a variety of Thymus serpyllum), the grasses, etc., have all climbed up from the moors below. This would have been impossible either on Teneriffe or Madeira, on account of the absence of moors of this description. Yet in the queer little gathering of half a dozen native plants, which Lowe describes as having found a refuge on the rocky crags of the summit of Madeira, there is a small effort in this direction. After removing from his list Cerastium tetrandrum (Curt.), as probably an introduced weed, there remain Arenaria serpyllifolia, Erica cinerea, Viola paradoxa, Armeria maderensis, and Avena marginata, the three last being first described by Lowe as peculiar to the island. Coming to the scanty vegetation of the high levels of Teneriffe, it is to be again observed, that apart from the perennial herbs (Arabis albida, etc.) it is the Retama broom (Spartocytisus nubigenus) that gives a character to the pumice-stone plains of the Canadas between 7000 and 9000 feet above the sea, a leafless shrub that climbs the steep lava slopes of the terminal cone to a height of $\mathbf{1 1 , 0 0 0}$ feet. The history of the Retama in this elevated area is implied in a remark of Hooker, that its Moorish name has come to be used by botanists for a small group of brooms, containing a few nearly allied species, that are widely spread throughout the region extending from Spain to the Canary Islands (Marocco and the Great Atlas, p. 27). A Violet, known as Viola teydensis and peculiar to the peak, clings to the soil at the upper edge of the Llano de la Retama, as the pumice-stone plains are called. Above this level, writes Johnson (Encycl. Brit. 9th edit. IV., 797), there is nothing but a little lichen.

We have remarked that the peculiar feature of the summit vegetation of the great cone of Pico, as compared with the Peak of Teneriffe and with Madeira, is that it is all derived from the moors below. This brings us to another distinctive feature in the zones of Pico. The wet and dry moors, which are so conspicuous around the middle levels of the mountain of Pico, having been formed at the expense of the upper woods or the Juniper zone, seem scarcely represented on Teneriffe and Madeira, hardly any of their characteristic plants being there present. This contrast is well reflected in the differences in the Sphagnum floras of the three groups, as brought out in Warnstorf's monograph on the Sphagnaceo (Das Pflanzenreich, 1911). Whilst in the Azores there are nine known species of Peat-mosses, of which two are peculiar to the group, there seems to be in each case only a single wide-ranging species in Madeira and the Canaries, a fact that points to prevailing unfavourable conditions for the development of Sphagnum moors in those islands.

The Plant-Stocking of the Macaronesian Islands.-But to return to our general comparison of the floras of the Macaronesian islands, there is a wider outlook of the question, such as Hooker presented in his Lecture on Insular Floras (1866), and in his discussion of the Canarian flora in his later work on Marocco (1878), and such 
as Christ offered some years after in his contribution to Engler's Botanische Jahrbucher (1885). According to Christ, the oldest constituents of the Macaronesian floras, such as occur in the Canaries and to a less degree in Madeira, are the African plants, as examples of which the Cactoid Euphorbias and the Dragon-trees (Dracaena draco) are amongst the first to attract the stranger's eye, when he first visits these islands. Then followed the invasion by Asiatic plants, now typefied by genera like Phoebe and Visnea, that are identical with or closely allied to genera now existing in the warm regions of Asia. Most of the peculiar Canarian genera appear to be connected with these early African and Asiatic invasions.

Since the American elements of the Canarian and Madeiran floras seem as a rule to retain their original generic characters, we may give third place to the invasion of American plants. They include Clethra arborea, a beautiful ericaceous tree, the labiate shrubs of Cedronella and Bystropogon, and species of the umbelliferous genus Bowlesia, genera that in the aggregate are now most typical of the warmer latitudes of South America and of the Andine region. The special difficulties concerned with the origin of these American elements of the Canarian and Madeiran floras are recognised by both Hooker and Christ, and both of them find an explanation in the transatlantic carriage of the seeds of the parent plants. Hooker writes that "we can but hazard the assumption that at some very distant date these genera existed in more eastern parts of South America, from whence seeds were transported across the ocean" (Marocco, p. 420). Christ appeals at once to the agency of the Gulf Stream. However, no evidence of the fitness of these plant genera for distribution by currents is produced, and I may say here, having had a long experience of the buoyant capacities of seeds and fruits, that the future experimenter will most probably find that the agency of the currents cannot be invoked. It is possible that the problem may assume quite another complexion, seeing that two of the genera concerned, Clethra and Cedronella, exist in Eastern Asia, as in Malaya and Japan. It may be that the American elements of the Macaronesian floras may require the same general explanation that is apparently demanded by the almost cosmopolitan connections that linked the Canaries and Madeira in the earlier stages of their floral history with the warmer regions of the globe. I refer to the original diffusion of the same plant-types around the tropics.

However this may be, the Azores were but little affected by the early invasions of Macaronesia by Asiatic, African, and American genera. Their floral history begins with the subsequent invasion of the same region by South European and Mediterranean genera, that now give character to the Laurel woods of the three Macaronesian groups. But even this invasion must have taken place at a period remote from the present. Although there has been no generic dissociation, several of the trees and shrubs are not to be found outside Macaronesia, and we should often look in vain in their original European home for the parent stocks. Yet, as is shown by Hooker and Christ, "the same plants, or their congeners or close allies, are found abundantly fossil in the Tertiary strata of 
many parts of Europe" (Hooker's Lecture, p. 26). Let me give an example, which is typical of much. If there is one tree that is characteristic of these Laurel woods of the Macaronesian islands, it is Laurus canariensis. Although it is now confined to these islands, it grew in South Europe in Upper Tertiary times. It was to this and its associated plants that Hooker was alluding when he wrote that the vegetation of Europe has undergone a complete revolution within the lifetime of species that now so forcibly arrest our attention in the forests of the Canaries, Madeira, and the Azores. These species, he continues, are living witnesses of that period, when trees, now characteristic of Asia and America, formed the forests of the European continents.

The last stage in the history of the indigenous flora of the Macaronesian islands is that represented by species that still exist in Europe and North Africa. It may be said to be still in progress and includes the minority of the trees and shrubs of the Laurel woods, and in the Azores, in particular, the plants of the upland moors.

Presumably, therefore, the Canary Islands and Madeira, especially the former, hold the wrecks of many floras. To the exclusion of the Azores, they possess a number of strange genera and peculiar species, that tells us of the ages which preceded the period indicated by the non-European trees and shrubs that are common to the Laurel woods of all three groups. The waves of African, Asiatic, and American plants that have in successive ages passed over this portion of the globe, left their wash on the Canarian and Madeiran groups before the Azorean islands became available for plant-stocking. Whilst the Azores possess no genus of their own, and relatively few peculiar species that are beyond suspicion, the Canaries hold some ten or twelve genera that are all their own, besides a number of genera, of which they share exclusive possession with Madeira. It is difficult to separate Madeira from the Canaries in the sense that we can detach the Azores; but the contrasts in the floral history of this region may be sufficiently illustrated by the circumstance, that, whilst quite one-third of the Canarian species are peculiar, the proportion amongst the Azorean plants would not exceed a tenth.

To the student of distribution the Azorean flora offers but few "problem" plants; whilst the other two groups, particularly the Canarian, present a host of difficulties of this kind. It is possible that important episodes in the history of the Azorean flora may have their only witnesses in Campanula vidalii and Myrsine africana, of which the first is peculiar to the group, while the second is an Asiatic and African plant that has been found neither in the Canaries nor in Madeira. But it would be idle to speculate on their stories now. I would rather close this chapter with the reflection that whilst in the Canaries and Madeira quite other questions are often raised than those concerned with existing means of dispersal, questions that might carry us far back in geological time, with the Azores questions dealing with existing modes of dispersal are imminent. When Wallace expressed the opinion in his Island Life and in his Darroinism that the plant-stocking of the Azores could be attributed 
to existing means of dispersal, he was in the main correct, the great mass of the plants being European species. The characteristic plants of the Laurel woods, being often peculiar to Macaronesia, do not come into this category; but it will be convenient to deal with their dispersal here. To the subject of the agencies of seed-dispersal in connection with the Azores, the next chapter will be largely devoted.

\section{Summary}

1. In dealing with the proportion of indigenous Azorean plants, it is first pointed out that the native flora was in all probability extremely limited. Although it is likely that the total number of the alien and native plants would now approach 600 , it is held that whilst the original flora did not comprise 200 species, the plants that gave character to the vegetation did not amount to 100. Multitudes of plants have been introduced, both intentionally and unintentionally, during the period of almost five centuries that has elapsed since the discovery of the group. Stress is laid on the importance of eliminating the effects of man's agency from every flora, and it is observed that such an inquiry would be almost as ruthless in its effects on the British flora as it undoubtedly would be in the case of the flora of the Azores (pp. 389-91).

2. The original forests of these islands were composed of evergreen shrubs and trees. Among the trees were Tree-Heaths (Erica), Laurels (Laurus and Persea), Fayas (Myrica), Hollies (Ilex), TreeEuphorbias, Junipers, Yews (Taxus), species of Rhamnus, Picconia, etc. Among the shrubs were species of Daphne, Vaccinium, and Viburnum (Laurestinus), and Myrsine africana (p. 391).

3. The prevailing impression that the original forests were similar to the present scrub growth is shown to be an error. There is abundant evidence that the islands were heavily timbered when first discovered, and that the destruction of the native woods, with their large trees, which has been in operation for centuries, has reduced the woods to their present condition. The process is still actively continued, and it is evident that for generations the visitor has formed his impressions of the native trees from "young wood." The trees attain a respectable size when preserved; but ages of unhindered growth would be required for the development of the timber forests that would supply materials, as in the early days, for erecting churches and building small ships (pp. 392-8).

4. The decrease in size of the timber is well illustrated in the case of the large size of the original Juniper trees as compared with the stunted crooked Junipers of our own times. Amongst the trunks of large trees that have been unearthed from the ashes and other materials thrown out during the early volcanic eruptions are the logs of this Juniper, which must have attained in those times the usual large dimensions of the species (J. oxycedrus). As we learn from the old writers, the value placed on its timber led to the destruction of this fine tree. Although volcanic eruptions must have played their part in the destruction of the original forests, the agency of man and animals has been the most effective. As the source of 
fuel, land has long been as much valued for the wood that grows upon it, as for the food raised from it (pp. 393-5).

5. The affinities of the native flora are then discussed, and it is shown that the characteristic plants of the woods, the moors, the ponds and lakes, and the seashore, exhibit a gradually extending scale of connections with the outer world, the connections being least with the plants of the woods and greatest with those of the seashore, the varying degree of isolation thus implied reflecting the differences in the history of the dispersing agencies. It is pointed out that this principle is of wide application to insular floras, although, on account of their lesser antiquity, it has been unable to find its full expression in the islands of the Azores. Though geographical isolation often counts for much in the differentiation of oceanic floras, it is shown that antiquity may largely counteract the effects of contiguity to a continent. The example is taken of the Canaries, a group probably far more ancient than that of the Azores. Although only some fifty miles from the nearest mainland as compared with 800 miles in the case of the Azores, the Canaries hold a flora that is far more differentiated, the proportion of peculiar species being at least three times as great (pp. 398-400).

6. After tabulating the distribution of the characteristic plants of the Azores according to their station, the writer shows how they illustrate the progressive widening of the connections with the outer world. With the plants of the woods the most conspicuous features are these. Whilst mainly non-European, they are largely Canarian and Madeiran, that is to say, Macaronesian. On the other hand, the affinities of the plants of the upland moors and of those of the ponds and lakes are very markedly European, there being no American connection that is not also European. In the case of the plants of the seashore, though predominantly European, we get the first indications of independent and direct connections with the American side of the Atlantic. Though the affinities of the flora are preeminently European, a possible derivation of European plants by the way of the mountains of North-west Africa is suggested in some cases (pp. 400-407).

7. The author then contrasts the zones of vegetation on the great cone of Pico as representing the Azores, on the Peak of Teneriffe as representative of the Canaries, and on Madeira. After describing those of Teneriffe, he discusses the differences that we ought to expect in the cases of Madeira and the Azores from the differences in latitude and the associated differences in climate. It is then inferred that the extensive lower zone (the African zone) of Teneriffe would be much restricted in Madeira, and absent altogether in the Azores, whilst the Laurel woods, which have many features in common in all three groups and lie from 2000 to 2500 feet above the sea on Teneriffe, would descend to about 1000 feet above the sea in Madeira, and, when permitted by the cultivator, would descend to the coast in the Azores. All these predictions are then shown to be substantially realised, but the reader is referred to the text for the particulars (pp. 407-10).

8. It is also brought out in this comparison that the Junipers 
of the upper woods of Pico, which descend to about 2000 feet above the sea, were originally well represented in the higher levels of Madeira (probably above 3000 feet), and also on Teneriffe, at elevations of 5000 to $\mathbf{7 0 0 0}$ feet, where they corresponded in their vertical range with the belt of Pinus canariensis, the pines being unrepresented either in Madeira or in the Azores (pp. 409-10).

9. A comparison is then made of the summit plants of Pico, Madeira, and Teneriffe, and it is shown that they have little in common, those of Pico being derived from the moors below, these upland moors with their plants being in a general sense unrepresented on either Madeira or Teneriffe (p. 411).

10. The chapter then closes with a short comparison of the histories of the plant-stocking of the three Macaronesian groups. Whilst with the Canaries, and to a less extent with Madeira, there were early invasions of African, American, and Asiatic plants, they made but little mark on the Azores. The Azorean flora appears not to have shared in such revolutionary changes, and its history begins with the later invasion in Upper Tertiary times from Southern Europe and the Mediterranean region of plants that in their descendants now give character to the Laurel woods of all three Macaronesian groups. The parent stocks have since been driven from their European home, and the Laurel woods of Macaronesia are all that remains of a period when trees now characteristic of Asia and America formed the forests of our continent (Hooker). The last invasion of Macaronesia, which has extended down to recent times, is indicated by those plants that still exist in South Europe and North Africa. It is represented by the minority of the plants of the woods, and particularly in the Azores by the plants of the moors (pp. 411-13).

11. In the case of the Canarian flora, which is made up of the wrecks of many floras, questions quite other than those concerned with existing means of dispersal are mainly raised. With the Azorean flora, however, which has shared only in the later revolutionary changes of the plant world in this region, the means of dispersal will figure prominently in any inquiry into its history; and to this subject the next chapter is largely devoted (pp. 413-14). 


\section{CHAPTER XIX}

\section{THE AZORES (continued)}

The Relation between the Differentiating Influences and the Dispersing Agencies.-Before referring to the modes of dispersal of the plants of different stations, I will briefly indicate how we may interpret the relation between the differentiating influences and the dispersing agencies. Though the specific divergence of most of the plants of the woods of the Azorean islands indicates a breaking of the link established by frugivorous birds with their European home, there is an important minority, as before remarked, made up of plants specifically identical with those of Europe, which testify that a connection has sometimes been maintained down to recent times. The majority include plants of the genera Hedera, Ilex, Laurus, Myrica, Rhamnus, Smilax, Vaccinium, etc., and the minority comprise species of Daphne, Juniperus, Viburnum, etc. But even with the minority there are signs of the rupture of the connection with the continent. Thus Juniperus oxycedrus has developed an Azorean variety (var. brevifolia) which has puzzled the botanist, and Viburnum tinus has developed an Azorean form (var. subcordata) which according to Trelease seems to be nearer to a Canarian species than to the parent species of the neighbouring continent. Looking at these facts we may regard the connection between the plants of the woods: of the Azores and those of Europe as either broken or breaking. But the connection has been kept up with Madeira and the Canaries, and it would seem that in recent times the activities of frugivorous birds as dispersing agents have been mainly restricted to the Macaronesian region. It is very different, however, with the plants of the mountain moors and with the aquatic and subaquatic plants, where the community with European species leads one to infer that the connection by birds has been usually continued down to recent times.

The Modes of Dispersal of the Plants of the Azores.-Generally speaking, the prevailing shrubs, trees, and climbers of the woods are known to be dispersed, or are regarded as likely to be dispersed, by frugivorous birds, such as those of the genera Daphne, Hedera, Ilex, Juniperus, Laurus, Myrica, Rhamnus, Smilax, Taxus, etc.; whilst the plants of the dry and wet upland moors of the genera Anagallis, Calluna, Carex, Hydrocotyle, Menziesia, Polygala, Potentilla, Thymus, etc., as well as those of the waters and of the borders of ponds of the genera Callitriche, Littorella, Peplis, Potamogeton, Scirpus, etc., possess small and often minute seeds or seed-like fruits, for the dispersal of which we must look to birds of other habits. The seeds 
of plants of the shores would be distributed directly by currents, as with Crithmum and Ipomøa, or indirectly in the crevices of drifting logs, as with the small-seeded Silene and Spergularia, or by seabirds through adhering to their feet and legs, as with Plantago and Juncus, or carried in their stomachs, as with Polygonum. Very few of the truly native plants of the Azores are fitted for attachment by hooks or similar appendages to birds, the Azorean Sanicula standing very much alone in this respect. It is a genus that has found its way in this manner to several oceanic islands besides the Azores, such as Madeira, the Canary Islands, Juan Fernandez, Hawaii, etc. The number of small-seeded flowering plants that must be lumped together under the head of those distributed in mud adhering to birds is large. This "limbo" of the student of dispersal, to which he assigns a multitude of plants, is not altogether satisfactory; but for the oceanic island we are left but little choice, since only the spores of cryptogams, as is shown below, are adapted for transport by winds over broad tracts of ocean, and not even the minute seeds of Juncus or the yet smaller seeds of Orchids could avail themselves of this agency. We come now to deal more in detail with the modes of dispersal of Azorean plants according to their stations, and will begin with those of the woods.

1. The Modes of Dispersal of the Plants of the Woods.-As already observed, most of them would be dispersed by frugivorous birds, such as pigeons. The specific or varietal differentiation of the majority of them within the Macaronesian region indicates, as we have seen, a breaking of the link with their original European home; and it is remarkable that this divergence corresponds with subspecific differentiation in the Macaronesian islands of the European wood-pigeon, Columba palumbus, whilst the rock-pigeon, Columba livia, has developed an Azorean variety (Hartert and Ogilvie-Grant, Godman). The Canarian wood-pigeons, as we learn from Lord Lilford's book on birds (1893, p. 70), and the Azorean pigeons, according to Drouet, feed largely on the fruits of Persea (Laurus) indica. Pigeons are credited with a liking for the fruits of other genera of plants found in the woods of the Azores, such as Ilex and Hedera. Doubtless the pigeons of Macaronesia are also partial to the fruits of Myrica faya, the hard stones of which would be probably ejected unharmed. The other genera of the woods, such as Daphne, Juniperus, Picconia, Rhamnus, Smilax, Taxus, Vaccinium, Viburnum, etc., would be distributed by frugivorous birds. It may be added that stragglers may have played an important part in this process, and that we are not restricted in this respect to birds that regularly visit the islands. In this manner the missel-thrush may have introduced the first seeds of the Yew (Taxus baccata) into 'the group, a matter dealt with in the remarks on that plant in a later page of this chapter.

2. The Modes of Dispersal of the Plants of the Upland Moors.Though we have here again to appeal to the bird, the indications are often largely conjectural. The plants concerned have for the most part either dry small seed-like fruits or minute seeds. The following is a series of measurements of some of the seeds stated 
in the order of their size-Juncus, $0.33 \mathrm{~mm}$.; Calluna vulgaris, Menziesia polifolia, Sibthorpia europoea, all $0.5 \mathrm{~mm}$.; Thymus serpyllum $0.66 \mathrm{~mm}$.; Anagallis tenella, $0.75 \mathrm{~mm}$.; Lysimachia nemorum, 1.0 $1.3 \mathrm{~mm}$.; Luzula, $1.3 \mathrm{~mm}$.; Potentilla tormentilla, $1.8 \mathrm{~mm}$.

The seeds of Juncus were found by Darwin and others in dried mud adhering to birds. (I do not find many references to Juncus in my notes, but species such as bufonius, effusus, capitatus, etc., are characteristic of the Azorean flora.) Probably the seeds of plants, like Anagallis tenella, that grow in boggy ground would be transported in the same way. But one could scarcely appeal to such an agency in the case of plants of dry moors, such as Calluna vulgaris and Menziesia polifolia. Yet many birds frequent such moors, even gulls and curlews in certain seasons, and it is possible that the minute seeds of Calluna might become entangled in their plumage, when, as often happens, they make their nests of heather.

Except with Luzula and Juncus, the seeds of but few of the Azorean moor plants would, according to my observations, emit mucus when placed in water, or become slimy when moistened, a property that enables seeds to adhere firmly to plumage on drying. But the quality is a variable one, even with the same species, as is indicated by their behaviour in my later experiments in England on the seeds of Luzula campestris, L. pilosa, and L. sylvatica, and of species of Juncus, a subject also dealt with in my previous work on the Pacific Islands (p. 567). It is highly probable that a bird brushing past such plants in wet weather would carry off on its feathers a number of the wet seeds of Luzula and Juncus, and that they would adhere firmly to its plumage when dry. The cause of this tendency to become slimy and sticky when wetted is described by Buchenau in the cases of the seeds of Luzula and Juncus in his monograph on the Juncacea (Pflanzenreich, 1906, pp. 25, 30). It is well exhibited, he says, in the case of a species of Luzula peculiar to the Canary Islands. At least five of the nine European species of Juncus found in the Azores display this property in their seeds, and several of the species most widely distributed over the world are known to exhibit it. The aid thus given to dispersal in the case of plants of many different genera was emphasised in my book on Plant Dispersal (p. 567); but it had long before been recognised by Kerner and others, and Buchenau also lays stress on the part which animals would thus play in the distribution of species of Luzula and Juncus. As they brush past the plants in wet autumn weather they would carry away either on their fur or on their plumage the sticky seeds from the open capsules.

Yet we are in the case of these small-seeded plants often brought into contact with problems that raise other questions than those of modes of dispersal. Let us take the three plants with seeds half a millimetre in size, Calluna vulgaris, Menziesia polifolia, and Sibthorpia europaea. Calluna has a solitary species which is mainly European, though it has obtained a hold on the Atlantic side of North America. Menziesia has half a dozen species found in Europe, Asia, and North America, but although one at least is common to the eastern and western hemispheres, $M$. polifolia is confined to 
Western Europe and the Azores. Sibthorpia holds a similar number of species which live in the Andes, in the mountains of Mexico, in Europe, in Africa, and in Nepaul. The Canary group has its own species, and Sibthorpia europaea not only extends to the Azores, but is found in the mountains of the Cameroons and in the Abyssinian Alps.

3. The Modes of Dispersal of the Aquatic and Subaquatic Plants.It may be observed that in most cases these Azorean plants possess minute seeds or very small seed-like fruits, such as we find in Peplis portula, Littorella lacustris, Callitriche aquatica, and Scirpus fluitans, which could have been transported to the group in mud adhering to birds. The small fruits of the common Potamogeton ( $P$. polygonifolius) are $2.3 \mathrm{~mm}$. in size and float in quantities on the surface of the ponds and lakes in the latter part of the summer. They would be readily swallowed by wild ducks and other waterfowl, and I have shown in my book on Plant Dispersal (pp. 369, 513), not only that the fruits of Potamogetons are to be found in the stomachs of these birds, but that they germinate much more readily after passing through a bird's digestive canal. This Potamogeton figures on the island of Pico as an aggressive species that is gradually taking possession of the mountain lakes and ponds and is ousting such plants as Littorella lacustris and Isoetes lacustris (I. azorica, D.) from the shallows. Doubtless it is a more recent arrival than the two species just mentioned. As to the spores of Isoetes it may be remarked that they were most probably brought in dried mud adhering to the feet of birds of aquatic habits. The seed-like fruits of the cyperaceous species that line the water's edge, Carex flara, Scirpus multicaulis, $S$. palustris, etc., were, it is likely, originally transported in the stomachs of waterfowl. Wild ducks, as has been shown in the work above quoted (p. 513), swallow the hard nutlets of Cyperacece in quantities, and these fruits readily germinate after being removed from the stomach and intestines. The fruits of Scirpus palustris sink, but those of Carex flara buoyed up by the utricle float for six months and more, and form a constituent of the floating drift of ponds.

4. The Modes of Dispersal of the Coast Plants.-The littoral flora of the Azores is scanty owing to the coast being usually rock-bound. We might have expected as in tropical regions that the currents would have been important agents in stocking these shores with their plants, but, unless we include the intermediate agency of the drifting log, they have not taken a prominent part. In this respect the littoral flora of the Azores behaves like the shore floras of temperate latitudes (see Plant Dispersal, p. 33). The following are the results of the writer's observations on the capacity of the seeds or fruits for direct transport by currents.

When the data are supplied by old experiments and observations to be found recorded in the writer's previous book on Plant Dispersal they are marked $\mathbf{O}$.

Beta maritima.-The nutlets sink in sea-water, but enclosed in the perianth, whether fresh or dry, they may float for two or three days $(0)$. 
Cakile edentula.-The upper joints of the fruits float for nine or ten days. Probably introduced in ballast from America (see p. 189).

Crithmum maritimum.-The original flotation experiments in sea-water covered ten months, 95 per cent. of the carpels remaining afloat $(\mathrm{O})$. They were subsequently extended to thirteen months, when 90 per cent. remained afloat, a few of which germinated in soil two months later.

Euphorbia azorica.-The seeds float in sea-water from one to two weeks, but the water soon penetrates their coats. In the case of $E$. peplis he has no data; but the floating powers are probably limited.

Hyoscyamus albus.-The seeds sink.

I pomce carnosa.-The seeds float unharmed in sea-water for twelve months and more and germinate afterwards (see p. 218).

Juncus acutus.-The seeds sink.

Plantago coronopus.-The seeds sink.

Polygonum maritimum.-The nutlets sink in sea-water, but enclosed in the perianth they float three or four days. The entire plant, or branches of it, would float five or six days when carried off a beach by the waves $(\mathrm{O})$.

Salsola kali.-Enclosed in the perianth the fruit floats in sea-water for a few days, but when detached it sinks. Portions of the plant bearing mature fruits float at first, but sink within ten days $(O)$.

Samolus valerandi.-The seeds sink (0).

Silene maritima.-Seeds sink $(\mathbf{O})$.

Solidago sempervirens.-No data, but prolonged buoyancy is unlikely.

Spergularia marina.-Seeds sink (O).

Of the fifteen shore plants above named only two, Crithmum maritimum and Ipomoea carnosa, can be regarded as adapted for transport by currents to the Azores. Nearly half of them have small seeds, namely, the species of Hyoscyamus, Juncus, Plantago, Samolus, Silene, and Spergularia. It is not unlikely that the seeds of the Hyoscyamus, Silene, and Spergularia, are carried in the crevices of drifting logs. But sea-birds are also able to assist in the distribution of these small seeds. Gulls, for instance, often make their nests on the faces of cliffs in the midst of a dense growth of SeaCampion (Silene maritima); and it would be surprising if they did not aid in the distribution of this plant. Still more likely would this be with Plantago coronopus, which grows on the rock-ledges where these sea-birds nest. Here the seeds emit mucus and become sticky when wetted, and they would adhere firmly to a bird's plumage when dry. The small seeds of Samolus valerandi have been found in mud adherent to birds; and the frequent growth of the plant in wet places by the sea would afford opportunities of this occurring (Kerner). The prickly pointed leaves of Salsola kali would enable bits of the plant carrying fruits to catch in feathers as readily as they do in one's clothes. Many granivorous birds are fond of Polygonum nutlets, which are often found entire in their stomachs; and doubtless birds frequenting beaches would swallow the seeds 
of Polygonum maritimum. The seeds of Juncus acutus, like those of other species of the genus referred to on a previous page, would probably become sticky when wet, and would thus adhere firmly to a bird's plumage.

The Efficacy of the Wind in the Oversea Dispersal of Seeds.-Much has been written, but few actual facts have been recorded relating to this subject. Mr. Wallace in his Darwinism (1889) made a strenuous appeal for the paramount influence of winds over birds in transporting small seeds like those of Sagina and Orchis over tracts of ocean 1000 miles in width. "For each single seed carried away by external attachment to the feet or feathers of a bird, countless millions (he says) are probably carried away by violent winds; and the chance of conveyance to a great distance and in a definite direction must be many times greater by the latter mode than by the former" (p. 373). He based his opinion upon the careful comparison of the size of a number of small seeds with those of quartz grains, $\frac{1}{250}$ th of an inch across, found in deep-sea deposits 700 miles from land and regarded by Sir John Murray as distributed by the winds.

There seems to be no question about the fitness of cryptogamic spores for dispersion by winds across broad tracts of sea. It is concerning the seeds of flowering plants that doubts would be raised. The great contrast in weight between the lightest of small seeds, as in those of orchids, and the average weight of a mushroom spore (orchids, 8000-15,000 seeds to a grain, Wallace and Kerner; mushroom spores, probably some hundreds of thousands to a grain) at once indicates problems of a very different nature. With regard to species of flowering plants represented in the Azores, the following measurements of size and weight were obtained by the author with the exception of those for Sagina procumbens which are supplied by Wallace in the work above named.

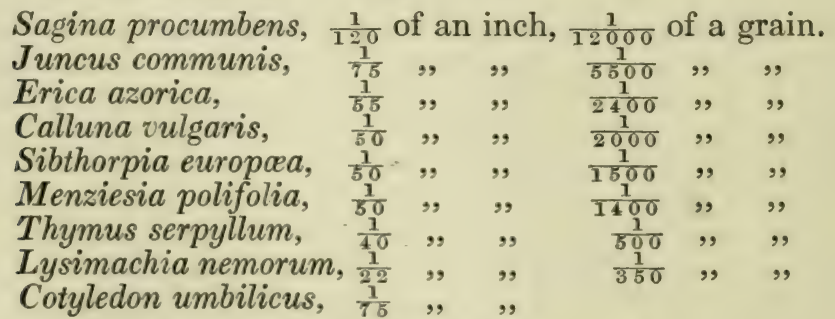

Note.-The relation between size and weight varies with the form of the seed. Thus the rounded seeds of Thymus are much heavier for their size than the oblong somewhat flattened seeds of Calluna.

Yet minute as the seeds of many widely distributed flowering plants may be, Wallace gave no weight to a very important factor in the continuous action of gravity, which seems to nullify any fitness such seeds might appear to possess for transport by the winds across a broad tract of ocean. All that follows, relating to this factor, is based either directly or indirectly on materials supplied by Mr. 
Lloyd Praeger in his botanical memoir published in the reports of the Clare Island Survey in 1911 (Proc. Roy. Irish Acad.). The application of his data to the Azorean flora is my own, and possibly the author may pardon me for making such a free use of his work; but it will best express the measure of my indebtedness.

The contrast in weight between the smallest seeds of flowering plants and the spores of cryptogams, reflects the difference between inefficient and efficient dispersal by winds over great distances. Mere reduction in size, writes Lloyd Praeger (p. 79), is not carried far enough in the flowering plants to produce efficient dispersal by winds. With their seeds we can detect a certain amount of relation in their responses to the action of gravity between their size and falling rates; but quite another order of things presents itself in the case of cryptogamic spores. Small and light as it is, the seed of an orchid falls through the air at least fifty tinies as fast as the spore of an ordinary mushroom. Here I have taken the average terminal velocity of an orchid seed at one foot per second and of a mushroom spore at $6 \mathrm{~mm}$. a second. It will be seen below that according to the data given in Prof. Buller's British Association paper (1909, p. 675) the average falling rate for hymenomycetous spores would probably be much less; but in order not to overstate the contrast the most rapid rate has been chosen. This comparison will serve to illustrate the remark in Lloyd Praeger's paper (p. 70) that the behaviour of small particles falling in air differs from that of larger bodies, inasmuch as with continual reduction in size the impelling force of gravity becomes rapidly smaller in comparison with the decrease of resistance offered by the air, so that very small velocities result.

At the close of Chapter XVI. this matter is briefly mentioned in connection with the Peat-mosses. Here it is treated more at length with reference to the Azorean flora. It would appear from the numerous experiments of Lloyd Praeger on the falling rate of seeds, using the term "seed" in a general sense as implying in the words of this writer the unit of dispersal, that except in the case of plumed seeds of the lightest weights, such as those of Typha and Epilobium, we could not appeal to the winds for the transport of even the smallest seeds of flowering plants, this agency being only available for the spores of cryptogams.

To postulate the effects of gravity, as indicated by the falling rate of seeds and spores, an initial altitude at the starting-place must be assumed. If the wind has been effective in stocking the Azores with plants we must regard Southern Europe as the starting-place, since that is the source of the great majority of the small-seeded flowering plants. Taking the distance of this group from the nearest coasts of Portugal at about 800 miles, I have below given the minimum initial elevation that would be required for seeds and spores to reach the Azores with a favourable wind blowing with the force of a strong gale at fifty miles an hour. The falling rates of the spores are taken from some of the results obtained by Prof. Zeleny and Mr. McKeehan, as well as by Prof. Buller, which are given in the British Association Report for 1909 (pp. 408, 675) and in Nature 
for October 14, 1909, those for the seeds being supplied by Mr. Lloyd Praeger's report in the Clare Island Survey (Proc. Roy. Irish Acad., XXXI., 1911). All the plants indicated under the various headings are with the exception of Typha latifolia represented in the present flora of the Azores.

Table illostrating the Fallixg Rates on Spores and Segds and the Initial ELEVATION THAT THEY WOULD REQUIRE IF TRANSPORTED BY THI WIND FROM the Uplands of Portegal to the Azores, a Distance op about 800 Mrles. (SHB ABOVE POR EXPLANATORY REMARKS.)

\begin{tabular}{|c|c|c|}
\hline & Falling Rate. & $\begin{array}{l}\text { Minimum Initial Elevation with } \\
\text { favourable wind blowing fifty } \\
\text { miles an hour. (Elevations } \\
\text { approximate.) }\end{array}$ \\
\hline $\begin{array}{l}\text { Hymenomycetes (mush- } \\
\text { rooms in a general } \\
\text { sense). }\end{array}$ & $\begin{array}{l}0.3 \text { to } 6 \mathrm{~mm} \text {. per second } \\
\text { (B.). }\end{array}$ & 57 to 1130 feet. \\
\hline Lycoperdon (puff-ball). & $\begin{array}{l}0.46 \text { mm. per second } \\
\text { (Z. and M.). }\end{array}$ & 86 feet. \\
\hline Polytrichum. & $\begin{array}{l}\text { 2.28 mm. per second } \\
\text { (Z. and M.). }\end{array}$ & 430 feet. \\
\hline Lycopodium. & $\begin{array}{l}17 \cdot 7 \text { mm. per second } \\
\text { (Z. and M.). }\end{array}$ & 3300 feet. \\
\hline $\begin{array}{l}\text { Typha latifolia (plumed } \\
\text { seed). }\end{array}$ & 12 feet in 34 seconds. & 20,000 feet or $3 \frac{1}{3}$ miles. \\
\hline Epilobium (plumed seed). & 12 feet in 20 seconds. & 35,000 feet or $5 \frac{5}{4}$ miles. \\
\hline $\begin{array}{l}\text { Sonchus oleraceus, } \\
\text { Senecio vulgaris } \\
\text { (both plumed seeds). }\end{array}$ & $\begin{array}{l}12 \text { feet in } 12 \cdot 7 \text { and } 12 \cdot 8 \\
\text { seconds. }\end{array}$ & $\begin{array}{l}54,000 \text { feet or nearly } 9 \\
\text { miles. }\end{array}$ \\
\hline Habenaria (orchid). & 12 feet in 12 seconds. & 58,000 feet or $9 \frac{1}{2}$ miles. \\
\hline $\begin{array}{l}\text { Carduus pyenocephalus } \\
\text { (plumed seed). }\end{array}$ & 12 feet in 5 seconds. & 138,000 feet or $22 \frac{1}{2}$ miles. \\
\hline Sagina procumbens. & 12 feet in 3.5 seconds. & 197,000 feet or 32 miles. \\
\hline Juncus. & 12 feet in 3 seconds. & 230,000 feet or 38 miles. \\
\hline
\end{tabular}

We may infer from the data just given, assuming that the argument is valid, that whilst there would be no difficulty in postulating the requisite initial uplift for cryptogamic spores we could not do so for the seeds of Juncus and Sagina procumbens, however small they may be. But the difficulty is not so great as it at first seems for those seeds that require an initial elevation of from six to ten miles, as in the case of Epilobium, Senecio, Sonchus, and Habenaria, Typha being excluded as it is not found in the Azores. If the wind blew with the extreme maximum force of a hurricane, say, at 100 miles an hour, the lift requisite for the seeds would be halved and the passage to the islands would be accomplished in eight hours. Under 
such conditions Epilobium would only require an initial elevation of about 17,500 feet. Senecio vulgaris and Sonchus oleraceus would require about 27,000 feet, and Habenaria about 29,000 feet. I am not assuming that any of these flowering plants were introduced into the Azores by the winds. In fact, there is good reason for holding that in the case of the plants with plumed seeds they were introduced as weeds. But it is quite possible that Epilobium seeds might be carried across a tract of ocean, a few hundred miles broad, if they began the passage high up a mountain's side.

The up-draught that occurs on the slopes of lofty mountains would soon carry the spores of cryptogams to levels several thousands of feet above the sea. These ascending currents, according to Whymper, Humboldt, and others, transport insects up to levels of from 15,000 to 19,000 feet on the Andes, and, as the writer himself observed, to the summit of Mauna Loa in Hawaii, about 13,600 feet above the sea (Plant Dispersal, p. 585). As discussed in the work just quoted, they form an important factor in the climatic régime of mountain regions, and as such they are treated by Samler Brown in the case of the Peak of Teneriffe in his Guide to the Canary Islands (1905, pp. e24-e29).

The most pertinent example of oversea transport of seeds by the winds that can be quoted in this connection is that given by Warming in his writings on Greenland and the Faroe Islands, and referred to by Sernander in his work on Scandinavian vegetation. Here large quantities of plant débris, mostly fruits of Calluna vulgaris mixed with blossoms of Erica tetralix, were, during a gale in February 1881, blown across the Cattegat from the Swedish coast to the eastern shores of Jutland, a distance of 110-120 kilométres. But if we wish to believe that the islands of the Azores were originally stocked with Calluna vulgaris in this manner, we are concerned with transport over a tract of ocean thirteen times as broad as the Cattegat. It is not possible to deal further with these matters here, and the reader may be referred for a general discussion of the subject of the wind as a transporting agency to Lloyd Praeger's pages and to Ernst's Nerw Flora of Krakatau.

\section{Notes on the Plants of the Azores}

These notes may be prefaced with the remark that there is in general a close agreement between the ranges of the altitudes obtained by myself on Pico and those ascertained for the same mountain by Hochstetter, with whose work I was at that time quite unacquainted. Watson (p. 114) writes in a depreciatory tone of the " alleged ranges of altitudes" given in Seubert's Flora, and ignores them altogether. They were all derived from Hochstetter, and are in my opinion generally to be relied on. They are often given in the following notes, some of them being taken from the paper by Seubert and Hochstetter in Wiegmann's Archiv.

Acrostichum squamosum, Sw.-Grows on Pico at altitudes of 2000 to 5000 feet. Hochstetter, 2500 to 5000 feet.

Anagallis tenella, L.- It is singular that a plant so abundant 
in the wet moors of the uplands of the island of Pico, should, as far as its previous identification by Drouet is concerned, have been regarded with a little suspicion by Watson (p. 213). With Arceuthobium oxycedri and Hydrocotyle vulgaris it escaped the notice of the Hochstetters. Drouet recorded it from Pico and Santa Maria. Trelease found it on Flores, and it can scarcely be doubted that it will prove to be abundant on San Jorge. It flowers abundantly in July, and grows at altitudes of 2000 to 4000 feet. The results of my observations on a peculiar habit of growth of the plant in England are given in Note 24 of the Appendix.

Arceuthobium oxycedri, M.B.-The name of this genus is a compound of two Greek words, and signifies "living on the Juniper," Juniperus oxycedrus serving as the host for this parasite in South Europe. The writer was the first to record this plant from the Azores. It first came under his notice in March 1913, growing plentifully upon the trunks and branches of the Junipers (J. oxycedrus, var. brevifolia) on the Bandeiras or north-west slopes of the great mountain of Pico at altitudes of 2500 to 2800 feet, its brownish-yellow or gamboge hue making it a striking object on the dark-coloured trees. During this season it did not come under my notice on the southern slopes of the mountain; and had it not been for a chance ascent above Bandeiras I should have left Pico, like the Hochstetters, without being aware of its existence. On sending the specimens to Kew, the Assistant-Director, Mr. A. W. Hill, wrote to me saying: "We are very interested in your discovery on the slopes of Pico. The parasite proves to be Arceuthobium oxycedri, M. Bieb. We have no specimen of this from the Azores, nor can we find any record of its having been found there previously." In the summer of the following year I came upon it growing frequently on the Junipers at elevations of 3000 to 4000 feet on the south-east and east slopes of the mountain. It also came under my notice off the mountain, growing on the Junipers in the vicinity of the Lagoa das Teixas which is situated at an altitude of $\mathbf{2 5 0 0}$ feet at the back of San Roque. Here its growth was more luxuriant than on the cone.

The species has a wide distribution in South Europe, and, as in the Index Kewensis, is generally credited also to North America; but Mr. Hemsley in a letter to me writes that it would be worth while looking into the question of the specific identity of the North American plant commonly referred to Oxycedri. Ten species are enumerated in the Index Kewensis, of which eight are confined to North America and one to the Himalayas, whilst the species under consideration is the only one common to Europe and North America. Sir D. Brandis in his Indian Trees states that A. oxycedri grows in the Himalayan region on Juniperus macropoda at elevations of 9000 to 11,000 feet. According to Arcangeli's Flora Italiana, Arceuthobium oxycedri ranges in South Europe from Spain to Servia, and occurs also in North Africa, the Taurus, and Persia. Harshberger, in his work on the Phytogeography of North America (pp. 555, 556, 608), mentions three species, all growing on Pines, one in the Southern Rocky Mountains at elevations of 8000 to 10,500 feet, and the two others in the Colorado and Californian regions. Urban (VII., 205) 
describes a new species from an altitude of 4000 feet in the mountains of San Domingo in the West Indies.

The mode of dispersal of the genus Arceuthobium is illustrated in the cases of $A$. oxycedri and $A$. occidentale as described by T. Johnson and G. J. Peirce in the Annals of Botany (Vols. II. 1888, XIX. 1905). The seeds are discharged "explosively," and are about a millimetre in size. Their flight may cover a distance of fifteen to twenty feet, and on account of their viscid exterior they adhere firmly to substances, the attachment holding for many months or even for a year. It is thus likely that birds actively disseminate the species, carrying the seeds firmly adhering to their plumage. In this respect Arceuthobium resembles Luzula, which is mentioned in this connection in an earlier page of this chapter, and it is noteworthy that the two genera have a similar distribution.

Cakile edentula, Big.-See p. 384.

Calluna vulgaris, S.-Begins to flower at the end of July. Grows at all elevations on Pico from the coast to the top of the peak.

Campanula vidalii, W.-This plant is peculiar to the Azores. It was first gathered by Captain Vidal in 1842 from " an insulated rock" off the coast of Flores. Watson subsequently made an unsuccessful search for it on the main island (p. 188). Afterwards (1844-48) Mr. Carew Hunt found it "very locally on the coasts of San Miguel and Santa Maria," and it was from one of these islands that it was introduced into English gardens (Ibid.). It is one of the most beautiful plants of the Azores, is stout and shrub-like, attains a height of two feet, and has milk-white flowers, one to oneand-a-half inches long, the corolla being constricted in the middle. Trelease, who visited the group in 1894 and 1896, speaks of it as then occurring "on cliffs and detritus by the seashore and on outlying rocks around the entire island of Flores" (p. 128). He alludes to the impression in the islands that it occurs in cultivation only outside Flores and was originally derived from that island. However, in 1909 Druce found it on the cliff-side at Capellas on the north-west coast of San Miguel (Journal of Botany, 1911), and the present writer came upon it there on the same cliff-side in 1913. As regards its habitats in the group, it should be borne in mind that when it was first collected by Captain Vidal amd Mr. Carew Hunt, 1842-48, the islands of San Miguel and Santa Maria were as much entitled as that of Flores to be considered the proper habitats of the species, since in all three cases the indications went to show that it was a scarce coast plant. Where observed by Mr. Druce and myself on the cliffs of San Miguel it was growing in its natural station. Both Dr. Carreiro and himself regarded it as truly indigenous in that locality. It did not come under my notice on Pico, but it may grow on San Jorge, and I am inclined to consider that it was originally widely distributed over the Azores and is on the road to extermination. It seeds profusely and germination takes place readily as the seeds lie on the soil. Like Watson, I raised plants in my garden from Azores seeds; but on the coast of South Devon they are much injured by the severer frosts when kept out of doors during the winter, but few surviving. 
Questions of modes of dispersal seem hardly pertinent in the case of a plant that like this species is restricted to a single group of islands. The seeds are smooth, $0.75 \mathrm{~mm}$. long, and they sink in sea-water. They appear as well fitted for wide dispersal as those of a multitude of small-seeded plants with great ranges. The history of this species probably carries us back to an early stage in the plantstocking of the Azores. Watson writes (p. 189) that each group of Atlantic islands (Azores, Madeira, Canaries, Cape Verdes) has its peculiar Campanula, the Madeiran and Canarian plants affording technical characters for generic distinction, whilst that of the Azores is " a true Campanula, though with the habit of a shrubby Sempervivum." A clue to the parentage of the Azorean species may perhaps be found in the form of the first leaves. Whilst the typical leaves are long, lanceolate-spathulate, and serrate, the cotyledons are entire, broad, and almost deltoid. The first leaf is similarly broad, but subcordate at the base, and fringed with long hyaline hairs. The serrations begin to develop in the second leaf, which is ovate in form. The transparent hairs disappear after the fourth leaf, which is broadly oval and deeply notched. The succeeding leaves rapidly assume the characteristic lanceolate-spathulate form which is acquired in the sixth or seventh leaf.

Daphne laureola, L.-The "Trovisco" of the Azoreans. Only recorded from Pico. Though Seubert, whose notes were supplied by the Hochstetters (1838), mentions no other island, Drouet who visited the group in $\mathbf{1 8 5 7}$ was assured that there was formerly much of it in the valley of Furnas, San Miguel. It is highly probable that it grows on San Jorge. I found it in flower-bud in the end of March and beginning of April 1913, and in early green fruit in the first half of July 1914. Evidently it flowers in May. Grows on Pico at levels between 3000 and 5000 feet. According to Hochstetter it is found at elevations of 3000 to 4000 feet. Watson observed it "probably between 4000 and 5000 feet" (Lond. Journ. Bot., 1843).

Dicksonia culcita, Hérit.-On Pico it grows at altitudes of 2000 to 4500 feet. Hochstetter places it in the zone of the upper mountain woods, 2500 to 4500 feet. In San Miguel it reaches the tops of two of the principal mountains, Pico da Vara, 3570 feet, the highest peak in the island, and Agua de Pao, 3070 feet.

Erica azorica, Hochst.-Flowers in May and June. When men or cattle brush against the branches in June dense clouds of pollen are given off. Fruits in July and August. Ranges in altitude on Pico from the coast to 6000 feet, but it is much dwarfed in the higher levels, namely, above 4500 feet. Seubert, quoting Hochstetter, states that it ascends this mountain to above 6000 feet.

Euphorbia azorica, Hochst.-Commencing to flower in the middle of March 1913.

Euphorbia mellifera, Ait. (=E. stygiana).-Recorded from all islands except Graciosa, San Jorge, Terceira, and Santa Maria, but doubtless it exists or did exist there. According to Seubert it grows in the mountain ravines of Fayal and Flores at elevations of 2000 to 3000 feet. On Pico it grows usually between 3000 and 4000 feet. Often grows sporadically, when it may attain a height of eleven or 
twelve feet; but sometimes gregariously, when it is usually three to six feet high and may form thicket-like growths.

Hedera canariensis, W.-Fruits in winter as with our English species. Observed in mature black fruit in February and up to the end of March. The fruits had all fallen by the end of June. Evidently, therefore, as with our Ivy, they fall in April and May. On Pico it may reach as high as $\mathbf{3 5 0 0}$ feet, but it is most characteristic of the Faya zone, that is, below 2500 feet.

Hypericum foliosum, Ait.-Flowers in June and July. The empty fruits remain on the plant during the winter and spring. Plants in full bloom in June may still carry the old fruits of the previous year. Typical of the lower woods, that is, below 2000 feet.

Hydrocotyle vulgaris, L.-First recorded from the group by Trelease from Flores in 1894. I found it in 1914 to be one of the most abundant plants on the moist upland moors of Pico, 2000 to 4000 feet above the sea. Doubtless it also grows on San Jorge.

Ilex perado, Ait.-The "Azevinho" of the Azoreans; but the word is so clipped that it sounds like "Azvi." The time of flowering depends on the altitude. Thus in the lower levels this usually occurs in April and May, as in Madeira (Lowe); but in the high levels in June and July. According to Seubert it is in flower in the mountains in June when it is in mature fruit in the gardens. However, on Pico it was frequently to be observed bearing ripe red fruit at the latter end of March, and on one occasion I found the same tree in early flower and mature fruit. It is equally characteristic of the upper and lower wood zones of Pico between 1000 and 5000 feet. According to Seubert and Hochstetter it grows in the higher levels of all the islands, and on Pico at 4000 to 5000 feet. The genus, though so widely distributed over the world, seems rarely to occur in oceanic islands. It would appear that the distribution of the primitive family type over the Pacific took places ages since, and that with the breaking up of the connections through the failure of the dispersing agencies differentiation has been induced. Thus, although no species of Ilex is known from the islands of the tropical Pacific, they possess in Byronia another genus of the family which they share exclusively with Australia, Hawaii holding one species, Tahiti another, whilst Australia claims a third.

I pomoa carnosa, R. Br.-See p. 218.

Isoetes azorica, D.-This species was first catalogued by Watson as $I$. lacustris. Since the genus was once regarded as monotypic and later as holding a few species, whilst at the present it is credited with more than fifty species, there is room for the view that the larger conception of the specific value may be the most correct. The plant was first found by Watson on Corvo in 1842. After more than half a century (1894-6) it was rediscovered there by Trelease, whilst his son found it on Flores. The present writer discovered it in the lake district of Pico in 1914. In all probability it grows on San Jorge. That curious association of Isoetes with Littorella at the borders of a pond or lake, which has so often been remarked in other parts of the world, is to be observed on Pico. There are 
some points of resemblance between two types of plant life, otherwise so widely divergent from each other, notably the similarity in general appearance between the aquatic long-leaved forms. From the standpoint of dispersal one inference seems permissible, namely, that the two plants reached the Azores in a similar manner. From this arises the implication that the Isoetes spores were not brought by the winds, but, like the small seed-like fruits of Littorella, in mud adhering to aquatic fowl.

Juniperus oxycedrus (var. brevifolia, Hochst.).-The "Cedro" of the islanders. We learn from Seubert and Drouet that this tree was especially frequent on Flores where the largest individuals occurred. It would seem that it matures its fruit in the autumn. But the data at my disposal do not decide this point. Aiton in his Hortus Kewensis speaks of $J$. oxycedrus as "the brown-berried Juniper," and this name would apply also to the Azorean variety, the ripe fruits rarely colouring and then only to a slight extent. On Pico in March, June, and July, full-sized fruits were often abundant. On the higher slopes of Pico da Vara (San Miguel) fruits were scanty on February 23. Evidently the fruits often remain on the trees during the winter, probably those that fail to mature by the autumn. In this respect one may note that Sernander (pp. 321, 328, etc.) places Juniperus communis amongst the numerous Scandinavian plants that are most actively dispersed in the winter on account of the fruits remaining on the tree. Strange to say, the greatest display of fruit in the case of the Azorean Juniper was exhibited on April 1 on the snow-covered upper slopes of Pico at an altitude of $\mathbf{5 2 0 0}$ feet. Two old trees, about ten feet high and standing all alone, were simply laden with full-sized fruit carrying mature seeds and in some cases slightly coloured.

The vertical range of the Azorean Juniper on the slopes of Pico was placed by the Hochstetters at 2500 to 5000 feet. This fairly represents the usual limits. But in the dwarfed semi-prostrate condition I found it scrambling up the lava slopes on the eastern side to nearly 6000 feet; whilst it would be more correct to place the lower average limit at 2000 feet, though it may occur sporadically as low as 1200 or 1300 feet. Off the mountain the Juniper is most at home in the lake district of Pico. There, at altitudes of 2500 or 2600 feet, it attains a greater size and exists in larger quantity than on the slopes of the cone where it is to be found best represented in the upper woods of the eastern slopes about 4000 feet up.

There has been much discussion as to the relation of the Azorean Juniper to Juniperus oxycedrus of South Europe. But Seubert and Hochstetter designated it as a variety of the European species under the name of "brevifolia." There seems a great deal to support the view of Seubert that it stands to $\boldsymbol{J}$. oxycedrus as $\boldsymbol{J}$. nana does to $J$. communis. Let us take the case of the last named. Scott Elliot in Botany of To-day (1910, p. 94), writes as follows in this connection. "In the lowland districts this is a large shrub or small tree, which is occasionally thirty feet high. But in the mountains it becomes a dwarf form ( $J$. nana), which is seldom one foot high. 
If one cultivates $J$. nana in the lowlands, as has been done both in the Berlin and in the Zurich botanical gardens, it changes into Juniperus communis. This has been tried both with seeds and by transplanting a mature specimen (Kirchner)." Baron von Mueller in his Select Extra-Tropical Plants (p. 170) writes that under favourable circumstances $\boldsymbol{J}$. communis may attain a height of nearly fifty feet.

The behaviour of $\boldsymbol{J}$. oxycedrus is much the same. In South Europe it rarely exceeds the dimensions of a bush, five or six feet high. Yet Hooker in his book on Marocco (p. 252) refers to the occurrence at an altitude of about $\mathbf{3 5 0 0}$ feet on the slopes of the Great Atlas of " an old weather-beaten trunk measuring about five and a half feet in circumference and seemingly of high antiquity." In Madeira, as we are told by Mr. J. Y. Johnson (Encycl. Brit.9th edit., XV., 180), $J$. oxycedrus was formerly abundant and grew to a height of forty or fifty feet. It is, therefore, highly probable that under the favourable conditions for forest growth which evidently prevailed in the Azores at the time of their discovery, the present Juniper trees, which do not usually exceed ten or eleven feet high, may have attained the great dimensions attributed in the pages of the historians of the group to the " cedros" of the original forests.

But the points we are most concerned with here are the shortening of the leaves in the present Azorean Junipers and the validity of regarding this feature as a specific distinction. The matter is thus stated by Watson (p. 224): "The leaves (of the Azorean plants) are wide and blunt in comparison with those of the South European Oxycedrus, and only half their length." From somewhat limited materials at his disposal he formed the opinion that the Azorean Juniper seems a wider divergence from the European Oxycedrus than are the Junipers of Madeira and the Canaries, the transition, however, being slight from the Azorean to the Madeiran form and from this again to the Canarian form. However, it stands as a peculiar Azorean species in the Index Kewensis, and Prof. Parlatore takes the same view in De Candolle's Prodromus. The same view is taken, according to Trelease, by Antoine in his Kupressineengattungen.

I will now give my own observations. On Pico I found that there were two forms of the plant connected by intermediate stages, the one with short obtusely pointed leaves tending to lie close to the stem, and near the " brevifolia " type, the other with long almost linear acutely pointed leaves tending to spread away from the stem, and near the "oxycedrus" type. As regards the position and relative length and breadth of the leaves these are also the characters, as indicated by a figure after Warming given in Schimper's Plant Geography (p. 36), which distinguish $\boldsymbol{J}$. nana from the ordinary type of $\boldsymbol{J}$. communis.

On the wind-swept upper slopes of Pico da Vara in San Miguel, where the plants are much dwarfed, I found the short-leaved type prevailing. In the Carreiro herbarium in the Municipal Library at Ponta Delgada there are short-leaved specimens from Pico de Vara and long-leaved specimens from Siete Cidades. On the slopes of Pico I often found the two forms associated in the same locality 
together with the intermediate forms. Subjoined are some measurements of leaves made on dried specimens.

Long-leaved form from Pico, length and breadth of leaf, 9-9.5 $\times 1.5 \mathrm{~mm}$. Intermediate

Short-leaved

Short-leaved

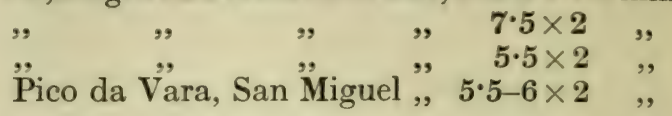

Schimper (Ibid.) refers to Warming's view that the tendency of the leaves of the form nana of $\boldsymbol{J}$. communis to be appressed to the stem as compared with those of the common form, where they stand apart from it, illustrates a method of protection against transpiration. My data indicate that the appression and shortening of the leaves is most characteristic in the Azores of the dwarfed plants on windswept mountains. The most typical forms of the long-leaved or Oxycedrus type on Pico grew in relatively sheltered situations, whilst the plants found in exposed localities at altitudes of 5000 feet and over belonged for the most part to the intermediate and short-leaved types. Viewing the " brevifolia" variety as an adaptation to the inclement climatic conditions of the higher levels of the Azores, it is quite likely that the typical long-leaved, or Oxycedrus type, largely disappeared with the destruction of the timber forests that originally clothed the lower slopes of the islands.

Laurus canariensis, Webb (= Persea azorica, Seubert).-The "Louro" or "Loro" of the Azoreans and Canarians. Flowers profusely in the Azores. According to the observations of the Hochstetters and of Drouet it is in full bloom in May, but, as I found on Pico and San Miguel, in 1913, the process may begin in March. It is in green fruit in July, and probably matures its fruit in August. The Hochstetters restrict it to the lower mountain woods of Pico between 1000 and 2500 feet; but I found it to be also abundant in the upper mountain woods, which extend to 4500 feet. Its usual range on Pico is 1000 to 4000 feet, but it may extend to nearly 5000 feet. In the upper levels it is much dwarfed, the tree attaining its greatest size in the lower levels (1000 to 2000 feet). On San Miguel it occurs as a stunted growth at an elevation of 3000 feet.

Littorella lacustris, L.-First recorded by Watson from Corvo in 1842, but not again collected in the group until 1914, when I found it in abundance on Pico. That it exists on San Jorge is highly probable.

Lysimachia nemorum, L.-Under the name of $L$. azorica, Hornem., this was at first regarded as a distinct species, and it was so viewed by Watson, though he speaks of it as nearly allied to $L$. nemorum. However, the two are united in the Index Kewensis as well as in the monograph by Pax and Knuth on the Primulacece in the Pflanzenreich series (1905). During the last half of March 1913, on the slopes of Pico, I found it in leaf and fruit, but rarely in flower. In June and July of the following year it was abundantly in flower. It is one of the most characteristic plants of the upland moors of Pico, 2000 to 4000 feet; but when it finds protection in the beds of Heather (Calluna) it may extend far up the steep lava slopes of the mountain, even to 5600 feet. Seubert, who, it may be remarked referred it to 
the Linnean species, adopts Hochstetter's altitudes of 1000 to 3000 feet.

Menziesia polifolia, Sm.-In the first week of April on the slopes of Pico it merely carried the last year's dried fruits with seeds. In June and July it was in abundant bloom. Though it occurs in the greatest profusion on the scantily vegetated lava slopes of the central cone, extending from $\mathbf{5 0 0 0}$ feet to the summit, it is also a characteristic plant of the higher levels of the upland moors 3000 to 4000 feet and may reach down to $\mathbf{2 5 0 0}$ feet. Hochstetter refers it to the highest zone on Pico, namely, above $\mathbf{5 0 0 0}$ feet, and it is certainly most typical of those levels. Though probably distributed over nearly all the islands from Terceira westward, it has apparently not been recorded from either San Miguel or Santa Maria, the two easternmost and best-explored islands of the group.

Myrica faya.-Flowers according to Seubert in May and June. On Pico it ripens its fruits at end of July and in August. Trelease in his list of localities names all the islands except Terceira and San Jorge. I found it on the first named, and recognised it on the steep slopes of San Jorge from the steamer's deck. It is one of the most characteristic trees of the lower woods of the Azores, and Seubert remarks (following Hochstetter) that it occurs on all the islands up to 2000 feet. This, as I found, is the usual upper limit both on Pico and on San Miguel, and where it extends three or four hundred feet higher it no longer forms a conspicuous feature of the vegetation. At times one may find it growing in the bottom of a deep gulch higher up the slopes of Pico. Thus I noticed it growing under these conditions at an altitude of 3300 feet, where it had found protection from the prevailing strong winds at these heights. My guide was much surprised, and on his pointing out to me the usual upper limit of the tree I found it to be about 2000 feet above the sea. It descends to the coast, where it may be seen on old lava-flows and on steep declivities. The island of Fayal is said to have derived its name from this tree; but there is a coast village of the name at the south-east corner of San Miguel; and a town, river, headland, and islet on the north-east coast of Madeira are thus called. The Azores were occupied by the Portuguese about thirty years after the occupation of Madeira in 1420, and the connection between the tree-name and the place-name is by no means free from doubt.

In Lacerda's Portuguese and English Dictionary (1871) "Faia" or "Faya" is the proper name for the Beech, and "Faial" is " a place where beech trees grow, or a plantation of beech trees." Prof. Henriques, who very courteously replied to my queries in the matter, tells me that Fagus sylvatica is not met with in Portugal. It is, however, curious that George Forster, who visited the island of Fayal in the Resolution in 1775, speaks of the "great quantities of beeches called faya," naming the genus Fagus (Voyage round the $W$ orld, 1777, II., 581-604). In Portugal, as Prof. Henriques informs me, Myrica faya is known as "Faia das ilhas," or "Faia of the Isles."

This brings me to remark that this tree has long been established in different parts of Portugal. Indeed, Dr. Christ in his paper on 
the Canarian flora (Engler's Jahrbücher, bd. VI., 1885) apparently implies that it is indigenous in the Portuguese mountains. Prof. Henriques, who tells me that possibly we might to-day consider it as almost indigenous in the mountains of Algarve, the southern province of Portugal, gave me Brotero's reference to it in the Flora lusitanica: "Hab. quasi spontanea in pineto regione circâ Leiria, Cintra, etc., ex insulâ Fayal et aliis Azoricis advecta." B. A. Gomes and Da S. Beirão in their catalogue of the plants in the botanic garden of the medical school of Lisbon (1852) speak of Myrica faya as the "Faya of the Isles" and under its habitat name Madeira, the Azores, and Algarve in Portugal. Here "Faya" is also given as the name of two European species of Poplar, Populus alba, the "Faya branca" or "White Poplar," and P. tremula (nigra, H.B.G.), the "Faya preta " or " Black Poplar." They also speak of "Samôco" as another Portuguese name of Myrica faya, a name also supplied to me by Prof. Henriques; but I can find nothing about its significance.

Myrsine africana, L.-The "Tamujo," or "Tamucho," or "Tamuzo" of the Azoreans, the final vowel being dropped in the vernacular. The early Portuguese colonists evidently gave it the name of plants of similar appearance in their home-land. In Portuguese and Spanish dictionaries the name is applied to Rhamnus lycioides, but Prof. Henriques tells me that in Portugal it is given to Securinega buxifolia. The earlier botanists regarded the plant as a species of Buxus, and its appearance might suggest it.

Watson and Trelease refer it to the variety retusa of De Candolle; but this variety is not differentiated by Mez in his work on the Myrsinaceoe (Pflanzenreich, 1902). It flowers in April and May (Seubert). Evidently the shrub bears the ripening fruit through the winter. In the Furnas Valley at the end of February I found it in nearly mature fruit. Druce, who visited this locality in March, speaks of the plant's copious berries covered with bloom (Journ. Bot., Jan. 1911). On Pico in the latter half of March it was frequently observed by me in mature fruit. At the end of June and the beginning of July it carried only immature green fruit. These shrubs begin to appear on Pico about 600 or 700 feet above the sea. Though abundant in the Faya zone, that is, below 2000 or 2500 feet, it extends in quantity considerably higher, as far, in fact, as the upper woods go, namely, to 4000 or 4500 feet; and in a dwarfed form it ascends in places the steep lava slopes of the central cone, the extreme altitude noted being 5200 feet. Hochstetter's observations gave similar results, since he places it in the lower and upper woods ranging between 1500 and 4500 feet. It grows in a stunted form on the summits of the principal mountains of San Miguel, the highest of which rises to nearly 3600 feet.

Osmunda regalis, L.-Recorded in Trelease's pages from Corvo, Flores, Fayal, Terceira, and San Miguel. I found it characteristic of Pico; but although seemingly Seubert did not include this island in his list of localities, this fern is named (p. 6) amongst the plants characterising the lower mountain woods of Pico. It was in these woods at altitudes ranging from 1200 to 2500 feet that this fern 
often came under my notice, both on the great mountain and in the lake district to the east of it. In all probability Osmunda also grows on San Jorge.

Persea indica, Spr. ( = Laurus indica of Lowe's Madeiran flora).The "Vinatico" of the Azores and Madeira. Evidently exists or did exist in nearly all the islands of the Azores; but there is a doubt about its nativity. Seubert, who was dependent on the Hochstetters for his information, does not mention it; and Watson remarks that as seen by himself in Fayal and Flores the tree had a questionable claim to be considered indigenous. However, Drouet refers to entire woods of it in the other islands. Trelease gives no opinion on the matter; but the symbol used indicates that he regarded it as indigenous. Yet, considering that the tree is entirely confined to the Macaronesian islands, it would not be a subject for surprise if it was indigenous in the Azores as well as in Madeira and the Canaries. We have seen that a number of peculiar Macaronesian species (Ilex, Rhamnus, Picconia, Laurus, Myrica, etc.) give a common character to the woods of all the three groups and the exclusion of this handsome tree from the list can on this ground scarcely be justified. I found it growing commonly in colonies in the woods at the back of Magdalena, Pico, two miles inland, and 600 to 800 feet above the sea. The trees, fifty feet in height, were in early fruit in the latter part of March, whilst great numbers of the previous year's seeds lay germinating on the ground beneath the trees, often forming seedlings five or six inches high. Solitary trees are to be noticed in the gardens. As elsewhere observed, the fruits are a favourite food of Azorean and Canarian pigeons.

Picconia excelsa, DC. ( = Notelcea excelsa, Webb).-The "Pao branco " of the Azores and Madeira, and the "Palo blanco" of the Canaries. Seubert states that this tree flowers in May. I found it on Pico in flower in April. It probably exists or did exist on all the islands; but its hard timber is much appreciated by the Azoreans, and on the mountain of Pico it only escapes destruction by taking refuge in some inaccessible gulch or small crater. I only came upon three or four solitary trees in the woods of the great mountain of Pico at altitudes of 1000 to 2000 feet. They are said to be more frequent off the mountain, as on the slopes above Lagens. Seubert, whose work is concerned with the Azorean flora in the first half of last century, alludes to this tree as a constituent of the lower mountain woods of Pico, that is, below 2500 feet, and as occurring in nearly all the islands at elevations of 2000 to 3000 feet (Hochstetter), though rather uncommon. Drouet remarked that in his time (1857) it was more frequent on Santa Maria than elsewhere. In some islands, as in San Miguel, where it used to be planted with the Faya for the protection of the Orange trees (Seubert), it was, however, truly native (Hunt quoted by Watson). Lowe states that it is very rare in Madeira, growing to a height of forty to sixty feet, one or two trees together. It there flowers, February to July. Fruits, August to September.

Polygala vulgaris, L.-It is remarkable that this plant has only been found in the Azores on the island of Pico. Since it was collected 
there by the Hochstetters in 1838 no other botanist has discovered it in any of the other islands. Its vertical distribution on the great mountain is stated in Seubert's work, from information supplied by Hochstetter, to range from 4000 feet almost to the summit. However, I found it at lower levels. It is a characteristic plant of the upland moors and of the grassy intervals in the open woodlands between 3000 and 4000 feet, and it grows under the same conditions off the mountain in the lake district to the eastward at an altitude of 2500 feet. On the exposed higher slopes of the great cone, amongst the ashes and the old lava-flows, it seeks the protection of the beds of Calluna vulgaris, and in this manner reaches almost to the summit. Details of its occurrence in these high levels are given on previous pages. It in all probability grows on the uplands of San Jorge.

Rhamnus latifolia, L'Her.-The "Sanguinho" of the Azoreans, a name suggested by the reddish hue of the wood. This small tree, which behaves in winter as a sub-evergreen, apparently retaining its summer foliage in the mild winter, attains a height usually of ten to fifteen feet, at times reaching twenty feet. It flowers in May and June, and matures its fruit in July and August. In Seubert's work it is stated to be common in the woods of all the islands, extending up to nearly 3000 feet, and in the zones of vegetation on Pico, which he gives (p. 6) from the notes of the Hochstetters, he places it in the lower-woods zone, that is, below 2500 feet. This corresponds with my own observations on the mountain, where I found it most typical of the lower woods below 2000 feet, but frequently reaching to 3000 feet. It shows itself shortly after one passes the cultivated zone in the ascent of the mountain, namely, at 1000 feet. The island of Pico is not mentioned in Trelease's list of localities, which include Flores, Fayal, San Miguel, and Santa Maria; but, as has just been implied, it was found there by the Hochstetters as far back as 1838. Lowe, writing in the middle of last century, indicates that in Madeira it was then apparently extinct as a wild plant.

Sibthorpia europcea, L.-Distributed over the group. Common in the upland moors of Pico between 2000 and 4000 feet and extending at times to nearly 5000 feet. Hochstetter gives it an altitude of about $\mathbf{4 0 0 0}$ feet on Pico. It cccurs on the summit of Pico da Vara, the highest point of San Miguel, 3570 feet above the sea. On Pico it was in flower and fruit in July, the flowers examined having five calyx segments. Several years ago I kept some English plants under observation in South Devon. Both out of doors and under cover most of the fruits failed to mature, and only a few dehisced, behaviour which seems to indicate the northern limit of the climatic conditions suitable for the species.

Taxus baccata, L.-The "Teixo" of the Azoreans. Watson remarks that he had no confirmation of its existence in the mountains of these islands, alluding to a report to that effect mentioned by Seubert. However, Drouet refers to it as growing in 1857 on Flores, but beginning to be rare, the wood being much valued by cabinetmakers. Trelease, who visited the group forty years later, writes that it "formerly occurred in workable size on Corvo and Flores, whence it was exported as a source of royal revenue. Now seemingly 
exterminated." However, it still exists in the island of Pico. In 1914 I came upon a few young trees in the woods at the back of Caes-o-Pico at an altitude of nearly 2000 feet, and was informed that more grew on the sides of gulleys in the mountains behind San Roque, which lies a little more to the east. The Pico islanders are familiar with the tree by reputation, though as it has long been very scarce, but few could have seen it growing in the woods. In fact, the tree was first described to me on the other side of the island by men who knew it only by reputation as supplying good timber for houses. At Praynha do Norte I was told that up to recent times the wood of the "Teixo " was to be seen in a few of the oldest houses. As already remarked a lake in the mountains behind San Roque is still known by some as the "Lagoa das Teixas" (Taxus), though the tree must be almost extinct there now. According to Walker the old Portuguese historians of the group of the sixteenth century, and Linschoten at its latter end, described the Teixo as abundant on Pico. Linschoten especially noticed that this Pico tree was known for its "excellent and princely wood." Coming down to later times, Dr. Webster in his Description of the Island of St. Michael, Boston, 1821, writes that " the wood of Pico appears to be a species of yew. Considerable quantities were formerly sent to Lisbon, where it was manufactured into work-tables, desks, etc." (p. 214).

Lowe includes Taxus baccata amongst the indigenous trees of Madeira; but it is characterised by him in the middle of last century as being very rare.

As regards the dispersal of this tree by birds, reference is made in an article in the Times on Bird Gardeners (October 16, 1915) to the distribution of the fruits of churchyard Yews in Breconshire by missel-thrushes, which drop the undigested seeds on rocky crags a thousand feet up the mountain slopes, where young Yews subsequently spring up. These birds, according to Ogilvie-Grant (Novit. Zool., XII., Jan. 1905), are very rare stragglers in the Azores.

Vaccinium cylindraceum, Sm.-The "Romano" or "Romani" of the Azoreans. Flowers in May and June. Begins to form fruit in the latter half of July and matures it in August. Seubert, relying on Hochstetter, gives its vertical range on Pico as 1000 to 5000 feet. This exactly corresponds with my observations. Above 4000 feet, when it ascends the scantily vegetated precipitous lava slopes, it becomes stunted; and at the highest levels observed, 5000 to $\mathbf{5 2 0 0}$ feet, it found shelter in the Calluna beds, where it was only a few inches high. In the woods it often attains a height of nine or ten feet, and when particularly luxuriant in its growth, as in the humid plains of the lake district, it may reach fifteen feet; but it is then almost straggling in its habit.

Viburnum tinus, L.- The Laurestinus of our gardens. In England it flowers in midsummer and midwinter, and evidently it fruits twice in the year, namely, at the end of summer and in April. Arcangeli states that it flowers in the Mediterranean region in January and August. In the Azores according to the observations of Drouet and myself it flowers in April and May, showing the early flowerbuds at the end of February and in March. It ripens its fruits in 
the end of June and in July. But since on the higher slopes of the mountain of Agua do Pao (San Miguel) it presented itself in mature fruit as well as in early flower-bud at the end of February, it would seem that there may be a second flowering in the early winter, though I fancy that this is exceptional. Trelease apparently found the plant in fruit in summer.

Seubert, relying on Hochstetter, states that it occurs in the mountain woods of the Azores between 1000 and 2000 feet. This corresponds with the results of my observations on Pico, where it ranges from levels of 700 or 800 feet, where the cultivated zone gives place to the lower woods, up to 2000 feet. On the slopes of Agua do Pao in San Miguel it ascended to 2500 feet, but in the condition of scrub. As Seubert observes it is rather uncommon in the group, but I may add that it is frequent in places. Seubert (1844) gives Fayal and San Miguel. Watson (1870) adds Flores and Corvo. Trelease adds Santa Maria, and I have added Pico. When San Jorge is better known botanically, the existence there of this shrub will probably be established. On Pico it seems to be far from abundant. Only at times one comes upon it in the wooded region at the western end of the island; but it is fairly frequent in the vicinity of Cabeza Grande. On the south side, corresponding to the great mountain, it may perhaps be rather more frequent; but it is never generally distributed. My notes contain no reference to it either on the other slopes of the mountain or in the lake district to the eastward.

Its leaves are subcordate and broader and more obtuse than European specimens; and Trelease distinguishes it as an Azorean variety, subcordatum, remarking that it is apparently more closely related to the Canarian $V$. rigidum than to $V$. tinus of the Mediterranean region. Probably the Canarian species is a derivative of that species (H.B.G.).

\section{Summary}

1. Before dealing with the modes of dispersal of the plants of the Azores, it is observed that whilst the connection between the plants of the woods of this group and those of Europe is either broken or breaking, it is still kept up with Madeira and the Canaries. In the case of the plants of the mountain moors and of those of the ponds and lakes the connection with Europe has been sustained down to recent times (p. 417).

2. The plants of the woods would in most cases be dispersed by frugivorous birds, such as pigeons; and it is remarked that the break-

- ing of the link with their European home, as indicated by their specific or varietal differentiation, corresponds with the subspecific or varietal differentiation of the pigeons of the Macaronesian islands (p. 418).

3. The minute seeds or small seed-like fruits of the plants of the upland moors would probably be transported in mud adhering to birds' feet or in their plumage. The capacity possessed by Luzula and Juncus seeds of sticking firmly to a bird's feathers after being wetted is observed; but it is remarked that these small-seeded plants often raise other questions than those of dispersal (p. 419). 
4. In the case of the aquatic and subaquatic plants it is shown that whilst those with small seeds, such as Peplis, Littorella, etc., would be dispersed by waterfowl that would be likely to carry dried mud on their feet and legs, others like Potamogeton, Carex, Scirpus, etc., possess small fruits that are known to be swallowed and ejected unharmed by waterfowl (p. 420).

5. As in temperate latitudes, currents have not taken a prominent part in stocking the seashore plants of the Azores with their plants, unless we include the intermediate agency of the drifting log; andi appeal is made to a variety of other dispersing agents (p. 420).

6. In regard to the strenuous appeal of Wallace for the paramount influence of winds over birds in transporting small seeds like those of Sagina and Orchis over tracts of ocean 1000 miles in width, it is remarked that although there seems to be no question about the fitness of the spores of cryptogams for dispersion by winds across: the ocean it is concerning the seeds of flowering plants that doubts would be raised. In this connection the results of the experiments of Lloyd Praeger on the falling rates of seeds are utilised to show that the great contrast in weight between the smallest seeds of flowering plants and the spores of cryptogams reflects the difference between inefficient and efficient dispersal by winds over great distances. Though so minute in size and so light in weight, the seed of an orchid falls through the air at least fifty times as fast as an ordinary mushroom spore. To counteract the effects of gravity, as measured by the falling rates of seeds and spores, an initial elevation at the startingplace must be assumed; and it is shown that before a wind blowing. at the speed of fifty miles an hour, the initial altitude requisite for a spore or seed to reach the Azores from the European sea-borders: would be only a few hundred feet for a mushroom spore and nearly ten miles for an orchid seed. It is shown, however, that with "plumed seeds," such as those of Typha and Epilobium, the difficulty is not quite so great; but even here an initial elevation of 20,000 feet would be required in the first case and of 35,000 feet in the second case to reach the Azores. It is urged that the up-draught on the slopes of lofty mountains would provide the initial altitude for cryptogamic spores and perhaps also for plumed seeds of the types above named. But this would be impossible both for the seeds of orchids and for the pappus-fruits of Composite plants, like Senecio and Sonchus, where initial elevations of nine or ten miles would be needed (p. 422).

7. The last part of the chapter is devoted to notes on the plants of the Azores (p. 425).

LIST OF WORKS DEALING WITH THE PLANTS OF THE AZORES OR QUOTED IN THE DISCUSSION IN THIS AND THE TWO PRECEDING CHAPTERS

(See also list of works on Azorean botany in Trelease's paper below mentioned.)

BaLl, J., The Mountain Flora of the Great Atlas, given in Hooker's book on Marocco below named.

BeIrão, C. M. F. dA S. See under Gomes.

BoID, Description of the Azores: London, 1835. 
BULlaR, J.
BULlaR, H. A Winter in the Azores: London, 1841.

CARDot, J., The Mosses of the Azores, Eighth Annual Report of the Missouri Botanical Garden : St. Louis, 1897.

Chaves, F. A., Gisements de Diatomées fossiles à Furnas (Ile de S. Miguel), Bull. de la Soc. Portug. des Sci. Nat., II., 1909 : Lisbonne.

Christ, D. H., Vegetation und Flora der Canarischen Inseln, Englen's Botanische Jahrbücher, VI., 1885.

_- Spicilegium Canariense, Engler's Botanische Jahrbiucher, IX., 1887-8.

Drouet, H., Catalogue de la flore des Iles Açores : Paris, 1866.

Druce, G. C., Plants of the Azores, Journal of Botany, January 1911, and in The Chemist and Druggist about the same year.

Forster, G., Plantæ Atlanticæ ex insulis Madeiræ, Sti Jacobi, Adscensionis, Stæ Helenæ, et Fayal reportatæ, Commentationes Societatis Regia Scientiarum Gottingensis, Vol. IX., 1787 : Gottingæ, 1789.

Godman, F. DU C., Natural History of the Azores : London, 1870. (The botanical section is by Watson.)

Gomes, B. A., and C. M. F. DA S. Beirão, Catalogus Plantarum Horti Botanici MedicoChirurgicæ Scholæ Olisiponensis: Olisipone, 1852. (List of plants introduced from various parts of the world.)

Goppy, H. B., Notes on the Native Plants of the Azores, Bulletin, Roy. Bot. Gard. Kew, 1914.

Hartung, G., Die Azoren : Leipzig, 1860. (Descriptive of the geology of the islands ; but about forty pages are devoted to the flora, the materials mainly derived from Seubert, Hochstetter, and Watson.)

Hemsley, W. B. A few remarks on the Azores in a discussion of the floras of the Canary and Cape Verde groups, Science Progress, II., 379, 1894.

Hochstetter, C. See under Seubert.

Hoorer, J. D., Insular Floras, Brit. Assoc., 1866; Marocco and Great Atlas, 1878.

Hont, Carew, Descriptions of the islands of St. Mary and St. Michael in the Azores, Journ. Roy. Geogr. Soc., XV., 258, 1845. (Botanical remarks are scanty.)

LINSCHOTEN, J. H. VAN. An account of his sojourn in the Azores, about 1589, is given in "Purchas, His Pilgrimes," edit. 1905, Vol. XVIII., derived from the original account of his voyages.

Lowe, R. T., A Manual Flora of Madeira, 1857.

Masson, F., Account of San Miguel, Philos. Trans., 1778.

Mayor, F. S., Traveller's Guide to St. Michael's, Ponta Delgada, 1911.

Morelet, A., Iles Açores, L'Histoire Naturelle: Paris, 1860. (Contains valuable remarks on the flora.)

SeUbERT, M., and C. Hochstetter, Übersicht der Flora der azorischen Inseln, Wiegmann's Archiv fuir Naturgeschichte, Jahrg. IX., band i. : Berlin, 1843.

Flora Azorica, by Seubert, from the collections and notes "Hochstetteri patris et filii": Bonn, 1844.

Trentease, W., Botanical Observations on the Azores, Eighth Annual Report of the Missouri Botanical Garden: St. Louis, 1897.

WALKER, W. F., The Azores, 1886.

Wallace, A. R. Discussions of the Azorean flora from the standpoint of dispersal in his works on Island Life, 1880, and Darwinism, 1889.

Warnstorf, C., Sphagnaceæ, Pflanzenreich, heft 51 : Leipzig, 1911.

Watson, H. C., Botany of the Azores. See Godman above. Also earlier papers in the London Journal of Botany, Vols. II., 1843; III., 1844; VI., 1847.

Werster, J. W., Description of the Island of St. Michael, etc. : Boston, 1821 (mainly geological). 


\section{APPENDIX}

\section{List of Notes}

Note 1. The time occupied by bottle-drift in the traverse in the Main Equatorial Current from the Gulf of Guinea to the coast of Brazil and to the West Indies.

„2. The local beach-drift of the Turks Islands.

"3. The effects of wind-pressure on some of the shrubs of the more exposed cays of the Turks Islands.

4. On the experiments of Prof. Ch. Martins on the effects of sea-water immersion on the fruits of Cakile maritima.

5. The synonymy of Scaevola plumieri, Vahl, and Sccevola konigii, Vahl.

6. The strand plants of Teneriffe and of the north-east corner of Grand Canary.

7A. The plant-stocking of islets in the Florida Sea.

"7 7. A comparison of the vegetation of sand-islets in the coralreef regions of the West Indies, and of the Pacific and Indian Oceans.

„ 8. The lake of the Grand Etang in Grenada.

, 9. Guilandina bonduc and other species.

, 10. Mucuna pruriens, DC.

"11. The relation between the floras of Ascension and St. Helena and the currents.

, 12. Bottle-drift on the Azores.

, 13. Bottle-drift in the Turks Islands.

, 14. Bottle-drift on the Bermudas.

"15. The circuit of the North Atlantic accomplished by bottledrift.

, 16. Traverse of the North Atlantic by the derelict W.L.White.

, 17. Mr. Lloyd Praeger's experiments on seed-buoyancy.

" 18. The differentiation of the Main and South Equatorial Currents in mid-Atlantic.

„, 19. The Guinea Current.

,20. Bottle-drift from the South-east Bahama seas to the coast of Ireland and back.

,21. On some small-seeded West Indian littoral plants.

,22. The Azores and their African connections as illustrated by Sphagnum.

,23. Pumice on the beaches of the Azores.

"24. Trailing growth of Anagallis tenella.

"25. Sabine's record of the drifting of casks of palm oil from the Gulf of Guinea to Hammerfest. 
,

,

,

,

,

$\bullet$

,

, 9

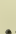

,"

,

,9

,

, 39

26. A bottle-drift from Ascension to Guernsey.

27. Bottle-drift on the Canary Islands.

28. Bottle-drift on Madeira.

29. Sargasso or Gulf weed in Azorean beach-drift.

30. Iguanas, snakes, and alligators in the Turks Islands.

31. Dracana draco (Dragon-tree).

32. A comparison of the old and later charts of the Turks Islands.

33. Plants collected by George Forster in Fayal.

34. Observations on the medanos or moving sand-hills of the Ancon coast region in Peru.

35. Bottle-drift in high latitudes of the North Atlantic.

36. The wells of Pico in the Azores.

37. Uncinia.

38. The fruiting behaviour of Atriplex portulacoides, L., at Salcombe, South Devon.

39. Recent observations in the western Bahamas by Dr. Vaughan and other American geologists.

\section{Note 1 (p. 70).}

The time occupied by bottle-drift in the traverse in the Main Equatorial Current from the Gulf of Guinea to the coast of Brazil and to the West Indies.

Since the data for bottle-drift at my disposal only apply to the traverse west of St. Paul's Rocks and Ascension, it will be necessary to supply the deficiency from an authoritative nautical publication. In so doing we shall be able to compare results obtained by the navigator with those supplied by the floating bottle.

It is highly probable that the drifting bottle in the first half of the passage would travel eastward at a greater rate than twenty miles a day, which is the average rate to the west of St. Paul's Rocks. This is directly indicated in the Admiralty publication, the Africa Pilot (Part I., p. 52, London, 1907), where we find the following statement: "The Equatorial Current appears to attain its greatest volume and velocity during the season of the northern summer. From the African coast to about the 15th degree of west longitude, the maximum strength, sixty miles a day, has been observed in May and June, and during this period its direction is more regular, being west (true). Westward of that meridian, at successive later periods, or between July and October, it is probably subject to irregularities in strength, depending on the winds."

This current is regarded in the pages of the work above named as commencing in the neighbourhood of Anno Bom in the Gulf of Guinea. From this locality to the West Indies (Trinidad and the neighbouring islands) the distance along the track of the current would be about 4000 miles. We can allow for the increased velocity in the first third of the traverse from the Gulf of Guinea to the West Indies by assuming an average drifting-rate of thirty miles a day for a bottle over the whole distance. This gives a result of 133 
days, the estimate employed in my table being 118 days. It may be remarked that Laughton gives the average velocity of the current as twenty to thirty miles a day (Physical Geography, 1873, p. 187). A considerably shorter time would be occupied by the current in carrying a bottle from the Gulf of Guinea (Anno Bom Island) to the coast of Brazil (Cape St. Roque), a passage of about 2500 miles. At the average rate of thirty miles a day it would require twelve weeks, which is the estimate accepted in this work.

We will proceed now with the discussion of the bottle-drift materials employed in this treatment of the Main Equatorial Current. The data may be arranged in the following groups: (a) those supplied by the bottles thrown into the sea in the vicinity of Ascension, which lies within the current but near its southern border; $(b)$ those data concerning bottles thrown into the northern portion of the current in the vicinity of St. Paul's Rocks; (c) those of bottles thrown into the centre of the stream between St. Paul's Rocks and Cape St. Roque; $(d$ and $e$ ) those of bottles thrown overboard off the Amazon estuary.

(a) The Ascension Area.-Probably the slackest portion of the current is near its southern border in the vicinity of Ascension. In the case of three bottles thrown overboard on successive days in February from a ship on the course between St. Helena and Ascension the following minimum daily rates are supplied by Schott (pp. 14, 27; Maps I. and IV.) :-

(1) 11.3 miles from a position half-way between these two islands to Paranahiba on the coast of North Brazil.

(2) 11.7 miles from about 200 miles south-east of Ascension to the Lesser Antilles (Grenadines).

(3) 18.1 miles from a position fifty or sixty miles south-east of Ascension to Jamaica (Morant Bay).

Since the swiftest rate is afforded by the bottle that made by far the longest passage ( 4017 miles), it is fair to conclude that there was not the delay in its recovery that there was in the other two cases, and probably nineteen or twenty miles a day would represent the speed of its passage to the West Indies. It may be added that a bottle dropped into the sea about 100 miles north-west of Ascension in January 1822, which was picked up on Trinidad, gives a minimum daily drifting rate of $15 \cdot 6$ miles (No. 45, Nautical Magazine, 1852).

(b) The St. Paul's Rocks Area.-Just as Ascension lies a little within the southern border of the current, so St. Paul's Rocks lie just within its northern border. There are, in the first place, at my disposal data for thirteen bottles dropped over in mid-Atlantic between the meridians of $22^{\circ}$ and $32^{\circ} \mathrm{W}$. and the parallels of $5^{\circ} \mathrm{N}$. and $2^{\circ} \mathrm{S}$., most of the materials being supplied by the American charts. Of these, nine were stranded on the West Indian islands between Trinidad and Martinique (inclusive), giving rates during passages of from 1900 to 2400 miles of $20,19 \cdot 817 \cdot 2,16,16$, and $14 \cdot 4$ miles a day in the six most rapid cases. The two greatest velocities apply to bottles that were thrown over in March and November, 
the first being especially important, since the bottle was found by fishermen afloat off the island of St. Lucia, and the element of uncertainty that attends most records of bottle-drift is thus removed (Schott, p. 16). Of the other four bottles, one was stranded at Cayenne in French Guiana, and three broke through the line of islands of the Lesser Antilles, one of them reaching Porto Rico; whilst the other two after crossing the Caribbean Sea entered the Gulf of Mexico, one of them being stranded at Vera Cruz, and the other ultimately arriving at the Florida keys. The last mentioned, which was thrown over in the St. Paul's Rocks area in March, performed a passage of nearly 4000 miles, its minimum daily drift rate being computed in the American chart at 18.4 miles.

Dr. Schott (p. 16) gives an interesting series of records which confirm these results. Of three bottles dropped into the sea on different days in January between $0^{\circ}$ and $7^{\circ} \mathrm{N}$. lat. and $27^{\circ}$ and $31^{\circ} \mathrm{W}$. long., that is to say, in the neighbourhood of St. Paul's Rocks, all were found in the following May on different parts of the coast of Trinidad, the respective daily rates indicated being $\mathbf{1 7 \cdot 7}, \mathbf{1 7} \cdot \mathbf{1}$, and $17 \cdot 0$ miles.

(c) The Region between St. Paul's Rocks and Cape St. Roque.-If bottles thrown into this current in mid-Atlantic near its northern and southern borders are carried to the West Indies at the rate of nineteen or twenty miles a day, it is likely that in the centre of the stream they would attain a greater velocity. Dr. Schott (p. 16) gives the rates for seven bottles placed in the sea during February, March, and April, between St. Paul's Rocks and Cape St. Roque, or a little to the eastward, namely, between the parallels $0^{\circ}$ and $7^{\circ} \mathrm{S}$. and the meridians $27^{\circ}$ and $32^{\circ} \mathrm{W}$. They were all recovered on Trinidad and the adjacent island of Tobago, four of them giving minimum daily rates exceeding twenty miles, the greatest being $27 \cdot 2$ miles. We may take them as indicating an average velocity of at least twenty-five miles during this part of the passage, and if we allow for the "speeding up " of the current on approaching the Brazilian coast it is probable that the average velocity of the thread of the current in the latter half of its traverse to the West Indies would be nearer thirty miles a day.

(d) Off the Amazon Estuary and thence to the West Indies.-According to the known behaviour of this powerful current, its speed increases greatly after passing Cape St. Roque, and we should expect that bottles cast into the sea off the mouths of the Amazon would be transported to the West Indies at a rate of from thirty to fifty miles a day. The data for nine bottles, mostly derived from the American charts, are here employed. They were thrown over in March, April, and May of different years at a distance of from 200 to 300 miles from the mouths of the Amazon. As indicated by the dates of their recovery on Trinidad and Tobago three of them performed the passage of from 900 to 1100 miles at minimum daily rates of $43 \cdot 5,36 \cdot 1$, and thirty-four miles. But the greatest velocity recorded for a bottle thrown into the sea in this locality was attained by one that was recovered on the Virgin Islands twenty-eight days after its start, having accomplished a drift of $\mathbf{1 4 0 0}$ miles at fifty miles a day. This bottle was cast over with two others on the same day 
and in the same locality, about 200 miles off the Amazon estuary, its two associates being afterwards stranded on Trinidad, the minimum daily rates recorded being 43.5 and $36 \cdot 1$ miles (U.S. Chart for the N. Atlantic, May 1909). The behaviour of these three bottles is most instructive. Evidently there was considerable delay in their recovery on Trinidad, and very little delay in the case of the one that reached the Virgin Islands. We should probably, therefore, not go far wrong if we assumed that in the last part of its oceanic passage along the coasts of North Brazil and the Guianas the Main Equatorial Current carries bottle-drift to the West Indian region at the average rate of forty miles a day.

(e) Off the Amazon Estuary and thence to the Florida Coasts.-With reference to the time occupied by drift in the passage from the vicinity of the Amazon estuary to the Florida seas the following data may be employed. The track assigned in both the American and German maps to bottles that arrive on the coasts of Florida from latitudes in the tropical Atlantic south of $10^{\circ}$ N. lies across the Caribbean Sea and through the Straits of Yucatan. This is well illustrated by the drift of two bottles that were dropped into the sea on the same day of April within twentyfive miles of each other and about 130 or $\mathbf{1 4 0}$ miles off the coast of French Guiana, the details of which are given in the U.S. North Atlantic chart for May 1909. One was recovered in the Gulf of Honduras 111 days afterwards, the distance of 1920 miles being covered at a minimum rate of $\mathbf{1 7 \cdot 3}$ miles a day (not $27 \cdot 3$ miles as stated in error in the chart). The other was found on the east coast of Florida north of the Straits in lat. $26^{\circ} 56^{\prime} \mathrm{N}$. Up to the date of recovery 182 days had passed and the minimum rate over a distance of 2640 miles is placed at $\mathbf{1 4 . 5}$ miles a day. Very remarkable is it that a third bottle thrown over on the following day from the same ship in lat. $10^{\circ} \mathrm{N}$, , and about six degrees east of Trinidad was recovered 143 days afterwards in the same place on the Florida coast, the estimated minimum rate over a distance of 2400 miles being 16.8 miles a day. Since the bottle was recovered thirty-eight days before the other, which was found in the same locality, it is probable that it was picked up with but little delay.

Another record from this part of the Atlantic, though evidently a belated one, concerns a bottle thrown over from the Prince Eugene in March, about 300 miles north-east of the mouths of the Amazon. It has already been mentioned in Chapter III. It was found on the east coast of Florida in lat. $27^{\circ} 30^{\prime} \mathrm{N} .279$ days afterwards, and therefore farther north than the two bottles above referred to, and like them it had been carried through the Florida Strait. The distance as determined by the U.S. Hydrographic Office is $\mathbf{3 3 2 0}$ miles, and the rate about twelve miles a day. From the foregoing data it may be fairly assumed that an average daily rate of seventeen miles between the Amazon coasts and the shores of Florida is not an excessive estimate for bottle-drift. Taking the distance at $\mathbf{3 2 0 0}$ miles, it would be covered in 188 days or about six months.

Doubtless the track taken by these bottles across the Caribbean Sea and the Gulf of Mexico was also followed by a bottle, already 
referred to, which reached the Florida keys from the St. Paul's Rocks area, travelling at a rate of not less than $18 \cdot 4$ miles a day.

\section{Note 2 (p. 10). \\ The local beach-drift of the Turks Islands.}

The beach-drift derived from strand plants growing on the Turks Islands is often disguised by the mass of the foreign drift. But in the islands where there are mangrove swamps, as on Grand Turk, the germinating fruits and seedlings of the trees composing them, Rhizophora mangle, Avicennia nitida, and Laguncularia racemosa, are not infrequently thrown up on the beaches on the weather coasts. Although it is safest to assume that most of them are of local origin, some of the seedlings of Rhizophora mangle that I observed had all the appearance of having been long afloat; and it is likely that they came with the foreign drift. Several of the stranded Rhizophora seedlings, which had been more or less covered over with the Sargasso weed that is heaped up in quantities on these beaches, had established themselves firmly in the sand by rootlets three or four inches long.

The larger local drift other than that derived from the mangroves is represented by the fruits of Coccoloba uvifera. However, much of the local beach-drift is made up of the small seeds and seed vessels of plants growing in the vicinity, such as Ipomoea pes-caprce, Sccevola plumieri, Suriana maritima, Tournefortia gnaphalodes, etc. This fine drift is sometimes sifted out by the waves and deposited higher up the beach away from the heavier large foreign drift, where it is generally associated with small rounded pumice pebbles 5 to $12 \mathrm{~mm}$. across.

\section{Note 3 (p. 278).}

The effects of roind-pressure on some of the shrubs of the more exposed cays of the Turks Islands.

These effects are well exhibited in the two small wind-swept islands of Pear Cay and Eastern Cay on the weather or eastern borders of the group. The trade winds seem to blow home with greater force on the weather cays, and it is here that the frequent gales and the occasional hurricanes seem to expend much of their repressive influence on the vegetation. The adaptive habit of growth is strikingly shown in the cases of Corchorus hirsutus, Suriana maritima, and Tournefortia gnaphalodes. They all at first bend prone with the wind, the trunks and prostrate branches rooting in the sand, held down firmly by rootlets several inches long, the subsequent behaviour varying in the different plants.

In the case of Corchorus hirsutus the plant was prostrate along its entire length, its leafy branches spreading out like a fan on the sand and rooting freely and firmly, the whole measuring from ten to fifteen feet instead of three or four feet, the usual height of the erect individual. In such wind-swept stations it made no effort to assume the upright position. On the other hand, with the shrubs of Tournefortia and Suriana the erect habit ultimately asserted itself, the leafy 
branches rising into the air and concealing the original prostrate growth. With Tournefortia gnaphalodes the main trunk branched low down close to the ground, the primary branches lying prone for a distance of two and a half or three feet and rooting firmly in the sand; whilst from them sprang the secondary branches, which, lying prostrate at first, finally arose erect and developed leafy stems two or three feet in height. With Suriana maritima the secondary leafy branches were upright and three or four feet high; but the main stem and primary branches for a distance of two and a half or three feet were prone and firmly held by their rootlets in the sandy soil.

\section{Note 4 (p. 188).}

On the experiments of Prof. Ch. Martins on the effects of sea-water immersion on the fruits of Cakile maritima (Bull. Soc. Botanique de France, tome IV., p. 324 : Paris, 1857).

These experiments were made on the seeds and fruits of a large number of plants with the object of determining the persistence of the germinative capacity after long immersion in the sea; but, as I point out in my book on Plant Dispersal (p. 539), an objection previously made by Thuret and Hemsley (Ibid.), the investigator often leaves us in doubt, when speaking of the floating capacities, whether he is referring to the initial or to the sustained buoyancy. His remarks on some of the fruits, including those of Cakile maritima, might lead one to suppose that germination occurred after fortyfive days' flotation in sea-water ; but it may be that only immersion is implied, since he placed in the same category the fruits of Beta vulgaris, Eryngium maritimum, Pancratium maritimum, Ricinus communis, Salsola kali, etc., which, according to the observations of Thuret and myself, sink in a few days. Lloyd Praeger places the limit for Salsola kali at five and a half days (see Note 17).

\section{NOTE 5 (p. 227).}

\section{On the synonymy of Sccevola plumieri, Vahl, and Scaevola konigii, Vahl.}

Before making the acquaintance of Sccevola plumieri in the West Indies I was led by the occasional application of the name Sc. lobelia to both plants to infer that they were forms of one species; and $S c$. konigii was therefore credited in my book on Plant Dispersal with a distribution over the tropies of the globe. Schimper in his Indomalayische Strandflora (p. 130) was led into a similar error, since he states that $\boldsymbol{S} c$. plumieri is distributed over most tropical and subtropical coasts of both hemispheres.

The exceedingly puzzling synonymy has been in recent years made clear in the monograph of the Goodeniacea by Krause (Das Pflanzenreich, IV., 277, 1912). The two plants, as was evident to me when I first met Sc. plumieri in the West Indies, are quite distinct, and could not be mistaken by any one with both before him. The German author, who refers them to different subgroups of the 
genus, points out (p. 18) that the confusion of the two species has frequently given rise to very inaccurate accounts of their distribution. The difficulty seems to have arisen in connection with the early use of the specific name of lobelia as imposed by Linnæus. Krause in re-examining the whole question must have experienced some difficulty in the process of selection, and it is not surprising that there is an omission here and there. Thus I found Sc. konigii to be in 1888 a characteristic plant of Keeling Atoll, where it had been previously collected by Darwin in 1836, the list of his plants being determined by Henslow (Ann. Nat. Hist., I., 337, 1838; Chall. Bot., IV., 113 ; Journ. Vict. Inst. London, 1889).

\section{Note 6 (p. 407).}

\section{The strand plants of Teneriffe and of the north-east corner of Grand Canary.}

I examined the strand vegetation at various places on the coast of Teneriffe, namely, between S. Juan de la Rambla and Orotava, at Punta Hidalgo and in its vicinity, at Taganana and Armasiga, between Santa Crux and S. Andres, and to the south of Santa Cruz. The shore was mostly rock-bound, the beaches being generally few and scanty, so that the littoral plants as a rule were those that find their home on coastal rocks and on sea-cliffs as well as on the beaches. However, the beach flora was well developed on the sandy isthmus connecting La Isleta with the north-east corner of Grand Canary. But a much more extended acquaintance with the group would be required before one could venture to discuss the shore flora of the Canary Islands as a whole. Here there is merely offered a contribution to the subject from the standpoint of dispersal.

In addition to several plants familiar on our English beaches, such as Atriplex portulacoides, Beta maritima, Crithmum maritimum, Euphorbia paralias, etc., there were a number of others, that either do not extend north of Southern Europe and the Mediterranean region or are confined to this and other Atlantic archipelagos (Azores, Cape Verde Islands), such as Frankenia ericifolia, $\boldsymbol{F}$. pulverulenta, Mesembryanthemum crystallinum, $\boldsymbol{M}$. nodiflorum, Zygophyllum, etc. Then there was the local element, which we should expect to find in all strand floras where the inland plants come down to the coast. Thus in places those strange-looking shrubs, the cactoid Euphorbia (E. canariensis) and Plocama pendula, which so often give a character to the barren hill-slopes of basic tuffs and lavas that descend steeply to the sea-border, come down to the coastal rocks, where they associate with typical shore plants like Crithmum maritimum and Zygophyllum.

Amongst other strand plants of Teneriffe may be mentioned a Statice and a stout fleshy yellow umbellifer unknown to me. Both grow on the coastal rocks and ascend the precipitous lava slopes for 100 or 200 feet or more. The umbellifer is remarkable on account of the greenish-yellow hue of the whole plant, its leaves being deeply cut into three cuneate lobes indented on their upper border. I may remark that in addition to the ordinary form of Crithmum mari- 
timum, where the separate carpels are about $6 \mathrm{~mm}$. long and about $4 \mathrm{~mm}$. broad, there is a variety with longer and relatively narrower fruits (9 or $10 \mathrm{~mm}$. long, $4 \mathrm{~mm}$. broad), which seems to be confined to lava rocks at the coast, and does not like the usual form grow also on the beach.

The locality in which I found the strand flora most developed was on the west side of the low sandy isthmus which connects La Isleta with the north-east corner of Grand Canary. Euphorbia paralias was the most frequent of the beach plants and extended inland for some hundreds of yards over the dunes. Amongst other plants growing on the sandy shore were Atriplex portulacoides, Frankenia, Heliotropium, Mesembryanthemum crystallinum, $\boldsymbol{M}$. nodiflorum, Zygophyllum, etc. The last named also grew along the upper drift line where the beach was shingly and on the rocks bordering the beach at La Isleta.

A few remarks on the modes of dispersal of some of these plants may here be made. We cannot exclude human agency in the case of the two species of Mesembryanthemum, which were extensively cultivated in the group in the eighteenth century for the extraction of soda, according to Samler Brown's Guide to the Canary Islands (1905, $d, 9)$. These two plants grow also on the Salvages (Lowe's Florulce Salvagicce Tentamen, 1869), and were employed in making barilla (soda) by men engaged in the trade, who often visited the islands for that purpose (Ibid.). The dispersal of the carpels of Crithmum maritimum across the sea by the currents and locally by the winds is discussed in my book on Plant Dispersal (p. 542). It is there remarked that they are very buoyant and can float for several months in sea-water. They are so light that a strong wind blows them along the beach and up the faces of the sea-cliffs. (More recent experiments showed that the carpels in some cases germinated after floating for thirteen months in sea-water.)

I experimented on the fruits of a species of Zygophyllum that flourished on the beach of the low isthmus connecting La Isleta with the north-east corner of Grand Canary. It is probably $\boldsymbol{Z}$. fontanesii, a littoral plant found also in the Cape Verde Group (Schmidt and Coutinho) and on the Atlantic coast of Morocco (Hooker, p. 339). From the results of the experiments below given it may be inferred that the species tested has but a limited capacity for dispersal by currents. It might, however, accomplish a sea-passage of from 100 to 200 miles. This would be quite sufficient for its derivation in the case of the Canary Islands from the neighbouring African coast and for its distribution over that group.

The dry cocci of this species of Zygophyllum are 7 to $8 \mathrm{~mm}$. long. They possess a solitary crustaceous seed $(2.5 \mathrm{~mm}$. in length) in the midst of spongy air-bearing tissue, and are so light in weight that like the carpels of Crithmum maritimum they are blown about on the beach by the winds. They would have possessed similar great floating powers, did they not tend to gape at the inner angle. As it is, the sea-water soon penetrates through the opening, and in consequence they float for only eight or ten days. The seed itself sinks. 
From experiments made on the fruits of Atriplex portulacoides growing at Salcombe in South Devon (see Note 38 of the Appendix), it was evident that whilst the seed-like fruit sinks it can float when surrounded by the perianth between two and four weeks, buoyed up doubtless by air-bubbles. It thus might easily have been carried by the sea to the Canary Islands from the adjacent continental coasts. On the other hand, in the case of Beta maritima, which occurs in Madeira and in the Azores as well as in the Canaries, the direct action of the currents must be excluded, since the buoyancy of the fruit is limited to a day or two (Plant Dispersal, p. 542). Three other of the shore plants of this group, Euphorbia paralias and the two species of Frankenia, may here be noticed from the standpoint of dispersal. The seeds of the first named float for a long time unharmed in sea-water (Ibid., p. 543); whilst the very small seeds of Frankenia are probably distributed by birds.

Note 7A (p. 10).

\section{The plant-stocking of islets in the Florida Sea.}

One of the most methodical series of observations on the stocking of islets in coral-reef regions with plants are those made by $\mathrm{Mr}$. Lansing (junior) in 1904 on the sand-keys of Florida to the westward of Key West. He had been commissioned by the Field Columbian Museum of Chicago to earry out this inquiry. He collected specimens of everything he saw, noting carefully the plant arrangement in each islet, and laying down his results on maps made on the spot. His collections, together with his comprehensive notes and maps, supplied materials for a detailed consideration of the flora of these islets in a paper by Dr. Millspaugh published by the Museum in 1907. "As was to be expected" (to quote from this paper), "this archipelago proves to be vegetated with only the usual broad strand species common to similar situations on the Antillean islands in general." In discussing the results Dr. Millspaugh brought to bear an experience derived from a wide field of study of insular and strand formations in the Antillean region. The value of this paper for us lies in its illustrating the process of plant-stocking in the case of newly formed low islets in the West Indies.

These sand-keys vary greatly in size, the smaller being usually from thirty to a hundred yards long, whilst the larger may measure a mile or more. Their elevation is generally two to four feet; but it may be as low as one foot and as high as nine feet. Of the nineteen keys examined only three exceeded four feet. The numerous small keys, consisting exclusively of mangrove colonies, are not specially dealt with in this paper. They, however, represent the earliest stage in the plant-stocking process. My remarks here will be mainly restricted to a consideration of these results from the standpoint supplied by my observations and experiments on the coral islets of the Indian and Pacific Oceans, as well as by those on the small cays of the Turks Group in the West Indies. In so doing I shall as a rule be following Dr. Millspaugh's guidance, though in my own fashion. 
Different stages in the process are readily distinguished. It begins with the partial emergence of a bank of coral sand, which under the influence of the currents gradually acquires a more or less curved or crescentic form, its convexity facing the currents. For convenience we will take a medium-sized key and will designate the convex side of the bank as its weather margin. Whilst the bank is still washed over by the seas in places, various floating seeds and fruits, as well as seedlings, are cast up on its surface, those of the mangroves, more particularly the seedlings of Rhizophora mangle, establishing themselves under the shelter of the bank on its lee side. Islets may remain in the condition of a mangrove colony for some time. But as the exposed surface increases in extent typical beach plants begin to establish themselves. The seeds of some are brought by sea-fowl; but, as will be shown later on, the currents probably do most of the work. One of the first to establish themselves on the bank on the weather side is Sesuvium portulacastrum, and it is this plant that Dr. Millspaugh places at the head of his list illustrating the sequence of appearance of the most characteristic beach plants on these keys. This is followed in the order fixed by this authority by Cakile fusiformis, Euphorbia buxifolia, Cenchrus tribuloides, Cyperus brunneus, Uniola paniculata, Andropogon glomeratus, Suriana maritima, Tournefortia gnaphalodes, Borrichia arborescens, Iva imbricata, and Ambrosia hispida (A. crithmifolia).

Two strand plants not sufficiently frequent on these keys to be included in the most representative plants, but amongst the first to establish themselves through the aid of the currents, not only on West Indian beaches, but also on new islets in the Indian and Pacific Oceans, are Canavalia obtusifolia and Ipomoea pes-caprce. Their place in the above list would be with the plants immediately following Sesuvium portulacastrum. Another of the early plants would be Scaevola plumieri, though it only grows on a few of the keys.

By the time that the sandy surface is well stocked with beach plants the mangrove colony on the concave side of the bank has increased extensively, and we notice that though in great mass of Rhizophora mangle, two other mangroves, namely, Avicennia nitida and Laguncularia racemosa, have established themselves on the border facing the sandbank, where they are associated with Conocarpus erectus. The mud-flat in the neutral zone between the beach plants and the mangroves is ultimately occupied by Salicornia ambigua, Batis maritima, and Sesuvium portulacastrum.

We now approach the completed stage in the history of such a key, a condition which it is likely to preserve, provided man does not intervene, as long as the present relation between land and water prevails. Be the islet small or large, a limit to its growth at the borders is reached in the deeper water, both on the weather side, where the waves cease to heap up the sand, and on the lee side, where the Rhizophora colony no longer extends seaward. Through the reclaiming agency of the mangrove, the area of the swamp is much reduced and the beach plants advance on the new surface. The islet loses its crescentic form, and in the final stage it is mainly appropriated by the beach plants, amongst which Suriana maritima 
often predominates in the interior with shrubs like Tournefortia gnaphalodes on its weather border, and beyond them, reaching to the wash-line of the sea, Euphorbia buxifolia, Cakile fusiformis, Sesuvium portulacastrum, I pomoea pes-caprae, etc.

In those cases where the original sand-keys lie close together and are only separated by shallow channels the mangroves lead to their ultimate union. Cases are cited in this paper where two keys, separated at the time the islets were charted by the U.S. Hydrographic Survey, were found by Mr. Lansing to be joined together. Writing of the Marquesas Group of these Florida sand-keys, Dr. Millspaugh says that through the growth of the mangroves and the upwashing of the light coral sand by the waves all the keys will in course of time unite to form a solid island embracing the whole group. It is, however, instructive to note that this growth of islands, whether singly or in combination, takes place under the conditions of the present sea-level. We get no indication in this paper of the formation of the æolian sandstone which has so long puzzled the geologist both in the Bermudas and in the Bahamas. The conditions for its development are not presented in the history of these Florida sand-keys.

With reference to the means of dispersal through which these keys received their plants, Dr. Millspaugh holds that the balance is on the side of the bird, and he appeals mainly to the medium of the feet of sea-birds. However, I have endeavoured to adjust our views in the remarks made below on the probable mode of dispersal of the nineteen plants he names as most typical of these keys, to which I have added four which deserve a place in this treatment of the subject of dispersal, namely, Ipomoea tuba (=Calonyction album), Ipomoa pes-caprae, Canavalia obtusifolia, and Scovola plumieri. A grouping of the plants according to their probable mode of reaching the Florida sand-keys is here presented. For particulars reference should be made to other pages of this work, to my book on Plant Dispersal, to my paper on Keeling Atoll, and to Dr. Millspaugh's paper.

(A) Plants brought by the currents, the seeds, fruits, seedlings, etc., being able to float long enough to reach these sand-keys: Avicennia nitida, Batis maritima, Cakile fusiformis, Canavalia obtusifolia, Conocarpus erectus, Ipomœa pes-capro, I pomœa tuba, Laguncularia racemosa, Rhizophora mangle, Salicornia ambigua, Suriana maritima, Tournefortia gnaphalodes.

(B) Plants brought by currents and frugivorous birds : Scaevola plumieri.

(C) Plants brought through the adherence of their fruits to birds' plumage: Cenchrus tribuloides, Euphorbia buxifolia (Millspaugh's authority).

(D) Plants with small seed-like fruits that possess sufficient floating power to enable them to be brought by currents from neighbouring coasts, but which could also have been transported in the crevices of drifting logs : Ambrosia crithmifolia, Borrichia arborescens.

(E) Plants with small seeds or seed-like fruits, all non-buoyant, 
brought by drifting logs or attached to the feet of sea-birds: Cyperus brunneus, Dondia linearis, Iva imbricata, Sesuvium portulacastrum.

(F) Plants, like Uniola paniculata and Andropogon glomeratus, that may have been brought, as Millspaugh suggests, by currents (Uniola), or through the agency of birds (Andropogon), but concerning which observation is needed.

Only the most characteristic plants are here dealt with. Quite half of the twenty-three plants above named would owe their presence on the Florida sand-keys to the direct agency of currents. In the case of a quarter, the agency of the drifting log could be appealed to. Though one may be too much inclined to fall back on the drifting $\log$ in cases of difficulty, its intervention is much more than a mere possibility. On Keeling Atoll I found a stranded log honeycombed by the Teredo, the empty burrows of which were filled by sand, with which many of the small pyrenes of Tournefortia argentea and other small seeds were mixed. With a high tide and a heavy sea this log could have been swept off the beach and carried seaward. Birds might have aided in the case of the remainder. Frugivorous birds probably played a small part, since, if we except Sccevola plumieri, but few of the plants would possess fruits that would attract them. However, the plant just named was more probably brought by currents. But one or two of the plants not named in the list, such as Ernodea litoralis, might have been brought here in this way. Dr. Millspaugh informed me that the seeds of Euphorbia buxifolia become adhesive when moistened. So it has been placed in the group with Cenchrus tribuloides. The attachment of the prickly fruits of Cenchrus to one's clothes will be familiar to all who have sojourned in the tropics, one of the American names of the species above named being "claw-grass."

Of the plants in the first group some would be dispersed through the floating seedling, as in the case of the species of Rhizophora and Avicennia, and also of Batis and Salicornia, though with the last two plants the seeds (Batis) and the detached seed-bearing joints (Salicornia) possess independent buoyancy. The dispersal by currents of Salicornia peruviana, $S$. herbacea, Batis maritima, etc., is dealt with in my work on Plant Dispersal.

\section{Note 7в (p. 5).}

A comparison of the vegetation of sand-islets in the coral-reef regions of the West Indies, and of the Pacific and Indian Oceans.

For this purpose the results of Mr. Lansing's observations on the Florida sand-keys will be utilised, as given in Dr. Millspaugh's paper. Although the present writer has no acquaintance with the Florida sand-keys, he formed a close acquaintance with nearly all their characteristic plants on the shores of the Turks Islands. On Keeling Atoll and on North Keeling Island, on the south coasts of Java, in the Solomon Islands, and in Fiji, he became familiar with 
the plants with which currents and birds stock the newly formed islets thrown up on the reefs of those seas. His first study in the plant-stocking process of such islets was made in the Solomon Islands in 1882-3, the particulars of which are given in his work on those islands and in the Appendix of Mr. Hemsley's volume on the botany of the Challenger expedition. Although the following remarks mainly apply to the region of the Western Pacific, it might in most respects apply to islets in the Indian Ocean, such as are presented on Keeling Atoll and in the small island of North Keeling to the north of it, many of the plants being the same.

There are some points of similarity as well as great points of contrast between the vegetation of reef-islets in the Western Pacific and in the Florida seas. In appearance there is a great contrast, since the large trees, often with handsome flowers and large fruits (Barringtonia speciosa, Calophyllum inophyllum, Cerbera odollam, Guettarda speciosa, Hernandia peltata, Ochrosia, Pandanus, etc.), that line the beach in a Pacific islet are not to be found on islets in West Indian waters, where the vegetation bordering the beach is formed of shrubs and small trees of a very different character. Then, again, we miss in the Florida sand-keys the tall trees of Canarium, Eugenia, and Ficus (banyans) that occur in the interior of islets in the Western Pacific-islets only a few hundred yards in length and heaped up but two or three feet above the waves. These trees represent the work of the fruit-pigeons, an agency ever in operation in these seas.

The similarity is greatest in the case of the plants creeping on the sand, and with the shrubs and small trees with their climbers that form the outposts of the beach vegetation. Canavalia obtusifolia, I pomøa pes-caprce, Sesuvium portulacastrum, and Suriana maritima occur alike on the Florida sand-keys and on the coral islets of the Indian and Pacific Oceans. But representative species of the same genus may play the same rôle in the different regions. On the Florida sand-keys and in the Turks Islands bushes of Scaevola plumieri and Tournefortia gnaphalodes give the same character to the sanddunes bordering the beach that is displayed by Sccevola kœnigii and Tournefortia argentea on Keeling Atoll and in the islets of the Western Pacific.

The differences also extend to the composition of the mangrove colonies formed on the lee side of the islets. Of the three mangroves, Rhizophora mangle, Avicennia nitida, and Laguncularia racemosa, on a Florida sand-key, only the first might be found in the Pacific islet, though its place would more probably be taken by the Asiatic species, Rhizophora mucronata. The species of Laguncularia would be represented in the Pacific by a species of Lumnitzera, an allied genus. The genus Avicennia would not be present.

If we except the agency of the fruit-pigeon in the Western Pacific, the currents would seem to be more effective in that region than in the Florida seas. Practically all the large trees lining the beach in the Pacific islets owe their presence there to the currents, whilst the fruit-pigeon has stocked the interior. 


\section{Note 8 (p. 131).}

\section{The lake of the Grand Etang in Grenada.}

Situated in the centre of the island at an elevation of 1800 feet, this lake is 500 or 600 yards in length, and, as I ascertained by sounding in February 1909, rather under three fathoms in maximum depth. Since its depth is placed at fourteen feet in the eleventh volume of the Encyclopadia Britannica (ninth edition), a volume issued in 1880, it is apparent that there has not been much change in depth in a period of at least thirty years. Exaggerated notions prevail with regard to the depth, size, and even altitude of this mountain lake. Although it shallowness has long been known, I came upon, during my sojourn in the island, many coloured people who believed it to be unfathomable. Its circumference would measure barely a mile, yet the lake has been described as over two miles round and "no less than $\mathbf{3 2 0 0}$ feet above the sea" (Stanford's Compend. Geogr., A. Keane, West Indies, 1901, p. 409).

Its aquatic and subaquatic vegetation calls for a few remarks. Whilst a water-lily (Nymphoca ampla) occupies the shallows, a dense swampy belt of tall sedges, chiefly Cladium jamaicense, forms the borders. Arborescent aroids (Montrichardia arborescens), five or six feet in height, spring up in the midst of the Cladium belt, which is fringed at the water's edge by an equisetum-like Scirpus (either plantagineus or constrictus). Sclerias of more than one species grow in abundance among the low trees at the border of the lake; and clambering over the branches of these trees Dioclea reflexa is frequently to be observed, with occasionally a Mucuna that comes near M. altissima, DC., as described in Grisebach's pages. [Specimens of the Cladium from this locality in the herbarium of the Botanic Garden in Grenada are named $\mathrm{Cl}$. jamaicense, $\mathrm{Cr}$., on the authority of Prof. Urban. In the same collection the Nymphaea from the same lake is named $N$. ampla, DC.]

It is considered by Prof. Harrison that the lake of the Grand Etang probably occupies the place of a former crater. Its shallow depth, however, is not in favour of this view. If an accurate survey of the upland region of the island were made it would show that this shallow lake occupies the expanded head of a valley open to the north; and as far as the surface configuration is concerned I doubt if it would be at all suggestive of a crateral origin. I would imagine that the denuding agencies have re-shaped the central mountainous portion of the island to such an extent that the present valleys and mountain profiles have little or no relation with those of the era of volcanic activity.

The overflow water is carried away by an effluent on the north side, which, according to the level of the lake, varies between seven and fourteen feet in breadth and between ten and thirty inches in depth. If this channel was deepened to the extent of twelve or fourteen feet the lake would be emptied. During heavy rains the level of the lake will rise a foot in the course of a night. Thus during one night of my sojourn, when $2 \cdot 60$ inches of rain fell at the rest-house 
near by, the lake's level rose eleven inches. On account of the large amount of sediment that must be carried into the basin by the numerous small streams and rivulets that empty into it, the lake is evidently gradually filling up. Most of these materials are deposited in the basin, and I should fancy that in a few centuries the lake will have disappeared. This result will be brought about not merely through the silting process in the basin, but through the deepening of the channel of the effluent by its own erosion.

During three days in the middle of February, when the temperature of the air in the shade at the lake-side ranged between $65^{\circ} 5^{\circ}$ and $73.0^{\circ} \mathrm{F}$., that of the water of the lake's surface ranged from $71 \cdot 8^{\circ}$ to $73 \cdot 7^{\circ} \mathrm{F}$., and that of the effluent $71 \cdot 5^{\circ}$ to $72.8^{\circ} \mathrm{F}$.

\section{Note 9 (pp. 13, 87, 92). \\ Guilandina bonduc and other species.}

Guilandina bonduc, though fairly well distributed, is not nearly so common in the West Indies as G. bonducella. Though both are littoral species, $G$. bonduc seems to be the species that is most at home inland. But the questions raised by these two plants, that often travel around the tropics of the world together, are much more complex in the New World than in most other regions. Yet even in the Pacific islands, as I have shown in my work on Plant Dispersal, they give rise to several difficulties; but the tendency to differentiation that they there display is much more marked in the American continent, and there is ground for the belief that the two types will admit of being broken up into several smaller specific or subspecific groups. Urban in his Symbola Antillanae (II., 270-6), though he does not separate them from the Cæsalpinias, describes eight or nine peculiar West Indian species of the Guilandina type, usually with yellow or orange-coloured seeds, and mostly from Cuba. But island groups like the Bahamas, and even the Caymans, may possess their own peculiar forms, and Millspaugh has described a new shore species from the last-named locality that stands nearest to G. bonducella (Planta Utorwance).

My inference in the Pacific that seed-buoyancy in Guilandina goes with station rather than with species, plants of the beach having buoyant seeds and those from inland seeds that sink, would not seem to be of general application in the West Indies. Thus on the beaches of St. Croix I found Guilandina bonduc associated with $G$. bonducella, but only the last had buoyant seeds. Indeed, my data seem to indicate that in the West Indies seed-buoyancy in Guilandina goes with species rather than with station. When in Grenada I tested the buoyancy of the seeds of $G$. melanosperma, a variety of $G$. bonduc with black seeds, from Antigua; but they all sank in sea-water. The lack of buoyancy of the seeds of this species in the West Indies may be predicated from their rarity in beachdrift. An indication in the same direction for the genus is afforded by the fact that in the case of an inland species, apparently undescribed, that I found in the woods on the lower slopes of Mount 
Diablo in the heart of Jamaica and 1500 or 1600 feet above the sea, 33 per cent. of the seeds floated in sea-water. All these facts and inferences for Guilandina in the West Indies invite further inquiry into the relation between seed-buoyancy and station. Guilandina bonducella, true to its behaviour in the tropics of the Old World, possesses typically buoyant seeds. The difficulty of connecting a littoral station with seed-buoyancy is concerned with G. bonduc and the inland species of the genus.

A few remarks on the station of Guilandina bonduc in the West Indies may here be added. Sloane, writing of the plants of Jamaica in the latter part of the seventeenth century (Nat. Hist. Jam., II., 41 ), states that the Nicker plant with yellow seeds $(G$. bonduc) grew everywhere in the Jamaican savannahs. I found it associated with $G$. bonducella on the beaches of St. Croix; and the two species are characteristic littoral plants in the Virgin Islands (Harshberger, Phyt. N. Amer., p. 686). It grows, according to Grisebach, on the sandy seashore of Antigua.

I raised some young plants of perhaps an undescribed species from chocolate-brown Guilandina seeds gathered from amongst the Orinoco drift washed up on the south coast of Trinidad. The seeds are ovoid but rather compressed, and measure $27 \times 20 \times 14 \mathrm{~mm}$., and float buoyantly. The plants, when eight inches high, had prickly stems. The leaflets, in three or four pairs, were three to four inches long, lanceolate or ovato-lanceolate, with a rounded, rather oblique base, and a long tapering aristate apex.

The species, above mentioned as growing as a stout climber in young wood 1500 or 1600 feet above the sea on Mount Diablo in Jamaica, may perhaps be one of Urban's Cuban species. It was neither in flower nor in fruit, the seeds (yellow, oblong, $23 \times 15 \mathrm{~mm}$.) of the previous season lying on the ground. The leaflets, in five or six pairs, were two to three inches long, oblong or obovate, rounded or subcordate at the slightly oblique base, with usually a tapering apex terminating in a hair-line point. No stipules observed.

\section{Note 10 (p. 122).}

\section{Mucuna pruriens, DC.}

The use of the name Mucuna pruriens, DC., as applied to a species with large globoid seeds, an inch across, which occur in West Indian beach-drift and are washed up on the shores of Europe, has led to some confusion. It is not clear how the confusion arose; but two species have been thus confounded, $M$. pruriens, DC., an annual and a weed of cultivation which has been spread by man all around the tropics, and $M$. urens, DC., a stout-stemmed, woody climber that grows on high trees at the borders of forests in the New and in the old World and is found also at the coast. The first is known as the Cow-itch plant, and, as I observed in the West Indies, is common in land once cultivated, as in abandoned sugar-cane fields. The plant is a great nuisance when the pods dry and the covering of stinging hairs comes off. In Tobago it was credited with keeping Indian 
coolies out of the island. The second is known in the West and East Indies as the Horse-eye and Donkey-eye plant, from the peculiar appearance of the seeds. Its pods have also a covering of stinging hairs; but, as the writer knows from a personal experience of both plants, the irritation produced from this cause is much less than with the Cow-itch.

It is not often that we can recognise the confusion between the two species as clearly as we can in the case of a reference to Mucuna pruriens in the System of Botany, by Le Maout and Decaisne (Engl. edit., 1873, p. 373). We there read that it is an Indian annual called Cow-itch, the seed being " called Donkey's Eye, from the large, pupil-like areola of the testa." Here we have the true $M$. pruriens credited with the seeds of $\boldsymbol{M}$. urens, the seeds of the two species being, as will be shown below, utterly different in appearance. An crror in the reverse direction is sometimes found. Thus Hillebrand, in his book on the flora of the Hawaiian Islands, after describing the true $\boldsymbol{M}$. urens observes that it is "well known as the Cow-itch plant" and is a native of the West Indies and of tropical America. The true $M$. pruriens, which is a pest both for man and beast in old clearings and abandoned cultivations, is the plant, it may be here repeated, that is known as Cow-itch.

In his Report on the Botany of the Challenger Expedition (I., 43; IV., 141, 277, 299) Hemsley applies the name of Mucuna pruriens, DC., to the Mucuna seeds found in West Indian beach-drift and washed up on the coasts of Europe. The seed which at the end of the seventeenth century Sloane recognised amongst the stranded seeds (Molucca beans) of the Orkney Islands as the "Horse-eye bean "familiar to him in Jamaica (Phil Trans., XIX., 398, 1695-7) is identified in this report (IV., 277) as M. pruriens. The two species are there mentioned under the name of $\boldsymbol{M}$. pruriens, DC., on different pages. In the one case, we have a plant "commonly cultivated and now almost cosmopolitan in the tropics" (IV., 141). In the other case, it is a plant the seeds of which were found by Morris in Jamaican beach-drift, and they are described as "sometimes washed ashore on the western coast of Europe" (IV., 299). As is remarked below, the seeds of $\boldsymbol{M}$. pruriens proper do not occur in beach-drift and possess no floating powers.

Yet as a result of the confusion, which probably dates back to the early part of last century, botanists must have often experienced the same difficulties. For instance, Ernst in his account of the new flora of Krakatau (1908, pp. 36, 37, 41, 46) mentions $M$. pruriens DC., as amongst the new vegetation that has established itself since the great eruption on the coasts of the neighbouring island of Verlaten, where it climbs on the strand trees. Schimper makes no reference to such a species in his work on the Indo-Malayan strand flora, and we can only conjecture that it was not the annual species, the weed of cultivation, to which this specific name was originally applied.

It would seem that botanists have been misled by the lack of any description of the seed of Mucuna pruriens in the works most accessible to them, De Candolle's Prodromus (tome II., 1825) and Grise- 
bach's Flora of the British West Indian Islands (1864). Yet, as pointed out by Sagot, when writing in the Bulletin de la Société Botanique de France in 1875 (XXII., 292), the seed was very accurately described by Jacquin in his work on American plants in the middle of the eighteenth century. It was also described and figured by Bentham a hundred years after in the Flora Brasiliensis of Martius (Vol. XV., part 1, p. 169, tab. 46, 1859-62). Both these works are quoted by Grisebach in connection with the plant, and his lack of reference to the seed seems unaccountable. Perhaps the reason may lie in the same doubt that first suggested itself to Sagot; that is to say, whether two plants, like $\boldsymbol{M}$. urens and $\boldsymbol{M}$. pruriens, that are associated in the same genus by their floral characters, would possess seeds so different. Grisebach, with Jacquin's and Bentham's volumes by his side, says nothing of the seed of either species.

The difference in appearance between the large, globoid, iron-grey seeds of Mucuna urens and the small, sub-reniform, mottled brown, shining seeds of $\boldsymbol{M}$. pruriens is well brought out in Bentham's figures. The first are thick-shelled, an inch across, and nearly surrounded by the black raphe. The second, which the present writer compares with ordinary Phaseolus seeds and Sagot with small haricots, are relatively thin-shelled, barely half an inch in length, and possess a large scar but no circular raphe. The seeds of $\boldsymbol{M}$. urens, again, possess great buoyancy. Those of $\boldsymbol{M}$. pruriens, as my experiments indicate, possess none. The first are distributed unharmed by the ocean currents. The second have evidently been dispersed by man along trade routes. The first are characteristic of beach-drift in the West Indies and elsewhere. The second have never been recorded from beach-drift, nor are they at all likely to occur there.

For a long while I clung to the use of the name of Mucuna pruriens as applied to a species with seeds of the $M$. urens type, since its employment was backed by high authorities. However, when I included seeds of this type under the name in a collection of West Indian drift sent to the Natural History Museum in 1912, Dr. Rendle kindly pointed out that they were not those of $M$. pruriens, which were much smaller and more oblong in form, and that they were probably those of $\boldsymbol{M}$. urens. This decided the matter. In the treatment of the drift seeds of Mucuna in other parts of this work it is pointed out that there are two kinds of seeds of the urens type dispersed by currents; and the specific name of "pruriens" was in the above-named collection applied by me to the seeds which are now designated in these pages as "near urens," seeds that may be those of M. altissima, DC., a matter discussed on p. 120.

Note 11 (p. 60).

The relation between the floras of Ascension and St. Helena and the currents.

As we learn from Hemsley (Chall. Bot., III., 32-4), we have no positive proof that more than two of the flowering plants of Ascen- 
sion are really indigenous, namely, Hedyotis adscensionis and Euphorbia origanoides, both of which are endemic. The first is more nearly related to African and Asiatic species than it is to the St. Helena, $\boldsymbol{H}$. arborea. The second has its nearest ally in $\boldsymbol{E}$. trinervia from the Guinea coast, there being no indigenous species of Euphorbia in St. Helena. Current-borne seeds could only reach Ascension through the agency of the Main Equatorial Current, which would carry drift to it from tropical Africa and from the extra-tropical southern part of the continent, the South African Current here coming into play.

St. Helena, lying as it does in the track of the South Equatorial Current, which is fed by the off-shore waters of the South African Current, would not receive any African drift except from the southern extremity of the continent; but through the intermediate agency of the South Atlantic Connecting Current it would be the recipient of drift from the South American region gathered by the Brazil Current between Cape St. Roque and the River Plate. It would be quite cut off by the currents from Ascension and could receive no drift from the north, Dr. White's contention that the flora and fauna arrived from the north in the direction of the Cape Verde Islands being quite untenable (quoted by Scharff, p. 388). If the currents have been concerned in stocking the island, they would have brought to it seeds from South Brazil and the River Plate as well as from the Cape. It is noteworthy that whilst Hooker finds the most characteristic affinities of the flora in southern extra-tropical Africa, Hemsley, following Bentham, points to equal or closer affinities between its arboreous Compositæ and South American types (Ibid., III., 59).

Though there is no evidence that the plants concerned are distributed by the currents, it is remarkable that this agency, if effective, might possibly explain in both Ascension and St. Helena the affinities determined by the botanists. Yet from the endemism of the genera with South American affinities, it may be inferred in the case of St. Helena that whilst the South American connection is largely a thing of the past, that with South Africa has been maintained up to relatively recent times. (The system of currents prevailing in the South Atlantic is discussed in Chapter III. and Note 18.)

\section{Note 12 (pp. 51-55).}

\section{Bottle-drift on the Azores.}

The answer to the question as to the source of the vegetable drift stranded on the Azores is plainly given in the results tabulated below for bottle-drift. All the seeds stranded there must come from the west, namely, from the coasts of the New World between Newfoundland and the West Indies. Nothing comes from the eastward, and it will subsequently be shown that bottles dropped into the sea in the vicinity of this group either display the same easterly drift or are carried south into the North Equatorial Current, ultimately reaching the West Indies. This conclusion applies to all seasons of the year, 
the lack of data in the American charts for the summer months being supplied in Schott's memoir.

All of the twenty-seven bottles dealt with in this table came from the region between Sable Island off the Nova Scotian coast and Cuba, but the number for each locality is no indication of relative frequency, since most of the experiments were begun in the north. It is noteworthy that none of these bottles approach the group from the southward, all from the quarter between West and North-northwest - a fact brought out in the cases of those dropped into the sea in mid-ocean to the westward of the islands. To the southward and westward lies a debateable region from which, according to the compiler of the American charts, but few bottles are ever recovered, though "crossed by numerous sailing and steamship routes and within which in all probability are cast as many bottle papers as in other portions of the ocean." This region lies between the main drifts of the Gulf Stream and North Equatorial Current, and, according to the same authority, is confined between $25^{\circ}$ and $40^{\circ} \mathrm{N}$. lat. and $30^{\circ}$ and $60^{\circ} \mathrm{W}$. long. But even if we curtail these limits a little, since bottles can reach the Azores from the same parallel a few hundred miles to the west, the fact remains that in this part of the central Atlantic there is interposed between the Azores and the New World to the south-west the vast area of the Sargasso Sea, covering some 120,000 square miles, where, as Laughton (p. 221) observes, collects a very large proportion of the drift or wreckage which floats about the Atlantic. This may explain why four and even six years may elapse before some of the bottles are recovered on the Azores. Indeed, the progress of drift to the Azores seems to be never rapid. Of the rates given for nineteen bottles not one reaches ten miles a day. Though those drifted there from the vicinity of Cape Hatteras seem to travel at the same speed as those that are carried to Europe from the same locality, the passage from the Nova Scotian region is very tedious, bottles taking rather longer for the drift from that region than they do from Cape Hatteras, although the distance is much less.

The fate of other bottles thrown into the sea in the vicinity of the Azores, between 60 and $\mathbf{1 5 0}$ miles east and west of the group, is illustrated in Dr. Schott's paper. Of four, one was recovered on the coast of Norway, and the others, after being carried south, were transported by the North Equatorial Current to the West Indies, being found on the Bahamas, on one of the northern islands of the Lesser Antilles, and on the north-west coast of Cuba.

It would seem, therefore, that whilst the islands of the Azores can only receive drift from the coasts of North America and from the West Indies, they can supply it to the coasts of Europe and to the West Indian region.

The Prince of Monaco's observations in 1885 and 1887 to the N.N.W. and N.W. of the Azores at distances of 200 to 800 miles, largely confirm the results above given, in the case of bottles thrown overboard 200 to $\mathbf{7 5 0}$ miles W. and N.N.W. of the group. Of eleven floats that reached there from distances between 280 and 460 miles N.N.W. of the islands, the three most rapid drifts gives a mean of 
$6 \cdot 9$ miles a day $(7 \cdot 7,7 \cdot 3,5 \cdot 7)$. Of twenty-six floats thrown over between the Azores and the Great Bank of Newfoundland, the five most rapid drifts give a mean daily rate of $5 \cdot 3$ miles.

\section{Tablg Illostrating the Localities from which Bottle-Drift REACHES THE AZORES}

(The averages for the time occupied in the drift and for the daily rate are estimated from the shortest periods elapsing between the dates of the start and recovery of the bottle, as given in the last column. Most of the data are from the American charts, the remainder are from Schott's memoir, but all the daily rates are based on the former, the details of the references being given on p. 47).

\begin{tabular}{|c|c|c|c|c|c|}
\hline \multirow{2}{*}{ Starting-place } & \multirow{2}{*}{$\begin{array}{c}\text { Number } \\
\text { of } \\
\text { Bottles }\end{array}$} & \multirow{2}{*}{$\begin{array}{l}\text { Distance } \\
\text { in } \\
\text { Nautical } \\
\text { Miles }\end{array}$} & \multicolumn{2}{|c|}{ Averages } & \multirow{2}{*}{$\begin{array}{c}\text { Shortest } \\
\text { Drifts in Miles } \\
\text { per Day }\end{array}$} \\
\hline & & & Days & $\begin{array}{l}\text { Miles per } \\
\text { Day }\end{array}$ & \\
\hline \multicolumn{6}{|l|}{$\begin{array}{l}\text { South of Cape Sable and Sable } \\
\text { Island between } 38^{\circ} \text { and } 43^{\circ} \mathrm{N} \text {. }\end{array}$} \\
\hline lat. $\cdot . \cdot \cdot \cdot$ & 8 & 1500 & 294 & $5 \cdot 1$ & $5 \cdot 6 ; 4.5(A)$ \\
\hline $\begin{array}{l}\text { Off Cape Hatteras within a } \\
\text { radius of } 300 \text { or } 350 \text { miles . }\end{array}$ & 8 & 2400 & 273 & $8 \cdot 8$ & $9 \cdot 9 ; 7 \cdot 7(\mathrm{~B})$ \\
\hline Off the E. coast of Florida. & 1 & 一 & - & - & - \\
\hline Off the N.W. coast of Cuba & 1 & 3180 & 435 & $7 \cdot 3$ & - \\
\hline \multirow[t]{2}{*}{$\begin{array}{l}\text { To the westward of the Azores, } \\
200-750 \text { miles W.-N.N.W. }\end{array}$} & 9 & 400 & 71 & $5 \cdot 6$ & $6 \cdot 4 ; 4.8(C)$ \\
\hline & 27 & 一 & - & 一 & 一 \\
\hline
\end{tabular}

(A) Drift-rates for 6 bottles.

(B) , , , 8 ,

(C) , , , 5 ,

Note 13 (pp. 56-58).

Bottle-drift in the Turks Islands.

The Turks Islands, with the neighbouring Caicos Islands and the two Inaguas, have received a large amount of bottle-drift. We learn from the Rev. J. H. Pusey's Handbook (1897) of these islands that bottles are "constantly being picked up by the natives." During my sojourn in the Turks Group in $1911 \mathrm{I}$ found that the coloured people had lost their interest in returning the enclosed records, since no money was forthcoming. Fortunately plenty of material is at my disposal for determining the directions from which bottle-drift reaches this region, and also the direction it takes when it passes the islands to places beyond. Below will be found data for thirty-three bottles which were recovered in these islands, and for forty bottles which were dropped into the sea in the middle of the channel between the Turks Islands and the Hispaniola coast.

We see there that three bottles reached here from the vicinity of the Azores; one from off the south-west of Ireland; one from off 
Lisbon; fourteen from the region included in the Madeira, Canary, and Cape Verde Groups; two from mid-Atlantic to the eastward; eight from a few hundred miles N.-E.N.E. of the Turks Islands; three from between Bermuda and the Bahamas; and one from off Cape Hatteras. But this list of localities should be supplemented from the data supplied by bottles that passed between the Turks, Caicos, and Inagua Islands and were recovered on the Bahamas farther west, as well as on the north coast of Cuba. The Bahamian islands receive bottle-drift not only from the localities above named, but also from the eastern side of the Lesser Antilles and from the shores of the Guianas and North Brazil. The Antillean Current, referred to in Chapter III., would be instrumental in this direction, and a good instance is there mentioned of a bottle which was stranded in the middle Bahamas after being thrown into the Main Equatorial Current between St. Paul's Rocks and Cape St. Roque.

All the bottles that reach the south-eastern Bahamas from the eastern side of the North Atlantic have followed the track of the North Equatorial Current to the West Indies; and where, as often happens, they have started as far south as the Cape Verde Islands, they cross the Atlantic well south of the 20th parallel and arrive at the Turks Group after brushing the coasts of the northern islands of the Lesser Antilles. A glance at the map will show that in the last case the drift approaches the Turks Islands from E.S.E., and that these islands receive the drift which in the Antillean Current has traversed the Lesser Antilles between Porto Rico and Guadeloupe. The tracks of several bottles, as laid down in the American charts, directly indicate that much drift from the south-east, which would otherwise have arrived at the south-eastern end of the Bahamas, has been intercepted by Porto Rico, the Virgin Islands, St. Thomas, and other islands in that region.

Just as suggestive of the prevailing direction taken by drift, when traversing the south-eastern Bahamas, are the results given a page or two later for a large number of bottles dropped into the sea between the Turks Islands and Hispaniola. Out of forty all were carried to the westward, and nearly all entered the passage between Cuba and the Bahamas leading to the Florida Strait. Though most of them were stranded on the way, usually on the Cuban side, three passed through and reached the straits. Of these, two got no farther and were beached on the coast of Cuba; but one was caught in the swift current of the Gulf Stream, and after a drift across the Atlantic was recovered 337 days afterwards on the west coast of Ireland. This westward trend of the bottle-drift after passing between the Turks Islands and Hispaniola is the effect of the Antillean Stream.

The conclusion to be drawn from all these bottle-drift data is very significant of the direction of the drift traversing the south-eastern Bahamas. There is a prevailing set in a W.N.W. direction towards the Florida Strait; but although much of the drift is stranded on the way a certain proportion reaches the straits, and some of it gets within the influence of the Gulf Stream. The indications are, therefore, that the Turks Islands lie in the track of drift on its way in the 
Antillean Stream to the Florida Strait from regions to the eastward and southward.

But in the winter months, when the North-east Trade blows freshest and is often very northerly, these islands are also the recipient of drift from the northward and eastward, probably mostly material that would otherwise have passed to the eastward of the Turks Group, but is thrown back on the beaches by the strong " northers" that are not infrequent in this season. During the winter bottledrift may even arrive at these islands from the vicinity of Bermuda. Dr. Schott (p. 13) in this connection observes that the N.W. direction of the drift in the seas between the Bahamian and Bermudian Islands is not always illustrated by the bottle-drift, and he gives a case where a bottle thrown over early in February about 150 miles S.S.W. of the Bermudas was recovered on the Turks Group forty-nine days later, the distance covered being $\mathbf{5 4 2}$ miles.

I will first give the data concerning bottles stranded on the islands forming the south-eastern extremity of the Bahamas, namely, the Turks and Caicos Islands and the two Inaguas. They are mainly supplied in the American charts and in Dr. Schott's paper; but a few are taken from the Nautical Magazine for 1852. The following is a grouping of the materials according to their starting-places.

\section{Sources of bottle-drift found on the south-eastern islands of the Bahamas.}

A. Vicinity of the Azores within a radius of 400 miles .

B. Off the south-west coast of Ireland, 260 miles distant

C. Off the coast of Portugal, near Lisbon, 50 miles from land

D. In the vicinity of Madeira and the Canary Islands within a radius of 160 miles $\cdot$.

E. About 120 miles off Cape Blanco and halfway between the Canary and Cape Verde Islands

F. In the vicinity of the Cape Verde Islands within a radius of 250 miles to the north, south, and west

G. In mid-ocean, 1000 to 1500 miles E.-E.S.E. of the Turks Islands

3 bottles

1,

1,

6 ,

1

7 ,

2 ,

H. Between 100 and 350 miles N.-E.N.E. of the Turks Islands between December and March

I. Between Bermuda and the Bahamas during January and February .

J. Off Cape Hatteras

\begin{tabular}{rrr}
8 & $\Rightarrow$ & $(25 \%)$ \\
3 &, & $(9 \%)$ \\
1 & $\Rightarrow$ & $(3 \%)$ \\
\hline 33 &, & $(100 \%)$
\end{tabular}


The above list, as already implied, does not exhaust the sources of the bottle-drift stranded on the south-eastern Bahamas. On the islands of the same group, farther to the north-west, have been recovered bottles dropped into the sea off the east side of the Lesser Antilles and off the coasts of the Guianas and of North Brazil, which, as they were borne along in the Antillean Stream, must have passed between the Turks, Caicos, and Inagua Islands, to reach their destinations.

The subjoined notes refer to the results above given :-

A. The average distance by Madeira and the Cape Verde Islands route would be about 4200 miles, the greatest daily rate indicated being $\mathbf{7 \cdot 2}$ miles.

B. Recovered after 597 days, giving a minimum daily rate of 8.5 miles over a distance of $\mathbf{5 1 0 0}$ miles (see Note 20).

C, D, E, F. Except in two cases only the tracks on the chart are given. In one of them a belated drift of only 3.5 miles a day was indicated. In the other, which is given in Purdy's Columbian Navigator for 1839, a bottle from off Madeira was found ten years afterwards on the Turks Islands.

G. The fastest daily rate up to the time of recovery was $5 \cdot 3$ miles.

H, I. All were stranded during the winter months, a season when the Trade may blow strongly for long spells from the north. The number of bottles thrown over a few hundred miles to the northward and eastward give an excessive idea of the relative frequency of drift from this quarter, since the captains of one or two ships seem to have been especially interested in this point. At this season, also, drift may arrive from the vicinity of the Bermudas.

J. Recovered after 309 days. It probably accomplished a short circuit of the North Atlantic by being deflected south in the neighbourhood of the Azores. Several bottles thrown over at the same time reached the shores of Europe (see p. 49).

Equally suggestive, as significant of the direction pursued by floating drift in this region, are the indications of bottles dropped overboard in the seas between the south-eastern Bahamas and Hispaniola. In the American charts are given the data for forty bottles thrown over between October and May just half-way between the Turks Islands and the coast of Hispaniola in or about $20^{\circ} 30^{\prime} \mathrm{N}$. and $71^{\circ} 30^{\prime} \mathrm{W}$., and about forty miles S.S.W. of the Turks Group. They were mostly cast over from the S.S. New York in 1906; but some were thrown over from the S.S. Cherokee in 1905, besides one or two from other vessels. There was evidently a special reason for selecting this locality, which on account of the number of bottles thrown over there, probably some hundreds, if we allow for the nonrecoveries, must be nearly un ique in the West Indian region. Doubtless it was concerned with the investigation of the Antillean Stream, which is the current that tra verses this region on its way northward and westward towards the Florida Strait. The results of these experiments are now given. 
Places of recovery of forty bottles cast overboard about half-way between the Turks Islands and the adjacent coast of Hispaniola.

A. North coast of Cuba .

B. Middle and north-west Bahamas

C. Jamaica and the Cayman Islands

D. Yucatan

E. Ireland

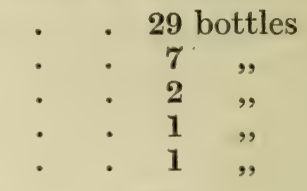

A. Most of them were stranded on the north-east coasts of Cuba, but two or three were carried farther and thrown ashore on the Cuban side of the Florida Straits. The average daily drift rate indicated was not over eight or nine miles.

B. The average drift was five or six miles a day.

D. Stranded on or near Cozumel Island : daily drift $9 \cdot 6$ miles.

E. Recovered on the coast of County Mayo 337 days afterwards, giving a daily drift rate over $\mathbf{4 1 4 0}$ miles of $\mathbf{1 2 \cdot 3}$ miles (see Note 20 ).

Note 14 (p. 49-54).

The bottle-drift of the Bermudas.

(Materials mainly supplied by the American charts, but also by the papers of Dr. Schott and the Prince of Monaco.)

As regards its relation to the circulatory system of currents in the North Atlantic, Bermuda may be viewed as situated near the inner end of an eccentric spiral, of which the outer end may be considered as represented by the Gulf Stream, as it rushes through the Florida Strait, and the terminal portion as represented by the Antillean Stream curving northward and eastward from the region dividing it from the Bahamas. On the face of things, therefore, we should expect that these islands would receive much and impart but little.

I have at my disposal the records of about forty bottles, recovered on these islands, which ought to supply sufficient materials for a preliminary inquiry into the subject; but it will be necessary to make at first a brief reference to the implications involved in such an investigation. As regards the Bermudian fauna and flora opinion seems to fluctuate between two schools of thought : the older school typified in the views of Wallace, Hemsley, and others, who consider that the islands have been stocked through the agencies of birds and currents, and the newer school typified in the views of Dr. Scharff and others, who see in the Bermudian indigenous plants and animals the remains of an ancient fauna and flora which this region received when joined to the North American continent (Scharff's Distribution and Origin of Life in America, pp. 183-95).

As far as the starting-places indicate, bottle-drift may reach the Bermudas from all points of the compass. Bottles have arrived there 
from off the Nova Scotian coast due north of the group (one); from between the Azores and the Great Bank of Newfoundland (three); from the Eastern Atlantic opposite the Bay of Biscay in about longitude $18^{\circ}$ W. (two); from the Eastern Atlantic in the latitude of the Canary Islands, but about 800 miles further west (one); from mid-Atlantic between the parallels of $20^{\circ}-23^{\circ} \mathrm{N}$. and the meridians of $40^{\circ}-50^{\prime} \mathrm{W}$., within the northern border of the North Equatorial Current (three); from Florida coasts and from Cuban seas (three); from off the continental coasts to the westward in the region of Cape Hatteras (fifteen); and from a number of directions all around the group in the case of bottles dropped overboard in the vicinity. The possibilities of Bermuda as a gathering-place for drift are great when we regard the area of the region indicated by the starting-places of the bottles that have been thrown up on its shores. Such a region would comprise the breadth of the North Atlantic from coast to coast between the 20th and 50th parallels of latitude. Although the possible starting-place might lie anywhere at the borders of this region, the point of approach would be nearly always from the west, the range varying usually between north-west and south-west.

This brings one to remark that the Bermudas occupy a singular position with regard to the two principal currents that could supply them with drift-the Gulf Stream from the New World and the North Equatorial Current from the old World. It receives what is played off from the borders of one current and what is brought to it by a connecting stream from the other.

As regards the Gulf Stream, it receives the "tailings " of the current as it proceeds northward to Cape Hatteras and is gradually deflected eastward towards Europe. This is well shown when we compare the daily rates of bottle-drift reaching Bermuda from the Cape Hatteras region with those for bottles reaching Europe from the same locality. Thrown overboard within a radius of 250 or 300 miles from Cape Hatteras, which would include the main stream of the current, bottles are carried to Europe, a passage of over 3000 miles, at an average rate of eight to nine miles a day, whilst the passage of 500 or 600 miles to Bermuda is accomplished at an average rate of rather over five miles a day. The American charts supply data for fifteen bottles that reached Bermuda from the Hatteras region. The quickest minimum rate of $\mathbf{5 \cdot 4}$ miles a day was attained in two cases, whilst the three bottles next in speed gave rates of $5 \cdot 3,5 \cdot 3$, and 5.1 miles. The consistency in the five fastest rates enable one to largely eliminate the effects of delay in the recovery of the bottles. The contrast between the slow drifting rate to Bermuda and the fast drifting rate to Europe is well illustrated by a set of five bottles that were thrown over together from the S.S. Cherokee about a hundred miles north of Cape Hatteras, the particulars of which are given in Chapter III. Two bottles recovered on the Bermudas gave minimum daily rates of $\mathbf{3 \cdot 1}$ and five miles, whilst those picked up on the Scottish coast, on the Shetlands, and near the North Cape of Norway, gave minimum rates of $7 \cdot 8,6 \cdot 9$, and $10 \cdot 2$ miles respectively. The playing off of drift from the outer border of the Gulf Stream towards the Bermudas is probably continued as the current heads 
towards Nova Scotia after passing Hatteras. That the process begins soon after the current emerges from the Florida Strait is indicated below.

West Indian vegetable-drift, as is well known, is thrown up on the Bermudas in quantity; but the indications of bottle-drift are that it would be usually belated. Vegetable-drift reaching the islands from this region would hail from the seas between South Florida, Cuba, and the Bahamas and from the coasts around. In most cases, however, there would seem to be great delay, and it is evident from the behaviour of bottle-drift that it may be carried around the North Atlantic before it is stranded on the Bermudian coasts. There is the case of a bottle that was recovered in Bermuda nearly three and a half years after it had been dropped into the sea, in February 1902, between Key West and the Cuban coast (Amer. chart, Febr. 1909). There is another case of a bottle that after being dropped over near Key West, in October 1901, was picked up on Bermuda five and three-quarter years afterwards (Amer. chart, Oct. 1908). Then we have a bottle which was found on Bermuda 466 days after it had been cast into the sea about 200 miles to the northward of Great Abaco (N.W. Bahamas), though the direct passage across the sea was barely 600 miles (Amer. chart, Febr. 1909). But that the passage of West Indian drift to these islands may at times be fairly rapid is illustrated by a bottle that was recovered in Bermuda seventy-three days after it had been cast overboard in the northern part of the Florida Strait, the passage of 900 miles having been accomplished at a minimum daily rate of rather over twelve miles (Amer. chart, Nov. 1908). The behaviour of this bottle indicates that the tailing off of drift from the Gulf Stream towards Bermuda may begin soon after the current issues from the Florida Strait.

From the data above given, as far as they go, it may be inferred that West Indian seed-drift may reach the Bermudas in the following ways. It may be deflected eastward from the Gulf Stream soon after the current issues from the Florida Strait, when the passage would occupy two or three months. This deflection may not take place until the current passes Cape Hatteras, when the time occupied would be five or six months. The drift may be carried past the Bermudas in the Gulf Stream and accomplish the circuit of the North Atlantic, returning in the North Equatorial Current, which would cover three years. Drift from the north-west Bahamas would probably only reach Bermuda by getting within the influence of the Gulf Stream farther north, a tedious process that is illustrated by one of the bottles.

With the North Equatorial Current, the carrier of drift from the Old World, the Bermudas are connected by means of the Antillean Stream (see Chapter III.), as is explained by Schott (p. 13). But probably they would only receive in this way the drift in the slack waters of the North Equatorial Current north of the 20th parallel. In the American chart (May 1909) the track is given of a bottle, thrown over in mid-Atlantic in lat. $22^{\circ} 54^{\prime} \mathrm{N}$. and long. $39^{\circ} 42^{\prime} \mathrm{W}$., which accomplished a passage computed at 2430 miles at the mini- 
mum rate of $7 \cdot 8$ miles a day. In the same charts, but for December 1908, there is a track of a belated bottle which reached Bermuda from a position about 600 miles further west on the 22nd parallel. In both these cases allowance is made for the northward curve of the Antillean Stream towards Bermuda, which the bottles approach from the south-west. The same plan is followed by Schott in laying down the tracks of bottles reaching Bermuda after traversing the Atlantic in the North Equatorial Current, though he gives the Antillean curve a greater sweep and makes them approach the islands from the west. According to this chart one such bottle which was thrown into the sea about the 28th parallel and about 800 miles west of the Canaries was picked up at sea nearly 200 miles N.E. of Bermuda.

But two bottles have been stranded on these islands which were cast into the sea in the eastern Atlantic only 400 or 450 miles northwest of Cape Finisterre. On their way south in the Portuguese or North African Current they would pass near Madeira and the Canary Islands before coming within the influence of the North Equatorial Current, and the whole passage of about 4300 miles would probably occupy about two years. No details are given either by Dr. Schott or by the Prince of Monaco, from whose pages these two records are taken; but from the data for similar traverses given in Chapter III. we should probably be not far wrong, if, after allowing for the delay in reaching and leaving the North Equatorial Current, we placed it at about six miles a day. In Dr. Schott's example we can determine the approximate position of the startingplace $\left(46^{\circ} \mathrm{N} .19^{\circ} \mathrm{W}\right.$.) from his map; but in that of the Prince of Monaco we can only say that it was one of a large number of floats that were dropped over in 1886 along the 18th meridian of west longitude and between the parallels of $42^{\circ} 30^{\prime}$ and $50^{\circ} \mathrm{N}$.

Still more interesting are the records of three floats thrown over in the Prince of Monaco's observations of $\mathbf{1 8 8 7}$ between the Azores and the Great Bank of Newfoundland, as well as to the north of that group. They form 2 per cent. of the recoveries, and taking the Prince's general estimate of such drifts at $6 \cdot 4$ miles a day, the passage of about $\mathbf{5 0 0 0}$ miles implied would occupy about twenty-six months, and would almost involve the circuit of the North Atlantic by way of the Portuguese and North Equatorial Currents. An approach yet nearer to the completion of this circuit is concerned with a bottle thrown over about 130 miles to the south-east of Cape Sable (Nova Scotia) and recovered in Bermuda 1602 days afterwards. In the American chart (Dec. 1908) the passage is computed at 5880 miles, which gives a minimum rate of only $3 \cdot 7$ miles a day, and the compiler characterises it as "almost completing the circuit of the ocean." It is noteworthy that although this bottle was cast over about 580 miles north of Bermuda, its passage to those islands involved a distance tenfold in amount. This well illustrates the peculiar position of Bermuda with regard to the currents of the North Atlantic. It is in the track of none of them, yet at the end of all of them.

This brings one to notice another feature in the relation of these 
islands to the North Atlantic currents. Whilst they may receive drift from all round this ocean, they do not figure often as distributors of drift to distant regions. The records of bottle-drift at my disposal for the North Atlantic number some hundreds; but there is only one record of any distant region having received drift from the vicinity of the Bermudas. They give nothing to the adjacent coasts of America only a few hundred miles away. Bottles thrown into the sea within a day's steaming from their shores usually find their way back to the islands sooner or later, even if years elapse. I have the records of seven bottles dropped in the seas around Bermuda, to the north, south-east, south-west, west, and north-west, at distances ranging between 200 and 350 miles. Five out of them were recovered on the islands; but only in one case is a rapid passage indicated; and here a bottle was recovered twenty-five days after it had been dropped overboard about 300 miles to the south-east of the group. Of the other four, one from 240 miles to the north was found seven months afterwards; another from 300 miles W.N.W. was picked up also after seven months; another from 350 miles to the west was recovered after nearly six months; and the last from 200 miles to the south-west was not found on the islands until two years had passed. It does not, therefore, seem easy for drift to leave the Bermudas, since at most if it obtained an offing it would be caught in the baffling play of the currents around the islands and would be returned after an interval perhaps of months or years. The behaviour of bottle-drift in Bermudian waters was evidently a source of difficulty with Schott, who remarks (p. 13) on the numerous examples from this region concerning which it is scarcely possible to determine their tracks.

Yet under certain conditions it might be possible for the Bermudas to establish a connection with the Bahamas. But apparently it would be only in the winter months, when the North-east Trade blows freshest and blows home in these seas, that such a connection would be practicable-a matter mentioned in the treatment of the bottle-drift of the Turks Islands in Note 13. Schott (p. 13) gives an instance of a bottle, which, dropped over about 150 miles S.S.W. of Bermuda, early in February, was picked up on the Turks Islands, at the extremity of the Bahamas, forty-nine days later. He quotes the ship's log to the effect that at the time of the start the conditions of wind and current were unfavourable for any drifting passage to the Turks Islands; but with this exception we know nothing of the actual conditions experienced by the bottle in this remarkable drift. The possibility, however, of the passage of drift from Bermudian seas to the Bahamas is illustrated in the preceding note on the Turks Islands. It is there shown that many bottles reach the south-east Bahamas during the winter months from the northward and eastward, the longest drift being accomplished by bottles from within 300 miles of Bermuda. Here I may mention the tracks of five others, referred to in the American charts for the winter months from November to March, where the bottles reached San Domingo and the central and north-west Bahamas from about half-way between Bermuda and the Bahamas. 
Occasionally, again, a bottle breaks away altogether from the eddies of the Bermudian seas and reaches the opposite coasts of the Atlantic; but it starts from the Gulf Stream side of the islands 200 miles to the westward, and would represent the track not of Bermudian but of West Indian and American drift. Thus in the American chart for February 1909 the track is given of a bottle that was recovered on the Orkney Islands fourteen months after it had been thrown over about 200 miles W.N.W. of Bermuda.

Viewing the group as the recipient rather than as the distributor of drift, it is curious to notice how many localities on the opposite coasts of the North Atlantic would supply it with these materials. Though well outside the tropics, it figures as regards vegetation mainly as an outlier of tropical lands to the south and west. It is in that direction that we must chiefly look for results of effective dispersal by currents. The current that brings it seed-drift from that quarter would derive it from Cuban and Florida seas, as well as from the continental shores brushed by it as far north as Cape Hatteras; but for the most part the Cuban and Florida drift would be alone effective. The currents that brought bottle-drift from a few hundred miles off Cape Finisterre sweep past the coasts of Morocco and the islands of Madeira and the Canaries, and would doubtless bring seed-drift from those localities, which, however, would be mostly ineffective for the purpose of dispersal, since a passage of one and a half and two years would be involved. Strange but useless gifts might arrive from the shores of Nova Scotia and Newfoundland after a circuit of the North Atlantic covering about three years.

The Bermudas would be practically cut off from South America and from the regions from which the Main Equatorial Current derives its drift. I have no record of any bottle reaching these. islands from equatorial regions or from the South Atlantic. There is, however, a possible connection through the Antillean Stream; but the drift which that current supplies to Bermuda would be the drift it receives at its eastern border from the northern portion of the North Equatorial Current, and not the drift that its main stream at times brings to the Bahamas from the coasts and rivers of the Guianas and Brazil. Bottle-drift from the South American localities just named may, as we have seen in Chapter III., reach the Florida seas; but $I$ have found no record of its having ever been. recovered on the Bermudas. Still, the possibility remains.

\section{Note 15 (p. 51).}

\section{The circuit of the North Atlantic accomplished by drift.}

It would not be possible in the case of bottle-drift to be absolutely certain that one and the same bottle had accomplished this circuit, since evidence such as is supplied by derelicts of the position at different stages of the passage would not be forthcoming. The chances, however, of its having happened often are very great. Its antecedent possibility is proved over and over again in piece- 
meal fashion in the bottle-drift charts. For instance, the traverse from the West Indies to the coasts of Europe by the Gulf Stream route and back again in the North Equatorial Current in tropical latitudes is there many times illustrated. Several bottles have performed the greater part of the circuit. Thus, one from the Cape Verde Islands which reached the coast of Ireland must have taken the West Indian route (see p. 59). Then, again, we get cases of this kind. Bottles have been found on the Turks Islands from off the Irish coast, and on the west coast of Ireland from the vicinity of the Turks Islands (Note 20); the route in the first case being by the Cape Verde Islands and the North Equatorial Current, and in the second by the Straits of Florida and the Gulf Stream. An assumption that the circuit of the North Atlantic has been almost accomplished is justified where bottles have been thrown over in the vicinity of the Nova Scotian coast and are found four years after on a Bermudian beach (see Note 14).

The circulatory movement of the waters in the North Atlantic was established by the Prince of Monaco's extensive experiments, as discussed in Chapter III.; but since his field of observation did not extend to the western part of the ocean his conclusion was mainly based on the drifting of his floats from positions north-west and east of the Azores to the West Indies, the western portion of the circuit being assumed, according to common knowledge, to be the work of the Gulf Stream. The nearest approach to the completion of the circuit by a single float was displayed in three cases, where his floats thrown over to the north-west of the Azores were subsequently recovered on the Bermudas.

The principal delay in the circuit of the North Atlantic would take place in the eastern portion of the ocean in the passage south from European waters to the zone of the North Equatorial Current in the vicinity of the Cape Verde Islands. This is indicated in the table in Chapter III. dealing with the drifting rates of bottles; and it is well brought out in the circular drift of the derelict Alma Cummings from off Cape Hatteras to Panama, where drifting rates of sixteen or seventeen miles a day characterised the Atlantic traverses in the Gulf Stream and in the North Equatorial Current and a rate of only four miles a day in the passage of the intervening zone (Schott). The track of the Alma Cummings is described by Schott (p. 13, map 1) from materials given in the Nautical Magazine for 1896. Since its positions were fixed during its passage and the date of its beaching on the coast of the Panama Isthmus was known, the estimate that it accomplished a passage of $\mathbf{5 3 2 0}$ miles at the average rate of ten miles a day is well founded.

Note 16 (p. 50).

Traverse of the North Atlantic by the derelict "W. L. White."

An interesting record is supplied in the case of the derelict schooner W. L. White, which was drifted to the Hebrides from Baltimore 
Bay (about 240 miles north of Cape Hatteras) in rather over ten months (315 days). Dr. Schott, who gives the data in his memoir (p. 10, map 1), obtained them from the supplementary pilot chart of the North Atlantic for February 1889 (U.S. Hydr. Office). From the several positions determined during its passage it is apparent that about five months were occupied in drifting about within an area a few hundred miles across to the eastward of Newfoundland. Had it not been for this interruption the traverse of the ocean would have been accomplished within six months. After the first two months the vessel was water-logged and was entirely under the influence of the current. In the first half of the traverse, before the decks were awash, the average daily rate was sixteen miles; but the last 550 miles were covered at ten miles a day. The general track of the derelict may be placed at about 3200 miles, which gives an average daily rate of ten miles on her course from Baltimore Bay (March 13, 1888) to the Hebrides (Jan. 23, 1889).

\section{Note 17 (p. 447)}

\section{Mr. Lloyd Praeger's experiment on seed-buoyancy.}

In a paper entitled " The Buoyancy of the Seeds of some Britannic Plants," which was published in the Scientific Proceedings of the Royal Dublin Society for 1913, Mr. Lloyd Praeger gives the results of by far the most extensive series of experiments hitherto made in this inquiry. He gives his own results for 786 species of flowering plants, and supplementing them with those obtained by others for plants not experimented on by himself he supplies the data for just 900 British plants. I may be pardoned for adding that the results, to use the author's own words, fully bear out the conclusion formed by me as the outcome of an earlier series of experiments that "the buoyant-seeded plants in our flora are in the main inhabitants of either riverside or seashore" (p. 49).

This investigator also improved on the methods of his predecessors as far as direct experiment is concerned. The discrepancies between his own results and mine may be due, as he remarks, partly to the variable behaviour of the plants themselves and partly to different conditions of experiment. Of the first kind he gives some striking examples. His results also support the conclusion first formed by Darwin, and confirmed by those who followed him, that the great majority of seeds possess little or no floating power, probably not less than 90 per cent.

Unfortunately space does not allow me to do more here than to refer to these very important investigations; but I may remark that my results were also based on prolonged observations on the floating seed-drift of ponds and rivers. A combination of the two methods may remove some of the difficulties. Any young naturalist eager to take the subject up would find opened up for him a very interesting field of inquiry, and a very good guide in the paper of Mr. Lloyd Praeger. 
Note 18 (p. 60).

\section{The differentiation of the Main and South Equatorial Currents in mid-Atlantic.}

I will here deal with the indications that in mid-Atlantic the Main Equatorial and South Equatorial Currents can be differentiated, and that they are separate but contiguous currents. They are afforded by six bottles that were dropped into the sea at different times in the vicinity of the island of Ascension, the data for which, supplied in five cases by Schott and in one case from the Nautical Magazine, are given in the table below. They were cast over in three cases on the north side of Ascension and in the other three on the south side at distances varying between $\mathbf{5 0}$ and $\mathbf{3 5 0}$ miles from the island. The southernmost, thrown over in $11^{\circ} 38^{\prime} \mathrm{S}$. lat., was stranded on the coast of North Brazil $\left(2^{\circ} 40^{\prime} \mathrm{S}\right.$. lat.); the others being recovered in three cases on Trinidad, one on the Grenadines, and one on the south-east coast of Jamaica. All these bottles, even the southernmost, were borne along in the Main Equatorial Current, none of them being carried south of Cape St. Roque. The first three were solitary bottles that were thrown over in different months and different years. The last three were thrown over on three successive days from a ship proceeding north-west on the track between St. Helena and Ascension, and they require particular attention in this connection.

The first thrown over about half-way between the two islands in lat, $11^{\circ} 38^{\prime} \mathrm{S}$. was stranded at Paranahiba on the north coast of Brazil in lat. $2^{\circ} 40^{\prime} \mathrm{S}$. The second starting from a position nearer Ascension in lat. $10^{\circ} 4^{\prime} \mathrm{S}$., reached the Grenadines in the Lesser Antilles in lat. $12^{\circ} 42^{\prime} \mathrm{N}$. The third cast over in lat. $8^{\circ} 39^{\prime} \mathrm{S}$. and about fifty miles south-east of Ascension was recovered near Morant Bay on the south-east coast of Jamaica in lat. $17^{\circ} 56^{\prime} \mathrm{N}$. The implication is that bottles thrown over in the Main Equatorial Current in the vicinity of Ascension reach the West Indies; whilst those thrown into the same current half-way between St. Helena and Ascension reach the coast of Brazil north of Cape St. Roque, which divides the Main and South Equatorial Currents. From this we should expect that if from the same ship bottles had been cast over near St. Helena they would have been carried south when approaching Cape St. Roque in the southern current. From this point of view Ascension would be regarded as within the zone of the Main Equatorial Current and St. Helena as in the track of the South Equatorial Current.

This is what was meant by the differentiation of these two equatorial currents in mid-Atlantic, the drift of the main stream ultimately getting into the Guiana Current and that of the southern stream into the Brazilian Current. This distinction acquires importance when we come to consider the current connections of Ascension and St. Helena. From this standpoint they would be quite isolated as far as direct communication by currents is concerned. Such a view is supported by data supplied by a bottle which after being 
thrown into the Indian Ocean off the coast of Natal was recovered at Alcobaco in Brazil in lat. $17^{\circ} 30^{\prime} \mathrm{S}$. It was held by Dr. Schott (pp. 19, 27, map 4) that the track of this bottle probably lay near St. Helena. Fuller details of this interesting drift have been given on p. 63.

Data relating to Bottles thrown over in the vicinity of Ascension ( $7^{\circ} 56^{\prime}$ S. LAT.; $14^{\circ} 22^{\prime}$ W. LoNG.)

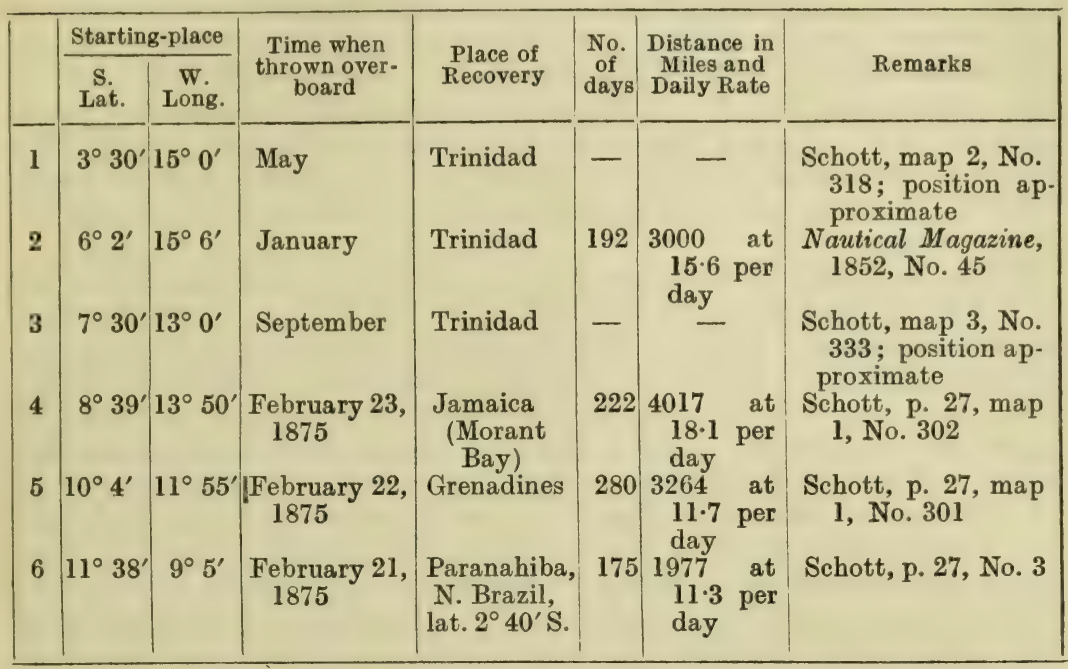

Note.-Nos. 6, 5, 4, were dropped over from the ship Schwan on three successive days.

Note 19 (p. 59).

\section{The Guinea Current.}

In the region between $2^{\circ} \mathrm{S}$. and $10^{\circ} \mathrm{N}$. lat. and $20^{\circ}$ and $32^{\circ} \mathrm{W}$. long., where the Guinea Current flows east between the North and Main Equatorial Currents, lies an area of conflicting streams, a subject which is discussed in detail by Dr. Schott (p. 17). A bottle thrown over in its centre in May would be cast up on the coasts of Africa; whilst if dropped over in October it would be carried to the West Indies. The effect of the shifting boundaries of these currents is well illustrated in the vicinity of St. Paul's Rocks in the south-west corner of this region. Here in certain months of the year it would be difficult to predict whether the bottle would drift to the east or to the west. A striking example is supplied by Schott in the case of two bottles thrown overboard together on February 24, 1893, in lat. $1^{\circ} 44^{\prime} \mathrm{N}$. and long. $27^{\circ} 16^{\prime}$ W. (pp. 10, 18, map 1). One was recovered on the coast of Sierra Leone on September 8 of the same year, and the other on the Nicaraguan coast on March 8 of the following year.

The Guinea Current must often carry back to the African coasts 
drift that it has captured from the two equatorial currents. This would be especially the case, as pointed out by Schott (p. 17), with the drift of the southern current. But the important feature is that the Guinea Current during the northern summer extends much farther west than in winter. During a portion of the year this current is restricted mainly to the eastern half of the Atlantic; but it may at other times extend to the vicinity of the South American and West Indian region and assume the rôle of a true counter-equatorial stream. The extension westward and the withdrawal eastward of this current greatly affects the drifting direction of bottles thrown overboard in the area above described. Schott carefully worked out this point, and from his results, elaborated on page 17 of his memoir, it appears that we have the real explanation why bottles dropped into the sea in this area at the same place in different seasons arrive in one case at the American and in another at the African side of the ocean.

Whilst the varying behaviour of the bottles as indicated by Schott would limit the extension and retreat of the Guinea Current within the meridians $22^{\circ}$ and $32^{\circ} \mathrm{W}$., the actual extension westward may be much greater. We learn from the Admiralty publication (Africa Pilot, Part I., 1907, p. 49), that its western limit can be traced at all seasons of the year as far as the 23rd meridian (W. long.), but that in the summer and autumn months an easterly current extends as far west as the 53rd meridian. "This is probably" (as the writer proceeds to remark) "an expansion of the Guinea Current proper, or a counter-equatorial current." Laughton (p. 225) is representative of those who treat the counter-equatorial current as a thing apart from the Guinea current. It may be that the difference in view is only concerned with a difference in names. The Admiralty view that the first is a summer and autumn extension of the second is directly stated in Captain Jackson's Winds and Currents (p. 26, 1904).

It is in its character as a counter-equatorial stream that the Guinea Current attracts the interest of the student of the trans-oceanic distribution of seeds in this part of the Atlantic. We are wont to consider that through the agencies of the two equatorial streams Africa figures only as the giver and the West Indian and tropical American region as the recipient in the process of distribution of seeds by currents in these warm latitudes. But here we have presented the possibility of a reversal of the operation, when Africa becomes the borrower from the New World. On account of the great predominance of the westerly drift currents in these seas the indications of the floating bottle would as a rule illustrate only the transference of drift from the African to the American side of the Atlantic. But occasionally the track of a bottle from the American to the African side breaks through this routine. Thus in Schott's first map there is the course laid down of a bottle (No. 425) which was recovered on the coast of Sierra Leone after being cast overboard in March about 270 miles N.E. of Cape St. Roque, and less than a hundred miles north of the island of Fernando Noronha, the approximate position being in about $2^{\circ} \mathrm{S}$. lat. and $32^{\circ} \mathrm{W}$. long. Its track 
has the appearance of lying athwart the stream of the South Equatorial Current; but since the 32nd meridian in March represents the westerly limit from which, according to Schott's tabulated results (p. 17), bottle-drift reaches the African coast, we have here evidently the result of the extended Guinea Current acting as a true counter-current across the breadth of the Atlantic. At such a time the counter-stream might readily capture some of the vegetable drift washed off the coasts of North Brazil.

There is thus a possibility that at certain seasons seeds may be transported from this part of the South American sea-border to the shores of Sierra Leone and Liberia. It is here that the South American and African continents make the nearest approach, only about 1550 miles separating Cape St. Roque from the nearest point of Africa. It is only a possibility, and, although the event may be of very rare occurrence, it cannot be ignored.

Note 20 (p. 72).

Bottle-drift from the South-east Bahama seas to the coast of Ireland and back.

The following two bottles performed between them the circuit of the North Atlantic, the track of the first being by the Straits of Florida and the Gulf Stream route, that of the second by the North African and North Equatorial Currents.

(a) Thrown over in April 1906, in the channel between the Turks Islands and the Haitian coast. Recovered 337 days afterwards on the west coast of Ireland (lat. $53^{\circ} 45^{\prime} \mathrm{N}$.), having covered 4140 miles at the minimum rate of $12 \cdot 3$ miles a day (see Note 13). The details are given under Bottle 59 in the U.S. chart of the North Atlantic for May 1909.

(b) Thrown over in January 1900, about 260 miles to the west of the south-west coast of Ireland in lat. $51^{\circ} 15^{\prime} \mathrm{N}$. and long. $17^{\circ}$ $16^{\prime} \mathrm{W}$. Recovered after 597 days on the Caicos Islands at the south-eastern end of the Bahamas, having covered 5100 miles at the minimum daily rate of 8.5 miles. The details are supplied in the U.S. chart of the North Atlantic for December 1908.

Note 21 (p. 85).

On some small-seeded West Indian littoral plants.

Brief reference may here first be made to the group of four smallseeded littoral West Indian plants, Sesuvium portulacastrum, Portulaca oleracea, Herpestis monniera, and Heliotropium curassavicum, that are generally distributed in the tropical and subtropical regions of the globe- the two first being characteristic of the sandy beach, the third of marshy ground, and the last often of saline mud around lagoons. In all cases the seeds possess little or no buoyancy, and doubtless much of the cosmopolitan range of each of these plants is due to the agency of the drifting log bearing the seeds in its crevices, 
to the unintentional assistance of aboriginal man in his long canoe voyages, and to birds. They came under my notice on almost every coast I visited in warm regions, whether insular or continental. To discuss the various interesting points raised by these plants would be to travel beyond the limits assigned to this work. Not the least important is the presence in some regions side by side with these cosmopolitan plants of peculiar species of the genus. Thus, both the Hawaiian and West Indian Islands have in each case peculiar species of Portulaca. That men and animals have been active factors in the dissemination of some of these plants in inland regions is very evident. Thus, Portulaca oleracea is not only a plant of the sandy beach, but it grows in waste ground away from the sea. There was a story told, I believe, by the late Sir Joseph Hooker, relating to a botanist, who, on landing on one of the uninhabited islands of the Southern Ocean that had never been explored, fell on the sand with his face in the midst of a patch of Portulaca oleracea.

The above list could be much extended if we added plants not quite so widely spread. Thus, to take the case of Corchorus hirsutus, a typical West Indian shore shrub, also found on the east coast of Africa and in Australia. Its seeds are about $1.5 \mathrm{~mm}$. in size, and the species owes its wide distribution over the warm regions of the globe doubtless to a variety of agencies human and otherwise. Then there are the salt-loving herbaceous plants that are widely distributed in the New World growing on the mud-flats bordering lagoons and coastal swamps, such as Salicornia ambigua and Batis maritima. Although, as is shown in my book on Plant Dispersal in the cases of other species of Salicornia and in that of Batis maritima, these plants are especially well fitted for dispersal by currents, since the seeds germinate in sea-water and the floating seedlings there thrive, it is obvious that considerations other than those concerning means of dispersal are here presented to us. Salicornia is a genus distributed over the greater part of the globe, and Batis, which holds only a single species, is restricted to the New World. Batis maritima has been recently introduced into the Hawaiian Islands, having been first found by Hillebrand in a small island off Honolulu in 1859 , and no doubt its introduction was due to human agency.

\section{Note 22 (p. 343).}

\section{The Azores and their African connections as illustrated by Sphagnum.}

One of the most useful features in Warnstorf's monograph on the $S$ phagnacea is a list of all the known species of Sphagnum grouped according to the floral regions. It often happens that the student of distribution has to make such a list for himself; but here he finds reference made easy; and the amount of time thus saved is very considerable. But the method has its disadvantages, since much explanatory material is needed to safeguard the student against pitfalls; and perhaps it would be wisest in the absence of such matter to employ such a list with caution when drawing general inferences. A case in point is represented in this work. At the end of the list 
of African species (p. 35) it is pointed out that the majority of them are endemic, the only exceptions being ten species that are there named. But unless the student goes through the whole list, there is nothing to indicate, what is actually the fact, that seven of these species are not known from the African continent at all, and only come into the list as components of the Sphagnum flora of the Azores, a group of islands placed here under Africa. All the seven species range widely over the globe, and their inclusion as African would thoroughly change the character of the Sphagnum flora of the continent, especially as concerning its external connections, Africa being almost a closed region as far as the Peat-mosses are concerned. With respect to Sphagnum, the Azores are plainly a part of the European region, there being no African affinity, and no North American connections except such as are also European.

\section{NoTE 23 (p. 38).}

\section{Pumice on the beaches of the Azores.}

Pumice is washed up in quantities on Azorean beaches, but doubtless it is almost all of local origin. On the north coast of San Miguel it is very abundant, being evidently brought down in the rainy season by streams from the inland districts. Pumice-tuffs often predominate in the interior, and as a result of their disintegration pumice is strewn over great areas of the surface. The pumice is evidently andesitic, being naturally darkish in colour but presenting a light-coloured, weathered exterior. The fragments are as a rule very buoyant when freshly removed from the tuffs, and no doubt would float for years. (In one of my experiments in the Solomon Islands, referred to in my book on the geology of that group, andesitic pumice pebbles originally gathered in the tow-net at sea remained afloat after two and three-quarter years.) In time, however, pumice lying exposed on the surface in wet localities loses its buoyancy. Thus I found that after being exposed for a long period on the scantily vegetated higher slopes of Pico da Vara in San Miguel, where the rainfall is great, the pumice fragments had become sodden and no longer floated. On the shores of Lake Furnas in the centre of the island they may be seen in a well-rounded state, due to attrition during prolonged flotation in its waters. In that state they are carried down by the effluent streams to the sea. It is therefore necessary to remember that pumice may begin its trans-oceanic voyage in a well-worn condition.

Note 24 (p. 377).

\section{Trailing growth of Anagallis tenella.}

A singular variation in growth was displayed in an experiment made in South Devon some years ago. The typical plants are usually described as possessing creeping stems a few inches long (three or four inches). However, in the spring of 1906 I noticed 
growing in a large pot containing a shrub some young plants of this species. I had been in the habit of mixing Sphagnum with soil for potting purposes, and evidently the plant had been introduced in this way in the previous autumn. As the soil-conditions were very much drier than those of the boggy ground in which the species normally grows, I resolved to note their effect on the young plants in question.

During the summer of 1906 they developed a trailing habit, the main stems, seven inches long with secondary leafy shoots two inches in length, hanging over the sides of the pot. Through the winter they remained in the same leafy state, and in the spring rapid growth took place, so that by July 1907 the main stems were seventeen inches in length (three inches in the pot and fourteen inches hanging over), the secondary shoots or branches being proportionately long. Flowering now occurred, and the pot draped all around with the hanging stems formed quite a pretty spectacle. It remained thus until the autumn, when I went abroad and the experiment ended. The experiment was repeated in November 1912, when I put some other plants in an ordinary pot of soil and kept them in the same conditions as before. After flowering in midsummer the plants began to trail over the sides of the pot, producing stems about six inches long. When in the Azores, I watched carefully on the moors for evidence of this trailing habit, but only found a tendency in this direction in the case of plants growing in drier conditions on the sides of banks.

The leaves in these experiments were much larger than with the typical growth, $7 \times 6 \mathrm{~mm}$. instead of $3 \times 2.5 \mathrm{~mm}$. The usual winter leaf of the normal plant is particularly small, 2 to $3 \mathrm{~mm}$.; whilst the summer leaf is as a rule markedly larger; but $\mathbf{I}$ found that this is only indirectly due to the season. In November of two different years I noticed that the typical small leaves were produced when the plant lay flat on the oozy mud or on a level patch of boggy ground, which would be usual in winter. In places, however, where the plants were creeping over loose-growing Sphagnum or clambering over stocks of Carices, under circumstances where the lower leafsurfaces were freely exposed to the air, the size of the leaf was increased to between 4 and $6 \mathrm{~mm}$.

The interesting point in these observations is that the plants in the first experiment assumed the habit of growth of Anagallis filiformis (Ch. and Schl.), where the stems attain a length of eight inches $(20 \mathrm{~cm}$.). This is a peculiar extra-tropical South American species growing in sandy and moist places in South Brazil (Primulaceo by Pax and Knuth, Pflanzenreich, 1905). Although at first regarded as a distinct species of the Tenella group of the genus, it is viewed in De Candolle's Prodromus as only a variety of Anagallis tenella; and it is noteworthy that the species just named is not known either from South or from North America. The essential differences are slight, and are chiefly concerned with the degree of woolliness of the filaments and with the extent of the adhesion in their lower part. The stamens of the flowers were especially examined only in the second experiment, and displayed the characters of those of $A$. 
tenella. In this species, as we learn from Pax and Knuth, the filaments are woolly along most of their length, and they unite to form a free tube one-third of their length. In $A$. filiformis the filaments are only woolly below their middle, and their cohesion concerns but a fourth or fifth of their length.

Should any botanist in South Brazil be kind enough to send me specimens of Anagallis filiformis both in flower and in mature seed, I could try the effect of growing the plant under the conditions of an English peat-bog.

\section{Note 25 (p. 76).}

Sabine's record of the drifting of casks of palm oil from the Gulf of Guinea to Hammerfest.

Sir Edward Sabine in one of the notes appended to his English edition of Humboldt's Kosmos (Vol. I., note 373, p. 454, 1846) gives particulars of a remarkable case of drift from the Gulf of Guinea to the vicinity of the North Cape, which naturally attracted the attention of Gumprecht, Fogh, Vibe, and others who have written on the subject. As evidence that portions of the cargoes of vessels wrecked on the coast of West Africa may reach Norway after making a double traverse of the Atlantic in the Main Equatorial Current to the West Indies and in the Gulf Stream to Europe, Sabine writes as follows: "Such an instance occurred when the Editor was at Hammerfest, near the North Cape of Europe, in 1823; casks of palm oil were thrown on shore belonging to a vessel which had been wrecked at Cape Lopez, on the African coast, near the Equator, under circumstances which made her loss the subject of discussion when the Editor was in that quarter of the globe, the year preceding his visit to Hammerfest." The matter is also mentioned by Lady Sabine in her translation of Humboldt's Ansichten der Natur (Vol. I., p. 161, 1849).

I have not found any fuller details of this wonderful drift, which is properly characterised by Gumprecht as the most interesting recorded fact, and by Fogh as sufficiently marvellous. These casks would have taken the course by the West Indies indicated by Sabine, and the only question arising in this respect is whether they reached the starting-place of the Gulf Stream in the Florida seas by way of the Caribbean Sea and the Gulf of Mexico, or in the Antillean Current skirting the northern and eastern shores of the Lesser Antilles. From the evidence given in Chapter III. the former course is most probable. The circumstance that not a single cask only but "casks" are stated to have been washed ashore at the same place, and apparently about the same time, after a drifting passage of from 10,000 to 11,000 miles, discloses the first point for criticism. For reasons given in Chapter III. it is highly improbable that casks could keep together during a double traverse of the ocean, for which a period of at least two years would be needed.

According to the tables given in Chapter III. the time occupied would be about twenty-six months by the Caribbean Sea route and about twenty-four months by the Antillean Stream route. Com- 
mander Campbell Hepworth's estimate for the first route, as quoted below, is at least thirty months. But Sabine's record would seem to suggest a period of only about a year, which involves an average drifting rate of from twenty-seven to thirty miles a day for the whole distance. Much depends, however, on the exact dates. If the interval between his visit to West Africa in 1822 and his sojourn at Hammerfest in $\mathbf{1 8 2 3}$ covered the period between the early part of one year and the latter part of the other year, the objection against the excessive drifting rate would be to some degree removed. There remains, however, the question of the identity of the casks.

In this difficulty I applied to Commander Campbell Hepworth, Marine Superintendent of the Meteorological Office, one of our leading authorities in matters connected with the Gulf Stream, and he very kindly gave me the following reply: "It is possible that casks of oil could be preserved long enough to drift to the north of Norway, but they would be so covered with barnacles, etc., that they would be unrecognisable. By a somewhat careful calculation I find that the drift would occupy at least 900 days, say, two and a half years." Then he proceeded to point out that the track would follow the course in the Equatorial Current via the Gulf of Mexico to the Strait of Florida, and subsequently northward and eastward to the Grand Banks, then through the Iceland-Faroe Channel to the north coast of Norway. I may add here that the possibility of this drift is increased by the behaviour of a bottle mentioned in the following note, which thrown into the sea close to the island of Ascension was recovered afloat off the coasts of Guernsey; but here a difficulty also arises, though it is concerned not with the identity of the drifting object, but with a possible confusion of dates, the genuineness of the actual drift being viewed as outside dispute.

\section{Note 26 (p. 76). \\ A bottle-drift from Ascension to Guernsey.}

Major Rennell in his work on the Currents of the Atlantic, and Commander Becher in the Nautical Magazine for 1852 and 1854, refer to a bottle which on October 15, 1820, was thrown overboard about two and a half leagues north-east of Ascension from the American vessel Lady Montague. It was picked up afloat off the western coasts of Guernsey on August 6, 1821, after an interval of 295 days. On these points both authors agree, and Rennell adds that notice was sent to the Admiralty. He rightly terms it " a remarkable instance," and assigns to it the route via the Caribbean Sea and by the Gulf Stream. But here we meet the same difficulty that was presented by Sabine's casks of palm oil referred to in the previous note. To accomplish this passage of some 9000 miles between these dates a drifting rate of about thirty miles a day is needed. In this connection it is possible that there has been some confusion in the dates. Rennell refers incidentally to a record of the Pique, as though there was another similar record; and whilst the starting-point given by him is in $7^{\circ} 55^{\prime} \mathrm{S}$. and $14^{\circ} 23^{\prime} \mathrm{W}$., the position assigned 
in the Nautical Magazine for 1852 is $7^{\circ} 7^{\prime} \mathrm{S}$. and $8^{\circ} 6^{\prime} \mathrm{W}$., which is quite inconsistent with the statement associated that the bottle was cast over two and a half leagues north-east of Ascension. It is unfortunate that, as with Sabine's remarkable case of drift, there is here the suspicion of a doubt, which in neither case, however, affects the possibility of the passage, though in the one it is concerned with the identity of the casks and in the other with the dates assigned for the start and recovery of the bottle.

\section{Note 27 (p. 38).}

\section{Bottle-drift on the Canary Islands.}

From what has been said in Chapters II. and III. it will be gathered that the Canary Group lies in the track of that portion of the seeddrift of the Gulf Stream which, after passing north of the Azores and approaching the European sea-border, is deflected south in the Portuguese or North African Current. Losing much of its materials on the shores of South-western Europe and on the coast of Morocco, the bulk of the residue traverses the Canaries, and continuing south turns westward near the latitude of the Cape Verde Group, finally reaching the West Indian region in the North Equatorial Current. All the records supplied by bottles and floats would therefore be expected to come from the north and north-west. The data to be now given indicate that this is actually the case, there being no records from the south. (The materials are supplied from the American charts, the Prince of Monaco's papers, Dr. Schott's monograph, the Nautical Magazine, etc.)

Of the twenty-eight bottle-drift records at my disposal, one came from the vicinity of Cape Sable (Nova Scotia), sixteen from the region between the Azores and the Banks of Newfoundland, one from off Cape Farewell (Greenland), and ten from the seas north of the Canaries, between the meridians of $13^{\circ}$ and $18^{\circ} \mathrm{W}$., and at distances ranging from 500 to 1200 miles north of the group $\left(37^{\circ}-49^{\circ} \mathrm{N}\right)$. Though there is no record of a bottle or float from West Indian waters, several of the floats dropped over by the Prince of Monaco between the Azores and the Banks of Newfoundland must have begun their drifting passage in the middle of the track pursued by West Indian seeds across the North Atlantic; and doubtless instances of stranding on the Canaries would have been forthcoming with more extensive data at one's disposal.

The daily rate of the drift from the North-west Atlantic to these islands is evidently small. Of 996 floats thrown over in 1887 by the Prince of Monaco between the Azores and the Great Bank of Newfoundland (including sixty-five from positions to the north of the Azores), 142 were recovered, and of these fourteen (10 per cent.) were found on the Canary Islands. The mean daily drift of the five recovered in the shortest time is placed by him at $5 \cdot 32$ miles. If we place the average distance traversed at about 2000 miles, about a year (376 days) would be covered in the passage. A period of only six months between the times of the start and recovery is 
implied in the Nautical Magazine for 1852 in the case of a bottle (No. 102) thrown over in November 1835 about forty miles south of Cape Sable (Nova Scotia), and picked up in May 1836 on the island of Fuerteventura (Canaries). The distance traversed would not be less than $\mathbf{3 6 0 0}$ miles, which gives a daily rate of about twenty miles, an estimate that is very excessive for the traverse of this part of the North Atlantic, and it is likely that there has been a printer's error here, as affecting the dates.

One of the most interesting of the records for the Canary Islands is given by Rennell in his work on the Currents of the Atlantic. When in command of H.M.S. Hekla in lat. $58^{\circ} 13^{\prime} \mathrm{N}$. and long. $46^{\circ} 55^{\prime}$ W., about 140 miles S.W. of Cape Farewell (Greenland), Captain Parry threw over a bottle, which rather over two years afterwards (June 16, 1819, to July 29, 1821) was recovered on Teneriffe. This is evidently the "enigmatical drift" (räthselhafte Trift) to which Dr. Schott, quoting the Physical Atlas of Berghaus (1837), alludes in his paper (p. 1). It does not, however, appear to be quite so mysterious when we reflect that four bottles thrown over by Captains Parry and Ross in Davis Strait, 1818 to 1821, between $59^{\circ}$ and $65^{\circ} 40^{\prime} \mathrm{N}$. lat., were found between eight and fourteen months afterwards floating off and stranded upon the coasts of Northwest Ireland, West Scotland, and the Outer Hebrides. All of them must have got into the main track of the Gulf Stream, and we have seen in the earlier chapters of this work that Gulf Stream drift may be stranded anywhere on the coasts of Europe between the North Cape of Norway and Morocco, and that no inconsiderable portion of it may be returned by the way of Madeira and the Canaries to the West Indies. If, therefore, drift can reach the Irish and Scottish coasts from Davis Strait, the passage of drift from Cape Farewell to Teneriffe would be quite probable (see Note 35).

Note 28 (p. 38).

\section{The bottle-drift of Madeira.}

All that has been said in the previous note of the Canary Islands might be expected to apply to the neighbouring islands of Madeira, which lies in the course of the same North African or Portuguese Current-a current representing the southerly deflection of the great North Atlantic easterly surface-currents that bear the Gulf Stream seed-drift to Europe. Like the larger islands of the Canaries, Madeira is ill-adapted for receiving and holding bottle-drift, and the records are scanty. But they are sufficient to show that we have here the same story of drift from the North-west Atlantic and from the seas in European latitudes to the north of the island, none coming from the south.

The Prince of Monaco gives six records for floats that were recovered in Madeira after being dropped overboard in 1885 and 1887 in the region between the Azores and the Banks of Newfoundland. In the American charts there is the record of a bottle (October 1908, No. 4) which reached Madeira from a position about 400 miles due 
north of the large islands of the Western Azores. With reference to bottles arriving from European latitudes to the north of Madeira, Schott gives a record (No. 24, map 2) and the American charts give another (March 1909, No. 98). Here the bottles reached the island after being cast over 300 to 360 miles N.N.E. The average daily rate for this part of the Atlantic would be about five miles. It is highly probable that West Indian drift after traversing the Atlantic in the Gulf Stream track is at times diverted to Madeira; but the records of bottle-drift at my disposal are too scanty to afford a direct indication of this fact.

Note 29 (p. 38).

Sargasso or Gulf weed in Azorean beach-drift.

The Sargasso weed is only represented by scattered fragments more or less incrusted with polyzoa. Gulf weed seems to be rarely carried eastward of the group except in this condition. Captain Ostboe of the fruit-steamer Fix, who had accomplished about eighty voyages between London and Hamburg and the Azores, told the writer that he had never seen living patches of Sargasso, such as are met with a few hundred miles to the south-west of the islands. Authorities vary somewhat in placing the north-east limit of the Sargasso Sea. All, however, place it to the southward and westward of the group, and if we regard the nearest approach as 250 or 300 miles south-west of Flores we shall probably be near the limit. It is possible that during south-west gales the living weed may reach the islands, but I found no fragment that did not indicate a prolonged flotation of months in the dead state. The south-east trend of the currents would under ordinary circumstances only permit its approach from the north-west far beyond the area where the living weed is found.

It would, indeed, appear probable that the fragments of dead Sargasso which reach the Azores have accompanied the drifting West Indian seeds in their circuitous passage from the Florida seas past Cape Hatteras, as described in Chapter III. Sargasso weed seems to possess a fugitive vitality outside its usual waters. Rennell in his work on the Currents of the Atlantic Ocean (p. 183) refers to the observations of Lieutenant Evans, who contrasts the great masses of living weed that were met with in the Gulf of Mexico with the old brown patches of the weed covered with "barnacles" observed in the Florida Stream.

Walker in his book on the Azores (p. 47) speaks of quantities of Sargasso weed being washed ashore at certain seasons of the year on Graciosa, the islanders employing it for fertilising the land. It is likely that this is not the true Sargasso, but another weed altogether. The people of Magdalena at the west end of Pico, give the name, as the present writer ascertained, to quite another sea-weed that was washed up in abundance during the heavy north-west gales that prevailed during his sojourn there in March. Like the Graciosa men they use it for enriching the soil. They are familiar with the 
true Sargasso, but they call it " Plante do Golfe" (Gulf weed). The other weed evidently grows around the coasts, and is torn off by the breakers in heavy weather. In this connection it may be noted that fragments of true Sargasso have been found on the coasts of Cornwall and on the Shetland beaches, probably in the dead state.

\section{Note 30 (p. 210).}

\section{Iguanas, snakes, and alligators, in the Turks Islands.}

It is probable, that iguanas, snakes, and alligators were all of them frequent in these islands before their occupation by white men. The iguanas have been exterminated on all but two or three of the islands. The snakes are now confined to a single cay. The alligators have disappeared, and as their presence would not have been welcome on such small islands they were doubtless effectually destroyed. There can be no difficulty in explaining the existence of snakes and alligators on these islands, since San Domingo lies only about a hundred miles distant from the southernmost cay.

Large snakes and crocodiles are known to have been transported alive across far broader tracts of sea. For instance, they have reached Keeling Atoll that lies 700 miles from land in the Indian Ocean. When on the atoll in $1888 \mathrm{I}$ was told of three or four living snakes and of a living crocodile that had been stranded there on drift-wood some years before. (See my paper on Keeling Atoll in the Journal of the Victoria Institute of London, 1889.) That this attempt on the part of nature to re-stock the atoll with snakes and crocodiles is always going on is evidenced by the remarks of Wood-Jones, who was on the Keeling Islands in $\mathbf{1 9 0 5}$. He refers to the preservation in the Governor's house of the skulls of two crocodiles that had been shot on the atoll after arriving in this fashion. Many snakes must have reached the islands since my visit, clinging as he says, to floating drift. "There are several instances" (he writes) "of large snakes having been killed in the atoll, and others have been picked up on the beach" (Coral and Atolls, 1910, p. 295).

There must be several records of this kind relating to the West Indian region. Purdy in The Columbian Navigator (1839, III., 31) makes the following interesting note: "Some years back a very large cedar came on shore at Sable or Sandy Bay (St. Vincent), bringing with it a large female boa constrictor, which took to the neighbouring wood, and when shot, some days after, was found to contain many young ones, nearly ready to escape; and which, but for the destruction of the old one, would have taken up their abode in the woods." I may add that large snakes of this description exist on the island of Tobago about 100 miles away; but it would seem most likely that it arrived at St. Vincent with Orinoco drift, and in that case the distance traversed in the swift equatorial current would have been about $\mathbf{3 0 0}$ miles.

The following notes are taken from my journal in the Turks Islands. Although the large iguanas evidently once existed on all the islands of this small group, they seem now (1911) to be principally, if not 
entirely, restricted to the uninhabited islands of Long Cay and Greater Sand Cay. In the last named they are particularly abundant, in spite of the fact that numbers are captured by fishing parties of the coloured natives from Salt Cay and Grand Turk that from time to time make a brief sojourn there. The fruits of Genipa clusiifolia (Seven-year Apple) are evidently appreciated by these reptiles; and it is remarked, when dealing with this plant, that the two islands now frequented by them are just those where the Seven-year Apple grows in greatest quantity. Reference has already been made (p. 277) to the allusion to the iguanas of the Turks Islands in the Annual Register of 1764 (Watkins). As a change from salt-pork, we are told that the flesh of these creatures was much prized by the early Bermudian salt-rakers. Iguanas formed a staple article of diet of Bahamians in Catesby's time, about 1725 (II., 64); and they are still appreciated by the coloured people of the Turks Islands. We brought back with us to Grand Turk from Greater Sand Cay a number of iguanas alive in a sack; and I learned that they are often transported to Grand Turk and Salt Cay from the islands in which they abound. Not improbably the Caribs did the same when carrying provisions for their voyages; and it is not unlikely that they intentionally stocked with these reptiles some of the isolated cays of the Bahamian seas which served as resting-places during their passages.

The existence of a large snake on Eastern Cay was reported to me by several persons familiar with that island; but it did not come under my notice during my two visits in February 1911. Alligators are not now known to exist in the group; but about two years before my stay there a dead alligator was found on a beach in Cotton Cay partially buried in the sand. The postmaster, Mr. Lea Smith, whose brother had made the discovery, informed me that it was probably washed ashore in a dead or dying condition. These reptiles would even now find congenial surroundings in the mangrove swamps of South Creek in Grand Turk; and it is more than probable that they originally infested these islands, having been exterminated by the inhabitants.

\section{Note 31 (p. 408). \\ Dracana draco (Dragon-tree).}

This interesting tree, which is confined to the Canaries, the Madeiras, and the Cape Verde Islands, though in the lasi two nearly or quite extinct, specially attracted my attention on Teneriffe, as I had been previously familiar with Draccena aurea, the peculiar Hawaiian species, which is the only representative of the genus in Polynesia. Of the forty species distributed over the warmer parts of the Old World, these two on account of their restricted range are amongst the first to draw the attention of the student of distribution.

Whilst still well represented in the Canaries, favouring, as Dr. Christ remarks, the steep sides of the rocky ravines and gorges as they descend to the coast, it seems to be almost extinct in Madeira. In fact. it is stated that Webb a couple of generations ago saw the 
last Madeiran plant. Yet Lowe in his Manual of the Madeiran flora (1857) includes it amongst the very rare indigenous plants. In the Cape Verde Islands it was recorded only from St. Antonio, but as a cultivated plant, by Schmidt in the middle of last century (Flora der Cap Verdischen Inseln, 1852). However, Hemsley in Science Progress for 1894 (Vol. II.) states that it is still said to exist here and there in the mountains of St. Antonio and St. Nicolas. But it is not named by Prof. Coutinho in the list of the plants of the islands in his Catalogus Herbarii Gorgonei Universitatis Olisiponensis, Lisbon, 1914-15. It may be added that although the tree is not a native of the Azores, it is to be occasionally observed in gardens as on Pico and on San Miguel.

In addition to the numerous solitary specimens of the Dragontree planted in and near towns on Teneriffe, I came upon it in 1906 growing wild on the Taganana coast near the north-east extremity of the island. Here in the company of the cactoid Euphorbia (E. canariensis) it grows on the faces of rocky declivities in inaccessible parts of the precipitous slopes of the Roque de las Animas, a pinnacle mountain rising 1400 or 1500 feet above the sea. Though growing singly, there were several trees scattered about on the mountain-side in situations suggestive of dispersal of the seeds by birds. Its station may be compared with that of the Hawaiian Draccena aurea, which is not uncommon in the open wooded districts up to 3000 feet, but grows in a variety of situations. Thus, I found it once in the brokendown caverns of an old lava-flow frequented by pigeons that doubtless brought the seeds.

Hillebrand gives no affinities for the Hawaiian species; but Sir Joseph Hooker has some very suggestive reflections on Draccena draco in one of the appendices of his book on Marocco and the Great Atlas, where the Canarian flora is discussed (pp. 410, 417). It has, he says, " only one near ally, $D$. ombet, which is confined to Abyssinia, Southern Arabia, and the intervening island of Socotra." He suggests the hypothesis that at a very remote period this Dracana, together with the tropical trees of Myrsineo, Laurinea, etc., that belong to the Canarian flora, flourished in the area included in North-west Africa and its adjacent islands, and that they have been expelled from the continent by altered conditions of climate. In this connection he also links with the Draccena the Sapotacece of Madeira and the Cape Verde Islands, plants that in the islands of the Pacific and elsewhere raise much the same issues. This explanation seems very probable as concerning Draccena draco, but it could not be applied to the Hawaiian plant.

Let us look for a moment at the modes of dispersal possessed by Dracænas generally. Though in the cases of the Canarian and Hawaiian species the seeds even after prolonged drying possess no buoyancy, being in this respect doubtless typical of the genus, the berries would readily attract birds. The seeds of Dracænas are indeed well fitted for withstanding a transport in a bird's stomach, the small embryo being protected by a very tough albumen. But whether they could be thus carried unharmed across the 3000 to 4000 miles of ocean that intervene between the eastern borders of Asia 
and the Hawaiian Islands is another matter. Yet in Hawaii, Draccena aurea shares this difficulty with several other trees, such as Sideroxylon (Sapotaceec) and Elococarpus, that are known in other localities to be locally dispersed by pigeons (Plant Dispersal, pp. 372-4, 377).

One point that should be remembered in connection with the survival of species of Dracana on islands is the tenacity of life displayed by $D$. draco in the Canaries. That the tree would make a vigorous effort to contest extinction is indicated not only by the manner of its growth, but also by its capacity of vegetative reproduction. Not only can it be raised from cuttings; but it seems highly probable that if the tree was greatly injured by the wind, so that it lay in fragments on the ground, it would sometimes be able to reproduce itself from the tops of the branches. An experiment by Mr. Bain in this direction is recorded in the ninth edition of the Encyclopadia Britannica (XII., 236). After the top of a Dracoena draco, which had been slowly separated from the stem, had been suspended some months in a bushy covering, it protruded roots, and subsequently established itself when lowered into the soil.

\section{NOTE 32 (p. 265).}

A comparison of the old and later charts of the Turks Islands.

Here are compared a French chart of 1753 and the British Admiralty chart mainly based on the survey of 1830 . The French chart, which is in the British Museum library, describes itself as "from a survey made in 1753 by the sloops L'Aigle and L'Emeraude by order of the French Governor of Hispaniola with improvements from observations made in 1770 in the Sir Edward Harvke, King's Schooner." It was published in 1794 by Laurie and Whittle, 53 Fleet Street, London; and is drawn on a scale of three inches to four miles. The Admiralty chart (No. 1441) is based on Captain Owen's survey of 1830 with additions to 1845 and large corrections in 1864-5 and 1898, the scale being much the same as in the French chart.

The names of the larger islands in the French chart are those in present use. Thus we have Grand Turk, Cotton Island, Salt Key, and Sand Key; but the last, which is now known by the inhabitants as Greater Sand Key, is there stated to be "sometimes called Foul Key or Seal Key." The names of the smaller islands are all different from those in the Admiralty chart which are those now employed in the group. Thus Long Key is there named Pelican's Island, Pear Key is Bird's Island, Eastern Key is Breeches Island, and Toney Rock to the south of Eastern Key is called The Centry. Gibb Key and Round Key are named The Twins. However, the small eastern islands are only rudely indicated in the French chart, and Penniston Key is omitted altogether - an evident error, since it could not be of recent origin.

For nautical surveys in those times and in those seas, this early French chart may be regarded as fairly complete. Three fixed positions were obtained by astronomical observation, the latitude and longitude for the south-west corner of Grand Turk, and the latitude 
for the middle of Salt Cay and the middle of Greater Sand Cay. The error in the longitude, as compared with the Admiralty chart, is about forty minutes on the minus side, and that of the latitude ranges from almost nothing to two miles. Except in the case of Grand Turk, the dimensions of the larger islands as given in both charts do not differ greatly-the length of Grand Turk in the French chart being three and three-quarter miles instead of nearly five and a half miles as in the later chart. Unfortunately the period for the valid comparison of the two charts is limited to only sixty years, namely, between 1770 and 1830 , since the additions are not discriminated in either case.

The soundings in the French chart, though far fewer than in the Admiralty chart, are fairly well distributed over the bank. The comparison, as far as it goes, indicates that the maximum depths over the bank were the same at the time of the French survey as they were during the English survey. But the depths were more uniform; and evidently the numerous shoals that now exist in different localities between the islands, as between Grand Turk and Cotton Cay, were not charted by the early surveyors. The limits of the bank are imperfectly determined in the French chart; but one or two areas lend themselves for comparison. All the area of the bank lying south and east of a line drawn from Greater Sand Cay through Salt and Cotton Cays to Pear Cay, and thence north-east to the edge of the bank, displays a uniform depth in the French chart of nine or ten fathoms. This is in a general sense the depth-condition exhibited in the Admiralty chart over the greater part of this area, except amongst the cays between Salt Cay and Toney Ruck. Here soundings of seven and eight fathoms prevail towards the edge of the bank, and further in amongst the cays numerous shoal patches covered by less than three fathoms of water exist, the prevailing intervening depths being about five fathoms.

Considerable changes seem also to have occurred in the area between Cotton Cay and Grand Turk. Here the sea is so beset with shoals and reefs that, as I know from my own experience, navigation at night is dangerous. In the French chart it is credited with a uniform depth of three and four fathoms, three in the northern half and four in the southern half of the area. In the Admiralty chart, although maximum depths of three fathoms in the northern third and of four and five fathoms in the southern two-thirds are indicated, numerous shoals, often with rocks awash, are also marked. Reefgrowth has evidently been active in these waters since the time of the French survey, and it is probable that Lesser Sand Cay, a conspicuous sandbank midway between Grand Turk and Cotton Cay, on which vegetation at times gains a hold, did not then exist.

With reference to the changes in the islands indicated by a comparison of the two charts, the most noticeable one is the filling up of a channel two feet deep, which in 1753-70 cut off the northern third of Greater Sand Cay. In Captain Owen's chart the island appears to consist of two parts connected by sandbanks that are covered at high-water. But it may be that this was its condition in 1898, when the last important additions were made. At the 
present time, as I was informed, the neck of sand south of Beacon Hill is sometimes breached by the seas during stormy weather. In 1911 the islet off the north-east side was separated by a narrow, shallow passage nearly exposed at low-water.

A puzzling feature in connection with Grand Turk is that the North Creek is represented in the Admiralty chart as cut off from the sea to the north by a tract of low land half a mile broad. This seems inexplicable. The present condition is well brought out in a map of the island made in 1902-4 by J. F. Osborn, Colonial Surveyor, where it is shown that the North Creek approaches within about 300 yards of the sea, with which it once communicated by a broad passage, 200 yards across, that is now more or less silted up.

In connection with Greater Sand Cay there is a note in the old French chart to the following effect: "Upon this Bluff (the southern end of the island) the French, after the late Peace, erected a Sea Mark, which they were soon after obliged to demolish." This may perhaps explain a reference to this island in the West India Pilot, Part III., p. 370, 1909, where it is stated that "the remains of some remarkably solid masonry on the cay are similar to those which may be seen at Cape Isabella on Santo Domingo-Haiti."

Note 33 (p. 361).

Plants collected by George Forster in Fayal (Azores) in 1775.

(Commentationes Societatis Regice Scientiarum Gottingensis, Vol. IX., 1787. The paper is entitled "Plantæ Atlanticæ ex insulis Madeiræ, St. Jacobi, Adscensionis, St. Helenæ, et Fayal reportatæ." The species are stated to be all Linnean. A indicates that the species has not since been recorded from Fayal but from other islands of the group. F indicates that it has since been found by Watson, Brown, and others on Fayal.)

F. Verbena officinalis.

F. Cyperus esculentus.

Cyperus compressus.

F. Milium lendigerum (= Gastridium lendigerum, B.).

F. Polycarpon tetraphyllum.

F. Scherærdia arvensis (= Sherardia arvensis).

Borago officinalis.

F. Physalis peruviana.

F. Solanum pseudo-capsicum.

Nerium oleander.

Gentiana centaurium ( = Erythræa ramosissima, Pers. I K). ${ }^{1}$

A. Erica scoparia. ${ }^{2}$

F. Reseda luteola.

1 It seems likely that Erythroe centaurium, Pers., is here meant. It is now common over the group, including Fayal, and was found by Hochstetter as far back as 1838.

- Trelease suggests that the true Erica scoparia, L., which was found on the island off Villa Franca (San Miguel) by Hochstetter, was merely a form of Erica azorica, the common Tree-Heath of the islands. This, however, appears unlikely, since Hochstetter himself differentiated the Azorean species. 
F. Mentha rotundifolia.

F. Mentha pulegium.

Malva mauritiana ? ${ }^{1}$

F. Spartium junceum.

F. Vicia sativa.

A. Ornithopus perpusillus.

F. Trifolium arvense.

F. Lotus angustissimus.

A. Hypericum perforatum.

F. Hypericum humifusum.

F. Crepis virens.

Hypocharis radiata (= Hypochœris radicata).$^{2}$

Carthamus tinctorius (Safflower).

F. Gnaphalium luteo-album.

F. Pteris aquilina.

F. Asplenium marinum.

Lycopodium plumosum.

These plants were collected during a stay of four or five days in July 1775, made by the Resolution under Captain Cook. Of the thirty species above named, three-fourths are included in Watson's catalogue. This proportion would be considerably increased if we dealt with the species of Gentiana, Malva, and Hypochoris, as indicated in the footnotes, and considered that the Safflower and the Oleander as cultivated plants would have been excluded by Watson altogether.

With the exception of the two ferns and the lycopod there is hardly a plant in this list that could be regarded as having been present in the Azores before the discovery of the group in the first half of the fifteenth century. Of the flowering plants two-thirds are weeds of cultivated and waste places, many of which are known to have been spread through man's agency over much of the world. Others, such as the species of Physalis, Solanum, and Spartium, as well as Cyperus esculentus, are stated by Watson and Trelease to have been introduced, or are labelled as weeds without comment, and most of them are well known to be plants, as in the first three cases, that have often been introduced by man, either intentionally or accidentally, in other parts of the world. The Safflower and the Oleander, as above indicated, are not included by Watson and Trelease in their lists of plants, either indigenous or introduced. They may be observed in the small cottage gardens and ornamental gardens of our own time.

The above list is useful as showing that many of the plants that do not belong to the Azorean flora were introduced long ago. Most of them, it is true, were observed by Hochstetter in 1838, but for the plants it concerns this list carries us sixty-three years further back. Within a year or two of each other, George Forster (1775) was

1 Malva nicaensis, All., collected by Watson and Godman only in Fayal, was in the first place named by the former $M$. rotundifolia.

${ }^{2}$ Possibly Hypochceris glabra, L., which much resembles $H$. radicata, L. (B. and H.), and has been since found on Fayal and other islands. 
collecting the weeds and Francis Masson (1777-8) was enriching the gardens at Kew with the indigenous trees and shrubs of these islands (Aiton's Hortus Kervensis, 1789). Yet if man's interest is more attracted by the second, the history of our race is intimately bound up with the first, and weeds offer from this standpoint almost virgin ground for the investigator.

\section{Note 34 .}

Observations on the medanos or moving sand-hills of the Ancon coast region in Peru. (General remarks on this subject will be found on p. 271).

The following observations were made in February 1894 in the Ancon district north of Callao. Broad, sandy, and almost barren plains extend inland from the shores of Ancon Bay for about three miles to the foot of the mountains, rising in that distance 200 to 300 feet, the sand on the plains being only a foot or two in depth. A sand-covered spur of the mountains descends to the coast on the south side of the Ancon plains, having an elevation opposite the town of $\mathbf{4 0 0}$ feet. Immediately south of the spur is a large sandy beach, the Playa Mayor, more than a mile in length, which was the starting-place of a line of medanos that at the time of my visit took an oblique north-easterly course before the prevailing south-west winds of four and a half to five miles to the base of the inland range of mountains. The whole of the region here concerned up to an elevation of 500 feet was only a sandy waste, where a tumble-weed of the genus Tillandsia alone found a home.

As typically displayed, these sand-hills are crescentic in form, twenty-five to thirty feet across, and six to ten feet high, the concavity being in front. That they are ever advancing was indicated by the way in which they lay astride the beaten tracks. I observed these medanos after they had reached in irregular order the top of the spur overlooking the Ancon plains. One was perched on the crest at an elevation of 200 feet above the beach, another on the crest at 300 feet, and a third at 360 feet. Before a light wind with a force of about three the sand was steadily moving across the crest, the heavier particles along the surface and the lighter blown through the air. In ten minutes, sand of the weight of 108 grains was blown into the mouth of a round tube, an inch in diameter, that had been placed on the surface. I felt a light rain of sand on my face as I sat watching, and when the wind freshened for a few moments my face was "peppered" with sand. All the sand of the surface was in motion on the crest, both on the medanos and in the spaces between them. I noticed that after the medanos had crossed the ridge they re-formed in an irregular fashion on the descending slopes, unless the descent was steep, when the sand formed a continuous slide. On reaching the plains, 200 to 350 feet below, the medanos resumed their typical shape and gathered into line, or rather into column, for the traverse of the plains. Arranged two or three irregularly abreast in a column about 100 paces in width, 
the medanos crossed the plains obliquely in the same north-easterly direction for about three miles to the foot of the mountains, ascending the lower slopes about 500 feet, and here the sandy area terminated. In their traverse of the plains this column of medanos crossed two hill ranges that rose 100 and 150 feet above the plains.

By careful measurements on three medanos I ascertained that in five days they had advanced about a foot, the prevailing winds being light and from the south-west. From time to time slides take place down the steep face of the concavity, the sand caking a little on the surface and forming layers, a half to an inch thick, that slide to the bottom. Impelled by fresh winds, the medanos may move yards daily, and when driven by violent winds, as we learn from Dr. von Tschudi, the medanos pass rapidly over the plains. Strewn over the ground all over the medano region is a much coarser sand that could be moved only by strong winds. It is arranged in wavelets about two feet apart and one to three inches high, and remains at rest when the lighter medano sand is moving briskly along.

Measurements of the Sand-grains in the Region of Medanos (moving Sand-dunes) in the Ancon Coast-district of Pertu.

\begin{tabular}{|c|c|c|c|c|}
\hline & $\begin{array}{l}\text { Finest } \\
\text { Material aver- } \\
\text { aging } \cdot 2 \mathrm{~mm} \text {. } \\
\text { in size }\end{array}$ & $\begin{array}{l}\text { Medium } \\
\text { Material a ver- } \\
\text { aging ' } 3 \mathrm{~mm} \text {. }\end{array}$ & $\begin{array}{l}\text { Coarse } \\
\text { Material aver- } \\
\text { aging } 5 \mathrm{~mm} \text {. }\end{array}$ & $\begin{array}{l}\text { Extra-coarse } \\
\text { Material aver- } \\
\text { aging 1-2 mm. }\end{array}$ \\
\hline $\begin{array}{l}\text { Sand blown through the } \\
\text { air a foot above the ground. }\end{array}$ & $95 \%$ & $5 \%$ & - & - \\
\hline $\begin{array}{l}\text { Sand blown along the } \\
\text { sarface of the ground. }\end{array}$ & $80 \%$ & $20 \%$ & - & - \\
\hline $\begin{array}{l}\text { Sand of a typical meda- } \\
\text { no four miles from the } \\
\text { starting-place above the } \\
\text { beach. }\end{array}$ & $55 \%$ & $44.5 \%$ & $0.5 \%$ & - \\
\hline $\begin{array}{l}\text { Sand of a typical meda- } \\
\text { no one mile from the } \\
\text { starting-place above the } \\
\text { beach. }\end{array}$ & $41 \%$ & $58 \%$ & $1.0 \%$ & - \\
\hline $\begin{array}{l}\text { Drift sand blown up the } \\
\text { hill-slopes } 30 \text { feet above } \\
\text { the beach just mentioned. }\end{array}$ & $11 \%$ & $69 \%$ & $20 \%$ & - \\
\hline $\begin{array}{l}\text { Sand from the wavelets } \\
\text { spread over the medano } \\
\text { plains. }\end{array}$ & - & - & - & $100 \%$ \\
\hline
\end{tabular}

Note.-The prevailing winds were light with an average force of three.

The sand is derived from the disintegration of andesitic rocks. It is composed in their order of frequency of grains of felspar, magnetite, semi-vitreous volcanic rocks, pyroxene, quartz, brown mica, horn- 
blende, etc., calcareous particles being either absent or very scanty. The magnetite mostly gathers among the finest materials, being there especially frequent in the sand blown along the ground and in the medanos that have travelled four miles from their starting-place, the proportion making up 25 or 30 per cent. of the total. It is also well represented amongst the finest materials of the sand blown through the air. The grains of magnetite are always smaller than those of the felspar. Thus in the case of the sand blown through the air the magnetite grains average $0.12 \mathrm{~mm}$. in size and the felspar grains as much as $0.23 \mathrm{~mm}$. The beach sand from between the tidemarks has the same composition as the sand of the medanos and of the plains.

It is interesting to notice how the fine materials are appropriated by the medano as it proceeds inland from the coast. In the beach sand blown up the hill-slopes, but below the place where the first medano shapes itself, there is only 11 per cent. of fine materials. When the medanos have travelled a mile inland the proportion is about 40 per cent., and when they have extended four miles from the starting-place it is $\mathbf{5 5}$ per cent. Except when composed of softer calcareous materials, as in the case of the æolian deposits of the Bahamas, "the ordinary drifted sands of seaside dunes show little rounding " (see Grenville Cole's Practical Geology, 1898, p. 189). This is especially true of the dunes or medanos of the Ancon district. The sand-grains of the medanos four miles from the beach were most affected by attrition; but even they could only be described as sub-rounded. The sand-grains of the medanos a mile from the starting-place and the sand blown through the air were still less rounded, and could be only termed sub-angular. The extra-coarse sand of the wavelets or ripplets spread over the surface of the medano plains, however, displayed the effects of attrition in a marked degree, the angles of the grains being well rounded.

\section{Note 35 (pp. 55, 484).}

\section{Bottle-drift in high latitudes of the North Atlantic.}

The tracks are given in the American charts for several bottles thrown into the sea between Newfoundland and Greenland which were cast up on the coasts of Ireland, Scotland, and Norway, reaching even to the North Cape, the velocity of the swiftest being eight to nine miles a day. One, however, dropped over about 100 miles south-east of Cape Race, was recovered on the south coast of Iceland sixty-seven days afterwards, the distance of 1950 miles having been accomplished at a minimum daily rate of twenty-nine miles (see No. 95 in the U.S. Pilot Chart of the North Atlantic for November 1908). The most northerly traverse of the North Atlantic that is illustrated in the American bottle-drift charts is one marked 109 in the U.S. chart just named. Here a bottle drifted from a position about 300 miles south-east of Cape Farewell to the North Cape of Norway. However, through a printer's error, the daily rate is given as $34 \cdot 6$ miles instead of $3 \cdot 46$ miles. But bottle-drift from off the 
southern end of Greenland is just as likely to be carried south in its traverse of the Atlantic. Rennell mentions a bottle that was recovered on Teneriffe rather over two years after it had been cast over from H.M.S. Hekla (Captain Parry) on June 16, 1819, in a position about $\mathbf{1 4 0}$ miles south-west of Cape Farewell. This is evidently the "highly remarkable and even enigmatical drift" to which Dr. Schott refers on the first page of his memoir, though he here quotes from the Physical Atlas of Berghaus. However, in the light of facts to be now given the track of this bottle loses a little of its remarkable character.

Rennell gives the records of four bottles thrown over in Davis Strait in 1818 and 1821 by Captains Parry and Ross, the northernmost in lat. $65^{\circ} 40^{\prime}$. After periods of from eight to fourteen months they were recovered on the coast of Donegal (two cases), the west coast of Scotland, and the Hebrides. Two of them dropped over within two days of each other and about three degrees of latitude apart $\left(62^{\circ} 5^{\prime}\right.$ and $\left.59^{\circ} 8^{\prime}\right)$ were found afloat within a fortnight of each other, thirteen and a half and fourteen months afterwards, off the Donegal coast and off the Isle of Staffa (W. Scotland).

\section{Note 36 (p. 388).}

\section{The wells of Pico in the Azores.}

Just as on San Miguel and other large islands of the group, there are no permanent rivers and but few surface streams on Pico; but as the frequent occurrence of the local name of "Ribiera" indicates, there are numbers of torrent-beds and watercourses, which, although they carry off the water after heavy rains, are dry during most of the year. One of the sights of the great cone of Pico is the deep gorge of the Ribiera Grande, which has been scooped out of the precipitous mountain-side to the east of San Mattheus, the slopes rising up from the coast to a height of 3000 feet within half a mile. It is probable that at the time of their discovery, when the islands of the Azores were densely wooded, the streams were more permanent in their character. Generally speaking, on the island of Pico at the present day the only surface water is the standing water of the upland swamps and of the mountain lakes and ponds. I did not come upon any thermal springs on this island, nor does there appear to be any stream of a permanent character partially fed by hot springs, such as we find in the case of a stream draining the Furnas Valley in San Miguel, which empties into the sea at the village of Ribiera Quente.

The condition of things on the island of Pico is probably to some degree typical of the other large islands of the group, excepting perhaps San Jorge. There are no springs on the great mountain, and apparently but few in the eastern part of the island. Yet fresh water oozes into the sea all around the coasts. Those of the peasants of the coast villages, who are too poor to build a covered rain-tank of masonry, obtain their water supply from wells sunk in the rubble of large and small blocks of lava immediately behind the beach. 
Probably most of the water issues at the coast between the tidemarks, and it is here that women living far from a well often wash their linen.

The seaward soakage of the underground waters is a frequent phenomenon around the shores of lofty volcanic islands, or of high volcanoes rising like that of Etna near the sea. Often the water gathers in subterranean streams which emerge at the coast and in the depths beyond, as I have described in the case of Hawaii and Etna in the first volume of my Observations of a Naturalist in the Pacific (p. 38). In Pico, as above observed, it displays itself chiefly in the oozing of fresh-water between the tide-levels on the beaches.

At times the seaward soakage of underground waters gives rise to a number of subterranean streams of fresh-water that well up in the sea off the coasts of large islands. Mr. Samler Brown in his Guide to Madeira and the Canary Islands $(1905, e, 22 ; i, 2)$ refers to the streams of fresh-water that rise up in the sea near the coasts of those islands. In La Palma, for instance, much of the rainfall on the wooded slopes of the mountains "filters through into the sea at short distances from the coast-line." My readers will recall Humboldt's reference to the occurrence, a few miles off the Gulf of Xagua on the south coast of Cuba, of very extensive fresh-water springs, from which ships can water (Lady Sabine's translation of Ansichten der Natur, I., 161). But submarine springs may exist along continental coasts, even where there is no great elevation. Thus Dr. Scharff in his book on The Origin of Life in America (1911, p. 169) quotes Prof. Shaler to the effect that along the coasts of Florida there arise from beneath the sea a number of submarine springs.

But to return to the subject of the coast wells of Pico, it may be observed that the water is always a little brackish. As with those of San Mattheus, Magdalena, Caes-o-Pico, Praynha do Norte, and other places at the sea-border, the wells have sometimes to be sunk to a depth of fifteen to twenty feet, the level of the water being that of the sea. But their water is in summer much cooler than that of the sea. At 5 p.m. on July 28 , when the temperature of the well-water at Praynha do Norte was $60^{\circ} \mathrm{Fahr}$., that of the sea was $72 \cdot 5^{\circ}$. Permanent springs, as I have said, are only to be found off the great mountain, and they are few in number. However, the coast village of Santo Amaro is supplied with water by a spring which issues on the mountain slopes about 2000 feet above the sea, its temperature at 3 p.m. on August 3 being $54^{\circ}$ Fahr., or about ten degrees cooler than the mean temperature of the air in the shade at that altitude.

A similar spring is said to exist far up the mountain-side behind Caes-o-Pico; but it is not utilised by the villagers. At the head of a gully, some 500 or 600 feet above this place, there is a watersource which has been protected by masonry; but it seems to be only used for washing clothes. Here the water is derived from the drippings of cliff-faces on either side, the line of underground soakage being cut across by the gully, a circumstance which shows that in this eastern part of the island there is a large amount of fresh-water available. But lack of funds is the great obstacle, though a little enterprise, like that displayed by the inhabitants of Santo Amaro, 
might provide several other of the coast villages with good water from the mountains. Dripping-cliffs, in particular, ought to be fairly common; and, since they afford a substitute for permanent springs, they might readily be utilised for this purpose.

\section{Note 37 (p. 358).}

\section{Uncinia.}

It has been shown in Chapter XVI. that a few species of Carex have probably crossed the Southern Ocean between the southern portion of South America and the Australian and New Zealand region. Considerable light is thrown on the possibility of this oceanic traverse by the distribution in high southern latitudes of another genus of the Caricoidece, namely, Uncinia, which is essentially a genus of these latitudes, since four-fifths of its species are there confined.

The twenty-four species recognised in Kükenthal's monograph on the Caricoidece (Pflanzenreich, 1909) are chiefly divided between the two widely sundered regions centering in the southern extreme of South America and in New Zealand. The two regions, however, are connected by a single species (U. macrolepis) found both in the southern island of New Zealand and in Fuegia; and they are indirectly linked together by the association in the intervening islands of Amsterdam and St. Paul of a New Zealand species, U. compacta, and a Fuegian species, U. brevicaulis (see Hemsley's Chall. Bot., III., 159, 267).

The species are about equally divided between the two regions, South America holding twelve and New Zealand thirteen species. Of the South American species six are confined to the southern portion extending from South Chile to Fuegia; two are spread over much of the continent and reach in one case Central America; one (U. jamaicensis) is confined to the tropical and subtropical portions of South America and to Central America and the West Indies, occurring often at high altitudes; one is peculiar to Juan Fernandez; and the last two are Antarctic species, extending in one case to the islands of Tristan da Cunha, St. Paul, and Amsterdam, and in the other to the South Island of New Zealand. Of the New Zealand species seven are restricted to that region and to the neighbouring small islands (Stewart, Antipodes, Chatham, etc.); and six extend to regions outside, namely, four to Australia and Tasmania, one to Hawaii, and one to Antarctic South America. This does not exhaust the limits of dispersal from the New Zealand centre, since among the species it has lent to Australia one has reached New Guinea and another Amsterdam and Kerguelen Islands.

Two significant facts of distribution are here disclosed. In the first place, as regards the New Zealand group of plants Australia has no species of its own, every species occurring outside New Zealand and the small islands near being a New Zealand species, even in such distant localities as New Guinea and Hawaii. In the same way the southern part of South America is still the abode of ten out of the 
twelve species found in that continent. The other fact is the absence of Uncinia from South Africa and from the African continent generally. One might have looked for a representative on Table Mountain of a genus that has found a home on the isolated oceanic islands of Tristan da Cunha and St. Paul, etc., on either side of the continent.

Yet the absence of Uncinia from South Africa is quite consistent with the usual behaviour of plants common to the southern part of South America and the Australian and New Zealand region. Hemsley gives a long list of plants (Chall. Bot., I., 52) illustrating the relationship of these two regions. A large number of flowering plants belonging to about ninety-three genera are included, the grasses being excluded. The mode of presentation does not admit of one's giving a precise numerical value to the results; but it would appear that not over one-tenth of the species common to the South American and to the Australian and New Zealand regions occur in Africa. The indications of the cyperaceous species in this list alone are very suggestive. Out of a dozen species, belonging to six genera, all either occur both in South America (mainly in the south) and in the Australian and New Zealand region, or they are represented there by closely related forms; but only two of them are also found in South Africa. When dealing with Carex in Chapter XVI., it was pointed out that of twenty-one Australasian species found outside that region six occur in South America and only one in South Africa.

It has already been remarked that the South American and New Zealand centres of Uncinia are still in touch with each other, since they hold a species in common and since species from the two centres meet in the intervening islands. The point we are now concerned with is the direction in which the inter-communication takes place; in other words, the direction in which species of Uncinia would be likely to travel around high southern latitudes. The latitudes involved correspond approximately with the zone of the Westerly Winds, the belt of the Roaring Forties. Those who, like the writer, have performed the voyage before the strong Westerlies from the Cape to Australia in a sailing vessel and have watched the sea-birds following in the ship's wake for weeks together will be in a position to appreciate the influences at present determining the part taken by the bird in distributing seeds in these latitudes. These sea-birds travel around the globe in the belt of the Westerlies, and a case has been recorded where a Cape Pigeon (Daption capensis), marked by a ribbon around its neck, followed a ship for 5000 miles on its way home from Australia by Cape Horn (Coppinger's Cruise of the Alert, p. 18). Ever since 1888, when a letter of mine appeared in Nature (May 10) concerning this matter, I have held the view that South America has been a funnel from the Fuegian tip of which plants have through the ages been detached and carried ever eastward through the agencies of the westerly winds, the west-wind driftcurrent, and sea-birds. The efficacy of the sea-bird in these latitudes was brought home to me a few years before that date, when in 1881 I found a seed, apparently sound, in the stomach of a Cape Pigeon caught by one of my mess-mates 550 miles east of Tristan da Cunha (Nature, XXVI., 12; Chall. Bot., I., 45; IV., 313). 
It is to the sea-bird that we are obliged to appeal in the case of Uncinia, the hooked fruits of which, as is observed below, are well fitted for attachment to a bird's plumage. Yet Sir Joseph Hooker in the case of the flora of Kerguelen, whilst admitting that the winds which blow, as he remarks, from Fuegia to Kerguelen almost throughout the year, are the most powerful natural agents for distributing cryptogamic spores, rejects the agency of the bird. He finds it difficult to imagine how seeds could adhere to birds in their flight of 4000 miles across a rough ocean, which is the traverse here implied (Phil. Trans. Roy. Soc., Vol. 168, 1879; see also Hemsley in Chall. Bot., I., 51). Yet the later observations of Moseley, Kidder, and others well illustrate how from their nesting habits in the islands of the Southern Ocean, such as Kerguelen, Tristan da Cunha, etc., albatrosses, petrels, and other sea-birds would be very likely to transport seeds in their plumage, a subject discussed in my work on Plant Dispersal (p. 276, etc.). This would certainly apply to the case of Accena, one of the most typical genera of these regions, the fruits of which, as Moseley observes, stick like burrs to feathers.

Observation has shown that the hooked fruits of Uncinia may be as firmly entangled in a bird's plumage as those of Accena. Morris, in a paper in Nature (Dec. 16, 1886) on the dispersal of plants by birds, takes the fruits of Uncinia jamaicensis to illustrate dispersal in a bird's feathers. This species, which has a wide distribution in Central America and in tropical and subtropical South America, grows on the highlands of Jamaica at altitudes of 5000 to 6000 feet. Migratory birds, as he states, on their way north and south between North and South America rest on these Jamaican uplands, and so exhausted are they that they have been easily caught with the hands. In two cases he found small migratory birds on these mountains, which were so completely entangled in the hooks of Uncinias that they were unable to escape. Large birds, he says, would break away; but not without carrying off in their plumage a number of the fruits. The exserted hooked "rachilla" of the fruit is, he says, excellently adapted for catching firmly in plumage.

Assuming that birds have thus distributed Uncinias over the Southern Ocean, there can be no hesitation in considering that their flight must nearly always have been east before the westerly winds. Under these circumstances one could scarcely look for any very definite arrangement of these and other plants concerned, since Fuegia would be ever supplying them to New Zealand and the intervening islands, and New Zealand would be ever returning them to Fuegia. Yet such an arrangement can be to a small extent detected. Hemsley, though he does not accept the implication, writes that " numerically there is a preponderance of Fuegian forms represented in Kerguelen and the other islands under consideration (Marion, Crozets, Heard), as opposed to what may be termed New Zealand forms" (Chall. Bot., III., 253). The endemic species of these islands, he adds, "exhibit, perhaps, a closer affinity with Fuegian than with New Zealand species." Yet, notwithstanding, he considers that "with all the facts before us there does not seem to be a 
special affinity between the floras of Kerguelen, etc., and Fuegia, as distinguished from the flora of the zone generally.'

Perhaps fresh light may be cast on this matter if we regard the story of the differentiation of the genus within itself as indicated in Kükenthal's pages. Of the two subgenera recognised by Clarke and himself, Pseudo-Carex and Eu-Uncinia, the first holds only a single species, Uncinia kingii, which is confined to Fuegia and from its near approach to Carex supplies a connecting link between the two genera (Kükenthal, pp. 25, 66, 109; Hemsley, Chall. Bot., I., 31). Carex microglochin, which belongs according to Kükenthal (pp. 11, 26) to Primocarex, the oldest of the four subgenera of Carex, is the species to which it is most closely related. It is an arctic-alpine plant of Eurasia and North America, and is associated with Uncinia kingii in Fuegia. The second subgenus, Eu-Uncinia, holds the other twentythree species. It was subdivided by Clarke, and his opinion is adopted by Kükenthal, into two sections, Platyandrce and Stenandroe, the distribution of which offers the critical point in this discussion. The first holds six species, all of which are South American, one of them reaching the islands of Tristan da Cunha, Amsterdam, and St. Paul. The second section, Stenandrae, holds seventeen species, or about three-fourths of the species of the genus. Four of them are exclusively South American (South Chile and Fuegia). One (U. macrolepis) is common to Fuegia and the South Island of New Zealand. The rest belong to the New Zealand centre, seven being endemic, the others spreading to Tasmania, Australia, Amsterdam, and Kerguelen, and even to New Guinea and Hawaii.

The situation thus revealed is this. Although the species of the genus are about equally shared between the two centres, South America and New Zealand, South America holds both subgenera and both the sections of the subgenus, Eu-Uncinia. On the other hand, the New Zealand centre holds only one subgenus and only one of its two sections, namely, Stenandrue; but it claims the majority of its species. The upshot of the discussion is that whilst South America was the original differentiating ground of the genus, New Zealand has been the principal centre of "formative power" in later times, the single section, which the last-named region holds, being the most vigorous and productive of the Uncinias. Some of the general arguments that would assign to Eu-Carex, the subgenus comprising two-thirds of the known species of Carex (793 in all), the last place in the development-scale of the genus (see Kükenthal, pp. 11, 25, 26), could be applied to the section Stenandrce in the case of Uncinia, both of them holding the bulk of the species and displaying in their development of new forms as well as in their great range the highest degree of virility.

Note 38 (p. 450).

The fruiting behaviour of Atriplex portulacoides, L., at Salcombe, South Devon.

This plant came under my notice only in one locality in the Salcombe district, namely, on the shore of Blanksmill Creek, where it 
formed in 1906 a single patch a few feet across. The following notes were made on it in that year.

Jan. 17, in full leaf; some stems bearing immature fruits. June $\mathbf{3 0 \text { , }}$ beginning to flower. Aug. 31, flowering copiously, also in early fruit. Oct. 5, foliage still abundant; in seed; but the nuts are soft and whitish and the albumen is creamy and not set, whilst the fully formed dark-green embryo seems almost escaping through the delicate membranous fruit-covering. Nov. 9, abundant healthy green foliage and abundant green fruit; the fruit still soft, but the green embryo has grown at the expense of the creamy albumen, though still within the fruit-coverings.

Evidently the plant this year has been on the eve of vivipary. The albumen never hardened and there was no rest period. Since the plant appears to be most at home in the warmer climes of the Mediterranean, it would almost seem that in the northern part of its range it may endeavour to counteract the effects of colder climatic conditions by dispensing with the rest period of the seed. From this point of view the vivipary of the mangroves in the tropics might be regarded as due to their endeavour to accommodate themselves to climatic conditions cooler than those that once prevailed in those regions.

\section{Note 39 (Chapter XI).}

\section{On recent obsercations in the Western Bahamas by Dr. Vaughan.}

The writer is deeply indebted to Dr. Vaughan of the U.S. Geological Survey for his great courtesy in sending him some of his papers on the Bahamas and in replying to his numerous queries on the subject; but unfortunately his letter came too late to enable its contents to be utilised in Chapter XI, which is concerned with the geology of the Turks Islands. The remarks below refer to points raised in that chapter under the pages indicated.

The oolitic character of the grains of the coolian formation or calcareous sandstone of the Bahamas (p. 260). - In the first place, it should be noted that L. Agassiz, in his paper on the Salt Key Bank, long since remarked the occurrence of oolitic grains in the fine sand of the bank, which is covered by four or five fathoms of water. Dr. Vaughan has watched the growth of oolitic grains in the shoal-water muds of the Bahamian seas, muds that "only need induration to become oolitic limestones." The precipitation of the carbonate of lime is attributed to denitrifying bacteria, which, as shown by Drew and Kellerman, exist in enormous quantities in the surface ooze of the Florida and Bahamian shoals. These oolitic grains ultimately form the beaches and the dunes and the more or less compacted æolian rock.

Comparison of the colian formation of the Bahamas and the Bermudas (p. 273).-According to Dr. Vaughan, although both are calcareous, the mechanical conditions of the Bermudian and Bahamian formations are very different. Whilst in the first case the deposits are composed of broken-up shells, tests of foraminifera, and occasional coral fragments, in the second case through chemical 
precipitation in sea-water these materials have formed "nuclei" for the development of oolitic grains.

The foundations of the aolian rock or wind-blown oolite of the Bahamas (p. 262). - In reply to a question put by the writer, Dr. Vaughan states that in the western islands the wind-blown oolite rests on a foundation of marine oolite, and that in no instance did he find "really coral reef rock interbedded with the oolitic rocks." He adds that " after the (submarine) formation of the oolite, probably during a period of uplift, considerable quantities of material were blown up by the wind and formed the dunes." These windblown materials gave rise to the more or less compacted rolian rocks; and it would seem to the present writer that a critical point of first importance would lie in the determination by borings and other methods of the relation of the level of the base of the windblown rock with reference to that of the sea. According to his view the junction of the wind-blown with the marine oolite would be found at or about the present sea-level; but if, as held by $\mathbf{A}$. Agassiz, there has been a subsidence of 300 feet since the formation of the islands, it would be found far below that level.

The non-existence in South Florida of the calcareous aeolian oolite of the Bahamas (p. 273).- It is a very significant fact that, as Dr. Vaughan has informed the writer, this formation does not exist in South Florida. Yet the islands of the neighbouring Bahamas from end to end of the great archipelago are composed of this formation. There are extensive areas underlain by the marine oolite in South Florida, but no wind-blown oolite is known. The sands strewn over the interior of the peninsula, as well as those of the coast dunes, are mainly siliceous.

The ocean-holes of the Bahama Banks (p. 258).-Dr. Vaughan tells me that A. Agassiz was undoubtedly correct in his inference of a considerable subsidence, which was based on the occurrence of these holes in the banks. With much diffidence I would suggest that their preservation during the ages that have since elapsed presents a difficulty, since it is not easy to perceive why they were not obliterated during the great destruction of the land-surface that, according to Agassiz, accompanied the submergence and by the accumulation of débris and the growth of marine organisms in later times. These ocean-holes are described as representing blowholes, sinks, caverns, cañons, etc., in the original land-surface. Some of the smaller holes may have vertical sides with a sheer drop of ten fathoms and more, and one might imagine that the same submarine influences that produced them are still preserving their patency.

A suggestion of the present writer for the comparison of the behaviour of sand-dunes of different mineral composition.- It may be that we cannot strictly compare the movement of sand in dunes formed of calcareous oolitic grains with that of sand in dunes derived from the disintegration of volcanic rocks, such as has been described in Note 34 of this Appendix on the moving sand-hills of the Ancon plains of Peru. A comparison of the two kinds of moving sandhills on the lines adopted in that note may be suggested. In the 
case of calcareous sand-dunes formed of oolitic grains, as in the Bahamas, we might obtain some interesting results, and it may be that under present conditions the behaviour of the calcareous sandhills of the Bahamas would be very different from that of the medanos or moving sand-hills formed of volcanic rocks in Peru. In the case of the Bahama deposits we ought to know in what way the oolitic grains of the æolian rock differ as regards form and external markings from those of the beach sand and from those of the mud on the submerged banks. The effects of attrition ought to be very pronounced in the case of the grains of the wind-blown rock. Much depends on the answer to the query whether such effects of attrition display themselves; and in this and in other connections concerned with these æolian rocks of the Bahamas we must be prepared for surprises.

(In addition to the papers of Dr. Vaughan, named at the end of Chapter XI, may be mentioned a very interesting note comparing the formation of the Floridian and Bahamian oolites in the Journal of the Washington Academy of Sciences, May 19, 1913. The origin of these oolites is also discussed in papers of more recent date on the Floridian Plateau and on shoal-water samples from Murray Island (Australia), the Bahamas, and Florida, in publications 133 and 213 of the Carnegie Institution of Washington, as well as in a paper on the geology of the Bahamas and Southern Florida in the Yearbook of the same institution for 1914.) 


\section{GENERAL INDEX}

NoтR.-Several subjects are worked up in this index, which, on account of the plan of the book, could not be treated connectedly in the text; for example, the sources of bottle-drift thrown upon the Irish coast and on the Carribean shores of Central America.

Except where several references of importance are given, the figures in largen type indicate the pages where the subject is treated at length, or where the most important points are discussed.

ACAOIA, 167, 168, 171; A. acuifera, 287; A. farnesiana, 166, 287

Acæna, 294, 500

Acer, 326

Acrocomia, 3, 4, 11, 86, 91, 160

Acrostichum squamosum, $370,375,380$, 425

Adder-stones, name of stranded West Indian seeds, 21, 23

Adenocarpus viscosus, 408

Eolian rocks, in the Turks Islands and Bahamas generally, 254-276, 452, 502504

Africa, Carex and Sphagnum floras, 332$358,341-347$, 356; current-connections, 294-312, 300-305, 311, 475477, 478; Uncinia, 499

West; comparison of littoral flora with that of the West Indies, 83-95, 141, 194, 207; bottle-drift, 49-53, 59, $67-71,76-81,475-477$. See Sierra Leone.

East; bottle-drift, 50, 300-305

North; bottle-drift on coast of Morocco, 51, 52, 53

South; bottle-drift, 63,77

Agassiz, A.; on the formation of the Bahamas, 254-261, 269, 274-276, 503; on the early maps of the group, 264, 275

L.; on the Salt Key Bank, 261, 274, 276, 502

Agrostis castellana, 370, 372, 386

Agua do Pao, a mountain in San Miguel, Azores, 438

Aiton, 361, 493

Alacran Shoals, plants, 187, 188, 201, 231, 240,250

Albatross; in seed-distribution, 500

Alcyonarian sea-shrubs, in the Scilly Islands and Norway, 21
Alder, name of Conocarpus erectus in the West Indies, 201

Aleurites moluccana, 160

Algaroba, 102

Algarve (Portugal), introduction of Myrica faya, 434

Allen, E. J., Physaliæ on English beaches, 29

J. A., on distribution, 325

Alligators, 102, 105, 107, 175; drifted to the Turks Islands, 487. See Crocodiles.

"Alma Cummings" (derelict), its track, $69,72,472$

Alnus maritimum (Conocarpus erectus), 201

Alternanthera, 85

Amarantaceæ, 85

Amazon; seed-drift, 7, 8, 13, 19, 39, 74, 75, 81, 128, 129, 142; bottle-drift from off the estuary, $62,67,70,71,74,75,80$, 444,445 ; plants chiefly of the estuary, $7,128,131,133,135,141,160,212$

Ambrosia crithmifolia (A. hispida), 87, $172,279-283,288,291,451,452$

America, Central; recipient of seed-drift by the North and Main Equatorial currents, $8,72,73$; seed-drift on opposite coasts, 17, 19; bottle-drift from off the shores of Europe, 48, 53, 57; from the vicinity of the Canary and Cape Verde Islands, 57, 58; from between St. Paul's Rocks and the coast of Brazil, 50, 61; from off the Amazon estuary, 75; from between Hispaniola and the Turks Islands, 466; derelict from off Cape Hatteras, 50, 472

North; bottle-drift to Europe, 5255, 66, 68; Carex and Sphagnum floras, $332-358$

South; current-connections, 294312, 297, 299, 310; Carex and Sphag. 
num floras, 332-358, 335-341, 356; Uncinia, 498-501

American genera in Macaronesia, 408, $410,412,413,416$

Amsterdam Island; Sphagnum and Uncinia, 344, 346, 498, 501

Amulets, West Indian drift-seeds as, 22, 24

Anacardium occidentale (Cashew-nut), $28,36,173$

Anagallis filiformis, 480, 481

_ tenella, 371, 377, 379-381, 387, $402,417,419,425,479$

Anchovy Pear. See Grias cauliflora.

Ancon (Peru), See Medanos.

Andira inermis (Angeleen-tree), 4, 11, 16, $86,88,91,92,95,150$

Andrews, E. C., on the Australian flora, $171,317-319,322,330$

Andropogon glomeratus, 451, 453

Angeleen-tree. Bee Andira inermis.

Annual Register, 277, 487

Anona, 174-181; A. cherimolia, 177; A. glabra, 181; A. klainii, 181; A. muricata (Sour Sop), 177, 181; A. palustris, $4,5,18,86,90,174-181,194$; A. reticulata (Custard Apple), 177; A. senegalensis, 181 ; A. squamosa (Sweet Sop), 177

Antarctica, as a centre of dispersion, 309, 328,330

Antarctic latitudes (Southern Ocean); seed-distribution by sea-birds, 294, 498-501; Carex and Sphagnum, 337$340,348,349$; Uncinia, 498-501; bottle-drift, wreckage, and currents, 295, 296, 299, 300, 306, 310

Antidote Vine: See Ferillea cordifolia.

Antillean Stream, 10, 14, 19, 58, 62, 73, $79,463-469,471,481$

Antilles, Grester; bottle-drift, 56, 57, 61, $72,73,442-445$

- Lesser; bottle-drift, 57, 58, 60, $61,62,69,71-75,442-445$

Antipodes Island, 348, 498

Antoine, 431

Aquatic plants ; in Jamaica, 16, 104-107; in Azores, 371, 378-382, 387, 403, 405, $407,417,420,439$

Arabis albida, 411

Arachis hypogæa; in European beach drift, 28,29

Araucaria, 294, 328

Arbutus, 408

Arcangeli, 405, 426, 437

Arceuthobium oxycedri, 360, 370, 375, $379,386,401,426$; distribution of genus, 426

Arctic latitudes, bottle-drift, 484, 495

Arenaria serpyllifolia, 411

Argemone mexicana, 290

Argythamnia argentea, 287

Aridity and cold currents, 271, 272, 275
Armeria ; maderensis, 411 ; maritima, 187

Aroids; climbing, 16; arborescent, 455

Arundo saccharoides, 105, 106

Ascension Island; bottle-drift and position as regards currents, $60,67,70,76$, $81,443,460,474,475,482,483$; flora, 459,460

Asplenium marinum, 492

Astrocaryum, 6, 12-14, 25-27, 37, 38, $86,91,181$

Atlantic, currents and bottle-drift, 46-82, 475-477; drift-rates, 65-71; general results, 71

- North; currents and bottle-drift, 46-59; circulatory morements, 51 , $54,55,71,72,80,471$; bottle-drift in high latitudes, 484, 495; genersl results, 71. See Gulf Stream, North Equatorial, Guinea, and Counter Equatorial Currents.

- South; current-system, 59, 60, 62 ; bottle-drifts, $59-64,67,69,70,71$; current-connections with Indian and Pacific Oceans, 63. See Main Equatorial, Brazilian, Guinea, and Counter Equatorial Currents and Amazon bottle-drift.

Atlas, Great; plants in the Azores, 405, 408

Atriplex portulacoides, 448-450, 501

Australia ; current-connections and bottledrift, $49,60,63,140,294-312,297$, 309,310 ; differentiation of flors, 228 , 229, 317-319; Carex and Sphagnum, 332-358, 347-352, 357 ; Seævola, 227236; Acacias, 167, 171, 319; Myrtaceæ, 317; Leguminosæ, 318; Eucalyptus, 318,319 ; Uncinia, 498-501; as a source of wide-ranging littoral plants, $171,192,207,228,229$; drift-seeds in South Australia, 140, 164." See under West Australian Current.

Avena marginata, 411

Aricennia (genus), 309, 454

- nitida, 181; distribution, 86, 181, 454 ; as a constituent of the mangrove formation, $4,10,15,90,100,106,108$, $109,202,203,283,289,290,452$; represented in stranded beach-drift and floating estuarine drift, $10,12,15$, $17,182,446$; mode of dispersal, 4,18 , $86,90,182,451,452$; effect of drying on germinating fruit, 182 ; viviparous habit, 4, 182

Azevinho. See Hex perado and $I$. azevinho.

Azolla, 16, 105, 107

Azores :

Author's sojourn, 359; his ascents of Pico, 360; history of botanical investigation, 361,385 ; heights of the islands, 364; conditions for forest-growth compared with those 
Azores (continued)-

of Madeira and the Canaries, 365, 385 ; profile of the mountain of Pico, 365 ; bluffs of Ribiera grande, 366 ; extent of vegetation on Pico, 367, 385 ; the zones of vegetation on Pico, 367,386 ; their comparison with those of Teneriffe and Madeira, 407411,415 ; prevailing climatic conditions of Pico, 371; snow on the mountain, 372 ; general account of the vegetation of Pico, 372, 387; the summit-plants of Pico, and their comparison with those of Teneriffe and Madeira, 370, 372-374, 386, 411, 416; vegetation of the upland moors of Pico, 376, 386; secondary cones of Pico, 378; wells of Pico, 388, 496; lake-district of Pico, 378, 387; sanctuaries for plants on Pico, 374, 375, 387 ; extensive Sphagnum region on Pico, 377.

Bottle-drift on the Azores, 49-55, 64, 68,460

Firewood in the Azores, 397, 398

Notes on Azorean plants, 425; plants collected by Forster on Fayal, 491 ; coast plants of Azores, 218, 219, 384, 388; uplands of San Miguel, 382, 387 ; Terceira, 383,387 ; species of Sphagnum in the Azores, 343, 478; Sargasso weed on Azorean beaches, 485 ; list of works on the plants of the Azores, 439

Proportion of native plants of Azores, 389,414 ; characters of the original forests, 391, 414, and the large size of the trees, 392, 414; large trunks buried in volcanic ashes, 393,414 ; maximum size of existing trees, 395 , 414; causes of the destruction of the original forests, 396,414 ; affinities of the native flora, 398-411, 415; distribution of characteristic native plants, 400; plant-stocking of the Macaronesian Islands, 411, 416; derivation of some plants from the Great Atlas, 405; relation between the differentiating and dispersing agencies, $399,417,438$; modes of dispersal of Azorean plants, 417, of those of the woods, 418,438 , of aquatic and subaquatic plants, 420 , 439 ; of coast plants, 420,439 ; of the plants of the moors, 418 , 438; the efficacy of winds in plant-dispersal, 422, 439; early cultivated plants of the Azores, 397.

Pumice on the beaches of the Azores, 479

West Indian seeds carried to the Azores, 27, 3\%, 122, 158, 181
Babington, on Iceland beach-plants, 187

Baccharis dioica, 285, 292

Bactris, 4, 13

Bahamas, including the extreme southeastern islands (Turks, Caicos, etc.):

Bottle-drift stranded on the islands, $49,51,54,56-58,61,62,64,71-73$, $79,462-465,470,471,477$.

Bottles dropped overboard in their vicinity or passing near them "en route," $14,72,463,465,466,468$, 477. See Turks Islands.

Climate, Aridity of, in past ages; 271, 272,275 .

Flora, 117, 168, 192, 198, 202, 210, 224, 225, 284, 290. See Turks Islands flora.

Geology, 254-276 (see Turks Islands), 502-504; Bahama Banks, 254, 255; former land connections, 272,273 ; evidence of change in old charts, 264, 275

Bahia, bottle-drift, 71

Bain, on Dracæna draco, 489

Baker, E. G., on Sacoglottis amazonica, 137

Ball, J., on plants of the Great Atlas, $405,408,439$

Baltic coasts, West Indian seeds, 36

Barbados olive, 286

Barringtonia, 5, 168, 175, 213, 214, 243, 454

Barrow, on drift-wood stranded in high northern latitudes, 35, 45

Batatas acetosæfolia, 217

Bates, H. W., on Amazon drift, 75, 128

Batis maritima, 101, 106, 108, 283, 290$292,451-453,478$

Bauhin, C., on the seeds of Ipomoea tuberosa, $32,42,161-163$

- J., on the fruits of Sacoglottis amazonica, 42, 137

Beach-drift, West Indian; sources, 1, 3, 18; sorting process and fine drift, 6 , 241 ; general description and characters, $2,6,18$; list of plants supplying it, 5, 6; contrasted with West Indian, Indian Ocean, and tropical Pacific beach-drift, 5, 18; selection of the Turks Islands for the study of its oceanic transport, 8, 14, 19; comparison of beach-drift on the Pacific and West Indian coasts of tropical America, 17, 19. See also under Jamaica, Trinidad, Turks Islands.

Beach plants of West Indies and West Africa compared, 87, 88, 91-95

— of West Indies. See under Littoral plants.

sand-rock, 263

Becher, A. B., on bottle-drifts in the North Atlantic, 46, 50, 57, 66, 81 
Beirko, C. M. F. da, concerning plants from the Azores, 364, 434, 439

Bentham, on plant-distribution, 324,327 , $329,330,354$; Acacia farnesiana, 166 , 171; Cassytha, 191, 193; Chrysobala. nus icaco, 196; Dioclea reflexa, 131; Dodonæa viscosa, 206; Mucuna, 121, 459 ; St. Helena flora, 460 ; Thespesia populnea, 244

Bent-stone. See Buesteen.

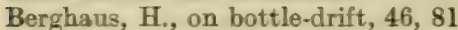

Bermuda; its stranded bottle-drift, 49 , $51-54,62,65,466-471$; its relation to the currents, 466-471; West Indian seed-drift on its shores, 38, 139, 158, 468; flora, 146, 204, 466; geology, 259, 273 , 502; supposed continental con. nection, 466

Beta maritima, 384, 404, 420, 447, 448, 450

- vulgaris = Beta maritima

Bibliographies, or lists of works quoted: botanical works, at the beginning of volume; West Indian seed-drift on European shores, 42 ; bottle-drift, 81 ; geology of the Turks Islands and Bahamas, 276; current-connections in southern hemisphere, 312 ; concerning plant-distribution, 330 ; plants of the Azores, 439

Bigbury Bay (South Deron); West Indian seed-drift, 28, 134

Birds; as seed-dispersers, 32, 175, 192, $198,252,291,294,354,418-422,435$, $437,450,454,489,499,500$; sea-birds, 32, 294, 421, 499, 500; pigeons, 175 , $192,198,252,418,435,454,489$; parrots, 175 ; wild ducks, 420

- and Currents associated in seed. dispersal, 192, 230, 232, 252

- migration to Africa, 354; to the West Indies, 500

Biscay, Bay of; stranded bottle-drift 49, 52-56. (At least two-thirds of the bottles included in the tables as re. covered on the coasts of France and Spain would be placed under this head.)

Black River. See Jamaica.

Blechnum spicant, 371, 374, 377

Blue Hole. See Jamaica.

"Blue Jacket," figurehead washed ashore at Fremantle, 296, 298

Boa constrictor, stranded on St. Vincent, 486

Boid, on the ascent of Pico, 361, 372, 439

Bolle, on Juniperus oxycedrus in the Canaries, 408

Bontia daphnoides (Barbados olive), 198, 286

Boobies, swallowing seeds of Guilandina bonducella, 32

Boodle: on the character of the timber of a buried Azorean tree, 395
Borago officinalis, 491

Borgesen, on West Indian seeds stranded on the Faroe Islands, 35,42

Borrera thymifolia, 285, 286, 288

Borrichia arborescens, 87, 183, 194, 202, 279-283, 286, 289-291, 451, 452

Bottle-drift :

Chapter dealing with, 46-82; drifting rates, $64-71$; summary, 78 ; tables, $52,53,57,61,65,66,67,71,462,464$, 466,475 ; history of the investiga. tion and sources of materials, 46, 47 ; the value of bottle-drift data, 48 ; proportion of recoveries, 48 , and the associated difficulties, 49 ; tracks of bottles thrown over together, 49 ; divergent tracks of derelicts and casks, 50

Illustration by bottle-drift of the distribution by the equatorial currents of seed-drift over the West Indies, 72; the burden of the Main Equatorial current, 73 ; the island of Trinidad as a centre of seed-drift dispersal, 74; the transport of Amazon drift to the West Indies, Florida, and Europe, 75; the bslance of the account between the Old and the New World, 76; drift carried by currents round Cape Horn, Cape Agulhas, and the North Cape, 78

Surface-circulation of the North Atlantic, 51 ; the passage of bottledrift from the West Indies to Europe, 52, and from Europe and North-West Africa to the West Indies, 58

The currents of the South Atlantic, 59; the transport of bottle-drift in the Main Equatorial Current, 60; the South Equatorial and the Brazil currents, 62; the current-connections of the South Atlantic with the Indian and Pacific Oceans as indi. cated by bottle-drift, 63

The difficulties connected with the drift-rates of bottles across the Atlantic, 64; the drift-rates from the West Indies to Europe, 65, 66; from Europe to the West Indies, $66,67,68$; from tropical Africs to Brazil and the West Indies, 67, 69; from off the Amazon estuary to Florida, 70, and in the Brazil current, 70 ; general results for the Atlantic, 71

See Africa, Amazon, America, Ant. arctic latitudes, Antilles (Greater and Lesser), Antillean Stream, Arctic latitudes, Ascension, Atlantic, Australia, Azores, Bahamss, Bermuda, etc.

Boulogne, West Indian drift-seed, 28 
Bourbon, Island of; Carex and Sphagnum, 343-346

Bowlesia, 412

Bracken. See Pteris aquilina.

Brand, J., on turtles stranded on the Shetland Islands, 40, 42

Brandis, D., on Arceuthobium oxycedri, 426

Brazil, bottle-drift, 8, 61, 63, 69-71, 76, 474, 475

Brazilian Current, 60, 62, 63, 70, 80, 89

Britton, N. L., on Bahamian and Jamaican plants, 9, 106, 205, 284

Broadway, W. E., on Entada scandens in the West Indies, 118

Brooke, A. de Capell, on West Indian seeds and mahogany baulks cast on the Norwegian and Orkney coasts, 25, $34,35,40,43$

Brotero, on Myrica faya in Portugal, 434

Brown, A. Samler; no reference to West Indian seed-drift on the Canaries, 39; comparison of the slopes of the cones of Pico and Teneriffe, 366; Juniperus oxycedrus on Palma, Canaries, 408; ascending air-currents on the Peak of Teneriffe, 425 ; Mesembryanthemum in Canaries, 449; submarine freshwater springs off the Canaries, 497

C. S., on Azorean plants, 218, 359, $364,384,385$

- R., on a Guilandina seed on the Irish coast, 30

— Miss S., on the buried Junipers of the Azores, 394

Brownson Deep, 258

Bruguiera, 309

Buch, Von, on the zones of vegetation of Teneriffe, 407

Buchensu, on the means of dispersal of Junous and Luzula, 419

Bucida buceras, 16, 17

Buesteen (Bent-stone), 23, 27, 208, 209

Bulimoid shells in rolian rock in the Turks Islands, 260

Bullar, H. ), on the Azores, 361, 397, - J. $\int 398,440$

Buller, A. H., on the falling rate of spores, 355,423

Bullock, on seeds of Entada scandens on Orkney and Norwegian beaches, 34, 36

Buoyancy of seeds and seed-vessels; comparison of behaviour in fresh water and sea-water, 117, 123, 124, 132, 139; investigations of Lloyd Praeger, 473

Results of experiments; West Indian littoral and estuarine plants, 86, 87; species of Anona, 177; Cakile, 189; Scærola, 236; Tournefortia, 251. Other results, $123,169,173,174,180$, $183,190,192,199,204,207-209,218$, $221,223,225,237-239,242,247,421$, $428,447,449,450,456-458$. (For the principles involved, see under Littoral plants and in my previous work on Plant-Dispersal.)

Burkill, I. H., concerning Acacia farnesiana, 171, and Thespesia populnea, 246

Burnt-bush. See Euphorbia vaginulata.

Bussu palm, Manicaria saccifera, 128

Butter-nut. See Caryocar nuciferum.

Button-tree. See Conocarpus erectus.

Byronia, 429

Bystropogon, 410, 412

Cabarita River. See Jamaica.

Cabeza Norte (Pico, Azores), 378

Cabral, the Portuguese navigator, 396

Cacoon, 205. See Cocoon.

Cactaceæ, 168

Cactus. See Opuntia.

Cæsalpinia, 456. See under Guilandina. - bonducella, 139. See Guilandina bonducella.

Caicos Islands; bottle-drift, 56, 462-465, 477 ; flora, 224, 284, 286, 287, 290 ; banks on which they lie, 255-258, 290. See Turks Islands and Bahamas.

Cakile, 87, 184-189, 219, 282, 288, 291, $384,404,407,421,427,451,452$

Calabash. See Crescentia.

Calabash-tree. See Crescentia cujete.

Californian current and climate, 272

Callitriche in the Azores, 371, 378, 382, $387,402,417,420$

Calluna vulgaris (Ling); in the Azores, $370-374,376,377,379,383,386,387$, $398,402,411,427$; means of dispersal, $417,419,422,425$

Calonyction album, 221, 452; synonym of Ipomcea tuba, q. $v$.

Calophyllum, 175; C. calaba, 11, 12, 155, 215 ; C. inophyllum, $155,156,454$

Calotropis procera, 290

Cambage, R. H.; on Acacia farnesiana and other Australian plants, 170, 171, $318,319,330$

Campanula, in the North Atlantic islands, 428

\section{8}

Canadas (Teneriffe), 408, 411

Canarina, 327

Canarium, 454

Canary Islands; stranded bottle-drift, $48,52-54,56,69,483,484$; bottles cast overboard in the vicinity, 57,66 , 67, 68; West Indian seed-drift, 38; shore plants, 448 ; flora compared with those of the Azores and Madeira, 365, 368,369 , 385, 398-416; history of the plant-stocking, 411-413, 416. See Teneriffe.

Canavalia, 133; C. obtusifolia, 5, 12, 17, $87,92,189,283,291,451,452,454$ 
Candolle, A. de, 76, 89, 120, 152, 159, 166, $172,193,196,207,216,362,480$

Cannaceæ, 315

Cape of Good Hope and Cape Agulhas; doubling the southern extreme of Africa by seed and bottle-drift, 39, 62 , $63,78,81$

Cape Horn, doubled by bottle-drift, 63 , 78,81

Cape-pigeon (Daption capensis), as a seeddisperser, 499

Cape Race. S?e under Newfoundland bottle-drift.

- Varde Islands; bottles dropped over in vicinity, 57, 6/, 69; Acacia farnesiana, 170; Cassia fistula, 155

Сагара, 141, 228, 309; C. guianensis, 3-5, 11-13,18, 86, 90, 141; C. moluccensis and C. obovata, 141-143

Cardot, J., the Mosses of the Azores, 440

Carex compared with Sphagnum :

Influence of the divergence of the continents on their distribution, 332-358; both respond to the same law, 332; comparison of the East and West Hemispheres in the north, 335; connections of the South American Carex and Sphagnum floras, 335 ; the stream of arctic and subarctic species down the Andes to Cape Horn, 337; the Carex and Sphagnum connections between South America, Africa, and the Australian and New Zealand region, 339; the isolation of Africa, 341, 342 ; the outside connections and sources of the African Peat-mosses and Carices, 344-346; Sphagnum and Carex in Australia and New Zealand, with their Asiatic and South American connections and the bridg. ing over of the gap in Malaya, 347353; the insular factor, 343 ; the distribution of the Carices by birds and of the Peat-mosses by winds, 354 ; summary, 355 . See also Africa, South America, Australia, etc.

Carex acutiformis, 342,345 , 346 ; brunnea, 345,350 ; breviculmis, 350,351 ; canescens, $338,339,352$; cernua, 345 , 346,349 ; darwinii, $340,349,352$; divisa, $342,345,346$; extensa, 342 , 345,346 ; flava (see note below), 371 , $380,381,387,402,420$ (included here amongst the subaquatic plants, though it is also abundant in the wet moors); lagopina, 351, 352; macloviana, 338, 339; microglochin, 338, 501; œderi (see note below), 339, 341, 345, 346, 349, 351, 352; œderi, var. cataractæ, 346,351 ; pseudo-cyperus, 339, 342, 351,352 ; pumila, $339,340,351,352$; stellulata, 351, 371, 375, 378, 387, 403 (its fruits float for a year and more and occur in the floating drift of ponds; the plant's name should be associated with Carex flava on p. 420); trifida, 340, 349, 352 ; vulpina, 342, 345, 346. (Single references to many other species will be found on pp. 338-352.)

Note.-Carex oderi, regarded by Bentham and Hooker as a form of the Linnean species, C. flava, is separated by Kükenthal. Both are European and North American; but C. cederi, in the form of var. cataractr, extends to the southern hemisphere (Chile, Patagonia, South Africa, Tasmania, New Zealand).

Caribbean Sea; traversed by bottledrift and seed-drift brought by the equatorial currents from off the West African coasts, the Amazon estuary, Brazil, the Guianas, the Orinoco, etc., $58-61,73,75,444,445$; bottle-drift from the Caribbean Sea to Europe, 59, 76 ; mingling in this sea of drift brought by the north and main equatorial currents from African and South American waters, 62,73

Carreiro, Bruno T., on the Azorean flora, $359,364,385,427$

Carthamus tinctorius (Safflower), 492

Caryocar nuciferum (Butter-nut), 28, 30

Cashew-nut. See Anacardium occidentale.

Casks, drifted by currents, 50, 76, 81, 299, 481

Cassia fistula, 6, 11-13, 28, 36, 152; C. grandis, $4,11,13,16,152$

Cassytha, 171, 207; C. filiformis (= americana), 87, 92, 191

Castillo, Drake del; on Pacific Island plants, 157, 171

Catesbcea, 287

Catesby, M.; on Genipa clusiifolia, 210 ; on the Manchineel of the Bahamas, 286 ; on the iguanas of the Bahamas, 487

Cattegat, fruits of Calluna vulgaris, etc, blown across, 425

Cattle, spreading the seeds of Acacia farnesiana, 169, and those of Pithecolobium saman (Morris in "Nature," March 15, 1888).

Cauliflory, 147, 211

Cayman Islands; seed-drift and bottledrift brought by the equatorial currents, $8,61,76,130,145$; electric-light bulbs, 165; Guilandina, 138, 456; Cakile, 186; Cassytha, 192; Coccoloba uvifera, 197; Conocarpus erectus, 201; Ipomœa carnosa, 218, and I. tuba, 221 ; Mammea americana, 145; Morinda royoc, 225; Sophora tomentosa, 237; Suriana maritima, 240; Tournefortia 
gnaphalodes, 250; Vigna luteola, 251; Passiflora cuprea, 289; Dodonæea viscosa, 206

Cears (Brazil), bottle-drift, 8, 76, 130

Cedar, Cedro. See Juniperus oxycedrus.

Cedrela odorata, 111

Cedronella, 410, 412

Cenchrus echinatus, 282, 291 ; C. tribu. loides, $85,451-453$

Cerastium tetrandrum, 411

Ceratophyllum demersum, 16, 104, 105, 107

Cerbera odollam, 5, 168, 454

Chaparral sorub, 168, 169, 229

Charms, West Indian drift-seeds as, 22, 24

Chastenet-Puységur, De; old chart of some Bahama shoals, 264

Chatham Islands; Carex and Sphagnum, 348 , 349, 352; Uncinia, 498; cask drifted from the Macdonald Islands, 299

Chaves, F. A., concerning the Azores, $359,364,365,394,396,440$

Cheeseman, T. F., 171, 220, 246; on New Zealand weeds, 391

"Cherokee," s.s.; bottles thrown over. board from, $49,65,465,467$

Chile, North; influence of Humboldt Current on climate, 271, 272, 275

Chimborazo forests, 212

Christ, D. H., on the Canarian flora, 406$408,412,440,487$

Chrysobalanus, 83, 181, 193-196, 204, 326 ; Chr. pellocarpus, 193

_- icaco (Coco-plum), 5, 12, 87, 92, $151,179,181,193,197,205,207$

Chrysodium vulgare (Swamp Fern), 105

Cladium, 179, 455

Clarke, C. B., on Ipomcea kentrocaulos, 161

Claussen, P., on West Indian seeds on Scandinavian beaches, $21,23,34,35$, 41,43

Claw-grass, 453

Clerk, W., on a West Indian seed from the Orkneys, 163

Clerodendron, 175

Clethra, 408, 410, 412

Climate, aridity and cold currents, 271, 272,275

Clusius (De l'Escluse), concerning West Indian drift seeds, $20,32,41,43,45$, $137,161,162$

Coccolobs, 197-200; C. laurifolia, 198

- uvifera (Seaside-grape); general treatment, 197-200; distribution, 87 , 197; station, 109, 116, 168, 194, 197, $198,200,206,210,237,244,279,283$, $286,288,289$; means of dispersal, 87 , $94,195,198-200,291$; fruits in beachdrift, $5,12,198,446$

Cockayne, on Dodonæa viscosa in New Zealand, 207
Cocoon, 16, 30, 31, 34. See Entada scandens.

Coco-plum. See Chrysobalanus icaco.

Cocos nucifera (Coco-nut), 28, 29, 35-37

Codeso (Adenocarpus viscosus), 408

Coix lachryma, 106

Cole, Grenville, on dune sand, 495

Colon, beach drift, $6,13,14$

Colubrina, 200; C. asiatica, 5, 85, 87, 92, 200

Columba livia, in Azores, 418; C. palumbus, 418

"Columbian Navigator." See Purdy.

Commelyna, 106, 107

Compositæ, dispersal by winds, 424, 425, 439

Congo, a source of seed-drift for the New World, 39, 74, 81

Conifers, Mesozoic, 328

Conocarpus erectus (Button-tree); general treatment, 201; variety, 202, 279; distribution, $87,95,201$; station, 5,10 , $105,109,168,197,200,201-203,206$, $244,279,280,283,289,451,452$; dispersal by currents, $87,92,93,95,203$, 204, 291, 452; in beach-drift, $5,12,17$

Convolvulus acetosæfolius, 217; C. soldanella, 217, 220, 294, 307, 308, 311

Coppinger, Dr., on the long flight of the Cape-pigeon, 499

Corals; floating, 164

Corchorus hirsutus, 278, 280, 286, 291, 446,478

Cordeiro, old writer on the Azores, 393

Cordia, 175

Cornwall; West Indian seeds on beaches, $28,45,123$; Cakile, 186, 188

Cotula; dispersal by sea-birds, 294

Cotyledon umbilicus, 422

Coutinho, A. X. P., Cape Verde plants, $170,449,488$

Cow-itch (Mucuna pruriens), 457, 458

Cozumel Island (Yucatan), bottle-drift, 466

Crantz, on drift-wood in high northern latitudes, 45

Crassulaceæ, in Canary Islands, 408

Crepis virens, 492

Crescentia, 145-150; gourds probably carried to European shores, 25, 26, 36, 146

- cucurbitina (Paki), 3, 11, 13, 15-17, $86,91,145-150$

cujete (Calabash-tree), 3, 11, 13, $15-17,86,91,145-150$

Crinum, 3, 15, 16

Crithnum maritimum, 384, 388, 404, 418, 421, 448, 449

Crocodiles, stranded on Keeling Atoll, 303,486 . See Alligators.

Crospunk, the Hebrides name for Entada scandens, 25

Croton hjalmarssonii, 285 
Crudya, 83, 84, 204, 206, 326; Cr. spicata, $3,16,86,90,106,204$

Crueger, Dr., on Sacoglottis amazonica, 134

Cryptogams. See Spores.

Cuba; seed-drift brought by the equatorial currents, 8 ; bottle-drift, 52,56 , $58,61,463,466$; forest-trees, 112, 117 , 215; submarine fresh-water springs, 497

Cucurbita, 145; C. lagenaria, 146

Julcita fern. See Dicksonia culcita.

Currents, as illustrated by bottle-drift. See under Bottle-drift, Atlantic, Australia, Equatorial Currents, Gulf Stream, Indian Ocean, Pacific Ocean, etc.

- (cold) and aridity, 271, 272, 275

Cycas circinalis, 5

Cyperaceæ, 105, 106, 109, 353

Cyperus, 15, 353; C. brunneus, 85, 278$281,291,451,453$; C. compressus, 491 ; C. elatus, 105, 106; C. esculentus, 491,492

Dabney, American Consul-general in the Azores, 362, 372

Dahl, F., on the arctic centre of dispersal, 325

Dana, J. D., Bahamian geology, 255, 262, 263,276

Daphne; dispersal by birds, 417, 418; D. gnidium, 405

- laureola, 370, 374, 375, 386, 392, 401, 405, 428

Daption capensis (Cape-pigeon), 499

Darrell, J. H., on Bermudian plants, 197

Dartmoor vegetation, compared with that of the moors of Pico, 371, 376, 386

Darwin, C. ; petrels of St. Kilda swallowing West Indian drift-seeds, 32; West Indian drift-seeds on the Azores, 37, 122 ; plants of Keeling Atoll, 170, 448; coral reef theory, 255; dispersal of plants from the north, 327; Darwinian evolution, 319,322

Datura stramonium, 290

Daussy, on bottle-drift, $46,69,81$

Davey, F. Hamilton, on seeds of Entada scandens on the Cornish coast, 28

Davis, Ainsworth, quotation cited concerning currents, 39

- Strait; bottle-drift, 55, 79, 484, 496; casks from a wrecked ship, 50 . See Greenland.

Dayssy. See Daussy.

Deane, H., on the Tertiary flora of Australia, 318

Debes, L. J., on the occurrence in the Faroe Islands of the seeds of Entrda scandens, $21,23,33,34,41,43$

Decaisne, J., on Mucuna pruriens, 458
Deffarges, M., bottle-drift on the Chilian coast, 300

De l'Escluse, 20. See Clusius.

Denmark; West Indian seeds on the coast, $27,36,37$; bottle-drift, 53

Derelicts and currents, $48,50,68,69,72$, 472,473

Descourtilz, on Calophyllum calaba, 156

Desmanthus, 326

Deutsche Seewarte, bottle-drift, 47, 54, 66,74 , etc. See under Schott.

Devonshire; seeds and fruits from the West Indies and elsewhere in the beach-drift, 28-30, 123, 134; pelagic organisms stranded, 29; Cakile maritima, 185, 188

Dicksonia culcita, 370, 375, 380, 382, 383,428

Dieffenbachia seguine (Dumb-cane), 107

Differentiation theory, 313-322, 323, 329

"Difficult" plants. See Problem plants.

Dildo, name of a species of Opuntia, 278, 287

Dimorphandra mora, seeds in beachdrift, 12,13

Dioclea, 133; D. guianensis, D. panamensis, D. violacea, 132; D. reflexa, $4,7,11-13,25,26,33,34,86,91,130$, 455

Dioscorides, on the small Acacia, 172

Distribution; its controlling factors, 323330 ; discontinuity, $83,94,326,330$.

Dixon, C., on Brazilian drift seeds in the Fulmar petrel, 32

Dodonæa, 171, 193

- viscosa, 86, 92, 109, 198, 206, 237, $286,288,291$; variety, D. burmanni, 109, 206

Dolichos urens (= Mucuna urens), 32, 35

Dondia, 453

Donkey-eye bean (Mucuna urens), 458

Dracæna aurea, 487-489; D. ombet, 488 _draco (Dragon-tree), 408, 410, 412, $48 \%$

Drepanocarpus lunatus, $11,86,88,90$, 159

Drew, on denitrifying bacteria, 502

Drift-wood, in high latitudes in the North Atlantic, 35, 40, 45

Dripping cliffs in the Azores, 497, 498

Droseraceæ, 315

Drouet, H., on the Azorean flors, 359, $363,368,382,383,385,394,418,428$, $432,435-437,440$

Druce, G. C., on Campanula vidalii, 427 ; on other Azorean plants, $364,434,440$

Drude, O., on southern floras, 294

Ducks, Wild, as seed-dispersers, 420

Dumb-cane, 107

Dwarfing of trees and shrubs; in the Azores, 367, 373, 374, 382, 386, 387, 428-432, 437; in the Turks Islands, $202,279,283,446$ 
Dyer, W. T. Thiselton; theory of centre of dispersion in the north, 323-330, 332; evidence supporting it in this work, Anona, 181, Chrysobalanus, 181, 196, Cakile, 187, Morinda, 226, Ximenia, 253, Carex and Sphagnum, 353

Eagle-stones, Norse name for West Indian drift seeds, 21

Easter Island plants, 156, 246

Ecastaphyllum in Turks Islands drift, genus doubtful, 111

brownei, 5, 11, 12, 14, 17, 87, 88, $92,95,159,194,197,207,244$

Echites, 287

Echium, 408

Ecuador :

Beach-drift, 17, 145, 182, 190, 209; beach flora, 191, 203, 227; infiltration of sea-water landward, 101; Rhizophora, 99

Guayas or Guayaquil River; floating drift in the estuary, $3,17,145,179$, $182,209,212,222,252$; vegetation of estuary, 99, 178, 180, 222; salinity, 100, 180 ; underflow of seawater in the estuary, 102

Eggers, von, on West Indian plants, etc., $98,201,203,217,227$

Elæocarpus, 489

Electric-light bulbs in beach-drift, 165

Elliot, G. Scott; on Cassytha filiformis, 192; on Juniper growth, 430

" Ely" (whaler), drift of a cask, 299

Enallagma cucurbitina, 147

England; bottle-drift, 52, 53; West Indian drift seeds, $26,28,45,123,134$

Engler, A., southern floras, 294

English, T. M. Savage; seed, bottle, and other drift on the Cayman Islands, 8, $76,130,145,165$; Ipomœa acetosæfolia, 218; Sophora tomentosa, 237; Passiflora cuprea, 289

Entada, 83, 118, 120, 133; E. polystachya, 118

_ scandens seeds (Cocoon); general treatment, 86, 91, 117; in West Indian beach-drift, 4, 6, 11-13,17, 117, 118; in European beach-drift, 22-28, 30-36, 42,45 ; in Azorean beach-drift, 37, 38; in river-drift, 4, 119; drift seeds used as snuff-boxes in Europe, 25, as tinderboxes in the Hebrides, 25, and for medicinal purposes, 24; superstitions concerning the drift seeds in Europe and the popular names given to them, 21-25

Epilobium; dispersal by winds, 423-425, 439

Equatorial currents of the Atlantic :

Counter Equatorial, 59, 77, 89, 91, 93, $94,235,301,476$. See under Guinea current.

L L
Main Equatorial; differentiated from the South Equatorial, 60, 79, 474; indications of bottle-drift, $8,58,59$ $62,67,69-76,79,80,442-446$; 89 a carrier of seed-drift, 7, 8, 72-78, 81, 84-89, 94; bearing Amazon bottle and seed drift to the West Indies, 7, 8, 70, 75, 76, 81, 444-446; carries to the West Indies the sweepings of both sides of the South Atlantic, 73, 74, 81; mingling of its drift with that of the North Equatorial in the Caribbean Sea, 62, 73,81

North Equatorial; indications of bottle-drift, 51-60, 57-59, 67, 69, 71, 72, 73-76, 79, 80

South Equatorial; 59, 60, 62, 80, 474. See above under the main current.

Equatorial currents of the Indian Ocean; indications of bottle-drift, 301-307, 311

Equatorial currents of the Pacific Ocean; indications of bottle-drift, 297, 298, 310

Erica arborea, Canarian and Madeiran Tree-Heath, 406-408, 410

- azorica, Azorean Tree-Heath, 369, $370,373-379,382,386,392,394-396$, $398,401,422,428$

- cinerea, 411; E. scoparia, 491; E. tetralix, 425

Ernodea littoralis, 85, 291, 453

Ernst, A., on the re-stocking of Krakatau, $116,142,154,190,207,425,458$

Erodium, 390

Erslev, on tropical seeds on the Jutland coast, 37,43

Eryngium maritimum, 447

Erythræa centaurium, 491 ; E. maritima, 404 ; E. massoni, $371,374,377,379$, 387,402 ; E. ramosissima, 491

Erythrina, seeds in European drift, 23, 25-27, 33, 208 (see Buesteen, the Norse name); E. corallodendron, 209; E. velutina, 209

Estuaries; plants, 86, 88, 90, 94 (see Mangroves); salinity and its influence on station, 99-104, 110, 180; underflow of sea-water, 102, 110

Etna, subterranean and submarine streams, 497

Eucalyptus, the question of its Australian origin, $318,319,322$

Eucarex, 345

Eugenia, 318, 454

Euphorbia azorica, 384, 388, 404, 407, 421, 428 . See E. pinea. 452

buxifolia, 86, 279-283, 288, 291, 451 . canariensis (Cactoid Euphorbia) $408,412,448$ lecheoides, 286 
Euphorbia mellifera (Tree-Euphorbia), 401, 407, 410, 428. See E. stygiana, its Azorean form.

- origanoides, 460

- paralias, $448-450$

peplis, 219, 384, 388, 404, 421

pinea, 384, 388, 404. See E.

azorica.

— piscatoria, 410

- polygonifolia, 186

- stygiana (Tree-Euphorbia), Azorean

variety of $\mathbf{E}$. mellifera (see above), 370 ,

$374,375,379,386,392,401,428$

— trinervia, 460

- vaginulata (Burnt-bush), 198, 280,

$281,283,285,288,289$

Euphrasia grandiflora, 375

Europe :

Bottle-drift, 46-82; from West Indies to Europe, 52-55, 59, 65-68, 71, 76, 79,80 ; to the West Indies from Europe, 56-59, 66, 68-69, 71, 79, 80 ; from the African side of the Atlantic to Europe, 59, 76; from off the Amazon estuary, 70, 71, 75; from Ascension, 76, 482

West Indian seeds and fruits on European beaches, 20-45; baulks of mahogany washed ashore, 35,40 , $42,48,78$

Euterpe, 16

Evans, Lieut., on Sargasso weed in the Florida Stream, 485

Ewart, A. J.; on seeds of Guilandina bonducella and Mango stones washed ashore on south coasts of Australia, 140, 164; on the seeds of Canavalia obtusifolia, 190; on Convolvulus soldanella in Australia, 220

"Extensionists," their views, 272, 273, 275

Faba marina, name of Entada scandens,21

- orcadensis, name of Ipomoea tuberosa, 161,163

Fagus, 294, 326, 328, 433

Fairies' Kidneys, a Norse name for the stranded seeds of Entada scandens, 23, 25. See Vette Nyre.

Falkland Islands, bottle-drift, $63,74,78$

Families of plants; grouped into Primitive and Derivative families, 314-316, 321 ; their evolution, 319,322

Farewell, Cape, Greenland, bottle-drift from the vicinity found on Teneriffe, $483,484,496$, and near the North Cape of Norway, 495

Faroe Islands, West Indian seeds stranded, 21, 23, 25, 27, 34, 122; drift-wood, 40; current-connection with Iceland, 187

Fawcett, W., on Jamaican plants, 178, $185,193,194,197,198,200,253$
Faya, name of Myrica faya, q.v., 433, 434

zone, on Pico, 369,386

Fayal, origin of name, 433,434

Fernando Noronha; drift seeds, 121; Acacia farnesiana, 170 ; Canavalia obtusifolia, 191; Ipomøea tuba, 220

Fernow, on Cuban trees, 112, 215

Ferns. See Acrostichum, Asplenium, Dicksonia, Hymenophyllum, Osmunda, Pteris, Trichomanes, etc.

Fevillea cordifolia (Antidote Vine), 3, 7, $11,12,13,15,16,86,90,124$

Ficus, 454

Field Columbian Museum, 9, etc.

Fielden, H. W., on a drift seed in the Hebrides, 24, 32, 43, 162

Fiji, 142, 146, 191; Rhizophora, 96-100

Finmark, West Indian drift seeds, 35,36

Fire-shrub, 285

Firewood, in Azores, 397, 398

Flores, Azores, junipers, 395, 397

Florida region :

Bottle-drift; stranded in this region, $51,57,58,61,67,70-73,75,79,444$, $445,463,466$; dropped overboard in this region, $52,54,58,59,65,66$, $71,75,467,468,471$

Flora, 93, 106, 114, 178, 179, 192, 194, $210,220,225,252$

Geology, 258, 503

Sand-keys, plants. See Lansing.

Seed-drift from the Amazon and Orinoco, 7

Fogh, C., West Indian drift on European beaches, $20,36,41,43,481$

Forbesian hypothesis, extension of Europe, 389

Forster, G.; plants of Fayal, 361, 385, $389,433,440,491$; plants of Easter Island, 156, 246, and of Cape Verde Islands, 170

Foula Island (Shetlands), absence of West Indian seed-drift, 34

Fox, J., West Indian seeds, etc., in the Shetland Islands, 34, 40, 162

France; West Indian seeds stranded, 26,28 ; bottle-drift, $52,53,68$. See Biscay.

Frankenia, 388, 448-450

Fredholm, stranded coco-nuts on the Lofoten Islands, 37

Frigate-bird, seed-dispersal, 32, 279

Fructuoso, on the original woods of the Azores, 393

Fuegia; Carex and Sphagnum, 337-341, 352; Uncinia, 498-501; bottle-drift and its bearing on dispersal of seeddrift, 63, 74, 78, 294-312, 294-296, $301,306,310$

Fulmar Petrel, swallowing West Indian drift seeds, 32

Furnas Valley (Azores), 496 ; trees buried in volcanic ashes, 383,394 
Galapagos Islands, their plants, 176, 201, $227,236,400$

Garcinis mangostana (Mangosteen), fruit on Scandinavian coast, 28,36

Gastridium lendigerum, 491

Genipa clusiifolia (Seven-year Apple), 87, $194,197,198,209,279-283,287,291$, 487

Gentiana centaurium, 491

Geraniaceæ, 315,316

Geranium, 315; weeds in Azores, 390, 391

Glacial period and plant distribution, 326,327

Glaux maritima, 187

Glossopteris flora, 328

Gnaphalium luteo-album, 492

Goats; destructive of young plants in the Turks Islands, 139, 231, 232, 277, 281; dispersers of Manchineel seeds, 115

Godman, F. du C.; on the Azorean flora, $359,362,364,367,385$, 390, 392, 399, 440 ; on the snow-cap of Pico, 367, 372

Gomes, B. A., concerning plants from the Azores, 364, 434, 440

Goodeniaceæ, as an Australian family, $227,228,314,317$

Gosse, P. H., on Jamaican pigeons and Anona dispersal, 175

Gourds, in Scandinavian beach-drift, 36 , 146. For general details see under Crescentia, 145 , etc.

Grand Canary, strand plants, 448

Grant, Ogilvie; on the vegetation of the higher slopes of Pico, 367; on the Juniper trees of San Jorge, 396; on the Azorean pigeons, 418; on misselthrushes in the Azores, 437

Gray, Asa; Cakile, 184; plant-distribution, $327,329,330$

Great Lakes of North America, shore plants, $\mathbf{1 8 6}$

Greenland, West Indian seeds and logs of mahogany, 35, 40, 42. See Davis Strait and Cape Farewell for bottledrift, etc.

Greenman, Dr., on a new species of Morinda, 226

Grenada; beach plants, 116, 245; stranded seed-drift, 6, 13; Grand Etang, the lake and its plants, 131, 455

Grias, 212, 213

- cauliflora (Anchovy Pear), 3, 6, 7, $12,14-17,86,90,106,124,147,205$, 211

Grisebach, A. H. R. ; on West Indian plants, 114, 116, 118, 121, 143-147, $150,152,156,157,161,201,202,205$, $210,211,218,225,227,250,251,285$, 294, 457-459

Guayas or Guayaquil River. See Ecuador.
Guernsey, bottle-drift from Ascension, 76, 81,482

Guettarda, 175, 287, 454

Guianas; distribution of estuarine drift, $13,19,74$; bottle-drift, $61,73-75$; Carapa, 141, 142

Guilandina (genus), 133; seed buoyancy and an inland station, 456

- bonduc (Yellow Nicker), 12, 32, 87, $92,140,456$

bonducella (Grey Nicker) :

Distribution and dispersal by currents, $87,92,138,139,291$

General treatment, 138

Seeds; in beach drift, West Indian, 5, 10-12, European, 23-28, 30-36, Azorean, 37, 38, and Australian, 140; drift seeds used medicinally and as charms, 24 ; swallowed by sea-birds, 32 ; trade in the seeds, 140 ; buoyancy, $87,139,456,457$

Station, 138, 194, 197, 200, 244, 245, 287,288

- melanosperma, 456

- species not identified; seeds in

Trinidad beach-drift, 13, 457; plant

in Jamaican forests, 457

Guinea Current, 59, 77, 475

- Gulf of ; bottle-drift, $67,71,74,76$,

80,81 ;' casks drifted to Norway, 481

Gulf Nut, name of West Indian seeds on

European beaches, 22

- Stream; early reference to it as a seed-carrier, 21, 33; ancient course across Florida, 93; bearing West Indian seeds, 1, 7, 20, 21, 26, 29, 33, 37,89 ; the indications of bottle-drift, $51-55,58,65,66,68,71-81,466-471$, 482-484

Weed. See Sargasso.

Gulls, Sea, as seed-dispersers, 421

Gumprecht, T. E. ; on drift-products of the currents in the North Atlantic, 20, $36,40,41,43,45,481$; old Scandinavian names of stranded West Indian seeds, 23, 209

Gunnerus, J. C., on the tropical seeddrift of the Scandinavian coasts, 22, $35,36,41,43,146,153,173$

Guthnick, the Azorean flora, 359, 362, 385

Gygax, a Swiss mineralogist who visited the Azores, 362

Haacke, W., polar origin of faunas, 325

Habenaria, 375, 377; capacity for wind dispersal, 424,425

Haiti. See Hispaniola.

Halophytes, 478; Turks Islands, 290

Hammerfest, drifting of casks from the Gulf of Guinea, 481

Hammocks of the Florida vegetation, 93, 114,225 
Harrison, Prof., on the lake of the Grand Etang in Grenada, 455

Harshberger, J. W., 331; Ambrosia in North America, 173; Anona palustris in South Florida, 175-179; Arceuthobium in North America, 426; Woodwardia growing in Sphagnum tussocks, 378; Bahamas, 192; Bermuda, 206; Cuba, 215, 253; Florida, 114, 157, 175179, 194, 210, 225; Jamaica, 17, 168, 211, 243; Turks Islands, 287; Virgin Islands, 116, 244, 457; other West Indian islands, 119, 151, 202, 250; Lower California, 201, 218, 227; Mississippi delta and Louisiana coast, 191, 218,252; Texas and Mexico, 167, 168, 229; southern migration of North American plants, 336; the sunken Caribbean lands, 152, 213; centrifugal dispersion from the north, 327 ; saltmarsh and estuarine plants of New Jersey, 100, 104, 110

Hart, J. H.; Herbarium List of the Trinidad flora, 118, 212, 251; Sacoglottis amazonica, 7, 134; Entada scandens, 118; Fevillea cordifolia, 126; Grias cauliflora, 212; Ipomca carnosa, 218; Thespesia populnea, 244; Vigna luteola, 251

Hartert, E., on the pigeons of the Azores, 418

Hartung, G., 363, 385, 440; buried Juniper trees, 392,394

Hatteras, Cape; bottles thrown over in its vicinity, $49,50,52,54,55,65,66$, $78,467,468$; derelicts from this neighbourhood, 50, 72, 472, 473; turtle carried past in the Gulf Stream, 41

Hawaii; Acacia farnesiana, 167, 169-171 ; Ipomøa carnosa, 218; Cassytha filiformis, 191; Carex and Sphagnum, 343, 345; Dracæna aurea, 487-489; transport of spores only by winds to this group, 354,355 ; ascending aircurrents on Mauna Loa, 425; submarine streams of fresh water, 497; Azorean and Hawaiian floras compared, 399,400

Heather, W., old chart of the Azores, 366

Hebrides; stranded West Indian seeds, 22-26, 31, 32, 122; derelicts, 50, 68, 472 , bottle-drift, 52,53 , and turtles, $40-42$

Hedera, dispersed by birds, 417, 418

- canariensis; in Azores, 369, 376, 392, 401, 429; in Canaries, 406

Hedley, C., palæographical relations of Antarctica, 294, 309, 312, 328, 330, 331

Hedyotis adscensionis, 460

Heer, O., 329, 363

Heilprin, A., æolian rocks in Bermuda, 259,262
"Hekla," H.M.S., bottle-drift in high northern latitudes, 484,496

Heliotropium, 449; H. curassavicum, 278, 291,477

Hemsley, W. B., 43, 294, 440; West Indian beach-drift, $12,13,126,128$, 143; West Indian seeds on European beaches, $21,24,42,146,153,154$, and on Azorean shores, 37; dispersal by currents, 158, 187, 193, 204, 447, and by birds, 198, 252; Arceuthobium, 426; Bermudian flora, 466; Ascension and St. Helena floras, 459, 460; Ipomcea tuberosa, 24, 161, 162; Sempervivum in Canary Islands, 408; Mucuna pruriens, 458; Weeds, 391; Uncinia, 498-501; miscellaneous plants, $116,147,156,157,160,167,171,201$, $225,227,246,250,251,488$

Henriques, Prof., buried Juniper trees in the Azores, 395; Myrica faya in Portugal, 433, 434; the popular Azorean name of Myrsine africana, 434

Hensen, experiments on currents in Kiel Bay, 50

Henslow, J. S., plants of Keeling Atoll, 448

Hepaticæ, in Azores, 375, 383

Hepworth, W. W. Campbell; southern pelagic organisms stranded in the south of England, 29; Labrador Current, 272; Sabine's casks of palm oil, 482; Gulf Stream, 43

Heritiera littoralis, $\mathbf{5}$

Hernandia peltata, 454

Herpestis monniera, in the West Indies, 105,477

Hibiscus elatus, 16, 214

- tiliaceus, $5,6,17,87,92,116,168$, $170,172,178,214,245-247$

Hill, A. W., Arceuthobium oxycedri in the Azores, 426

Hillebrand, W., Acacia farnesiana in Hawaii, 167-171; other Hawaiian plants, $218,246,458,478,488$

Hillier, J. M., Sacoglottis amazonica, 28, 134

Hippocratea, in Trinidad beach-drift, 13

Hippomane mancinella (Manchineel); beach-drift, $5,11-14,17,115$; distribution, $87,88,93,113,114$; dispersal by currents, $87,88,93,95,113$, 115; station, $93,114,194,244,245$; doubtful identity of the tree in the Bahamas, including Turks Islands, 286

Hispaniola (San Domingo and Haiti); bottle-drift, $56,58,61,62,65,462$, 463, 465, 477; Acacia farnesiana, 167, 168; old masonry on coast, 491

Hjalmarsson, J. A., flora of Grand Turk, $185,283,286$

Hoban, M. A., West Indian seeds on Irish coast, 31 
Hochstetter, C. (father and son); on the Azorean flora, 359, 362, 363, 365, 370, $376,385,389,392,428,440,491,492$; zones of vegetation of Pico, 368,376 ; vertical ranges of plants, $362,363,376$, 425, 428-430, 432-438

Hog-Gum tree. See Symphonia globulifera.

Hog-Plum. See Spondias lutea

Hollies. See Ilex.

Honduras; bottle-drift, 57, 58, 61, 75. See Central America, Nicaragua, and Yucatan.

Hooker, J. D. ; dispersal of plants from the north, 324, 327, 329, 330, 354; southern floras, 294; plant-stocking of the Macaronesian islands, 411, 412; insular floras, 440; Kerguelen, 500; St. Helena, 460; West Indian drift seeds on the Azores, 37; Dracæna draco, 488; Chrysobalanus icaco, 196 ; Conocarpus erectus, 204; Portulaca oleracea, 478; St. Kilda petrels and drift seeds, 32

- W. J., Niger flora, 99, 131, 194, 196

Horn, Cape; bottles and figurehead drifting from off the Horn to Australia, $49,63,295,296,298$; doubling of the Horn by bottle-drift and probably seed-drift, $63,74,78,81,300$

Horne, J., Fijian plant, 171

Horse-eye Bean (Mucuna urens), 34, 458

Hubbard, Mrs., fruit of Sacoglottis amazonica on the coast of Devonshire, $28,134,136$

Humboldt, F. H. A. von; West Indian seed-drift in Europe, 20, 41, 43; ascending air-currents in the Andes, 425; submarine springs off Cuba, 497

- or Peruvian Current, influence on the climate of North Chile and Peru, $271,272,275$

Hunt, Carew; plants of the Azores, 359 , $363,385,427,435,440$; trees buried in volcanic ashes, 394

Hydrocotyle umbellata, in Jamaica, 104, 105,107

- vulgaris, in Azores, 360, 371, 377, $379-381,387,402,417,429$

Hymenæa courbaril (Locust-tree); pods in the foreign drift of the Turks Islands, 11,140

Hymenomycetes. See Mushrooms.

Hymenophyllum tunbridgense, in Azores, $375,379,387$

Hyoscyamus albus, in Azores, 384, 388, 404, 421

Hypericum, 410; H. foliosum, 369, 392, 400,429 ; H. grandifolium, 400, 407; H. humifusum, 492 ; $H$. perforatum, 492

Hypochœris radicata, 492
Ianthina shells on English, 29, and Azorean beaches, 38

Iceland; stranded West Indian seeds and mahogany logs, $35,40,42$; stranded bottle-drift, 52, 53, 495; shore-plants, 187; current-connections, 187

Iguanas; in the Turks Islands, 486, 487 ; as seed-dispersers, $175,178,210,211$, 291

Ilex, 406, 408, 417, 418, 429; I. azevinho, 407

- perado, 369, 370, 373-375, 378, 386, $387,392,398,400,406,407,429$; at great altitude in Azores, 373

Inagua Islands (Bahamas); plants, 168 , 284, 286, 287, 290; bottle-drift, 464

Indian Nuts, old name in Scotland for West Indian drift seeds, 23, 24, 31

Ocean; its traverse by seed-drift as illustrated by bottle-drift, 47, 50, 297 , 298, 301-305, 306-308, 311; passage into South Atlantic by bottle-drift, 62 , $63,74,80$

Ink-berry. See Scævola plumieri.

Insular factor in distribution, 334, 343, 358

Ipomœa acetosæfolia, 217

工 carnosa, 87, 92, 21\%, 384, 404, 421

- kentrocaulos, 161

- pes-capræ; general treatment, 219 ; seeds in beach-drift, $5,6,12,17,219$, 242, 446; dispersal by currents, 87,92 , 219,291 ; distribution of the species, $87,217,218,219$; on the Turks Islands, 278-283, 288, and the Florida sand-keys, 451, 452, 454; compared with Convolvulus soldanella as regards range, 220

tuba, 87, 92, 220, 280, 281, 291, 292, 452

- tuberosa; general treatment, 161 ; popular name, 210; seeds in West Indian beach-drift, 11, 12, 162, and in European beach-drift, 24-27, 32-34, 161-163, being used as charms in the Hebrides, 24

Ireland :

Stranded West Indian seeds, 26, 30, 122

Stranded bottles; one from the vicinity of the Cape Verde Islands, $59,72,76$; one from the channel between the south-eastern Bahamas and Hispaniola, 65, 72, 466, 477; one from the Caribbean Sea to the south of Jamaica, 59,76 ; three from the seas between Cuba, Florida, and the Bahamas, 52; seven from the vicinity of Cape Hatteras, 49, 52; one from a position to the south-east of Cape Cod, 50 ; ten from the seas south of Nova Scotia and Newfoundland, 52; two 
Ireland: Stranded bottles (continued) from Davis Strait, 484, 496; twenty. three from mid-Atlantic to the north-west of the Azores, 52, 53; range of the sources of Irish bottledrift from the New World, 55, 79

A bottle reaching the Bahamas from the vicinity of the Irish coast, 57, $66,69,72,79,464,465,477$

Irminger, C.; currents, drift-wood, and drift-seeds in the North Atlantic, 20, $35,40,41,43,45$

Isatis tinctoria (Woad), early cultivation in the Azores, 397

Islands. See Insular factor.

Islets, Coral-reef; plant-stocking in the West Indies and Pacific Ocean com. pared, 453,454

Isnardia palustris, 104, 105

Isoetes in the Azores, 380-382, 387, 420, 429

Iva imbricata, 451,453

Jackson, Capt., on the Guinea Current, 476

Jacquin, Von, Rhizophora mangle, 96; Hippomane mancinella, 114; Mucuna pruriens, 459

Jacquinia armillaris, 86, 109

Jamaica :

Rhizophora mangle, 98-101

Black River district; infiltration of sea-water into the Great Morass, 101; underflow of sea-water up the estuary, 102; springs of the Great Morass (Blue Hole), 104; vegetation of the river, riverside, and Great Morass, 104-106; Great Lake at Pondside, 107; Salt Lakes district and the vegetation, 107-109, 206

Savanna-la-mar district; vegetation, 106; Cabarita River, 106; Bowen's River, 107

Vegetation, bordering the beaches, 244; of the woods, $16,111,118,144,155$, $160,226,243$; of rivers, ponds, mangrove-swamps, 15-17, 104-109; of the Blue Hole spring, 104; of the Roaring River Falls, 16, 147, 211

Migrating birds on the highlands, 500

Beach-drift, 3, 6-9, 11, 12, 129; seed-drift brought by the Main Equatorial Current, 8, 129

Bottle-drift; brought by the North Equatorial Current, 56, 57; by the Main Equatorial Current, 61; and from the vicinity of Ascension, 474, 475

Japan; Sphagnum, 334, 343, 349; Carex, 349

Johnson, J. Y.; the Juniper in Madeira, 410,431 ; plants of the Peak of Teneriffe, 411
Johnson, T., Arceuthobium, 427

Jones, F. Wood, 82, 312; bottle-drift as illustrating plant-dispersal in the Indian Ocean, 50, 302, 303, 305, 308; snakes and crocodiles drifted to Keeling Atoll, 303,486 ; floating corals, 165

J. M., Sapindus saponaria in Bermuda, 157

Jonston, J., 43; early allusion to the drift fruits of Sacoglottis amazonica, 137

Jouan, H.; on Tahitian and Marquesan plants, 171, 247

Jourdan, S., early reference to Bermudian plants, 204

Juan Fernandez, Uncinia, 498

Juglandeæ; fruit in Azorean beach-drift, 37,38

Juglans; fruit in West Indian beachdrift, 12, 13; distribution of the genus, 326

Juncus, 382; capacities for dispersal by birds and winds, 418, 419, 422, 424

- acutus, in Azores, 384, 388, 404, 421,422

Juniper, Brown-berried; J. oxycedrus, 430

- zone in the Macaronesian islands and on the Great Atlas, See under J. oxycedrus.

Juniperus bermudiana, 204; J. brevifolia (see J. oxycedrus); J. communis, 401, 430; J. macropoda, 426; J. nana, 401, 430

- oxycedrus (Cedro, Cedar); Azorean variety, brevifolia, 430 :

Affinities of the Azorean tree, 401, 430-432

Dwarfing, 373, 374, 382, 383, 387; large size in the original forests, 392 , 396 ; trees buried in volcanic ashes, $363,393-395$; use of the wood, 393 , 397

Juniper-zone; on Pico, 369, 370, 371, $373-375,386,430$; on Teneriffe, Madeira, and the Great Atlas, 408$410,415,416$

Junipers of the Lake District of Pico, 379,387 ; of San Miguel, 382; of Terceira, 383

Source in the Great Atlas, 405, 406; dispersal by birds, 417,418 ; the host of Arceuthobium, 370, 375, 379, 386, 426 ; fruiting, 373, 430

Jussiæa, 105

Jutland coast, stranded West Indian seeds, 37

Kamel, Father, mentioned by Petiver, 163 Keane, A., the lake of the Grand Etang, 455

Kearney, T. H., the salt in sea-beaches and halophily, 186 
Keating, P., buried Juniper trees in Flores, 395

Keeling Atoll; plants, 170, 240, 247, 248, 448; beach-drift, 132,142 , 143; vegetable drift, snakes, and crocodiles from Malaya, 302, 303, 486; bottle-drift indications, 50, 303-305; stranded log carrying seeds, 453; floating corals, 165; frigate-birds and boobies and seed-dispersal, 32

Islands. See above.

Island, North, 453

Kellerman, K. F., on denitrifying bacteria, 502

Kerguelen; bottle-drift and its indications, $295-300,310$; a habitat of Uncinia, 498-501

Kermadec Islands, 220

Kerner, 96, 419

Kidder, Dr., seed dispersal in the Southern Ocesn, 500

Kilkee (Ireland), stranded West Indian seeds, 31

Kleinia neriifolia, 408

Knowles, Miss M. C., stranded West Indian seeds on the Irish coast, 31, 123

Knowlton, F. H., Cretaceous and Tertiary plants of North America, 328

Knuth, R., Lysimachia, 432; Anagallis, 480, 481

Kohl, J. G., on the vegetable drift transported in the Gulf Stream to Greenland, Faroe Islands, and Europe, 20, $35,40,41,43,81$

Krakatau, its re-stocking with plants, $116,142,190,192,200,207,253$, 458

Krause, K., on Scævola, 227-232, 235, $236,447,448$

Kükenthal, G., on Carex, 334-358; on Uncinia, 498-501

" L'Aigle," Trench sloops in theWest

"L'Emeraud," $\}$ Indies in 1753 ; 264, 489

Labrador Current and climate, 272

Laccadives, compared with the Bahamas, $255,256,274$

Ladrones, 201

"Lady Montague" (American ship), bottle-drift, 76, 482

Lagenaria vulgaris, gourds on Scandinavian beaches, 36,146

Lagoas, in Pico. See Lakes of Pico.

Laguncularia, 309

racemosa; general treatment, 221; distribution, 86, 221; comparison of the West Indian and Ecuadorian plants, 222; vivipary, 4, 221, 222 ; fruits in river-drift, 222 , and in beach-drift, $4,12,17,222,446$; plant as a constituent of the mangroveformation, $4,10,15,100,106,108,109$,
202, 203, 283, 289, 454; dispersal by currents, 4, 18, 86, 90, 222, 291, 452 ; Florida sand-keys, 182, 451, 452

Lakes of Pico; Caiado, Das Teixas, Do Ilheo, Negra, Paul, Rosada, 379-381, 437

Lamium purpureum, 391

Lansing, O. E., on the vegetation of the Florida sand-keys, 9, 115, 139, 156, 173, $183,186,190,198,203,219,231,240$, 250,450

Lantana involucrata, 285, 288, 292

La Palma, Canary Islands, 497

Lapland, stranded seed of Entada scandens, 36

Lathyrus maritimus, 186, 187

Laughton, J. K., 43; West Indian and Mexican seeds and logs of mahogany on the shores of Greenland and Iceland, 35, 40; Main Equatorial Current, 70, 443; Counter Equatorial Current, 476; Sargasso Sea, 461; waters of Amazon estuary, 75

Laurel-woods of Macaronesian Islands, $365,368,369,386,393,401,406-410$, 412-416. See Laurus, L. canariensis, Persea indica, Oreodaphne fotens, Phœbe barbusana.

Laurestinus. See Viburnum tinus.

Laurus, 417

- canariensis (Persea azorica); in Macaronesia, 401, 413; Pico, 369, 370, $374,375,380,386,387,392,393$, 432; San Miguel, 382, 432; Teneriffe, 406, 408; Madeira, 407, 410; size of existing trees in the Azores, 392, 395; used for fuel, 398

indica. See Persea indica.

Leathery Turtle, caught off Scilly, 41

Lecythidaceæ, 211, 214

Lefroy, J. H., on Bermudian plants, 139, 197,245

Leguminosæ; behaviour of genera holding littoral species, 133; Andrews on the development of the family, 318

Le Maout and Decaisne, Mucuna pruriens, 458

Librocedrus, 318, 327

Lilford, Lord; on the food of Canarian wood-pigeons, 418

Limnanthemum humboldtianum, 223

Lindman, C., on Scandinavian beach-drift from the West Indies, 21, 27, 36, 42 , $43,122,123,146,153,162$

Ling. See Calluna vulgaris.

Linnæus, 22, 37, 173, 448

Linschoten, J. H. van; on the forest-trees of the Azores in the sixteenth century, $393,397,437,440$

Liquidambar, 318

Liriodendron, 318

Lithophila, 85 
Littoral floras, West Indian and West African compared, 83-95, 86; tropics of the Old and New World compared $309,453,454$

Littoral plants :

(a) Genera holding both littoral and inland species; Anona, 175; Barringtonia, 175; Calophyllum, 156, 175; Canavalia, 133; Chrysobalanus, 196; Clerodendron, 175; Coccoloba, 197; Colubrina, 200; Cordia, 175; Erythrina, 208; Guettarda, 175; Guilandina, 133, 456; Hibiscus, 214; Luffa, 223; Morinda, 175, 226; Portulaca, 478; Seævola, 175, 230; Sophora, 133, 237-239; Terminalia, 116, 175, 231; Tournefortia, 248. For a discussion of the subject, see chapters xiv, $x v, x v i$, of my book on Plant-Dispersal, a list of genera being given on p. 134 .

(b) The relation between a littoral station, buoyancy of seeds and fruits, and dispersal by currents, $139,140,169,216,223,229,238$, $239,456,457$

(c) The relation between a littoral station and xerophily, 169, 175, 216, 229, 239, 288, 293. See pp. $32,39,201,515$, of PlantDispersal.

(d) The extension of inland plants to the coast, 229, 288, 293, 448 (see p. 131 of Plant-Dispersal); and the extension of littoral plants inland, 219, 227, 237-239, 288, 293. See under Littoral plants in index of Plant-Dispersal for further data.

(e) Littoral plants as parents of inland species, 226, 456, 478. See PlantDispersal, pp. 133-170.

(f) Littoral plants of the same genus dividing the tropical world between them, 227, 228; Carapa, 141, 228; Rhizophora, 141, 228; Scævola, 227, 247; Tournefortia, 228, 247

(g) Littoral plants where both frugivorous birds and marine currents disperse the species; Cassytha, 192; Scævola, 230, 232; Ximenia, 252

(h) Littoral plants of the Azores, 384, 404; Jamaica, 106, 244; Teneriffe, 448; Turks Islands, 290, 291; West Indies, 86, 87

Littorella lacustris in the Azores, 371, $378,380,381,387,403,417,420,429$, 432

Lloyd-Jones, A., Entada scandens seed in Swansea Bay, 30

Locust-tree. See Hymenæa courbaril.
Logs, drifting; transporting seeds, 248, $291,418,421$

Lomba, an eminence on the upper slope of Pico, 360

Loranths. See Arceuthobium and Phoradendron.

Lord Howe Island, possessing New Zealand Carices, 348

Loro (Louro), Laurus canariensis, 432

Lösningsteen, Norse name of Entada scandens, 23

Lottin, seed of Entada scandens found near the North Cape, 36

Lotus, 390 ; L. angustissimus, 492

Louisiana; stranded bottle-drift, 58; shore plants, 191, 218

Lowe, R. T.; Madeiran flora, 185, 406, $407,410,411,435-437,440$; the Salvages, 449

Löwenörn, Von; drift-wood in high northern latitudes, $35,40,45$

Lucuma, 29; L. mammosa, 29

Luffa, 223

Lumnitzera, 309, 454

Luzula, means of dispersal, 419, 427

- purpureo-splendens, 371, 377, 387, 402

Lycoperdon (Puff-ball), falling rate of spores, 424

Lycopodium; falling rate of spores, 424; L. selago, $371,374,377,379$; L. complanatum, 375, 380; L. plumosum, 492

Lyngbye, H. C., West Indian seeds and drift-wood in the Faroe Islands, 35, 40, 43,122

Lysimachia nemorum, var. azorica, 371, $374,377,379,387,402,419,422,432$

Macaronesian Islands (Azores, Canaries, Madeira); floras compared, 365, 385, $396,398-416$; plants of the woods, $406,407,415$; zones of vegetation, $407-411,415,416$; summit vegetation, 411,416 ; history of their plant-stocking, 411-414, 416; American elements, 412 ; comparison of climate and conditions, 365, 409; the dispersing agency and subsequent differentiation of the pigeons, 418; the Campanulas, 428; Juniperus oxycedrus, 431, 432

Machado, C., Portuguese botanist, 359, 364,385

McKeehan, L. A., falling rates of spores, 423

Madagascar; bottle and seed-drift and their tracks, 301, 304, 305; Sphagnum and Carex, 334, 343-346

Madeira :

Bottle-drift; recovered on the island, $52,53,54,484,485$; dropped into the sea in the vicinity, $56,57,67$, 464,465 
Madeirs (continued) -

Flora compared with those of the Azores and the Canaries (Teneriffe), $365,385,398-416,406-411$. See under Macaronesian Islands for the details of the comparison.

West Indian seed-drift, 38

Magdalena River, 17

Mahogany logs, transported by currents to Greenland, Iceland, and NorthWest Europe, 35, 40, 42, 48, 78

- canoe made of; stranded on the Faroe Islands, 40

Maiden, J. H., on the overlapping of the ranges of Ipomcea pes-capræ and Convolvulus soldanella in eastern Australia, 220

Maize, half-eaten cobs in beach-drift of South Devon, 29

Malagasy province, Sphagnum and Carex, $334,343-346$

Maldives, compared with the Bahamas, $255,256,274$

Malva; M. mauritiana, 492; M. nicæensis, 492

Mamillaria, 224, 287

Mammea, 84, 144, 326; M. americana, $4,11-13,87,91,144$

Manchineel. See Hippomane mancinella.

Mangifera indica (Mango); "stones" in beach-drift, 11, 30, 164

Mangle grande and Mangle chico (Rhizophora mangle), 99

Mangosteen (Garcinia mangostana), in European beach-drift, 28, 36

Mangroves :

Dispersal by currents, $86,90,94,96$, 451,452

Mangrove-formation; West Indies, 4, 18; Turks Islands, 10, 289; Jamaica, 15, 106, 108-110; Florida sand-keys, 450; West Indian and West African compared, 86, 89, 90 ; Asiatic and and American compared, 309, 454

Mangrove fruits and seedlings in beachdrift, $4,10,12,15,17,18,446,451$, 452

Stocking of islets with mangroves, 451

Vivipary of mangroves, 4, 502

(Further details will be found under Avicennia, Rhizophora, and Laguncularia)

Manicaria saccifera, 3-8, 11-14, 17, 25, $26,31,75,86,90,127$

Mann, H., Hawaiian flora, 170

Marantaceæ, 315

Marianne Islands, 201

Marias Islands, 201

Martin, M., on the West Indian seed-drift of the Hebrides and Mull, 22-25, 31, 41,43

Martins, Ch. ; effects of sea-water immersion on seeds, 188, 447; a pod of Cassia fistula washed up in the south of France, 154

Martius, on Manicaria saccifera, 128

Martyr, Cassia fistula in the West Indies, 155

Mary's Bean or Virgin Mary's Nut, names of stranded West Indian seeds in the Hebrides, 24

Mascarene Islands, Sphagnum and Carex, 334, 343-346

Masson, F., Azorean plants, 361, 385, 440, 493

Masters, on buried Juniper trunks from the Azores, 395

Matricaria maritima, 187

Mauritius, Carex and Sphagnum, 344-346

Mayor, F. S., earliest cultivated plants in the Azores, 397, 440

Medanos, moving sand-dunes in Peru, 270, 271, 493-495, 503, 504

Medicago, 390

Mediterranean, bottle-drift from the Atlantic, 53, 56

Melocactus communis (Turk's-head Cactus), 202, 224, 280, 283, 287, 292

Mentha; M. pulegium, 492; M. rotundifolia, 492

Menzies, Conocarpus erectus, 201

Menziesia, distribution, 419

- polifolia (St. Dabeoc's Heath), 370 $373,377,386,387,402,411,433$; means of dispersal, $417,419,422$

Mertensia maritima, 187

Mesembryanthemum; a doubtful species in the Azores, 384, 404; M. crystallinum and M. nodiflorum in the Canaries and Salvages, 448,449

Mesquite (Prosopis juliflora), 168

Mexico, Gulf of; bottle-drift and its indications, $57,58,61,67,71-73,79$, 444,445

Miers, J., on Crescentia cucurbitina, 149; on Grias cauliflora, 211

Milium lendigerum, 491

Millspaugh, C. F.; author's indebtedness, 9; Cakile, 184-189; Conocarpus erectus, 201, 203; Ipomœa carnosa, 217-219; Alacran Shoals, 187, 188, 201, 231, 240, 250; Cayman Islands, 138, 192, $197,201,206,221,225,240,250,251$, 456; Florida sand-keys, 115, 156, 182 , 183, 203, 204, 231, 232, 450-453; Turks Islands, 278-287, 291; Porto Rico, 99, 168, 192; Jamaica and Cuba, 168,251 ; Bahamas, 114, 210, 220, 225; Yucatan, 157, 227

Milner, Sir W., West Indian drift seeds in the crops of petrels at St. Kilda, 31,32

Mimosa scandens, 32,35

Missel-thrush, as a disperser of Juniper seeds, 437

Mississippi delta, vegetation, 218, 252 
Molesworth, Lord; marginal notes in Martin's book on the Hebrides, 43

Molucca Beans, old name in Scotland and the islands for West Indian drift seeds, 22-25, 31-33, 42, 163, 458

Monaco, Prince of, investigations with floats in the North Atlantic, 43, 47, $49,51,52,53-56,64,68,79-81,461$, $466,469,472,483,484$

Monarde, N., old Spanish botanist, 45

Montevideo, bottle-drift, 71

Montrichardia arborescens, 455

Morelet, A., on the Azorean flora, 363, $365,368-370,374,385,440$

Morinda, 175, 226; M. royoc, 87, 88, 93, 95,225

Morocco, stranded bottle-drift, 51, 52, 53

Moronobea coccinea, synonym in part for Symphonia globulifera, $q . v$.

Morris, Sir D.; Jamaican beach seeddrift, $7,11,12,75,112,118,128,152$, 190, 458; Sacoglottis amazonica, 28, 43, 133-137; dispersal of Uncinia, 337, 500; Orinoco and Amazon drift, 7, 75

Moseley, Miss M., a seed of Entada scandens near Boulogne, 28

- Prof.; seed-drift off the coast of New Guinea, 132, 155, 190; Fernando Noronha, 170, 191, 220; dispersal in the Southern Ocean, 500

Mouchoir Shoal, 255, 258, 264

Mountains, ascending air-currents, 355, 425,439

Mucuna; problems of the distribution of the genus, 133; unidentified species in the Trinidad beach-drift, 13, 121, 124

- altissima, 120-123, 455, 459

- pruriens, $122,457-459$

- urens; general discussion, 120; station, 16, 87, 91, 123; seeds in West Indian beach-drift, 11-14, 17, 121, 131 ; seeds in European beach-drift, 4, $22,25-28,26,31-36,122,123,131$; seeds in Azorean beach-drift, 37, 38; dispersal by currents, 87,123 ; species confused with M. pruriens, 122, 457459

- near M. urens, 87, 120; seeds in West Indian beach-drift, 11-13, 121, 131; seeds in European beach-drift, $26-28,34,122,123,131$, and in Azorean beach-drift, 37, 38

Mueller, Baron F. von; on Acacia farnesiana, 166, 172; on Juniperus communis, 431

Müller, K., currents and plant-dispersal in the southern hemisphere, 39,43

Mull, stranded West Indian seeds, 24, 31

Murray, Sir J., quoted by Wallace, 422

Musaceæ, 315

Mushrooms, falling rates of spores and dispersal by winds, $355,423,424,439$

Mutisiaceæ, 327
Myrica faya; in Azores, 369, 375, 376, $382,386,392-395,398,401,433,435$; in Canaries, 406, 408; in Madeira, 406, 407,410 ; means of dispersal, 417, 418; long established in Portugal, 361, 433, 434; origin of the name, Faya, 433

Myrsinaceæ, 314, 315

Myrsine africana, 369, 370, 374-376, 380, $382,383,386,392,401,406,413$, 434

Myrtaceæ, Andrews on the development of the order, 317

Myrtus communis, 392

Nash, G. V., plants in the Inaguas and in the Turks Islands, 286, 287

Natal, bottle-drift from off the coast to Brazil, 62, 63

Natural Order. See Family.

Nautical Magazine, bottle-drift data, 46, $50,54,57,66,69,443,464,474,482-$ 484 , etc.

Navidad Shoal, 255, 258, 264

Neill, P., Molucea beans, 43

Nepenthaceæ, 315

Nerium oleander, 491, 492

Nertera, 294

Neumayer, G., bottle-drift in high southern latitudes, 49,81

"Newcastle," H.M.S., bottle-drift in North Atlantic, 50

Newfoundland, bottles thrown overboard south of this region, $52,53,55,66,68$

"New York," s.s., bottle-drift, 49, 465

New Zealand; Sphagnum and Carex, 332-358, 347-352, 357 ; Uncinia, 498501 ; bottle-drift and current-connections, 294-312, 299, 309-312

Nicaragua, bottle-drift, 50, 57-59, 61, 475

Nicker (Nickar), West Indian name of Guilandina seeds, 30, 34, 140, 457

Niger; probability of its seed-drift reaching not only Brazil and the West Indies but also Europe, 74, 81 ; flora, 99, 131, $159,194,196,207$

Niihau (Hawaiian Islands), Ipomoea carnosa, 218

Nipa fruticans, 128, 168

Norfolk Island, possessing New Zealand Carices, 348; current-connections, 297, 298

North Cape (Norway); West Indian seeds stranded on and doubling the cape, $\mathbf{3 6}$, 78,81 ; stranded bottle-drift, $54,55,65$, 495

Norway; stranded West Indian seeds, 21-23, 27, 35, 36, 78, 81, 173; stranded bottle-drift, $52,53,65,495$; Cakile in beach-drift, 186, 188; casks from the Gulf of Guinea, 76, 81, 481; mahogany baulks from the West Indies, 40

Notelæa excelsa. See Picconia excelsa. 
Nova Scotia, bottles thrown overboard south of this locality, 52, 66

Nymphæa ampla ; in Jamaica, 16, 105 , 107 ; in Grenada, 455

Ocean-holes, in the Bahamas, 258, 276, 503

Ochrosia, 5, 454

O'Connell, S., West Indian seeds on Irish coast, 31

O'Dowd, Miss, seeds of Guilandina bonducella on the shores of South Australia, 140

Olafsen, drift-wood in high northern latitudes, 45

Oleander, 491, 492

"Olive " tree (Bucida buceras), 16, 17

Oliver, D., 134, 150, 251

Omphalea ; O. diandra, 11-13, 159, 227 ; O. triandra, 160, 226

Oolitic structure, in the æolian sandstone of the Bahamas, 260-262, 502-504

Opuntias, 168, 204, 224, 278-280, 282, 287

Orchids; falling rate of seeds and their dispersal by winds, $354,355,422-425$, 439. See Habenaria and Serapias.

Oreodaphne fœetens, 408

Orinoco seed-drift and its distribution over the West Indian region, 6, 7\%, 8, $13,19,74,75,81,129,141,486$

Orkney Islands; stranded West Indian seeds, 22, 25, 26, 32, 122, 162, 163, 458; stranded bottle-drift, $52,53,471$; stranded turtle, 40

Ormesteen (Adder-stone), old Norse name of the drift seed of Guilandina bonducella, 23

Ornithopus perpusillus, 492

Orton, Dr., pelagic organisms on English beaches, 29

Osborn, J. F., map of Grand Turk, 268, 491

Osmunda regalis, in Azores, 369, 376, 380,434

Ostboe, Sargasso weed in the vicinity of the Azores, 485

Ostenfeld, West Indian seeds on the Faroe Islands, 35, 44

Owen, Captain; survey of the Turks Islands, 489, 490

Oxalidaceæ, 315

Oxalis corniculata, in the Azores, 390, 391

\section{Pacific Ocean :}

Beach-drift of the tropical Pacific and of the West Indies compared, 5

Bottle-drift, seed-drift, and the currents; number of bottles, 47 ; connection round the Horn with the South Atlantic, 63, 74, 300; across the South Pacific from New Zealand and Antarctic Islands, 295, 299, 300,
Pacific Ocean (continued) -

306-310; across the tropical Pacific from equatorial America, 297, 298, 306,310

Vegetation of coral-reef islets in the West Indies and in the Pacific Ocean compared, 453, 454

Page, J. ; bottle-drift observations of the

U.S.A. Hydrographic Office, 81, 312; a remarkable drift from off Cape Horn to Queensland, 295, 296; an interesting drift in the tropical Pacific, 297

Paki, Jamaican name of Crescentia cucurbitina, q. $v$.

Palma (Canaries), Juniperus oxycedrus, 408

Panama Isthmus; plants, 132, 191 ; beach-drift, $6,14,17$; derelict stranded from Cape Hatteras, 72

Pancratium, 194, 447

Pandanaceæ, 315 ; Pandanus, 5, 454

Pantropical genera, 319

Pao branco, Azorean name of Picconia excelsa, $q . v$.

Paritium, synonym in part for Hibiscus. See under H. elatus, $H$. tiliaceus.

Parlatore, Prof., on Juniperus brevifolia, 431

Parrots, in connection with the dispersal of Anona seeds, 175

Parry, Captain, bottle-drift in high northern latitudes, 484, 496

Passiflora; fruits in beach-drift in South Devon, 30, 289; P. pectinata, 289; P. cuprea, 289; modes of dispersal, 289

Pauw, De, on drift-wood in high northern latitudes, 45

Pavonia corymbosa, 105

Pax, F., Hippocratea, 13; Hippomane mancinella, 113-115; Hymenæa, 140; Omphalea, 160, 227; Lysimachia nemorum, 432; Anagallis filiformis, 480, 481

Pea-nut. See Arachis hypogøa.

Peel, C. V., on West Indian seeds and turtles thrown up on the Outer Hebrides, $32,40,44,122$

Peirce, G. J., dispersal of Arceuthobium, 427

Pelagic organisms of warm latitudes on English beaches, 29

Pennant, T.; West Indian seeds and other drift stranded on the Hebrides, 22, 24, $32,40,41,44,161,163$

Penzig, O., the new Krakatau flora, 116, $142,154,190$

Peplis portula, in the Azores, 371, 378, $380,387,403,417,420$

Persea, 318

- azorica. See Laurus canariensis. indica (Laurus indica), 369, 386, 401, 406-408, 435; dispersed by pigeons, 418 
Peru; medanos or moving sand-dunes, $270,271,493$

Peruvian (Humboldt) Current, its influence on climate, 271, 272, 275

Peterson, P., respecting Foula in the Shetlands, 34

Petherick, on drift-wood in high northern latitudes, 45

Petiver, J.; West Indian seeds on European beaches, 41, 44; Ipomœa tuberosa, 33, 161, 163; Manicaria saccifera, 128; Sacoglottis amazonica, 137

Petrels; West Indian drift seeds in their crops, 31, 32; as seed-dispersers in the Southern Ocean, 500

Philodendron, 16

Phobe, 412 ; P. barbusana, 408

Phonix canariensis, 408

Phoradendron, 194

Phragmites, 179, 252, 377

Phyllanthus, 168; P. epiphyllanthus, 280, $281,283,285,288,292$; P. falcatus, 85 , 210

Physalia (Portuguese man-of-war), in beach-drift; south of England, 29; Azores and Canaries, 38

Physalis peruviana, 491

Phytelephas macrocarpa (Vegetable Ivory), 17

Piazza, Captain; bottle-drift on east coast of Africa, 303

Picconia excelsa (Notelæa excelsa), 369, $376,386,392,401,407,408,410,418$, 435

Pico (island and mountain of). See under Azores.

__ da Vara, San Miguel, 382, 383, 430432

Topo, corrected altitude of, 365,379

Pigeons, as seed-dispersers. See under Birds.

Pigs, agents in dispersing seeds, 112, 144, 175,243

Pines, in the Macaronesian islands, 408410

Pinus canariensis, 408, 409

"Pique," H.M.S., bottle-drift from Ascension, 482

Piscidia erythrina, 208, 209

Pistias, 3, 16, 104, 105, 107

Pithecolobium; represented in Turks Islands, 287, 292 ; P. filicifolium, 111

Plantago; mode of dispersal, 418, 421 ; Pl. coronopus, 384, 404, 421; Pl. lanceolata, $390 ; \mathrm{Pl}$ major, 390

Plate River (La Plata), estuary of, concerning the distribution of its seeddrift, $62,73,74,81$

Plocama pendula, 408, 448

Pluchea, 285, 292

Plukenet, on Manicaria saccifera, 31, 128, 129

Podocarpus, 294, 327
Polycarpon tetraphyllum, 491

Polygala vulgaris, on Pico, 370, 371, 372, $374,377,379,386,387,402,417,435$

Polygonum; dispersal by birds, 418, 421 ; P. glabrum, 105-107; P. maritimum, $219,384,388,404,421$

Polymorphous species, $313,314,322$

Polytrichum, growths of, in the Azores, $371,377,379,382,383,387$; falling rate of spores and their dispersal by winds, 424

Pontederia (Water Hyacinth), 3, 16, 105, 107

Pontoppidan, E., on the West Indian seeds of Scandinavian beaches, 21, 35, 41, 44

Populus (Poplar), Portuguese names, 434

Porto Pym (Azores), beach plants, 218, 219,384

- Rico, stranded bottle-drift, 56, 58, 62

Portsmouth (England), West Indian seed stranded, 28

Portugal; stranded bottle-drift, 52, 53, 68 ; bottles cast into the sea off the coast, 57, 66

Portuguese Current, 54, 56

Portulaca; P. halimoides, 109 ; P. oleracea $277,279-281,291,477,478$; peculiar species in islands, 478

Potamogeton; fruits in floating river and pond-drift, 16,420 ; dispersal by waterfowl, 417, 420; P. fluitans, 107; P. natans, 378; $\mathrm{P}$. plantagineus, 104, 105 , 107 ; P. polygonifolius, $371,378,380-$ $382,387,403,420$

Potentilla tormentilla, 371, 377, 379, 387, $402,417,419$

Pouchet, F. A., currents in the southern hemisphere, 39, 44

Povelsen, on drift-wood in high northern latitudes, 45

Praeger, R. Lloyd; West Indian seeds on the Irish coasts, 31 ; falling rates of seeds in connection with dispersal by winds, 354, 422-425, 439; seedbuoyancy, 447, 473

Prain, Sir D., on the wood of buried Juniper trees in the Azores, 395

Premna, type of buoyancy in "stones" of drupaceous fruits, 234

Prickles in beach-drift, 164

Prickly Pear. See Opuntia.

Prickly-Yellow (Zanthoxylum), prickles in beach-drift, 164

Primocarex, 345, 357, 501

Primulaceæ, 314, 315

"Prince Eugene," s.s., bottle-drift from off the Amazon to Florida, 75, 445

Prioria copaifera, fruits in beach-drift, 6,17

Problem plants. See Acacia farnesiana, Campanula vidalii, Chrysobalanus icaco, 
Colubrina asiatica, Crudya spicata, Grias cauliflora, Hibiscus tiliaceus, Hippomane mancinella, Myrsine africana, Symphonia globulifera, Thespesia populnea

Prosopis, 102, 168

Proterceæ, 317, 327

Prunus lusitanica, 392, 400

Psamma arenaria, 186

Pteris aquilina (Bracken), 371, 375-377, $379,387,492$

Puff-ball (Lycoperdon), 424

Pumice, in the interior of San Miguel, $382,383,479$; in beach-drift, 6,164 , $242,248,446,479$; as seed-carriers across seas, $248,291$.

Purdy, J., in "Columbian Navigator," 81 ; bottle-drift, 64,465 ; boa-constrictor transported across the sea, 486

Pusey, J. H. ; 'Turk's-head Cactus, 224 ; Grand Turk, 285; bottle-drift in Turks Islands, 462.

Quercus, 326

Race, Cape; bottle-drift. See under Newfoundland.

Randia aculeata, 287

Ravenala, 326

Rein, Dr., on the Calabash-tree in Bermuda, 146

Reinecke, F., Samoan flora, 171, 246

Remy, Niihau, Hawaii, 218

Rendle, Dr. :

Conocarpus erectus and its alleged occurrence in the Pacific islands, 201

Foreign seeds in European beach-drift; Ipomøea tuberosa, 162; Lucuma, species, 29

On Jamaican plants, 178, 184, 185, $193,194,197,198,200,253$

The use of the name, Mucuna pruriens, 459

Rennell, J.; currents of the North Atlentic, 20, 82; bottle-drift of high northern latitudes, $46,50,57,66,484$, 496; drift of a bottle from Ascension to Guernsey, 482; Sargasso weed, 485; drift-wood, 45

Reseda luteola, 491

Retama(Spartocytisus nubigenus), 409,411

Rhachicalius rupestris, 85, 279, 291 (Rh. maritima is a synonym)

Rhamnus, 406, 408, 417, 418; Rh. glandulosa, 410; Rh. latifolius, 369, 375, 386, $400,407,436$; Rh. lycioides, 434

Rhinoceros, seed of Entada scandens found in its cæcum, 120

Rhizophora; distribution, 141, 228, 309; period required for the growth of seedlings on the tree, 96, 109; Rh. conjugata, 96; Rh. mucronata, 96, 99, 100, 141 ; Rh. racemosa, 99
Rhizophora mangle :

Distribution, 86, 141, 228, 308; dispersal by currents, $4,86,90,291$; seedlings in beach-drift, 4, 12, 17, 446

Period required for the growth of the seedling on the tree, 96 ; on its ability to withstand drying, 96 ; on the proportion of germinating fruits with more than one seedling, 98; the absence of dimorphism in the West Indies, 99, 110; the length attained by the seedlings on the tree, 99 ; the influence of varying degrees of salinity on the station, 99; colonies in the midst of the Black River Morass, 102. In Jamaica, 15, 106, 108-110 ; Turks Islands, 10, 283, 289; Ecuador, 178; Florida sand-keys, 451-454

Ribiera Grande bluffs, Pico, 366, 496

Rice, Prof., Bermudian æolian rocks, 259

Ricinus communis, 290, 447

Ridley, H. N., plants of Fernando Noronha, 121, 170, 191, 220; Cassytha filiformis in the Malay Peninsula, 192

Rio de la Plata. See Plate River.

- Negro, 131

Rivers; as sources of seed-drift, $2,3,18$, etc.; germination of floating fruits and seeds in river-drift, $3,5,15,16,18$, $125,127,205,213,243$; temperature of head-springs, 104. See Black River under Jamaica, Guayas River under Ecuador, Amazon, Orinoco, etc., and Estuaries.

Robert, E., on the stranding of seeds of Entada scandens near the North Cape and in the White Sea, 36, 44; driftwood in high northern latitudes, 45

Rodriguez Island, Sphagnum plants, 344, 346

Romano, or Romani, Azorean name of Vaccinium cylindraceum, 437

Ross, Captain; bottle-drift in Davis Strait, 484, 496

Rubus species in Azores, 369, 376, 400.

Ruderal plants. See Weeds.

Rumex, 390

Russell, H. C.; bottle-drift in Australian waters, 295, 299, 312

Sabal; S. umbraculifera in Jamaica, 16, $105,106,109$; S. palmetto of South Florida, 179; S. blackburniana of Bermuda, 204

Sabine, Sir E., on the drifting of casks from the Gulf of Guinea to the north of Norway, 76, 81, 481, 482

Lady, 497

Sable Island and Cape Sable. See under Nova Scotia.

Sacoglottis amazonica, 3-7, 11-14, 17, $25-28,31,86-88,90,91,93,95,133$, 
For its representation in European beach-drift, see pages $26,133-137$.

Safflower, 492

Safford, W. E., on the genus Anona, 174181

Sagina procumbens, the possibility of its dispersal by winds, 422, 424, 439

Sagittaria; S. lancifolia of Jamaica, 16, 104-107, and of South Florida, 179

Sagot, M. P., on Mucuna pruriens, 459

St. Croix, 6 ; shore plants, $244,456,457$

St. Dabeoc's Heath. See Menziesia polifolia.

St. Helena; position with reference to the equatorial currents and the indications of bottle-drift, $60,443,474,475,531$; the flora and the currents, 459, 460; endemic species of Carex and Sphagnum, 343

St. Kilda, 31, 32

St. Michael's, Azores (San Miguel), 382, $387,393,396,397$

St. Paul, Southern Ocean, Uncinia, 498, 501

St. Paul's Rocks, Equatorial Atlantic, bottle-drift from their vicinity, 50, 59, $61,67,70,443,444,475$

Salcombe, South Devon, stranded West Indian seeds with other seed-drift and pelagic organisms, $28,29,30$

Salicornia; in Jamaica and Ecuador, 101, 106, 108, 109; S. ambigua in Turks Islands, 283, 290-292, and in the Florida sand-keys, 451-453; distribution and mode of dispersal of the genus, $452,453,478$

Salinity of estuaries. See Estuaries.

Salix, 179

Salsola kali; in the Azores, 219, 384, 388, 404,421 ; fitness for dispersal by currents and birds, 421,447

Salt Key Bank, L. Agassiz on the, 261

Lakes district. See under Jamaica.

Salt-rakers, in the Turks Islands, 277, 487

Salvages, Mesembryanthemum, 449

Samolus valerandi, Azores, 421

Sampaiao, J. A. N., Portuguese botanist in the Azores, 359, 364, 385

Sand-dunes, 503. See under Medanos.

San Domingo. See Hispaniola.

Sand-keys; Florida, vegetation and plant stocking, 450-453, comparison of vegetation of sand-islets in West Indies and tropical Pacific, 453

Sanguinho, Azorean name of Rhamnus latifolius, 436

Sanicula azorica, 375,418

San Jorge (Azores), 364, 397, 427-429, 432-438; Juniper trees, 396

- Miguel (Azores); flora, 382, 387; original forests and their destruction, 393, 396, 397; buried Juniper trees, 393-395
Santa Barbara, Terceira; vegetation, 383,387

- Maria, West Indian name of Calophyllum calaba, $q \cdot v$.

- Rosa River, Ecuador, 100

Sapindus saponaria, $11,25,26,37,87$, $88,91,95,156,219$

Sapium, 114

Sapotacea; seeds stranded on the Devonshire coast, 29; represented in the floras of Madeira, Cape Verde Islands, and Hawaii, 410, 488, 489

Sargasso Sea, 38, 64, 461, 485

Weed; in the Gulf of Mexico and the Florida Stream, 485; in the beach-drift of the West Indies, 6, of the Turks Islands, 446, of the Azores, 38, 485, of Cornwall and Shetlands, 486

Sarraceniaceæ, 314, 315

Sassafras, 318

Saussure, Necker de, 44; stranded West Indian seeds and turtles in the Hebrides, $32,40,41$

Savanna-la-mar, Jamaica, vegetation, 106

Scævola, 171, 175, 192, 193, 207, 227, 447 ; Sc. kœnigii, 227, 447, 454; Sc. lobelia, 447, 448; Sc. plumieri, 5, 17, $86,92,227-236,242,277-283,288$, $291,446,447,451-454$

Scandinavia; West Indian seod-drift, $21,23,25,27,35,78,81,122,146$, $153,162,173,208$; stranded bottledrift, 52, 53, 65, 495

Scharff, R. F., 331, 460, 497; similarity in the structure of the Bermudas and the Bahamas, 273; origin of the Bermudian flora and fauna, 466; on the North polar area as a dispersion-centre, 325

Schimper, A. F. W., 294; Indo-Malayan strand plants, 141, 157, 167, 192, 229, 458 ; littoral plants of tropical America, $143,156,203,204,447$; buoyancy of seeds and fruits and dispersal by currents, $93,116,156,203,207,225,231$, $234,242,248$; foliage of Juniperus nana, 431, 432

Schjöth, A., West Indian seed-drift on European beaches, 20, 44

Schmidt, J. A., on plants of the Cape Verde Islands, 155, 167, 170, 488

Schott, G., on bottle-drifts and their indications in the Atlantic, Indian, and Pacific Oceans; Atlantic, 46-82; Southern, Indian, and Pacific Oceans, 294-312; data relating to particular regions and localities and utilised in the Notes of the Appendix as given in the list on page 441, viz. on the Equatorial Atlantic Currents, Azores, Bermudas, Canaries, Madeira, Turks Group, etc. ; derelicts, 472, 473 
Schulz, on Cakile, 185

"Schwan," s.s., bottle-drift, 475

Scilly Islands; sea-fans, 22; capture of a Leathery Turtle, 41.

Scirpus, 417; S. constrictus, 455; S. fluitans and S. multicaulis, 371,378 , $380,381,387,403,420$; S. palustris, $381,403,420$; S. plantagineus, 105 , 455; S. savii, 378,403

Scitamineæ, 315

Scleria, 455

Scotland and the Hebrides; stranded West Indian seeds, 22-27, 31, 122; bottle-drift stranded, $49,52,53,65$, 68. See also Hebrides.

Sea-apple (Manicaria saccifera), 127

Sea-bean (Entada scandens), 21, 22

Sea-birds, as seed-dispersers. See Birds, Gulls, Petrels, Frigate-birds, Boobies.

Sea-coconut (Manicaria saccifera), 127

Sea Finns, West Indian drift seeds, 25

Sea-nut, West Indian drift seeds, 22

Sea-side grape, Coccoloba uvifera, $q . v$.

Securinega buxifolia, 434

Seeds; falling rates, $354,355,422-425$, 439; mucosity, 419, 421, 427; hypocotylar, 213, 214, 243

Seemann, B., Dioclea panamensis, 132 ; Acacia farnesiana, 171; Thespesia populnea, 246; Ximenia americana, 253

Selaginellæ, 375

Selala, the seedless Rhizophora of Fiji, 99,110

Sempervivum, in the Canaries, 408, and Madeira, 410

Senecio, capacity for dispersal by winds, 425,439

Sequoia, 318, 327

Serapias, 377

Sernander, R., West Indian seeds and fruits on the Scandinavian coast, 21 , $36,37,42,44,122,146,153,173$ dispersal of Juniperus communis, 430 ;

Sesuvium, 101, 279, 280, 290; S. portulacastrum, 278-281, 288, 291, 451-454, 477

Sete Cidades, Azores, 394, 396

Seubert, M.; on the flora of the Azores, 359 , 362, 363, 368-370, 385, 389, 392, $428-438,440$; zones of vegetation on Pico, 368; reliability of the altitudes, $362,363,425$

Seven-year apple. See Genipa clusiifolia, 210

Seven-year vine, Ipomœa tuberosa, 210

Seward, A. C., on the Glossopteris flora, 328,331

Shaler, Prof., submarine springs off Florida coast, 497

Sherardia arvensis, 491

Shetland Islands; West Indian seeds stranded, 22, 24, 27, 34, 122; also turtles and drift-wood, 40-42; stranded bottle-drift, $52,53,65$

Shreve, Forrest, the forests of eastern Jamaica, 156, 243

Sibbald, Sir R., West Indian seeds on the beaches of Scotland and of the islands, $23,31,33,44$

Sibthorpia, 420 ; S. europea in the Azores, $371,375,383,387,402,420,436$; on its fitness for dispersal, 419, 422

Sicyos angulatus, 294

Sideroxylon, in Hawaii, 489; S. mermulana, in Madeira, 410

Sierra Leone; bottle-drift from the vicinity of St. Paul's Rocks, 50, 59, 475 , and from off the north coast of Brazil, 59, 476

Silene maritima; in Iceland, 187; in the Azores, 384, 388, 404, 421 ; capacity for dispersal by currents and sea-birds, 418,421

Silver Bank, 255, 258, 264

"Sir Edward Hawke," King's Schooner, 265,489

Skye, Isle of ; bottle-drift, 68

Sloane, Sir H.; West Indian seeds on the Irish and Scottish coasts and on the Hebrides and the Orkneys, 21-24, 30$34,41,44,122,128,136,137$. Remarks on some Jamaican plants, Spondias lutea, 111, 113; Hippomane mancinella, 115; Mammea americana, 144; Crescentia cujete, 147; Cassia fistula, 152, 155; Sapindus saponaria, 157; Grias cauliflora, 211; Guilandina, 457. References to the drift fruits of Manicaria saccifera, 128, etc., Sacoglottis amazonica, 136, 137, and Ipomoea tuberosa, 161-163, the prickles of Zanthoxylum, 164, and the sea-fans of the Scilly Islands, 22

Smilax; in the Azores, 369, 376, 380, 392, 401; in the Canaries, 401, 406, 408; modes of dispersal, 417,418

Smith, Lea, stranded alligator in the Turks Islands, 487

Snakes, transported by currents to islands, Keeling Atoll, St. Vincent, Turks Islands, 303, 486, 487

Snuff-boxes, seeds of Entada scandens from European beaches thus used, 25, 33

Soap-berry. See Sapindus saponaria.

Solan Goose, Molucca beans found in its nest, 31

Solanum pseudo-capsicum, 491

Solidago sempervirens, 385, 404, 421

Solomon Islands, Dioclea reflexa, 132

Solvent-stone, signification of old Norse name for the stranded seeds of Entada scandens, 23

Sonchus oleraceus, capacity for dispersal by winds, $424,425,439$ 
Sophora, 133, 239; S. chrysophylla, 239; S. tetraptera, 239, 294, 307, 308, 311; S. tomentosa, 6, 12, 87, 92, 198, 207, $23 \%, 244,286,288,291$

Spain; stranded bottle-drift, 53, 68; bottles thrown overboard off the coasts, 57,66

Spartium junceum, 492

Spartocytisus nubigenus (Retama), 409, 411

Spergularia marina, 384, 388, 404, 418, 421

Sphagnum. See under Carex compared with Sphagnum, as indexed under Carex, 332-358. The principal species there referred to are: cymbifolium, 349 ; fimbriatum, 337-339, 348, 349; junghuhnianum, 350 ; medium, 337$339,348,349$; mexicanum, 337, 338 ; papillosum, 349; pappeanum, 344, 346 ; plumulosum, 337,338 ; pulchricoma, $337,341,344,346$; rufescens, 341 ; torreyanum, 337,338 ; turgidulum, 341.

Spirula, shells in beach-drift, 6,38

Spondias lutea (Hog-Plum), 4, 11-14, $17,87,91,111,193$

Spores, falling rates of, 355, 422-425, 439

Springs; probable sea-water springs in the Black River Morass, 101, 102; fresh-water springs in the same morass, 104; submarine springs, 497; springs on Pico, 496, 497

Spruce, R.; Carapa guianensis, 141, 143; Grias, 212; Manicaria saccifera, 128; Omphalea diandra, 160; Phytelephas, 17

Spunk-box, origin of the Hebridean name for Entada scandens, 25

Stachys arvensis, 391

Stapf, Dr., Sacoglottis amazonica, 134, 135

Statice; numerous Canarian species, 408,448 ; S. bahamensis, 285,286 ; S. limonium, 384

Sterility and cold currents. See Climate.

Sterpin, J., translator of the book of Debes on the Faroe Islands, 23

Stewart Island, Uncinia, 498

Storks, migrating from Europe to South Africa, 354

Ström, Norwegian naturalist of the eighteenth century, on the tropical seeds in Scandinavian beach-drift, 22, $35-37,41,44,146,153$

Suæda, 290

Subsecunda, Sphagnum subsection, similar behaviour in Africa and Australia, $344,353,357$

Sugar-cane, early cultivation in the Azores, 397

Suriana maritima; general treatment, 239; in the Turks Islands, 278-283,
288, 289, 291; in the Florida sandkeys, 451, 452; influence of wind-pressure on its growth, 446, 447; represented in beach seed-drift, $6,241,242$; distribution, $85,87,92$

Swallows, migration from Great Britain to South Africa, 354

Sweden; stranding of West Indian seeds, 27,36 , and bottle-drift, 52

Swietenia mahogani, 242; its associates in the open forests of Jamaica and Cuba, 111, 112. See under Mahogany.

Symphonia, 83, 84; S. globulifera (Hoggum); general treatment, 243; details, $3,15,16,83,86,88,90-92,95$, 159,205

Syngonium, 16

Tabernæmontanus, 44, 45

Tamarind, 155

Tamujo (Tamucho), name in Azores of Myrsine africana, 434

Tansley, A. G., Sphagnum tussocks, 377

Taxus baccata (Teixo), in the Azores, $369,370,380,386,387,392,393,401$, $405,406,417,418,436$

Taylor, N., plants of Grand Turk, 286, 287

Teneriffe; flora and zones of vegetation compared with those of Pico (Azores) and Madeira, 406-411, 415; summit plants, 411 ; shore plants, 448 ; Sphagnum, 344, 346; ascending air-currents, 425; climate compared with that of Pico and Madeira, 409; angle of the mountain's slope, 366; Dragon-tree, 487 ; beach-drift, 38 ; bottle-drift from Greenland waters, 484, 496

Terceira; Santa Barbara ascent, 383 , 387 ; original forests, 393 ; buried Junipers, 395

Terminalia, 83, 84, 116, 175, 204, 231 ; T. katappa, $6,11,116$

Tetragonia expansa, in Azores, 385

Texas, the chaparral scrub, 167-169, 229; bottle-drift stranded, 58. See under Mexico, Gulf of, for other data.

Thespesia, 83, 326; T. populnea, general treatment, 244; compared with Acacia farnesiana and Hibiscus tiliaceus, 172; seeds and capsules in beach-drift, 5, 6,12 ; references to station, etc., 87 , $92,116,168,194,197,200,287,288$, 291 ; T. danis, 246

Thomson, A. L., migration of storks, 354

Thrinax, 109, 287

Thuret, G., floating capacities of seeds, 447

Thymus serpyllum, var. angustifolius of the Azores, 370-373, 376, 377, 383, 386, 387, 402, 407, 411; concerning its dispersal, 417, 419, 422 
Tierra del Fuego. See Fuegia and Cape Horn.

"Tilbury," H.M.S., long drift of mast, 40 Tilia, 326

Tillandsia, tumble-weed in Peru, 271, 493

Tillinghast, W. H., on old maps of the Bahamas, 264, 276

"Times"; capture of a Leathery Turtle off Scilly, 41; bottle-drift in the Southern Ocean, 49, 300

Tobago; beach-drift, 6, 13, 121, 129; beach-trees, 245 ; stranded bottle-drift, $60,61,73,75$

Toland, J., marginal notes in a copy of Martin's book on the Hebrides, 43

Tomlinson, seed of Entada scandens on the Irish coast, 31

Tonning, West Indian seeds on Scandinavian coasts, $22,23,35,37,44,146$, $153,208,209$

Tournefortia, 248; T. argentea, 24ry$251,453,454$; T. sarmentosa, 248

- gnaphalodes; general treatment, 247-251; in the Turks Islands, 202, 278-283, 288, 291, 292; on the Florida sand-keys, 451-454; distribution and dispersal, $87,88,93,95,228$; represented in beach-drift, 6,242 ; influence of wind-pressure on growth, 446, 447

Tree-Euphorbias. See Euphorbia stygiana.

Tree-Heaths. See Erica arborea and E. azorica.

Tree-Lobelias, 321

Trelease, W., on the Azorean flora, 364, 385,440 ; proportion of indigenous plants, 389, 391; re-discovery of Isoetes, 429; on Campanula vidalii, 427 ; on other plants, $185,359,362$, $389,392,431,433-438,491,492$

Treub, M., the re-stocking of Krakatau with plants, $116,142,154$; experiments at Buitenzorg on Scævola koenigii, 234, and Tournefortia argentea, 249

Trichomanes speciosum, in Azores, 375, 379

Trifolium, 390; T. arvense, 492

Trinidad Island (West Indies); beachdrift, $6,13,121,129,130,131,136$, 143 ; as a centre for receiving and distributing seed-drift, 74,81 ; the home of Manicaria saccifera, 129, and Sacoglottis amazonica, 133-136; stranded bottle-drift, $60,61,67,70,73,174,75$, $80,442-445,474,475$

Tristan da Cunha; stranded seeds of Dioclea reflexa, 132; the habitat of Uncinia, 498-501

Tristram, H. B., on a north polar centre of dispersion, 325

Tropæolaceæ, 314, 316

M M
Trovisco, Azorean name of Daphne laureola, 428

Tschudi, J. J. von, on the medanos on moving sand-hills of Peru, 270, 271, 494

Tulloch, J., West Indian seeds from the Shetland coasts, 34, 131

Tumble-weed, in sandy plains of Peru, 271,493

Tunis, stranding of bottle-drift from the Atlantic, 53

Turk's-head cactus. See Melocactus communis.

Turks Islands :

Bottle-drift; stranded on the islands, $49,54-57,58,64,462-465$; bottles dropped overboard in the vicinity of the islands, 465,477 ; connection with Bermuda, 470

Iguanas, alligators, and snakes, 486

Stranded seed-drift; suitability of the islands for the study of oceanic seeddrift in transit, $2,8,14,19$; list of plants supplying the foreign seeddrift, 10, 11; the materials of the local seed-drift, $\mathbf{4 4 6}$

The flora; general description, 277293; the separate islands, Pear Cay, 278, Penniston Cay, 278, Long Cay, 279, Gibb Cay, 280, Eastern Cay, 280, Round Cay, 281, Greater Sand Cay, 281, Cotton Cay, 282, Salt Cay, 283, 289, Grand Turk, 283-290 ; dispersal agencies, 290; influence of windpressure on plant-growth, 446.

The geology and general characters, 254-276. See summary of results on p. 273.

Turtles, carried by the currents from West Indian waters to north-west Europe, $40,42,48,78$

Typha; in Jamaica, 15, 105-107 ; capacity for dispersal by winds, 423 424,439

Ubussu palm (Manicaria saccifera), 128

Ule, E., Sphagnum in South Brazil, 353

Umbelliferæ, unidentified shore plant of Teneriffe, 448

Uncinia, 294, 358, 498-501; dispersal by birds, 337,500 ; U. compacta, 498; U. brevicaulis, 498; U. jamaicensis, 500 ; U. kingii, 501 ; U. macrolepis, 498,501

Underground waters, soakage seaward in volcanic islands, 497

Uniola paniculata, 85, 280, 282, 291, 451, 453

United States Hydrographic Office, charts of bottle-drift tracks in the North Atlantic, 47, 54, 66, 75, 82, 466-471, etc. See under J. Page. 
Urban, I., references to West Indian plants in his Symbolæ Antillanæ, 92, $128,134,144-148,181,184,217,220$, $226,244,250,426,455-457$

Utricularia, in Jamaica, 16, 104, 105, 107

Vaccinium; in the Canaries, 406, 408; in Madeira, 407, 410; dispersal by birds, $418 ; \nabla$. cylindraceum, in the Azores, 369, 370, 374, 375, 380, 382, $383,386,392,401,437$

Vaughan, T. W.; on the formation of the Western Bahamas, 254, 276, 504; the rolian rocks of the Bahamas and Bermudas compared, 273, 502; oceanholes, 258, 503. A bulky volume by this author on reef-corals and their associated phenomena is now (October 1916) being published by the Carnegie Institution of Washington.

Vegetable-Ivory palm (Phytelephas), 17

Velellæ, washed up on the south coast of England, 29

Venezuela; bottle-drift brought by the Main Equatorial Current, 60, 61, 73, 75

Verbascum, in Azores, 375

Verbena officinalis, 491

Vette Nyre (Fairy kidneys), old Norse name for the stranded seeds of Entada scandens, 23,25

Vibe, A., West Indian seed-drift in Scandinavia, 20,36, 41, 44

Viburnum; in the Canaries, 405, 406, 408, 438; mode of dispersal, 418; V. tinus, in the Azores, 360, 369, 375, $376,382,386,392,401,405,437$

Vicia sativa, 492

Vidal, Captain; survey of the Azores, 365 , 366; discoverer of Campanula vidalii, 427

Vigna, 252; V. lutea, 250, 252; V. luteola, $6,87,92,250$

Vinca rosea, 290

Viola; palustris, 371, 377, 387, 402 ; paradoxa, 411 ; teydensis, 411

Virgin Islands, shore plants, 116, 244, 457

- Mary's Nut, Hebridean name of stranded West Indian seeds, 24

Visnea, 412

Vogel, Dr., on the shore vegetation of African west coast, 159, 194, 207

Wahlenberg, G., West Indian seeds stranded in northern Scandinavia, 35, 36,44

Wales, stranding of West Indian seeds and fruits, 26, 30

Walker, W. F., on the Azores, 440; the original forests and the trees buried in volcanic ashes, 393-397, 437; "sargasso "weed washed up on the islands, 485; the Madeir an juniper, 410
Wallace, A. R., the Azorean flora from the standpoint of dispersal, 390,413 , 440; dispersal of seeds by winds, 422, 439 ; plant-stocking of Bermuda, 466 ; survival of ancient groups of plants, 318

Wallace, Rev. J., ) on West Indian seeds, Wallace, Dr. J., $\}$ etc., thrown up on the Orkney Islands, $22,23,33,40,41$, 44, 131, 161-163

Waltershausen, S. von, on West Indian seeds and drift-timber stranded on Iceland, 20, 35, 41, 45

Warde, Mrs. H. B., 238

Warming, E., 45; seeds blown across the Cattegat, 425; foliage of Juniperus nana and $J$. communis, 431, 432

Warnstorf, C., Sphagnaceæ, 332-358, 411,440 ; the connections of the Azorean Sphagna, 478

Warren, Miss U.; seeds of Entada scandens on the north coast of Cornwall, 45

Water-hyacinth. See Pontederia.

Watkins, F. H., on the first salt-rakers and the original condition of the Turks Islands, 184, 276, 277, 487

Watson, H. C., on the Azorean flora, 359, $362,385,394,440$; the total number of plants and the introduced element, 389-391; the vertical distribution of Hochstetter and Seubert criticised, $362,363,425$; summit plants of Pico, 370 ; aquatic plants, 378 ; character and composition of the original forests, 391-393; beach plants of Porto Pym, 384 ; Campanula vidalii and the Macaronesian Campanulas, 427, 428; discovery of Isoetes azorica, 429, and Littorella lacustris, 432; the Azorean Juniper, 431 ; other references to plants $218,364,371,434-436,438,492$; the snow on Pico, 372

Webb, P. B., on Dracæna draco in Madeira, 487

Webster, J. W., on the Yew of Pico, 397, 437,440

Weeds, their significance, 391, 493

Wells of Pico, 497

Welwitsch, on Acacia farnesiana in the Cape Verde Islands, 170

West Australian Current; influence on the climate, 272 ; its probable rôle in seed dispersal, 301

- Indies; West Indian and West African strand-floras compared, 8395; West Indian seeds on European beaches, 20-45; bottle-drift from the West Indies to Europe, 52, and from Europe to the West Indies, 57. See the summary on p. 78 for a guide to the general bottle-drift results for the West Indies, also under Bahamas, Caribbean Sea, Greater and Lesser Antilles. 
Westmoreland Morass (Jamaica), vegetation, 16, 106

West-Wind Drift Current and the indica. tions of bottle-drift, 60, 295-300, 305312

White, Dr., on the source of the flora of St. Helena, 460

- Sea, West Indian seed-drift on its shores, 36,78

Whymper, ascending air-currents on the Andes, 425

Wiegmann's Archiv für Naturgeschichte, $362,368,425$

Wight, Isle of; stranding of a West Indian seed, 28

Wilkes, Captain, bottle-drift in the Southern Ocean, 49, 300

Willdenow, on the West Indian home of Acacia farnesiana, 167, 168

"William Torr," wrecked in Davis Strait; drift of casks, 50

Wilser, L., on the north polar centre of dispersal, 325

Wind; dispersal of seeds and spores, $354,422-425,439$; seeds of the mahogany tree carried by the wind, 243 ; ascending air-currents on mountains as seed and spore carriers, 425, 439; effects of wind-pressure on shrubs in the Turks Islands, 446.

"W. L. White," derelict schooner, drifted across the North Atlantic, 472

Woad (Isatis tinctoria), early cultivation in the Azores, 397
Woodwardia; W. radicans, 370,375 ; W. virginica, 378

Worm, O., an old Danish naturalist; on Scandinavian tropical seed-drift, 21, 35,45

Wortley, E. J., on Hymenæa courbaril in Jamaica, 140

Xerophily and a littoral station, 228, 229, 238,239 . For further references see Littoral plants $(c)$; and for a discussion of xerophily as a product of later geological ages, due to the progressive differentiation of climate, see p. 319 .

Ximenia, 83,253 ; X. americana, 87,92 , 252

Yew, in the Azores, 397, 437. See Taxus baccata.

Yucatan, bottle-drift stranded, 53, 466. See Central America, Honduras, Nicaragua.

Strait, traversed by drift brought by the equatorial currents, $58,70-72$

Yuccas, 168

Zanthoxylum, prickles in beach-drift, 164

Zaragoza mangrove (Conocarpus erectus), 201 Zeleny, J., on the falling rates of spores,
423

Zingiberaceæ, 315

Zygophyllum, in the Canaries, 448, 449

Additional Note on St. Helena.-Through an oversight, reference has not been made on p. 460 to the record by Barchell and Melliss of the frequent stranding of seeds of Entada scandens and Guilandina bonducella on the windward or southern coasts of this island (Chall. Bot. iii, 80; iv, 300, 302). The indications of the currents are that these seeds are most probably derived through the agency of the South Atlantic Connecting Current from Brazil, though a possible source from the East African coast around the Cape cannot be ignored. 
Printed in Great Britain By Richard Clay \& Sons, Lmited, BRUNSWIOK ST., STAMFORD ST., S.E., AND BUNGAY SUFFOLK. 


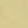


Date Due

\begin{tabular}{l|l|l|l}
\hline AUG 2 11995 & & \\
\hline 9951160 & & & \\
\hline & & & \\
\hline & & & \\
\hline & & & \\
\hline & & & \\
\hline & & & \\
\hline & & & \\
\hline & & & \\
\hline & & & \\
\hline & & & \\
\hline & & & \\
\hline & & & \\
\hline & & & \\
\hline & & & \\
\hline
\end{tabular}




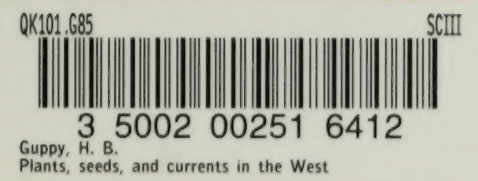


